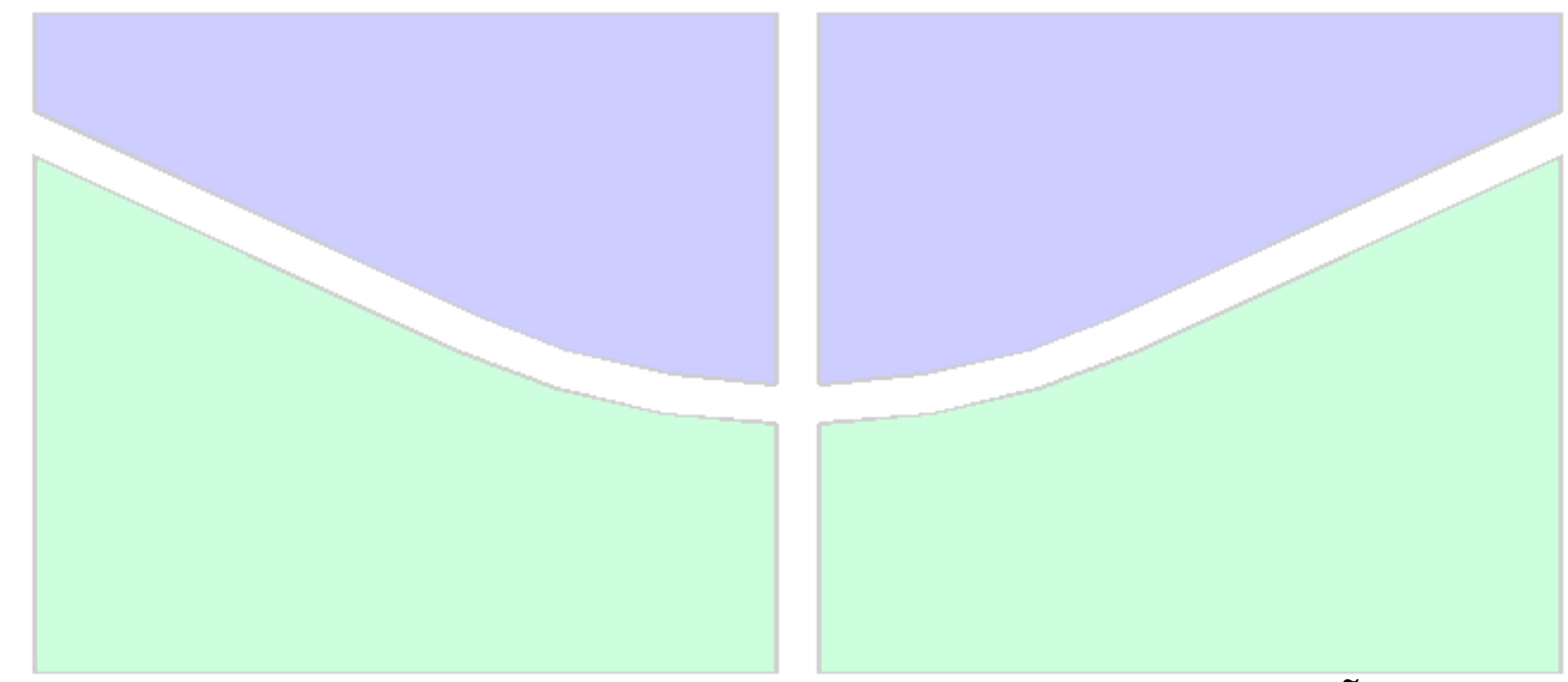

PROPOSTA DE UM AMORTECEDOR PARA ATENUACÃO DE VIBRAÇÕES EM PISOS DE CONCRETO:

ANÁLISE NUMÉRICA E EXPERIMENTAL

JORGE ELIÉCER CAMPUZANO CARMONA

\author{
TESE DE DOUTORADO \\ ESTRUTURAS E CONSTRUÇÃO CIVIL \\ DEPARTAMENTO DE ENGENHARIA CIVIL E AMBIENTAL
}

FACULDADE DE TECNOLOGIA

UNIVERSIDADE DE BRASÍLIA

FACULDADE DE TECNOLOGIA

DEPARTAMENTO DE ENGENHARIA CIVIL E AMBIENTAL 
PROPOSTA DE UM AMORTECEDOR PARA ATENUAÇÃO DE VIBRAÇÕES EM PISOS DE CONCRETO:

ANÁLISE NUMÉRICA E EXPERIMENTAL.

JORGE ELIÉCER CAMPUZANO CARMONA

ORIENTADORA: GRACIELA N. DOZ DE CARVALHO

TESE DE DOUTORADO EM

ESTRUTURAS E CONSTRUÇÃO CIVIL

BRASÍLIA/DF: JUNHO 23, 2016.

UNIVERSIDADE DE BRASILÍA

FACULDADE DE TECNOLOGIA

DEPARTAMENTO DE ENGENHARIA CIVIL E AMBIENTAL 
PROPOSTA DE UM AMORTECEDOR PARA ATENUAÇÃO DE VIBRAÇÕES EM PISOS DE CONCRETO:

ANÁLISE NUMÉRICA E EXPERIMENTAL.

JORGE ELIÉCER CAMPUZANO CARMONA

TESE DE DOUTORADO SUBMETIDA AO DEPARTAMENTO DE ENGENHARIA CIVIL E AMBIENTAL DA FACULDADE DE TECNOLOGIA DA UNIVERSIDADE DE BRASÍLIA COMO PARTE DOS REQUISITOS NECESSÁRIOS PARA A OBTENÇÃO DO GRAU DE DOUTOR EM ESTRUTURAS E CONSTRUÇÃO CIVIL.

\section{APROVADA POR:}

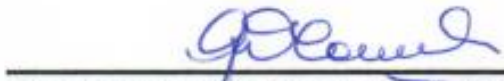

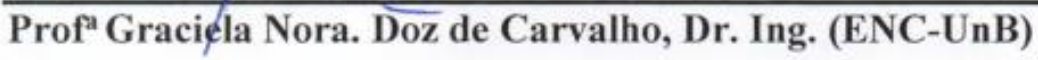

(Orientadora)

\section{Moune Anoelco Mellent shzu}

\section{Prof" Maura Angehica Milfont Shzu, DSe (UnB-Gamma)}

(Examinadora Interna)

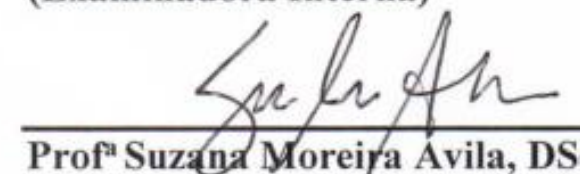

(Examinadora Interna)

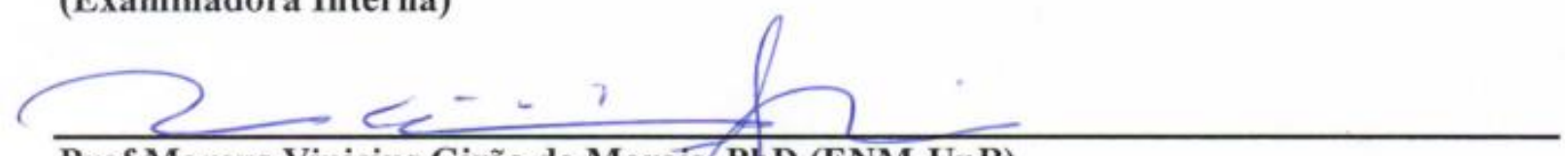

Prof Marcus Vinicius Girão de Moraís, PhD (ENM-UnB)

(Examinador Externo)

Prof Carlos Magluta, DSc (COPPE-UFRJ)

(Examinador Externo)

BRASÍLIA /DF, JUNHO 23, 2016. 


\section{FICHA CATALOGRÁFICA}

CAMPUZANO CARMONA, JORGE ELIÉCER

Proposta de um amortecedor para atenuação de vibrações em pisos de concreto: análise numérica e experimental.

[Distrito Federal] 2016.

xxiii, 287p, 297mm (ENC/FT/UnB, Doutor, Estruturas e Construção Civil, 2016).

Tese de Doutorado - Universidade de Brasília. Faculdade de Tecnologia.

Departamento de Engenharia Civil e Ambiental.

1. Amortecedor de massa sintonizado.

2. Vibrações induzidas.

3. Laje de concreto.

\section{REFERÊNCIA BIBLIOGRÁFICA}

CAMPUZANO CARMONA, J. E. (2016). Proposta de um amortecedor para atenuação de vibrações em pisos de concreto: análise numérica e experimental. Tese de Doutorado em Estruturas e Construção Civil, Publicação E.TD-1A/16, Departamento de Engenharia Civil e Ambiental, Universidade de Brasília, Brasília, DF, 287p.

\section{CESSÃO DE DIREITOS}

NOME DO AUTOR: Jorge Eliécer Campuzano Carmona.

TÍTULO DA TESE DE DOUTORADO: Proposta de um amortecedor para atenuação de vibrações em pisos de concreto: análise numérica e experimental.

GRAU / ANO: Doutor / 2016

É concedida à Universidade de Brasília permissão para reproduzir cópias desta tese de doutorado e para emprestar ou vender tais cópias somente para propósitos acadêmicos e científicos. O autor reserva outros direitos de publicação e nenhuma parte desta tese de doutorado pode ser reproduzida sem a autorização por escrito do autor.

oroge $\varepsilon$. Campuzano $C$.

Jorge Eliécer Campuzano Carmona. 
Aos meus Pais Jesús Arturo e Martha Carolina Aos meus irmãos José, Carlos e Ana Ao meu filho Alejandro Ao desenvolvimento da pesquisa cientifica e ao bem da humanidade 


\section{AGRADECIMENTOS}

Primeiramente a Deus que permitiu que este sonho fora uma realidade.

A meu pai Jesus Arturo e à memória de minha mãe Martha Carolina. Mãe quero compartir contigo este triunfo lá no mais alto do céu e espero algum dia estar de novo juntos na presencia de Deus. Te amarei por sempre.

A meus três irmãos que tem me dado todo tipo de apoio e ajuda na minha vida profissional.

Às minhas orientadoras e demais professores, pela ajuda, dedicação e pela orientação de meu trabalho de pesquisa.

Aos amigos e à família brasileira que contribuíram, direta ou indiretamente para a elaboração desta tese de doutorado.

À CAPES, pelo suporte financeiro. 


\section{RESUMO \\ PROPOSTA DE UM AMORTECEDOR PARA ATENUAÇÃO DE VIBRAÇÕES EM PISOS DE CONCRETO: ANÁLISE NUMÉRICA E EXPERIMENTAL}

\section{Autor: Jorge Eliécer Campuzano Carmona. Orientadora: Graciela Nora Doz de Carvalho. Programa de Pós-Graduação em Estruturas e Construção Civil Brasília, Junho de 2016.}

Este trabalho propor uma metodologia de projeto de um sistema para controle de vibrações em pisos de concreto. Com esse objetivo foi projetado, a partir de um estudo paramétrico, um amortecedor de massa sintonizada (AMS) e encontrada a melhor localização dele. Uma vez construído o amortecedor projetado, foram realizados ensaios em vibração livre e forçado na plataforma. Como excitação foram consideradas cargas harmônicas, cargas geradas pelo pulo continuo no centro da laje e cargas induzidas ao caminhar aleatoriamente na superfície da laje e ao pular desde uma carteira escolar no centro da plataforma. Com os resultados verificou-se o desempenho do AMS na redução da resposta das acelerações da estrutura. Foi constatado que o AMS cumpre com sua função de reduzir as vibrações em pisos geradas pelas pessoas em atividades rítmicas. O AMS mostra-se como uma solução alternativa para estruturas esbeltas no qual problemas de vibrações excessivas representam uma preocupação do projetista. O sistema de controle construído de forma geral é simples na construção e na manutenção, além disso, tem um baixo custo de fabricação.

Palavras-chave: Amortecedor de massa sintonizado, amortecimento, ensaios dinâmicos, vibrações em pisos, frequência natural, lajes, vibrações induzidas. 


\section{ABSTRACT \\ PROPOSAL FOR A DAMPER FOR ATTENUANTING VIBRATION IN CONCRETE FLOORS: NUMERICAL AND EXPERIMENTAL ANALYSIS}

\section{Author: Jorge Eliécer Campuzano Carmona \\ Coordinator: Graciela Nora Doz de Carvalho \\ Program Graduate in Structures and Civil Construction \\ Brasília, June, 2016.}

This paper proposes a methodology of a system for controlling vibrations in concrete floors. To this end was designed, from a parametric study, a tuned mass damper (TMD) and found the best location for it. Once built the damper tests were conducted in free and forced vibration on the platform. As excitement were considered harmonic loads, loads generated by the continuous leap in the center of the slab and induced by randomly walking on the surface of the slab and also jump from a school desk in the center of the platform loads. With the results TMD performance in reducing vibrations in floors generated by people in rhythmic activities was verified. The TMD is shown as an alternative solution for slender structures in which excessive vibration problems pose a concern designer engineer. The control system generally constructed is simple in construction and in maintenance, besides that, has low manufacturing cost.

Keywords: Tuned mass damper, damping, dynamic tests, vibrations floors, natural frequency, induced vibrations. 


\section{SUMÁRIO}

1. INTRODUÇÃO

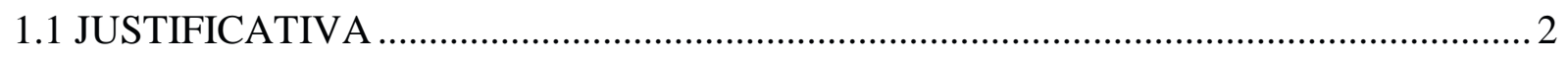

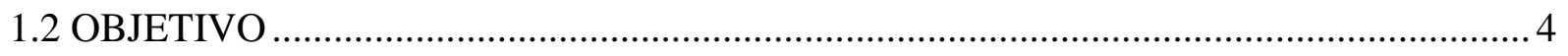

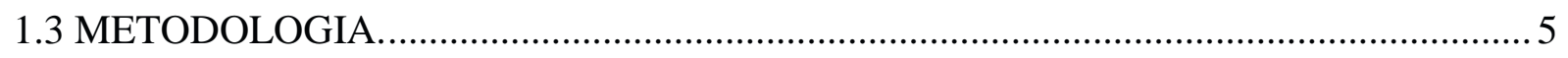

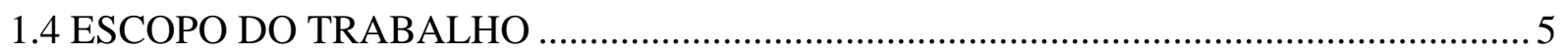

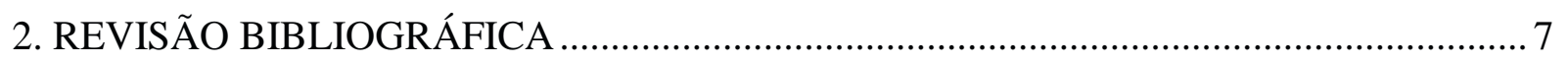

2.1. CONCEITOS E GENERALIDADES …………….................................................. 7

2.1.1. Estudos anteriores sobre amortecedores de massa sintonizada................................. 7

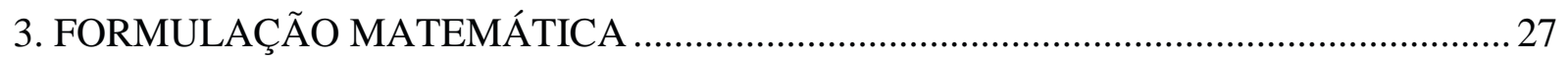

3.1 EQUACOES DE EQUILIBRIO DINÂMICO EM SISTEMAS DE VARIOS GRAUS DE

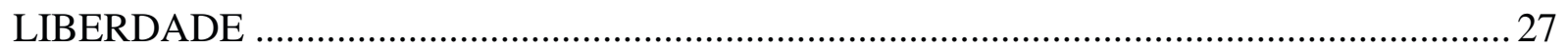

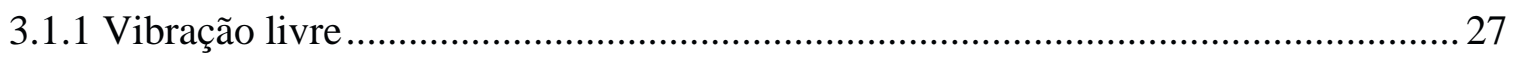

3.1.2 Equações de equilíbrio para excitação arbitraria...................................................... 28

3.1.3 Solução da resposta dinâmica para sistemas com vários graus de liberdade ............ 29

3.2 ABSORVEDOR DE VIBRAÇÕES AMORTECIDO …………………........................ 32

3.2.1 Seleção de valores de parâmetros ótimos para um AMS ........................................... 37

3.2.2 Amortecimento de Coulomb ……………………….......................................... 40

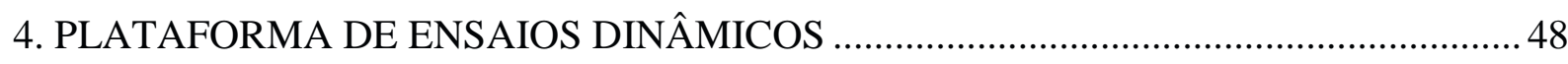

4.1 DESCRIÇÃO DA PLATAFORMA DE ENSAIOS DINÂMICOS ..................................... 48

4.2 RECUPERAÇÃO DA PLATAFORMA E ENSAIOS EXPERIMENTAIS APÓS A

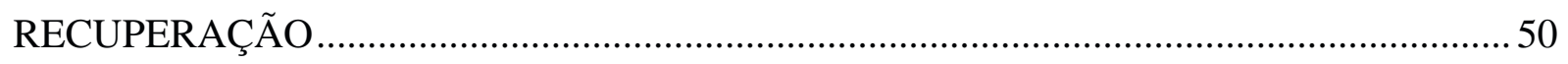

4.3 CARACTERÍSTICAS DINÂMICA DA PLATAFORMA DE ENSAIOS ........................ 50

4.4 COMPARAÇÃO ENTRE AS FORMAS NUMÉRICAS E EXPERIMENTAIS ............... 66

5. PROJETO E CONSTRUÇÃO DE UM SISTEMA DE CONTROLE DE VIBRAÇÕES ... 71 
5.1 ESTUDOS NUMÉRICOS COM VISTAS À DEFINIÇÃO DE UM SISTEMA DE CONTROLE .71

5.2 DESEMPENHO DE UM AMORTECEDOR FRENTE A VIBRAÇÃO FORÇADA ....... 82 5.3 FUNDAMENTOS TEORICOS PARA O PROJETO E CONSTRUÇÃO DO AMS ......... 86

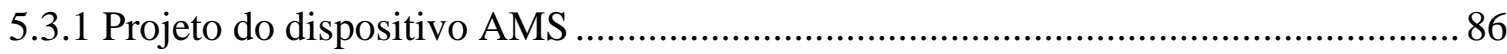

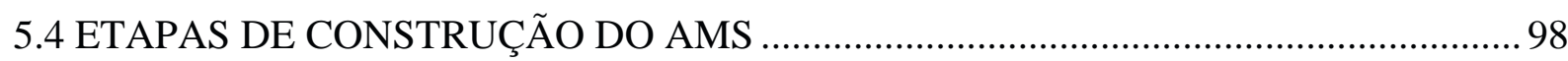

5.5 MONTAGEM DO AMS NA PLATAFORMA DE ENSAIOS DINAMICOS ................119

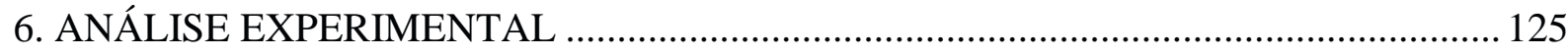

6.1 ESTUDOS EXPERIMENTAIS EM VIBRAÇÃO FORÇADA …………………............ 125

6.1.1 Ensaios experimentais de atividades ritmadas ...................................................... 125

7. ANÁLISE ESTATÍSTICA DOS RESULTADOS DOS ENSAIOS EM VIBRAÇÃO

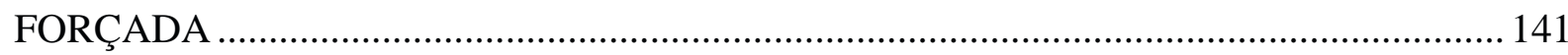

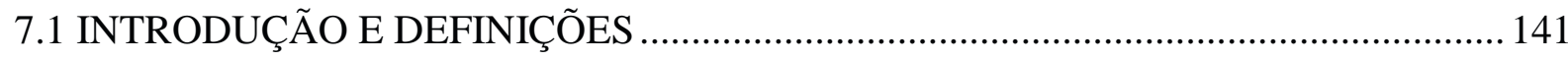

7.2 TRATAMENTO ESTATÍSTICO PARA OS ENSAIOS COM ESTIMULOS DE FORÇA QUE SIMULAM UMA AÇÃO HARMONICA NA BORDA DA LAJE ............................... 142

7.2.1 Excitação simulando força harmônica na plataforma sem AMS ............................. 142

7.2.2 Excitação simulando força harmônica na plataforma com AMS .............................. 145

7.3 TRATAMENTO ESTATÍSTICO PARA OS ENSAIOS COM FORÇA DE EXCITAÇÃO GERADA PELO PULO CONTINUO DE UMA PESSOA NO CENTRO DA LAJE........... 147

7.3.1 Excitação com pulo continuo no centro da laje sem AMS ...................................... 147

7.3.2 Excitação com pulo continuo no centro da laje com AMS ........................................ 149

7.4 TRATAMENTO ESTATÍSTICO PARA OS ENSAIOS COM FORÇA DE EXCITAÇÃO GERADA POR PESSOAS CAMINHANDO NA SUPERFICIE DA LAJE ......................... 151

7.4.1 Excitação gerada por pessoas caminhando na superfície da laje sem AMS ........... 151

7.4.2 Excitação gerada por pessoas caminhando na superfície da laje com AMS........... 153 


\subsection{TRATAMENTO ESTATÍSTICO PARA OS ENSAIOS DE FORÇA DE EXCITAÇÃO}

QUE PRODUZ O IMPACTO DE UMA PESSOA PULANDO DESDE UMA CARTEIRA ESCOLAR 155

7.5.1 Excitação gerada pulando desde uma carteira escolar na superfície da laje sem AMS 155

7.5.2 Excitação gerada pulando desde uma carteira escolar na superfície da laje com AMS 157

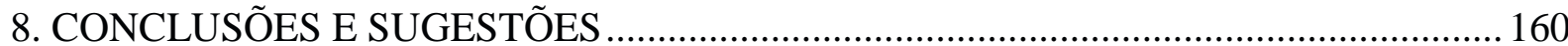

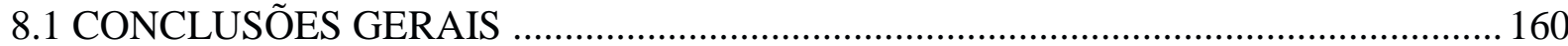

8.2 SUGESTÕES PARA TRABALHOS FUTUROS ...................................................... 166

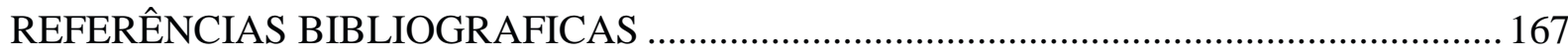

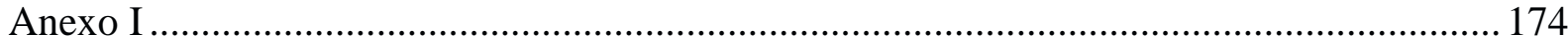

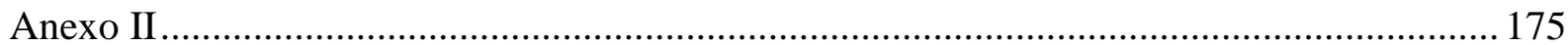

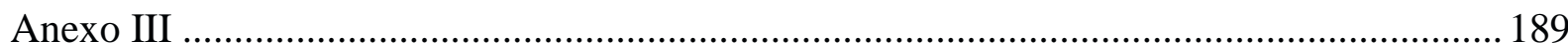

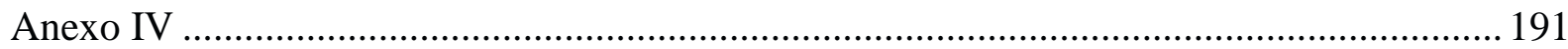

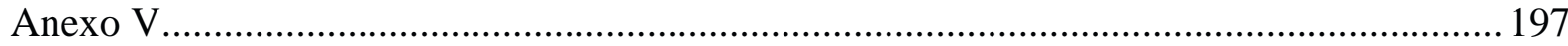

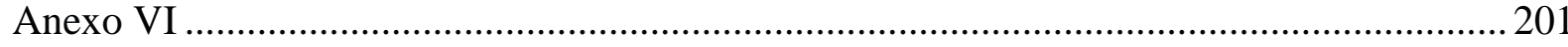

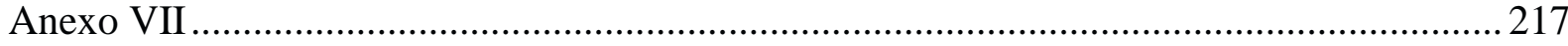

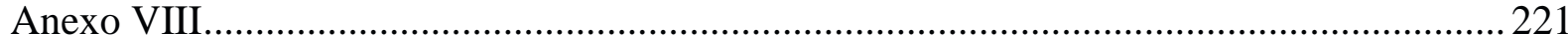

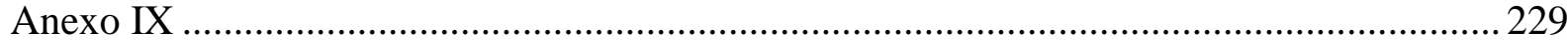

Anexo X

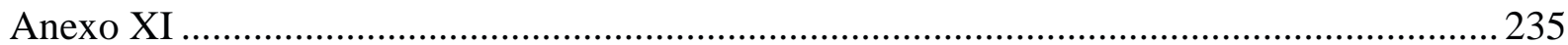

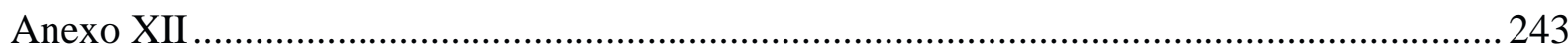




\section{LISTA DE TABELAS}

\section{CAPITULO 1}

Tabela 1.1- Frequências Naturais, do Estádio Morumbi em São Paulo.

\section{CAPITULO 2}

Tabela 2.1 - Frequências e razões ótimas dos AMSM, instalados no laboratório Rottmann e

Murray (1996) apud (Hanagan et al, 2003)........................................................................15

Tabela 2.2 - Parâmetros experimentais modais do piso. (Al-Hulwah et al, 2005) ..................17

\section{CAPITULO 3}

Tabela 3.1 - Equações para encontrar os parâmetros de ajuste ótimos de um AMS apud (Gutierrez, 2012).

\section{CAPITULO 4}

Tabela 4.1 - Comparação entre as frequências numéricas e experimentais...........................64

Tabela 4.2 - Resumo das diferentes frequências obtidas nos ensaios experimentais. .............64 Tabela 4.3 - Amortecimentos experimentais de cada modo de vibração pelo método FDD. ..64

\section{CAPITULO 5}

Tabela 5.1 - Amplitude da resposta em frequência variando-se os parâmetros para um único

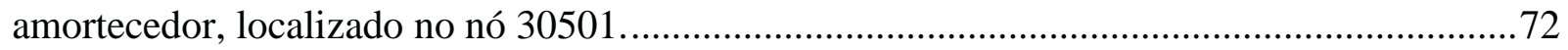

Tabela 5.2 - Coordenadas dos nós do estudo numérico.....................................................77

Tabela 5.3 - Amplitude da resposta em frequência variando-se os parâmetros de massa, amortecimento, rigidez e posição do AMS. .................................................................... 77

Tabela 5.4 - Valor calculado da constante de rigidez da mola tipo 1 . ..................................91

Tabela 5.5 - Valor calculado da constante de rigidez da mola tipo 2 . .................................92

Tabela 5.6 - Calculo da força normal em função do coeficiente de amortecimento equivalente.

Tabela 5.7 - Cálculo do torque necessário no parafuso para conseguir o amortecimento de Coulomb no sistema do AMS. .97

Tabela 5.8 - Pesos das diferentes peças da massa vibrante do AMS. .99 
Tabela 5.9 - Valores de massa vibrante do projeto calibrado em AutoCAD (2013) e comparado com valores reais experimentais do módulo 1. 100

Tabela 5.10 - Valores de massa vibrante do projeto calibrado em AutoCAD (2013) e comparado com valores reais experimentais do módulo 2 .

Tabela 5.11 - Parâmetros das molas adquiridas no comercio. 107

Tabela 5.12 - Rigidez analítica da mola comercial. 107

Tabela 5.13 - Valores das rigidezes das molas, encontrados experimentalmente. 110

Tabela 5.14 - Molas instaladas colocadas no AMS. 115

Tabela 5.15 - Tabela comparativa de dados numéricos e experimentais da massa e rigidez. 117

\section{CAPITULO 7}

Tabela 7.1 - Amplitude e número de classes dos registros de acelerações dos ensaios simulando força harmônica na plataforma sem AMS.

Tabela 7.2 - Distribuição de frequências por intervalos de todos os registros das acelerações do acelerômetro 2, simulando força harmônica na plataforma sem AMS.

Tabela 7.3 - Amplitude e número de classes dos registros de acelerações dos ensaios simulando força harmônica na plataforma com AMS.

Tabela 7.4 - Distribuição de frequências por intervalos de todos os registros das acelerações do acelerômetro 2, simulando força harmônica na plataforma com AMS. 145

Tabela 7.5 - Amplitude e número de classes dos registros de acelerações dos ensaios simulando pulo continuo na plataforma sem AMS.

Tabela 7.6 - Distribuição de frequências por intervalos de todos os registros das acelerações do acelerômetro 2, pulo continuo na plataforma sem AMS 148 Tabela 7.7 - Amplitude e número de classes dos registros de acelerações dos ensaios simulando pulo continuo na plataforma com AMS.

Tabela 7.8 - Distribuição de frequências por intervalos de todos os registros das acelerações do acelerômetro 2, com pulo continuo na plataforma com AMS

Tabela 7.9 - Amplitude e número de classes dos registros de acelerações dos ensaios de um grupo de três pessoas caminhando na plataforma sem AMS.

Tabela 7.10 - Distribuição de frequências por intervalos de todos os registros das acelerações do acelerômetro 2, força de excitação grupo de 3 pessoas caminhando na plataforma sem AMS. 
Tabela 7.11 - Amplitude e número de classes dos registros de acelerações dos ensaios de um grupo de três pessoas caminhando na plataforma com AMS.

Tabela 7.12 - Distribuição de frequências por intervalos de todos os registros das acelerações do acelerômetro 2, com força de excitação de grupo de 3 pessoas caminhando na plataforma com AMS. 154

Tabela 7.13 - Amplitude e número de classes dos registros de acelerações dos ensaios que produz uma força de impacto na plataforma sem AMS.

Tabela 7.14 - Distribuição de frequências por intervalos de todos os registros das acelerações do acelerômetro 2, força de excitação pulando desde carteira escolar na plataforma sem AMS.

Tabela 7.15 - Amplitude e número de classes dos registros de acelerações dos ensaios que produz uma força de impacto na plataforma com AMS

Tabela 7.16 - Distribuição de frequências por intervalos de todos os registros das acelerações do acelerômetro 2, com força de excitação pulando desde carteira escolar na plataforma com AMS. 158 


\section{LISTA DE FIGURAS}

\section{CAPITULO 1}

Figura 1.1 - Ponte Millennium Bridge, Londres (Gerb, 2001) ..........................................2 Figura 1.2 - Hotel "Marina Bay Sands, Singapura" Amortecedor de massa sintonizada (Maurer Söhne, 2011) 3

Figura 1.3 - Sistema de controle adotado no estádio Morumbi de São Paulo (Gerb, 1998). .....4

\section{CAPITULO 2}

Figura 2.1 - Localização dos AMSM nos casos estudados por (Thornton et al, 1990)..... 8

Figura 2.2 - Panorâmica e vista em planta do prédio com área afeitada pelas vibrações. (Webster

e Vaicaitis, 1992).

Figura 2.3 - Seção 1-1 do quadrante afeitado pelas vibrações provenientes da sala de dança (Webster e Vaicaitis, 1992).

Figura 2.4 - Vista em planta da plataforma experimental (Ritchey, 2003).

Figura 2.5 - Amortecedores passivo e semi-ativo tipo pêndulo, utilizado nos ensaios experimentais (Ritchey, 2003)

Figura 2.6 - Modelo experimental de dois graus de liberdade e componentes do sistema (Koo, 2003)

Figura 2.7 - Planta do laboratório de química, Shope e Murray (1995) apud (Hanagan et al, 2003).

Figura 2.8 - Amortecedor Líquido Sintonizado TLD, utilizado no laboratório de química, Shope

e Murray (1995) apud (Hanagan et al, 2003). 15

Figura 2.9 - AMS, utilizado no laboratório de química, Rottmann e Murray (1996) apud (Hanagan et al, 2003). .15

Figura 2.10 - Atenuador Dinâmico Sintonizado acoplado na plataforma experimental da Universidade Federal de Rio de Janeiro (Varela, 2004). .16

Figura 2.11 - Amortecedor viscoelástico de 3 graus de liberdade. (Al-Hulwah et al, 2005) ....17 Figura 2.12 - Panorâmica da passarela de Poznan e localização dos AMS, abaixo da passarela com massa total de 5,6 toneladas (Fiebig, 2010). .18

Figura 2.13 - Sistema de piso misto, estudado por (Lamb, 2011). 
Figura 2.14 - AMS duplo, utilizado na pesquisa de pisos de escritórios com vibrações

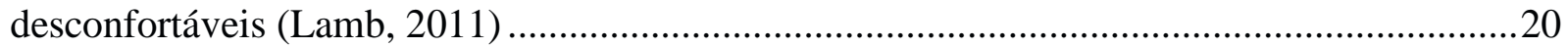

Figura 2.15 - AMS viscoelástico acoplado com viga de aço (Saidi, 2012)...........................21

Figura 2.16 - Sistema de AMSM instalado no piso do escritório com problemas de vibrações. (Saidi, 2012) .22

Figura 2.17 - Esboço de protótipo de AMS tipo pêndulo. (Lindenberg e Fraczek, 2013) .......23

Figura 2.18 - Amortecedor de dois graus de liberdade ( Picauly et al, 2014). .24

Figura 2.19 - Sistemas de controle passivo no protótipo, A) amortecedor liquido sintonizado, B) amortecedor liquido de coluna sintonizado C) amortecedor de massa sintonizado. (Bigdeli et al, 2015).

\section{CAPITULO 3}

Figura 3.1 - Sistema linear não amortecido de três graus de liberdade.(García, 1998)

Figura 3.2 - Sistema linear não amortecido de três graus de liberdade submetido a forças dinâmicas em suas massas. (García, 1998).............................................................................28

Figura 3.3 - Relação entre amortecimento e frequência, para amortecimento de

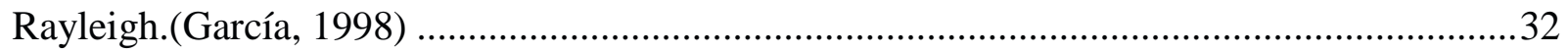

Figura 3.4 - Absorvedor de vibrações amortecido. (Den Hartog, 1985) ................................34

Figura 3.5 - Amplitudes de vibração da massa principal da Figura 3.4 para vários valores de amortecimento do absorvedor, no qual a massa do absorvedor é 20 vezes menor que a massa do sistema principal e é sintonizado na mesma frequência. 37

Figura 3.6 - Massa deslizando-se sobre uma superfície com coeficiente de atrito $\mu_{s .}$

Figura 3.7 - Diagrama de corpo livre do sistema da Figura 3.6 para um instante em que a velocidade é maior que zero.

Figura 3.8 - Diagrama de corpo livre do sistema da Figura 3.6 para um instante em que a velocidade $<0$.

Figura 3.9 - Resposta de vibração livre de um sistema com amortecimento de Coulomb. (Graham Kelly, 2012). .46

\section{CAPITULO 4}

Figura 4.1 - Plataforma de ensaios dinâmicos (Campuzano, 2011) .49

Figura 4.2 - Dimensões da plataforma de ensaios dinâmicos (Campuzano, 2011) 
Figura 4.3 - Plataforma de ensaios dinâmicos antes da recuperação, com flecha estática de 35

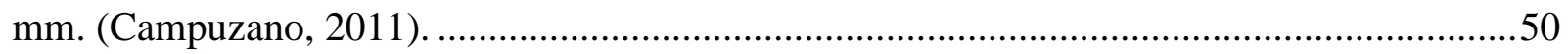

Figura 4.4 - Impactos com marreta para encontrar a frequência natural da plataforma. ...........51

Figura 4.5 - Impactos com o calcanhar para encontrar frequência natural da plataforma.........51

Figura 4.6 - (a) Mapeamento das trincas da laje no modelo numérico. (b) Trincas na lajes que foram preenchidas com graute epóxi fluido. ........................................................................52

Figura 4.7 - Instrumentação básica para os ensaios de vibração livre.......................................53

Figura 4.8 - Malha projetada na superfície da laje da plataforma para posicionar os

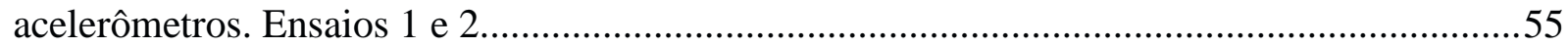

Figura 4.9 - Malha com 81 nós onde são registradas as acelerações..........................................55

Figura 4.10 - Localização no eixo $X$ do ponto onde se coloca o acelerômetro fixo...............56

Figura 4.11 - Localização no eixo $Y$ do ponto onde se coloca o acelerômetro fixo. ................57

Figura 4.12 - Malha projetada na superfície da laje de concreto e posição dos diferentes acelerômetros para os ensaios experimentais 3 e 4 .............................................................5

Figura 4.13 - Discretização da malha na laje de concreto no software ARTeMIS.....................59

Figura 4.14 - Vinculação dos sinais dos acelerômetros aos respectivos nós da laje. (Ensaio 3)

Figura 4.15 -Primeira forma modal numérica e experimental da laje de concreto da plataforma. Teste 4 frequência numérica $=3,36 \mathrm{~Hz}$, frequência experimental $=3,36 \mathrm{~Hz}$, amortecimento experimental $=1,83 \%$.

Figura 4.16 - Segunda forma modal numérica e experimental da laje de concreto da plataforma. Teste 4 frequência numérica $=15,67 \mathrm{~Hz}$, frequência experimental $=15,34 \mathrm{~Hz}$, amortecimento experimental $=0,65 \%$.

Figura 4.17 -Terceira forma modal numérica e experimental da laje de concreto da plataforma. Teste 4 frequência numérica $=23,64 \mathrm{~Hz}$, frequência experimental $=22,90 \mathrm{~Hz}$, amortecimento experimental $=0,58 \%$.

Figura 4.18 - Registro das acelerações no domínio do tempo. Vibração livre Teste 4, nó 20 onde se pegaram os resgistros das acelerações.

Figura 4.19 - Frequências naturais da laje de concreto. Vibração livre Teste 4, nó 20 onde se pegaram os registros das acelerações. .66

Figura 4.20 - MAC teste 1 (nó fixo 20). .67 


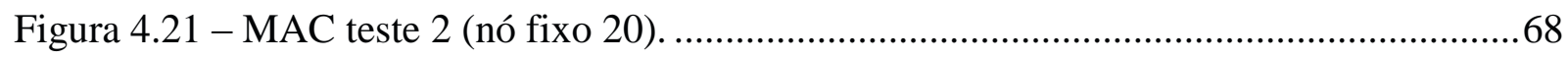

Figura 4.22 - MAC teste 3 (nó fixo 41)............................................................................68

Figura 4.23 - MAC teste 4 (nó fixo 41) ........................................................................69

\section{CAPITULO 5}

Figura 5.1 - Resposta em frequência do deslocamento do nó central da laje dos 7 modelos...73

Figura 5.2 - Resposta em frequência do deslocamento do nó central da laje sem controle e com

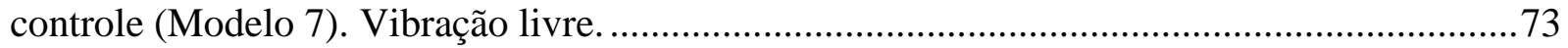

Figura 5.3 - Análise no domínio do tempo em função da aceleração (Modelo 7, 1 AMS).

Impacto seguido de vibração livre.

Figura 5.4 - Análise no domínio do tempo em função do deslocamento (Modelo 7, 1 AMS). Impacto seguido de vibração livre. .75

Figura 5.5 - Diferentes posições dos AMS nos ensaios. .76

Figura 5.6 - Resposta no domínio da frequência considerando a laje com sistema de controle. Impacto seguido de vibração livre. .78

Figura 5.7 - Resposta no domínio da frequência considerando a laje com sistema de controle Modelo 20 (3 AMS). Impacto seguido de vibração livre. .79

Figura 5.8 - Comparação da resposta em frequência dos modelos 7 e 20, com 1 e 3 AMS, respectivamente. Impacto seguido de vibração livre.

Figura 5.9 - Resposta no domínio do tempo em função da aceleração (Modelo 20, três AMS). Impacto seguido de vibração livre.

Figura 5.10 - Análise no domínio do tempo em função do deslocamento (Modelo 20, 3 AMS). Impacto seguido de vibração livre.

Figura 5.11 - Resposta no domínio do tempo em função da aceleração para uma pessoa pulando continuamente. Vibração forçada.

Figura 5.12 - Resposta no domínio da frequência para uma pessoa pulando continuamente. Vibração forçada. .84

Figura 5.13 - Resposta no domínio do tempo para três pessoas pulando continuamente. Vibração forçada.

Figura 5.14 - Resposta no domínio da frequência para três pessoas pulando continuamente. Vibração forçada. .85

Figura 5.15 - Tipos de molas a utilizar no projeto do AMS, medidas em mm. .87 
Figura 5.16 - Dimensões, em mm, das 24 chapas de aço de espessura de 12,5 mm que formam a massa vibrante do AMS.

Figura 5.17 - Dimensões, em mm, das 2 chapas de aço de espessura de 12,5 mm que formam o suporte superior do todo o conjunto do AMS.

Figura 5.18 - Dimensões, em mm, das 2 chapas de aço de espessura de $12,5 \mathrm{~mm}$ que formam o suporte inferior do todo o conjunto do AMS .88

Figura 5.19 - Dimensões, em mm, da peça com a qual pode-se obter o amortecimento por atrito e do anel para confinar as molas. .88

Figura 5.20 - Dimensões, em mm, do parafuso que fixa a chapas de aço, bitola parafuso 1/2 pol.

Figura 5.21 - Dimensões, em mm, do parafuso que fixa a molas de aço, bitola parafuso 1/2 pol.

Figura 5.22 - Dimensões, em mm, do eixo guia do AMS. .89

Figura 5.23 - Vista em perspectiva do amortecedor de massa sintonizado AMS. .89

Figura 5.24 - Vista superior, lateral e frontal do AMS. .90

Figura 5.25 - Amortecedor viscoso equivalente com mecanismo de dissipação de energia real por atrito. .93

Figura 5.26 - Energia dissipada por atrito em um ciclo de oscilação. .93

Figura 5.27 - Forças atuantes na rosca do parafuso (Juvinall e Marshek, 2012) .95

Figura 5.28 - A) Perfuração das chapas de aço que compõem a massa vibrante, B) Perfuração da chapa de aço que serve como suporte do AMS. .98

Figura 5.29 - Pesos obtidos na balança eletrônica das diferentes peças de aço do AMS. .99

Figura 5.30 - Massa vibrante do AMS, com novas peças para ajustar a massa experimental. .101

Figura 5.31 - Coordenadas, em mm, do centro de gravidade da massa vibrante do AMS....102 Figura 5.32 - AMS com os dois módulos juntos para vibrar como um único corpo rígido. ..103

Figura 5.33 - Peças que formam a massa vibrante. .104

Figura 5.34 - Valor das massas das duas peças que juntam os dois módulos das massas vibrantes. 104

Figura 5.35 - Processo de montagem da massa vibrante do modulo 1. 105

Figura 5.36 - Porcas a ser soldadas que fixam os 12 parafusos, os quais sustentam o AMS. 106 


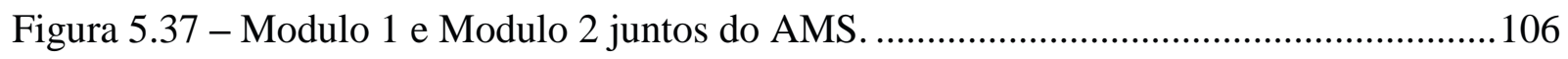

Figura 5.38 - Molas de compressão e pesos utilizados para o ensaio de compressão............108

Figura 5.39 - Magnitude dos pesos para os ensaios de compressão das molas. ........................108

Figura 5.40 - Montagem para obtenção da rigidez da mola. ....................................................109

Figura 5.41 - Rigidez experimental mola 1 .................................................................111

Figura 5.42 - Rigidez experimental mola 2 ..................................................................111

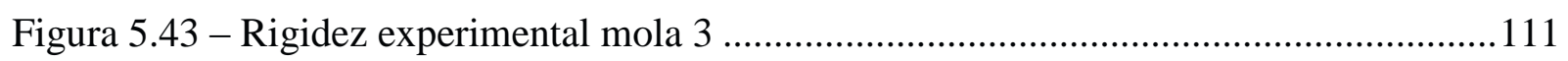

Figura 5.44 - Rigidez experimental mola 4 .....................................................................111

Figura 5.45 - Rigidez experimental mola 5 ……………..........................................111

Figura 5.46 - Rigidez experimental mola 6 ..................................................................111

Figura 5.47 - Rigidez experimental mola 7 ..............................................................112

Figura 5.48 - Rigidez experimental mola 8 ....................................................................112

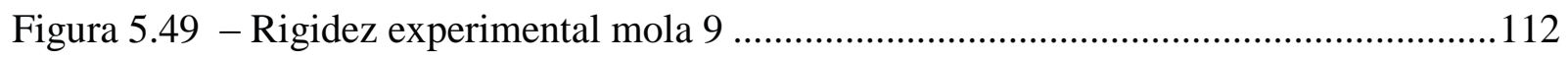

Figura 5.50 - Rigidez experimental mola 10 .................................................................112

Figura 5.51 - Rigidez experimental mola 11 .................................................................112

Figura 5.52 - Rigidez experimental mola 12 ...............................................................112

Figura 5.53 - Rigidez experimental mola 13 ....................................................................113

Figura 5.54 - Rigidez experimental mola 14 ..............................................................113

Figura 5.55 - Rigidez experimental mola 15 ..................................................................113

Figura 5.56 - Rigidez experimental mola 16 ...................................................................113

Figura 5.57 - Rigidez experimental mola 17 ..................................................................113

Figura 5.58 - Rigidez experimental mola 18 ..............................................................113

Figura 5.59 - Rigidez experimental mola 19 ................................................................ 114

Figura 5.60 - Rigidez experimental mola 20 ..............................................................114

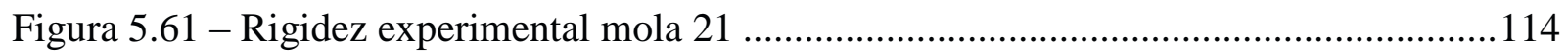

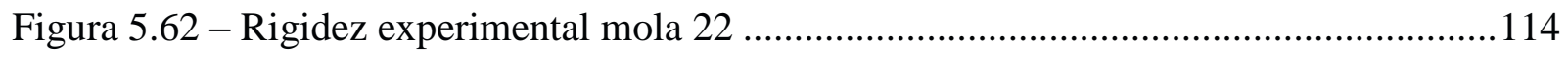

Figura 5.63 - Rigidez experimental mola 23 ...................................................................114

Figura 5.64 - Rigidez experimental mola 24 ....................................................................114

Figura 5.65 - Peças individuais que compõem o AMS...........................................................116

Figura 5.66 - Vista frontal AMS em sua forma final........................................................117

Figura 5.67 - AMS construído em sua forma final. .............................................................118 
Figura 5.68 - Desenho técnico do amortecedor com todas suas partes.

Figura 5.69 - Chapa gabarito de madeira utilizada na montagem do AMS 120

Figura 5.70 - Localização da chapa gabarito de madeira no centro da laje. 121

Figura 5.71 - Chumbadores de aço ancorados na laje de concreto.

Figura 5.72 - Processo da montagem do AMS na base da laje da plataforma de ensaios dinâmicos.

Figura 5.73 - Localização do AMS na laje de concreto da plataforma de ensaios dinâmicos.

\section{CAPITULO 6}

Figura 6.1 - Esboço dos ensaios em vibração forçada simulando força harmônica. 126 Figura 6.2 - Análise no domínio do tempo com e sem AMS. Teste de joelho semidobrados, simulando força harmônica.

Figura 6.3 - Análise no domínio da frequência com e sem AMS. Teste de joelho semidobrado, simulando força harmônica. Vibração forçada 0-10 segundos.

Figura 6.4 - Análise no domínio da frequência com e sem AMS. Teste de joelho semidobrado, simulando força harmônica. Vibração livre 10-20 segundos.

Figura 6.5 - Análise no domínio do tempo com e sem AMS. Ensaio com uma pessoa, pulo continuo durante 10 segundos.

Figura 6.6 - Análise no domínio da frequência com e sem AMS. Ensaio com uma pessoa, pulo continuo. Vibração forçada 0-10 segundos.

Figura 6.7 - Análise no domínio da frequência com e sem AMS. Ensaio com uma pessoa, pulo continuo. Vibração livre 10-20 segundos.

Figura 6.8 - Ensaios de vibração forçada. Pulos contínuos em grupo de 5 pessoas.

Figura 6.9 - Análise no domínio do tempo com e sem AMS. Grupo de 3 pessoas, pulo continuo de 10 segundos.

Figura 6.10 - Análise no domínio da frequência com e sem AMS. Grupo de 3 pessoas, pulo continuo. Vibração forçada 0-10 segundos.

Figura 6.11 - Análise no domínio da frequência com e sem AMS. Grupo de 3 pessoas, pulo continuo. Vibração livre 10-20 segundos.

Figura 6.12 - Ensaios de vibração forçada. Pessoas caminhando aleatoriamente na superfície da laje em grupos de 3 e 4 pessoas. 135 
Figura 6.13 - Registro da aceleração no tempo com e sem AMS. Grupo de quatro pessoas, caminhando continua e aleatoriamente durante 20 segundos. 136

Figura 6.14 - Registro de aceleração no domínio da frequência com e sem AMS. Grupo pessoas caminhando 20 segundos.

Figura 6.15 - Ensaio de uma pessoa pulando desde uma carteira escolar no centro da laje..138 Figura 6.16 - Análise no domínio do tempo com e sem AMS. Impacto produzido por uma pessoa pulando desde uma carteira escolar.

Figura 6.17 - Análise no domínio da frequência com e sem AMS. Impacto produzido por uma pessoa pulando desde uma carteira escolar.

\section{CAPITULO 7}

Figura 7.1 - Histograma de frequências de todas as acelerações registradas pelo acelerômetro 2 simulando força harmônica nos ensaios na plataforma sem AMS.

Figura 7.2 - Histograma de frequências de todas as acelerações registradas pelo acelerômetro 2 simulando força harmônica nos ensaios na plataforma com AMS.

Figura 7.3 - Histograma de frequências de todas as acelerações registradas pelo acelerômetro 2 com pulo continuo nos ensaios na plataforma sem AMS.

Figura 7.4 - Histograma de frequências de todas as acelerações registradas pelo acelerômetro 2 com pulo continuo nos ensaios na plataforma com AMS.

Figura 7.5 - Histograma de frequências de todas as acelerações registradas pelo acelerômetro 2 nos ensaios de três pessoas caminhado na plataforma sem AMS.

Figura 7.6 - Histograma de frequências de todas as acelerações registradas pelo acelerômetro 2 de três pessoas caminhado nos ensaios na plataforma com AMS.

Figura 7.7 - Histograma de frequências de todas as acelerações registradas pelo acelerômetro 2 nos ensaios de pulo desde carteira escolar na plataforma sem AMS.

Figura 7.8 - Histograma de frequências de todas as acelerações registradas pelo acelerômetro 2 de pulo desde uma carteira escolar nos ensaios na plataforma com AMS. 


\section{LISTA DE SÍMBOLOS, SIGLAS E ABREVIATURAS}

ADS Atenuador Dinâmico Sincronizado.

AMS Amortecedor de Massa Sintonizado.

AMSm Múltiplo Amortecedor de Massa Sintonizado.

g Aceleração devida a Gravidade.

ISO Organização Internacional de Normalização.

MTMD Múltiplo Amortecedor de Massa Sintonizado.

PTMD Amortecedor de Massa Sintonizado tipo Pêndulo.

rms Raiz Quadrada Média.

TLD Amortecedor Líquido Sintonizado.

TLCD Amortecedor liquido de coluna sintonizado.

TMD Amortecedor de Massa Sintonizado.

TVA Absorvedor de Vibrações Sintonizado. 


\section{INTRODUÇÃO}

A maioria dos prédios modernos é projetada considerando cargas de ocupação e peso próprio, uma vez que estes carregamentos estão sempre atuando nas edificações. As magnitudes destes carregamentos podem ser facilmente determinadas a partir das dimensões dos elementos estruturais, densidade e dos requerimentos de ocupação. Outros tipos de carregamentos que precisam, em alguns casos, ser levados em consideração são os dinâmicos. Assim, por exemplo, estruturas sujeitas a cargas provenientes do desenvolvimento de atividades físicas como correr, pular, dançar devem contemplar estes carregamentos. Por outro lado, sabe-se que as estruturas modernas, cada vez mais esbeltas, flexíveis, com maiores vãos apresentam frequências naturais de vibração cada vez mais baixas. Uma maior flexibilidade nas estruturas implica em vibrações com maiores amplitudes que são transmitidas às pessoas que utilizam esses espaços causando desconforto e interferência com suas atividades, prejudicando, por exemplo, a visão dos olhos e os movimentos das mãos e pés. Podem ocorrer ainda, em casos de fortes vibrações, alterações das funções fisiológicas como, por exemplo, aumento da frequência cardíaca, alterações neuromusculares, alterações cardiovasculares, respiratórias, endócrinas e metabólicas, alterações sensoriais e do sistema nervoso central, também pode-se ter o risco de problemas na espinha dorsal (Harris, 1988). É importante saber que essas vibrações, raramente afetam a segurança da estrutura e, por conseguinte, são tratadas geralmente como um problema de serviço (Bachmann, 1992). Para corrigir este tipo de problema em estruturas como escritórios, áreas comerciais, academias, estudos de dança, laboratórios, teatros e passarelas, entre outras, são utilizados dispositivos de controle estrutural como amortecedores de massa sintonizados (AMS). Os AMS são sistemas massa-mola-amortecedor projetados para terem a sua frequência fundamental próxima a uma dada frequência da estrutura à qual estão vinculados, de modo que seja transferida a ele parte da energia do sistema principal reduzindo, assim, as vibrações excessivas. Este tipo de amortecedor tem sido utilizado com sucesso em lajes de concreto (Varela 2004; Setareh et al 2006; Lima 2007; Setareh et al 2007; Varela e Battista, 2011; Santos et al 2013). 


\subsection{JUSTIFICATIVA}

Alguns dos problemas habituais apresentados em estruturas devidos às fortes vibrações são causados pelos movimentos do corpo humano ao realizar movimentos rítmicos como: caminhar, correr, pular, dançar. Vibrações induzidas por pessoas em movimento podem interferir na operacionalidade das construções, mas raramente na segurança das estruturas. Exemplos de estruturas que geralmente são submetidas a vibrações por pessoas praticando algum tipo de atividade rítmica são as passarelas, escadas, pisos de prédios, estádios de futebol, etc. (Bachmann et al, 1997).

No campo de vibrações produzidas por pessoas podem ser citados diferentes problemas em construções os quais foram solucionados de uma maneira satisfatória com dispositivos de controle como os relatados a seguir:

A passarela Millennium Footbridge, localizada em Londres, foi interditada dois dias depois de sua abertura devido à apresentação de fortes vibrações laterais (Abrams, 2006); durante os 18 meses seguintes a empresa construtora gastou 7 milhões de dólares desenvolvendo um sistema de amortecedores passivos destinados a controlar as vibrações (Roberts, 2005). Na Figura 1.1 (Gerb, 2001 ; Dallard et al 2001) se apresenta uma vista panorâmica da passarela e os amortecedores de massa sintonizados introduzidos posteriormente para reduzir as vibrações produzidas pelos pedestres.

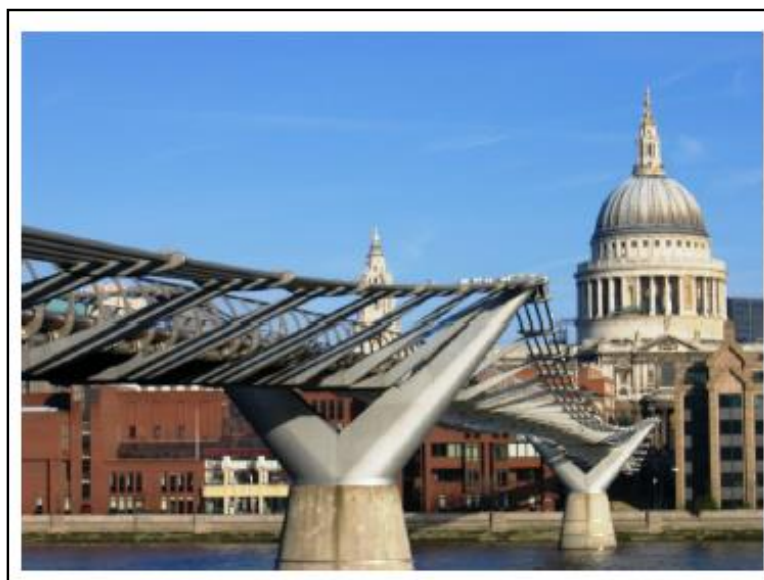

(a) Vista da ponte

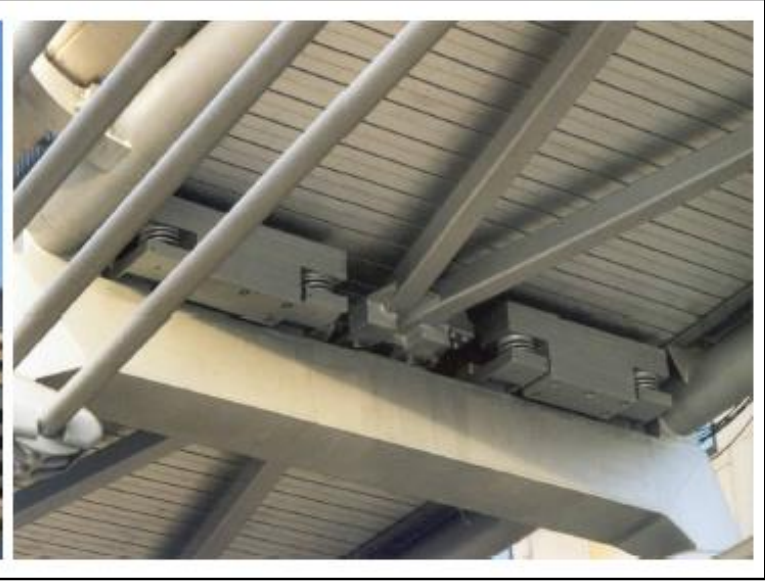

(b) Amortecedor de massa sintonizado

Figura 1.1 - Ponte Millennium Bridge, Londres (Gerb, 2001). 
Outro caso que merece ser mencionado é o hotel de luxo "Marina Bay Sands" localizado na cidade de Singapura. A estrutura do hotel é composta por 3 torres de 200 m e 55 andares cada uma. Na parte superior encontram-se jardins, piscina, restaurantes e bares. Na torre norte uma laje em balanço de $65 \mathrm{~m}$ suporta o jardim, nesta área se apresentavam fortes vibrações verticais causadas pelo vento e movimentos dos pedestres, com frequências entre 0,8 e 1,2 Hz. Para solucionar a ocorrência das vibrações indesejáveis foi projetado um amortecedor de massa sintonizado com uma massa de $6000 \mathrm{~kg}$, frequência de ressonância de $1,0472 \mathrm{~Hz} \mathrm{e}$ amortecimento máximo de 3978 Ns/m. Na Figura 1.2 mostra-se a localização e a estrutura do AMS (Maurer Söhne, 2011).

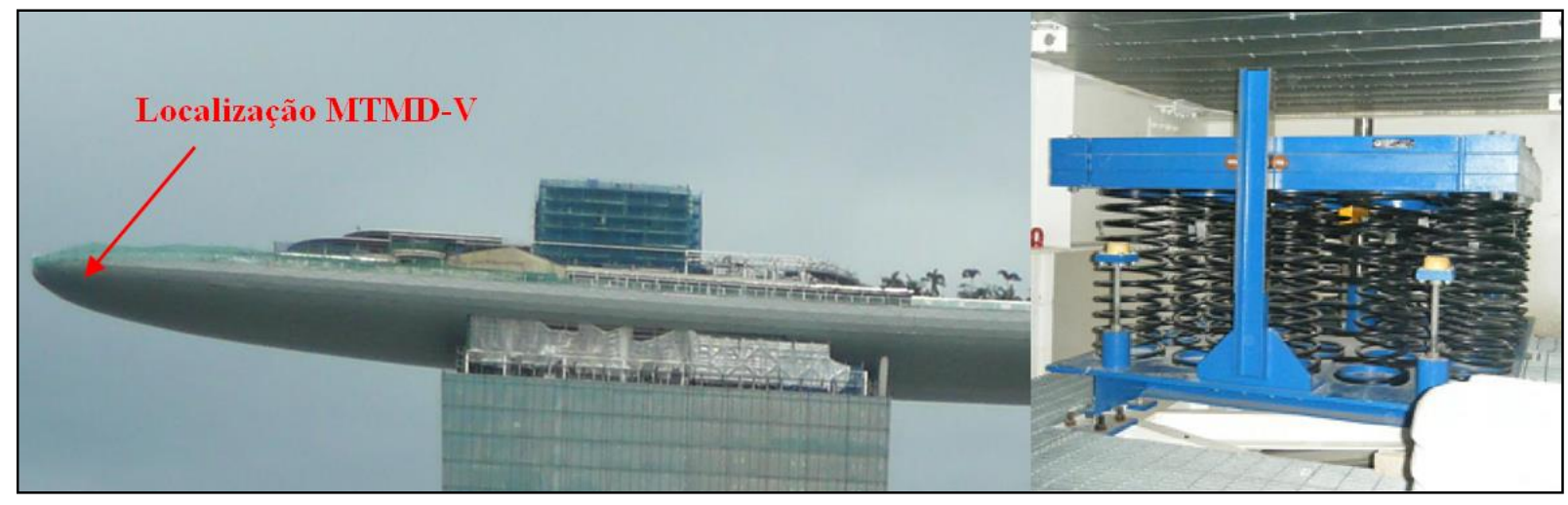

Figura 1.2 - Hotel "Marina Bay Sands, Singapura" Amortecedor de massa sintonizada (Maurer Söhne, 2011)

No Brasil, merece ser mencionado o caso do Estádio Morumbi, em São Paulo, onde foram adicionados AMSM conforme se indica na Figura 1.3 (Gerb, 1998). O sistema de controle passivo foi instalado nos anos 1998 e 2000 depois de um estudo motivado pelos grandes deslocamentos que apresentavam as arquibancadas durante as partidas de futebol. Durante os jogos foram observadas acelerações de até 9,7 \% da aceleração da gravidade que superavam as máximas aceitáveis, da ordem de $4 \%$ e $7 \%$ segundo o órgão normalizador internacional National Building Code of Canada (NBC). Os amortecedores instalados estão sintonizados nas três primeiras frequências naturais do estádio (vide Tabela 1.1) e, com essa solução, foram verificadas importantes reduções nas amplitudes das vibrações. 
Tabela 1.1- Frequências Naturais, do Estádio Morumbi em São Paulo.

\begin{tabular}{c|ccc}
\hline Frequência \# & Frequência $(\mathrm{Hz})$ & \multicolumn{2}{c}{ Taxa amortecimento (\%) } \\
\cline { 3 - 4 } & & Sem controle & Com AMSM \\
1 & 2,37 & 1,6 & 6,8 \\
2 & 2,41 & 1,8 & 6,4 \\
3 & 2,93 & 4,1 & 9 \\
\hline
\end{tabular}

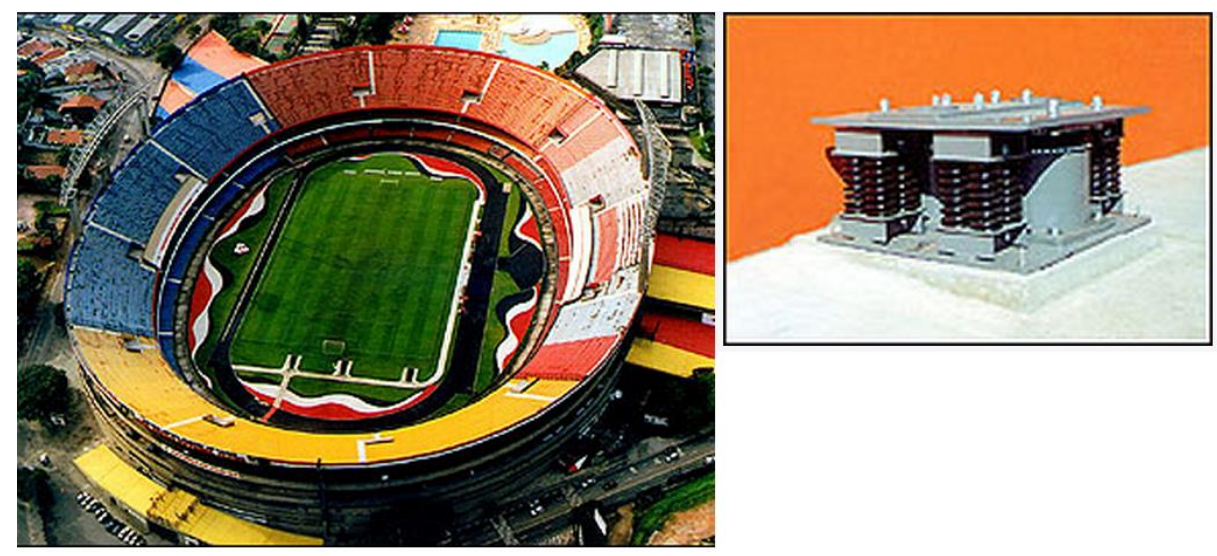

Figura 1.3 - Sistema de controle adotado no estádio Morumbi de São Paulo (Gerb, 1998).

Os três exemplos anteriores mostram a adoção de soluções para o problema de grandes oscilações mediante o uso de amortecedores de massa sintonizados. Entretanto, para a elaboração de um modelo numérico para controle de vibrações em lajes de edifícios sob ação de cargas dinâmicas produzidas por pessoas, torna-se necessário que esse modelo seja validado por meio de correlações teórico-experimentais das respostas dinâmicas da estrutura. Essas correlações devem ser feitas para históricos da resposta no tempo, em termos de deslocamento, amortecimento e principalmente em termos de acelerações, já que esta grandeza em várias normas é utilizada na avaliação dos níveis aceitáveis de vibração sob o enfoque do conforto dos usuários de certa edificação (Varela, 2004).

\subsection{OBJETIVO}

Com base no exposto, o objetivo deste trabalho é propor uma metodologia de projeto na qual se consiga desenvolver um sistema de controle de vibracoes que possa ser construído e instalado em pisos de edifícios, reduzindo-se assim vibrações produzidas por atividades rítmicas de pessoas. 


\subsection{METODOLOGIA.}

Para conseguir o objetivo proposto exposto anteriormente, é necessário primeiramente fazer uma revisão bibliográfica muito detalhada dos diferentes problemas de vibrações excessivas apresentados em estruturas e os quais são gerados por pessoas em atividades rítmicas. A maneira como é dada a solução aos problemas de vibração excessiva também é analisada. Uma vez feita a revisão bibliográfica, o seguinte passo é estudar o problema mediante as formulações matemáticas de sistemas de vários graus de liberdade e a teoria clássica do absorvedor de vibrações amortecidas. Seguidamente avalia-se uma estrutura que apresenta fortes vibrações verticais produzidas por pessoas em atividades rítmicas como é o caso da plataforma de ensaios dinâmicos que se encontra no laboratório de estruturas da universidade de Brasília UnB. Esta estrutura é modelada numericamente mediante elementos finitos, com um sistema de controle utilizando um ou mais amortecedores de massa sintonizados (AMS). A finalidade do modelo numérico é procurar os parâmetros ótimos do sistema de controle para que este tenha melhor desempenho na mitigação das vibrações. São modelados ensaios de atividades rítmicas das pessoas. Uma vez obtidos os parâmetros ótimos de massa, rigidez e amortecimento do AMS é projetado e construído o sistema de controle. Finalmente é feita a avalição por meio de ensaios dinâmicos na plataforma acoplada com o AMS. Os resultados obtidos são analisados criticamente.

\subsection{ESCOPO DO TRABALHO}

Este trabalho é constituído de 8 capítulos sendo este primeiro a introdução.

No segundo capitulo apresenta-se uma revisão geral bibliográfica, com o estado de arte sobre o assunto. Se apresentam diferentes tipos de amortecedores de massa sintonizado desde 1984 até 2015, utilizados como sistema de controle para mitigação de vibrações em estruturas civis.

No terceiro capitulo encontra-se a formulação matemática da teoria de vibração e também a formulação do amortecedor de massa sintonizado para o qual se apresentam as equações ótimas de amortecimento em função das taxas de massa e de frequência. Encontrando os parâmetros ótimos pode-se obter o melhor desempenho do sistema de controle. Também é apresentada a teoria de amortecimento por forças de Coulomb com a qual é projetado o AMS. 
No quarto capitulo se descreve a plataforma de ensaios dinâmicos e estudos numéricos prévios antes da recuperação da mesma. Logo depois da recuperação se atualizam os modelos numéricos da plataforma apresentando as diferentes formas modais.

O quinto capitulo trata-se da modelagem computacional da plataforma com o AMS acoplado, onde são apresentados vários casos de estudo para encontrar os parâmetros ótimos do AMS projetado. Em seguida é apresentado os fundamentos teóricos para o projeto e construção do AMS. Por último apresenta-se as etapas de construção e montagem do sistema de controle AMS na estrutura principal.

No sexto capitulo descreve-se os estudos experimentais em vibração livre e forçada realizados na plataforma de ensaios dinâmicos. Para a laje de concreto é realizado o estudo baseado na aplicação do Modal assurance criterion (MAC).

Um tratamento estatístico de todos os ensaios experimentais em vibração livre e forcada realizados na plataforma de ensaios dinâmicos é apresentado no capitulo sete.

No oitavo capitulo se colocam as principais conclusões e sugestões para trabalhos futuros. 


\section{REVISÃO BIBLIOGRÁFICA}

\subsection{CONCEITOS E GENERALIDADES}

\subsubsection{Estudos anteriores sobre amortecedores de massa sintonizada}

Allen e Pernica (1984) colocaram um absorvedor dinâmico para reduzir as vibrações de pisos com grandes vãos. Como médio de pesquisa os autores utilizaram uma plataforma experimental da Division of Building Research, National Research Council of Canada, na qual realizaram ensaios experimentais para comparar as curvas gráficas de resposta da estrutura com e sem o absorvedor dinâmico. Com as curvas gráficas anteriores se forneceram regras e fórmulas para orientar a construção de absorvedores de piso com parâmetros ótimos.

Thornton et al (1990) estudaram dois casos nos quais utilizaram AMSM (Amortecedores de Massa Sintonizados Múltiplos). O primeiro caso estudado é um colégio onde as acelerações do pavimento do primeiro andar eram de $2,5 \% \mathrm{~g}$ e as acelerações do pavimento do segundo andar eram de $0,6 \% \mathrm{~g}$, sendo $\mathrm{g}$ a aceleração da gravidade. Este nível de vibração foi induzido por atividades rítmicas que tiveram lugar dentro da academia e ocorreram em um intervalo de frequência de 2 até $2,5 \mathrm{~Hz}$. O coeficiente de amortecimento do segundo andar foi medido como sendo inferior a $1 \%$ do amortecimento crítico. A análise modal do segundo andar revelou que os quatro primeiros modos se caracterizam pelas frequências 4,0;4,6;5,3 e 6,2 Hz, respectivamente.

$\mathrm{O}$ amortecimento associado ao primeiro modo de vibração foi reportado em $1,7 \%$ e para o segundo modo de vibração foi de $0,9 \%$. Oito AMSM foram projetados e sintonizados nas frequências naturais da estrutura e instalados no prédio do colégio. Os amortecedores foram suspensos embaixo das vigas T de concreto do piso da academia. Após a instalação dos AMSM o primeiro e segundo andar apresentaram razões de redução nas vibrações maiores que dois. A localização dos AMSM no prédio do colégio se mostra na Figura 2.1.

O segundo caso estudado apresentado por Thornton et al (1990) foi de um prédio de universidade de 7 andares. No quinto e sexto andar, correspondentes à academia dos estudantes, as vibrações produzidas pelas atividades físicas produziam vibrações desconfortáveis no piso. Estas vibrações foram sentidas desde o segundo andar. 
A frequência fundamental do sistema era o dobro da frequência característica de atividades aeróbicas. AMSM foram projetados e apresentados em dois tipos de solução. A primeira é um esquema implementando pequenas unidades de AMS em locais específicos da estrutura, disfarçados de mobiliário nos espaços e suspensos abaixo do piso da academia. Os pesos dos AMSM variavam na faixa de 50.000 e 100.000 libras.

O segundo sistema envolveu o tratamento do sétimo andar, com 3 AMSM sintonizados em uma frequência de 3,5 Hz. Na Figura 2.1 se apresenta a localização dos AMSM tanto para o colégio como para a universidade.

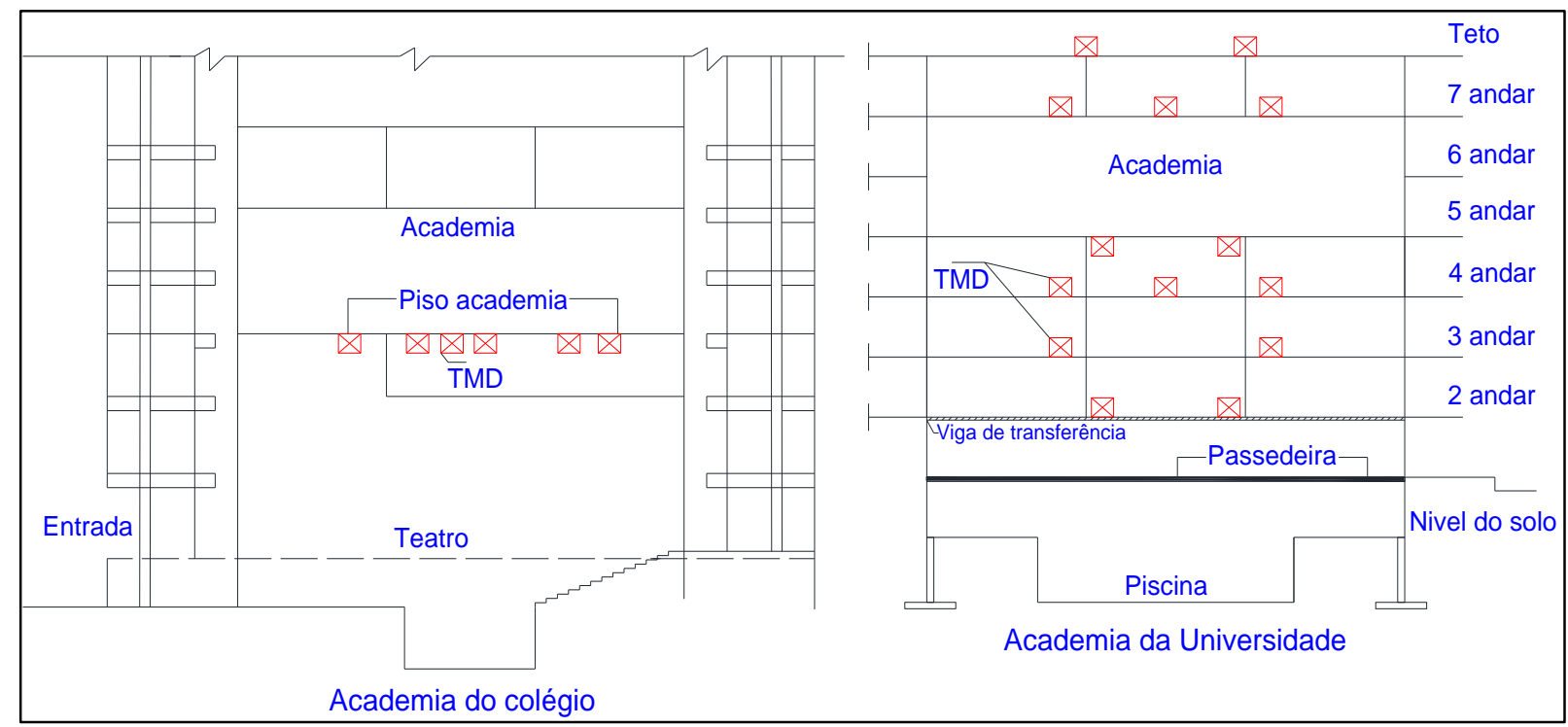

Figura 2.1 - Localização dos AMSM nos casos estudados por (Thornton et al, 1990)

Webster e Vaicaitis (1992) implementaram com sucesso um AMS para reduzir as vibrações de uma laje mista em balanço de um restaurante do edifício Terrace on the Park Building, localizado na cidade de New York. As vibrações eram produzidas por pessoas que dançavam, e causavam desconforto aos ocupantes de um restaurante durante o jantar, chegando a acelerações de 0,07 do valor da gravidade (g) e deslocamentos verticais de 3,3 mm. Comparando este valor com o limite aceitável para pisos de restaurante que, segundo Allen (1990), é de 0,03 g, pode-se observar que os valores são superiores aos limites. A estrutura tinha frequência fundamental de $2,3 \mathrm{~Hz}$. Os autores utilizaram o método das potencias médias de (Meirovitch,1967) obtendo experimentalmente o amortecimento do primeiro modo de vibração na área do restaurante de $2,8 \%$ do amortecimento crítico. Para reduzir as vibrações foram 
implementados AMSM, na ponta da viga em balanço, um dos pontos de maiores amplitudes de vibração. Com a colocação dos AMSM se conseguiu uma redução das vibrações de até um $60 \%$. O custo dos quatro AMSM foi de US \$ 220.000 o que representou menos de $15 \%$ do custo total estimado na construção do reforço estrutural (com novas colunas entre a sala de dança y o solo).

Na Figura 2.2 se mostra uma planta com a distribuição das vigas do prédio e a área atingida da sala de dança e do restaurante.

Na Figura 2.3 se apresenta a seção transversal 1-1 indicada na Figura 2.2 com a localização de um dos AMSM.
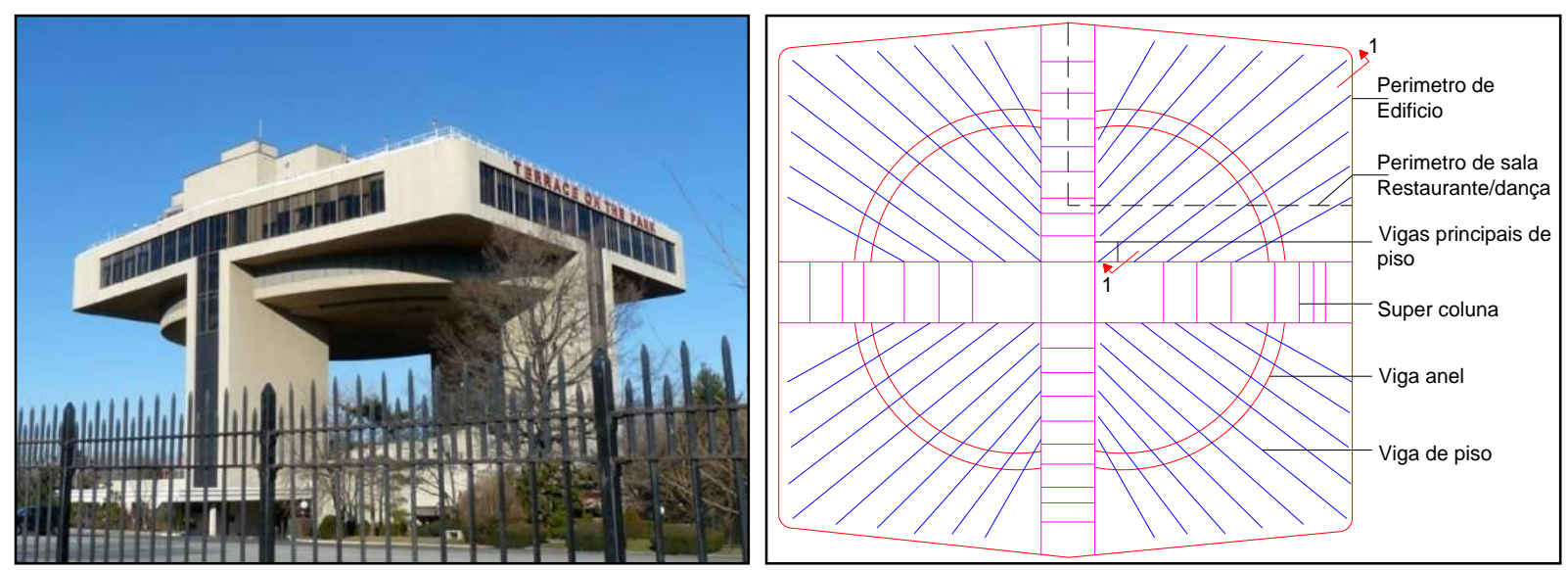

Figura 2.2 - Panorâmica e vista em planta do prédio com área afeitada pelas vibrações. (Webster e Vaicaitis, 1992).

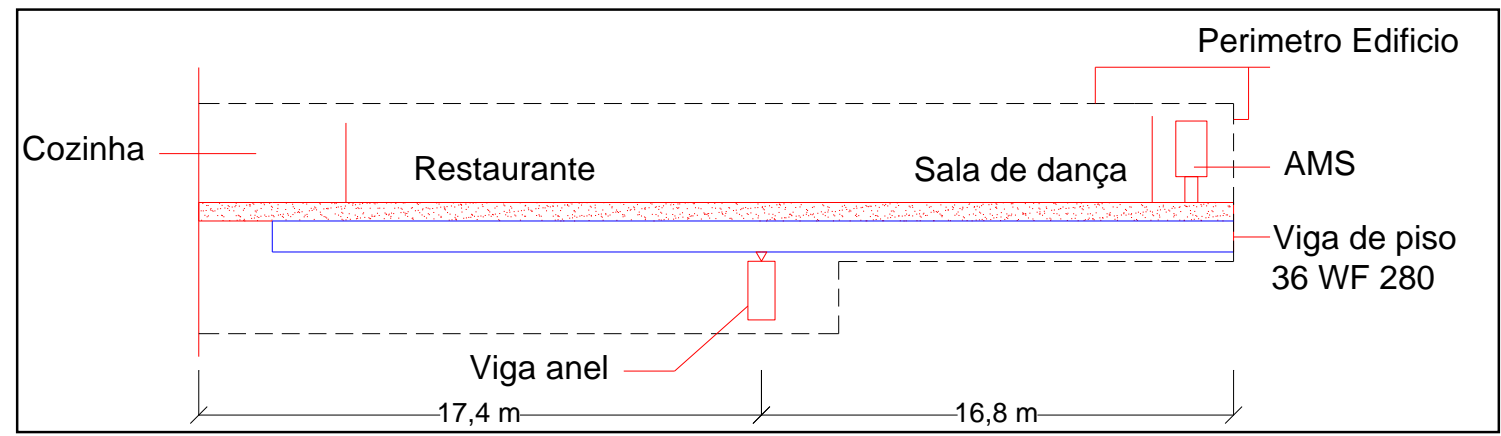

Figura 2.3 - Seção 1-1 do quadrante afeitado pelas vibrações provenientes da sala de dança (Webster e Vaicaitis, 1992).

Setareh e Hanson (1992) implementaram um sistema de AMSM para atenuar as vibrações de um camarote de teatro, na cidade de Detroit, Michigan, no qual se apresentavam concertos ao vivo. A estrutura do palco do teatro foi construída com treliças, vigas longitudinais e vigas transversais em balanço. Uma pesquisa experimental das vibrações do camarote foi realizada. 
No momento dos ensaios experimentais o camarote estava vazio sem pessoas e sem tapetes. Com o uso de um excitador eletromagnético (shaker) e transdutores se realizou o ensaio e se registrou a resposta dinâmica do sistema. As duas primeiras frequências naturais resultaram 2,93 e 4,24 Hz respectivamente. O amortecimento respectivo foi estimado entre 1,39\% e 1,83\%. Durante uma apresentação ao vivo com o teatro lotado as duas primeiras frequências naturais foram medidas como 2,75 e 3,85 Hz. Foi desenvolvido também um modelo computacional da estrutura incorporando o peso do esqueleto estrutural e do teto falso. As primeiras duas frequências naturais foram 3,16 e 4,54 Hz. Os respectivos amortecimentos modais foram 1,6\% e $1,1 \%$. Para estimar a resposta do camarote lotado, foi adicionado o peso dos assentos ao modelo. Com o novo modelo as duas primeiras frequências foram 2,55 e $3,68 \mathrm{~Hz}$ respectivamente.

Cinco AMSM foram construídos. Cada AMS é composto por chapas de aço, 8 molas e 2 amortecedores. Os parâmetros otimizados de sintonização foram determinados usando um modelo equivalente de um grau de liberdade. Dois AMSM com peso de 4000 libras foram implementados para atuar nos pontos de máxima amplitude do primeiro modo de vibração da estrutura, e três AMSM com peso de 2000 libras foram utilizados para atuar também nos pontos de máxima amplitude do segundo modo de vibração. Uma nova avaliação experimental das vibrações do camarote indicou acelerações na faixa de $2 \% \mathrm{~g}$ até $7 \% \mathrm{~g}$ dependo da ocupação e do tempo de registro das medições, faixa considerada aceitável segundo o critério da ISO. Em relação às vibrações originais foi registrada uma queda de aproximadamente $78 \%$.

Um estudo para eliminar as vibrações desconfortáveis de uma passarela de um museu foi feita por Bell (1994) colocando AMSM. Dentro do museu foi instalada uma laje, que funcionava como uma passarela, de frequência $3,7 \mathrm{~Hz}$ e amortecimento de $1 \%$. A laje da passarela foi construída com duas vigas longarinas e vigas transversais, esta laje de passarela apresentou vibrações que provocaram desconforto aos usuários do museu.

Como solução foi colocado um sistema de AMS que pesava $878 \mathrm{~kg}$, composto de molas e de um amortecedor viscoso. O sistema de AMS foi suspenso abaixo do centro da laje da passarela. O amortecimento do sistema aumentou assim de $1 \%$ para 5,8\%. Depois da instalação do mecanismo de controle as vibrações na laje da passarela resultaram aceitáveis. 
Na pesquisa de Ritchey (2003), foi utilizada uma plataforma de ensaios experimentais localizada no Laboratório de Estruturas e Materiais da Universidade Politécnica, em Virginia, Estados Unidos. A finalidade do estudo foi propor e estabelecer o desempenho de um amortecedor semiativo magneto-reológico para mitigar as vibrações do piso da plataforma. Para lograr a redução das amplitudes de vibração na plataforma da maneira mais eficiente foram comparadas as respostas analíticas e experimentais de um amortecedor semi-ativo tipo pêndulo e um amortecedor passivo tipo pêndulo.

A geometria da plataforma se mostra na Figura 2.4, na qual se observa a localização do AMS Já na Figura 2.5 se indicam os dos tipos de amortecedores dos ensaios experimentais, o amortecedor da esquerda é o amortecedor passivo AMS tipo pêndulo e o da direita é amortecedor semi-ativo magneto-reológico que retroalimenta o AMS tipo pêndulo. Os amortecedores foram testados em ensaios dinâmicos mediante excitações com um agitador (shaker) em uma faixa de frequências de 4 a $15 \mathrm{~Hz}$ durante 20 segundos, com a plataforma sem ocupantes. O segundo tipo de ensaio realizado considerou a plataforma com ocupantes, em grupos de pessoas de 2, 4, 6, 8, 12 e 16 de peso médio aproximado de 180 libras, em pé, sentados e em pé com os joelhos semidobrados. Foram realizados ensaios com o agitador (shaker) e com carregamentos gerados pelo impacto do calcanhar e por pessoas caminhando.

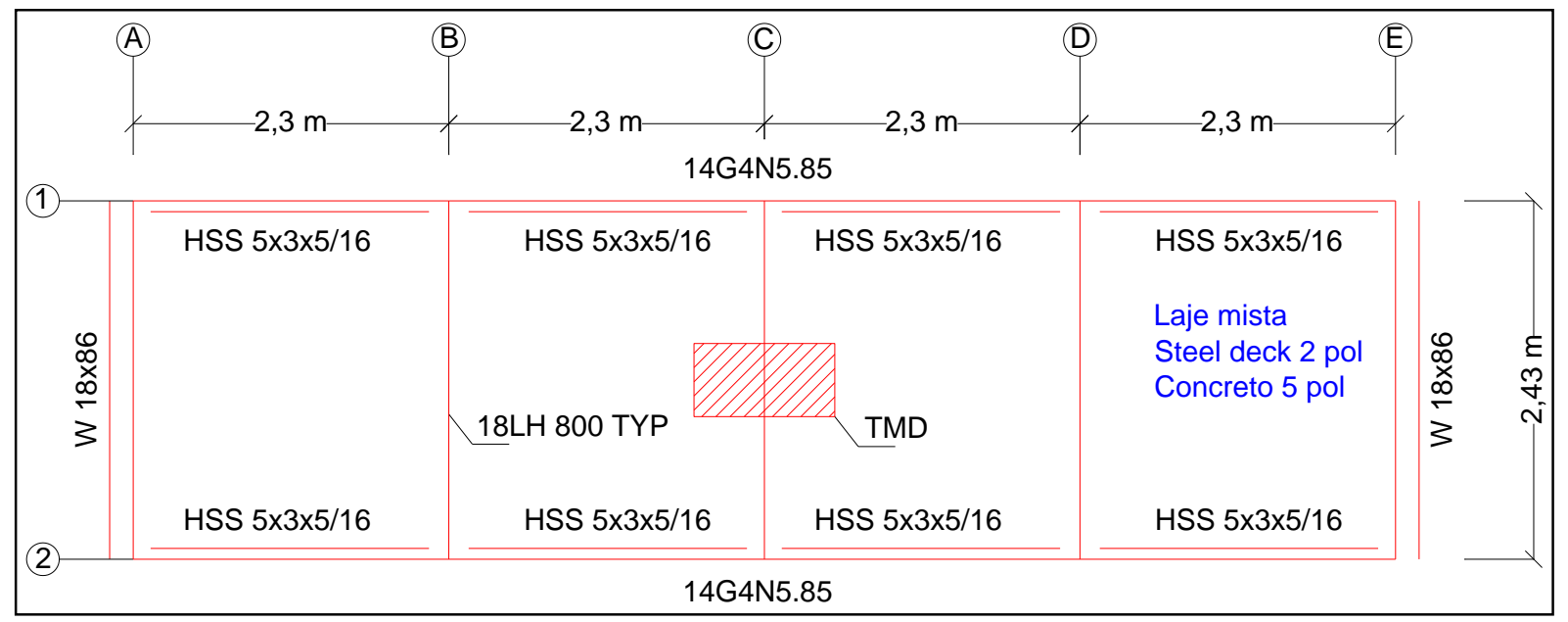

Figura 2.4 - Vista em planta da plataforma experimental (Ritchey, 2003). 


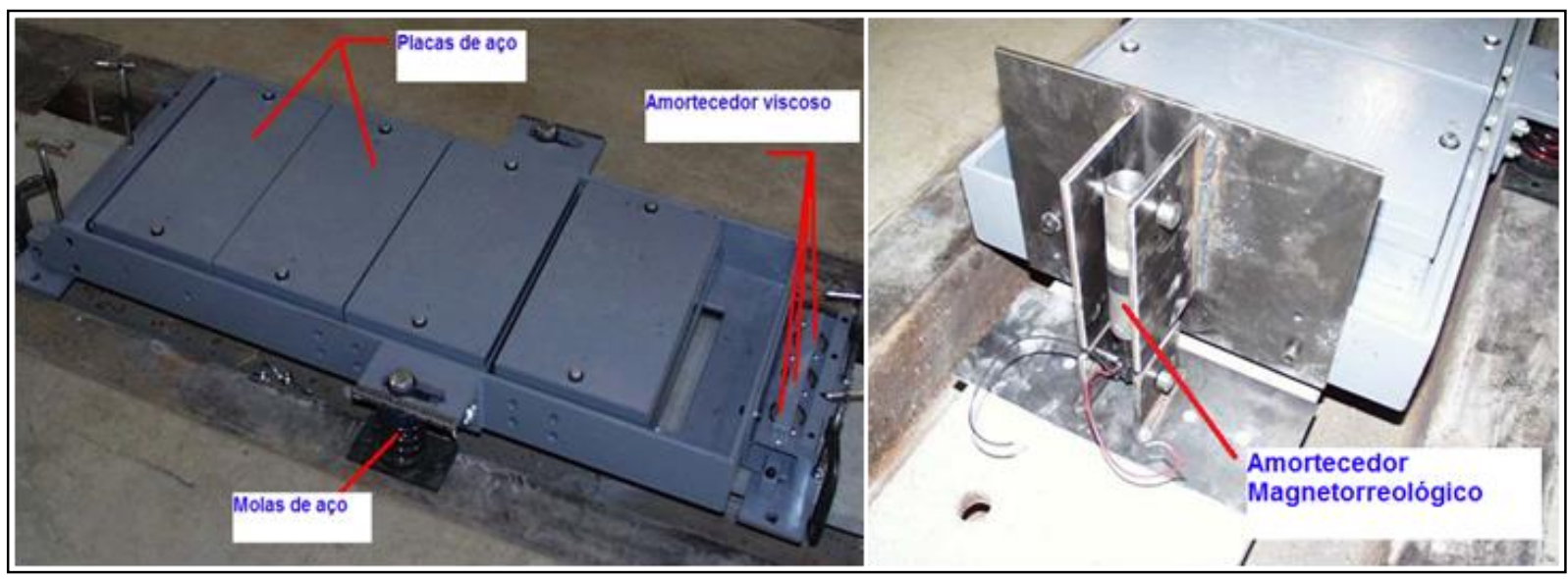

Figura 2.5 - Amortecedores passivo e semi-ativo tipo pêndulo, utilizado nos ensaios experimentais (Ritchey, 2003)

A frequência de vibração de ressonância da plataforma foi de $7,4 \mathrm{~Hz}$, e foi para esse valor de frequência que os amortecedores passivo e semi-ativo foram sintonizados.

Os autores concluíram que existe pouca diferencia na eficiência do amortecedor semi-ativo e do amortecedor passivo tipo pêndulo otimizado. Contudo, o sistema de amortecedor semi-ativo tipo pêndulo mostra-se um pouco melhor do que o sistema passivo na resposta de redução das vibrações produzidas por seres humanos.

Koo (2003) realizou um estudo numérico com um modelo de pórtico de dois grados de liberdade simulando um prédio de dois andares, onde a estrutura primaria é acoplada com um TVA (Absorvedor de Vibrações Sintonizado). Esta pesquisa considera quatro métodos de controle semi-ativo regulando o amortecimento com TVAs magneto-reológicos usando técnicas de otimização. O estudo experimental é realizado com um sistema de dois grados de liberdade acoplado a um TVA magneto-reológico, comparando o desempenho do amortecedor passivo e semi-ativo. Este estudo experimental justifica os benefícios da utilização dos amortecedores semi-ativos TVA magnetorreológicos em aplicações de controle de vibrações em pisos de edifícios. Na Figura 2.6 se mostra o modelo matemático e as componentes do sistema onde se realizaram as provas experimentais. 


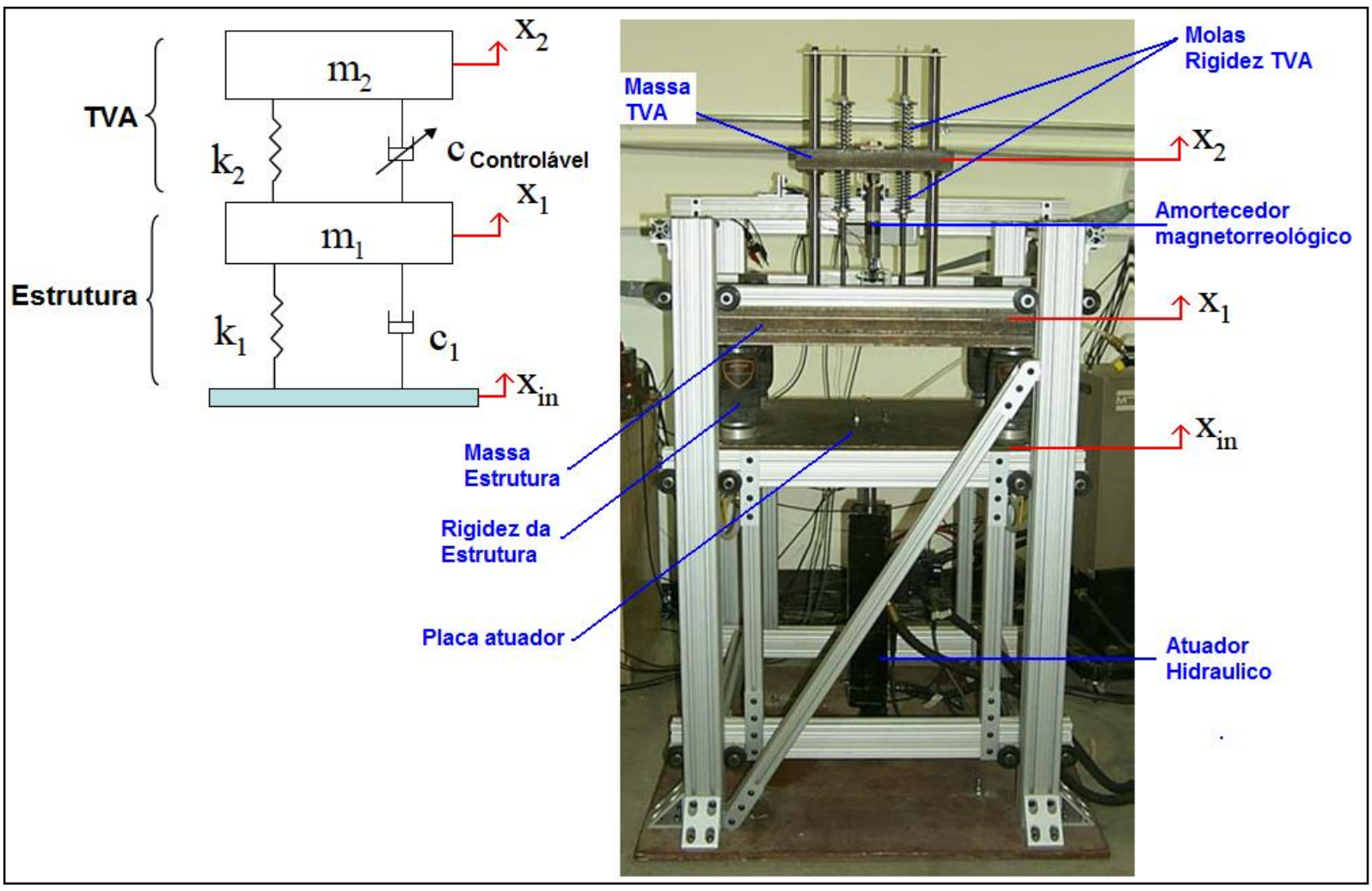

Figura 2.6 - Modelo experimental de dois graus de liberdade e componentes do sistema (Koo, 2003).

Os autores concluíram após os ensaios experimentais que o desempenho do amortecedor semiativo TVA magneto-reológico teve um melhor desempenho na redução das amplitudes de vibração do que seu equivalente passivo TVA. Além disso, o amortecedor magneto-reológico semi-ativo mostrou-se mais eficaz quando submetido a mudanças de parâmetros do sistema em comparação com o TVA passivo.

Duas configurações diferentes de AMS foram analisadas, com a finalidade de reduzir as amplitudes das vibrações de um piso que se utilizava como laboratório de química, onde microscópios sensíveis estavam em uso, e as vibrações observadas eram devidas ao caminhar das pessoas, Shope e Murray (1995) apud Hanagan et al (2003). O piso do laboratório que apresentava níveis de vibrações excessivas e no qual se realizaram os testes experimentais de controle passivo é mostrado na Figura 2.7. Utilizando a otimização de parâmetros para um AMS segundo Reed (1988) foram projetados AMSM. O primeiro amortecedor que foi testado no laboratório é um TLD (Amortecedor Liquido Sintonizado). Para excitar o piso do laboratório foi considerado o impacto produzido pelos calcanhares de uma pessoa. Dos ensaios foram 
obtidas as duas primeiras formas modais da estrutura e as duas primeiras frequências naturais que foram de 7,3 Hz e $17 \mathrm{~Hz}$ respectivamente. Além dos ensaios com os calcanhares foram feitos ensaios com pedestres caminhando perpendicularmente aos perfis principais de aço que suportam a laje. Instalaram-se quatro TLDs nos pontos de maior amplitude de vibração das duas primeiras formas modais, dois para cada modo de vibração. Com a instalação dos TLDs as acelerações pico médias foram reduzidas de $0,06 \mathrm{~g}$ para $0,01 \mathrm{~g}$ Na Figura 2.8 se mostra o desenho do TLD.

Uma segunda configuração de AMS foi testada no piso do laboratório de química e foram instalados 3 AMSM sintonizados nas frequências de 7,395; 9,375 e 16,75 Hz respectivamente Rottmann e Murray (1996) apud Hanagan et al (2003). Para reduzir as amplitudes de vibração do piso da primeira forma modal foi instalado um AMS no centro do pavimento, para a segunda forma modal se colocou outro AMS na borda lateral do laboratório, e por último, para controlar a terceira forma modal se colocou um AMS na borda lateral oposta do segundo AMS. Na Tabela 2.1 se apresentam as frequências e as relações de massa ótimas dos AMSM. Os valores médios quadráticos das acelerações induzidas (rms) pelos pedestres caminhando paralelamente aos perfis de aço foram reduzidas num fator de 5,5 e as devidas à caminhada perpendicular aos perfis foram reduzidas em um fator de 3,7. O segundo AMS se mostra na Figura 2.9.

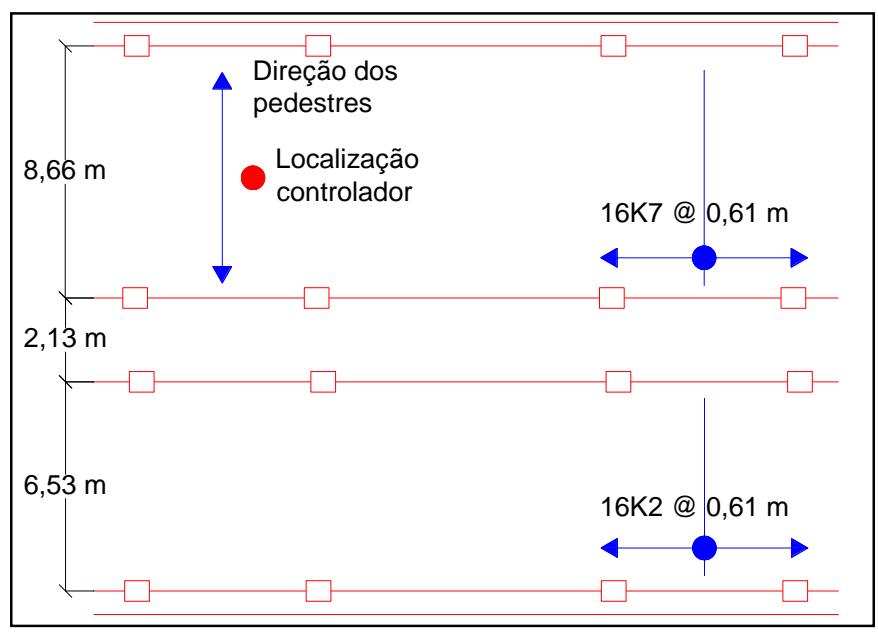

Figura 2.7 - Planta do laboratório de química, Shope e Murray (1995) apud (Hanagan et al, 2003). 


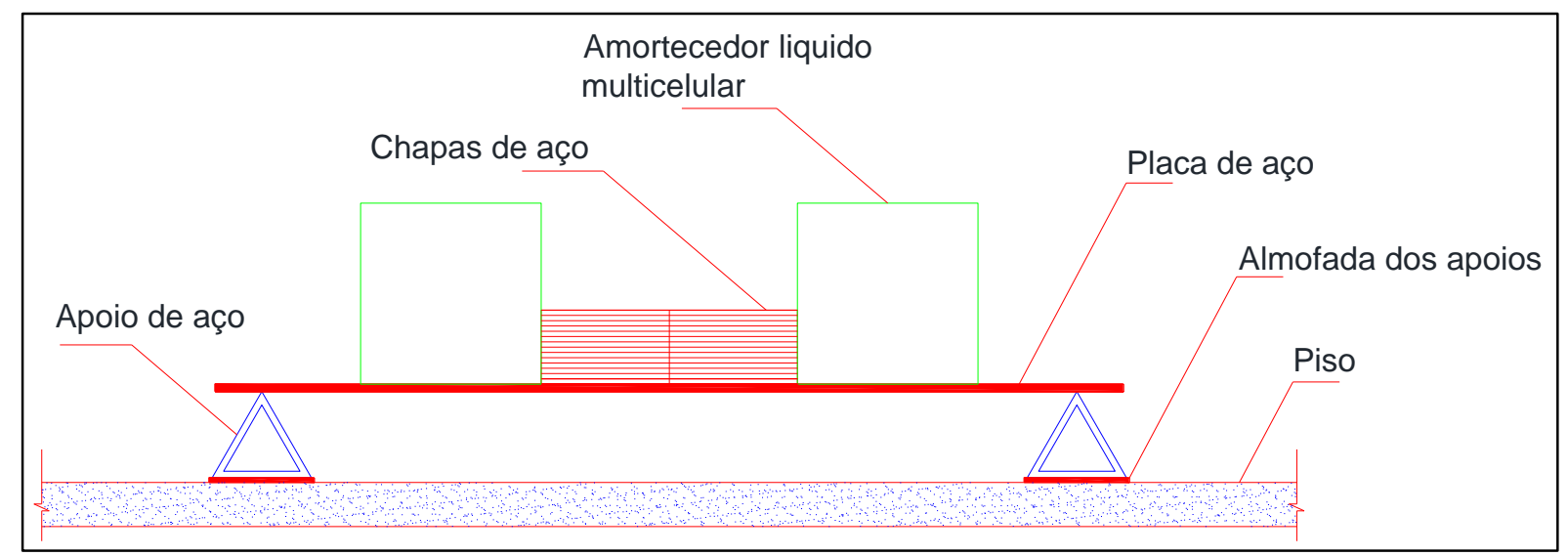

Figura 2.8 - Amortecedor Líquido Sintonizado TLD, utilizado no laboratório de química, Shope e Murray (1995) apud (Hanagan et al, 2003).

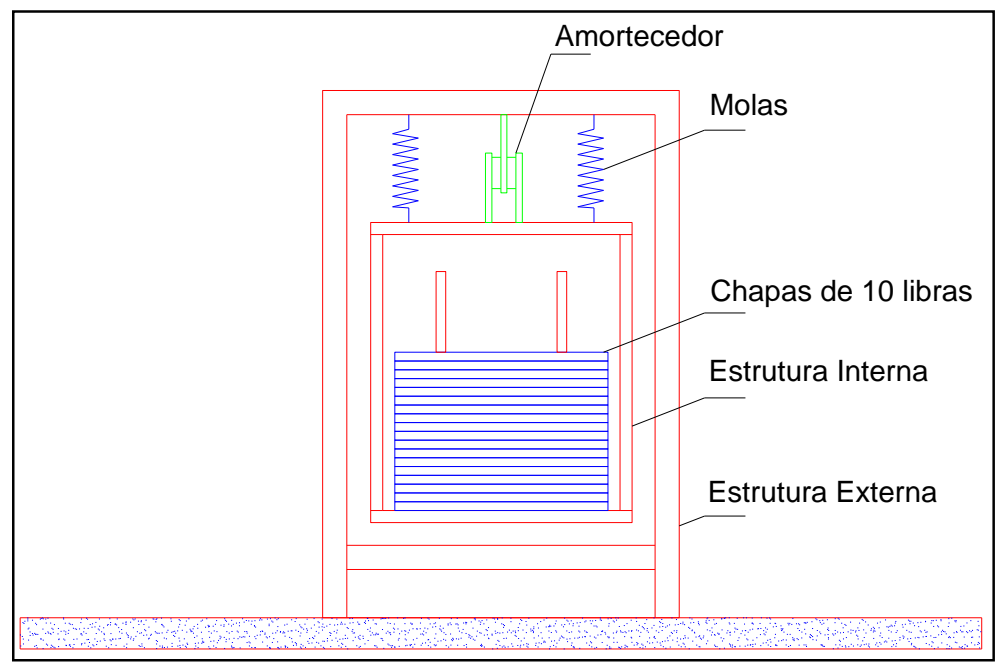

Figura 2.9 - AMS, utilizado no laboratório de química, Rottmann e Murray (1996) apud (Hanagan et al, 2003).

Tabela 2.1 - Frequências e razões ótimas dos AMSM, instalados no laboratório Rottmann e Murray (1996) apud (Hanagan et al, 2003).

\begin{tabular}{|c|c|c|}
\hline $\begin{array}{c}\text { Amortecedor de Massa } \\
\text { Sintonizado }\end{array}$ & Frequência AMSM (Hz) & Razão de Massas \\
\hline AMS 1 & 6,45 & 0,057 \\
\hline AMS 2 & 9,17 & 0,057 \\
\hline AMS 3 & 15,94 & 0,0912 \\
\hline
\end{tabular}

Varela, (2004) projetou ADS (Atenuadores Dinâmicos Sintonizados) para uma plataforma experimental localizada no Laboratório de Estruturas da Universidade Federal do Rio de Janeiro, COOPE. Foi instalado um sistema composto por dois ADS no centro da laje, com 
massas acopladas totalizando 94,4 kg e com taxa de amortecimento média de 1,5\%. Os ADS foram calibrados para atenuar as vibrações do primeiro modo da estrutura, que é o modo que apresenta as maiores amplitudes de respostas quando a estrutura é excitada pelo caminhar das pessoas. Dos ensaios experimentais pode-se concluir que os ADS reduzem bastante as amplitudes de vibração da estrutura, e, portanto, mostram-se eficientes. O autor sugere que para atender à norma 2631-2 (ISO, 1989), o sistema pode ser melhorado dobrando o número de ADS instalados na região central da estrutura, totalizando 1,0\% da massa modal (Battista, 1993).

O ADS e a plataforma onde foi utilizado o atenuador se mostram na Figura 2.10

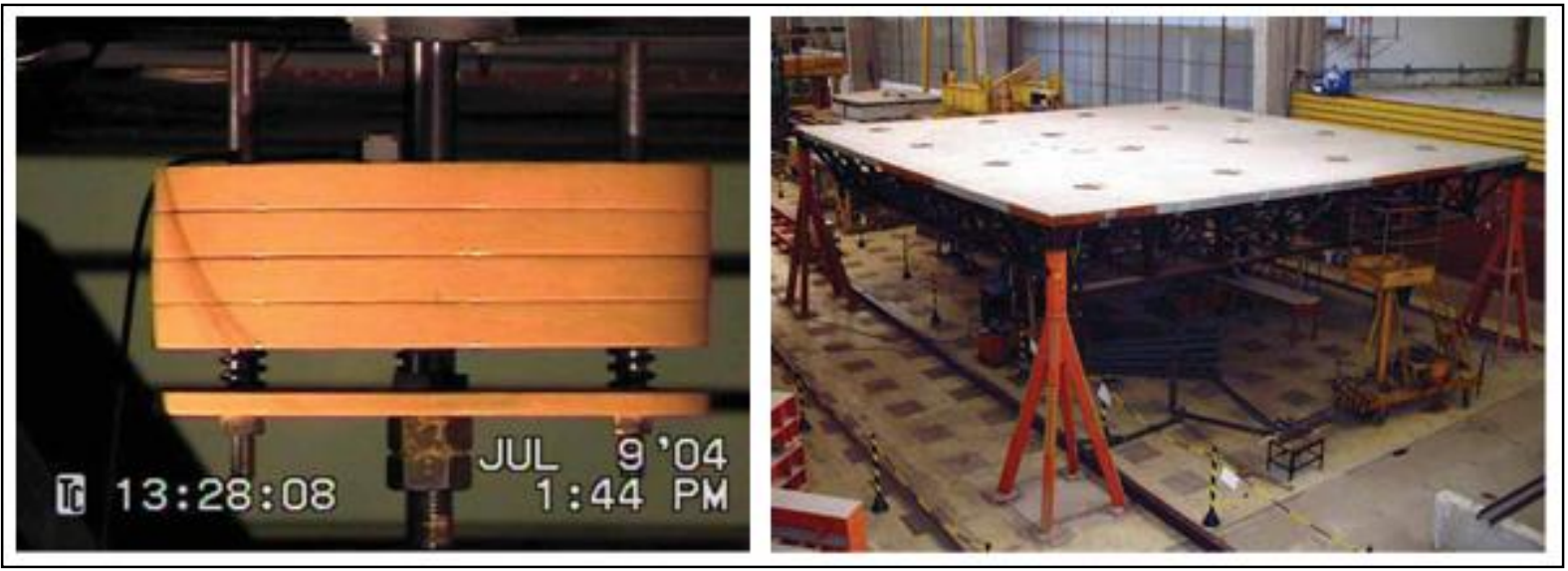

Figura 2.10 - Atenuador Dinâmico Sintonizado acoplado na plataforma experimental da Universidade Federal de Rio de Janeiro (Varela, 2004).

Um modelo em escala de um piso típico de escritório no qual se apresentam vibrações desconfortáveis foi estudado por Al-Hulwah et al (2005). O modelo é suportado por 4 colunas. As dimensões do modelo de piso são 1,27 x 0,76 m. O principal objetivo de fabricar este modelo em escala em um laboratório é verificar a eficácia de um mecanismo do amortecedor para piso proposto pelos autores. Nos ensaios experimentais, um acelerômetro e um excitador eletromagnético (shaker) são colocados perto do centro do modelo com a finalidade de encontrar os diferentes modos de vibração. O estudo experimental mostrou que as duas primeiras frequências naturais do modelo foram de 9,4 Hz e 13,1 Hz respectivamente. Na Tabela 2.2 se apresentam as frequências naturais e as taxas de amortecimento correspondente aos dois primeiros modos de vibração do modelo em escala. 
Tabela 2.2 - Parâmetros experimentais modais do piso. (Al-Hulwah et al, 2005)

\begin{tabular}{|c|c|c|}
\hline Modo & Frequência (Hz) & Amortecimento (\%) \\
\hline 1 & 9,375 & 5,8 \\
\hline 2 & 13,1 & 1 \\
\hline
\end{tabular}

Para mitigar as vibrações relacionadas com o primeiro modo de vibração foi colocado um AMS de 3 graus de liberdade, no centro do modelo. A contribuição mais importante proposta por este tipo de sistema é que não requere tanto amortecimento em comparação com um AMS de 1 grau de liberdade. Foi realizado previamente um estudo analítico, o qual indicou que uma taxa de amortecimento de $3 \%$ era adequada para cada um dos três amortecedores que conformavam o AMS de 3 graus de liberdade. Cada amortecedor consiste em uma viga em balanço (agindo como uma mola) e uma massa na ponta. Os dois tipos de amortecimento utilizados são: a) amortecimento de Coulomb e b) amortecimento viscoelástico. Cada viga em balanço é construída a partir de duas laminas de alumínio de seção transversal 2,54 x 1,59 mm e comprimento de 17,02 cm, as quais são aparafusadas uma à outra. Quando a viga começa a vibrar, as duas laminas de alumínio friccionam entre elas produzindo o amortecimento de Coulomb, obtendo-se uma taxa de amortecimento de 3,3\%. A segunda forma considerada para proporcionar amortecimento baseia-se na a utilização de materiais viscoelásticos. Assim utilizaram-se duas laminas de alumínio e um material viscoelástico de espessura de $10 \mathrm{~mm}$, fabricado pela empresa 3M. A construção do sistema do AMS consistiu em duas seções de material viscoelástico formando um sanduiche com as laminas de alumínio, como se mostra na Figura 2.11. Foi obtida uma taxa de amortecimento de $10 \%$ com a utilização deste material viscoelástico.

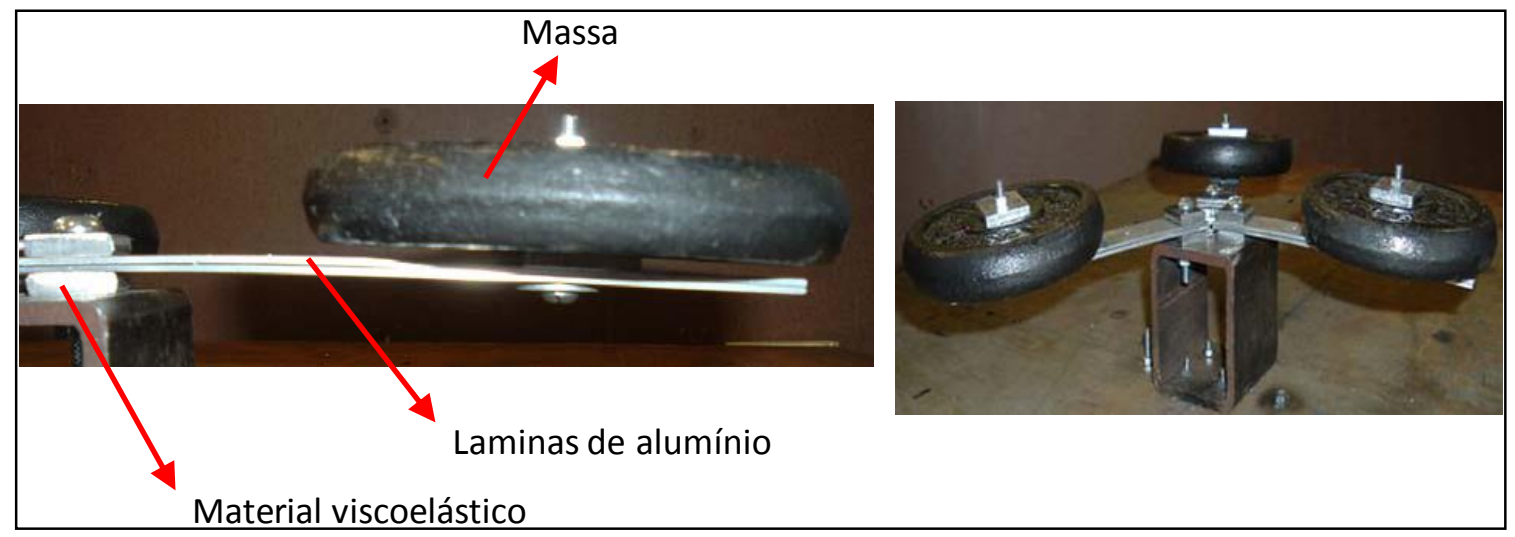

Figura 2.11 - Amortecedor viscoelástico de 3 graus de liberdade. (Al-Hulwah et al, 2005) 
A primeira viga do AMS de 3 graus de liberdade foi sintonizada em uma frequência de 9,375 $\mathrm{Hz}$, com um comprimento efetivo para colocar a massa concentrada de $11,43 \mathrm{~cm}$, os outros dois absorvedores foram sintonizados em frequências de $8,75 \mathrm{~Hz}$ e $10 \mathrm{~Hz}$ com comprimentos efetivos de 12,07 cm e 10,16 cm respectivamente. Em resumo pode-se dizer que com este tipo de amortecedor viscoelástico de 3 graus de liberdade, o piso passou de uma taxa de amortecimento para o primeiro modo de vibração de 5,8\% sem utilização do AMS, para uma taxa de amortecimento de $12 \%$ com o AMS, o que significa o dobro de eficiência na redução das vibrações.

As reduções das vibrações produzidas por pedestres em duas passarelas localizadas nas cidades de Poznan e Wroclaw na Polônia foram estudadas por Fiebig (2010). As oscilações foram diminuídas utilizando AMS. A máxima resposta de vibração vertical foi de $15 \mathrm{~cm}$. Os cálculos dos parâmetros dos AMS como massa efetiva, rigidez das molas e taxa de amortecimento, foram realizados a partir de um sistema de dois graus de liberdade. Finalmente foi decidida a instalação de 3 AMS. O primeiro e segundo AMS foram instalados a $1 / 4 \mathrm{e}^{3 / 4}$ do comprimento da passarela com uma massa efetiva cada um de $935 \mathrm{~kg}$, os quais atuavam na redução das vibrações correspondentes à primeira forma modal da passarela $(1,33 \mathrm{~Hz})$. $\mathrm{O}$ terceiro amortecedor foi colocado na metade do vão com uma massa efetiva de $2310 \mathrm{~kg}$, atuando na redução das vibrações relacionadas com a segunda forma modal da estrutura $(1,64 \mathrm{~Hz})$. Na Figura 2.12 se mostra uma panorâmica da passarela de Poznan e a instalação dos AMSM.
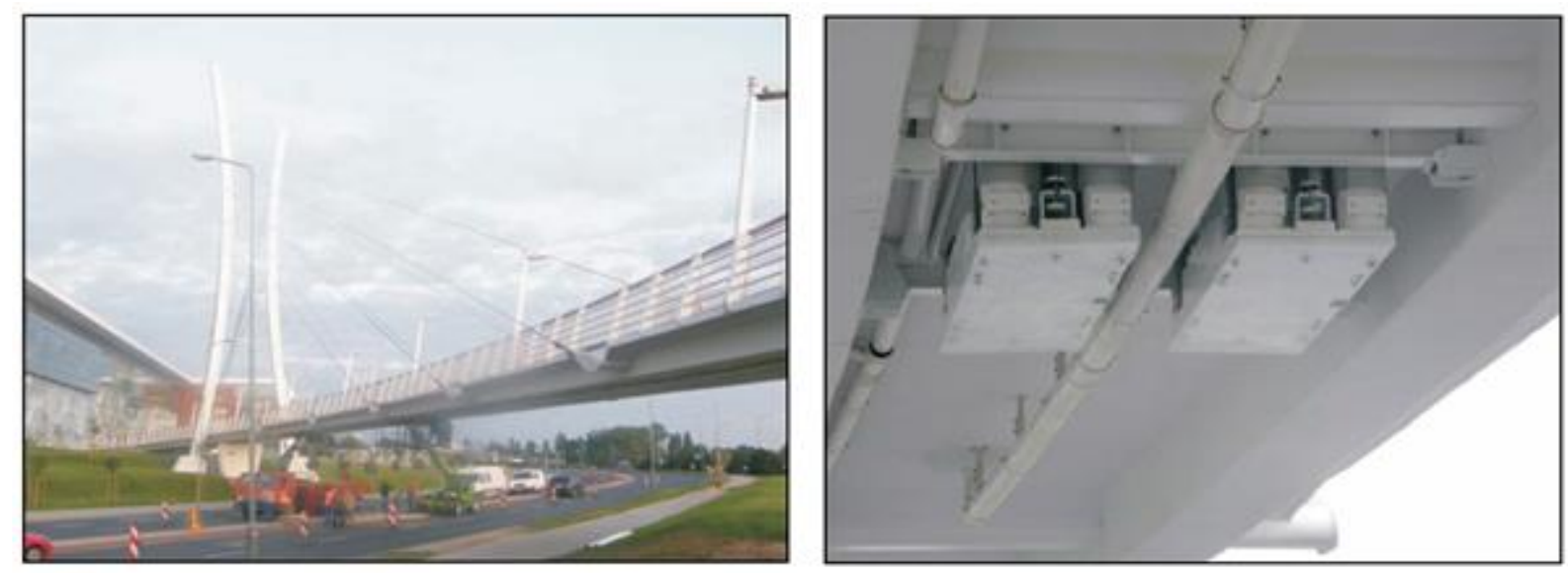

Figura 2.12 - Panorâmica da passarela de Poznan e localização dos AMS, abaixo da passarela com massa total de 5,6 toneladas (Fiebig, 2010). 
Lamb (2011), projetou um AMS para ser aplicado em um modelo de piso misto, que apresentava problemas de vibrações, causando desconforto aos usuários. O sistema de piso misto consiste em uma telha de aço galvanizado de 3 polegadas de profundidade, e uma camada de concreto de 3 polegadas na parte superior da laje. A resistência a compressão do concreto era de fc ${ }^{\prime}=3$ ksi, típico de escritórios de trabalho. O modelo é suportado por quatro perfis de aço como se mostra na Figura 2.13. Nos ensaios experimentais foram obtidas as três primeiras frequências naturais, de 4,6; 12,3 e 17,9 Hz respectivamente. O AMS projetado nessa estrutura consiste em duas vigas em balanço com massa concentradas nas pontas de 200 libras, e sintonizado em uma frequência de $4,5 \mathrm{~Hz}$, próxima da primeira frequência do piso. A posição ideal para a colocação do AMS é onde a amplitude do primeiro modo de vibração é um máximo (positivo ou negativo) que, para o caso do modelo estudado, foi na metade da viga W16x26 mostrada na Figura 2.13. A seção transversal do AMS se mostra na Figura 2.14. Uma análise espectral indicou que com a implementação do AMS no piso a amplitude da frequência para o primeiro modo de vibração foi reduzida em $24,7 \mathrm{~dB}$ na frequência de $4,5 \mathrm{~Hz}$ o que significou em uma redução no valor do primeiro pico em um fator de 17.

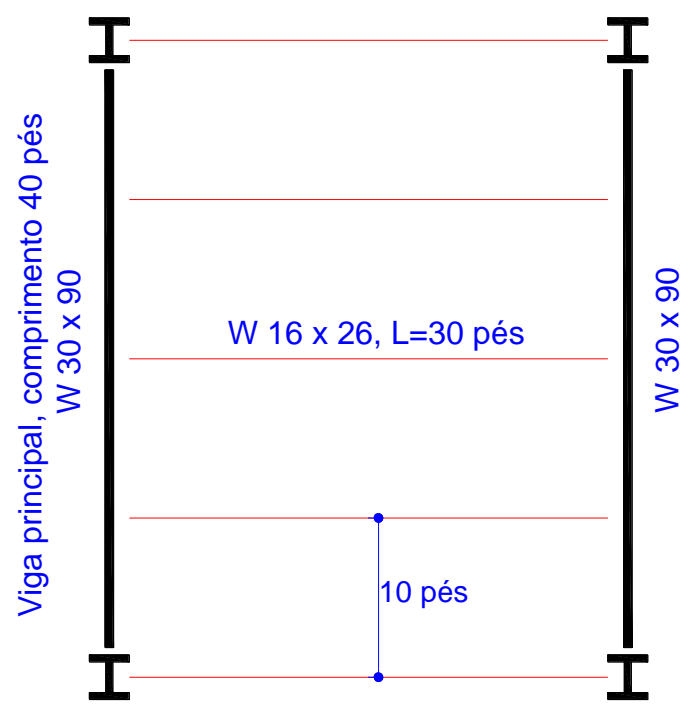

Figura 2.13 - Sistema de piso misto, estudado por (Lamb, 2011). 


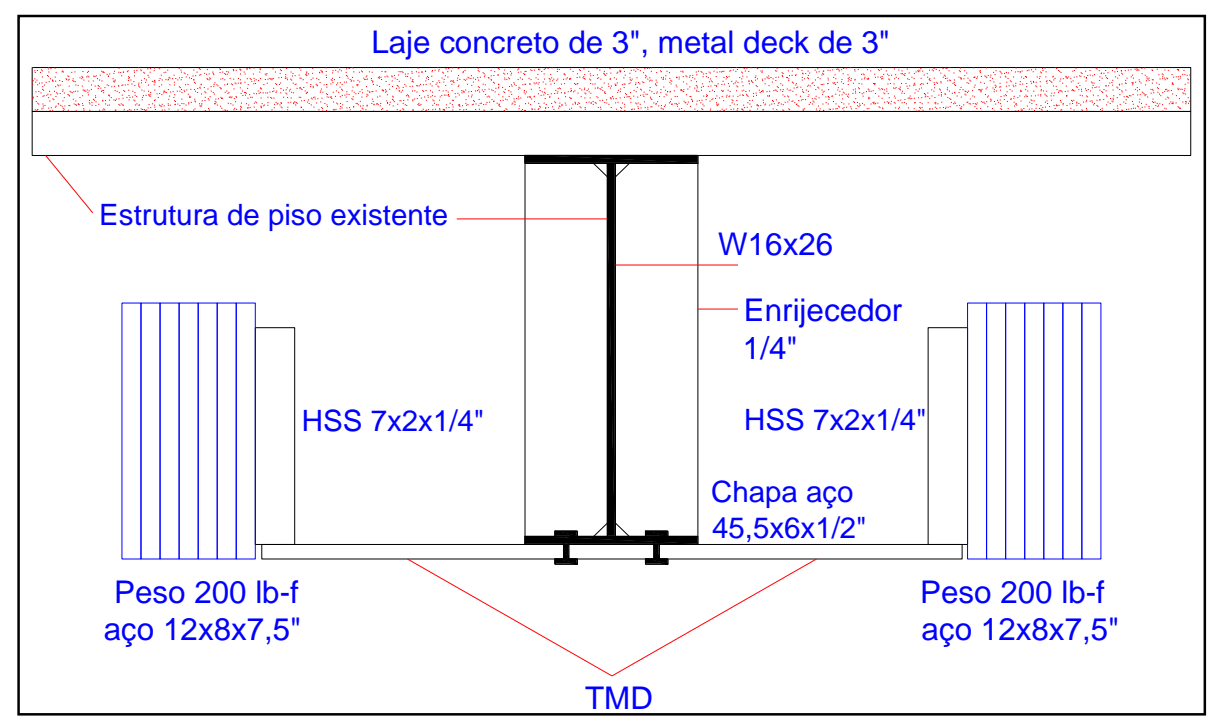

Figura 2.14 - AMS duplo, utilizado na pesquisa de pisos de escritórios com vibrações desconfortáveis (Lamb, 2011)

Saidi (2012) teve como objetivo desenvolver um AMS de maneira simples e com baixo custo, para dar soluções a sistemas de pisos com vibrações desconfortáveis. O amortecedor consiste de uma viga em balanço tipo sanduíche de dois materiais diferentes, limitados no topo e na base com aço e em seu interior com uma borracha viscoelástica. A vantagem deste tipo de amortecedor é que pode ser instalado em espaços de teto falso.

O AMS foi testado em duas vigas, a primeira é uma viga de aço simplesmente apoiada de $3 \mathrm{~m}$ de comprimento, a qual foi testada com uma excitação harmônica aplicada em um ponto localizado a 1/3 do apoio da viga. A frequência de excitação do agitador foi de 6,4 Hz, coincidindo com a frequência fundamental da viga do aço. O AMS foi colocado no centro da viga. As acelerações máximas registradas nos ensaios resultaram de $5,3 \mathrm{~m} / \mathrm{s}^{2}$, que caíram para $0,46 \mathrm{~m} / \mathrm{s}^{2}$ com a utilização do AMS. Na Figura 2.15 se mostra a viga simplesmente apoiada com o AMS e o excitador eletromagnético (shaker). 


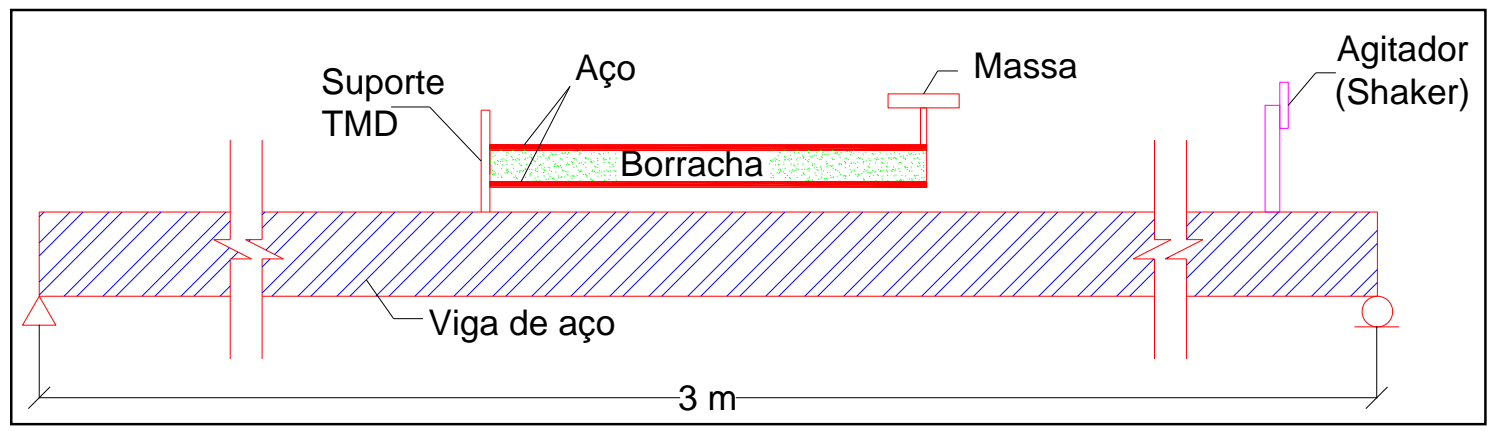

Figura 2.15 - AMS viscoelástico acoplado com viga de aço (Saidi, 2012).

O segundo caso estudado foi uma viga de concreto armado de seção T simplesmente apoiada, de comprimento de $9,5 \mathrm{~m}$, e com uma massa modal de $6000 \mathrm{~kg}$. A viga foi excitada com impactos dos calcanhares e também com um martelo especial. A partir dos ensaios numéricos realizados com o programa comercial de análise modal ARTeMIS encontrou-se a primeira frequência natural de $4,2 \mathrm{~Hz}$ e o amortecimento estrutural do primeiro modo de vibração de $1,9 \%$. O autor projetou um novo AMS viscoelástico com propriedades diferentes às do amortecedor da viga de aço. O novo AMS foi localizado no centro da viga de concreto armado e ajustado na primeira frequência de ressonância da viga.

Dos ensaios experimentais pode-se observar que a viga de concreto armado excitada com impactos dos calcanhares e sem atuação do AMS apresentou frequência natural de 4,2 $\mathrm{Hz}$ e amortecimento do primeiro modo de vibração de $2,9 \%$, já com o AMS o amortecimento foi de $6,1 \%$ obtendo-se um fator de redução das acelerações de 2,0. Para os ensaios com excitações dos pedestres caminhando na viga de concreto armado sem AMS a resposta da estrutura em termos de porcentagens da aceleração da gravidade foi de 2,7\% g e com AMS foi de $2 \% \mathrm{~g}$, o fator de redução na resposta da aceleração devida à excitação dos pedestres foi de aproximadamente 1,4 .

O autor concluiu que o AMS é muito eficiente quando a taxa de amortecimento do sistema principal (viga de concreto armado) é menor que 1\%. Já para valores maiores da taxa de amortecimento, o fator de redução da resposta diminui.

Posteriormente foi analisado um piso típico de escritório com problemas de vibrações, propondo soluções com um AMSM, com base nos estudos das vigas de aço e de concreto armado. Os testes in-situ permitiram identificar a frequência fundamental de $6,2 \mathrm{~Hz}$, a taxa de 
amortecimento de $3 \%$ e a máxima resposta de aceleração devida a excitação dos pedestres ao longo do piso de $0,67 \%$ g, excedendo o máximo nível aceitável para o conforto humano de 0,5\% g.

As acelerações registradas após a instalação do múltiplo amortecedor de massa sintonizado foram na faixa de $0,3 \%$ a $0,4 \%$ g, aceitável para o conforto humano. Na Figura 2.16 se apresenta o sistema múltiplo de AMS que deu solução aos problemas de vibração.

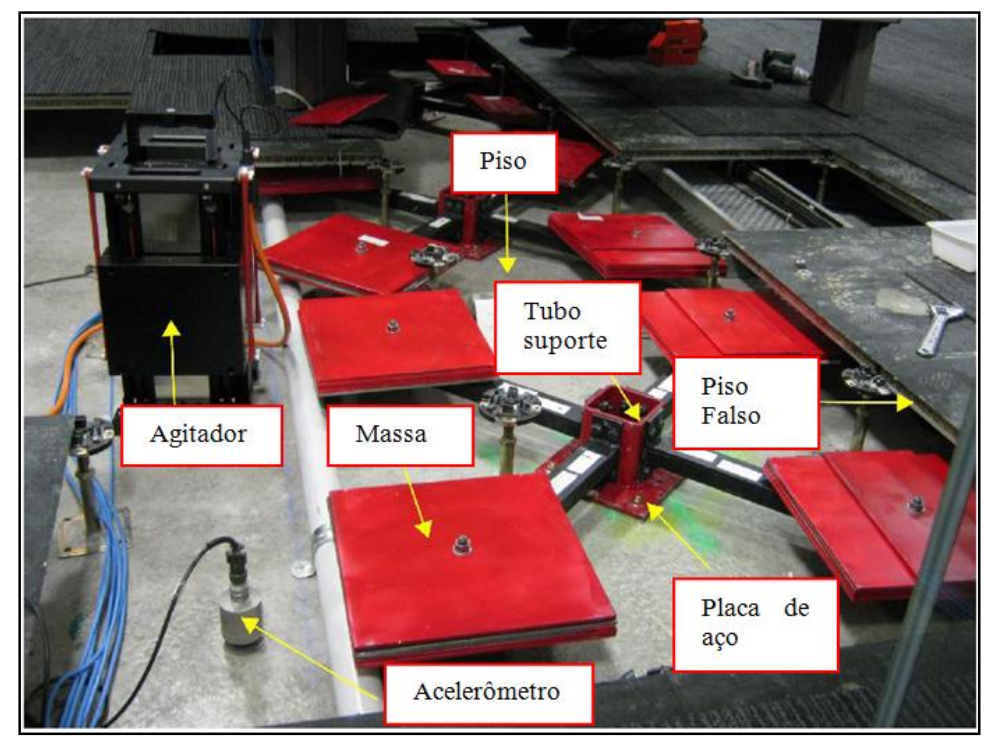

Figura 2.16 - Sistema de AMSM instalado no piso do escritório com problemas de vibrações. (Saidi, 2012)

Lindenberg e Fraczek (2013) projetaram um AMS tipo pêndulo para aplicação em um prédio de dois andares e de 40 anos de idade que foi reformado, e que logo depois da reforma apresentou vibrações significativas devidas ao caminhar das pessoas. O segundo andar foi reformado com lajes de concreto pré-moldadas suportadas por perfis de aço. A área atingida pelas vibrações tem $15,24 \mathrm{~m}$ de comprimento e $14 \mathrm{~m}$ de largura.

Uma série de testes experimentais foi feita com a finalidade de obter as respostas da estrutura tais como: frequências e amplitude de vibração, amortecimento e acelerações do prédio em pontos específicos. Estes ensaios experimentais foram realizados considerando como fonte de excitação a queda do calcanhar de uma pessoa de aproximadamente $91 \mathrm{Kg}$. Destes ensaios foram encontradas as primeiras quatro frequências naturais da estrutura 5,6;6,5; 7,3 e 9,2 Hz. A 
máxima resposta do piso em termos da aceleração da gravidade foi de 2,54 ultrapassando o máximo permitido pelo código AISC 1997, 0,5 \% g aproximadamente entre frequências de vibração de 4 Hz e 10 Hz.

O modelo numérico foi calibrado mediante o pacote de elementos finitos SAP2000 versão 15.1, utilizando técnicas recomendadas por Barret (2006). As primeiras quatro frequências naturais encontradas com este modelo numérico foram de 5,25; 6,25; 7,75 e 9,25 Hz.

Depois de calibrar o modelo os autores optaram pela construção de um AMS tipo pêndulo, para mitigar as vibrações que se apresentavam no prédio.

As características do AMS foram as seguintes: massa efetiva de $750 \mathrm{lb}$ e frequência de ressonância de 5,6 Hz que é próxima da primeira frequência do piso. O AMS tipo pêndulo se mostra na Figura 2.17. Com a colocação do AMS, os picos de aceleração passaram de 2,54\% $\mathrm{g}$ para $0,68 \% \mathrm{~g}$, o que significou um fator de redução de 3,7. As acelerações ponderadas a partir das medições de campo ainda ficaram um pouco acima do limite de conforto humano (AISC, 2003).

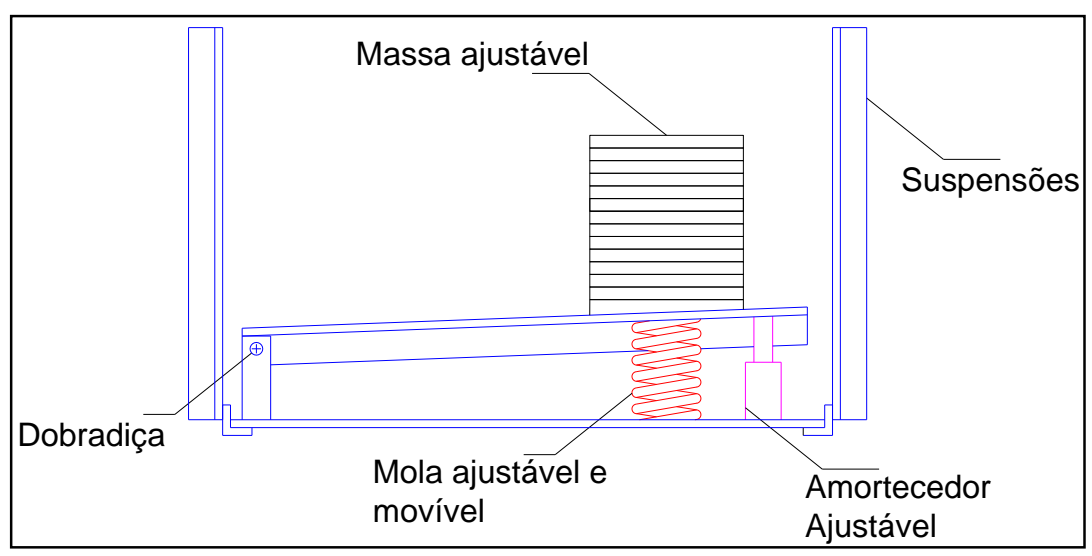

Figura 2.17 - Esboço de protótipo de AMS tipo pêndulo. (Lindenberg e Fraczek, 2013)

Picauly et al (2014) utilizou uma laje de concreto de $4 \mathrm{~m}$ de comprimento, 0,90 $\mathrm{m}$ de largura e 0,08 $\mathrm{m}$ de espessura para testar um tipo de amortecedor de massa sintonizado de dois graus de liberdade com um absorvedor adicional de chapas de metal com formato de $X$. 
A laje foi excitada com um shaker de $1 \mathrm{HP}$ de força. As vibrações foram registradas mediante dois acelerômetros e um sistema de aquisição de dados. A frequência fundamental da plataforma foi de $6,96 \mathrm{~Hz}$ e o amortecedor projetado foi sintonizado para este valor de frequência.

A laje tem uma massa de $691 \mathrm{~kg}$ e a massa efetiva do amortecedor de $13 \mathrm{~kg}$, resultando em uma relação de massas de quase $2 \%$. As chapas de aço que servem de absorvedor foram feitas de dimensões de 2x1mm com resistência de tensão de escoamento de 332,84 Mpa.

A partir dos resultados dos ensaios foram encontradas as taxas dos amortecimentos da laje sem amortecedor, com o AMS, e por último com o AMS melhorado com o absorvedor de chapas de metal com formato $X$. As taxas de amortecimento são: sistema original 1,82\%, sistema de laje de concreto + AMS 2,06\% e por último sistema original + AMS + absorvedor de chapas de metal formato $X 3,40 \%$.

Na Figura 2.18 se apresenta o AMS de dois graus de liberdade.

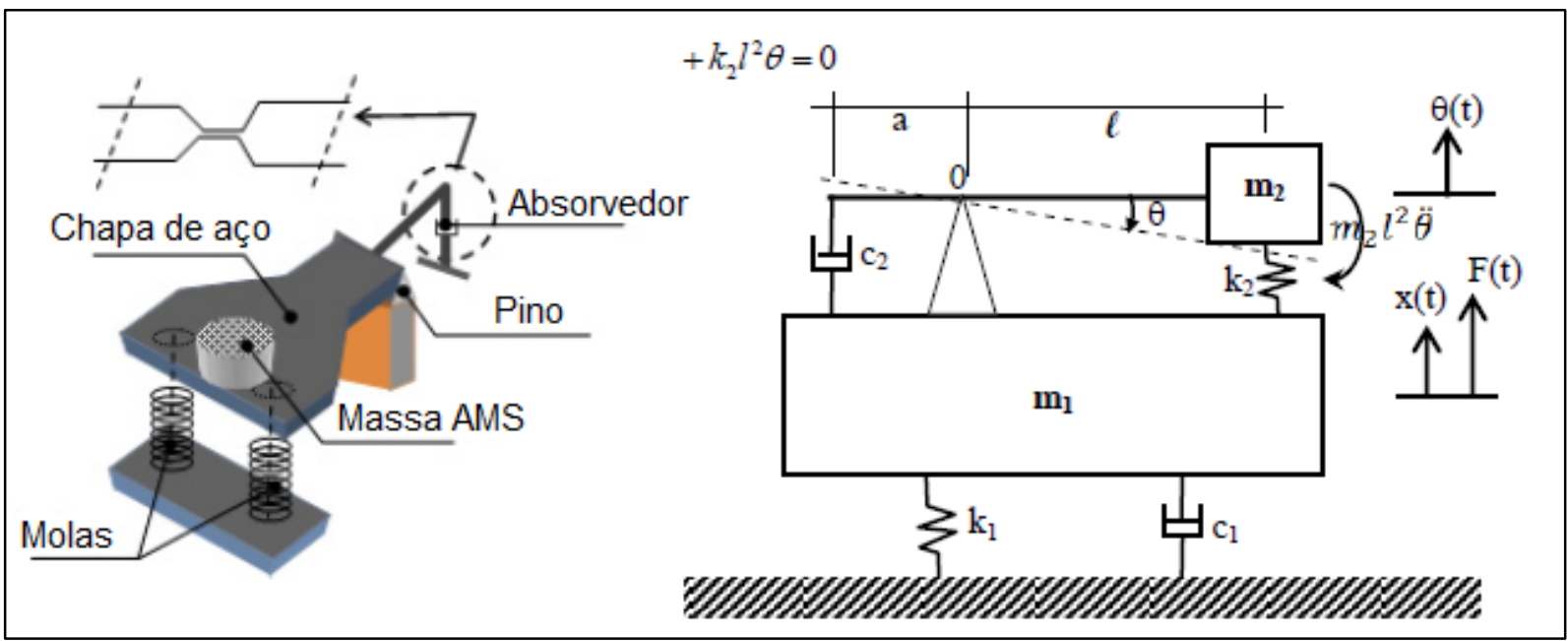

Figura 2.18 - Amortecedor de dois graus de liberdade ( Picauly et al, 2014).

Bigdeli et al (2015) pesquisou e comparou os efeitos de amortecimento horizontal em um protótipo de aço de 3 andares. Os três sistemas de controle passivo que ajudam no amortecimento da estruturas são: amortecedor de massa sintonizado (AMS), amortecedor liquido sintonizado (TLC) e amortecedor liquido de coluna sintonizado (TLCD). 
Cada andar do modelo reduzido tem dimensões de 300 x $300 \mathrm{~mm}$ e massa de $3436 \mathrm{~kg}$, o diâmetro de cada coluna é de $5 \mathrm{~mm}$ e a altura total do protótipo é de $930 \mathrm{~mm}$. A frequência natural da estrutura é de $2,7 \mathrm{~Hz}$.

Os ensaios experimentais foram feitos com a ajuda de uma mesa vibradora, acelerômetros e um sistema de aquisição de dados. Os sistemas de controle foram instalados no topo da estrutura como se apresenta na Figura 2.19.

As contribuições de amortecimento dos três sistemas de controle são consideráveis, no entanto, variam para cada amortecedor. Os ensaios mostram que o AMS tem a maior porcentagem na contribuição do amortecimento ao sistema, depois o TLCD e por último o TLD, estes dois últimos quase na mesma ordem.

Os melhores resultados dos ensaios experimentais foram encontrados para uma massa vibrante do amortecedor de $1,8 \mathrm{~kg}$. $\mathrm{Na}$ redução dos picos para o primeiro harmônico na análise no domínio da frequência se encontraram as seguintes porcentagens: $\mathrm{AMS}=59,9 \%$, TLCD $=$ $50,6 \%$ e $\mathrm{TLC}=46,9 \%$.

A redução das acelerações na análise no domínio do tempo foi de 16,9\%, $16 \%$ e 15\%, para o TMD, TLCD e TLC respectivamente.

Nos ensaios experimentais também se observou que para incrementos da massa do amortecedor nos diferentes tipos de amortecedor TMD, TLCD e TLC as porcentagens anteriores na redução das acelerações começavam a baixar.

Dos resultados nos diferentes ensaios o sistema de controle que teve melhor desempenho foi o AMS. 


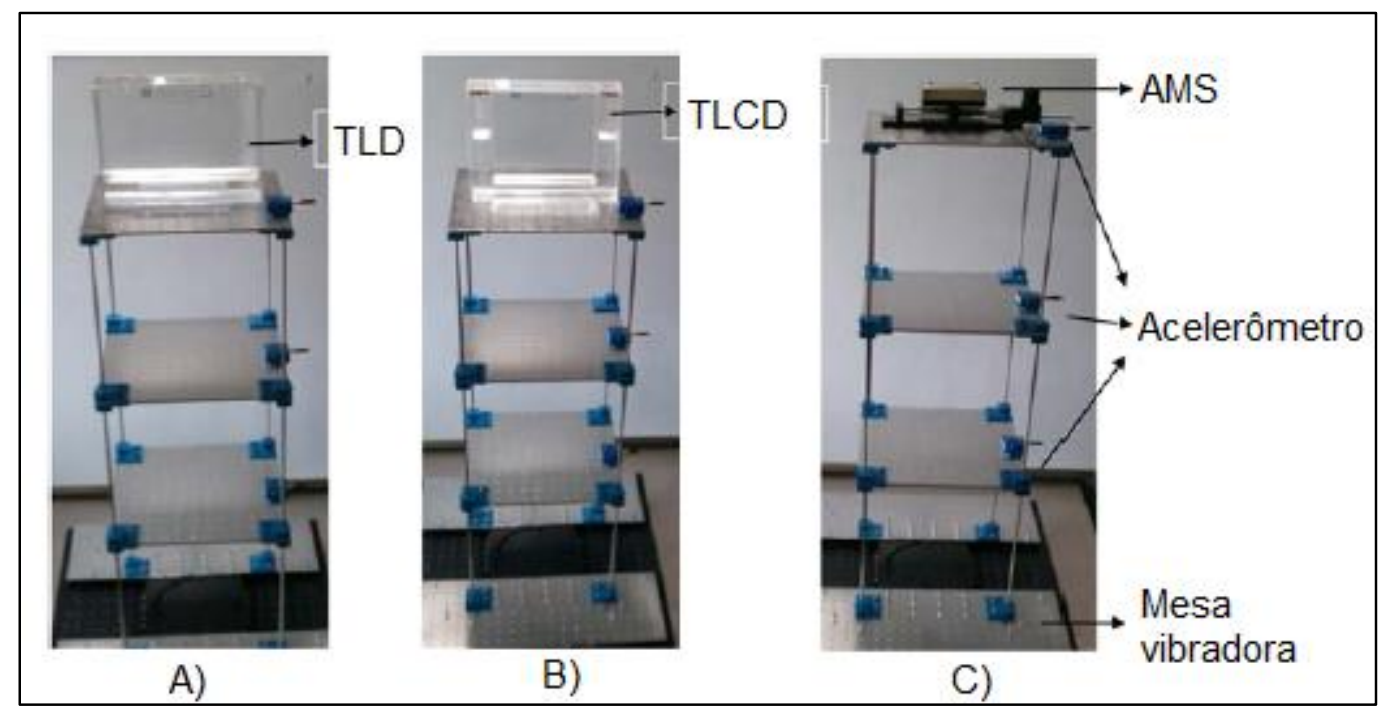

Figura 2.19 - Sistemas de controle passivo no protótipo, A) amortecedor liquido sintonizado, B) amortecedor liquido de coluna sintonizado C) amortecedor de massa sintonizado. (Bigdeli et al, 2015).

$\mathrm{Na}$ revisão realizada foram apresentados resumos das pesquisas de sistemas de controle que tiveram por finalidade a redução das amplitudes de vibração das diferentes estruturas onde foram testadas, implicando na diminuição das acelerações registradas. 


\section{FORMULAÇÃO MATEMÁTICA}

\subsection{EQUACOES DE EQUILIBRIO DINÂMICO EM SISTEMAS DE VARIOS GRAUS DE LIBERDADE}

\subsubsection{Vibração livre}

A partir de um sistema de três graus de liberdade linear, sem amortecimento, como o apresentado na Figura 3.1 pode-se observar o diagrama de corpo livre de cada uma das três massas que o compõem.

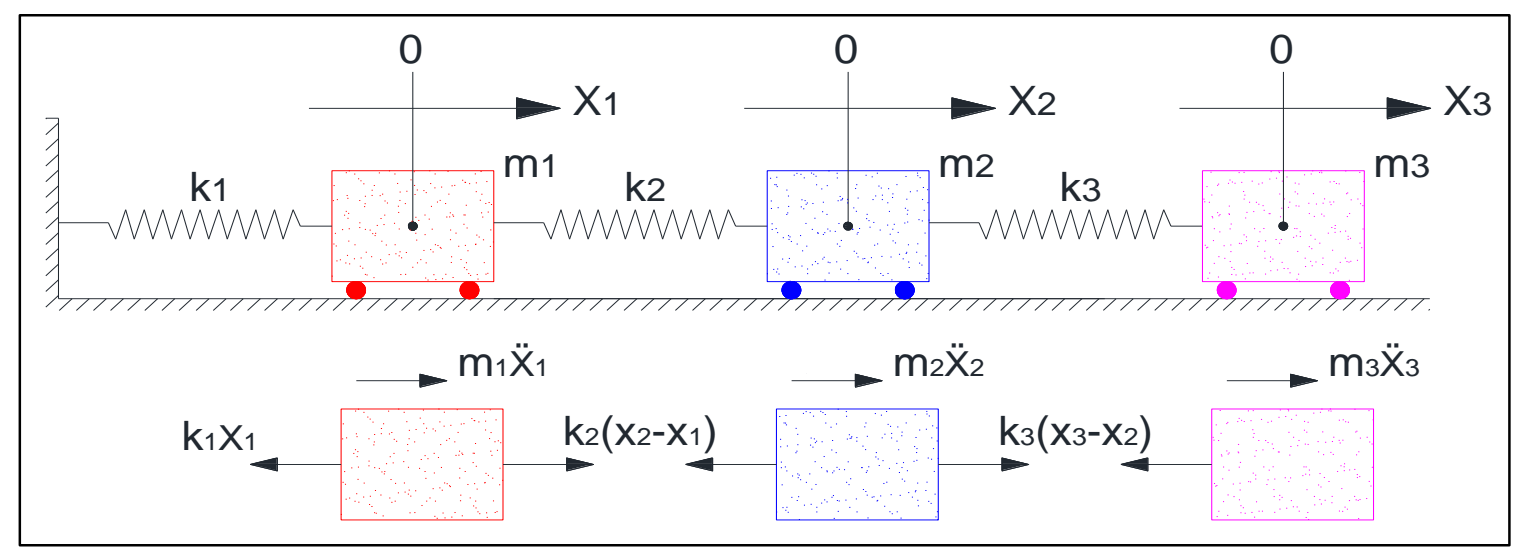

Figura 3.1 - Sistema linear não amortecido de três graus de liberdade.(García, 1998)

A partir das equações de equilíbrio onde m: massa, $\ddot{x}$ : aceleração, x:deslocamento e k:rigidez se obtém:

$$
\begin{aligned}
& m_{1} \ddot{x}_{1}+\left(k_{1}+k_{2}\right) x_{1}-k_{2} x_{2}=0 \\
& m_{2} \ddot{x}_{2}-k_{2} x_{1}+\left(k_{2}+k_{3}\right) x_{2}-k_{3} x_{3}=0 \\
& m_{3} \ddot{x}_{3}-k_{3} x_{2}+k_{3} x_{3}=0
\end{aligned}
$$

As equações simultâneas apresentadas em (3.1) podem ser expressadas matricialmente da seguinte maneira:

$$
\left[\begin{array}{ccc}
m_{1} & 0 & 0 \\
0 & m_{2} & 0 \\
0 & 0 & m_{3}
\end{array}\right]\left\{\begin{array}{l}
\ddot{x}_{1} \\
\ddot{x}_{2} \\
\ddot{x}_{3}
\end{array}\right\}+\left[\begin{array}{ccc}
k_{1}+k_{2} & -k_{2} & 0 \\
-k_{2} & k_{2}+k_{3} & -k_{3} \\
0 & -k_{3} & k_{3}
\end{array}\right]\left\{\begin{array}{l}
x_{1} \\
x_{2} \\
x_{3}
\end{array}\right\}=\left\{\begin{array}{l}
0 \\
0 \\
0
\end{array}\right\}
$$

$\mathrm{Ou}:$ 


$$
[M]\{\ddot{x}\}+[K]\{x\}=\{0\}
$$

\subsubsection{Equações de equilíbrio para excitação arbitraria}

Supondo que ao sistema apresentado na Figura 3.2 se aplica uma forca Pi(t), a cada uma das massas $i$ da estrutura, ou seja em correspondência com cada um dos graus de liberdade, como se mostra na Figura 3.2, as equações de equilíbrio resultam:

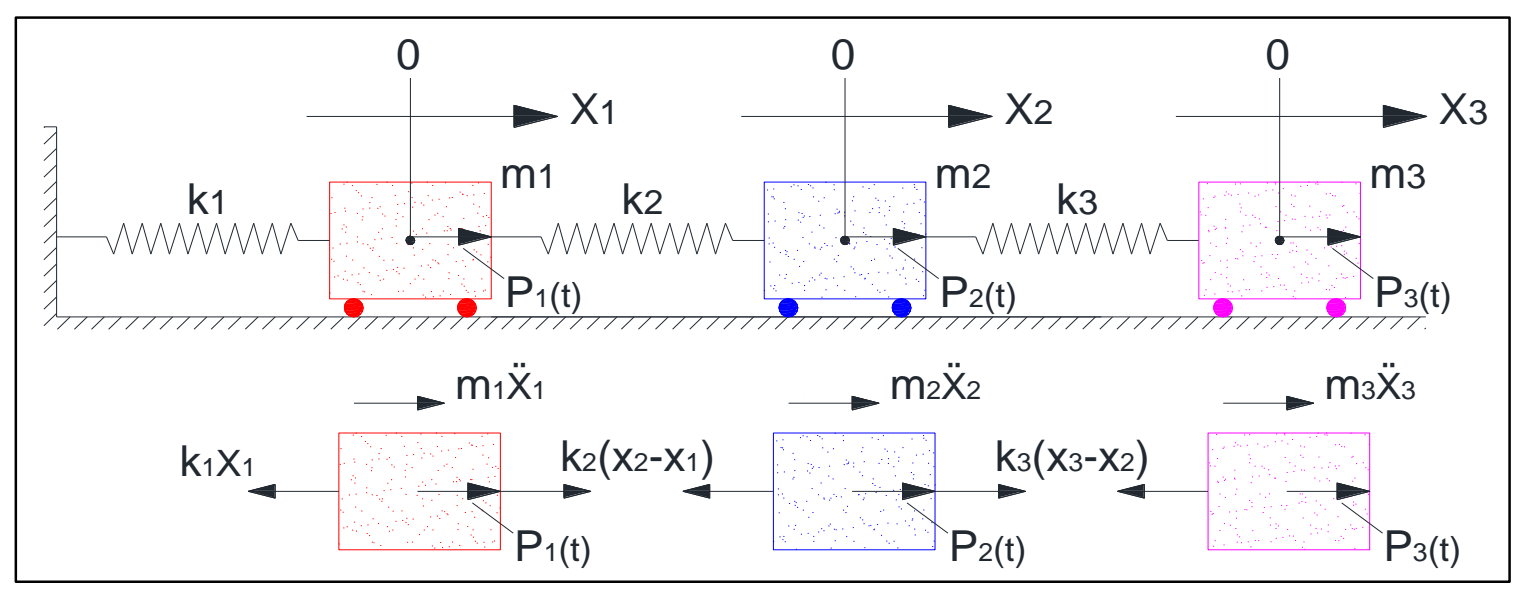

Figura 3.2 - Sistema linear não amortecido de três graus de liberdade submetido a forças dinâmicas em suas massas. (García, 1998)

A partir das equações de equilíbrio se tem:

$$
\begin{aligned}
& m_{1} \ddot{x}_{1}+\left(k_{1}+k_{2}\right) x_{1}-k_{2} x_{2}=P_{1}(t) \\
& m_{2} \ddot{x}_{2}-k_{2} x_{1}+\left(k_{2}+k_{3}\right) x_{2}-k_{3} x_{3}=P_{2}(t) \\
& m_{3} \ddot{x}_{3}-k_{3} x_{2}+k_{3} x_{3}=P_{3}(t)
\end{aligned}
$$

O sistema de equações (3.4) pode expressar-se da seguinte maneira:

$$
\left[\begin{array}{ccc}
m_{1} & 0 & 0 \\
0 & m_{2} & 0 \\
0 & 0 & m_{3}
\end{array}\right]\left\{\begin{array}{l}
\ddot{x}_{1} \\
\ddot{x}_{2} \\
\ddot{x}_{3}
\end{array}\right\}+\left[\begin{array}{ccc}
k_{1}+k_{2} & -k_{2} & 0 \\
-k_{2} & k_{2}+k_{3} & -k_{3} \\
0 & -k_{3} & k_{3}
\end{array}\right]\left\{\begin{array}{l}
x_{1} \\
x_{2} \\
x_{3}
\end{array}\right\}=\left\{\begin{array}{l}
P_{1}(t) \\
P_{2}(t) \\
P_{3}(t)
\end{array}\right\}
$$

$\mathrm{Ou}:$

$[M]\{\ddot{x}\}+[K]\{x\}=\{P(t)\}$ 


\subsubsection{Solução da resposta dinâmica para sistemas com vários graus de liberdade}

Existem várias formas de encontrar a solução do problema de vibrações forcadas: a solução modal, ou a solução por meio da integração das equações de equilíbrio. O primeiro método consiste em converter o sistema de equações simultâneas diferenciais, que descreve a condição de equilíbrio de cada um dos graus de liberdade, em um conjunto de equações de equilíbrio independentes. O segundo procedimento resulta da integração direta das equações de equilíbrio dinâmico.

A primeira metodologia, ou seja a solução modal, é aplicável apenas a sistemas que permaneçam na faixa linear de resposta.

\subsubsection{Solução modal para o caso não amortecido}

No caso de vibração livre, o sistema de $n$ equações simultâneas diferenças de equilíbrio pode ser escrito como:

$[M]\{\ddot{X}\}+[K]\{X\}=\{0\}$

Onde as matrizes $[\mathrm{M}]$ e $[\mathrm{K}]$ são as matrizes de massa e rigidez, respectivamente, e ambas são positivamente definidas, ou seja que para a posição de equilíbrio, a energia potencial do sistema é zero.

Após de um processo matemático e substituir as condições iniciais é determinado o determinante característico do sistema.

$\Delta=\left|[K]-\omega_{i}^{2}[M]\right|=0$

$\Delta$ se denomina o determinante característico do sistema de equações diferenciais simultâneas. Ao expandir este determinante encontra-se um polinômio de ordem $2 \mathrm{n}$, com potencias pares unicamente, e com $\omega^{2}{ }_{i}$ como variável. Esta equação chama-se equação característica ou equação de frequências. As $\boldsymbol{n}$ raízes desta equação são os quadrados das frequências naturais do sistema que se denominam valores característicos ou valores próprios, ou "eingevalues". Uma vez que as matrizes $[\mathrm{M}]$ e $[\mathrm{K}]$ são positivamente definidas, pode-se provar que as raízes da equação característica são sempre reais e positivas. Estas raízes se ordenam de menor a maior e 
representam as frequências naturais do sistema, em radianos por segundos. A frequência mais pequena, $\omega_{1}$, é denominada frequência fundamental:

$\omega_{1}^{2} \leq \omega_{2}^{2} \leq \omega_{3}^{2} \leq \ldots \leq \omega_{n}^{2}$

Para determinar os valores das amplitudes deste movimento harmônico $\left\{\phi^{(i)}\right\}$, se substitui os valores de $\omega_{\mathrm{i}}^{2}$ para obter assim $n$ sistemas de equações do tipo:

$\left|[K]-\omega_{r}^{2}[M]\right|\left\{\phi^{(r)}\right\}=\{0\} \quad \mathrm{r}=1,2, \ldots, \mathrm{n}$

Onde para cada valor $\omega_{\text {r }}$ existe um vetor $\left\{\phi^{(\mathrm{r})}\right\}$ que é uma solução não trivial do sistema de equações simultâneas implícito na equação (3.10). $\left\{\phi^{(\mathrm{r})}\right\}$ é um vetor característico ou modo de vibração ou "eigenvector". Assim, para cada frequência $\omega_{\mathrm{r}}$ corresponde um vetor $\left\{\phi^{(\mathrm{r})}\right\}$ que tem uma forma definida mas uma amplitude arbitraria.

\subsubsection{Análise modal com amortecimento}

Um sistema de vários graus de liberdade com amortecimento viscoso vibrando livremente é representado por:

$[M]\{\ddot{x}\}+[C]\{\dot{x}\}+[K]\{x\}=\{0\}$

O procedimento para definir os coeficientes da matriz de amortecimento [C] consiste, desde o ponto de vista análogo, ao empregado para determinar as matrizes de massa e de rigidez, em impor uma velocidade unitária ao sistema em correspondência com um dos graus de liberdade, enquanto a velocidade dos outros graus de liberdade se mantem como nulos. Desta forma, se obtém as forças internas de amortecimento em todos os graus de liberdade, as quais são devidas à velocidade do grau de liberdade selecionado. Estas forças correspondem às constantes da coluna da matriz de amortecimento do grau de liberdade selecionado.

Realizando estre trabalho sistematicamente para cada um dos graus de liberdade, se obtém a matriz de amortecimento [C] do sistema estrutural.

$[C]=\left[\begin{array}{cccc}c_{1,1} & c_{1,2} & \cdots & c_{1, n} \\ c_{2,1} & c_{2,2} & \cdots & c_{2, n} \\ \vdots & \vdots & & \vdots \\ c_{n, 1} & c_{n, 2} & \cdots & c_{n, n}\end{array}\right]$ 
Se a matriz [C] é desacoplada pelos modos de vibração pode-se escrever:

$$
[\phi]^{T}[C][\phi]=\left[2 \xi_{i} \omega_{i}\right]
$$

Onde a matriz $\left[2 \xi_{i} \omega_{i}\right]$ é uma matriz diagonal e $\xi_{\mathrm{i}}$ é o amortecimento viscoso associado com o modo i. Este tipo de amortecimento no qual a matriz de amortecimento [C] é desacoplada pelos modos de vibração obtidos das matrizes de massa $[\mathrm{M}]$ e rigidez $[\mathrm{K}]$, unicamente, se conhece com o nome de amortecimento clássico. Tendo em conta as imprecisões que seriam cometidas nesta situação, não tem muito sentido se obter a matriz [C] da maneira descrita (García, 1998).

O procedimento, comumente empregado, consiste em definir um amortecimento modal, com a seguinte equação:

$\ddot{\eta}_{i}+2 \xi_{i} \omega_{i} \dot{\eta}_{i}+\omega_{i}^{2} \eta_{i}=0$

onde:

$\eta$ : graus de liberdade generalizados.

$\xi_{\mathrm{i}}:$ amortecimento crítico.

$\omega_{\mathrm{i}}$ : frequência natural.

Supondo que a matriz de amortecimento tem uma forma tal que seja uma combinação linear das matrizes de massa $[\mathrm{M}]$ e rigidez $[\mathrm{K}]$, da seguinte maneira:

$$
[C]=\alpha[M]+\beta[K]
$$

Onde $\alpha$ e $\beta$ são constantes, é possível provar que esta matriz pode-se desacoplar por meio dos modos de vibração da estrutura como se apresenta:

$$
[\phi]^{T}[C \rrbracket \phi]=\alpha[\phi]^{T}[M \rrbracket \phi]+\beta[\phi]^{T}[K][\phi]=\alpha[I]+\beta\left[\omega^{2}\right]=\left[\alpha+\beta \omega_{i}^{2}\right]
$$

Onde a matriz $\left[\alpha+\beta \omega_{i}^{2}\right\rfloor$ é uma matriz diagonal. Cada um dos termos da diagonal desta matriz corresponde a $2 \xi \omega_{\mathrm{i}}$, então o amortecimento $\xi_{\mathrm{i}}$ em cada uma das equações desacopladas é:

$$
\xi_{i}=\frac{\alpha}{2 \omega_{i}}+\frac{\beta \omega_{i}}{2}
$$


O amortecimento descrito na equação (3.17) se conhece como amortecimento de Rayleigh. Este tipo de amortecimento é função da frequência que caracteriza o modo em análise, e por tanto, é diferente para cada modo.

A Figura 3.3 mostra a relação entre o amortecimento e a frequência e a forma que tem este amortecimento quando é proporcional à rigidez unicamente, ou à massa apenas, ou quando se combinam.

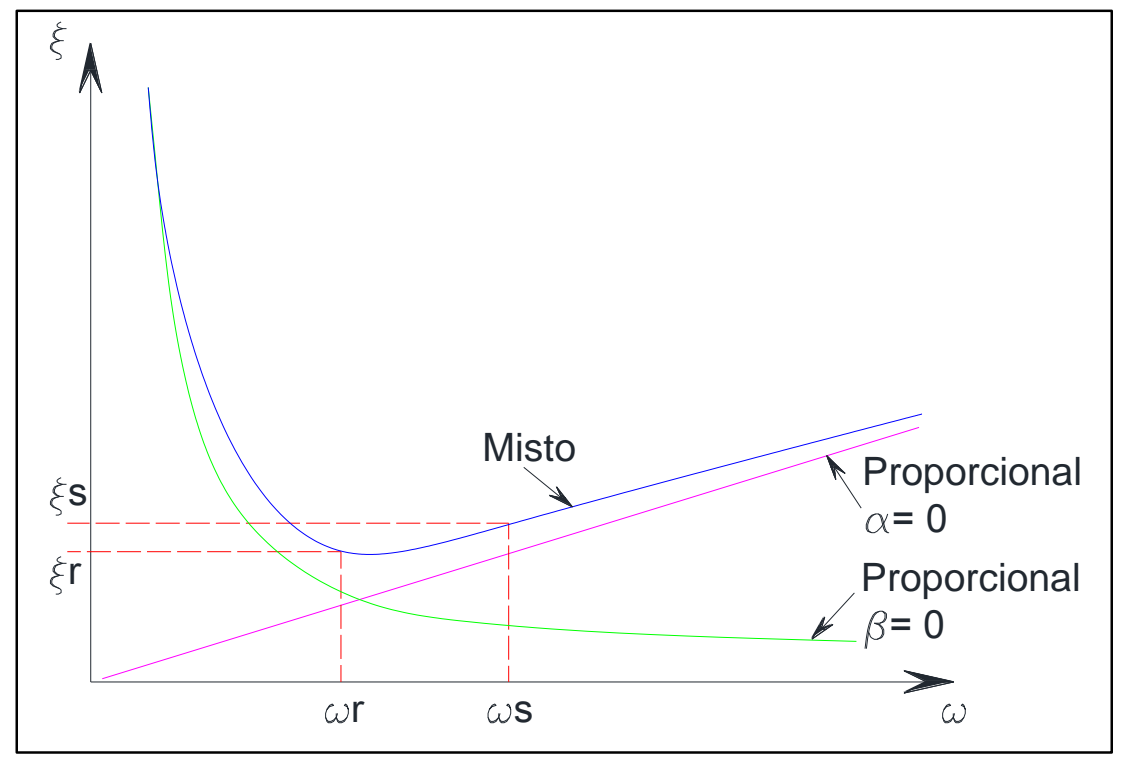

Figura 3.3 - Relação entre amortecimento e frequência, para amortecimento de Rayleigh.(García, 1998)

Para a solução do analise modal podem citar-se alguns métodos numéricos encontrados na literatura como são: método direto, método do barrido, método de Jacobi, método de iteração em um subespaço, quociente de Rayleigh. (García, 1998)

\subsection{ABSORVEDOR DE VIBRAÇÕES AMORTECIDO}

Den Hartog (1985) estudou o sistema de absorção mediante um modelo massa-mola com dois graus de liberdade, onde um grau representa o sistema principal e o outro o absorsor. Na Figura 3.4 se apresenta o sistema de controle. O sistema principal tem uma rigidez $k_{p}$ e uma massa $m_{p}$, enquanto o absorvedor tem uma $m_{a}$, um amortecedor $c_{a}$ e a mola de rigidez $k_{a}$ estas duas últimas 
estão posicionadas em paralelo entre as massas do sistema principal e do absorvedor. $\mathrm{O}$ amortecimento do sistema principal não é considerado nos cálculos.

O objetivo dos estudos de Den Hartog (1985) foi buscar uma relação entre os parâmetros do sistema principal e do absorsor que resulte na maior redução de vibrações possível. Essa relação ideal é também chamada de calibração ótima. Pode-se calibrar o sistema de absorção por meio da força de excitação ou das características da estrutura. A calibração do absorsor é realizada através da força de excitação, quando a estrutura é submetida a um carregamento harmônico fixo em uma determinada frequência. Para esta situação, a calibração ótima seria obtida projetando-se o sistema de controle para funcionar na mesma frequência da força de excitação. O ideal para esse caso seria que o absorsor não tivesse amortecimento. Quando a força de excitação imposta à estrutura é variável, não é mais possível calibrar o sistema de absorção em função da força de excitação, portanto, a calibração é feita em relação às características da estrutura (Louroza, 1997).

A calibração é determinada através das relações de: massas $\mu=m_{a} / m_{p}$, de frequências $\omega=\Omega_{a} / \Omega_{p}$ e dos coeficientes de amortecimento $\xi=c_{a} / c_{c}$

Onde:

$$
\begin{aligned}
& \Omega_{a}=\sqrt{\frac{k_{a}}{m_{a}}} \\
& \Omega_{p}=\sqrt{\frac{k_{p}}{m_{p}}} \\
& c_{c}=2 m_{a} \Omega_{p}
\end{aligned}
$$

A relação de massas $\mu$, é definida pelo projetista levando em conta a viabilidade executiva e, geralmente, não ultrapassa o valor de 5\%. As relações de frequências e de amortecimento devem então ser obtidas em função de $\mu$ (Louroza ,1997). 


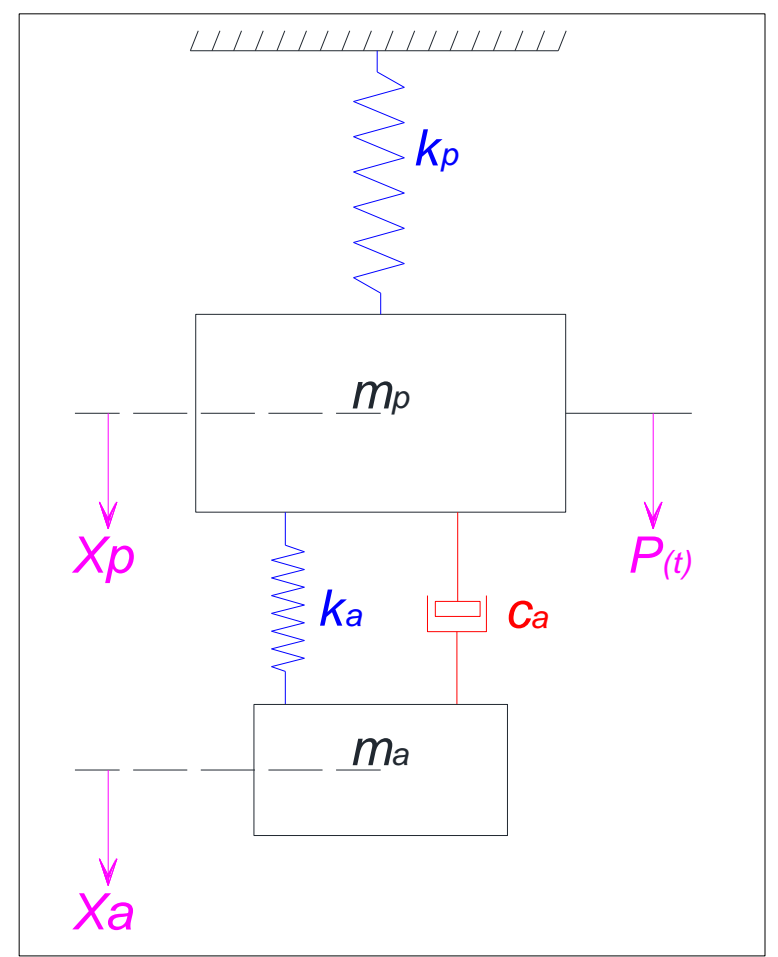

Figura 3.4 - Absorvedor de vibrações amortecido. (Den Hartog, 1985)

Do diagrama de corpo livre da Figura 3.4 pode-se obter o sistema de equações de equilíbrio:

$$
\begin{aligned}
& m_{p} \ddot{x}_{p}+c_{a}\left(\dot{x}_{p}+\dot{x}_{a}\right)+k_{p} x_{p}+k_{a}\left(x_{p}-x_{a}\right)=P(t) \\
& m_{a} \ddot{x}_{a}+c_{a}\left(\dot{x}_{a}-\dot{x}_{p}\right)+k_{a}\left(x_{a}-x_{p}\right)=0
\end{aligned}
$$

Tomando-se a força que age sobre a estrutura como:

$$
P(t)=F_{0} e^{i \Omega t}
$$

Tem-se como solução dos sistemas de equações (3.21) e (3.22):

$x_{p}(t)=a_{p} e^{i \Omega t}$

$x_{a}(t)=a_{a} e^{i \Omega t}$

Onde:

$F_{0}=$ magnitude da força de excitação. 
$\Omega=$ frequência de excitação.

$a_{p}=$ amplitude de deslocamento do sistema principal.

$a_{a}=$ amplitude de deslocamento do sistema de absorção.

Na Figura 3.5 se descrevem graficamente os comportamentos do sistema no qual a massa principal é 20 vezes maior que a massa do absorvedor, e para uma frequência do absorvedor igual à frequência da massa principal $(\omega=1)$. No eixo $Y$ estão os valores da relação do modulo de $\mathrm{a}_{\mathrm{p}}$ em relação ao deslocamento estático $\left(\mathrm{D}_{\mathrm{est}}=\mathrm{F}_{0} / \mathrm{k}_{\mathrm{p}}\right)$, e no eixo $X$ se encontram os valores da razão das frequências do absorsor e do sistema principal $\left(\Omega_{\mathrm{a}} / \Omega_{\mathrm{p}}\right)$, para uma razão de massas $\mu=1 / 20$, variando-se a relação de amortecimento $\mathrm{c} / \mathrm{c}_{\mathrm{c}}$ entre $=0,10$ e 0,32 . Tanto para $\mathrm{c}=0$ como para uma relação de amortecimento $\mathrm{c} / \mathrm{c}_{\mathrm{c}}$ que tende para o infinito, as duas massas vibram conjuntamente o que significa que a massa do absorvedor está vibrando junto com a massa do sistema principal formando-se um sistema de um grau de liberdade. Adicionando o absorvedor ao sistema, o objetivo é diminuir o valor do pico da amplitude de vibração da massa principal a um possível valor mais baixo.

Todas as curvas passam pelos pontos $\mathrm{P}$ e Q, que resulta da relação das amplitudes em função das quatro variáveis essenciais que são relação de massa $\left(\mu=m_{d} / m_{p}\right)$, razão de amortecimento $\left(c / c_{c}\right)$, razão de frequências naturais $\left(\omega=\Omega_{d} / \Omega_{p}\right)$ e razão de frequência forçada $\left(\gamma=\Omega / \Omega_{p}\right)$, as relações anteriores são válidas para qualquer relação de amortecimento. Para se alcançar a calibração ideal do absorvedor deve-se primeiro determinar um valor apropriado para as razões das frequências $\omega$, de modo que os pontos P e Q tenham a mesma amplitude. Depois deve-se escolher uma relação de amortecimento $\mathrm{c} / \mathrm{c}_{\mathrm{c}}$ adequada, para que a curva tenha uma tangente horizontal nesses dois pontos (Louroza, 1997).

Após algumas operações matemáticas Den Hartog (1985) obteve a relação ótima de frequências escrita em função da relação de massas como:

$\omega=1 /(1+\mu)$

A relação ótima das amplitudes é dada por: 
$\frac{D_{p}}{D_{e s t}}=\sqrt{1+\frac{2}{\mu}}$

Onde, $D_{\text {est }}$ é o deslocamento estático.

A relação ótima de amortecimento é dada por:

$\left(\frac{c}{c_{c}}\right)^{2}=\frac{3 \mu}{8(1+\mu)^{3}}$

onde:

$c=2 m_{a} \Omega_{a} \xi_{a}$

$c_{c}=2 m_{a} \Omega_{p}$

Substituindo-se as equações (3.29) e (3.30) em (3.28)

$\left(\frac{2 m_{a} \Omega_{a} \xi_{a}}{2 m_{a} \Omega_{p}}\right)^{2}=\frac{3 \mu}{8(1+\mu)^{3}}$

$\left(\xi_{a}\right)_{\text {ótimo }}=\frac{\sqrt{\frac{3 \mu}{8(1+\mu)^{3}}}}{\left(\Omega_{a} / \Omega_{p}\right)_{\text {ótimo }}}$

onde:

$\xi$ a: amortecimento ótimo.

$\mu$ : relação de massas.

$\Omega a$ : frequência de excitação do amortecedor.

$\Omega$ p: frequência de excitação do sistema principal.

A relação de massas para a maioria dos casos em estruturas civis tem como valor máximo 5\% pois para razões maiores, torna-se inviável a massa do absorsor. 


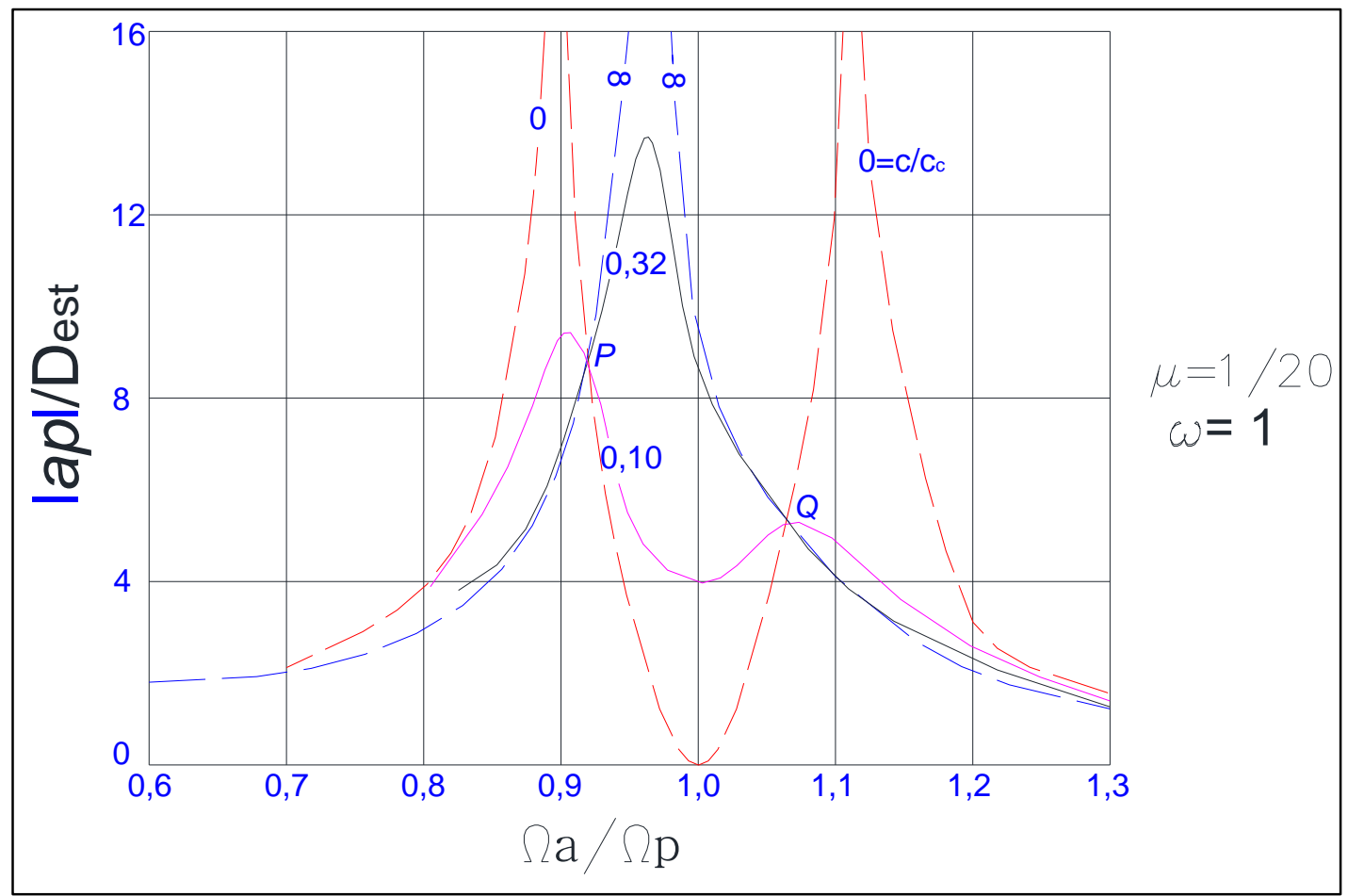

Figura 3.5 - Amplitudes de vibração da massa principal da Figura 3.4 para vários valores de amortecimento do absorvedor, no qual a massa do absorvedor é 20 vezes menor que a massa do sistema principal e é sintonizado na mesma frequência.

A teoria anterior foi desenvolvida para um sistema principal sem amortecimento no entanto ela pode ser utilizada com amortecimento muito baixo. Uma limitação desta teoria é a impossibilidade de se encontrar novas relações de frequências e amortecimentos caso as equações (3.26) e (3.28) não sejam satisfeitas. Uma alternativa a estas limitações é a busca de novos tipos de amortecimento como é o caso de amortecimento por forças de Coulomb (Louroza , 1997).

\subsubsection{Seleção de valores de parâmetros ótimos para um AMS}

Várias pesquisas sobre equações com valores de parâmetros ótimos para AMS usando diferentes critérios de aproximações são apresentadas por diversos autores. Na Tabela 3.1 se condensam todas as equações propostas. As maiorias dos pesquisadores apresentam valores ótimos e razões de frequências baseados em relações de massas (Gutierrez , 2012).

Warburton (1982) propus equações considerando excitações harmônicas em um sistema de um grau de liberdade com registros na média das razões dos amortecimentos dos modos de vibração, para um sistema sem controle e para outro controlado com AMS. 
Villaverde (1985) derivou equações para um AMS com amortecimento alto e pequenas relações de massas, reduzindo ao mínimo a resposta dinâmica devido a cargas sísmicas de uma estrutura de três andares em 2D e um prédio com 10 andares em 3D.

Fujino e Abe (1993) apresentaram quatro conjuntos de equações de parâmetros ótimos de um sistema de dois graus de liberdade para quatro casos diferentes: vibração livre, harmônica, auto excitado e excitações aleatórias com base em um procedimento de otimização, utilizando valores rms de soluções das respostas de deslocamento e assumindo relações de massas e de amortecimento estruturais inferiores a 0,02 .

Feng e Mita (1995) propuseram duas equações, a primeira para o deslocamento e a outra para a aceleração, para valores ótimos de relações de frequência e amortecimento de um AMS acoplado a um sistema de dois graus de liberdade para minimizar a resposta dinâmica em termos dos valores RMS do deslocamento e aceleração. Os autores estudaram o desempenho de suas equações em um edifício de $200 \mathrm{~m}$ de altura, com taxa de amortecimento estrutural de 0,02 submetido a excitações sísmicas.

Sadek et al (1997) modificaram as equações propostas por Villaverde (1985) encontrando parâmetros ótimos do sistema de AMS de maneira que com o sistema de controle os dois primeiros modos de vibração da estrutura tiveram a mesma relação de amortecimento. 
Tabela 3.1 - Equações para encontrar os parâmetros de ajuste ótimos de um AMS apud (Gutierrez, 2012).

\begin{tabular}{|c|c|c|c|}
\hline Autor & Relação de Frequência & Relação de amortecimento & Comentários \\
\hline $\begin{array}{l}\text { Den Hartog } \\
\text { (1956) }\end{array}$ & $\frac{1}{1+\mu}$ & $\sqrt{\frac{3 \mu}{8(1+\mu)^{3}}}$ & $\begin{array}{l}\text { Primeiras equações de } \\
\text { parâmetros ótimos de um AMS, } \\
\text { de um grau de liberdade sem } \\
\text { amortecimento, com excitação } \\
\text { harmônica. }\end{array}$ \\
\hline $\begin{array}{l}\text { Warburton } \\
\text { (1982) }\end{array}$ & $\frac{\sqrt{1-\mu / 2}}{1+\mu}$ & $\sqrt{\frac{\mu(1-\mu / 4)}{4(1+\mu)(1-\mu / 2)}}$ & $\begin{array}{l}\text { Baseada em excitações } \\
\text { aleatórias de acelerações com } \\
\text { ruído branco em sistema de um } \\
\text { grau de liberdade não } \\
\text { amortecido }\end{array}$ \\
\hline $\begin{array}{l}\text { Fujino and Abe } \\
\text { (1993) }\end{array}$ & $\frac{\sqrt{1-\mu / 2}}{1+\mu}$ & $\frac{1}{2} \sqrt{\frac{\mu(1+3 \mu / 4)}{(1+\mu)(1+\mu / 2)}}$ & $\begin{array}{l}\text { Baseada em excitações } \\
\text { aleatórias para um sistema de } \\
\text { dois graus de liberdade não } \\
\text { amortecido. }\end{array}$ \\
\hline $\begin{array}{l}\text { Feng and Mita } \\
\text { (1995) }\end{array}$ & $\frac{\sqrt{1-\mu / 2}}{1+\mu}$ & $\begin{array}{l}\text { (i) } \frac{1}{2} \sqrt{(1+\mu) \gamma^{4}+\gamma^{2}+\frac{1-3(1+\mu)^{2} \gamma^{2}}{(1+\mu)^{3}}} \\
\text { (ii) } \frac{\gamma}{2} \sqrt{(1+\mu) \gamma^{2}+1-\frac{1}{1+\mu}}\end{array}$ & $\begin{array}{l}\text { Baseada em excitações de ruído } \\
\text { branco para um sistema de dois } \\
\text { graus de liberdade. } \\
\text { (i) Deslocamento } \\
\text { (ii) Aceleração }\end{array}$ \\
\hline $\begin{array}{l}\text { Rudinger } \\
\text { (2006) }\end{array}$ & $\sqrt{\frac{(2+\mu)}{2(1+\mu)^{2}}}$ & $\sqrt{\frac{\mu(4+3 \mu)}{4(1+\mu)^{3}}}$ & $\begin{array}{l}\text { Baseada em excitações de ruído } \\
\text { branco em sistemas de um grau } \\
\text { de liberdade, r com } \\
\text { amortecimento linear e não } \\
\text { linear. }\end{array}$ \\
\hline $\begin{array}{c}\text { Krenk and } \\
\text { Hogsberg } \\
(2008)\end{array}$ & $\frac{1}{1+\mu}$ & $\frac{1}{2} \sqrt{\frac{\mu}{(1+\mu)}}$ & $\begin{array}{l}\text { Baseada em excitações de força } \\
\text { e ruído branco em sistema de } \\
\text { dois graus de liberdade } \\
\text { amortecido e não amortecido. }\end{array}$ \\
\hline
\end{tabular}


Rudinger (2006) utilizou ferramentas de estatística para derivar equações de parâmetros ótimos de um AMS para um sistema de um grau de liberdade amortecido, submetido a excitações de ruído branco. $\mathrm{O}$ autor concluiu que os parâmetros ótimos de sintonização do AMS são os mesmos para os sistemas controlados e não controlados que se comportem linearmente. Entretanto, os parâmetros ótimos para um sistema que se comporte de forma não linear com o AMS são dependentes do amortecimento estrutural e da intensidade da excitação (amplitude de vibração).

Krenk e Hogsberg (2008) apresentaram equações de sintonização ótima em sistemas não amortecidos e amortecidos de dois graus de liberdade sujeitos a excitações de forças e acelerações independentes das relações de amortecimento estrutural.

Hoang et al (2008) propuseram equações de parâmetros ótimos de um AMS para um sistema de vários graus de liberdade sujeito a excitação sísmica para diferentes faixas de relações entre a frequência dominante do solo $\left(\omega_{\mathrm{g}}\right)$ e a frequência da estrutura $\left(\omega_{\mathrm{s}}\right), \delta=\omega_{\mathrm{g}} / \omega_{\mathrm{s}}$, usando técnicas de programação não linear. Os autores apresentaram um exemplo numérico onde eles estudaram o efeito de grandes relações de massa para um AMS em uma ponte sujeita a carregamentos sísmicos. Eles observaram que um AMS com incrementos de relação de massas se obtém como resultado menor frequência de sintonização e maior relação de amortecimento. Concluíram também que o uso de uma relação de massa alta pode ajudar a melhorar as incertezas dos parâmetros do modelo teórico.

\subsubsection{Amortecimento de Coulomb}

O amortecimento de Coulomb é uma forma de dissipação de energia que ocorre devido ao atrito entre duas superfícies secas, quando uma superfície escorrega na outra.

O amortecimento de Coulomb se observa quando uma massa desliza sobre uma superfície seca como se mostra na Figura 3.6, uma força de atrito que se opõe ao movimento é desenvolvida entre a massa e a superfície de escorregamento. 


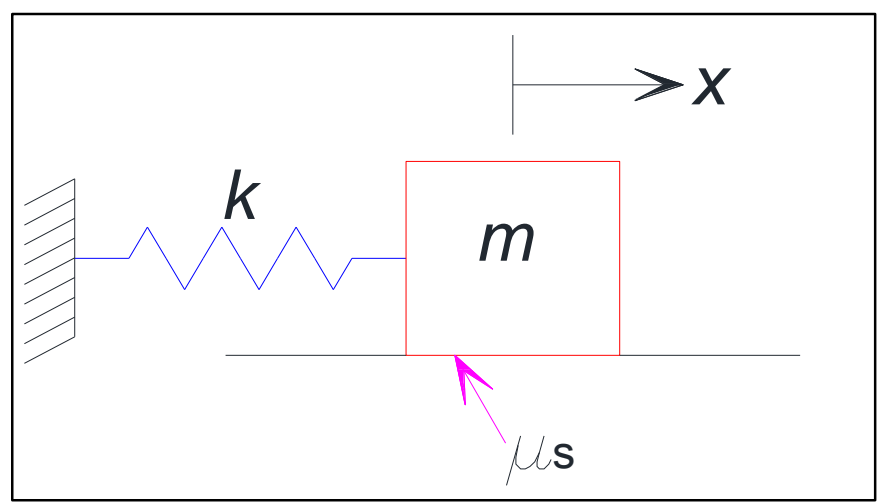

Figura 3.6 - Massa deslizando-se sobre uma superfície com coeficiente de atrito $\mu_{s}$.

Segundo a lei de Coulomb a força de atrito que se desenvolve entre a massa e a superfície é proporcional à força normal. A constante de proporcionalidade $\mu_{s}$, é chamada de coeficiente de atrito cinético. Uma vez que a força de atrito sempre resiste ao movimento, a sua direção depende do sinal da velocidade da massa.

Na Figura 3.7 e Figura 3.8 observa-se que a força de atrito $\left(\mu_{s} m g\right)$ é sempre contrária à direção do movimento, pois, por definição ela resiste ao movimento, logo seu sinal (ou sentido) será sempre contrário ao da velocidade.

Os diagramas de corpo livre para as situações: de velocidade positiva e negativa se mostram Figura 3.7 e na Figura 3.8 respectivamente.

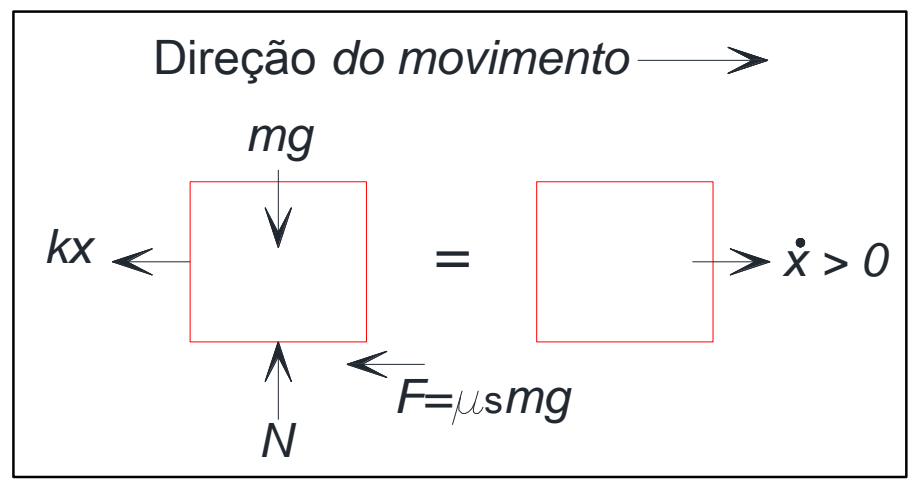

Figura 3.7 - Diagrama de corpo livre do sistema da Figura 3.6 para um instante em que a velocidade é maior que zero. 


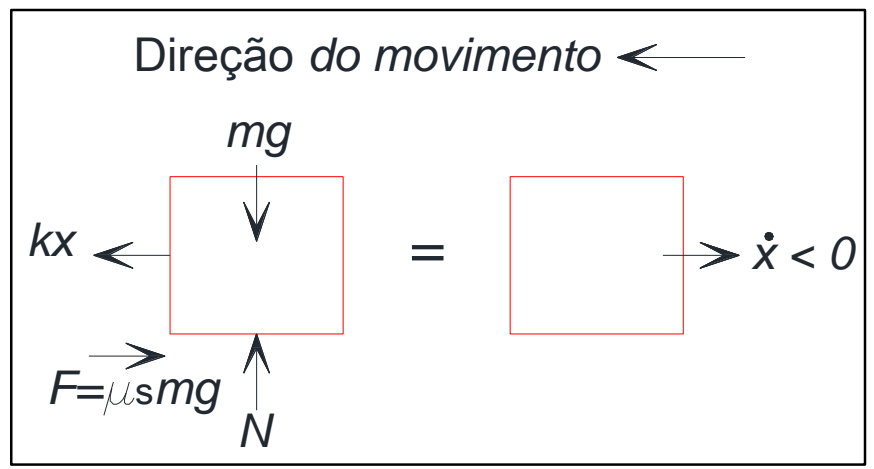

Figura 3.8 - Diagrama de corpo livre do sistema da Figura 3.6 para um instante em que a velocidade $<0$.

As equações diferenciais que caracterizam os sistemas indicados são:

$m \ddot{x}+k x= \begin{cases}-\mu_{s} m g & \dot{x}>0 \\ & \\ +\mu_{s} m g & \dot{x}<0\end{cases}$

As equações (3.33) são generalizadas usando a seguinte equação singular:

$$
m \ddot{x}+k x=-\mu_{s} m g \frac{|\dot{x}|}{\dot{x}}
$$

O termo da direita da equação (3.34) é uma função não linear. Assim, as vibrações livres de um sistema de um único grau de liberdade com amortecimento de Coulomb são reguladas por uma equação diferencial não linear. No entanto, existe uma solução analítica e é obtida resolvendo a equação (3.33).

Sem perda de generalidade, se pode assumir que as vibrações livres do sistema da Figura 3.6 são iniciadas por um deslocamento $\delta$ da massa a direita, seguidamente a massa é liberada do repouso a partir do deslocamento inicial $\delta$. Como a massa está conectada a uma mola, esta proporciona uma força de restituição, a qual faze que a massa volte à posição de equilíbrio, dessa forma a velocidade inicial é negativa, devido a que a massa tem movimento em direção a 
esquerda. A equação (3.33) aplica-se sobre a primeira metade do ciclo de movimento, até que a velocidade de novo torna-se zero.

O sistema da Figura 3.6 tem as seguintes condições iniciais:

$$
\begin{aligned}
& x(0)=\delta \\
& \dot{x}(0)=0
\end{aligned}
$$

Admitindo que a equação (3.37) é uma solução da equação homogênea (3.33), se segue que:

$$
\begin{aligned}
& x(t)=a \cos \omega_{n} t+b \operatorname{sen} \omega_{n} t+d \\
& \ddot{x}(t)=-a \omega_{n}^{2} \cos \omega_{n} t-b{\omega_{n}}^{2} \operatorname{sen} \omega_{n} t
\end{aligned}
$$

Onde:

a, b e d são constantes.

Substituindo as condições iniciais (3.35) e (3.36) nas equações (3.37) e (3.33) para $\dot{x}<0$, resulta em:

$$
\begin{aligned}
& a=\delta-\frac{\mu_{s} m g}{k} \\
& b=0 \\
& d=\delta-a
\end{aligned}
$$

Aplicando-se (3.39), (3.40) e (3.41) em (3.37), resulta em:

$$
x(t)=\left(\delta-\frac{\mu_{s} m g}{k}\right) \cos \omega_{n} t+\frac{\mu_{s} m g}{k} \quad\left(\dot{x}<0 \text { e } 0 \leq t \leq \pi / \omega_{n}\right)
$$

A equação (3.42) descreve o movimento até o instante $t=\pi / \omega_{n}$, quando a velocidade muda de sinal e passa a ser positiva.

$$
x\left(\frac{\pi}{\omega_{n}}\right)=-\delta+\frac{2 \mu_{s} m g}{k}
$$


Para $\pi / \omega_{n} \leq t \leq 2 \pi / \omega_{n}$ segunda metade do ciclo, onde $\dot{x}>0$, tem-se as seguintes condições iniciais da equação (3.33):

$$
\begin{aligned}
& x\left(\frac{\pi}{\omega_{n}}\right)=-\delta+\frac{2 \mu_{s} m g}{k} \\
& x\left(\frac{\pi}{\omega_{n}}\right)=0
\end{aligned}
$$

Aplicando-se as condições iniciais (3.44) e (3.45) na equação (3.37) e (3.33) para $\dot{x}>$ 0, obtêmse as constantes a, b, e d, com os seguintes valores:

$$
\begin{aligned}
& a=\delta-\frac{3 \mu_{s} m g}{k} \\
& b=0 \\
& d=\frac{-\mu_{s} m g}{k}
\end{aligned}
$$

Substituindo as equações (3.46), (3.40) e (3.48) na equação (3.37) obtêm-se:

$$
x(t)=\left(\delta-\frac{3 \mu_{s} m g}{k}\right) \cos \omega_{n} t+\frac{\mu_{s} m g}{k} \quad\left(\dot{x}>0 e \frac{\pi}{\omega_{n}} \leq t \leq \frac{2 \pi}{\omega_{n}}\right)
$$

A velocidade muda novamente após o ciclo completo $t=2 \pi / \omega_{n}$, quando:

$$
x\left(\frac{2 \pi}{\omega_{n}}\right)=\delta-\frac{4 \mu_{s} m g}{k}
$$

O movimento durante o primeiro ciclo é descrito pelas equações (3.42), (3.43) e (3.49), a amplitude de vibração muda diminuindo entre o começo e o final de cada ciclo, e o valor é:

$$
x(0)-x\left(\frac{2 \pi}{\omega_{n}}\right)=\frac{4 \mu_{s} m g}{k}
$$

O movimento é cíclico. Uma análise de ciclos subsequentes confirma que os ciclos sucessivos continuam da mesma maneira. As condições iniciais usadas para resolver o deslocamento 
durante meio ciclo são velocidade igual a zero e o deslocamento calculado ao final do meio ciclo anterior.

O período para cada ciclo é:

$T=\frac{2 \pi}{\omega_{n}}$

Assim, o amortecimento de Coulomb não altera a frequência natural do sistema que permanece inalterada durante o movimento.

Uma indução matemática é usada para desenvolver as seguintes expressões para o deslocamento da massa durante cada meio ciclo:

$x(t)=\left[\delta-(4 n-3) \frac{\mu_{s} m g}{k}\right] \cos \omega_{n} t+\frac{\mu_{s} m g}{k}$

Para $2(n-1) \frac{\pi}{\omega_{n}} \leq t \leq 2\left(n-\frac{1}{2}\right) \frac{\pi}{\omega_{n}}$

$x(t)=\left[\delta-(4 n-1) \frac{\mu_{s} m g}{k}\right] \cos \omega_{n} t-\frac{\mu_{s} m g}{k}$

Para $2\left(n-\frac{1}{2}\right) \frac{\pi}{\omega_{n}} \leq t \leq 2 n \frac{\pi}{\omega_{n}}$

Calculando-se o deslocamento para $T=\frac{2 n \pi}{\omega_{n}}$, tem-se que:

$x\left(2 n \frac{\pi}{\omega_{n}}\right)=\delta-\left(\frac{4 \mu_{s} m g}{k}\right) n$

A equação (3.55) mostra que a amplitude decresce ao final de cada ciclo em $4 \mu_{s} m g / k$. Assim a amplitude em vibração livre decai linearmente ao longo do tempo, como mostram as equações (3.53) e (3.54) na Figura 3.9

As amplitudes de ciclos sucessivos formam uma sequência aritmética. Se $x_{n}$ é a amplitude, no final de cada $n$ ciclo, então: 
$x_{n}-x_{n-1}=\frac{4 \mu_{s} m g}{k}$

Com $x_{0}=\delta$, a solução de esta equação de diferença é a equação (3.55).

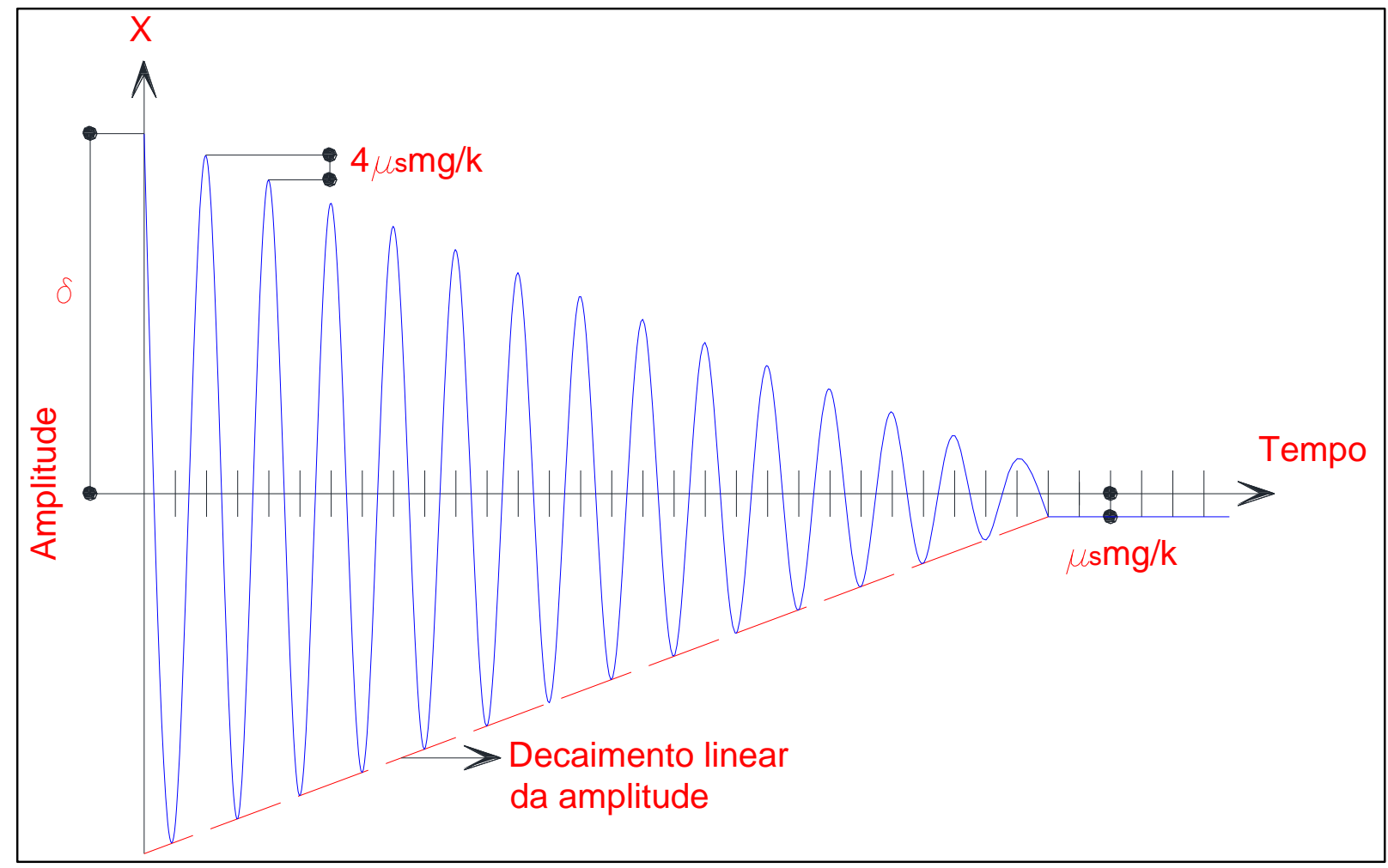

Figura 3.9 - Resposta de vibração livre de um sistema com amortecimento de Coulomb. (Graham Kelly, 2012).

A amplitude do movimento continua com decaimento constante, enquanto a força de restituição é suficiente para vencer a força de atrito. Isto ocorre quando a equação (3.57) é satisfeita.

$$
F_{\text {rest }}=k|x|\left(2 n \frac{\pi}{\omega_{n}}\right) \mid \leq \mu_{s} m g
$$

O movimento cessa, durante o ciclo $n$, onde $n$ e o número inteiro menor de tal forma que:

$$
n>\frac{k \delta}{4 \mu_{s} m g}-\frac{1}{4}
$$

Quando o movimento cessa, a amplitude fica distante da posição de equilíbrio de $\mu m g / k$ 
A teoria anterior de equações de equilíbrio dinâmico em sistemas de vários graus de liberdade para sistemas não amortecidos e amortecidos, além da teoria do absorvedor de vibrações servem de base para o entendimento e construção de um novo AMS que é o objetivo principal desta tese de doutorado. A teoria do amortecimento de Coulomb ou atrito em seco será parte fundamental do sistema de amortecimento no novo sistema de controle a projetar. 


\section{PLATAFORMA DE ENSAIOS DINÂMICOS}

Como já mencionado, o objetivo desta Tese é a elaboração de uma metodologia de projeto na qual se consiga desenvolver um sistema de amortecedor de massa sintonizado que possa ser construído e instalado em pisos de edifícios. Para o desenvolvimento desse trabalho foram realizados ensaios experimentais em uma plataforma de ensaios dinâmicos que foi construída no Laboratório de Estruturas da Universidade de Brasília (Campuzano, 2011). Entretanto, essa plataforma apresentava inicialmente, uma flecha excessiva e numerosas fissuras que obrigaram a um trabalho de recuperação prévio antes de seu uso nesta Tese. Esses trabalhos de recuperação e as características dinâmicas posteriores de descrevem sinteticamente neste capítulo.

\subsection{DESCRIÇÃO DA PLATAFORMA DE ENSAIOS DINÂMICOS}

A plataforma de ensaios dinâmicos consiste em uma laje de concreto com duas bordas semiengastadas e as outras duas bordas livres. A laje de dimensões de $6,1 \mathrm{~m}$ de comprimento, 4,9 m de largura e 0,1 m de espessura (vide Figura 4.1 e Figura 4.2), tem resistência a compressão de $25 \mathrm{MPa}$ e módulo de elasticidade do concreto aproximado de $30 \mathrm{GPa}$. Esta plataforma apresenta propositalmente, vibrações verticais excessivas quando é excitada com carregamentos provenientes de atividades humanas como pular, dançar e atividades aeróbicas, devido à sua reduzida rigidez a flexão. 


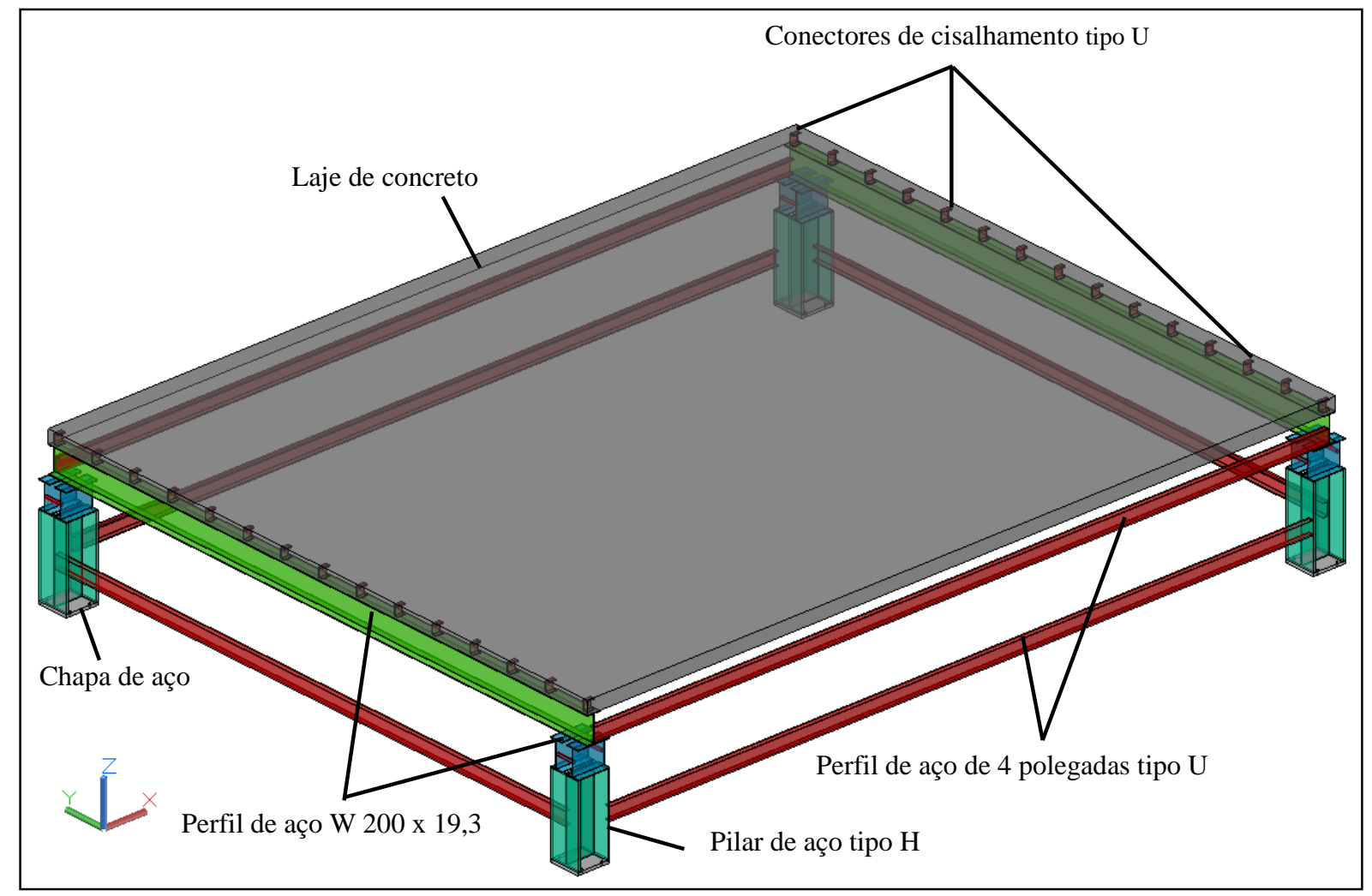

Figura 4.1 - Plataforma de ensaios dinâmicos (Campuzano, 2011)

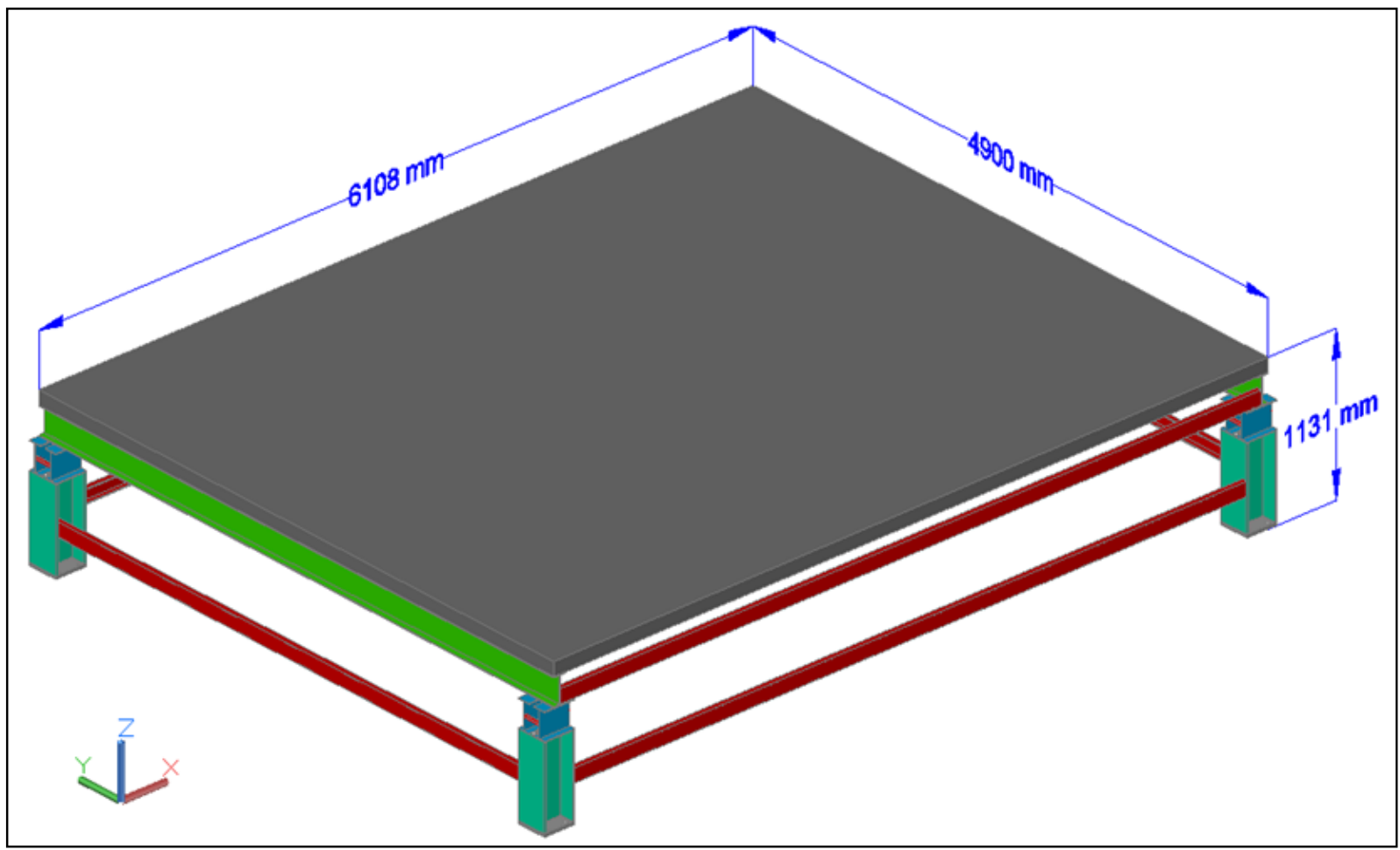

Figura 4.2 - Dimensões da plataforma de ensaios dinâmicos (Campuzano, 2011) 


\subsection{RECUPERAÇÃO DA PLATAFORMA E ENSAIOS EXPERIMENTAIS APÓS A RECUPERAÇÃO}

Após a construção da plataforma, esta apresentou uma grande deflexão estática depois da retirada do escoramento temporário, de aproximadamente $35 \mathrm{~mm}$, e que com o passar dos dias chegou até aos $70 \mathrm{~mm}$. A explicação possível para o ocorrido se baseia nas fissuras que surgiram na direção paralela aos perfis de aço por retração de secagem do concreto. A plataforma com a flecha inicial de $35 \mathrm{~mm}$ é apresentada na Figura 4.3.

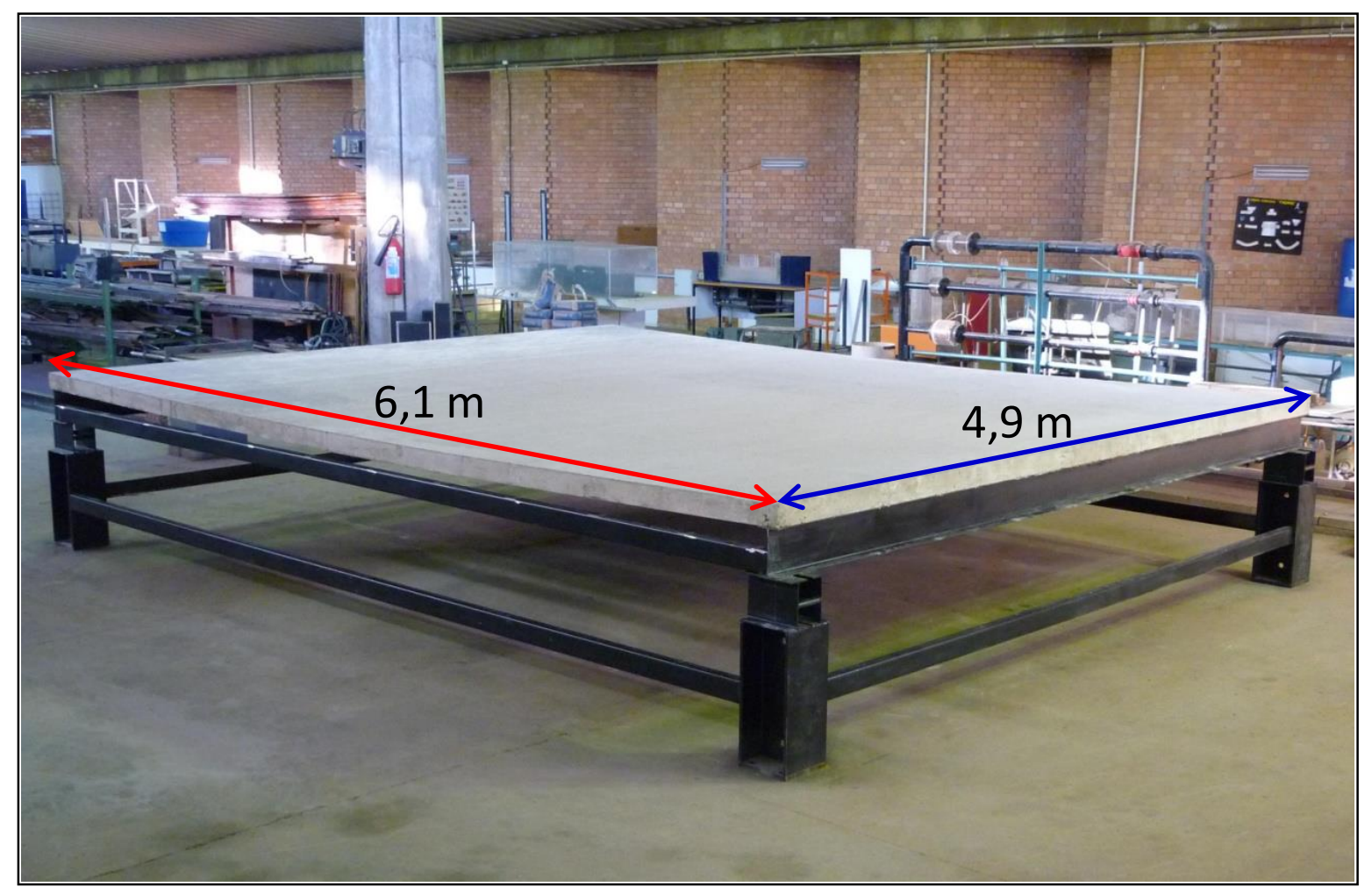

Figura 4.3 - Plataforma de ensaios dinâmicos antes da recuperação, com flecha estática de 35 mm. (Campuzano, 2011).

Todo o processo de recuperação da plataforma para redução da amplitude da flecha estática encontra-se descrito no Anexo II

\subsection{CARACTERÍSTICAS DINÂMICA DA PLATAFORMA DE ENSAIOS}

Foram realizados ensaios de vibração livre na laje após sua recuperação com o intuito de se obter os parâmetros modais. A plataforma foi excitada com impactos em sua superfície por meio 
da utilização de uma marreta de aço e uma borracha, e também com impactos com o calcanhar, vide Figura 4.4 e Figura 4.5

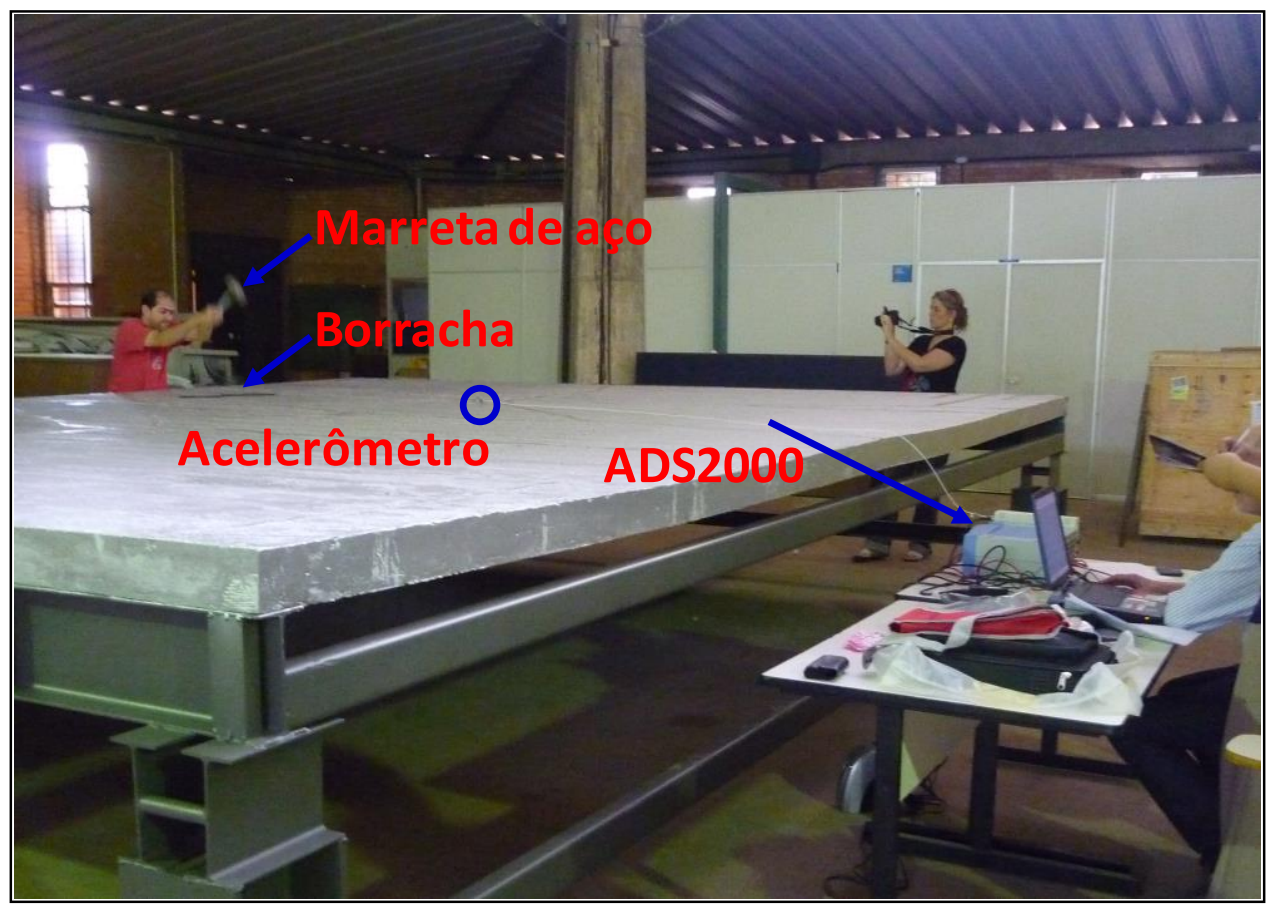

Figura 4.4 - Impactos com marreta para encontrar a frequência natural da plataforma.

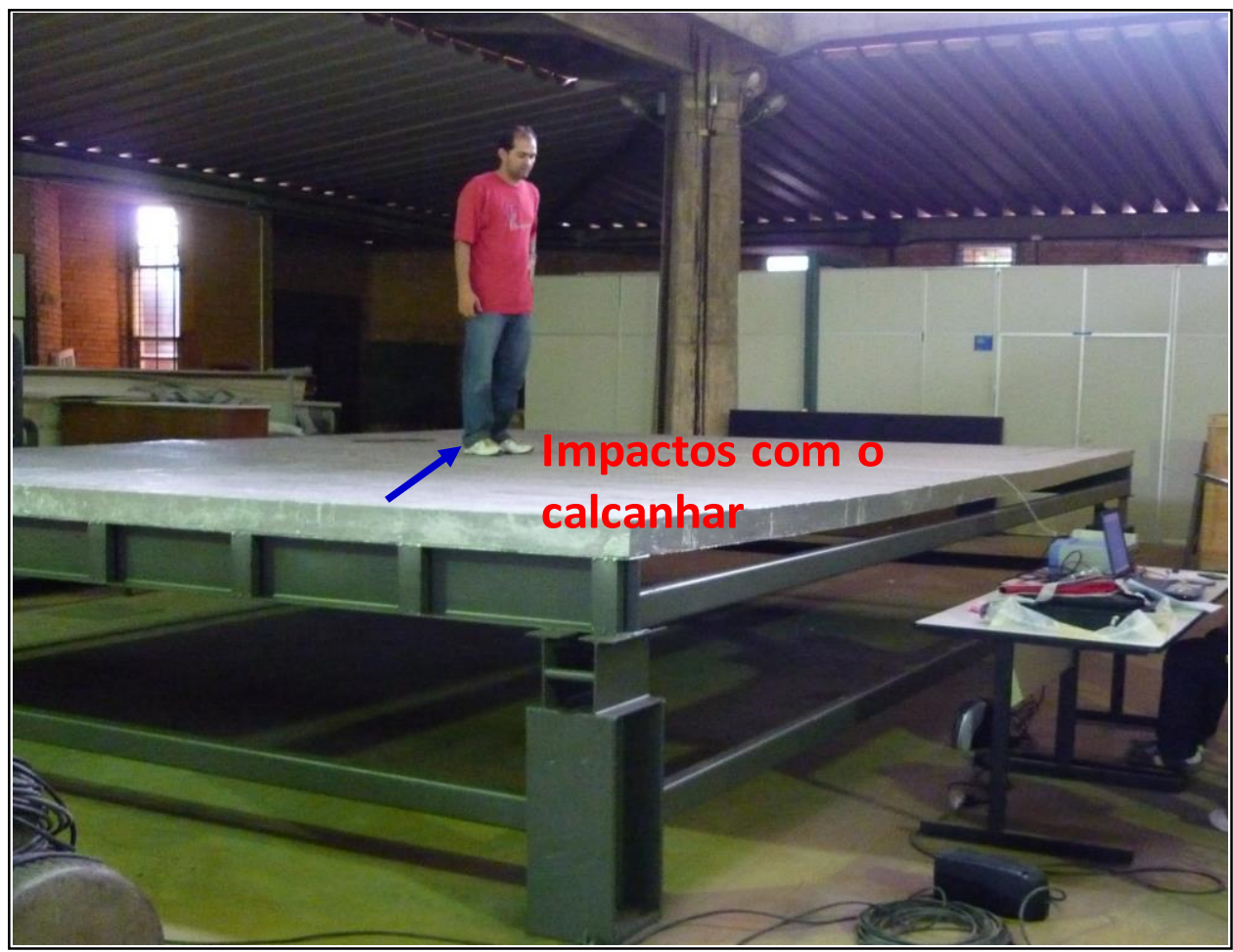

Figura 4.5 - Impactos com o calcanhar para encontrar frequência natural da plataforma. 
Com base nos resultados experimentais foi feita uma atualização do modelo numérico construído inicialmente, contemplando as fissuras que foram preenchidas com graute epóxi conforme procedimento de recuperação descrito no Anexo II.

Para isso foi necessário fazer um mapeamento real das trincas existentes na plataforma e levar em consideração que foram preenchidas com uma camada do produto Sikadur $42 \mathrm{Cl}$ com espessura $4,5 \mathrm{~cm}$ e largura de $2,5 \mathrm{~cm}$ conforme descrito no Anexo II.

O modelo numérico atualizado possui uma malha mais refinada em relação ao inicial para que as fissuras ficassem mais próximas das fissuras reais da plataforma, com elementos de aproximadamente $2,42 \mathrm{~cm}$. Com este novo modelo gerou-se um total de 97516 elementos dos quais 59536 correspondem aos elementos que simulam a laje de concreto e 37980 são elementos que modelam os perfis e pilares em aço.

Na Figura 4.6 (a) as linhas em cor violeta mostram o mapeamento das trincas modelado no programa ANSYS (2012) e na Figura 4.6 (b) a fotografia indica as trincas reais da plataforma antes de ser preenchidas com graute epoxi.

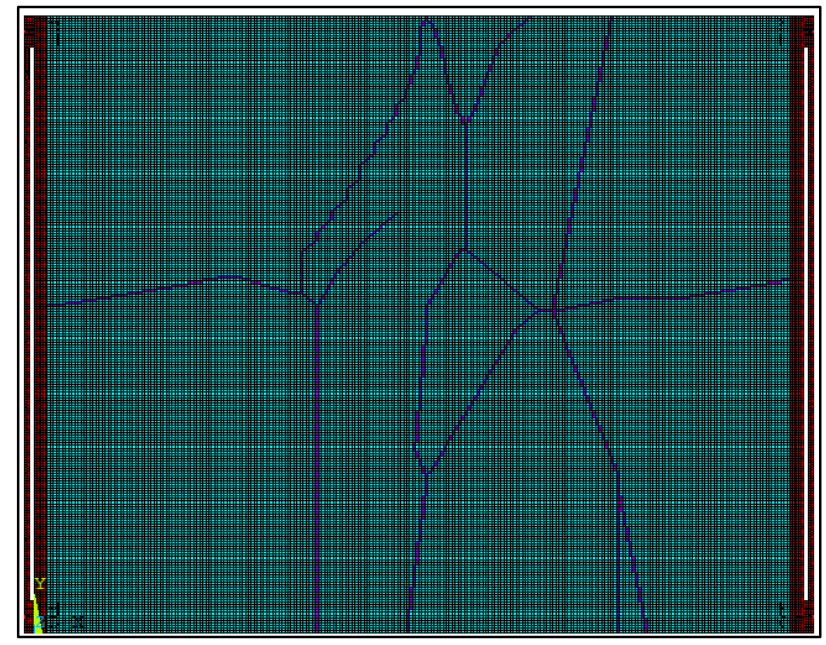

(a)

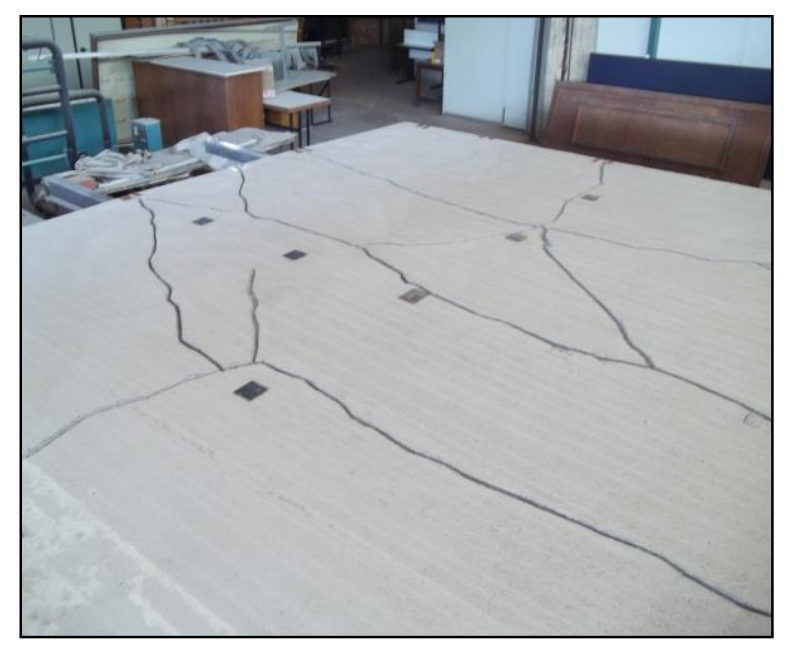

(b)

Figura 4.6 - (a) Mapeamento das trincas da laje no modelo numérico. (b) Trincas na lajes que foram preenchidas com graute epóxi fluido.

Para a realização dos ensaios dinâmicos, foi utilizado o seguinte aparato experimental: sistema de aquisição de dados, transdutores, condicionadores de sinal, cabos, conversores analógicodigitais, gravadores. A instrumentação consistiu em dois acelerômetros para os ensaios de 
vibração livre. Estes sensores são da marca PCB Piezotronics modelo 353B33, o qual tem uma sensibilidade de $5 \%\left[10,19 \mathrm{mV} /\left(\mathrm{m} / \mathrm{s}^{2}\right)\right]$. O condicionador de sinais e sistema de aquisição de dados é composto por um modulo ADS2000, fabricado pela empresa Linx Tecnologia Eletrônica com tem duas placas eletrônicas condicionadoras do tipo AI-2164, cada uma contendo 16 canais de aquisição de dados. Os dados são monitorados e gravados utilizando o software AqDados 7, instalado em um notebook. A configuração básica do sistema é mostrada na Figura 4.7.

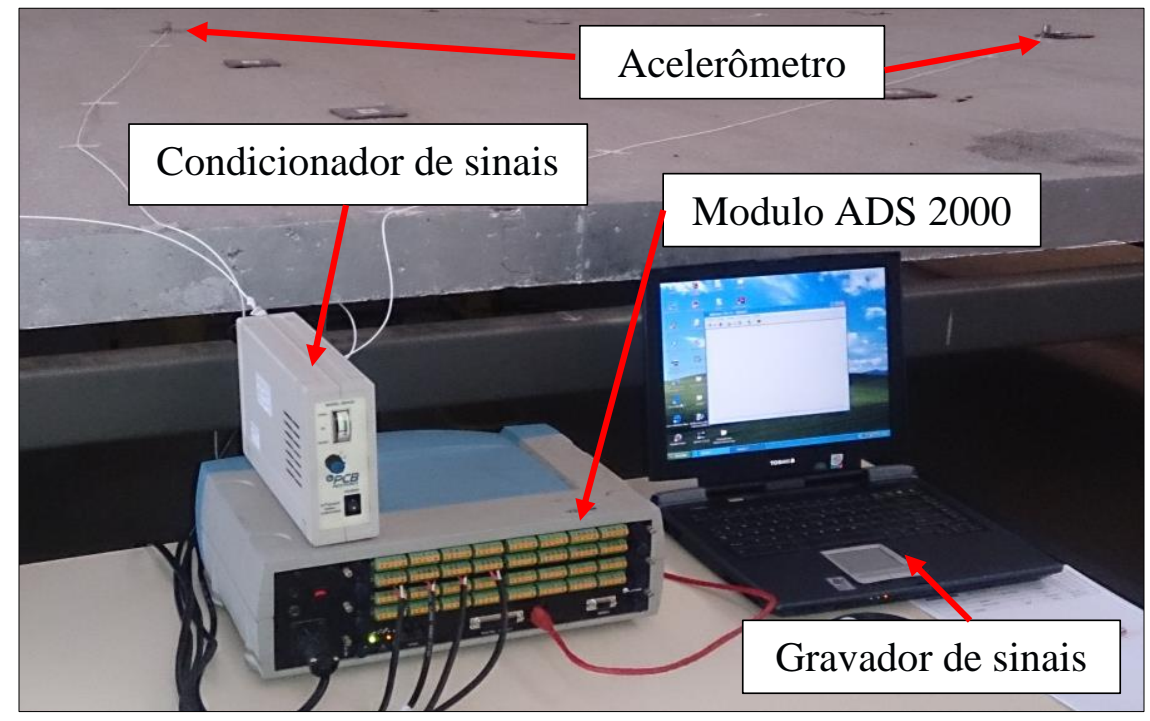

Figura 4.7 - Instrumentação básica para os ensaios de vibração livre.

Para a realização dos ensaios de vibração livre da plataforma foi necessário traçar uma malha na superfície da laje. Nos pontos de interseção das linhas traçadas (nós) foram fixados os sensores (acelerômetros), os quais registraram as acelerações dos diferentes ensaios. Assim, a superfície da laje foi dividida em 10 partes iguais na direção do comprimento eixo $X$ e também em 10 partes iguais na direção da largura eixo $Y$. Esta divisão acarreta em linhas perpendiculares ao eixo $\mathrm{Y}$ a cada $49 \mathrm{~cm}$.

A quantidade de nós é suficiente para determinar experimentalmente diferentes formas modais da laje de concreto, captando as acelerações dos diferentes, ensaios em quase a totalidade da superfície da laje. Para fixar os acelerômetros na laje foram utilizadas 81 chapas de aço de 
dimensões de $3 \mathrm{~cm}$ x 2,85cm, adequadas para o tamanho dos acelerômetros, as quais foram coladas na superfície da laje com ajuda de cola de sapateiro.

Para encontrar as formas modais experimentais da laje, foram realizados 4 tipos de ensaios reunidos em testes 1 e 2 e 3 e 4, os dois primeiros foram realizados da mesma maneira, com a finalidade de comparar resultados, de igual forma para os testes 3 e 4 . Cada ensaio foi composto de 160 registros de acelerações, analisando um total de 640 conjuntos de dados. Os ensaios foram executados utilizando-se dois acelerômetros, um fixo e outro móvel.

Na Figura 4.8 apresentam-se as dimensões da malha projetada na laje da plataforma, para realização dos ensaios de vibração livre chamados de 1 e 2, os círculos de cor azul são os nós onde se colocaram os acelerômetros móveis, o círculo preenchido em vermelho está sobre o nó onde ficou o acelerômetro fixo. A forma de posicionar o círculo em vermelho é explicada mais adiante.

Já a Figura 4.9 exibe a discretização da superfície da laje com a malha e em cada um de seus nós coladas às chapas de aço que serviram para fixar os acelerômetros nos ensaios experimentais. 


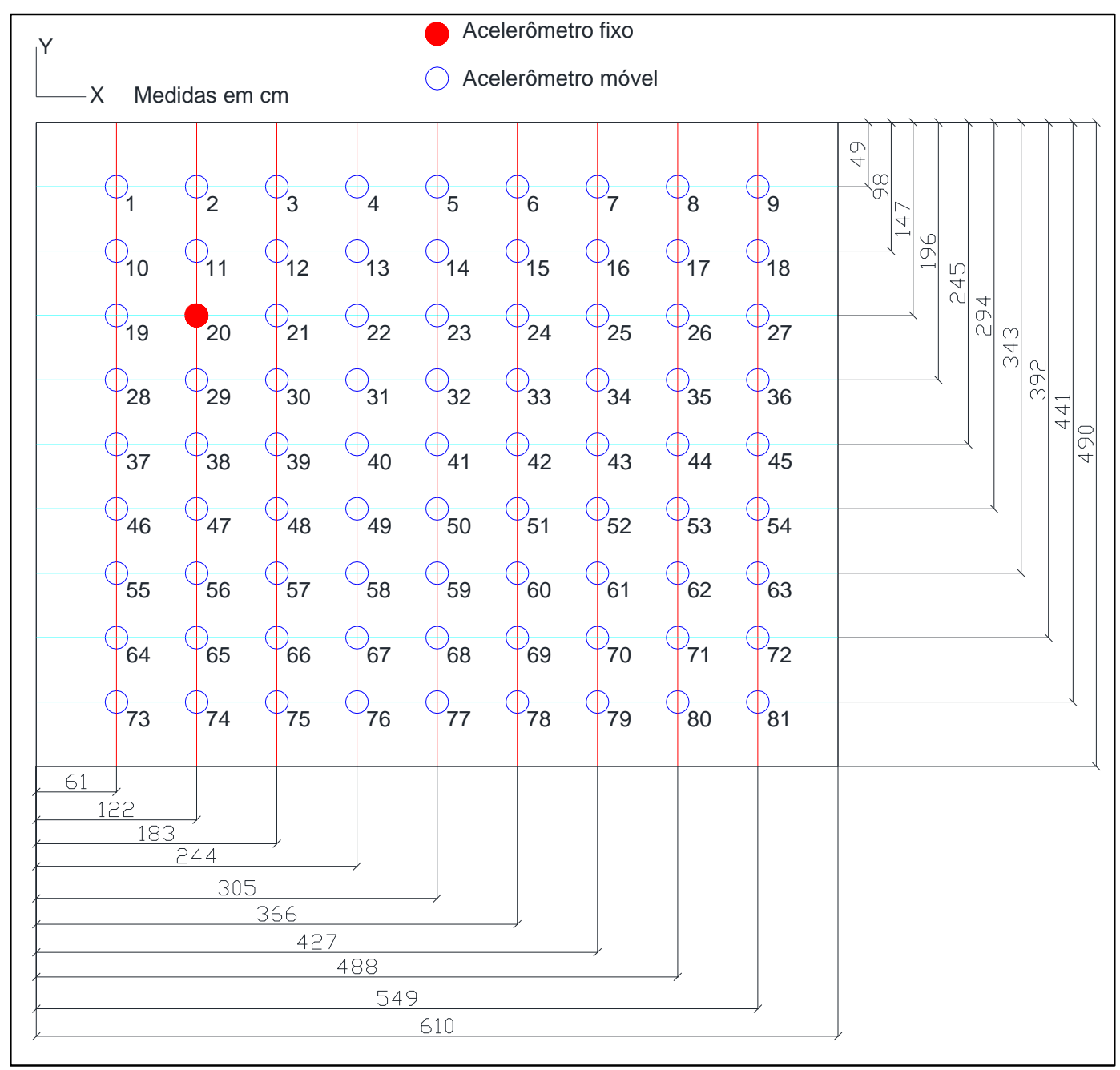

Figura 4.8 - Malha projetada na superfície da laje da plataforma para posicionar os acelerômetros. Ensaios 1 e 2.

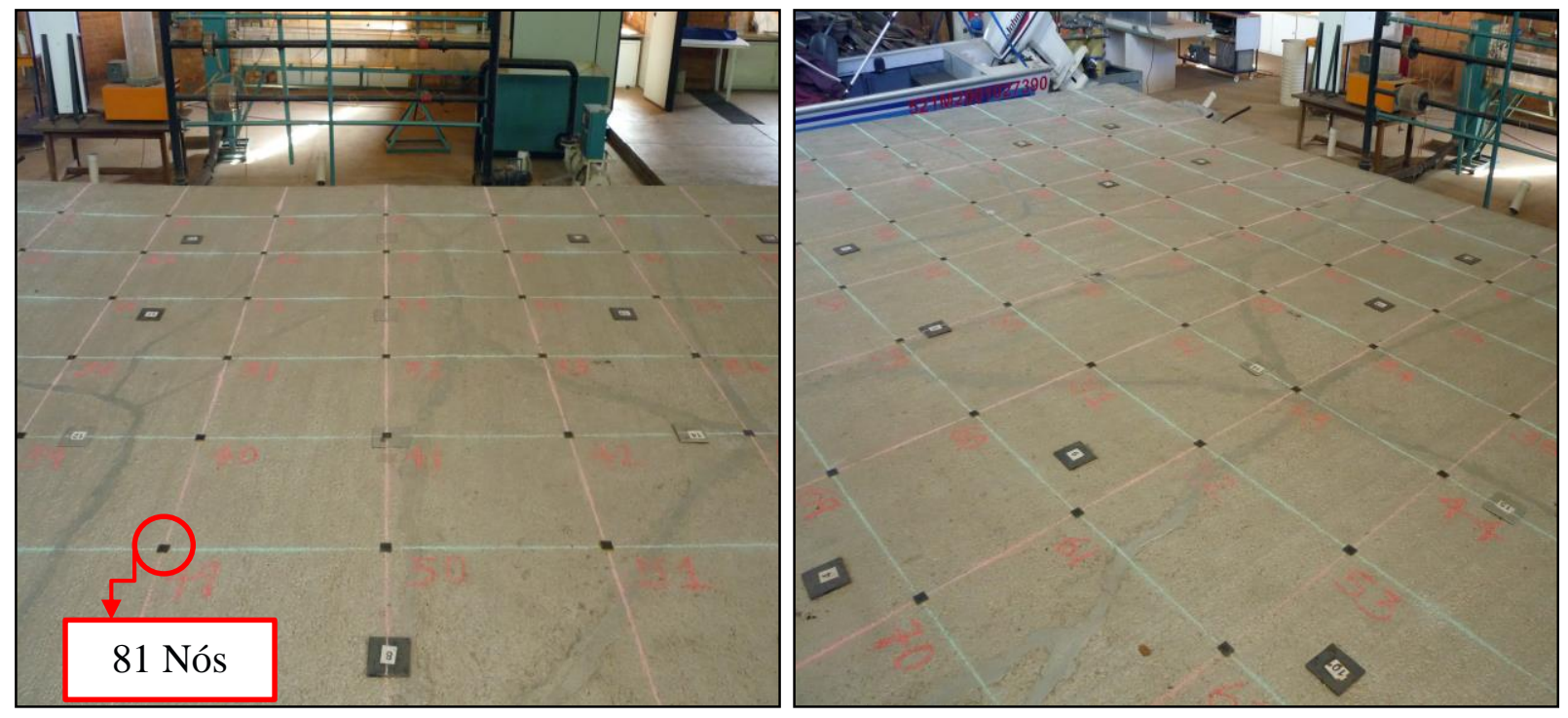

Figura 4.9 - Malha com 81 nós onde são registradas as acelerações. 
Com o intuito de saber a melhor localização dos acelerômetros foi realizada uma superposição das quatro primeiras formas modais obtidas numericamente. A projeção dessas formas modais sobre o eixo $X$ se ilustra na Figura 4.10 e sobre o eixo $Y$ na Figura 4.11. Observando os pontos com os deslocamentos não nulos em todas as formas modais consideradas obteve-se o ponto mais adequado para o acelerômetro fixo.

A partir das análises conclui-se que uma boa posição para o acelerômetro fixo seria a uma distância de 1,22 m do apoio do perfil de aço na direção X e uma distância da borda livre na direção Y de 1,96m. Esta localização anterior corresponde ao nó 20 conforme apresentado na Figura 4.8

Nos ensaios experimentais 1 e 2 fixou-se um acelerômetro no nó 20, e nos demais nós colocavase o acelerômetro móvel, modificando a posição dele para cada novo ensaio. Na Figura 4.10 a linha em vermelho passa por pontos de deslocamento nulos e a linha em magenta passa por pontos de deslocamento não nulo.

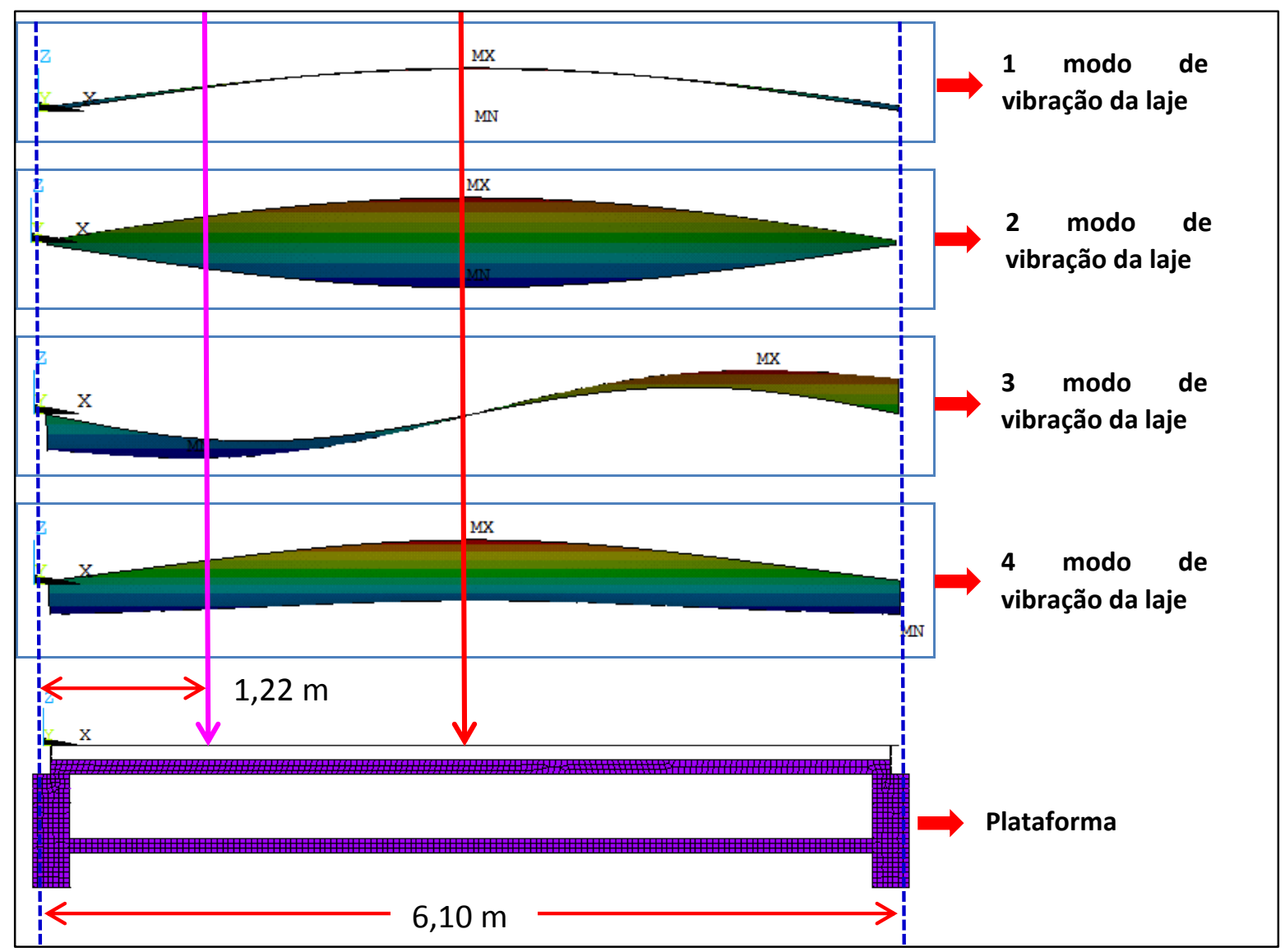

Figura 4.10 - Localização no eixo $X$ do ponto onde se coloca o acelerômetro fixo. 


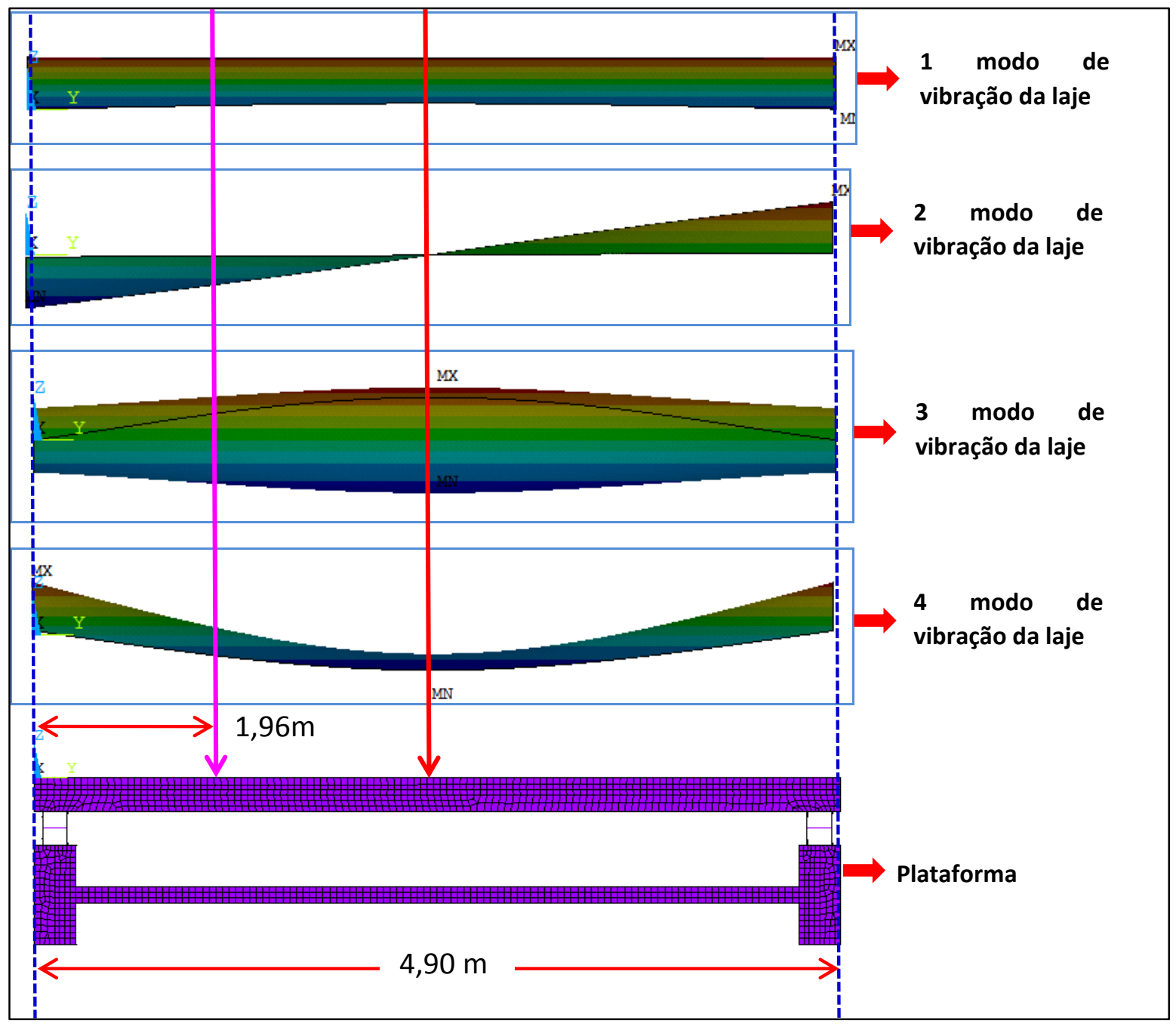

Figura 4.11 - Localização no eixo $Y$ do ponto onde se coloca o acelerômetro fixo.

Para os testes 3 e 4 fixou-se um acelerômetro no nó 41, correspondente ao centroide da laje. $\mathrm{O}$ nó 41 foi escolhido para os ensaios experimentais pois, apresenta o maior deslocamento da primeira forma modal no estudo numérico. Nos outros nós coloca-se o acelerômetro móvel, variando a posição para cada novo ensaio. A diferença entre os dois primeiros testes 1 e 2 e os dois segundos 3 e 4 foi a posição do acelerômetro fixo. A posição do acelerômetro fixo nos ensaios 3 e 4 e dos acelerômetros moveis é mostrada na Figura 4.12 


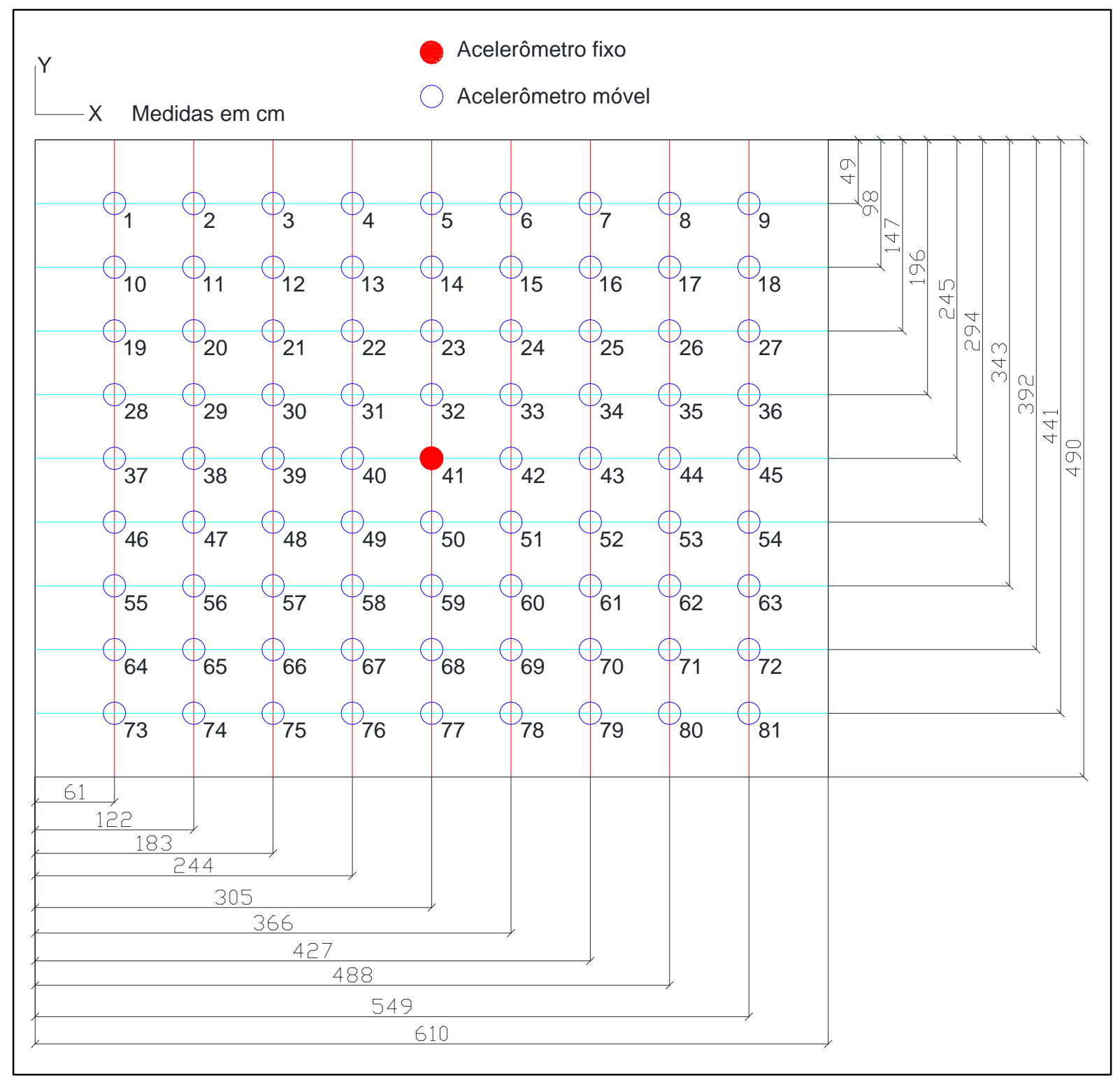

Figura 4.12 - Malha projetada na superfície da laje de concreto e posição dos diferentes acelerômetros para os ensaios experimentais 3 e 4 .

Todos os ensaios anteriores foram ensaios de vibração livre, excitando a laje com um impacto de calcanhar durante aproximadamente um segundo e logo deixando vibrar a laje por 15 segundos mais.

Após a obtenção dos resultados experimentais realizou-se o processamento dos mesmos utilizando o pacote computacional ARTeMIS, no qual a partir dos registros das acelerações experimentais podem ser definidas as diferentes formas modais experimentais da estrutura.

A Figura 4.13 apresenta a modelagem da plataforma no ARTeMIS. 


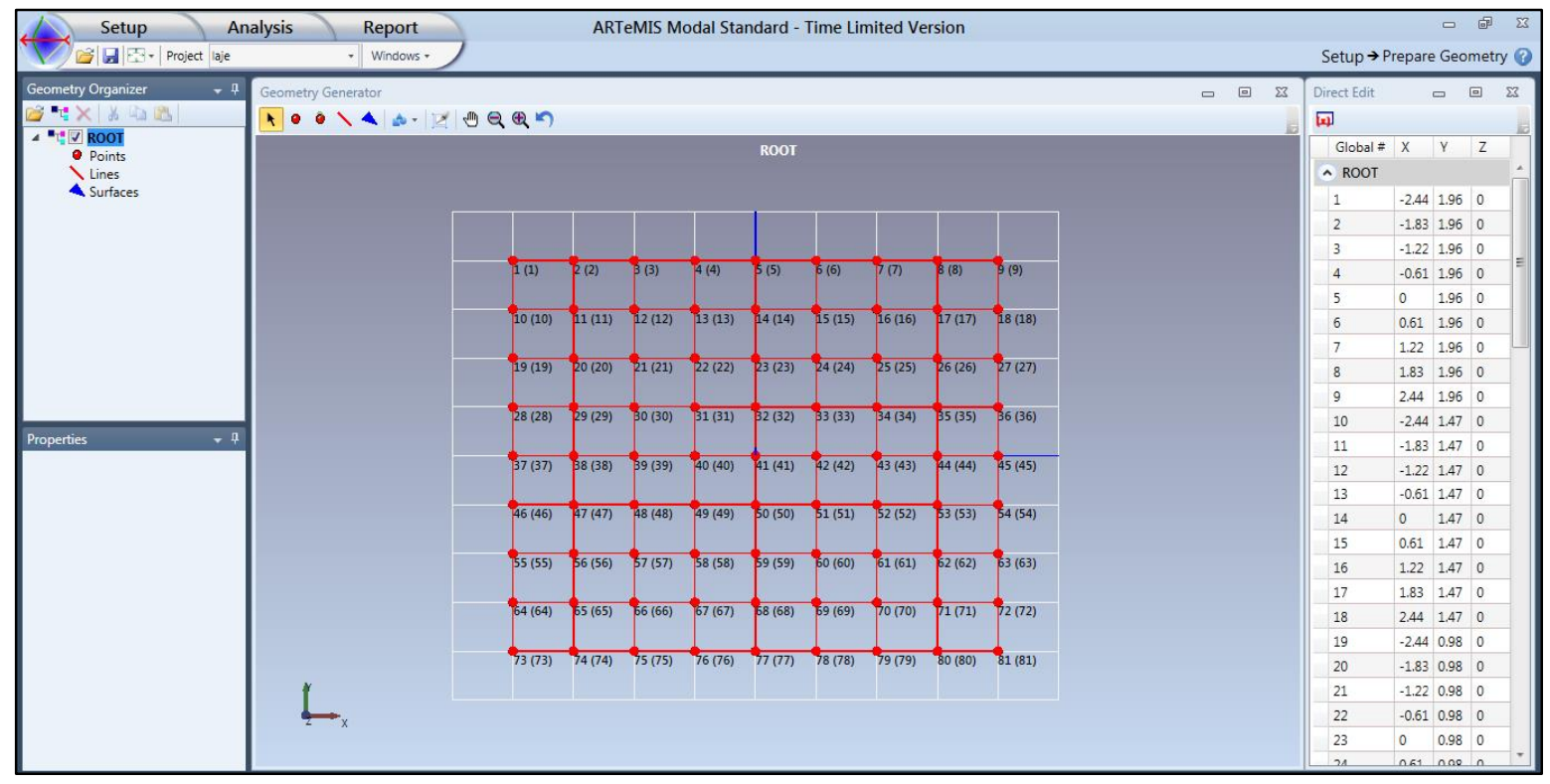

Figura 4.13 - Discretização da malha na laje de concreto no software ARTeMIS.

Em seguida, para cada ensaio realizado, inseriram-se no programa os 160 sinais dos acelerômetros correspondentes aos canais 1 e 2. Estes sinais correspondem às combinações dos sinais de todos os nós com o do nó 20 (fixo) para os testes 1 e 2, e em relação a sinal do nó 41 no caso dos testes 3 e 4 . Posteriormente foram vinculados os sinais dos acelerômetros aos nós correspondentes a cada medição, como se apresenta na Figura 4.14.

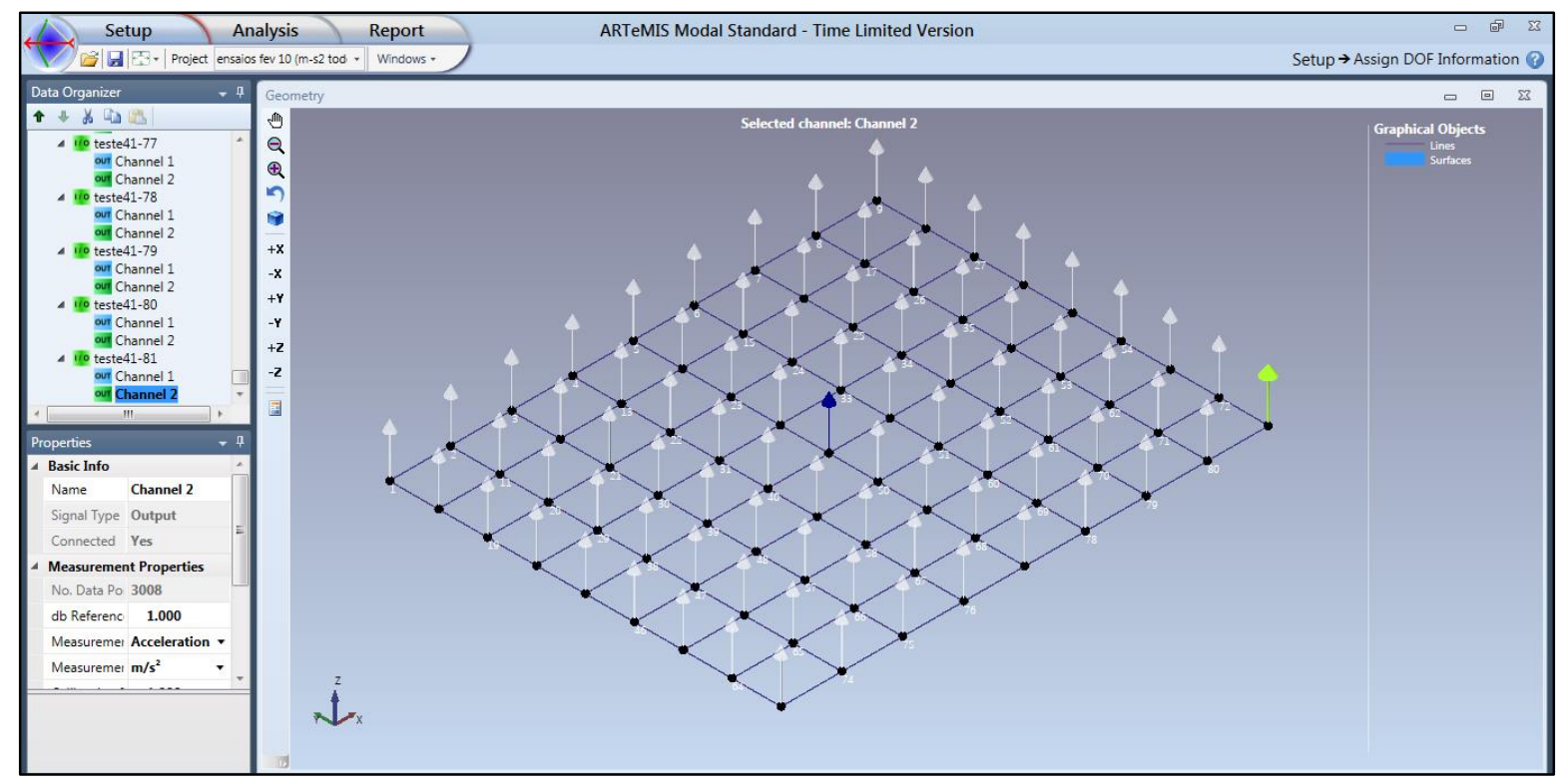

Figura 4.14 - Vinculação dos sinais dos acelerômetros aos respectivos nós da laje. (Ensaio 3) 
$\mathrm{Na}$ etapa seguinte realizou-se o processamento de dados pelo método Decomposição no Domínio da Frequência (Frequency Domain Decomposition FDD). O método utiliza um algoritmo para identificação das características modais da estrutura a partir de medições experimentais. A técnica do método FDD é baseada na decomposição de valores singulares (Singular Value Decompoition SVD) da matriz de densidade espectral (Spectral Density SD) no domínio da frequência, (Brincker, 2015).

O método FDD foi utilizado tendo como objetivo determinar as frequências naturais da laje de concreto e seus respectivos modos de vibração a partir dos testes experimentais.

Da Figura 4.15 até a Figura 4.17 comparam-se as 3 primeiras frequências naturais e as respectivas formas modais da laje de concreto encontradas numericamente e através das técnicas de identificação a partir dos dados experimentais. Na parte superior de cada figura encontra-se a forma modal obtida numericamente com o pacote computacional ANSYS (2012) e na parte inferior observa-se a forma modal obtida experimentalmente com ajuda do pacote computacional ARTeMIS.

Na Tabela 4.1 são apresentadas as frequências obtidas numericamente e através de identificação a partir dos dados experimentais, além da porcentagem da diferença entre os dois valores. 


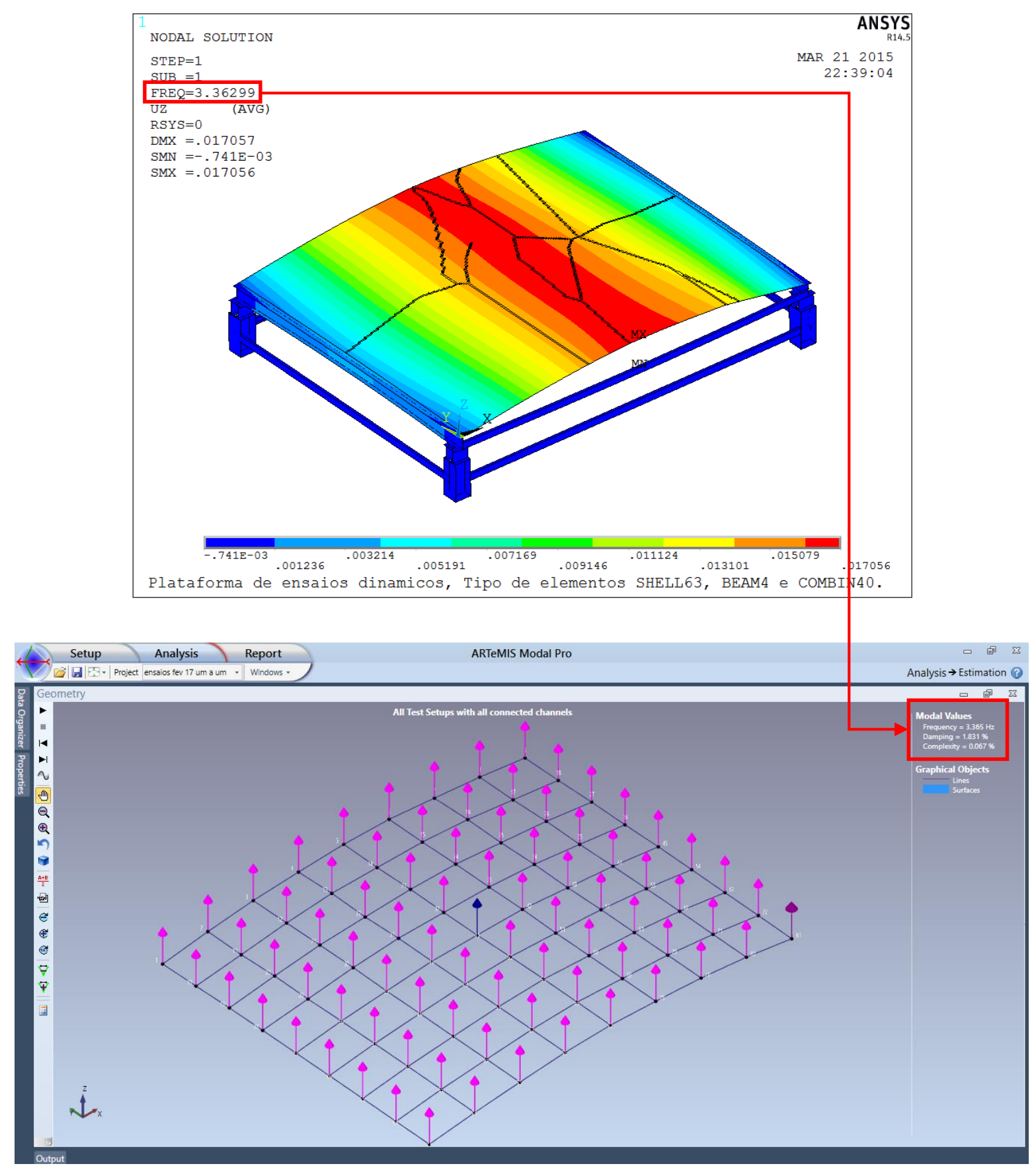

Figura 4.15 -Primeira forma modal numérica e experimental da laje de concreto da plataforma. Teste 4 frequência numérica $=3,36 \mathrm{~Hz}$, frequência experimental $=3,36 \mathrm{~Hz}$, amortecimento experimental $=1,83 \%$. 


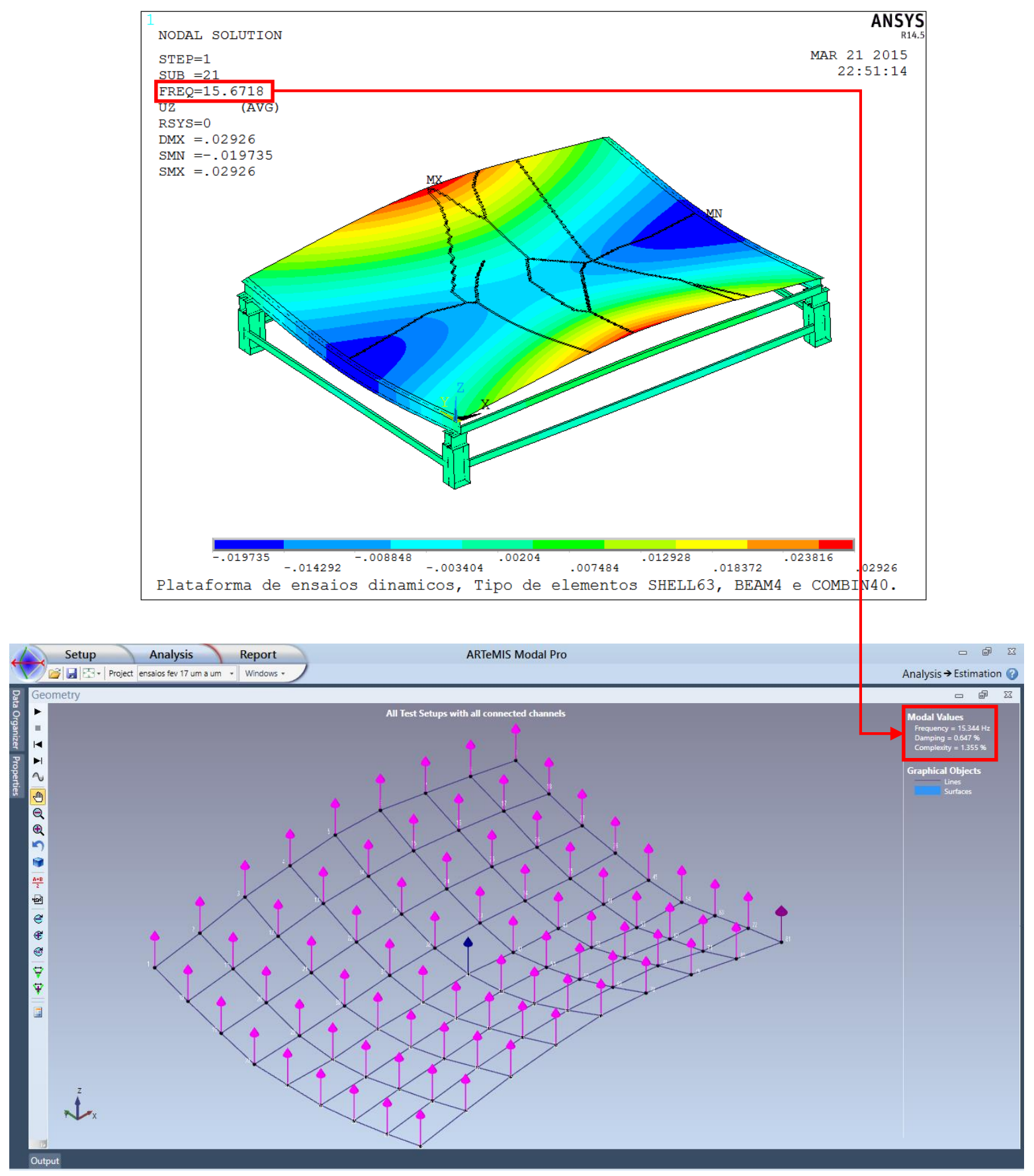

Figura 4.16 - Segunda forma modal numérica e experimental da laje de concreto da plataforma. Teste 4 frequência numérica $=15,67 \mathrm{~Hz}$, frequência experimental $=15,34 \mathrm{~Hz}$, amortecimento experimental $=0,65 \%$. 


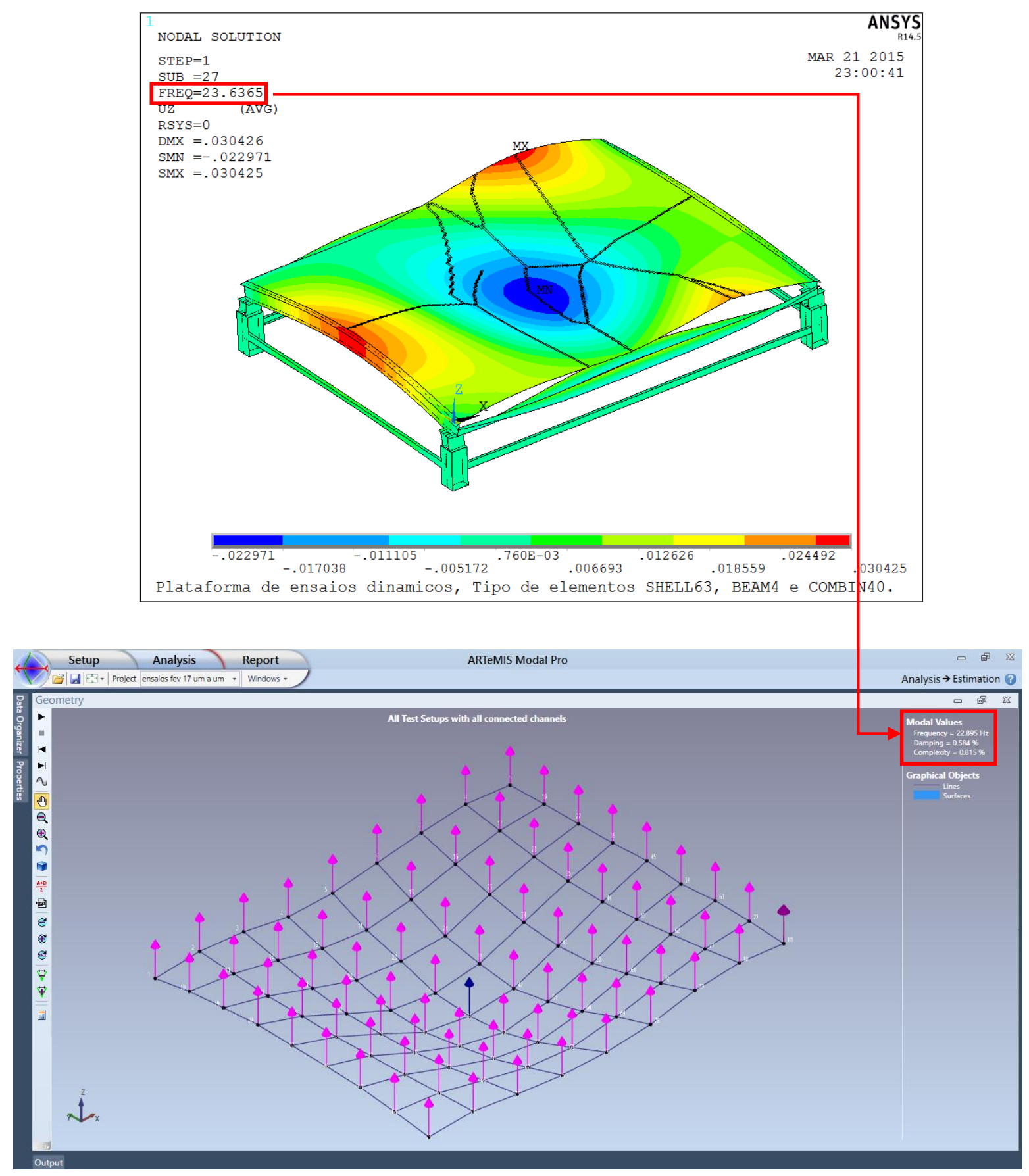

Figura 4.17 -Terceira forma modal numérica e experimental da laje de concreto da plataforma. Teste 4 frequência numérica $=23,64 \mathrm{~Hz}$, frequência experimental $=22,90 \mathrm{~Hz}$, amortecimento experimental $=0,58 \%$. 
Tabela 4.1 - Comparação entre as frequências numéricas e experimentais.

\begin{tabular}{|c|c|c|c|}
\cline { 2 - 4 } \multicolumn{1}{c|}{} & Frequência 1. & Frequência 2. & Frequência 3. \\
\hline Numérica & $3,36 \mathrm{~Hz}$ & $15,67 \mathrm{~Hz}$ & $23,64 \mathrm{~Hz}$ \\
\hline Experimental & $3,36 \mathrm{~Hz}$ & $15,34 \mathrm{~Hz}$ & $22,90 \mathrm{~Hz}$ \\
\hline Diferença & $0 \%$ & $2,11 \%$ & $3,1 \%$ \\
\hline
\end{tabular}

Da tabela anterior pode-se observar uma boa correlação entre os dados numéricos e experimentais para as três primeiras formas modais.

$\mathrm{Na}$ Tabela 4.2 apresenta-se um resumo das frequências que foram encontradas nos diferentes ensaios experimentais realizados. Pode-se observar que os resultados das três primeiras frequências mostram boa consistência entre si.

Tabela 4.2 - Resumo das diferentes frequências obtidas nos ensaios experimentais.

\begin{tabular}{|c|c|c|c|}
\hline Teste 1 & Teste 2 & Teste 3 & Teste 4 \\
\hline $\begin{array}{c}\text { Acel. nó fixo 20 } \\
\text { (canto laje) }\end{array}$ & $\begin{array}{c}\text { Acel. nó fixo 20 } \\
\text { (canto laje) }\end{array}$ & $\begin{array}{c}\text { Acel. nó fixo 41 } \\
\text { (metade laje) }\end{array}$ & $\begin{array}{c}\text { Acel. nó fixo 41 } \\
\text { (metade laje) }\end{array}$ \\
\hline $\mathrm{f} 1=3,32 \mathrm{HZ}$ & $\mathrm{f} 1=3,32 \mathrm{HZ}$ & $\mathrm{f} 1=3,42 \mathrm{HZ}$ & $\mathrm{f} 1=3,36 \mathrm{HZ}$ \\
\hline $\mathrm{f} 2=15,14 \mathrm{HZ}$ & $\mathrm{f} 2=15,23 \mathrm{HZ}$ & $\mathrm{f} 2=15,53 \mathrm{HZ}$ & $\mathrm{f} 2=15,34 \mathrm{HZ}$ \\
\hline $\mathrm{f3}=22,95 \mathrm{HZ}$ & - & $\mathrm{f3}=23,24 \mathrm{HZ}$ & $\mathrm{f3}=22,90 \mathrm{HZ}$ \\
\hline $\mathrm{f} 4=31,35 \mathrm{HZ}$ & $\mathrm{f} 4=51,76 \mathrm{~Hz}$ & $\mathrm{f} 4=85,25 \mathrm{HZ}$ & $\mathrm{f} 4=81,25 \mathrm{HZ}$ \\
\hline $\mathrm{f} 5=48,63 \mathrm{HZ}$ & - & - & - \\
\hline
\end{tabular}

Um registro de acelerações em função do tempo obtido no ensaio 4 é mostrado na Figura 4.18 enquanto a Figura 4.19 exibe a resposta no domínio da frequência para o mesmo ensaio.

$\mathrm{Na}$ Tabela 4.3 são apresentados os amortecimentos experimentais sem AMS para as três primeiras formas modais. Os amortecimentos foram extraídos do software ARTeMIS pelo método Decomposição no Domínio da Frequência (Frequency Domain Decomposition FDD).

Tabela 4.3 - Amortecimentos experimentais de cada modo de vibração pelo método $F D D$.

\begin{tabular}{|c|c|c|c|c|c|}
\hline \multicolumn{5}{|c|}{ Taxa de amortecimento em vibração livre. } \\
\hline \multicolumn{2}{|c|}{ Primeiro modo } & \multicolumn{2}{c|}{ Segundo modo } & \multicolumn{2}{c|}{ Terceiro modo } \\
\hline Amortecimento & $1,83 \%$ & Amortecimento & $1,36 \%$ & Amortecimento & $0,58 \%$ \\
\hline
\end{tabular}


Segundo De Silva (2007) o amortecimento estrutural do concreto varia entre 2 e $6 \%$. O resultado obtido para o primeiro modo é um pouco inferior aos sugeridos por De Silva (2007).

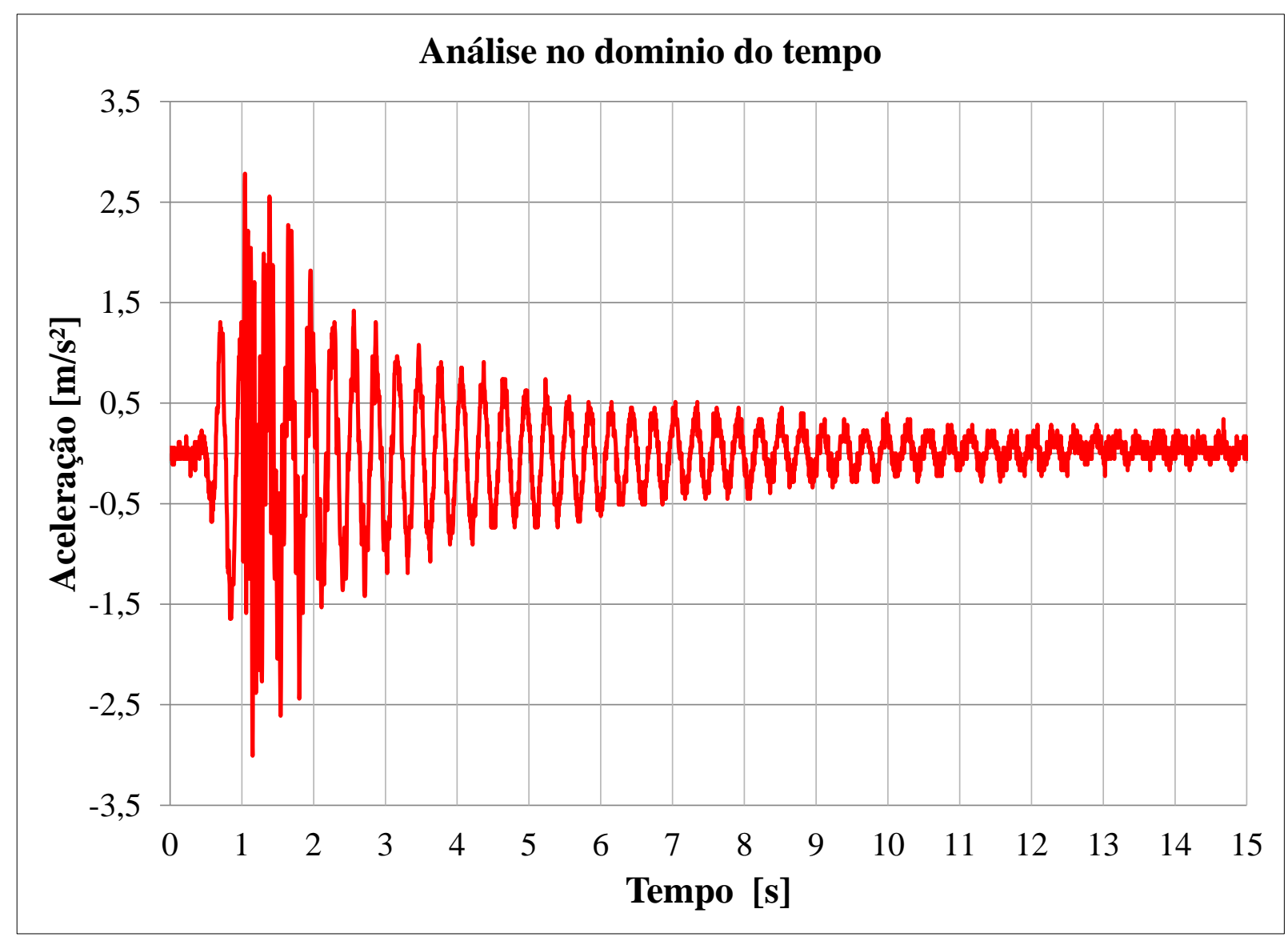

Figura 4.18 - Registro das acelerações no domínio do tempo. Vibração livre Teste 4, nó 20 onde se pegaram os resgistros das acelerações. 


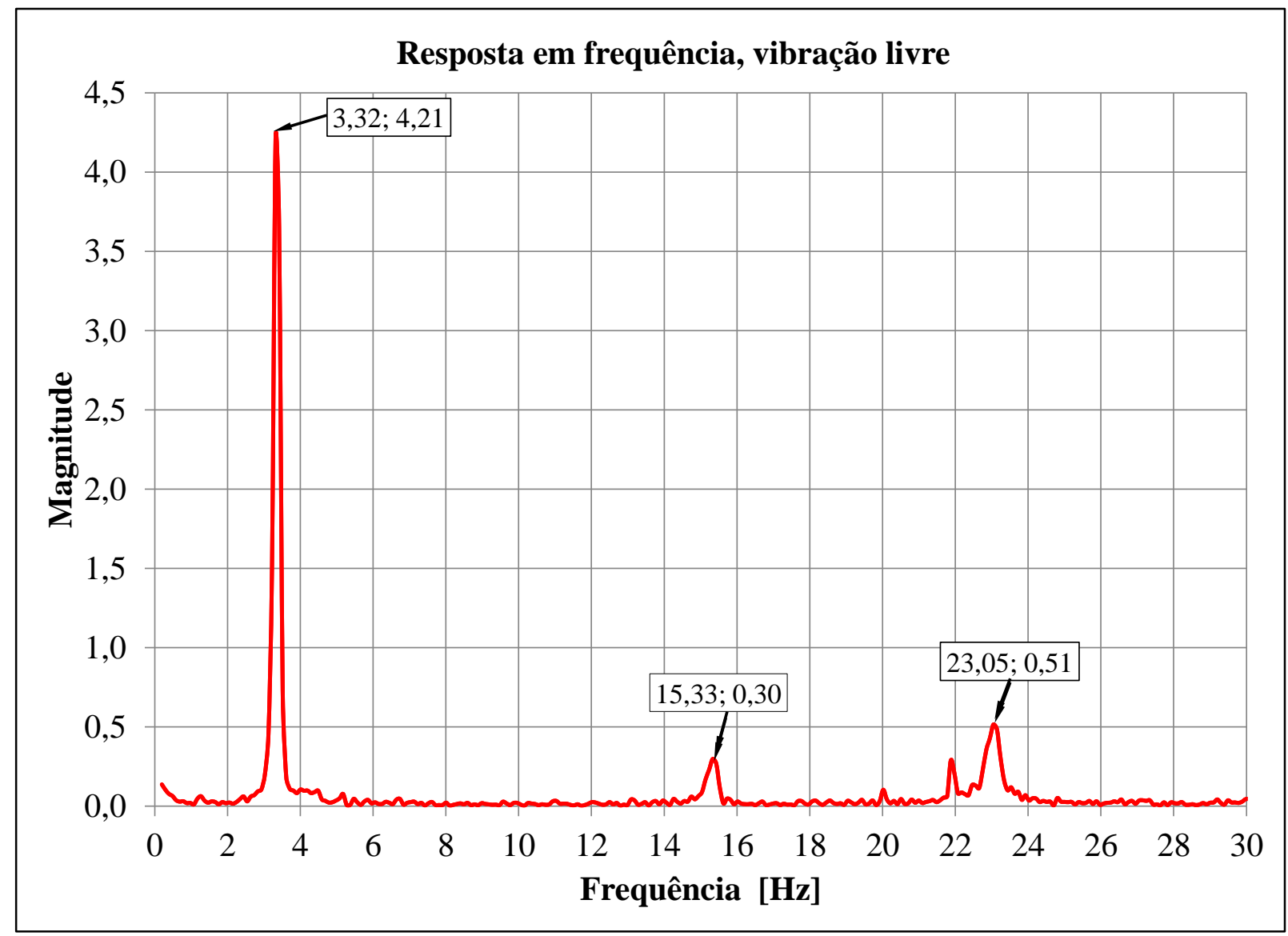

Figura 4.19 - Frequências naturais da laje de concreto. Vibração livre Teste 4, nó 20 onde se pegaram os registros das acelerações.

\subsection{COMPARAÇÃO ENTRE AS FORMAS NUMÉRICAS E EXPERIMENTAIS}

Foram comparadas as diferentes formas modais numéricas e experimentais da laje de concreto da plataforma mediante o critério MAC (Modal Assurance Criterion). O MAC corresponde a um escalar que não é mais do que uma medida da discrepância entre duas formas modais, sendo, no caso de correlação perfeita, igual à unidade. A aplicação deste critério exige a identificação dos modos presentes no processo experimental e a extração dos mesmos do modelo numérico, De Castro (1996).

Segundo Ewins (2000) o valor do escalar do MAC pode ser encontrado a partir da seguinte equação: 
$\operatorname{MAC}(p, x)=\frac{\sum_{j=1}^{n}\left[\left(\Phi_{x}\right)_{j}\left(\Phi_{p}\right)_{j}\right]^{2}}{\left(\sum_{j=1}^{n}\left(\Phi_{x}\right)_{j}\left(\Phi_{x}\right)_{j}\right) *\left(\sum_{j=1}^{n}\left(\Phi_{p}\right)_{j}\left(\Phi_{p}\right)_{j}\right)}$

Onde:

$\left(\Phi_{x}\right)$ : Deslocamento da forma modal experimental.

$\left(\Phi_{p}\right)$ : Deslocamento da forma modal teórica (para nosso caso é deslocamento numérico).

As amplitudes numéricas e experimentais dos 81 nós correspondentes às diferentes formas modais, se encontram tabeladas no Anexo VI.

Aplicando a equação (4.1) f oram encontrados os diferentes escalares no estudo $M A C$ para cada combinação das formas modais. Da Figura 4.20 até a Figura 4.23 apresentam-se os valores dos escaleres correspondentes aos 4 ensaios experimentais da laje da plataforma em vibração livre.

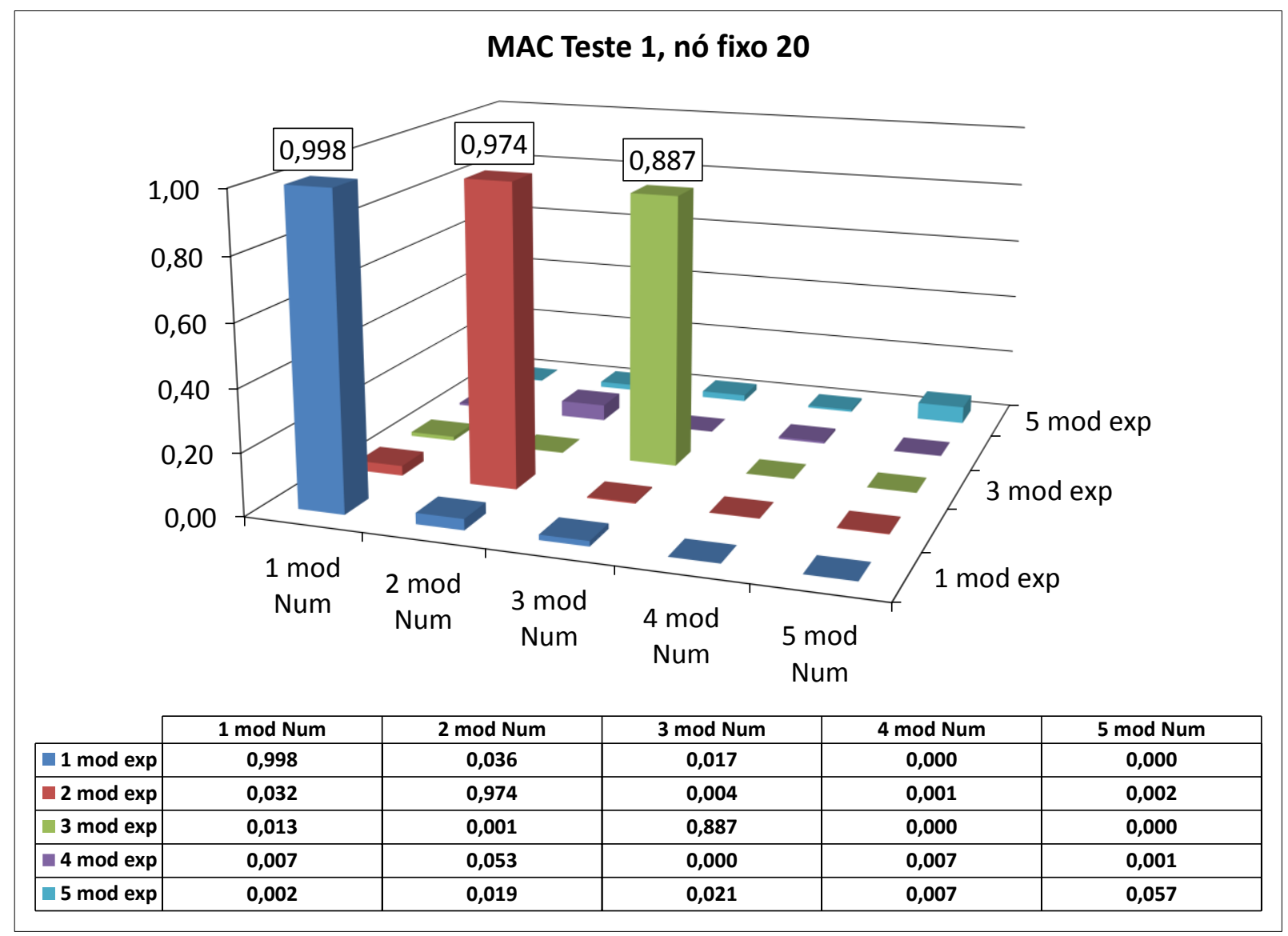

Figura 4.20 - MAC teste 1 (nó fixo 20). 


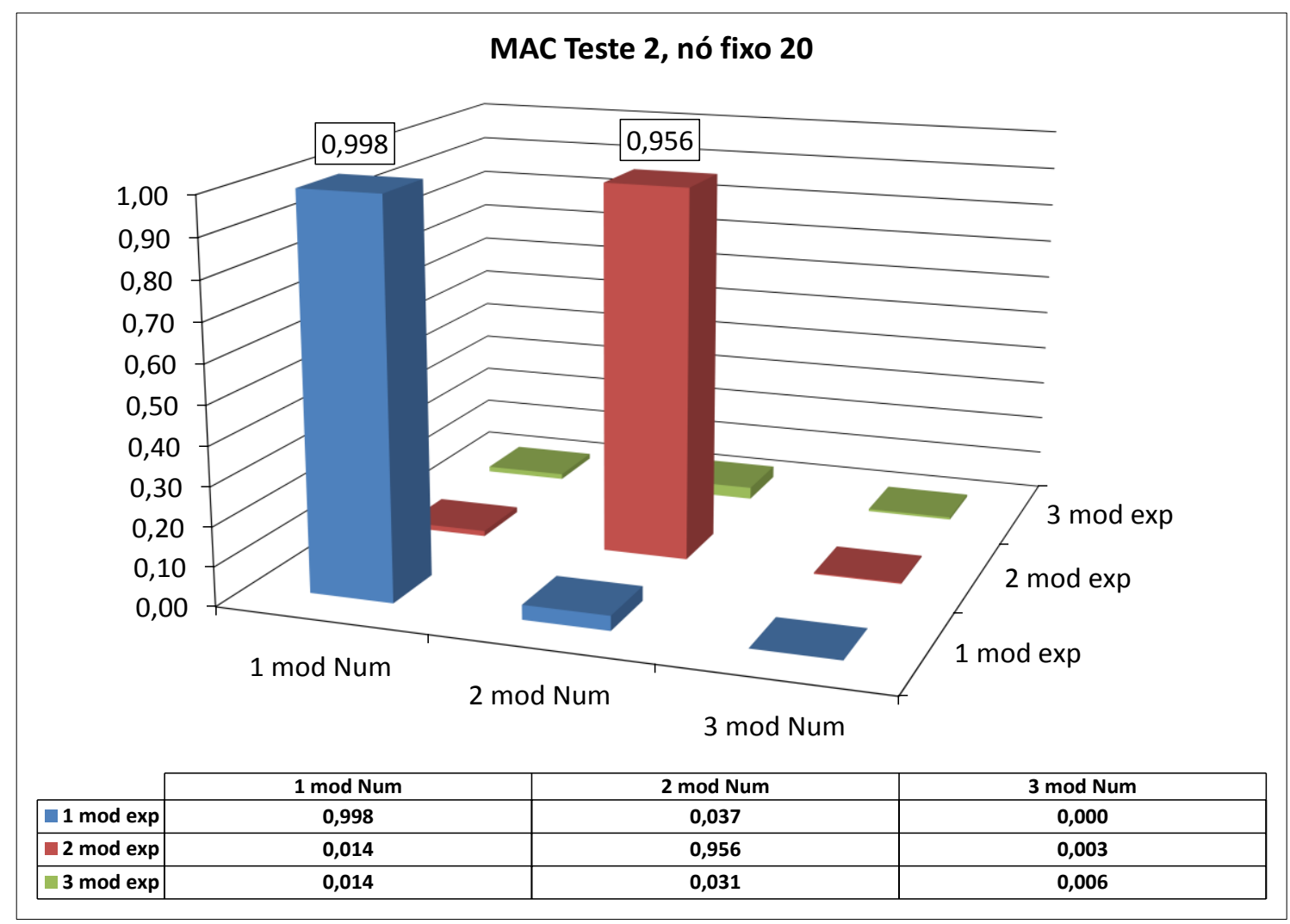

Figura 4.21 - MAC teste 2 (nó fixo 20).

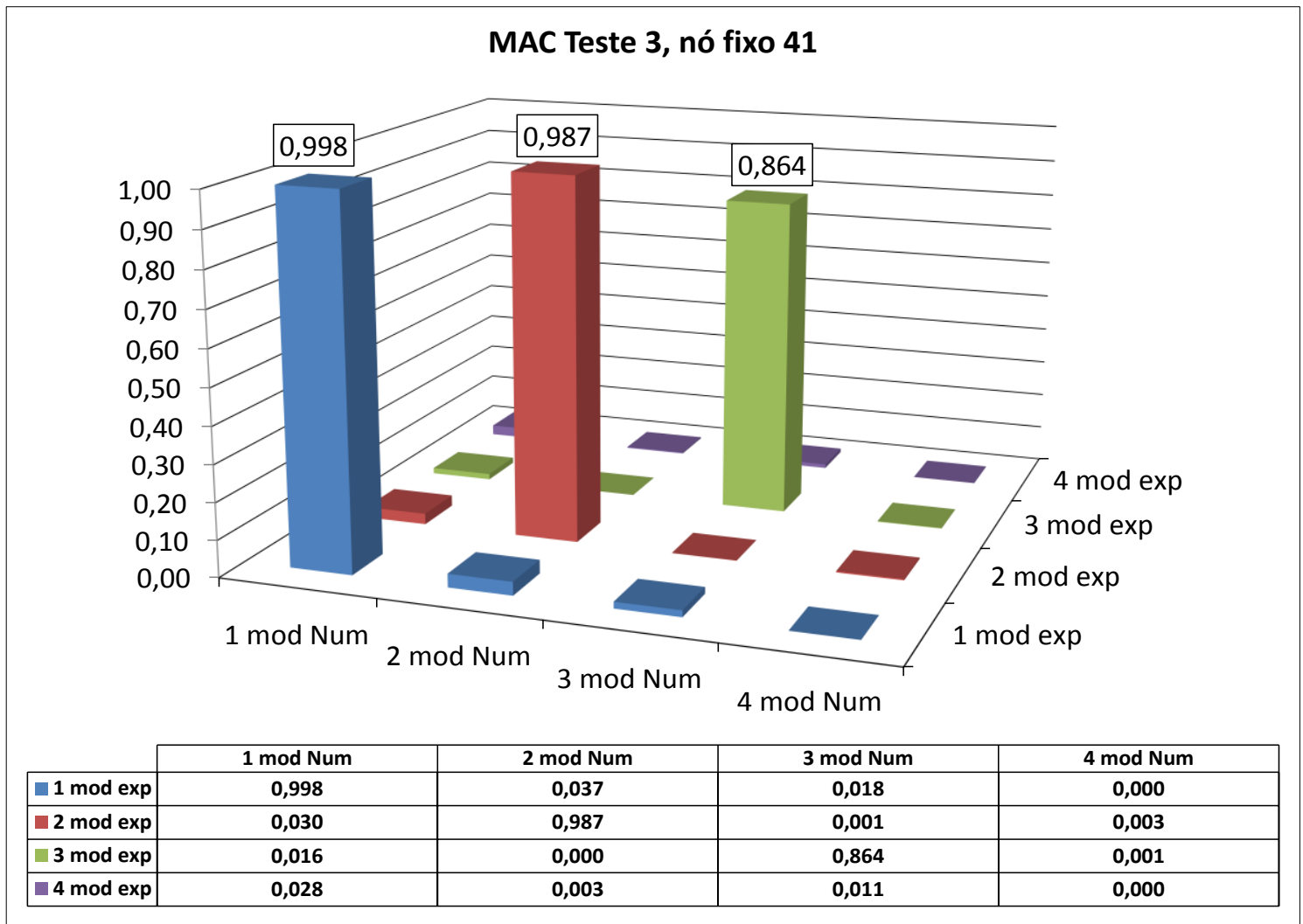

Figura 4.22 - MAC teste 3 (nó fixo 41). 


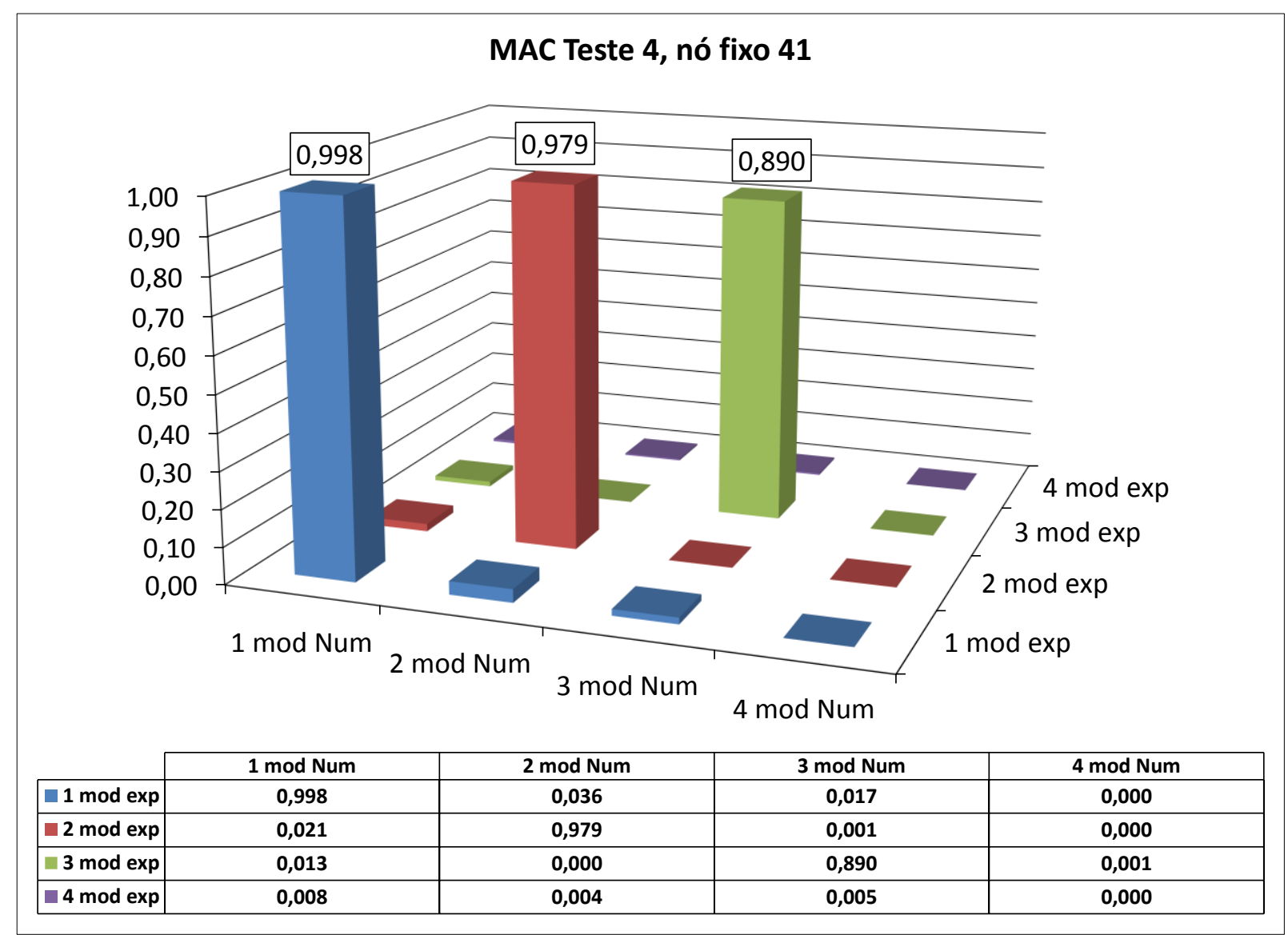

Figura 4.23 - MAC teste 4 (nó fixo 41).

No estudo do MAC se espera que os valores dos escalares da diagonal principal da matriz sejam 1 e que os demais escalares sejam 0 . Nas figuras anteriores pode-se observar que para os três primeiros modos os escalares variam de 0,86 para o terceiro modo até 0,99 para o primeiro modo. Segundo Braun (2002) valores maiores do que 0,9 dos escalares indicam uma correspondência consistente entre as formas modais experimentais e teóricas. Em todos os 4 testes os dois primeiros modos apresentam uma boa correspondência entre as formas modais experimentais e numéricas, uma vez que os valores são maiores do que 0,9. Já para o terceiro modo em três ensaios o valor do escalar se aproxima a 0,9 com o melhor valor no quarto ensaio. Em resumo pode-se dizer que as três primeiras formas modais experimentais e teóricas apresentam boa correlação.

Do estudo anterior se confirma a conclusão que a melhor posição para colocar o AMS é no centro da laje de concreto da plataforma, posição com maior amplitude modal, visto que a 
primeira forma modal numérica e a correspondente primeira forma modal experimental apresentam boa correlação.

A plataforma de ensaios dinâmicos já recuperada se apresenta como boa estrutura para a pesquisa de vibrações verticais fortes, a qual pode ser monitorada mediante ensaios experimentais de vibração livre e forcada. É ótima para estudos de caso nos quais as vibrações na estrutura são causadas por atividades rítmicas de pessoas como por exemplo caminhar, pular, dançar entre outras. 


\section{PROJETO E CONSTRUÇÃO DE UM SISTEMA DE CONTROLE DE VIBRAÇÕES}

Neste capitulo se apresentam os estudos levados a cabo com o intuito de se obter sistemas de controle de vibrações para uma laje e os detalhes do sistema projetado e construído.

\subsection{ESTUDOS NUMÉRICOS COM VISTAS À DEFINIÇÃO DE UM SISTEMA DE CONTROLE}

Conforme mencionado anteriormente, o objetivo desta Tese é trabalhar uma metodologia para se chegar a construir um sistema de controle de vibrações para pisos baseado na utilização de AMS. Este dispositivo tem como finalidade reduzir vibrações excessivas provenientes dos carregamentos induzidos por atividades humanas. O AMS deve possuir uma frequência natural fundamental igual ou próxima à frequência fundamental da plataforma de ensaios dinâmicos. São realizados dois estudos. O primeiro estudo consiste em trabalhar com um amortecedor posicionado no centro da plataforma variando os parâmetros que o caracterizam. O segundo estudo em trabalhar com uma combinação de mais de um amortecedor de massa sintonizado, variando os parâmetros e a localização dos AMS sob a laje de concreto.

\subsubsection{Primeiro estudo}

É realizada inicialmente uma análise paramétrica considerando um único AMS, no qual se variam os parâmetros do mesmo como rigidez e coeficiente de amortecimento. Inicialmente foi escolhida uma massa para o amortecedor de $120 \mathrm{~kg}$, representando uma relação de massas de aproximadamente $1,7 \%$. Com este valor fixo da massa foram variando-se os parâmetros do AMS nos diferentes modelos.

Para esta análise é levado em consideração que o primeiro modo de vibração associado à frequência fundamental da estrutura é um modo de vibração por flexão, vide Figura 4.15.

O AMS é localizado no centro da plataforma nas coordenadas $X=3,050 \mathrm{~m}$ e $Y=2,450 \mathrm{~m}$. Para a frequência associada a esse modo se sintoniza o amortecedor e se consideram vários modelos listados na Tabela 5.1, mudando os parâmetros do mesmo amortecedor. 
Nas análises realizadas é aplicada uma carga impulsiva no centro da laje durante um segundo e depois vibrar a mesma livremente.

A Tabela 5.1 apresenta as amplitudes da resposta em frequência para o caso sem e com controle dos modelos estudados com um único AMS, considerando como excitação uma carga impulsiva.

Na Figura 5.1 se apresentam, para os modelos estudados, as respostas no domínio da frequência sem e com AMS. Para uma melhor compreensão da Figura 5.1 apresenta-se na Figura 5.2 os resultados apenas do modelo 7 que apresentou o melhor desempenho.

Tabela 5.1 - Amplitude da resposta em frequência variando-se os parâmetros para um único amortecedor, localizado no nó 30501.

\begin{tabular}{|c|c|c|c|c|c|}
\hline Modelo \# & $\begin{array}{l}\text { Massa } \\
(\mathrm{AMS}) \\
{[\mathrm{M}] \mathrm{Kg}}\end{array}$ & $\begin{array}{l}\text { Amortecimento } \\
\qquad \begin{array}{c}\text { (AMS) } \\
{[\mathrm{C}] \mathrm{Ns} / \mathrm{m}}\end{array}\end{array}$ & $\begin{array}{c}\text { Rigidez } \\
\text { Mola } \\
(\text { AMS }) \\
{[\mathrm{K}] \mathrm{N} / \mathrm{m}}\end{array}$ & $\begin{array}{l}\text { Amplitude da resposta } \\
\text { em frequência sem } \\
\text { AMS. } \\
\text { Frequência } 3,36 \mathrm{~Hz}\end{array}$ & $\begin{array}{c}\text { Amplitude da } \\
\text { resposta em } \\
\text { frequência com AMS. } \\
\text { Frequência } 3,36 \mathrm{~Hz}\end{array}$ \\
\hline 1 & 120 & 380 & 48000 & \multirow{7}{*}{0,084} & 0,015 \\
\hline 2 & 120 & 370 & 50000 & & 0,014 \\
\hline 3 & 120 & 400 & 45000 & & 0.018 \\
\hline 4 & 120 & 370 & 54000 & & 0,016 \\
\hline 5 & 120 & 350 & 60000 & & 0,023 \\
\hline 6 & 120 & 330 & 66000 & & 0,034 \\
\hline 7 & 120 & 360 & 51000 & & 0,014 \\
\hline
\end{tabular}




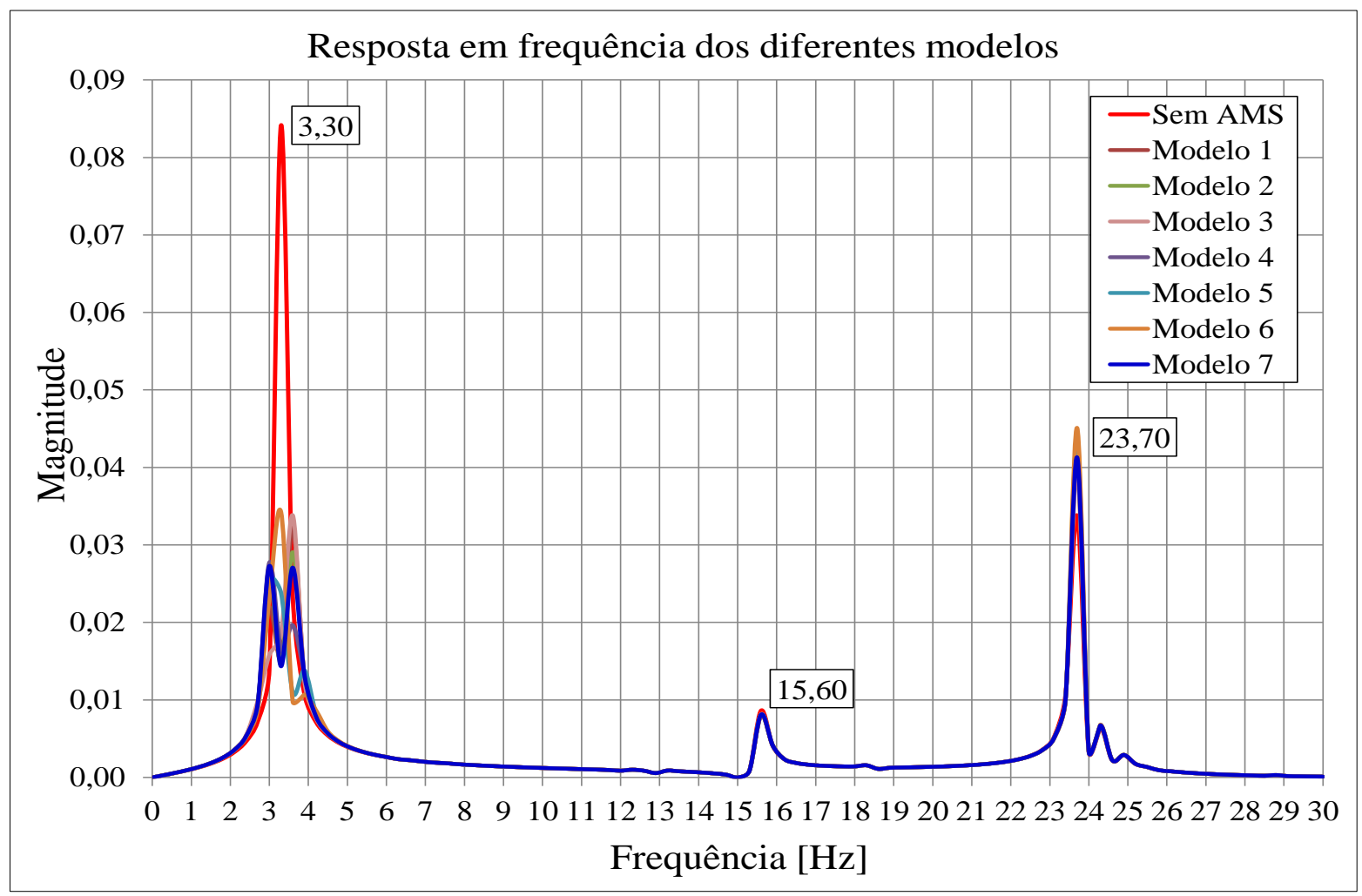

Figura 5.1 - Resposta em frequência do deslocamento do nó central da laje dos 7 modelos.

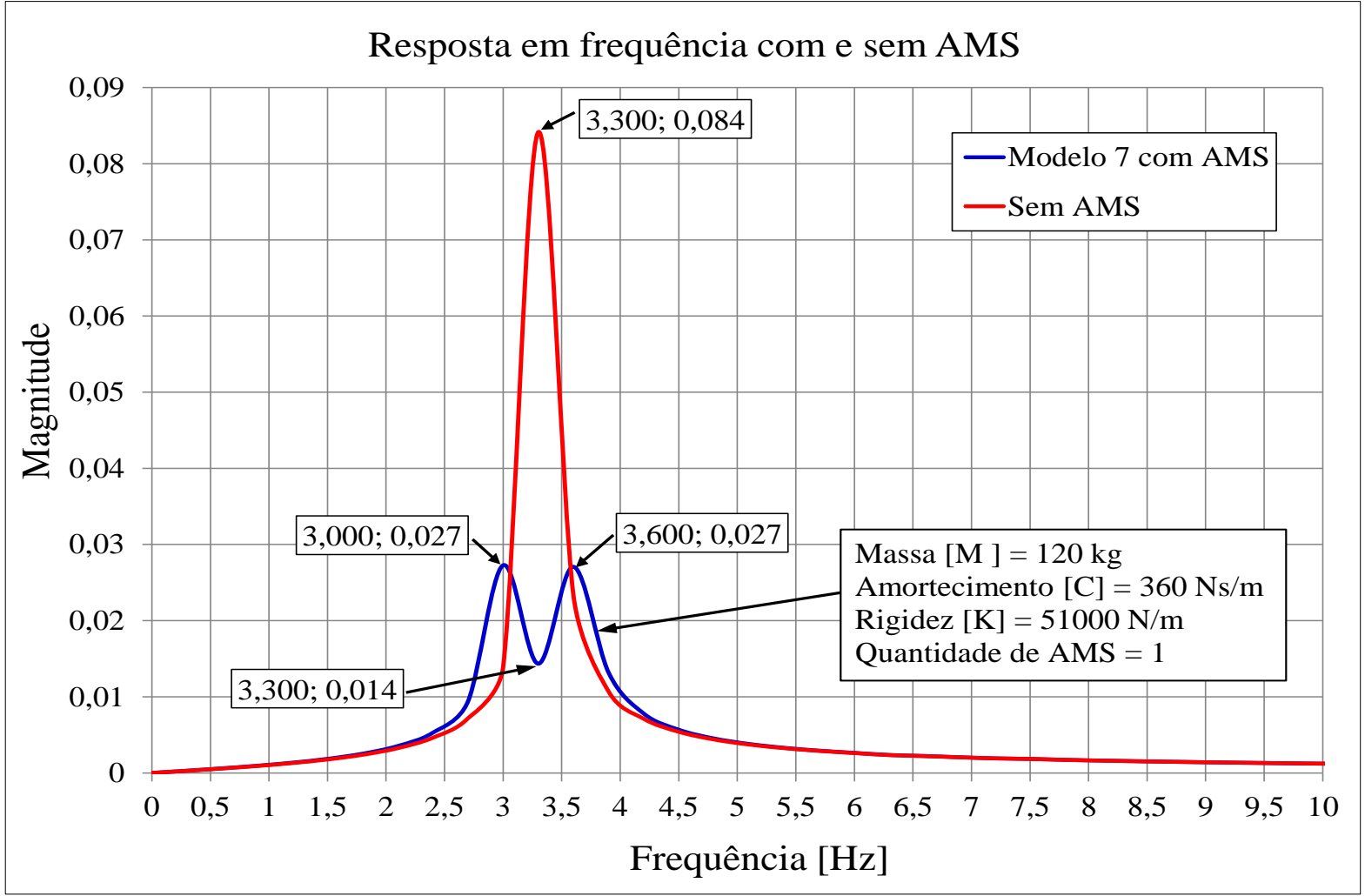

Figura 5.2 - Resposta em frequência do deslocamento do nó central da laje sem controle e com controle (Modelo 7). Vibração livre. 
O modelo 7 apresentou melhor redução da resposta em frequência de ressonância de 3,30 Hz, passando de uma amplitude de 0,08412 para uma amplitude de 0,01434, ou seja uma redução de aproximadamente 82,96\%. Da Figura 5.2 também observa-se que a primeira frequência fundamental natural da estrutura com o AMS é modificada para uma nova frequência de 3,0 Hz. Com esta frequência da estrutura a amplitude de vibração se vê reduzida em aproximadamente 3,11 vezes, o que representaria uma redução aproximada de 67,86\%.

Também na Figura 5.2 observa-se que a linha em azul que corresponde à resposta da estrutura com AMS tem dois picos correspondentes às duas primeiras frequências naturais de 3,0 e 3,6 $\mathrm{Hz}$ respectivamente. Os valores da ordenada são muito similares, podendo-se traçar uma linha horizontal entre estes dois picos. Segundo a literatura é possível traçar esta linha quando se tem uma calibração ótima dos parâmetros do AMS (Den Hartog, 1985).

Foi realizada em seguida uma análise transiente do modelo 7 para observar o comportamento da estrutura no domínio do tempo. Para isso, foi aplicada uma carga de impacto de 3000N no sentido negativo do eixo $\mathrm{Z}$ durante um intervalo de um segundo, simulando o impacto de uma pessoa de aproximadamente $100 \mathrm{~kg}$ e é obtida a resposta nos 50 segundos posteriores, como se pode observar na Figura 5.3.

Dessa figura podem-se analisar dois aspectos interessantes o primeiro é que a estrutura principal atuando sem o AMS possui um amortecimento estrutural muito baixo; apresentando ainda oscilações após 50 segundos de análise.

O segundo aspecto é que, no caso da resposta controlada, após 2 segundos da aplicação da força de impacto, o AMS começa a atuar diminuindo as acelerações na laje da plataforma, as acelerações cessam aos 20 segundos de análise e, praticamente, não ocorrem mais oscilações. As oscilações de laje são amortecidas em torno dos $29 \mathrm{~mm}$ como se apresenta na Figura 5.4 que é o novo valor da flecha estática da plataforma devida à adição da massa concentrada do AMS.

Da Figura 5.4 verifica-se que o amortecimento aproximado da estrutura com AMS é de 4,0\%. 


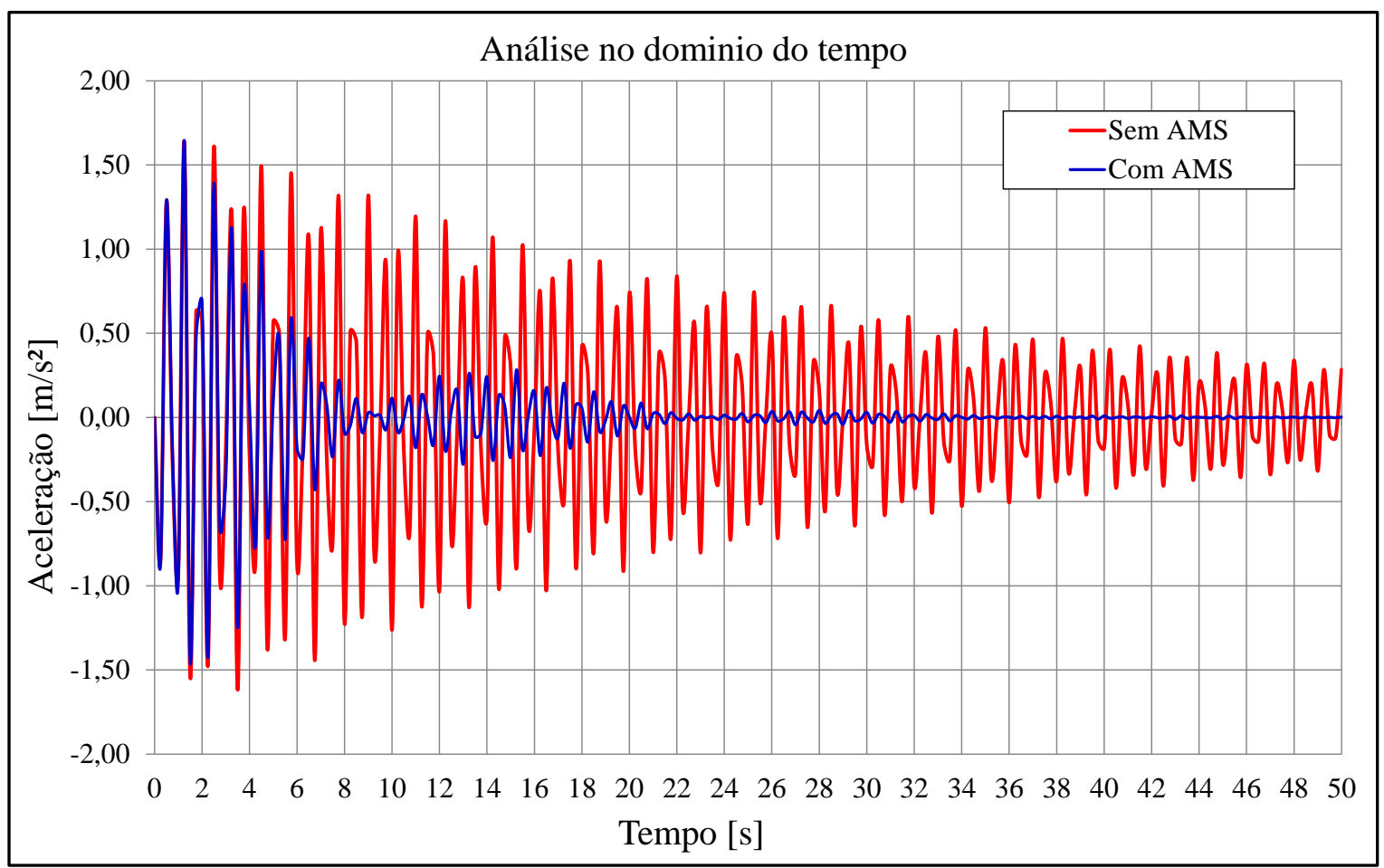

Figura 5.3 - Análise no domínio do tempo em função da aceleração (Modelo 7, 1 AMS). Impacto seguido de vibração livre.

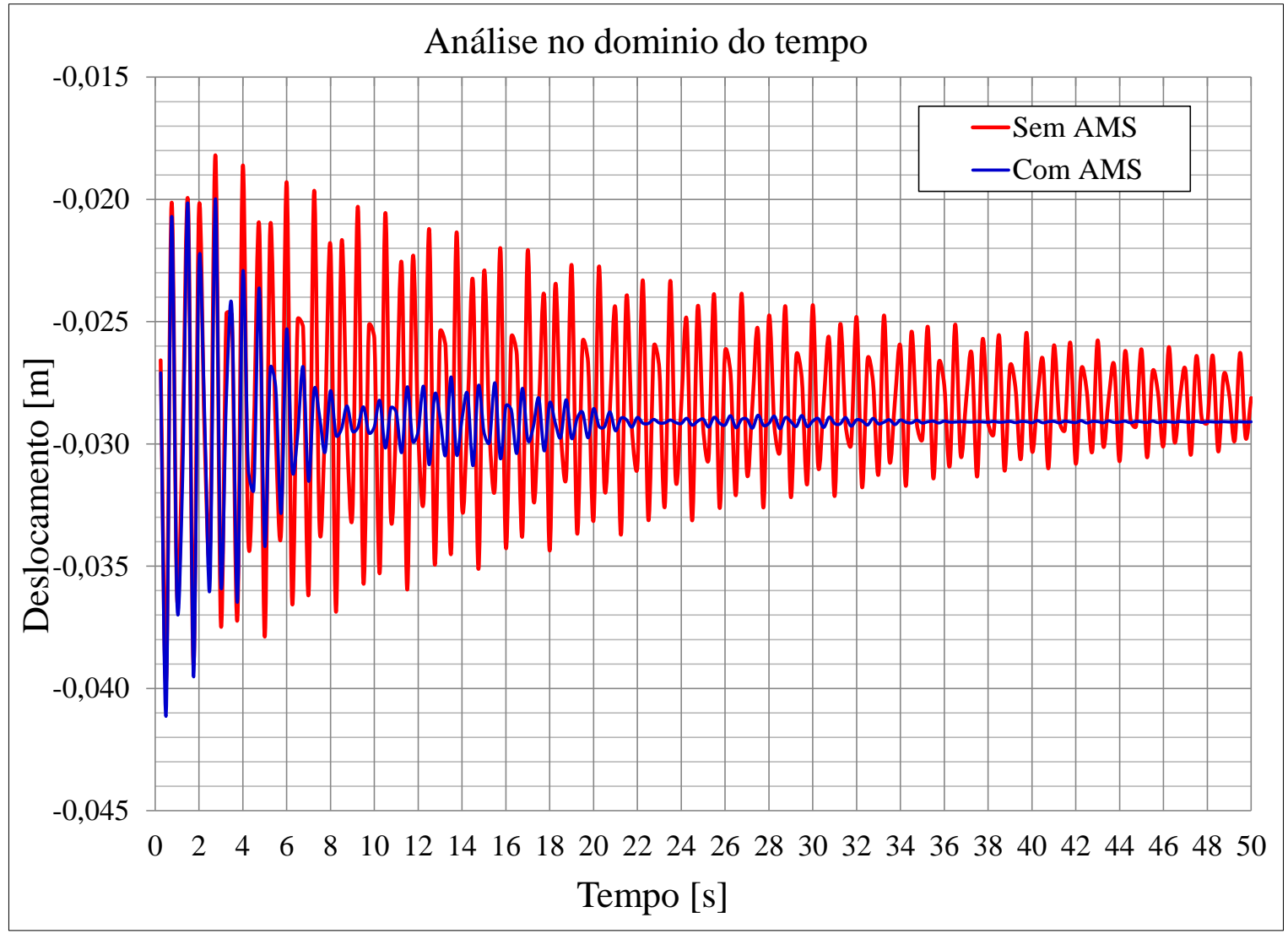

Figura 5.4 - Análise no domínio do tempo em função do deslocamento (Modelo 7, 1 AMS). Impacto seguido de vibração livre. 
Observando as análises da Figura 5.4 observa-se um incremento aproximado de 2,14\% no amortecimento da estrutura com a ajuda do AMS.

\subsubsection{Segundo estudo}

Foi realizado, em seguida, um segundo estudo paramétrico considerando dois e três amortecedores em diferentes posições como mostra a Figura 5.5. Na Tabela 5.2 são apresentadas as diferentes coordenadas dos nós onde foram posicionados os AMS nas diferentes situações e na Tabela 5.3 apresentam-se os resultados, devidos à excitação provocada por uma força impulsiva aplicada no centro da laje durante um segundo seguida de vibração livre. Na Figura 5.5 os modelos em amarelo $(8,9,10,11,12,13,14,15,16,17,18,19,22)$ foram analisados com três AMS, o modelo em vermelho (20) também com três amortecedores e modelo em roxo (21) com dois AMS.

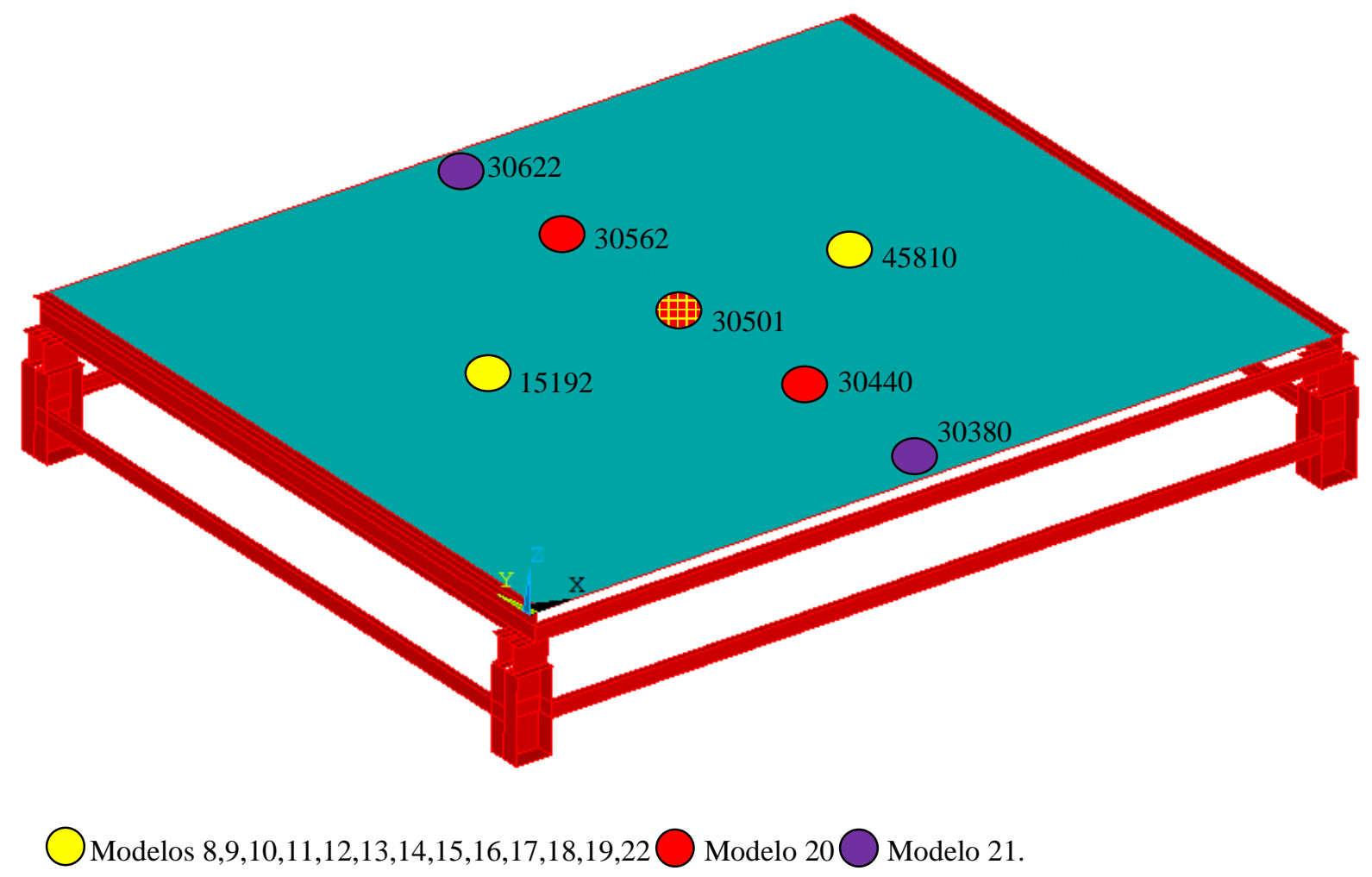

Figura 5.5 - Diferentes posições dos AMS nos ensaios. 
Tabela 5.2 - Coordenadas dos nós do estudo numérico.

\begin{tabular}{|c|c|c|c|}
\hline Número do nó & Cor & Coordenada X & Coordenada Y \\
\hline 30501 & & 3,050 & 2,450 \\
\hline 15192 & & 1,528 & 2,450 \\
\hline 45810 & & 4,574 & 2,450 \\
\hline 30440 & & 3,050 & 1,225 \\
\hline 30562 & & 3,050 & 3,675 \\
\hline 30501 & & 3,050 & 2,450 \\
\hline 30380 & & 3,050 & 0,020 \\
\hline 30622 & & 3,050 & 4,880 \\
\hline
\end{tabular}

Tabela 5.3 - Amplitude da resposta em frequência variando-se os parâmetros de massa, amortecimento, rigidez e posição do AMS.

\begin{tabular}{|c|c|c|c|c|c|c|}
\hline $\begin{array}{c}\text { Modelo } \\
\mathrm{N}^{\circ}\end{array}$ & $\begin{array}{c}\text { Massa } \\
\text { (AMS) } \\
{[\mathrm{M}]} \\
\mathrm{Kg}\end{array}$ & $\begin{array}{c}\text { Amortecimento } \\
\text { (AMS) } \\
{[\mathrm{C}]} \\
\mathrm{Ns} / \mathrm{m}\end{array}$ & $\begin{array}{c}\text { Rigidez } \\
\text { [K] } \\
\text { N/m }\end{array}$ & $\begin{array}{c}\text { Quantidade } \\
\text { AMS. }\end{array}$ & $\begin{array}{c}\text { Amplitude } \\
\text { Sem AMS } \\
\text { Frequência } \\
3,36 \mathrm{~Hz}\end{array}$ & $\begin{array}{c}\text { Amplitude } \\
\text { ComAMS } \\
\text { Frequência } \\
3,36 \mathrm{~Hz}\end{array}$ \\
\hline 8 & 40 & 120 & 17000 & 3 & \multirow{15}{*}{0,085} & 0,021 \\
\hline 9 & 40 & 130 & 15000 & 3 & & 0,026 \\
\hline 10 & 40 & 140 & 18000 & 3 & & 0,028 \\
\hline 11 & 40 & 140 & 16000 & 3 & & 0,025 \\
\hline 12 & 40 & 100 & 17000 & 3 & & 0,018 \\
\hline 13 & 50 & 90 & 15000 & 3 & & 0,031 \\
\hline 14 & 50 & 120 & 17000 & 3 & & 0,024 \\
\hline 15 & 40 & 120 & 16800 & 3 & & 0,021 \\
\hline 16 & 35 & 120 & 17000 & 3 & & 0,042 \\
\hline 17 & 45 & 120 & 17000 & 3 & & 0,020 \\
\hline 18 & 37,5 & 120 & 17000 & 3 & & 0,028 \\
\hline 19 & 39 & 120 & 17000 & 3 & & 0,023 \\
\hline 20 & 40 & 120 & 17000 & 3 & & 0,015 \\
\hline 21 & 60 & 180 & 25500 & 2 & & 0,014 \\
\hline 22 & 39,5 & 120 & 17000 & 3 & & 0,022 \\
\hline
\end{tabular}

Na Figura 5.6 é apresentada uma análise no domínio da frequência para os diferentes modelos trabalhando com vários amortecedores. 


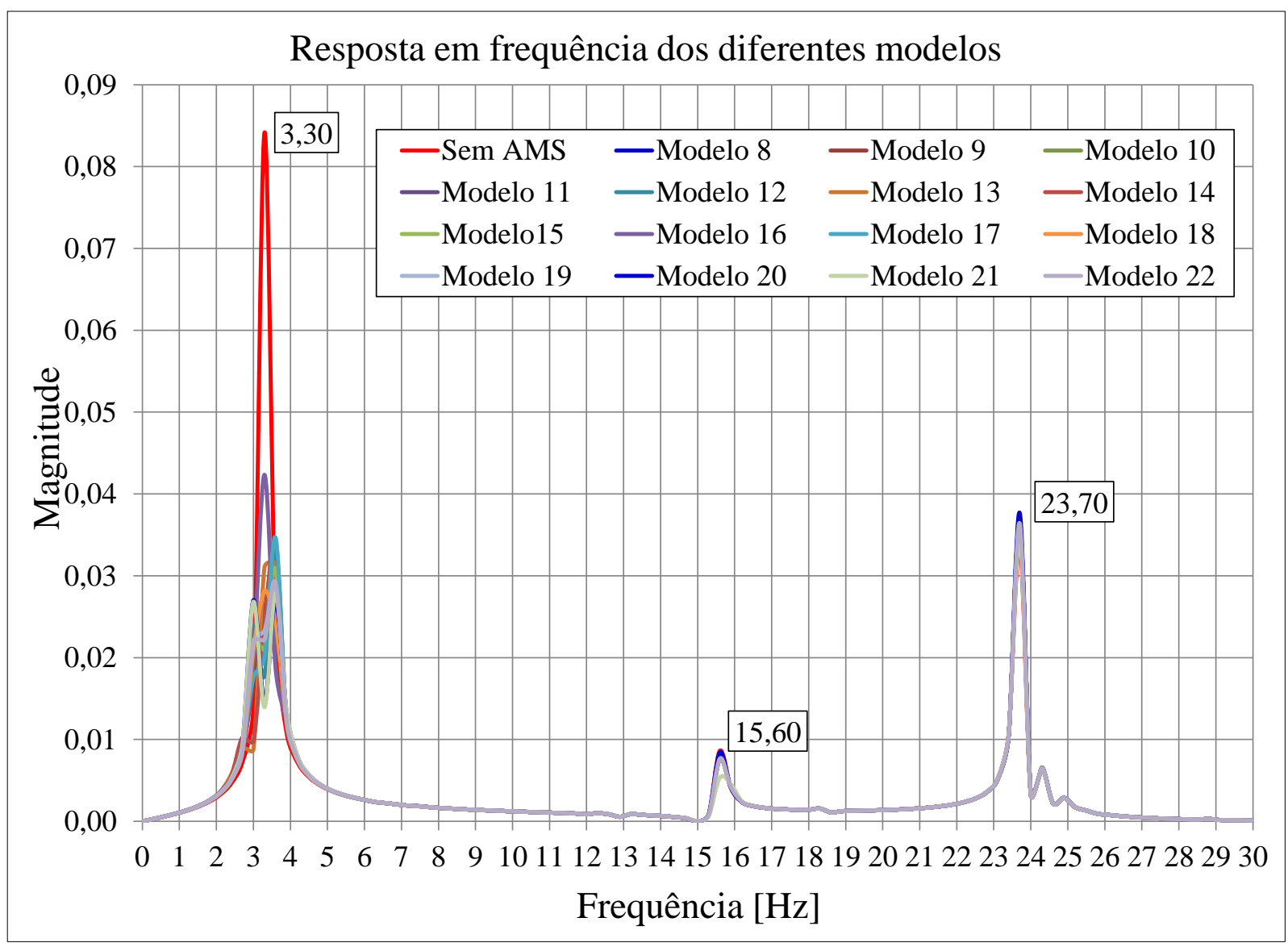

Figura 5.6 - Resposta no domínio da frequência considerando a laje com sistema de controle. Impacto seguido de vibração livre.

Para uma melhor compreensão apresenta-se na Figura 5.7 somente o sistema sem controle e o sistema com controle do modelo 20 com três amortecedores, que foi o que apresentou melhor desempenho. 


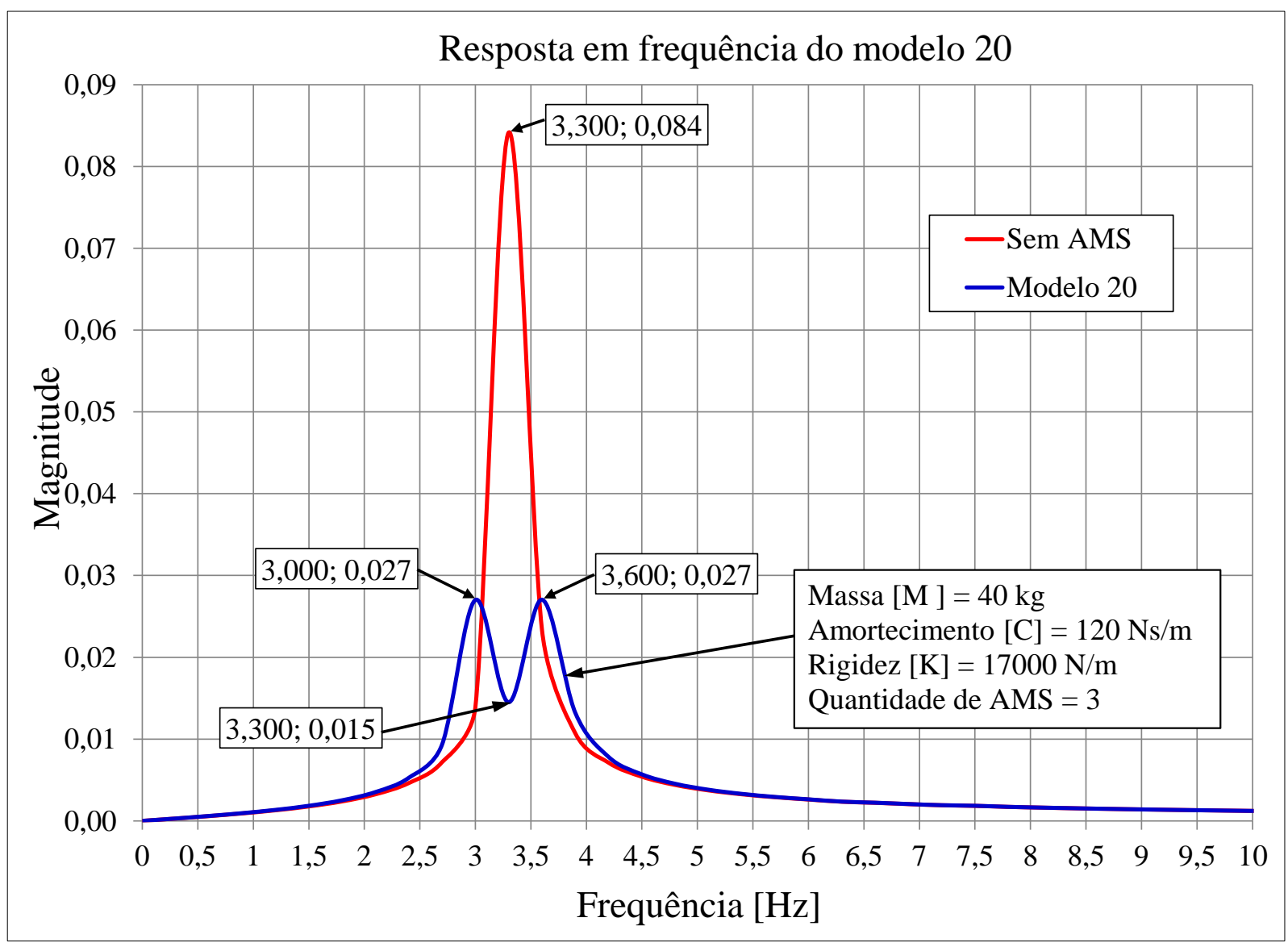

Figura 5.7 - Resposta no domínio da frequência considerando a laje com sistema de controle Modelo 20 (3 AMS). Impacto seguido de vibração livre.

Da Tabela 5.2 e Tabela 5.3 pode-se observar que amortecedores posicionados ao longo do eixo $Y$ (modelos 20 e 21) tem melhor desempenho que os amortecedores posicionados ao longo do eixo $X$ (modelo 8,9,10,11,12,13,14,15,16,17,18,19 e 22), isso devido ao fato dos amortecedores trabalharem melhor nas posições onde ocorrem as maiores amplitudes da primeira forma modal da laje de concreto como pode ser observado na Figura 4.15 e nas diferentes posições dos AMS da Figura 5.5.

Comparando-se todos os resultados apresentados na Figura 5.6, observa-se que o modelo 20 com 3 amortecedores apresentou melhor desempenho, com os seguintes parâmetros: M=40 kg $\mathrm{C}=120 \mathrm{Ns} / \mathrm{m} ; \mathrm{K}=17000 \mathrm{~N} / \mathrm{m}$. Embora o modelo 21 com dois amortecedores também apresente uma boa redução na amplitude de vibração, a diferença entre os modelos 20 e 21 é que este último não apresenta os mesmos valores da amplitude nos picos correspondentes as novas 
frequências de 3,0 Hz e de 3,6 Hz, lembrando como já foi mencionado anteriormente que uma boa sintonização do AMS requer que entre estes dois novos picos seja possível traçar uma linha horizontal. Na Figura 5.8 apresenta-se a resposta em frequência do nó central para o melhor resultado do sistema de controle com um só amortecedor que corresponde ao modelo 7 e o melhor resultado para o sistema de controle de 3 amortecedores trabalhando conjuntamente que corresponde ao modelo 20. Na Figura 5.8 pode-se observar que foram obtidos resultados coincidentes na redução das vibrações comparando-se o modelo 7 do primeiro estudo com único amortecedor e o modelo 20 com três amortecedores do segundo estudo, sendo que os parâmetros de massa, amortecimento e rigidez dos dois modelos são diferentes. Os dois modelos estão sintonizados para uma frequência de ressonância de $3,3 \mathrm{~Hz}$, que é a frequência fundamental da laje de concreto.

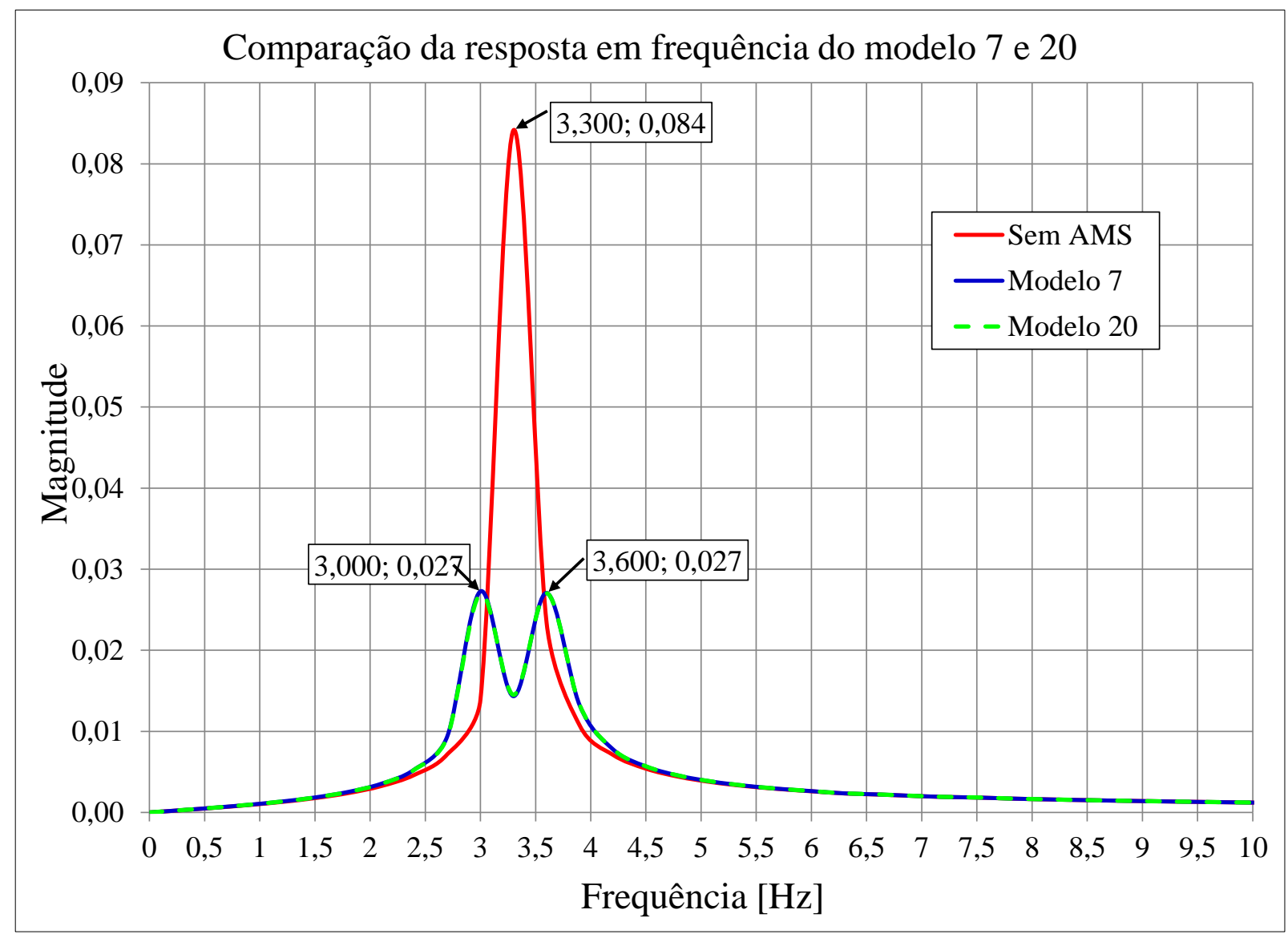

Figura 5.8 - Comparação da resposta em frequência dos modelos 7 e 20, com 1 e 3 AMS, respectivamente. Impacto seguido de vibração livre. 
Também foi feita uma análise no domínio do tempo para o modelo 20 que foi o modelo que apresentou melhor sistema de controle para combinação de mais de um amortecedor de massa sintonizado.

Na Figura 5.9 apresenta-se a evolução dos registros das acelerações do nó central da laje sem controle e com controle de 3 AMS (modelo 20), já na Figura 5.10 se apresenta uma análise no domínio do tempo em função do deslocamento da laje sem controle e com controle de três AMS (modelo 20).

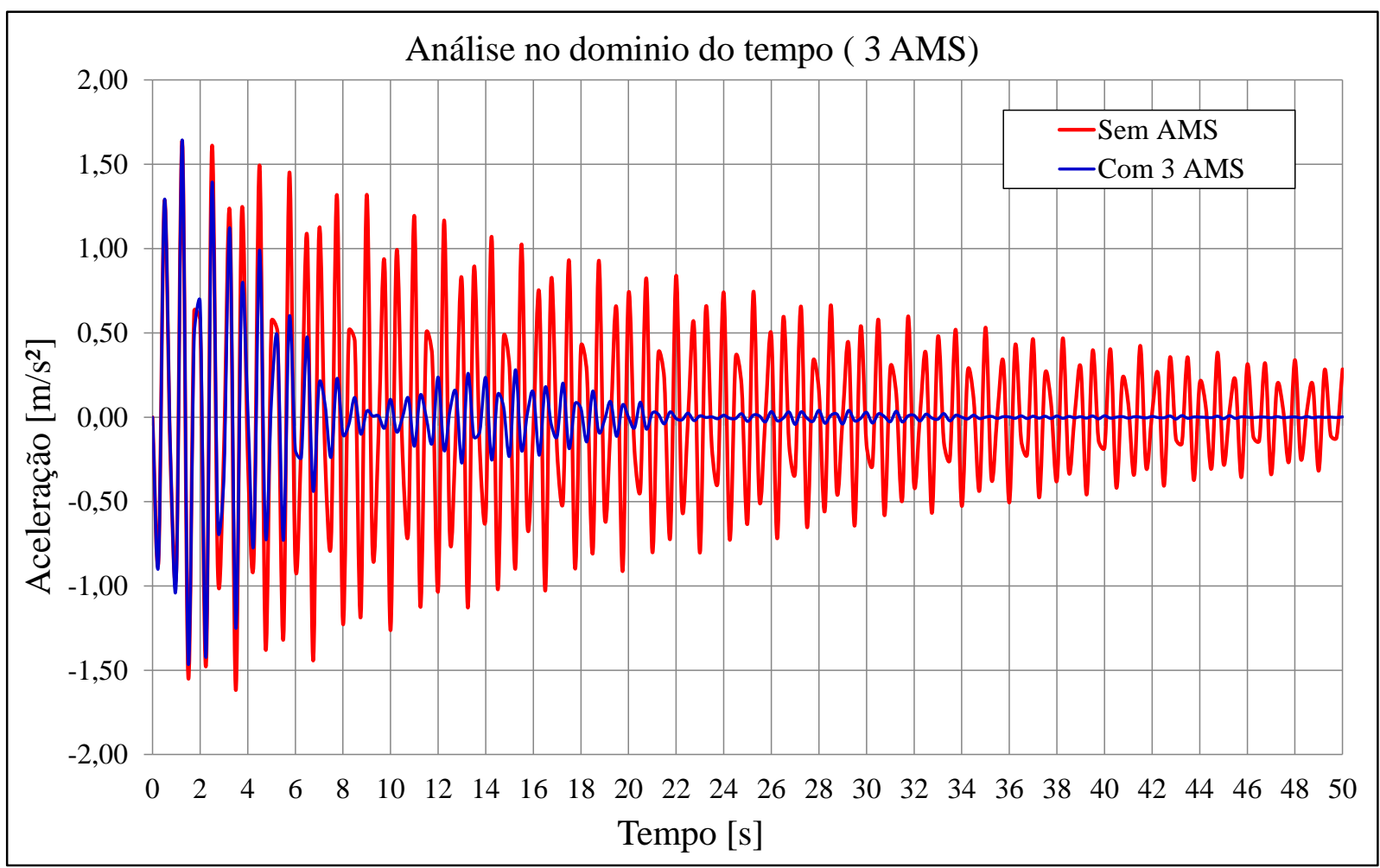

Figura 5.9 - Resposta no domínio do tempo em função da aceleração (Modelo 20, três AMS). Impacto seguido de vibração livre.

Da Figura 5.9 pode-se observar que aos nove segundos o sistema de controle reduz os registros de acelerações até em um 97,25\% e que passados 21 segundos praticamente não se apresentem registros de acelerações. 


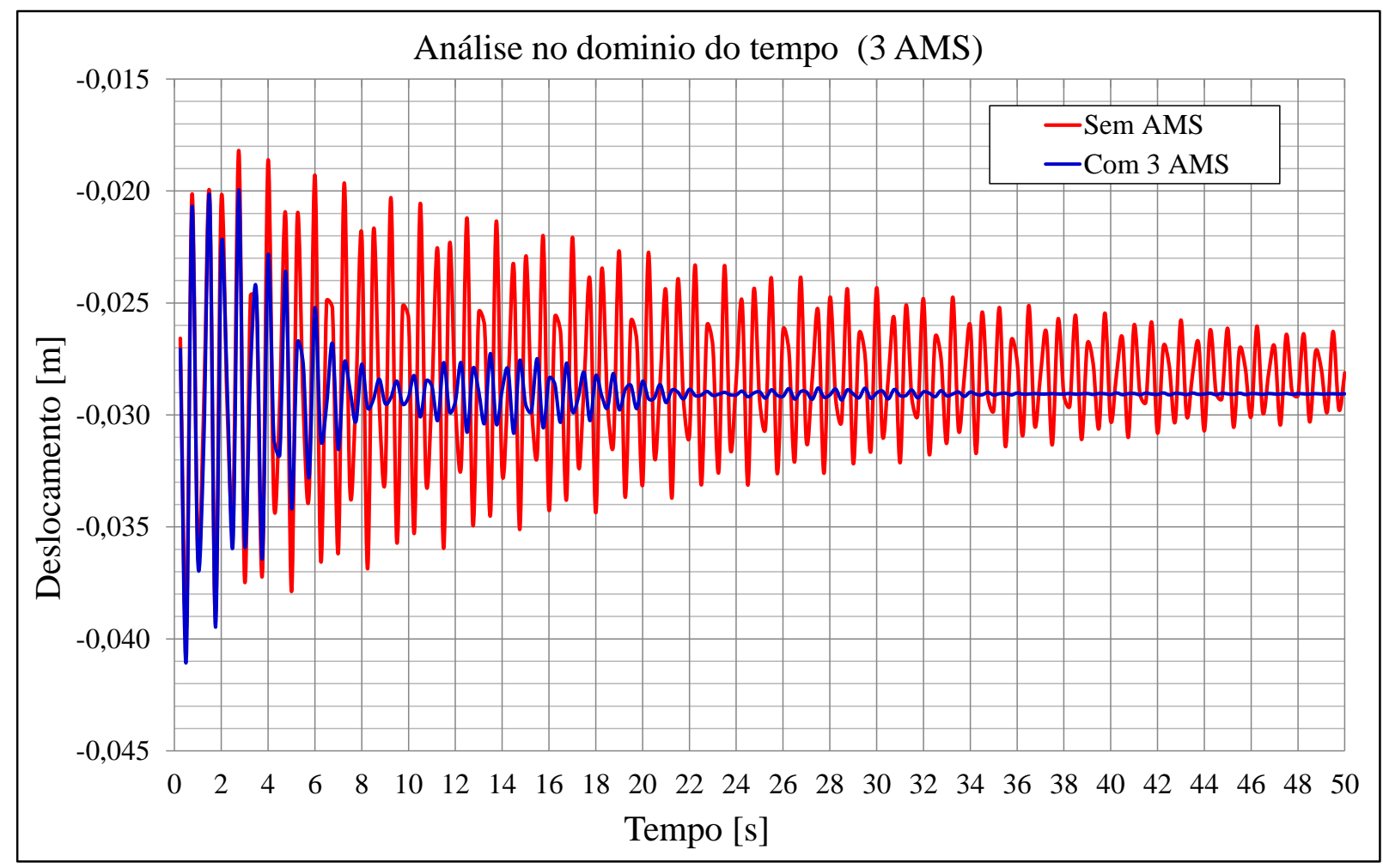

Figura 5.10 - Análise no domínio do tempo em função do deslocamento (Modelo 20, 3 AMS). Impacto seguido de vibração livre.

Comparando os resultados da Figura 5.2 e Figura 5.7; Figura 5.3 e Figura 5.9; Figura 5.4 e Figura 5.10, percebe-se que são praticamente iguais para o modelo 7 e 20 e com base nessa constatação optou-se por projetar e construir um único amortecedor, uma solução mais simples, rápida e de menor custo.

\subsection{DESEMPENHO DE UM AMORTECEDOR FRENTE A VIBRAÇÃO FORÇADA}

$\mathrm{O}$ amortecedor com os parâmetros do modelo 7 foi analisado e incorporado à plataforma e submetido a vibração forçada.

No primeiro modelo foi aplicada a carga proveniente de uma pessoa pulando continuamente no centro da laje durante 10 segundos e foram registradas as acelerações durante outros 40 segundos mais. No segundo modelo a carga provenia de, três pessoas espalhadas na laje em 
linha reta, pulando continuamente durante 10 segundos e também como no modelo anterior foi registrada a resposta durante 40 segundos mais.

Os resultados do primeiro modelo (pulo continuo de uma pessoa) no domínio do tempo se apresentam na Figura 5.11. A resposta no domínio de frequência se mostra na Figura 5.12 como resultado das transformadas rápidas de Fourier da resposta no domínio do tempo.

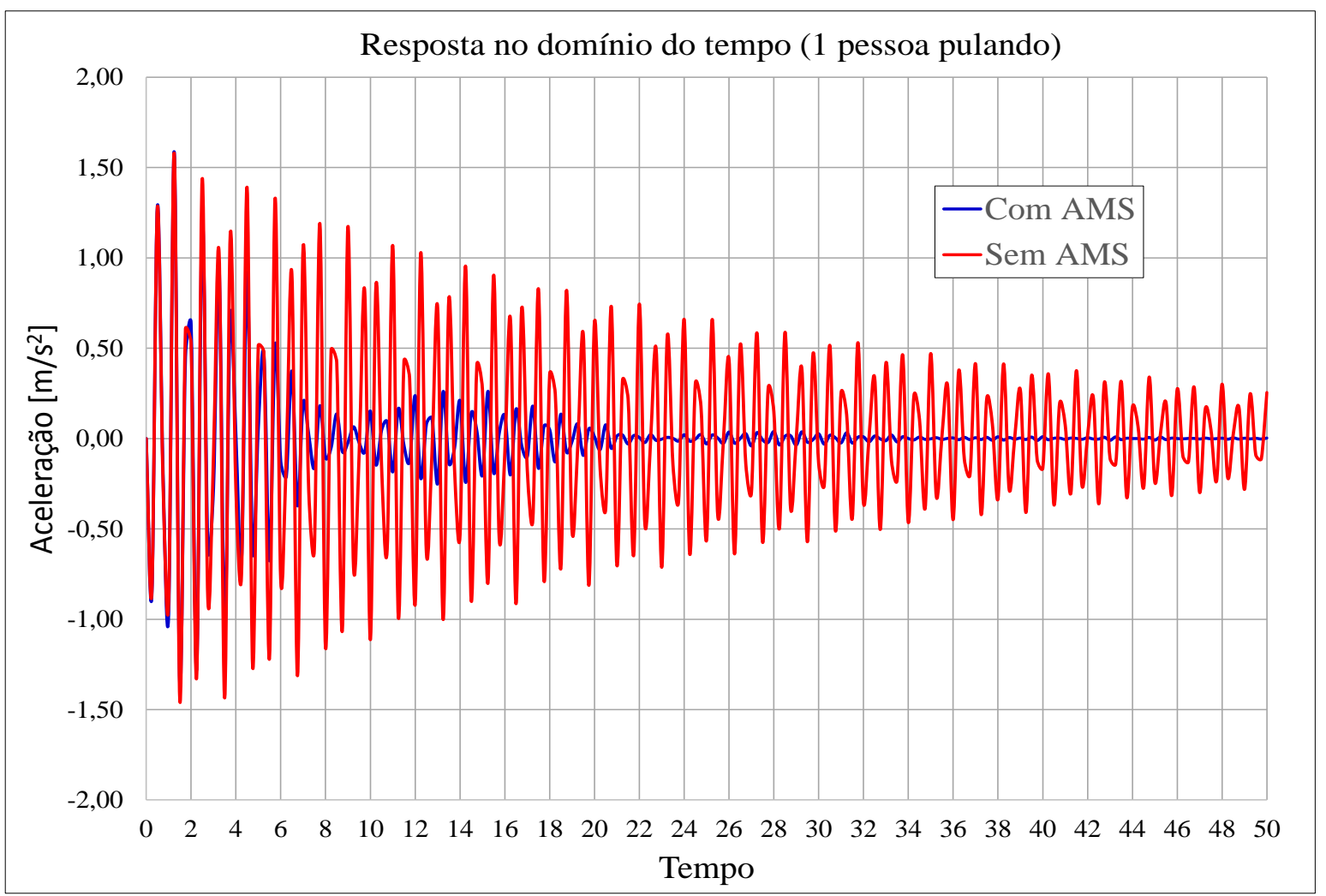

Figura 5.11 - Resposta no domínio do tempo em função da aceleração para uma pessoa pulando continuamente. Vibração forçada.

$\mathrm{Na}$ figura anterior se observa que o AMS controla bem as vibrações durante o tempo de atuação da forca induzida. Uma vez terminada atuação da força externa o sistema de controle continua reduzindo as acelerações até chegar a zero aos 20 segundos. Pode-se se observar que sem sistema de controle (linha vermelha) a plataforma apresenta vibrações consideráveis até os 50 segundos analisados.

Na Figura 5.12 observa-se que com sistema de controle (linha azul) as amplitudes do pico de $3,3 \mathrm{~Hz}$ são reduzidas consideravelmente. Com a colocação do AMS observa-se que a frequência para o primeiro harmônico da plataforma é modificada para 3,0 Hz. 


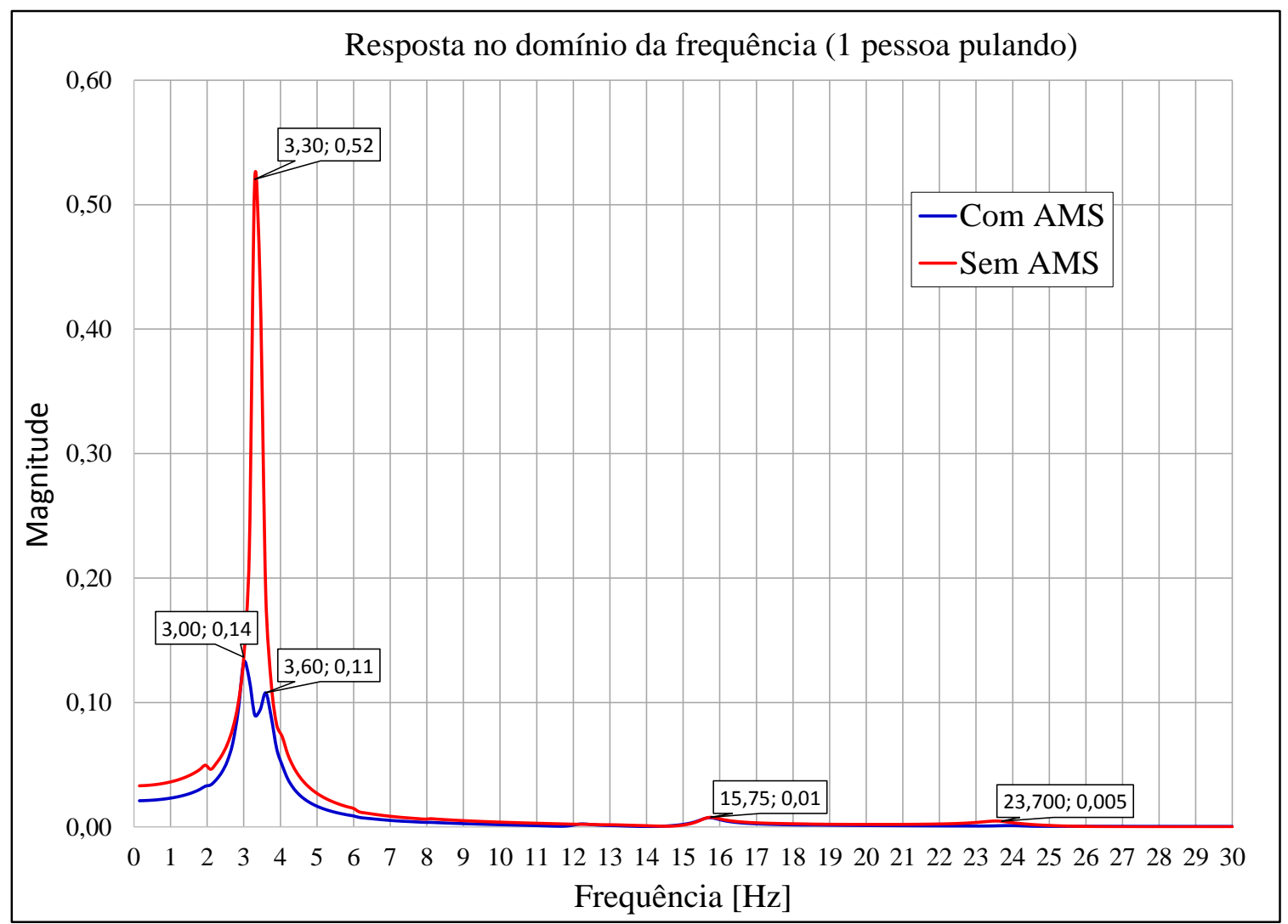

Figura 5.12 - Resposta no domínio da frequência para uma pessoa pulando continuamente. Vibração forçada.

Os resultados do segundo estudo com três pessoas podem ser observados na Figura 5.13 e na Figura 5.14.

Na resposta no domínio do tempo Figura 5.13 observa-se que os sistema de controle (linha azul) reduze bem as vibrações. Em linha em vermelha (sem AMS) as magnitudes das acelerações ainda são consideráveis até os 50 segundos analisados.

Na resposta no domínio da frequência Figura 5.14 pode-se observar que o sistema de controle (linha azul) mitiga muito bem as amplitudes de vibração para o primeiro harmônico, mas é desfavorável para o segundo e terceiro harmônico aumentando as amplitudes de vibração. 


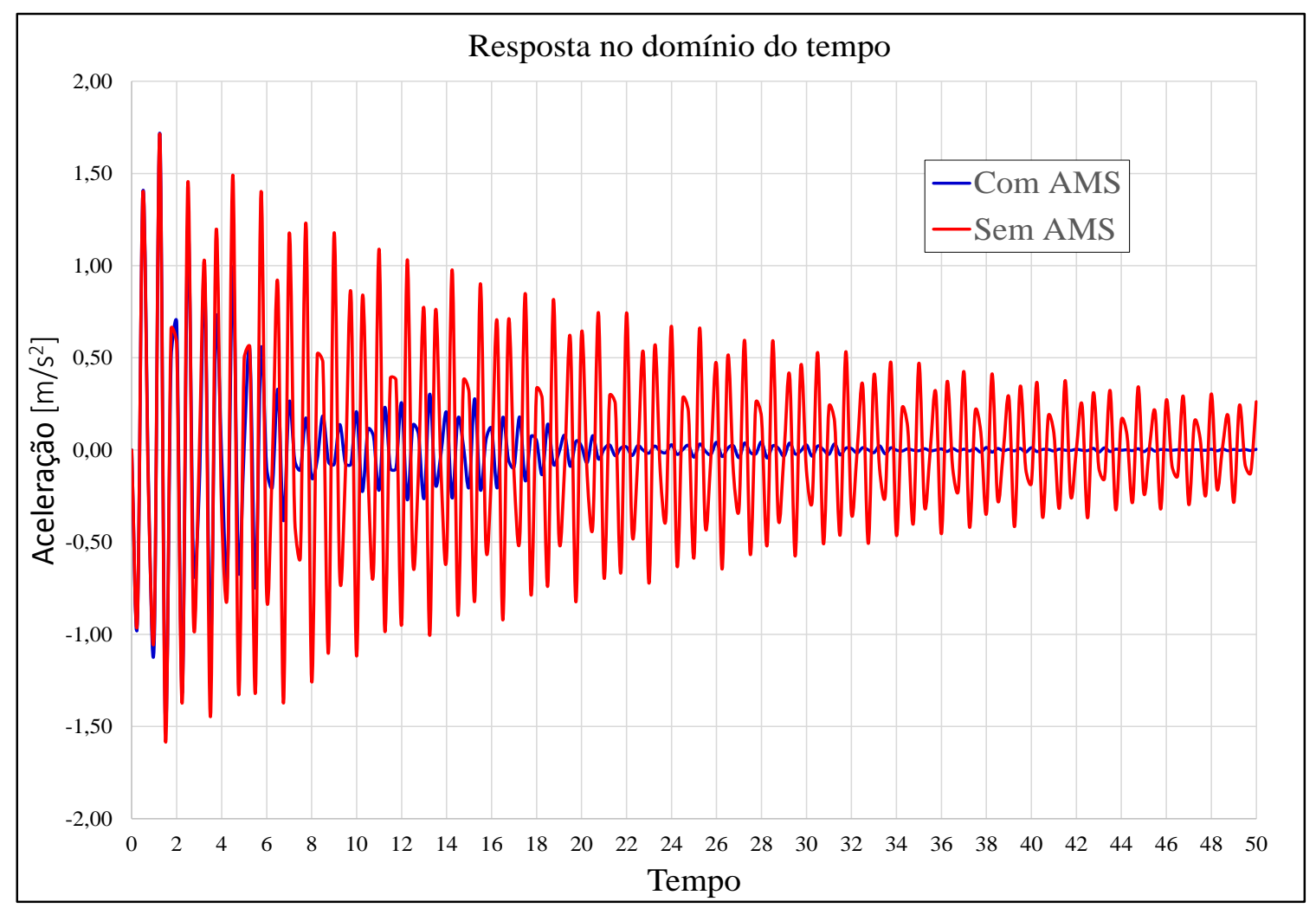

Figura 5.13 - Resposta no domínio do tempo para três pessoas pulando continuamente. Vibração forçada.

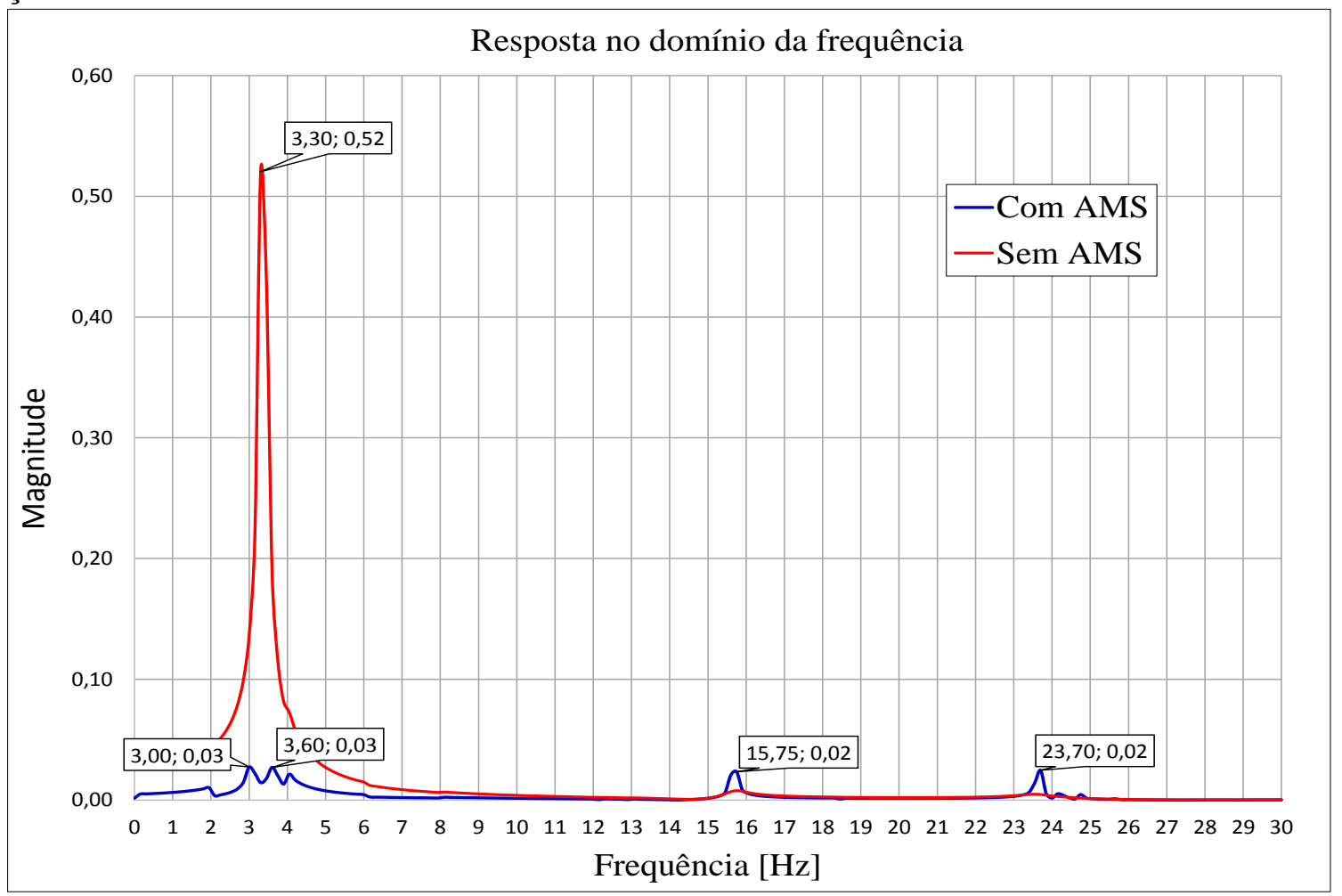

Figura 5.14 - Resposta no domínio da frequência para três pessoas pulando continuamente. Vibração forçada. 
Dos estudos numéricos em vibração forcada pode-se dizer que o sistema de controle proposto controla bem as vibrações produzidas pelas forças externas. Além disso também pode-se observar que AMS se encontra bem sintonizado com os parâmetros obtidos do estudo numérico em vibração livre.

\subsection{FUNDAMENTOS TEORICOS PARA O PROJETO E CONSTRUÇÃo DO AMS}

Baseando-se nos resultados apresentados anteriormente foram realizados os cálculos para o projeto e construção de um amortecedor (AMS) para a plataforma. As análises numéricas forneceram valores ótimos de parâmetros do amortecedor para uma boa sintonização da primeira frequência de ressonância da laje com a do AMS.

De acordo com as análises realizadas os melhores valores dos parâmetros do AMS para reduzir as vibrações verticais produzidas pelos carregamentos oriundos de atividades humanas na plataforma são:

Massa M=120 kg, Coeficiente de amortecimento C=360 Ns/m, Rigidez K=51000 N/m

Como se explicou anteriormente, a relação de massas entre a estrutura secundária e a estrutura principal tem uma relação aproximada de $1,7 \%$. O projeto de um amortecedor com estas características é realizado utilizando várias chapas de aço (constituindo a massa do AMS) e várias molas comprimidas trabalhando em paralelo (constituindo o parâmetro de rigidez). $\mathrm{O}$ efeito de amortecimento é gerado por forças de atrito que atuam em sentido contrário ao movimento do AMS. O amortecedor deve ser pendurado embaixo da laje e localizado no ponto central.

\subsubsection{Projeto do dispositivo AMS}

O AMS foi projetado, no presente trabalho, de forma a obter facilmente os valores de massa, rigidez e amortecimento necessários para a redução das vibrações da plataforma de ensaios dinâmicos. A massa do AMS foi constituída mediante a união de várias placas de aço de seção transversal dispostas uma sobre a outra e posicionadas verticalmente ao longo de um eixo de aço, o qual fica pendurado sob a laje de concreto. Da mesma forma para se obter a rigidez de 
projeto utilizam-se molas de aço em forma de espirais, posicionadas entre as chapas de aço, com a finalidade de proporcionar uma força de restituição à massa do sistema. Por último para se gerar as forças de amortecimento de Coulomb, considerando amortecimento por atrito, o atrito é gerado entre eixos guias e uma peça especial de aço. Os elementos isoladamente e também o AMS montado são apresentados nas Figura 5.15 a Figura 5.24

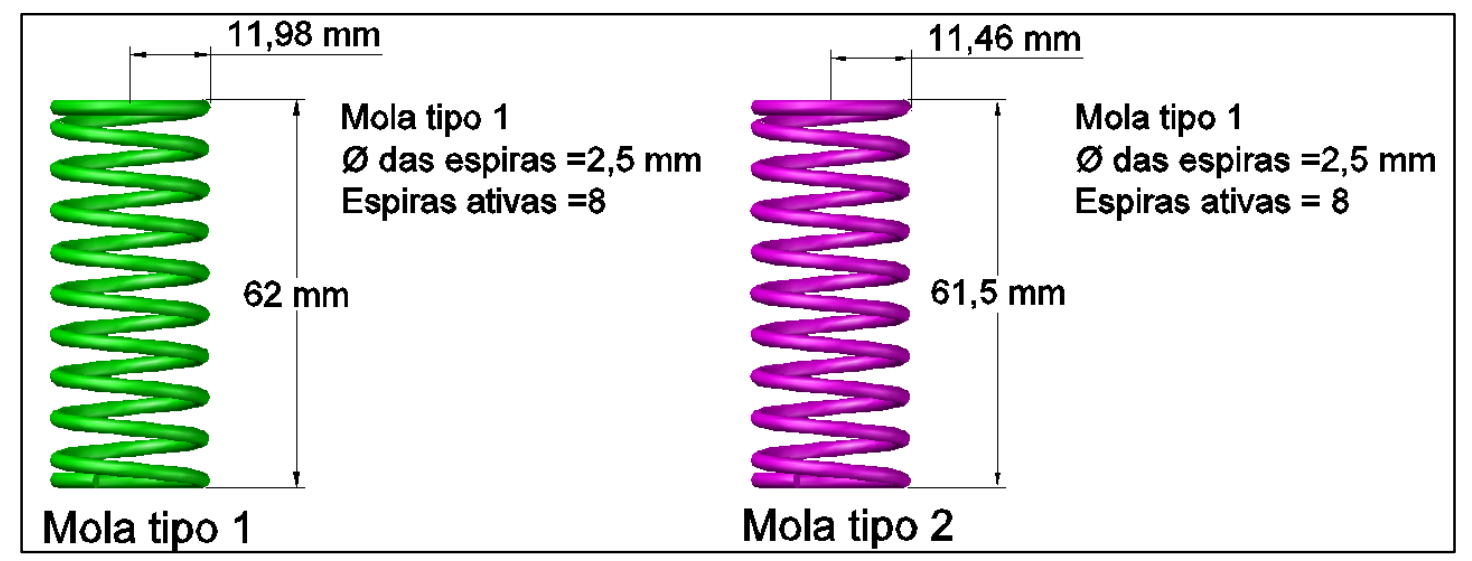

Figura 5.15 - Tipos de molas a utilizar no projeto do AMS, medidas em mm.

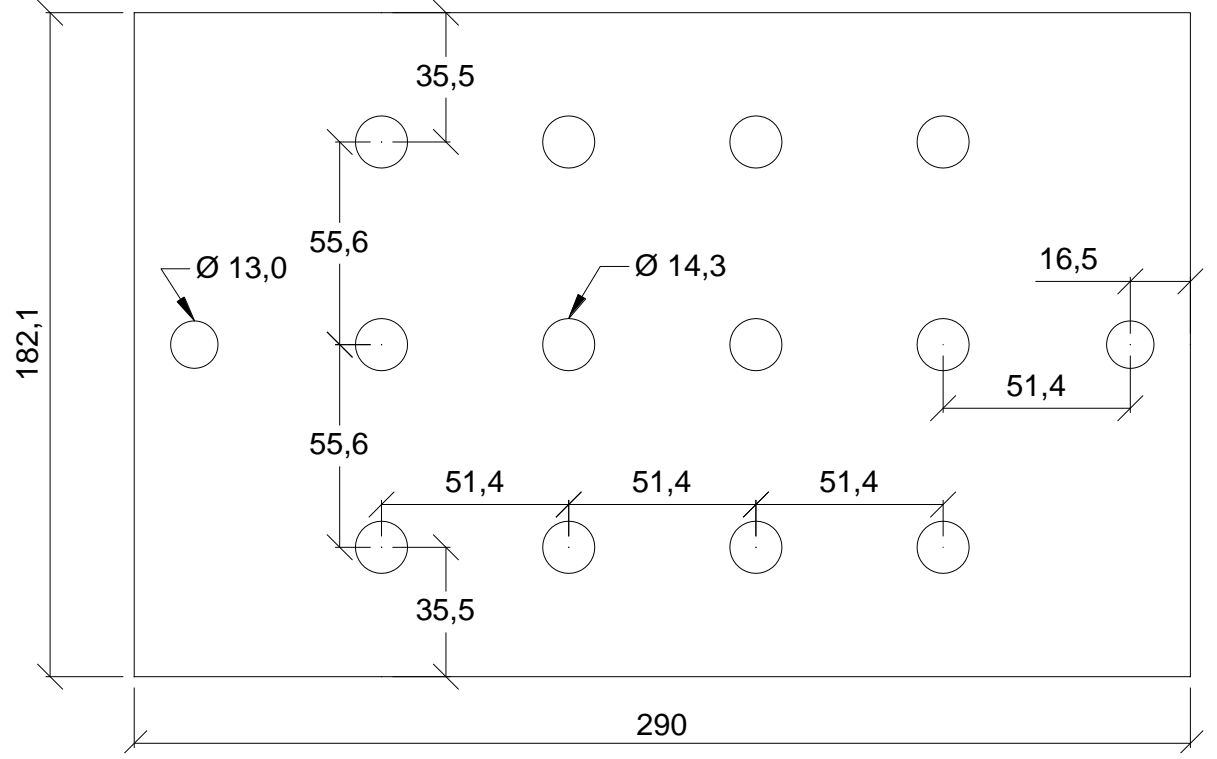

Figura 5.16 - Dimensões, em mm, das 24 chapas de aço de espessura de 12,5 mm que formam a massa vibrante do AMS. 


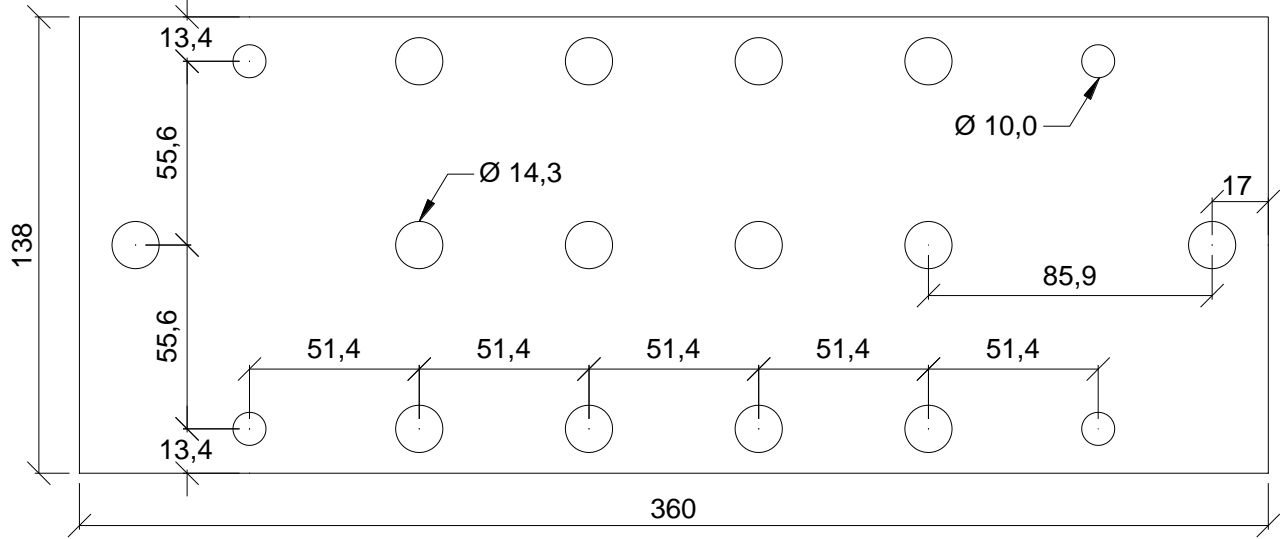

Figura 5.17 - Dimensões, em mm, das 2 chapas de aço de espessura de 12,5 mm que formam o suporte superior do todo o conjunto do AMS.

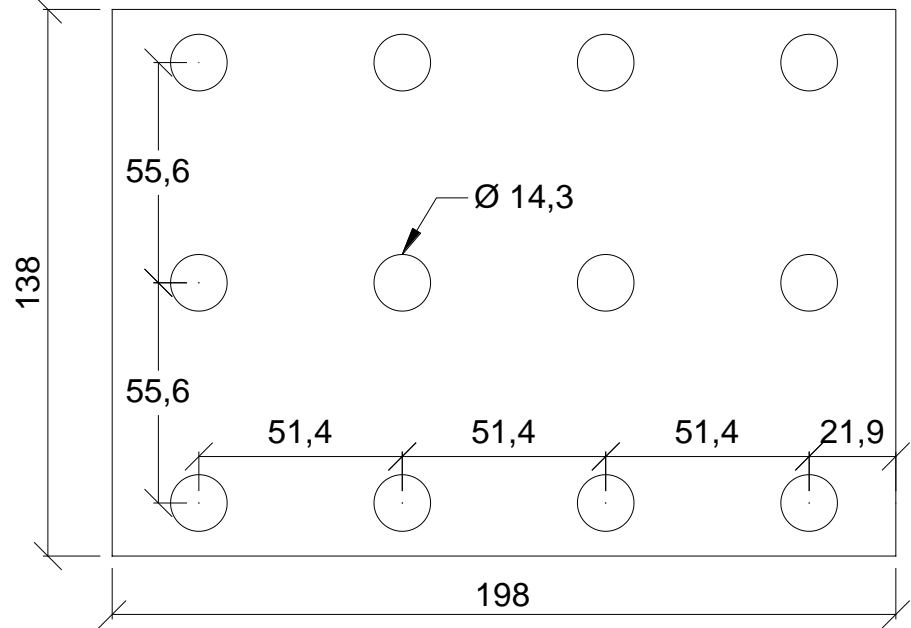

Figura 5.18 - Dimensões, em mm, das 2 chapas de aço de espessura de 12,5 $\mathrm{mm}$ que formam o suporte inferior do todo o conjunto do AMS.

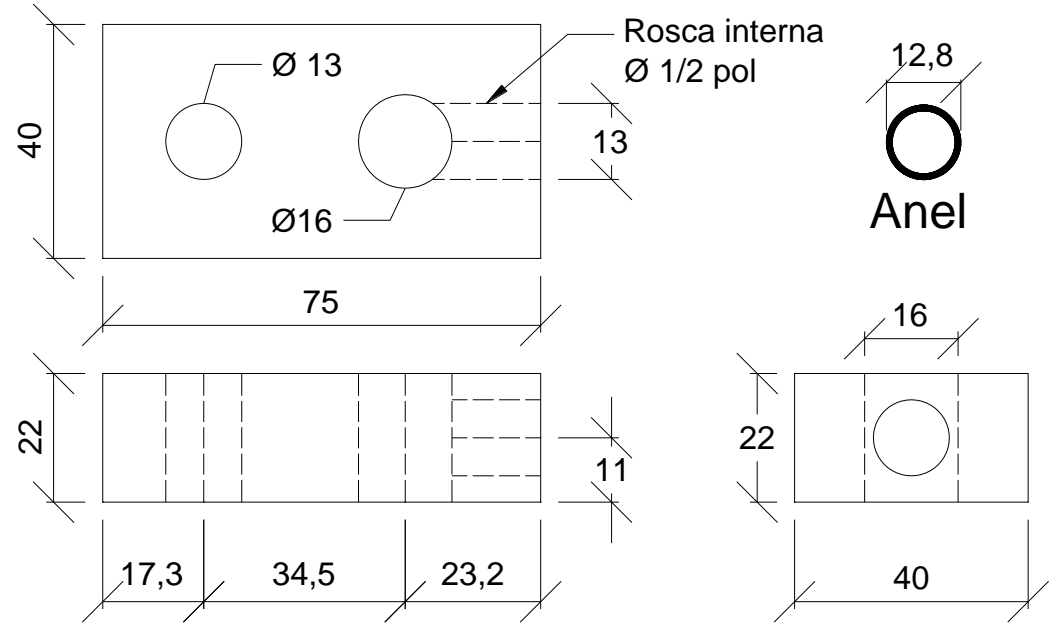

Figura 5.19 - Dimensões, em mm, da peça com a qual pode-se obter o amortecimento por atrito e do anel para confinar as molas. 


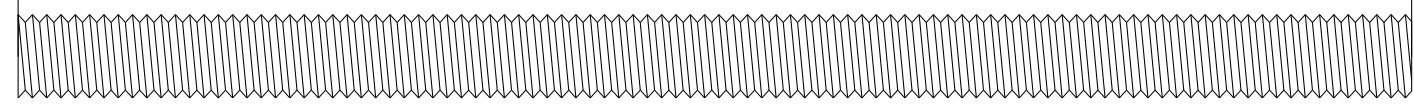

Figura 5.20 - Dimensões, em mm, do parafuso que fixa a chapas de aço, bitola parafuso $1 \frac{1}{2}$ pol.

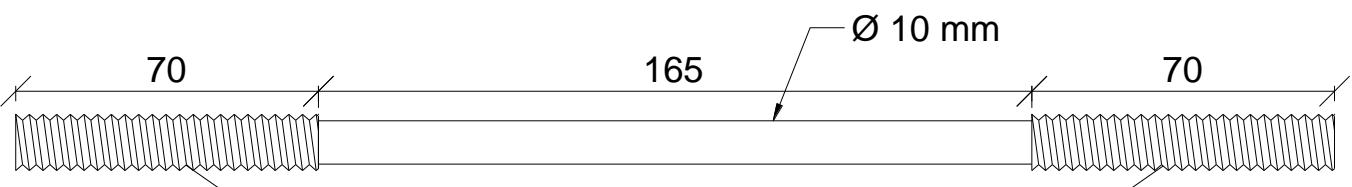

Rosca 1/2 polegada, 13 fios

Figura 5.21 - Dimensões, em mm, do parafuso que fixa a molas de aço, bitola parafuso $1 \frac{1}{2}$ pol.

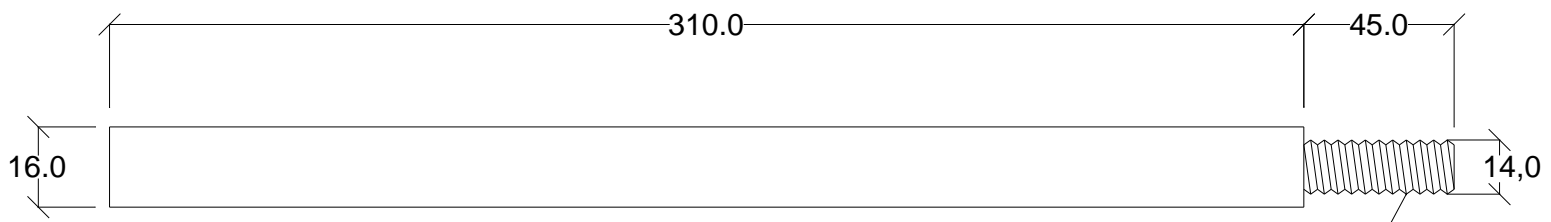

Rosca 9/16"

Figura 5.22 - Dimensões, em mm, do eixo guia do AMS.

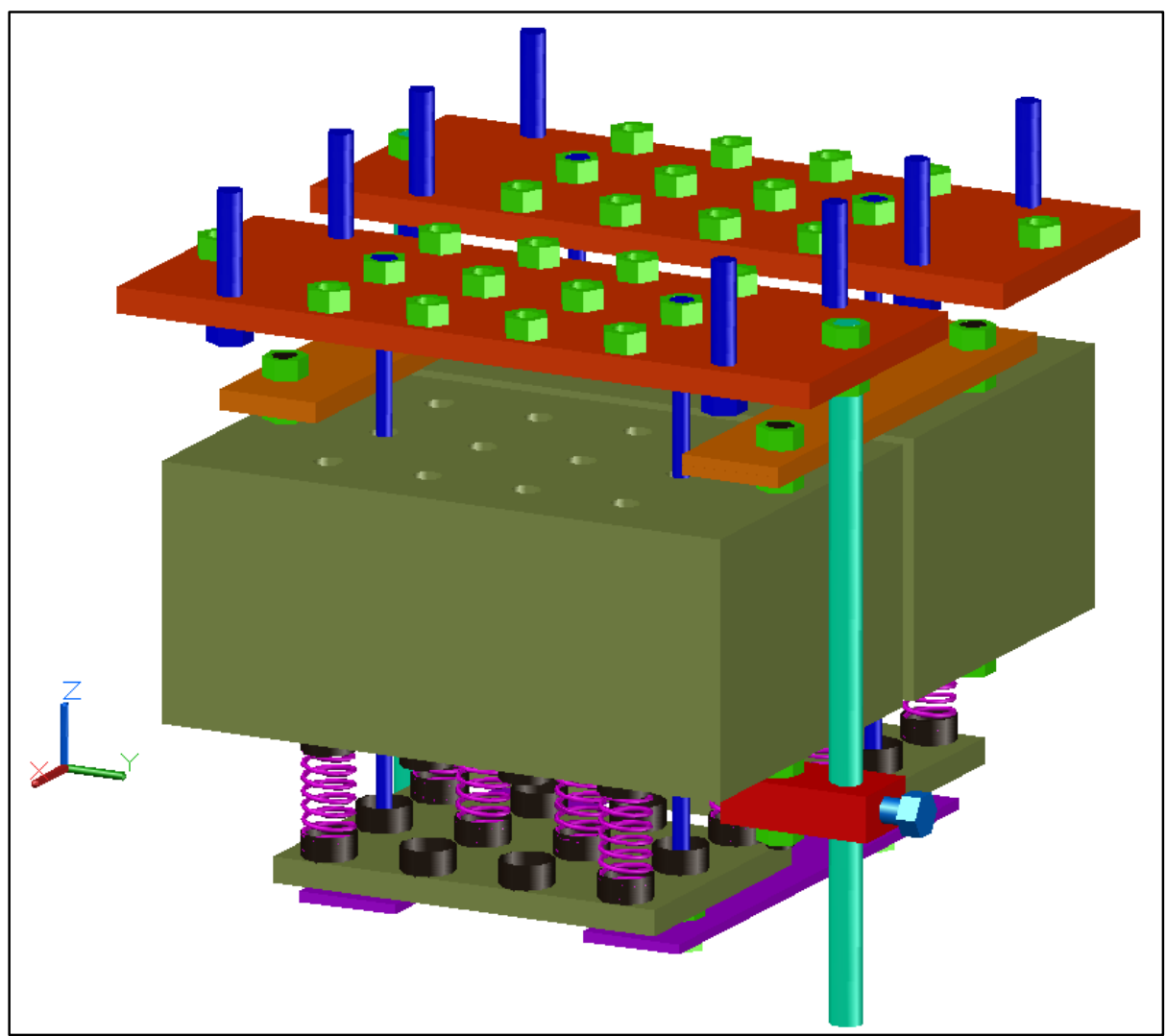

Figura 5.23 - Vista em perspectiva do amortecedor de massa sintonizado AMS. 

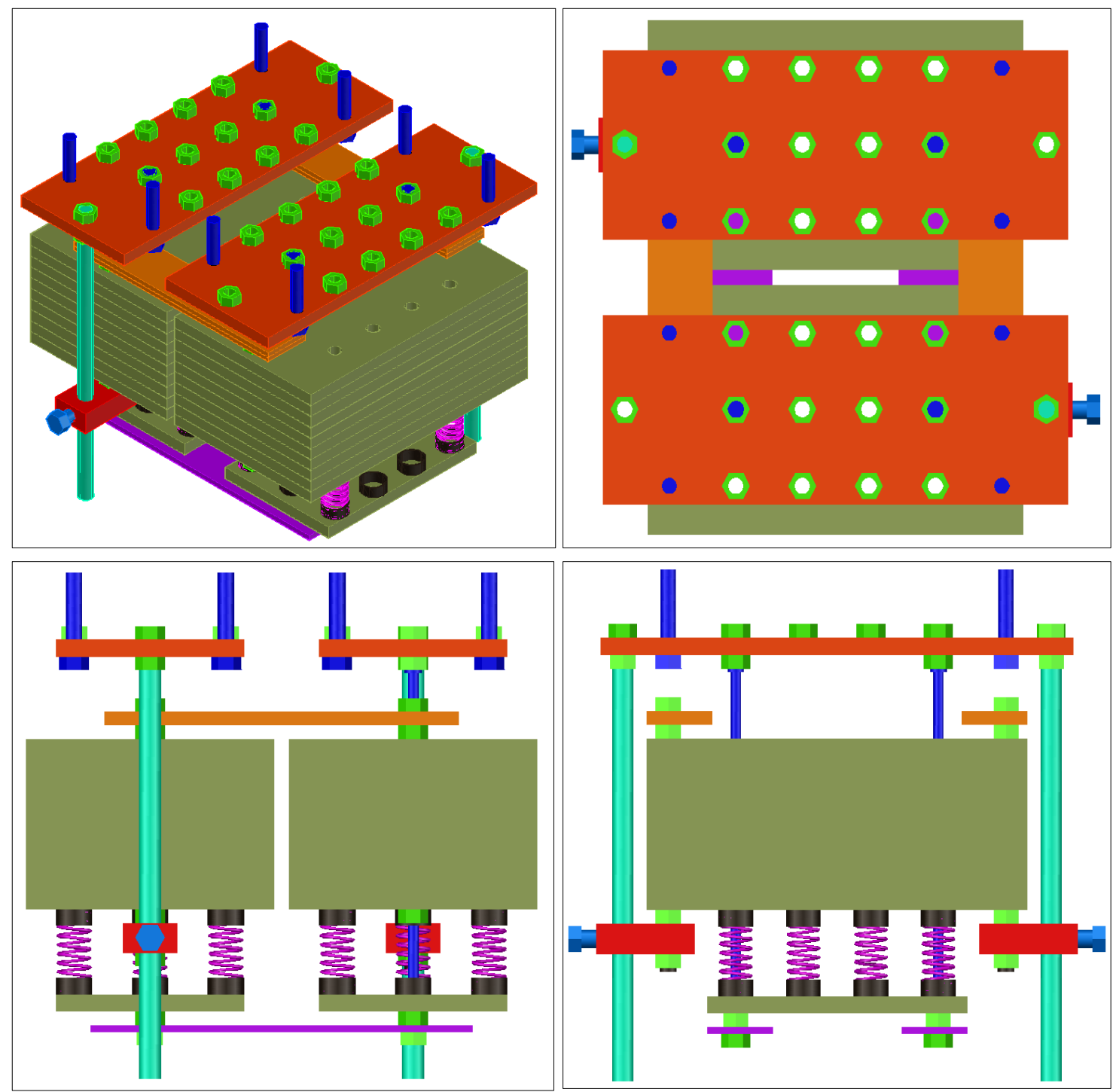

Figura 5.24 - Vista superior, lateral e frontal do AMS.

A partir das dimensões da chapa mostrada na Figura 5.16 pode-se encontrar o volume da mesma $\mathrm{V}=0,0006 \mathrm{~m}^{3}$, e multiplicando-se este valor pela densidade do aço $7850 \mathrm{~kg} / \mathrm{m}^{3}$ encontra-se uma massa de 4,97 kg para cada chapa. Para obter o valor da massa vibrante de projeto do AMS é necessário colocar para cada módulo 12 chapas dispostas uma sobre a outra, somando um valor aproximado de 59,64 Kg. Dois módulos de 12 chapas totalizam uma massa de 119,28 kg, valor aproximado do valor numérico de projeto. A forma como são dispostas as chapas de aço pode ser observada nas ultimas figuras, Figura 5.23 e Figura 5.24. 
Dois tipos de molas foram projetados para trabalhar em paralelo e assim os dois conjuntos de molas totalizar o valor da rigidez do amortecedor encontrada numericamente.

Para calcular a rigidez total do sistema primeiro deve-se calcular a rigidez de cada mola detalhada na Figura 5.15. A constante de rigidez da mola helicoidal é dada por Blevins (1979):

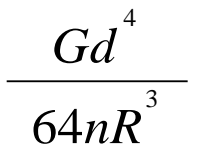

Onde:

$n=$ Número de espiras ativas

$d=$ Diâmetro da seção do arame

$G=$ Módulo de elasticidade transversal

$R=$ Raio da mola.

Nas Tabela 5.4 e Tabela 5.5 mostram-se os valores das constantes de rigidez para as molas tipo 1 e tipo 2 respectivamente.

Tabela 5.4 - Valor calculado da constante de rigidez da mola tipo 1.

\begin{tabular}{|l|r|}
\hline \multicolumn{2}{|c|}{ Mola Tipo 1 } \\
\hline$E=$ Modulo de elasticidade aço & $2,05 \mathrm{E}+11 \mathrm{~N} / \mathrm{m}^{2}$ \\
\hline $\mathrm{v}=$ Coeficiente Poisson aço & 0,3 \\
\hline $\mathrm{G}=$ Modulo de cisalhamento & $7,88 \mathrm{E}+10 \mathrm{~N} / \mathrm{m}^{2}$ \\
\hline $\mathrm{d}$ = Diâmetro do arame da mola & $0,0025 \mathrm{~m}$ \\
\hline $\mathrm{R}$ = Raio externo da mola & $0,01198 \mathrm{~m}$ \\
\hline $\mathrm{n}$ = Número de espiras ativas & 8 \\
\hline Altura mola & $0,062 \mathrm{~m}$ \\
\hline $\mathrm{K}=$ Rigidez da mola & $3498,65 \mathrm{~N} / \mathrm{m}$ \\
\hline
\end{tabular}


Tabela 5.5 - Valor calculado da constante de rigidez da mola tipo 2.

\begin{tabular}{|l|r|}
\hline \multicolumn{2}{|c|}{ Mola Tipo 2} \\
\hline$E=$ Modulo de elasticidade aço & $2,05 \mathrm{E}+11 \mathrm{~N} / \mathrm{m}^{2}$ \\
\hline $\mathrm{v}=$ Coeficiente Poisson aço & 0,3 \\
\hline $\mathrm{G}=$ Modulo de cisalhamento & $7,88 \mathrm{E}+10 \mathrm{~N} / \mathrm{m}^{2}$ \\
\hline $\mathrm{d}$ = Diâmetro do arame da mola & $0,0025 \mathrm{~m}$ \\
\hline $\mathrm{R}=$ Raio externo da mola & $0,01146 \mathrm{~m}$ \\
\hline $\mathrm{n}$ = Número de espiras ativas & 8 \\
\hline Altura mola & $0,0615 \mathrm{~m}$ \\
\hline $\mathrm{K}=$ Rigidez da mola & $3996,84 \mathrm{~N} / \mathrm{m}$ \\
\hline
\end{tabular}

Para alcançar o valor da constante de rigidez de projeto: $51000 \mathrm{~N} / \mathrm{m}$ necessita-se de 10 molas tipo 1 e 4 molas tipo 2, dispostas em paralelo como foi detalhado na Figura 5.23.

$$
K_{A M S}=10 * 3498,65+4 * 3996,84 \approx 51000 \frac{N}{m}
$$

Este valor fica muito próximo do valor da rigidez total encontrado no estudo numérico.

Por fim para encontrar o amortecimento adequado para que o AMS dissipe satisfatoriamente a energia é necessário encontrar um coeficiente de amortecimento viscoso equivalente, que iguale a energia perdida por ciclo do amortecedor por atrito com a energia perdida do amortecedor viscoso. Uma vez encontrado o valor do amortecimento viscoso equivalente $\boldsymbol{C e q}$, este será substituído em uma equação que está em função da forca normal $n$, o coeficiente dinâmico entre dois materiais $\boldsymbol{\mu}_{\boldsymbol{k}}$, frequência de ressonância $\boldsymbol{\Omega}$ e o deslocamento da massa vibrante $\boldsymbol{X}_{\boldsymbol{0}}$. Pretendese obter o amortecimento do AMS com ajuda de um parafuso de rosca helicoidal, o qual fara atrito em seco entre dois matérias de aço doce.

Salamanca (2010) mostra que a energia dissipada por ciclo por um amortecedor viscoso de coeficiente $c$ é $U_{d}$ :

$$
\begin{aligned}
& U_{d}=\int F_{d} d x=\int_{0}^{2 \pi / \Omega} c \dot{x} \frac{d x}{d t} d t=\int c \dot{x}^{2} d x \\
& U_{d}=c \int_{0}^{2 \pi / \Omega} \Omega^{2} X^{2} \cos ^{2} \Omega t d t=\pi c \Omega X^{2}
\end{aligned}
$$


Pode-se obter um amortecedor viscoso equivalente com valor de coeficiente de amortecimento, obtido igualando as energias dissipadas por ciclo em cada caso. Ou seja, para determinar $C_{e q}$ se iguala:

$$
U_{d}=\pi c_{e q} \Omega X^{2}
$$

Energia real dissipada por ciclo = Energia dissipada por amortecimento viscoso

Na Figura 5.25 mostra-se o sistema de dissipação de energia por atrito comparado ao sistema de dissipação de energia viscoso, com a finalidade de encontrar o coeficiente de amortecimento equivalente.

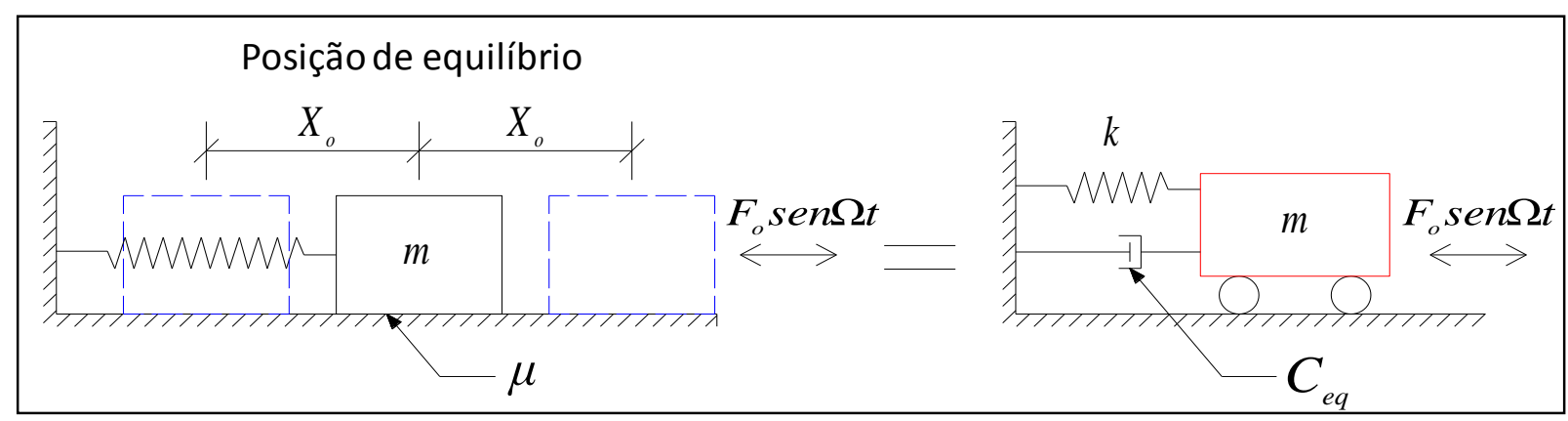

Figura 5.25 - Amortecedor viscoso equivalente com mecanismo de dissipação de energia real por atrito.

Da Figura 5.26 determina-se que a energia dissipada por ciclo devido ao atrito é:

$$
U_{d}=4 \mu m g X_{0}
$$

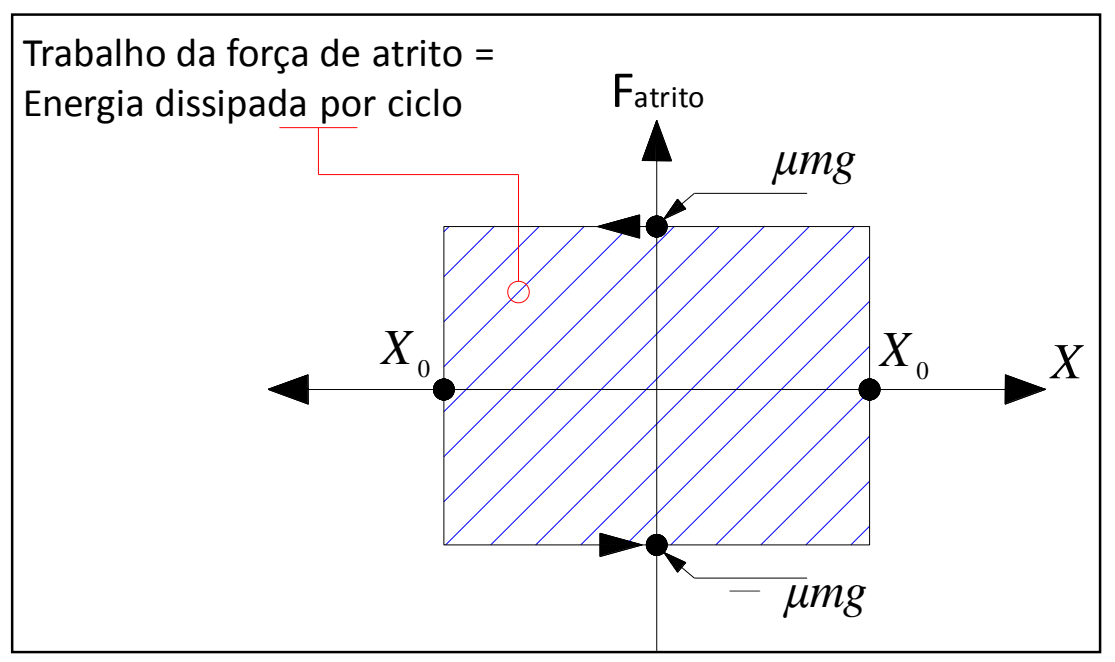

Figura 5.26 - Energia dissipada por atrito em um ciclo de oscilação. 
Substituindo a equação (5.6) na equação (5.5) e isolando $C_{e q}$ obtém-se o amortecimento equivalente:

$C_{e q}=\frac{4 \mu m g}{\pi \Omega X_{0}}$

Sabendo que:

$m g=n$

Pode-se expressar $C_{e q}$ como:

$C_{e q}=\frac{4 \mu n}{\pi \Omega X_{0}}$

Isolando da equação (5.9) a força normal tem-se:

$n=\frac{C_{e q} \pi \Omega X_{0}}{4 \mu}$

Os valores do coeficiente de atrito estático e dinâmico entre dois elementos de aço doce são segundo Serway e Jewett (2013) :

Coeficiente de atrito estático $\mu_{\mathrm{s}}=0,74$

Coeficiente de atrito dinâmico $\mu_{\mathrm{k}}=0,57$

Na Tabela 5.6 apresentam-se os valores a serem substituídos na equação (5.10) para encontrar o valor da força normal no parafuso apresentado na Figura 5.23. Com o valor correspondente a força normal pode-se conseguir um amortecimento por atrito ou forças de Coulomb.

Tabela 5.6 - Calculo da força normal em função do coeficiente de amortecimento equivalente.

\begin{tabular}{|c|c|}
\hline $\mathrm{C}_{\mathrm{eq}}$ & $360 \mathrm{Ns} / \mathrm{m}$ \\
\hline$\pi$ & 3,14159 \\
\hline$\Omega$ & $3,363 \mathrm{~Hz}$ \\
\hline $\mathrm{X}_{0}$ & $0,026 \mathrm{~m}$ \\
\hline$\mu_{\mathrm{k}}$ & 0,570 \\
\hline Normal $n$ & $43,373 \mathrm{~N}$ \\
\hline
\end{tabular}

onde: 
Ceq: é o valor do coeficiente de amortecimento equivalente.

$\pi$ : constante.

$\Omega$ : frequência de ressonância.

$\mathrm{X}_{\mathrm{o}}$ : deslocamento da massa vibrante.

$\mu_{\mathrm{k}}$ : coeficiente de atrito dinâmico entre dois aços doces.

Os valores encontrados na Tabela 5.6 se devem as seguintes razões:

O coeficiente de amortecimento equivalente $C_{e q}$ pode ser obtido a partir do estudo numérico mostrado anteriormente, o valor da primeira frequência de ressonância $\Omega$ é encontrado a partir da análise modal e o valor do deslocamento da massa vibrante $X_{0}$ é obtido em função do comprimento de compressão das molas, que é gerado pela massa das chapas de aço do AMS encontrado no estudo numérico.

Encontrado o valor da força normal no parafuso, deve-se encontrar o torque que deve ser aplicado na cabeça do parafuso para alcançar a força normal adequada. Para resolver o problema do torque analisam-se as forças atuantes entre a porca e a rosca do parafuso.

Um segmento infinitesimal da rosca é representado na Figura 5.27 pelo pequeno bloco sujeito à ação $w$ (uma parcela da carga axial total $W$ ), da força normal $n$ (mostrada na vista frontal abaixo e à esquerda), da força de atrito $f n$ e da força tangencial $q$. Se observa que a força $q$ multiplicada por $\mathrm{d}_{\mathrm{m}} / 2$ representa o torque aplicado ao segmento de rosca.

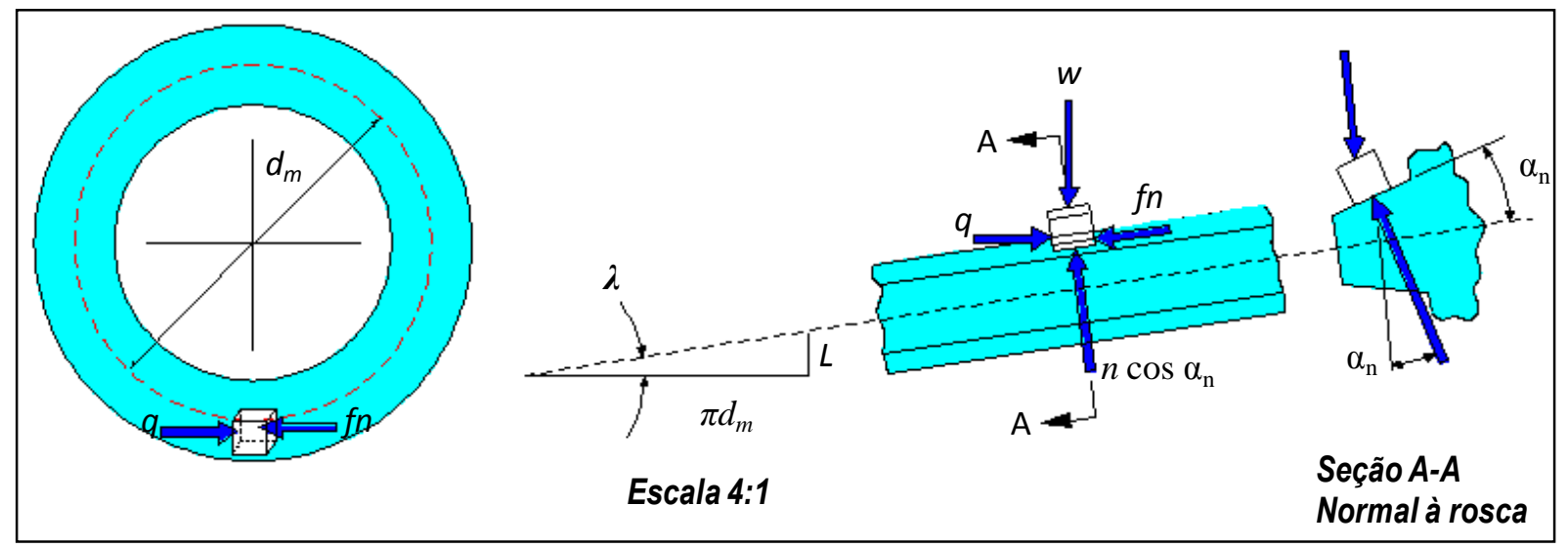

Figura 5.27 - Forças atuantes na rosca do parafuso (Juvinall e Marshek, 2012) 
Do triangulo da Figura 5.27 pode-se obter a seguinte relação:

$$
\operatorname{tg} \lambda=\frac{L}{\pi d_{m}}
$$

Onde:

$\lambda=$ ângulo de avanço

$\mathrm{L}=$ avanço

$d_{\mathrm{m}}=$ diâmetro médio de contato da rosca

O somatório das forças tangenciais atuantes no bloco (isto é, as forças horizontais na vista inferior esquerda) resulta:

$\sum F_{t}=0: q-n\left(f \cos \lambda+\cos \alpha_{n} \operatorname{sen} \lambda\right)=0$

O somatório das forças axiais (forças verticais na vista inferior esquerda) é:

$$
\Sigma F_{a}=0: w+n\left(f \operatorname{sen} \lambda-\cos \alpha_{n} \cos \lambda\right)=0
$$

$\mathrm{ou}$

$$
n=\frac{w}{\cos \alpha_{n} \cos \lambda-f \operatorname{sen} \lambda}
$$

Combinando-se as equações (5.14) e (5.16), tem-se

$$
q=w \frac{f \cos \lambda+\cos \alpha_{n} \operatorname{sen} \lambda}{\cos \alpha_{n} \cos \lambda-f \operatorname{sen} \lambda}
$$

O torque correspondente à força $q$ é $q\left(\mathrm{~d}_{\mathrm{m}} / 2\right)$. Como o pequeno bloco representa um segmento típico da rosca da porca, a integração ao longo de toda a superfície de contato da rosca resulta nas mesmas equações, exceto pelas cargas $q, w$ e $n$, que devem ser substituídas pelas cargas totais $Q, W$ e $N$, que representam as forças totais nas direções tangencial, vertical e normal, respectivamente, atuantes na rosca. Assim, a equação para o torque necessário para elevar o peso $W$ é:

$$
T=Q \frac{d_{m}}{2}=\frac{W d_{m}}{2} \frac{f \cos \lambda+\cos \alpha_{n} \operatorname{sen} \lambda}{\cos \alpha_{n} \cos \lambda-f \operatorname{sen} \lambda}
$$


Como avanço L, em vez do ângulo de avanço $\lambda$, tem geralmente um valor padronizado conhecido, uma forma adequada para a equação do torque é obtida dividindo-se o numerador e o denominador por $\cos \lambda$ e, em seguida, substituindo-se tg $\lambda$ por $L / \pi d_{m}$. Esta manipulação fornece:

$$
T=\frac{W d_{m}}{2} \frac{f \pi d_{m}+L \cos \alpha_{n}}{\pi d_{m} \cos \alpha_{n}-f L}
$$

Muitas aplicações dos parafusos requerem uma superfície de encosto ou anel de escora entre os componentes girantes e fixos. Em muitos casos, uma simples arruela de encosto é utilizada. Se o coeficiente de atrito do anel de escora ou do mancal é $f_{c}$, então o torque adicional necessário para a superação desse atrito é $W f_{c} d_{c} / 2$, e o torque total necessário para elevar o peso $W$ é:

$$
T=\frac{W d_{m}}{2} \frac{f \pi d_{m}+L \cos \alpha_{n}}{\pi d_{m} \cos \alpha_{n}-f L}+\frac{W f_{c} d_{c}}{2}
$$

Para o caso da construção do AMS o parafuso que produz a força normal com o eixo guia o qual se mostrou na Figura 5.23 tem um diâmetro do anel de escora $d c \approx 0$, por esta razão para calcular o torque necessário no parafuso se utilizará a equação (5.19).

Na Tabela 5.7 se mostram os valores utilizados das variáveis a serem substituídos para encontrar o torque necessário no parafuso de $1 / 2$ polegada e passo de 13 fios/polegada, que contribuirá com o amortecimento de Coulomb.

Tabela 5.7 - Cálculo do torque necessário no parafuso para conseguir o amortecimento de Coulomb no sistema do AMS.

\begin{tabular}{|l|r|}
\hline Avanço do parafuso, $\mathrm{L}=1 / 13$ & 0,0769 \\
\hline Diâmetro externo do parafuso & $0,0127 \mathrm{~m}$ \\
\hline Diâmetro da raiz da rosca & $0,0103 \mathrm{~m}$ \\
\hline Diâmetro médio da rosca do parafuso, $d_{m}$ & $0,0115 \mathrm{~m}$ \\
\hline Coeficiente atrito nos filetes, $f$ & 0,1200 \\
\hline Carga W = Força normal & $43,3730 \mathrm{~N}$ \\
\hline$\lambda=$ & 64,8420 \\
\hline$\alpha_{\mathrm{n}}=$ & 13,7901 \\
\hline Torque, $T$ & $0,7624 \mathrm{~N} \mathrm{~m}$ \\
\hline
\end{tabular}


O torque de 0,7624 $\mathrm{Nm}$ é obtido através de uma ferramenta chamada torquimetro, alternativamente pode-se pendurar um peso num extremo de uma chave combinada com aproximadamente 389 gramas e $20 \mathrm{~cm}$ de braço. Como no amortecedor em questão dois amortecedores atuam em paralelo, vide Figura 5.24, o torque no torquimetro que deve ser aplicado para cada parafuso é de $0,3812 \mathrm{Nm}$.

\subsection{ETAPAS DE CONSTRUÇÃO DO AMS}

Para a construção do amortecedor de massa sintonizado foi necessário realizar os seguintes procedimentos. Foram cortadas e perfuradas as chapas de aço para conformar a massa vibrante segundo o projeto indicados da Figura 5.16 a Figura 5.18. As chapas foram cortadas com maçarico, por esta razão as dimensões das peças não ficaram milimetricamente segundo o projeto e, como consequência disso, as massas ficaram um pouco abaixo de 4,97 kg. As chapas foram furadas em blocos de a cinco chapas com o gabarito, para garantir uma mesma distância entre furos em todas as peças. O processo de realização dos furos com a furadeira radial é mostrado na Figura 5.28.
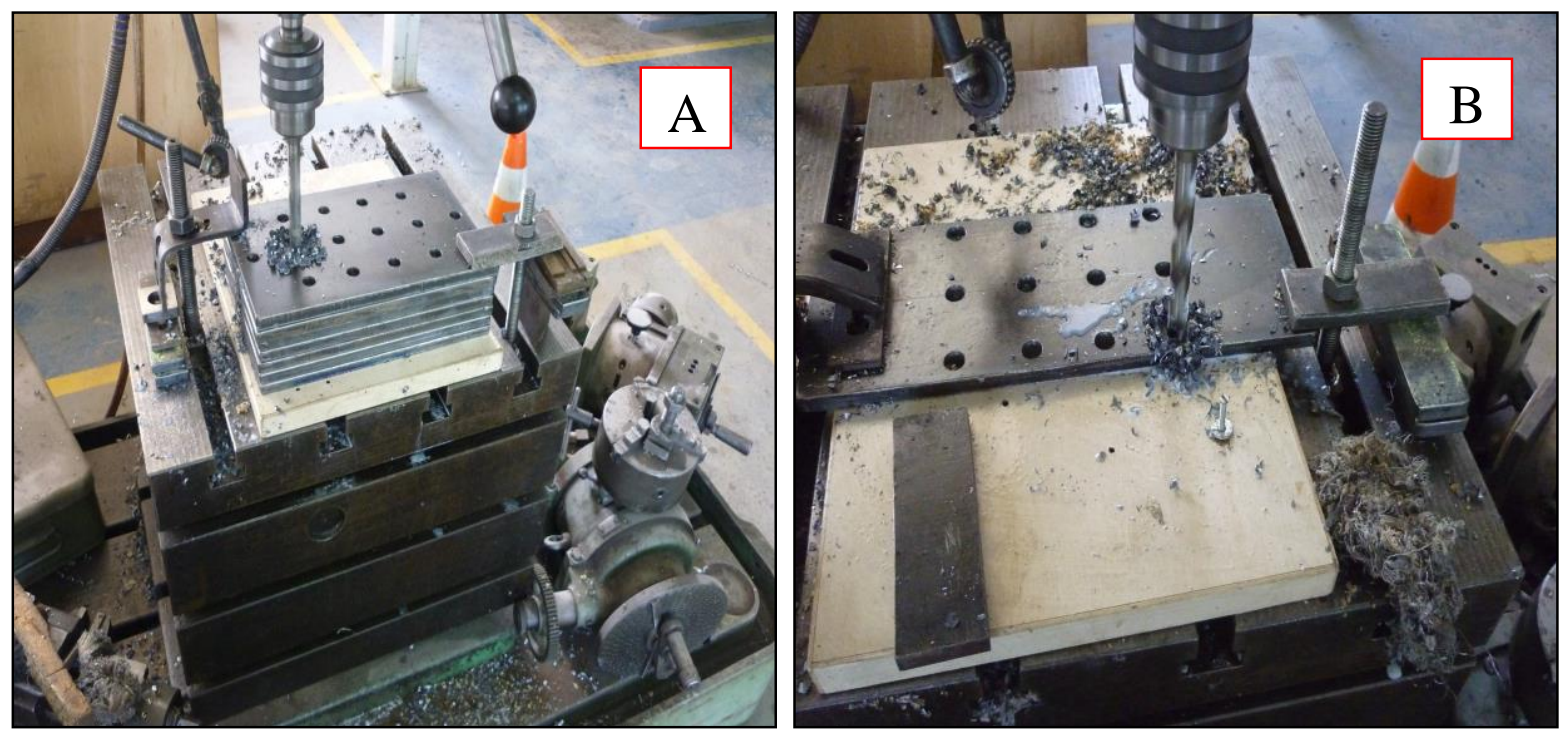

Figura 5.28 - A) Perfuração das chapas de aço que compõem a massa vibrante, B) Perfuração da chapa de aço que serve como suporte do AMS.

Em seguida, pesarem-se as peças que formam todo o conjunto do AMS. A balança eletrônica usada (Figura 5.29) tem uma precisão de 0,1 gramas. 
$\mathrm{Na}$ Tabela 5.8 encontram-se os pesos das diferentes peças do conjunto da massa vibrante do AMS.
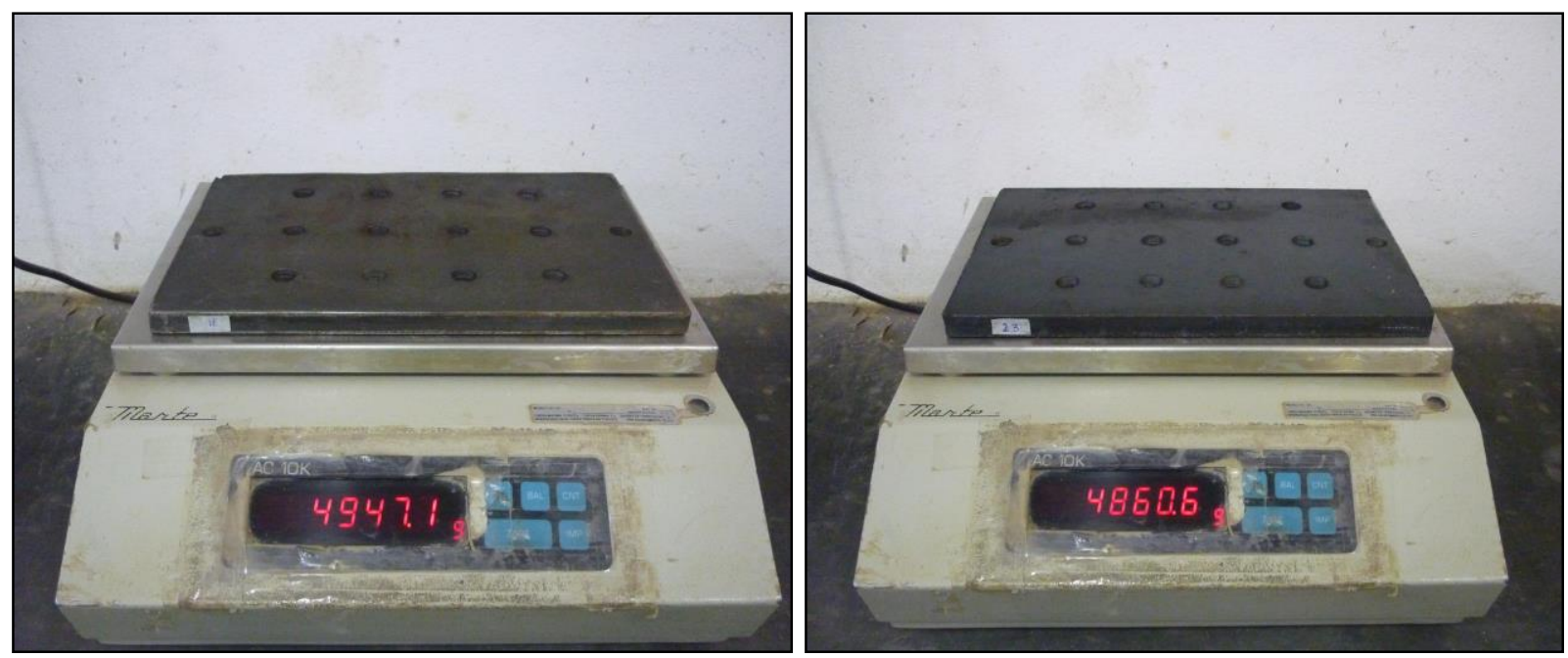

Figura 5.29 - Pesos obtidos na balança eletrônica das diferentes peças de aço do AMS.

Tabela 5.8 - Pesos das diferentes peças da massa vibrante do AMS.

\begin{tabular}{|c|c|}
\hline \multicolumn{2}{|c|}{ Módulo 1 } \\
\hline Placa 1+12 anéis & $5022.9 \mathrm{gr}$ \\
\hline Placa 2 & $4880 \mathrm{gr}$ \\
\hline Placa 3 & $4850,4 \mathrm{gr}$ \\
\hline Placa 4 & $4792 \mathrm{gr}$ \\
\hline Placa 5 & $4813,8 \mathrm{gr}$ \\
\hline Placa 6 & $4784,8 \mathrm{gr}$ \\
\hline Placa 7 & $4838,4 \mathrm{gr}$ \\
\hline Placa 8 & $4878,7 \mathrm{gr}$ \\
\hline Placa 9 & $4806,5 \mathrm{gr}$ \\
\hline Placa 10 & $4878,7 \mathrm{gr}$ \\
\hline Placa 11 \\
\hline Placa 12 \\
\hline Parafuso 1 & $4947,1 \mathrm{gr}$ \\
\hline Parafuso 2 & $214,2 \mathrm{gr}$ \\
\hline Peça atrito Direita & $214,4 \mathrm{gr}$ \\
\hline$\Sigma$ & $514,7 \mathrm{gr}$ \\
\hline
\end{tabular}

\begin{tabular}{|c|c|}
\hline \multicolumn{2}{|c|}{ Módulo 2 } \\
\hline Placa 14+a2 anéis & $4963,3 \mathrm{gr}$ \\
\hline Placa 15 & $4820 \mathrm{gr}$ \\
\hline Placa 16 & $4792,5 \mathrm{gr}$ \\
\hline Placa 17 & $4795,7 \mathrm{gr}$ \\
\hline Placa 18 & $4853,7 \mathrm{gr}$ \\
\hline Placa 19 & $4738,8 \mathrm{gr}$ \\
\hline Placa 20 & $4734,4 \mathrm{gr}$ \\
\hline Placa 21 & $4882,1 \mathrm{gr}$ \\
\hline Placa 22 & $4792,9 \mathrm{gr}$ \\
\hline Placa 23 & $4860,6 \mathrm{gr}$ \\
\hline Placa 24 & $4851,3 \mathrm{gr}$ \\
\hline Placa 25 & $4826,5 \mathrm{gr}$ \\
\hline Parafuso 1 & $214,7 \mathrm{gr}$ \\
\hline Parafuso 2 & $214,6 \mathrm{gr}$ \\
\hline Peça atrito Esquerda & $528,9 \mathrm{gr}$ \\
\hline$\Sigma$ & $58870 \mathrm{gr}$ \\
\hline
\end{tabular}

Somando os dois módulos encontra-se uma massa total de 118,03 kg, um pouco inferior à necessária de 120,00 kg. A diferença de 1,97 kg de massa é compensada adicionando-se duas 
peças de aço colocadas para unir as duas massas vibrantes, e assim garantir que os dois conjuntos vibrem como um único corpo rígido.

Com os valores de massa obtidos experimentalmente, foi atualizado o projeto do AMS no software AutoCAD (2013), com a finalidade de projetar a massa restante para obter-se os 120 $\mathrm{kg}$. Posteriormente utilizaram-se as ferramentas de propriedades de massa do software para encontrar as coordenadas do centro de gravidade da massa vibrante dos dois módulos trabalhado conjuntamente. $\mathrm{O}$ centro de gravidade da massa vibrante deve coincidir com as coordenadas do nó do estudo numérico, pelo fato que neste nó foi concentrada toda a massa do AMS. Na Tabela 5.8 foram apresentadas as massas das chapas obtidas experimentalmente da massa vibrante do AMS, devido a uma pequena diferença entre os valores encontrados experimentalmente e numericamente se faz necessário uma calibração do projeto numérico que se apresentam na Tabela 5.9 e Tabela 5.10 para os módulos 1 e 2 respectivamente.

Para encontrar os valores da massa vibrante foram utilizadas as propriedades de região e massa de sólidos 3D do software AutoCAD (2013).

Tabela 5.9 - Valores de massa vibrante do projeto calibrado em AutoCAD (2013) e comparado com valores reais experimentais do módulo 1.

\begin{tabular}{|r|l|}
\hline \multicolumn{2}{|c|}{ Módulo 1 } \\
\hline 0,007 & Volume em $\mathrm{m}^{3}$ obtido das 12 chapas de aço \\
\hline 59650,392 & Massa em gr obtido em autocad das 12 chapas de aço \\
\hline 58083,900 & Massa real em gr obtido em balança eletrônica, 12 chapas de aço. \\
\hline 1566,492 & Diferença em gr da massa das 12 chapas de aço em autocad e peso real \\
\hline 4970,866 & Massa última chapa de aço em autocad, sem calibrar com modelo experimental \\
\hline 3404,373 & Massa final da última chapa de aço para calibrar modelo numérico com experimental \\
\hline 0,007 & Novo volume em $\mathrm{m}^{3}$ obtido em autocad das 12 chapas de aço. \\
\hline 58083,900 & Massa em gr, autocad igual a massa real experimental das 12 chapas de aço \\
\hline 0,007 & Volume em $\mathrm{m}^{3}$ da massa vibrante calibrada, obtida em autocad \\
\hline 59034,031 & Massa em gr massa vibrante calibrada obtida em autocad \\
\hline 6,831 & Diferença em gr da massa vibrante calibrada em autocad e massa real experimental. \\
\hline
\end{tabular}


Tabela 5.10 - Valores de massa vibrante do projeto calibrado em AutoCAD (2013) e comparado com valores reais experimentais do módulo 2.

\begin{tabular}{|r|l|}
\hline \multicolumn{2}{|c|}{ Módulo 2 } \\
\hline 0,007 & Volume em $\mathrm{m}^{3}$ obtido das 12 chapas de aço \\
\hline 59650,392 & Massa em gr obtido em autocad das 12 chapas de aço \\
\hline 57777,000 & Massa real em gr obtido em balança eletrônica, 12 chapas de aço. \\
\hline 1873,392 & Diferença em gr da massa das 12 chapas de aço em autocad e peso real \\
\hline 4970,866 & Massa última chapa de aço em autocad, sem calibrar com modelo experimental \\
\hline 3097,473 & Massa final da última chapa de aço para calibrar modelo numérico com Experimental \\
\hline 0,007 & Novo volume em $\mathrm{m}^{3}$ obtido em autocad das 12 chapas de aço. \\
\hline 57777,000 & Massa em gr, autocad igual a massa real experimental das 12 chapas de aço \\
\hline 0,007 & Volume em $\mathrm{m}^{3}$ da massa vibrante calibrada, obtida em autocad \\
\hline 58740,262 & Massa em gr massa vibrante calibrada obtida em autocad \\
\hline 5,062 & Diferença em gr da massa vibrante calibrada em autocad e massa real experimental. \\
\hline
\end{tabular}

Tendo o modelo da massa vibrante numericamente calibrado com o modelo experimental, foram projetadas as peças que juntarão a massa vibrante dois dos módulos e permitirão que vibrem como um único corpo rígido, além de ajustar a massa vibrante que ainda falta para os $120 \mathrm{~kg}$ que é de aproximadamente $2,237 \mathrm{~kg}$. Foram projetadas 4 peças para ajustar a massa vibrante como se mostra na Figura 5.30. O volume total da massa vibrante que é de $0,015287 \mathrm{~m}^{3}$ se apresenta na Figura 5.31. Este valor, quando multiplicado pela densidade do aço de $7850 \mathrm{~kg} / \mathrm{m}^{3}$ dá como resultado uma massa vibrante de $120 \mathrm{~kg}$, valor que corresponde ao valor encontrado no estudo numérico feito em ANSYS (2012).

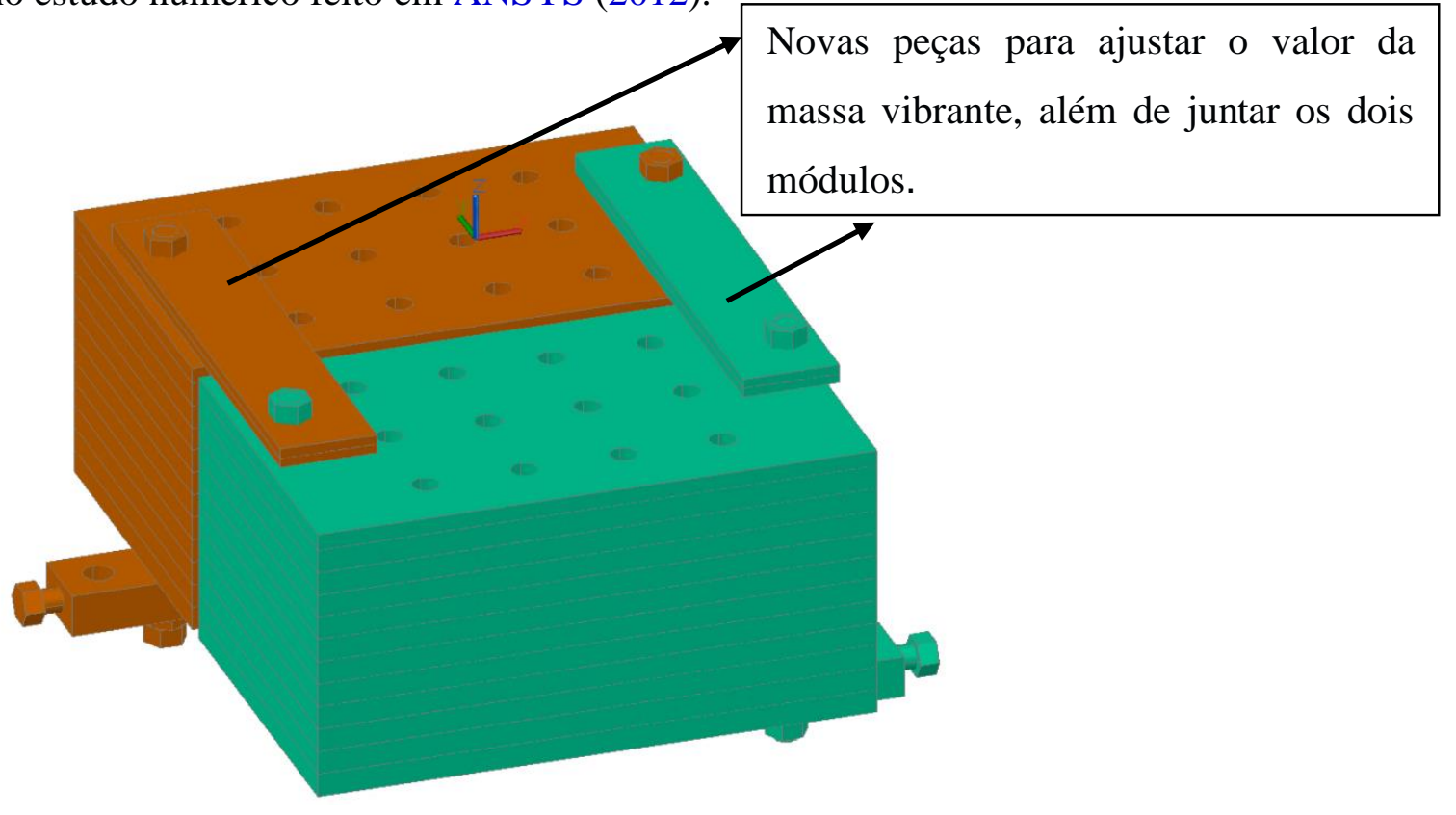

Figura 5.30 - Massa vibrante do AMS, com novas peças para ajustar a massa experimental. 
Como foi explicado com ajuda do software AutoCAD (2012) foram calculadas as coordenadas do centro de gravidade da massa vibrante as quais se apresentam na Figura 5.31.

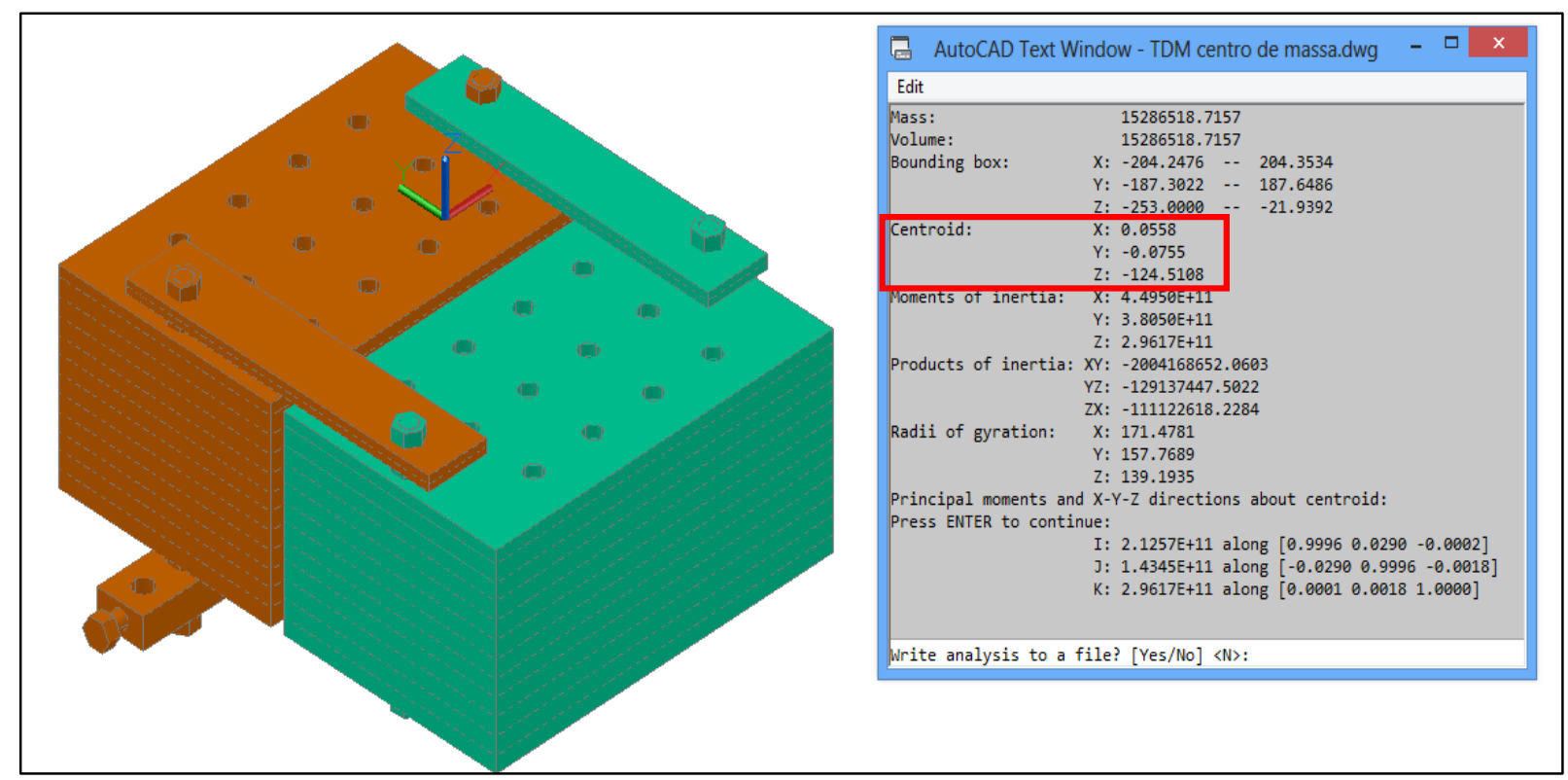

Figura 5.31 - Coordenadas, em mm, do centro de gravidade da massa vibrante do AMS.

As coordenadas do centro de gravidade são $\mathrm{x}=0,0558 \mathrm{~mm}, \mathrm{y}=-0,0755 \mathrm{~mm}$ e $\mathrm{z}=-124,5108$ mm. As coordenadas x e y são praticamente nulas, ou seja, o AMS ficará com a concentração de massa no mesmo nó do estudo numérico, que é no centro da plataforma.

Na Figura 5.32 apresenta-se o projeto do AMS com as novas peças de ajuste. 


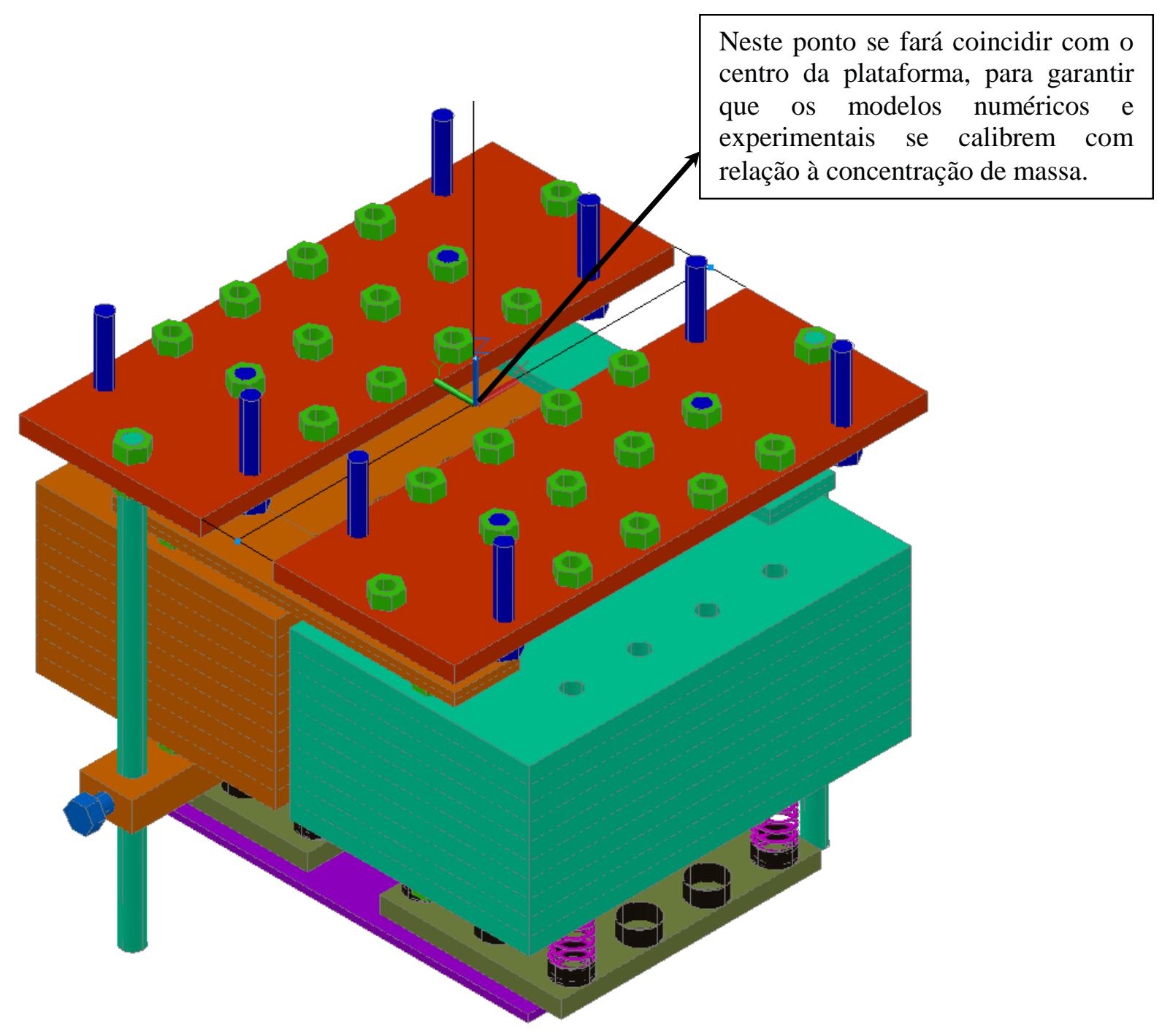

Figura 5.32 - AMS com os dois módulos juntos para vibrar como um único corpo rígido.

Depois de projetadas as 4 peças que conectam as duas massas vibrantes dos dois módulos, foram cortadas e perfuradas segundo as dimensões do projeto. Estas peças têm medidas de 260x50x5 mm e são construídas em aço. Com estas novas peças completa-se o valor experimental da massa vibrante em um total de $120,109 \mathrm{~kg}$. 
Na Figura 5.33 e Figura 5.34 são apresentadas as peças que juntam as duas massas vibrantes dos dois módulos com a finalidade de vibrar conjuntamente como um único corpo rígido e os seus valores de massas respectivamente.

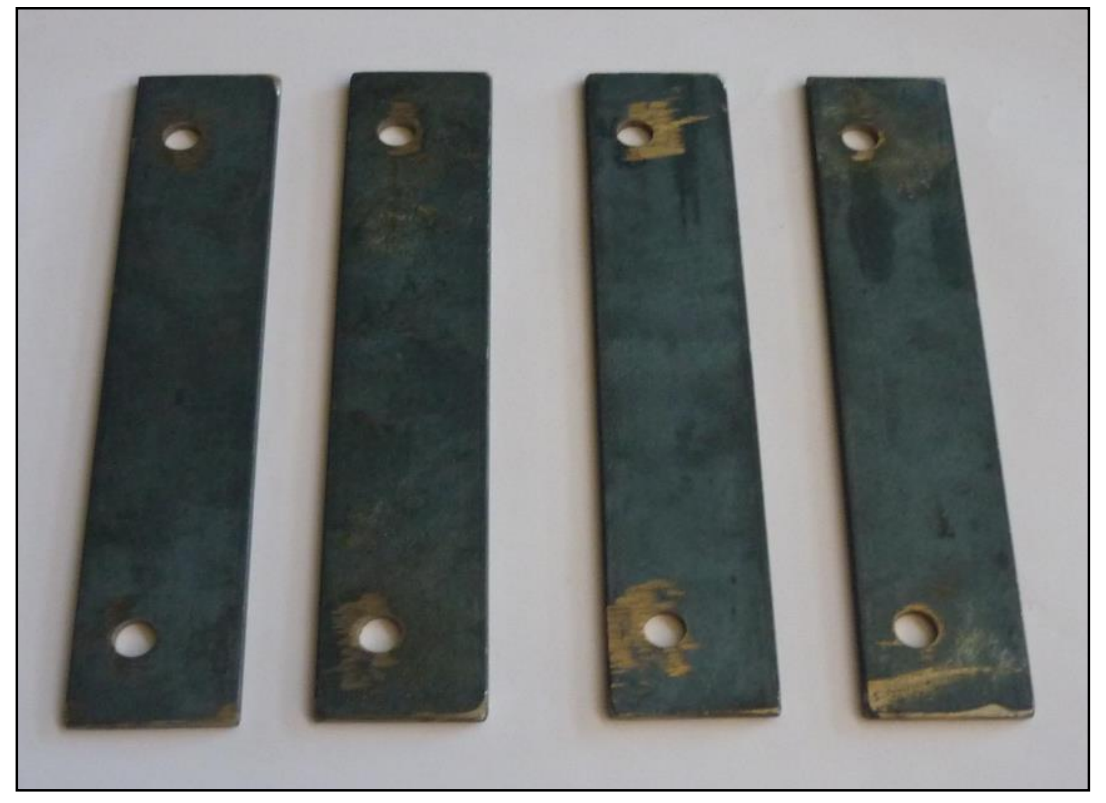

Figura 5.33 - Peças que formam a massa vibrante.
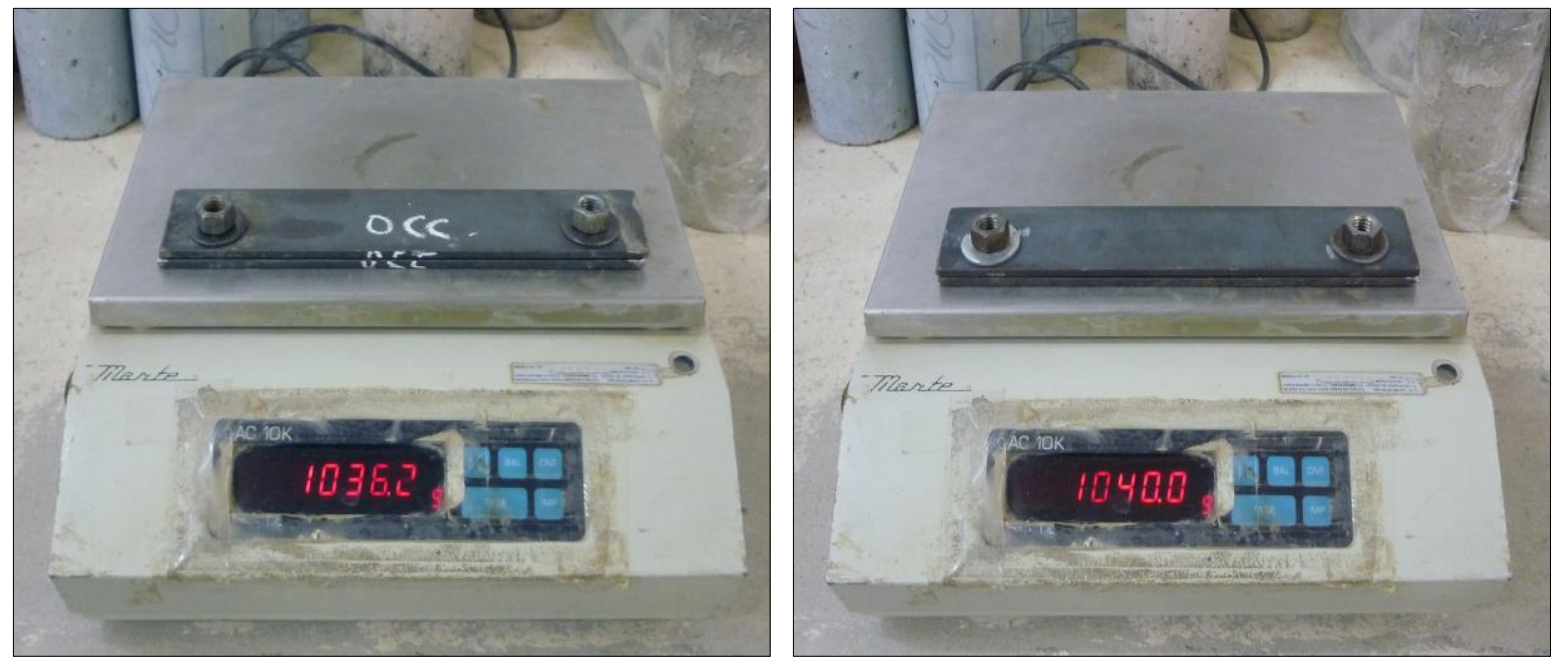

Figura 5.34 - Valor das massas das duas peças que juntam os dois módulos das massas vibrantes. 
Para o processo da montagem da massa vibrante foram usinados 4 eixos de aço com diâmetro de 14,0 mm, os quais atuam como eixos guias coincidindo com as posições de todos os furos das chapas de aço. Além dos quatro eixos guias foram colocados também dos parafusos de 1/2 polegada e de comprimento de $215 \mathrm{~mm}$, os quais fixaram as peças que fazem parte da massa vibrante. Na Figura 5.35 pode-se observar o processo da montagem da massa vibrante.

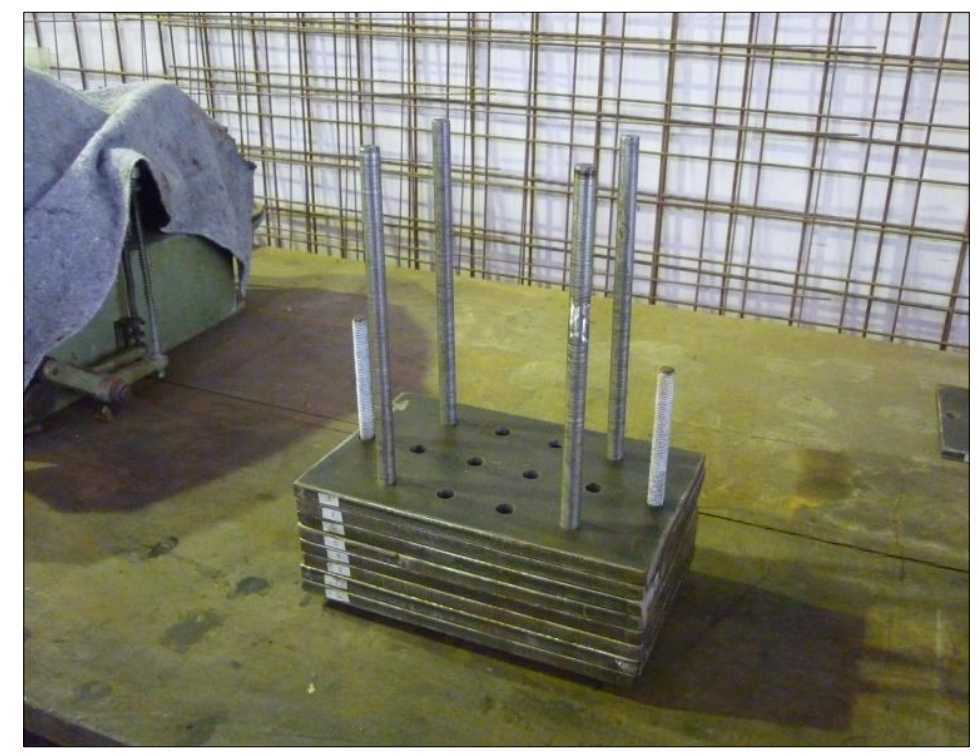

Figura 5.35 - Processo de montagem da massa vibrante do modulo 1.

Feita a montagem das massas foram alinhados, doze parafusos com a chapa base e a chapa suporte. Estes parafusos atravessam a massa vibrante com função de sustentar a chapa base, as molas de compressão e as chapas de aço que formam o conjunto. O processo da montagem da chapa base, parafusos, massa vibrante e chapas suporte com as porcas para soldar são ilustrados na Figura 5.36. 


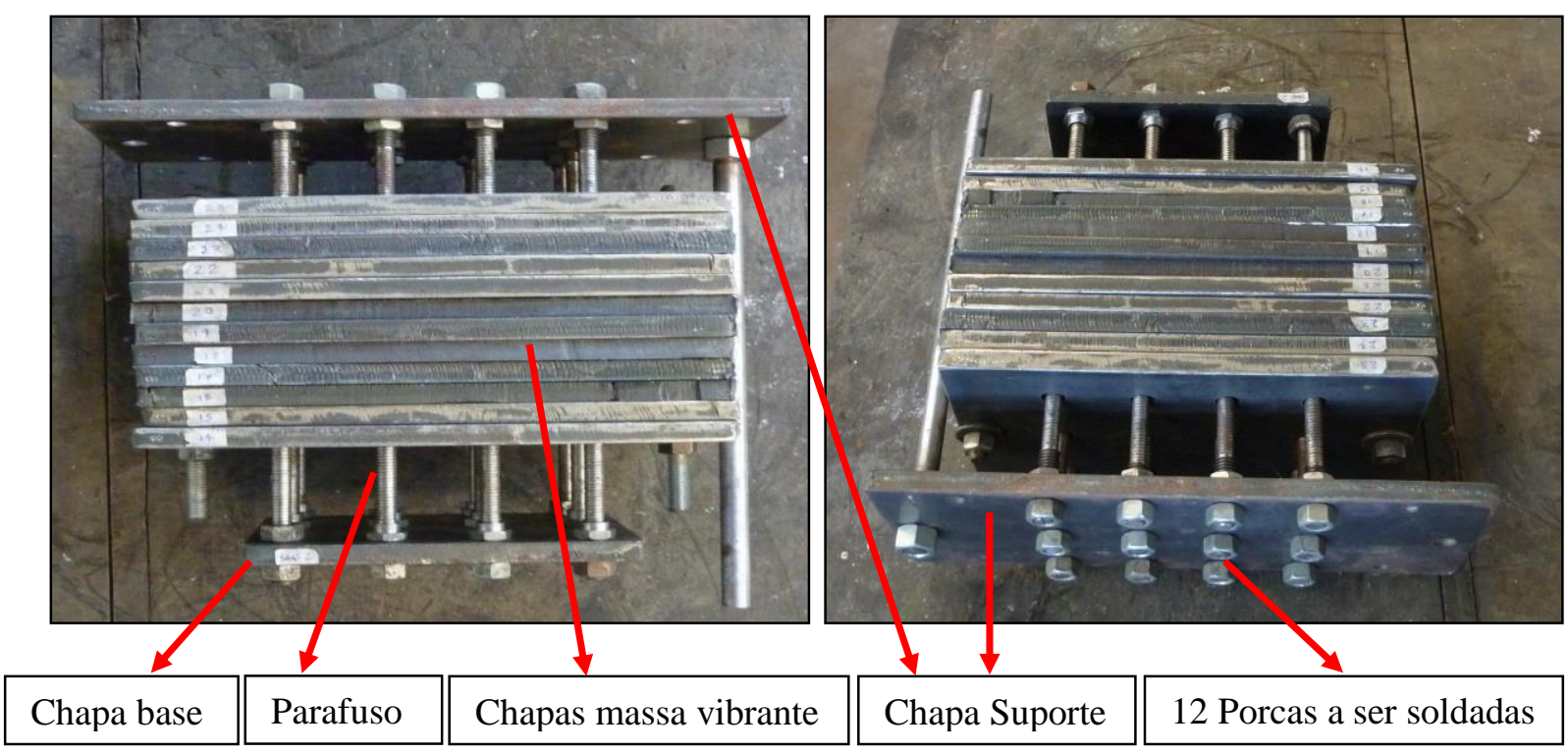

Figura 5.36 - Porcas a ser soldadas que fixam os 12 parafusos, os quais sustentam o AMS.

Na Figura 5.37 apresenta-se o AMS sem as molas e eixos que geram o atrito e com a peças de ajuste que conectam os dois módulos.
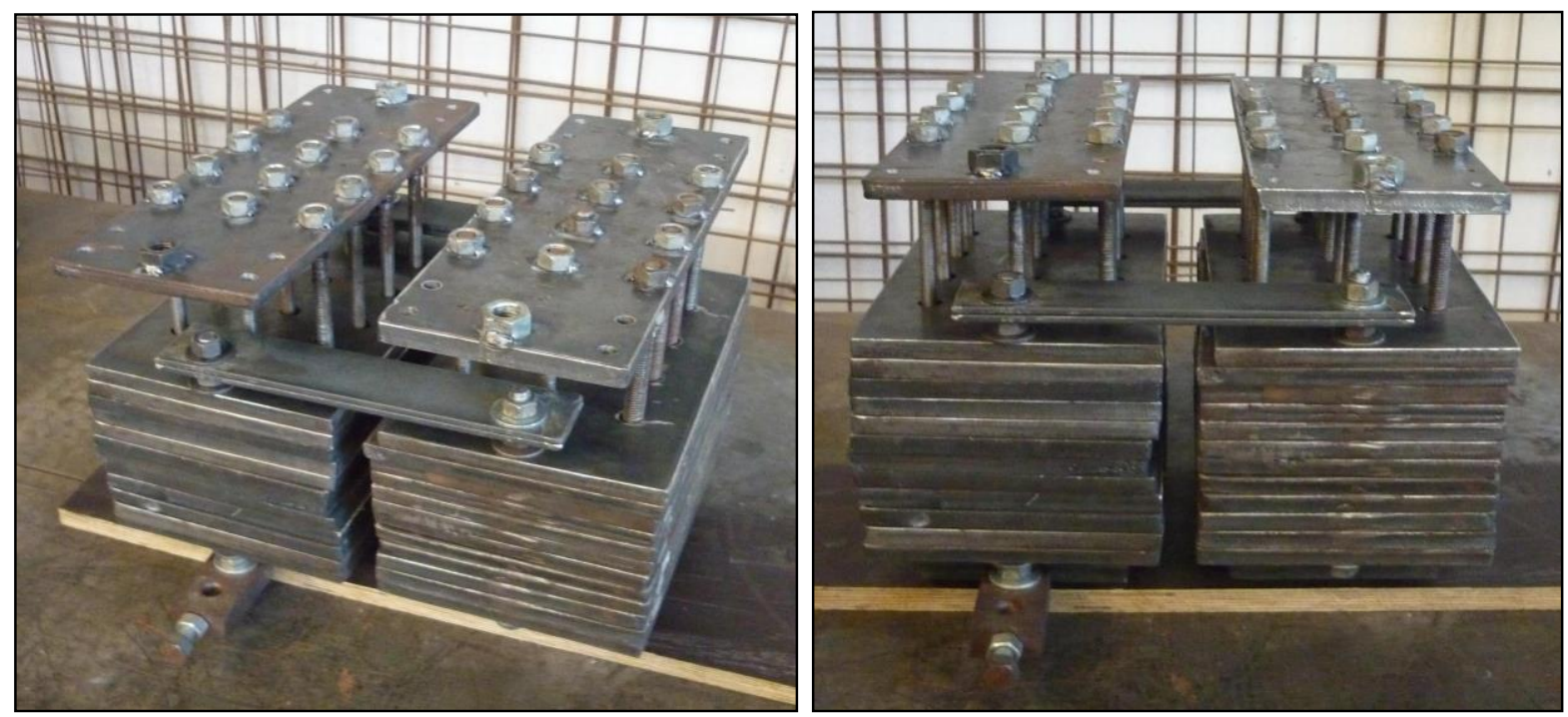

Figura 5.37 - Modulo 1 e Modulo 2 juntos do AMS.

Uma vez que as molas projetadas na Figura 5.15 não são comerciais, foi necessário comprar molas comerciais com dimensões aproximadas da mola tipo 2. Por isso foi medida experimentalmente a rigidez das molas disponíveis para aquisição em estabelecimentos comerciais. As molas que serão utilizadas têm em média os seguintes parâmetros: $\emptyset$ diâmetro 
das espiras de 2,45 mm, diâmetro externo da mola de 22,2 mm, espiras ativas 6. Na Tabela 5.11 apresentam-se apresentam os parâmetros das 24 molas adquiridas no comercio, já na Tabela 5.12 se mostra o valor analítico da rigidez de cada mola, utilizando-se equação (5.3).

Tabela 5.11 - Parâmetros das molas adquiridas no comercio.

\begin{tabular}{|c|c|c|c|c|c|c|c|}
\hline Mola N$^{\circ}$ & $\begin{array}{c}\varnothing \text { Mola } \\
(\mathrm{mm})\end{array}$ & $\begin{array}{c}\emptyset \text { Arame } \\
(\mathrm{mm})\end{array}$ & $\begin{array}{c}\text { Altura } \\
\text { mola }(\mathrm{mm})\end{array}$ & Mola N $^{\circ}$ & $\begin{array}{c}\emptyset \text { Mola } \\
(\mathrm{mm})\end{array}$ & $\begin{array}{c}\emptyset \text { Arame } \\
(\mathrm{mm})\end{array}$ & $\begin{array}{c}\text { Altura } \\
\text { mola }(\mathrm{mm})\end{array}$ \\
\hline 1 & 22,2 & 2,45 & 65,7 & 13 & 22,2 & 2,45 & 67,4 \\
\hline 2 & 22,0 & 2,45 & 68,0 & 14 & 22,3 & 2,45 & 66,4 \\
\hline 3 & 22,0 & 2,45 & 67,0 & 15 & 22,0 & 2,45 & 65,2 \\
\hline 4 & 22,3 & 2,45 & 66,5 & 16 & 22,0 & 2,45 & 67,0 \\
\hline 5 & 22,1 & 2,45 & 66,7 & 17 & 22,2 & 2,45 & 65,8 \\
\hline 6 & 22,0 & 2,45 & 65,1 & 18 & 22,4 & 2,45 & 67,3 \\
\hline 7 & 22,1 & 2,45 & 67,5 & 19 & 22,0 & 2,45 & 67,0 \\
\hline 8 & 22,3 & 2,45 & 67,4 & 20 & 22,5 & 2,45 & 66,4 \\
\hline 9 & 22,2 & 2,45 & 66,2 & 21 & 22,4 & 2,45 & 64,0 \\
\hline 10 & 22,3 & 2,45 & 67,1 & 22 & 22,0 & 2,45 & 66,4 \\
\hline 11 & 22,4 & 2,45 & 67,0 & 23 & 22,0 & 2,45 & 66,7 \\
\hline 12 & 22,0 & 2,45 & 66,1 & 24 & 22,1 & 2,45 & 67,0 \\
\hline
\end{tabular}

Tabela 5.12 - Rigidez analítica da mola comercial.

\begin{tabular}{|c|c|c|c|}
\hline Mola N $^{\circ}$ & Rigidez (N/m) & Mola N $^{\circ}$ & Rigidez (N/m) \\
\hline 1 & 5409,3 & 13 & 5409,3 \\
\hline 2 & 5558,2 & 14 & 5336,9 \\
\hline 3 & 5558,2 & 15 & 5558,2 \\
\hline 4 & 5336,9 & 16 & 5558,2 \\
\hline 5 & 5483,1 & 17 & 5409,3 \\
\hline 6 & 5558,2 & 18 & 5265,7 \\
\hline 7 & 5483,1 & 19 & 5558,2 \\
\hline 8 & 5336,9 & 20 & 5195,8 \\
\hline 9 & 5409,3 & 21 & 5265,7 \\
\hline 10 & 5336,9 & 22 & 5558,2 \\
\hline 11 & 5265,7 & 23 & 5558,2 \\
\hline 12 & 5558,2 & 24 & 5483,1 \\
\hline
\end{tabular}

A partir das informações da tabela anterior verifica-se que são necessárias aproximadamente 10 molas (Mola $\left.\mathrm{n}^{\circ} 1,4,8,9,10,11,14,18,20,21\right)$ trabalhando em paralelo para encontrar a rigidez total do sistema totalizando uma rigidez de 53159,4 N/m que uma rigidez próxima ao valor encontrado numericamente de 51000 N/m. Para encontrar a rigidez experimental do AMS, foram testadas as 24 molas obtidas comercialmente, verificando a rigidez individual mediante ensaios de compressão através de pesos. As molas e os pesos utilizados nos ensaios são mostrados na Figura 5.38 e Figura 5.39 respectivamente. 


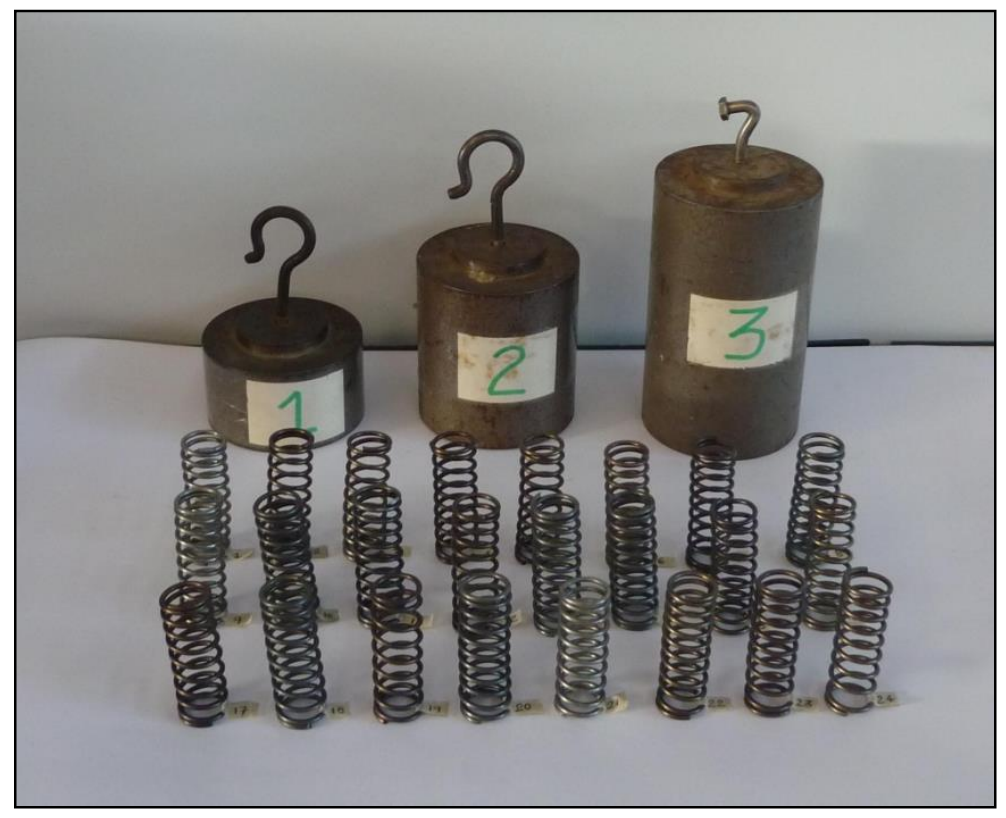

Figura 5.38 - Molas de compressão e pesos utilizados para o ensaio de compressão.

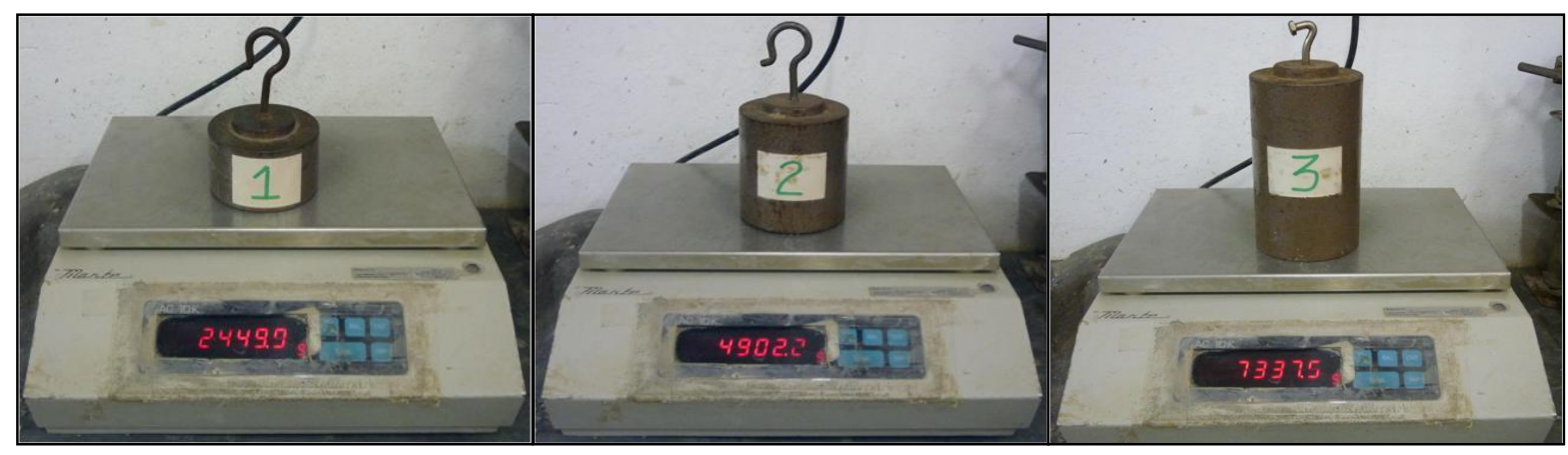

Figura 5.39 - Magnitude dos pesos para os ensaios de compressão das molas.

Para encontrar experimentalmente a rigidez de cada mola foi necessário medir a deformação a compressão produzida por um peso pendurado na parte inferior da mesma. A deformação foi medida usando um calibrador de profundidade de relógio com precisão de 0,01 mm de marca Huggenberger Zurich, com o qual se registrava o comprimento inicial da mola e o comprimento final da mola deformada. Para atingir estas deformações colocaram-se pesos de 2449,9 gr-f, 4902,2 gr-f e 7337,5 gr-f em diferentes ensaios com a finalidade de obter graficamente a linha que define a rigidez para cada mola. $\mathrm{O}$ processo e a montagem para medir experimentalmente a rigidez das molas são mostrados na Figura 5.40. A aceleração da gravidade local considerada foi de $9,7808439 \mathrm{~m} / \mathrm{s}^{2}$. 


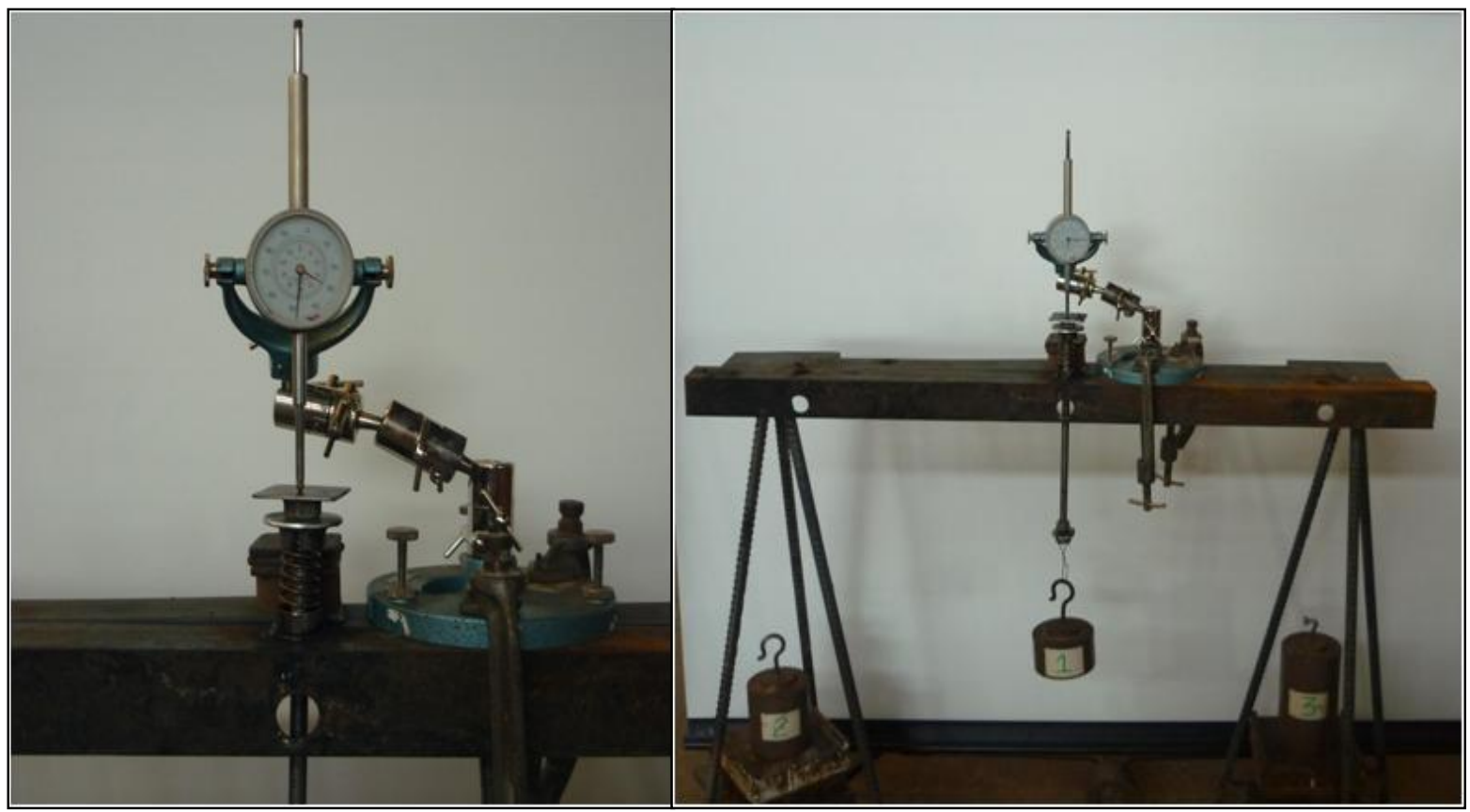

Figura 5.40 - Montagem para obtenção da rigidez da mola.

A Tabela 5.13 apresenta os diferentes resultados dos ensaios de compressão das molas.

Para cada mola foram realizados três ensaios de compressão com os respectivos pesos com o objetivo de obter três deformações diferentes. A partir destes resultados foi feita uma regressão linear pelo método de ajuste dos mínimos quadrados com o qual se obtêm a seguinte equação linear.

$$
y=m x+b
$$

onde:

$\mathrm{y}=$ valor do peso pendurado,

$\mathrm{m}=$ rigidez da mola,

$\mathrm{x}=$ deformação da mola,

$\mathrm{b}=$ ponto de interceptação da reta com o eixo das ordenadas.

Os ajustes e as equações dos valores encontrados experimentalmente das molas pelo método dos mínimos quadrados são apresentados desde a Figura 5.41 até Figura 5.64 
Tabela 5.13 - Valores das rigidezes das molas, encontrados experimentalmente.

\begin{tabular}{|c|c|c|c|c|c|c|c|c|c|c|c|}
\hline \multicolumn{4}{|c|}{$2449,9 \mathrm{gr}$} & \multicolumn{3}{|c|}{$4902,2 \mathrm{gr}$} & \multicolumn{3}{|c|}{$7337,5 \mathrm{gr}$} & \multirow{3}{*}{$\begin{array}{l}\text { Média } \\
{[\mathrm{N} / \mathrm{m}]}\end{array}$} & \multirow{3}{*}{$\begin{array}{c}\text { Mínimos } \\
\text { Quadrados } \\
\text { [N/m] }\end{array}$} \\
\hline \multirow{2}{*}{$\begin{array}{l}\text { Mola } \\
\text { No }\end{array}$} & \multicolumn{2}{|c|}{ Comprimento [mm] } & \multirow{2}{*}{$\begin{array}{c}\text { Rigidez } \\
{[\mathrm{N} / \mathrm{m}]}\end{array}$} & \multicolumn{2}{|c|}{ Comprimento [mm] } & \multirow{2}{*}{$\begin{array}{c}\text { Rigidez } \\
{[\mathrm{N} / \mathrm{m}]}\end{array}$} & \multicolumn{2}{|c|}{$\begin{array}{c}\text { Comprimento } \\
{[\mathrm{mm}]}\end{array}$} & \multirow{2}{*}{$\begin{array}{c}\text { Rigidez } \\
\text { [N/m] }\end{array}$} & & \\
\hline & Inicial & Final & & Inicial & Final & & Inicial & Final & & & \\
\hline 1 & 40,70 & 36,20 & 5444,22 & 39,93 & 32,21 & 6350,00 & 40,11 & 28,40 & 6266,01 & 6020,08 & 6355,5 \\
\hline 2 & 42,34 & 38,99 & 7313,13 & 42,53 & 34,71 & 6268,80 & 41,84 & 30,45 & 6442,05 & 6674,66 & 6313,3 \\
\hline 3 & 42,60 & 38,24 & 5619,04 & 42,50 & 33,38 & 5375,22 & 42,51 & 29,42 & 5605,42 & 5533,23 & 5550,4 \\
\hline 4 & 41,99 & 37,84 & 5903,37 & 41,98 & 33,61 & 5856,87 & 41,94 & 29,37 & 5837,31 & 5865,85 & 5834,5 \\
\hline 5 & 41,40 & 37,21 & 5847,02 & 41,46 & 33,19 & 5927,69 & 41,64 & 29,04 & 5823,41 & 5866,04 & 5840,7 \\
\hline 6 & 40,62 & 36,38 & 5778,07 & 40,65 & 32,24 & 5829,01 & 40,60 & 28,17 & 5903,06 & 5836,71 & 5900,0 \\
\hline 7 & 40,64 & 36,51 & 5931,96 & 40,54 & 32,29 & 5942,06 & 40,74 & 28,32 & 5907,81 & 5927,28 & 5912,1 \\
\hline 8 & 46,94 & 42,36 & 5349,13 & 46,99 & 38,11 & 5520,50 & 46,90 & 33,85 & 5622,61 & 5497,41 & 5628,1 \\
\hline 9 & 33,37 & 29,48 & 6297,94 & 33,31 & 25,73 & 6467,28 & 33,32 & 21,90 & 6425,13 & 6396,79 & 6445,9 \\
\hline 10 & 39,87 & 35,00 & 5030,60 & 39,85 & 30,43 & 5204,03 & 39,76 & 26,05 & 5351,93 & 5195,52 & 5351,5 \\
\hline 11 & 40,14 & 35,09 & 4851,29 & 40,00 & 30,00 & 4902,20 & 40,60 & 26,38 & 5159,99 & 4971,16 & 5130,2 \\
\hline 12 & 33,73 & 29,56 & 5875,06 & 33,65 & 25,32 & 5884,99 & 33,62 & 20,92 & 5777,56 & 5845,87 & 5788,1 \\
\hline 13 & 38,54 & 34,05 & 5456,35 & 38,62 & 29,14 & 5171,10 & 38,22 & 24,50 & 5348,03 & 5325,16 & 5296,6 \\
\hline 14 & 39,89 & 35,29 & 5325,87 & 39,89 & 30,66 & 5311,16 & 39,88 & 26,08 & 5317,03 & 5318,02 & 5314,9 \\
\hline 15 & 33,55 & 28,67 & 5020,29 & 33,26 & 24,39 & 5526,72 & 33,24 & 20,06 & 5567,15 & 5371,38 & 5611,1 \\
\hline 16 & 33,24 & 28,41 & 5072,26 & 32,95 & 23,45 & 5160,21 & 32,76 & 18,80 & 5256,09 & 5162,85 & 5254,0 \\
\hline 17 & 35,40 & 31,45 & 6202,28 & 35,39 & 27,52 & 6228,97 & 35,19 & 23,48 & 6266,01 & 6232,42 & 6264,7 \\
\hline 18 & 41,04 & 36,58 & 5493,05 & 41,04 & 32,12 & 5495,74 & 40,95 & 26,92 & 5229,86 & 5406,22 & 5249,1 \\
\hline 19 & 35,93 & 31,82 & 5960,83 & 35,70 & 27,55 & 6014,97 & 35,74 & 23,57 & 6029,17 & 6001,66 & 6033,0 \\
\hline 20 & 43,52 & 38,37 & 4757,09 & 43,58 & 33,50 & 4863,29 & 43,45 & 28,65 & 4957,77 & 4859,38 & 4957,6 \\
\hline 21 & 33,62 & 29,74 & 6314,18 & 33,48 & 25,72 & 6317,27 & 33,40 & 21,93 & 6397,12 & 6342,86 & 6388,6 \\
\hline 22 & 35,01 & 29,93 & 4822,64 & 34,91 & 24,79 & 4844,07 & 34,79 & 20,10 & 4994,89 & 4887,20 & 4978,7 \\
\hline 23 & 33,84 & 29,12 & 5190,47 & 33,85 & 24,64 & 5322,69 & 33,76 & 20,24 & 5427,14 & 5313,43 & 5428,4 \\
\hline 24 & 34,55 & 30,14 & 5555,33 & 34,01 & 25,77 & 5949,27 & 33,75 & 21,95 & 6218,22 & 5907,61 & 6221,5 \\
\hline
\end{tabular}




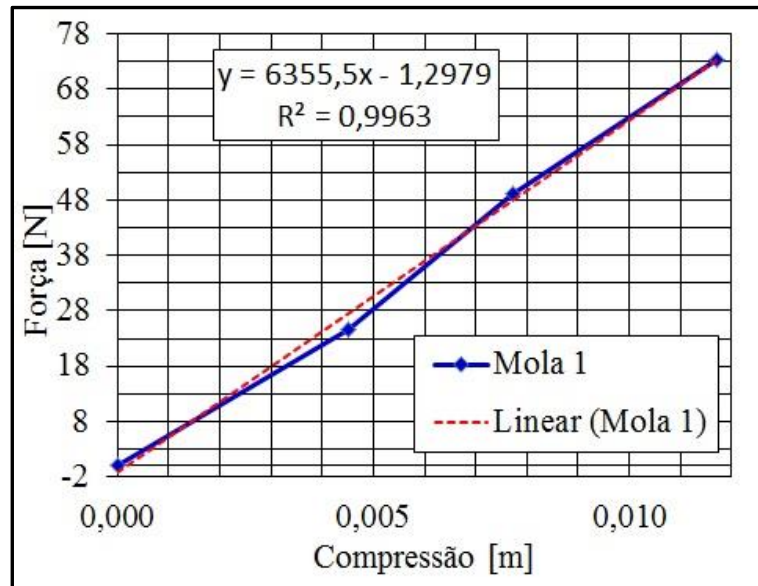

Figura 5.41 - Rigidez experimental mola 1

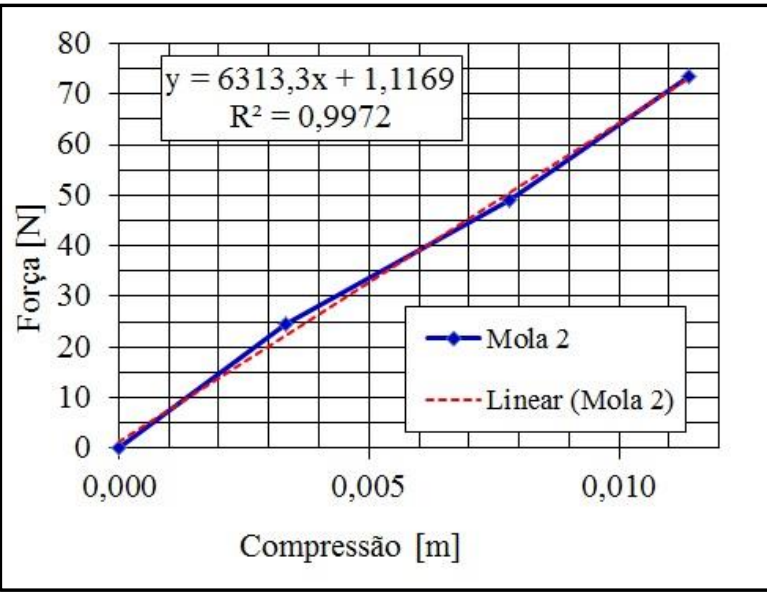

Figura 5.42 - Rigidez experimental mola 2

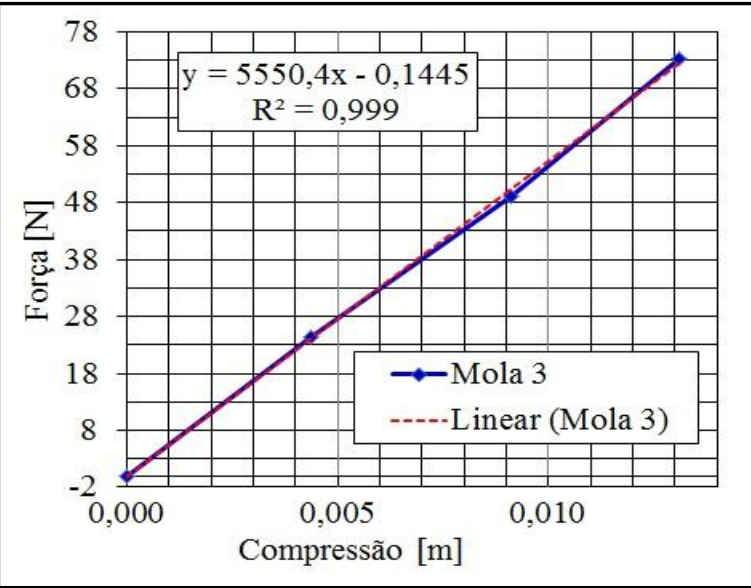

Figura 5.43 - Rigidez experimental mola 3

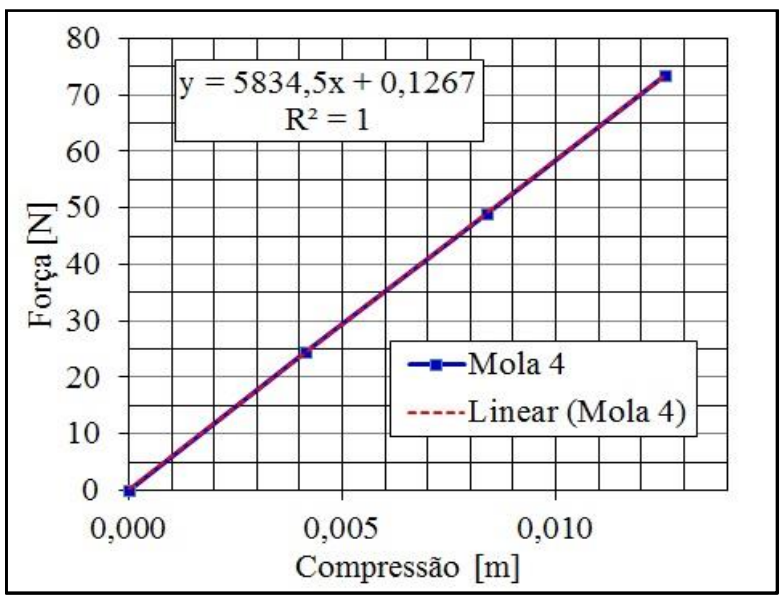

Figura 5.44 - Rigidez experimental mola 4

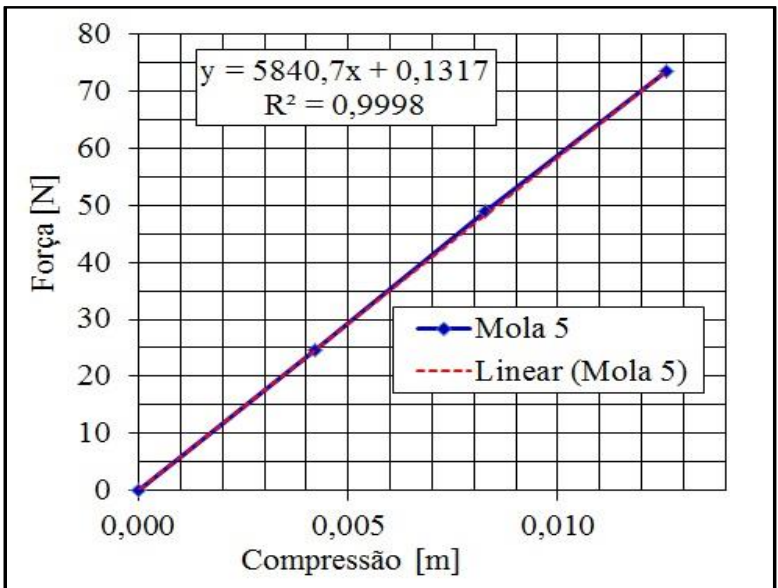

Figura 5.45 - Rigidez experimental mola 5

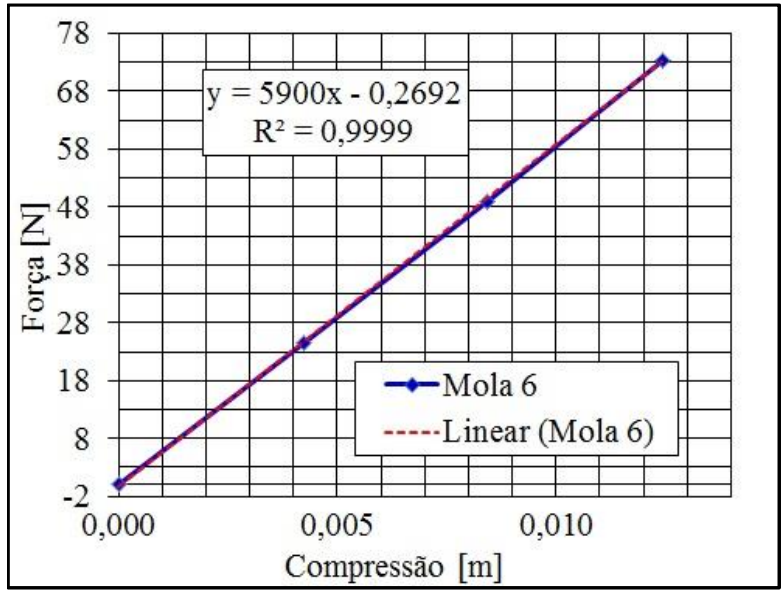

Figura 5.46 - Rigidez experimental mola 6 


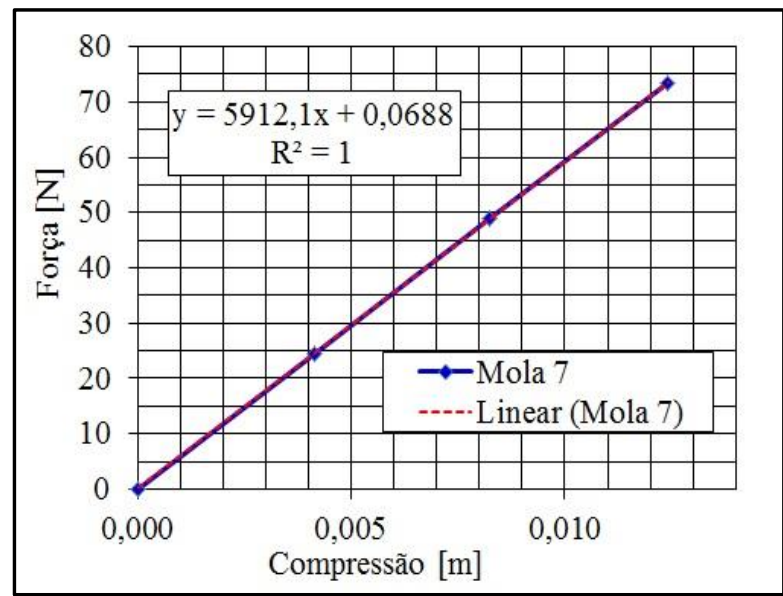

Figura 5.47 - Rigidez experimental mola 7

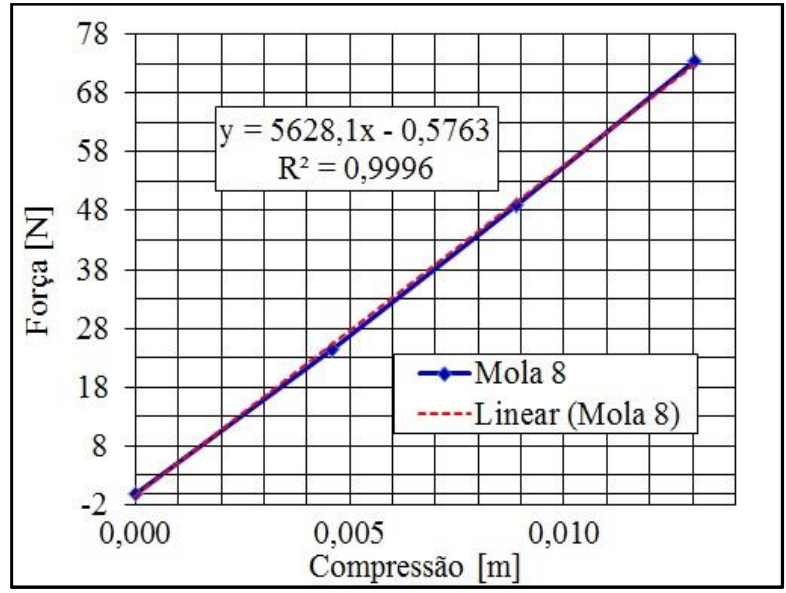

Figura 5.48 - Rigidez experimental mola 8

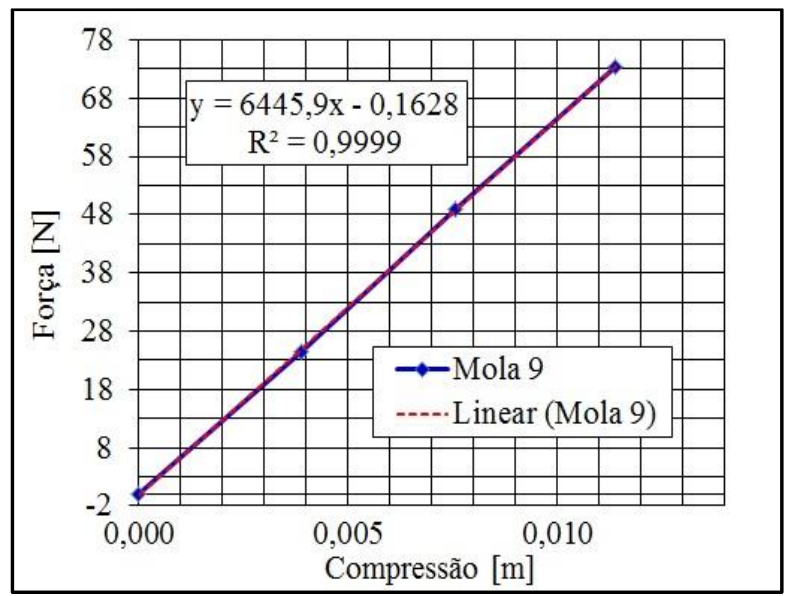

Figura 5.49 - Rigidez experimental mola 9

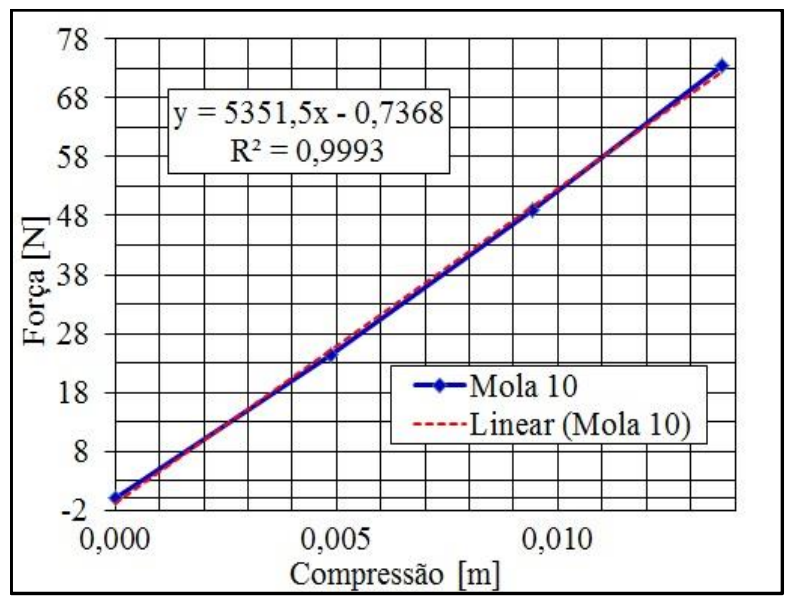

Figura 5.50 - Rigidez experimental mola 10

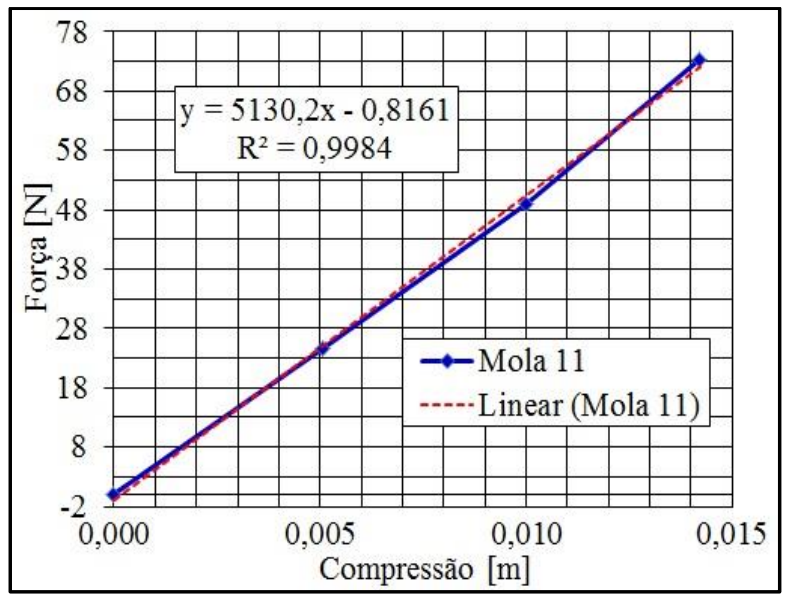

Figura 5.51 - Rigidez experimental mola 11

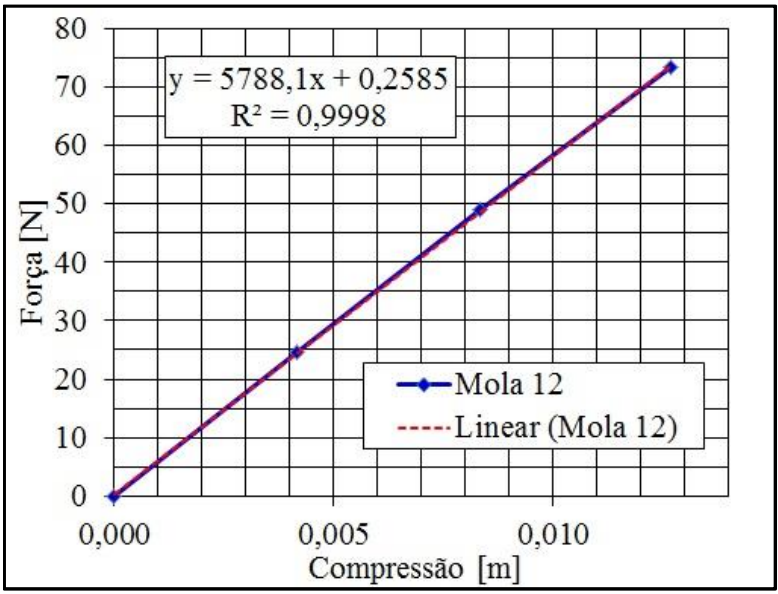

Figura 5.52 - Rigidez experimental mola 12 


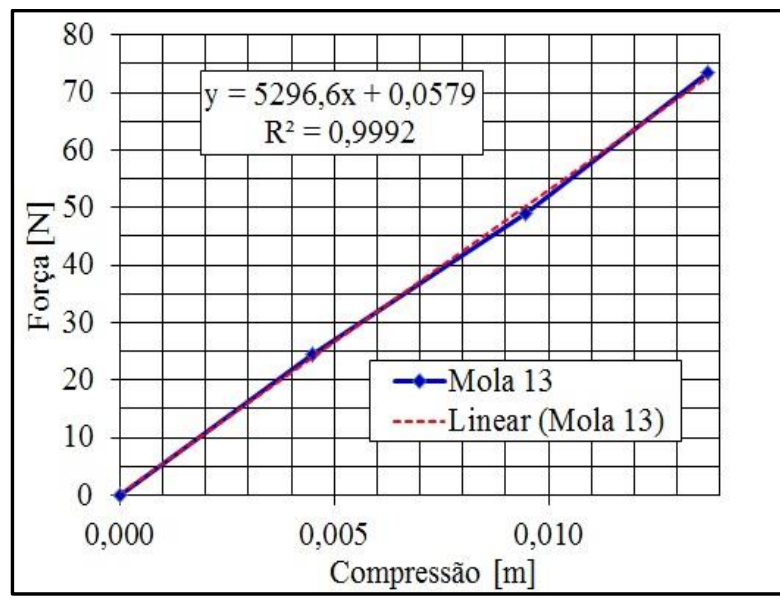

Figura 5.53 - Rigidez experimental mola 13

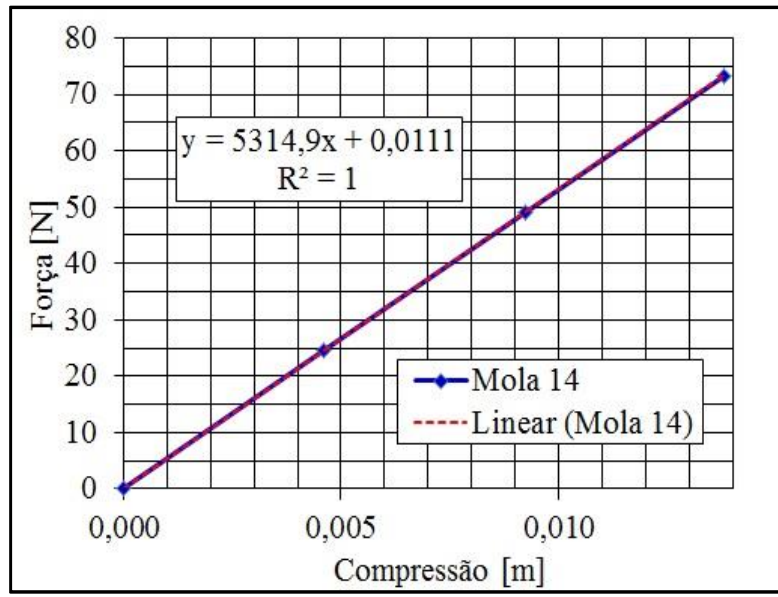

Figura 5.54 - Rigidez experimental mola 14

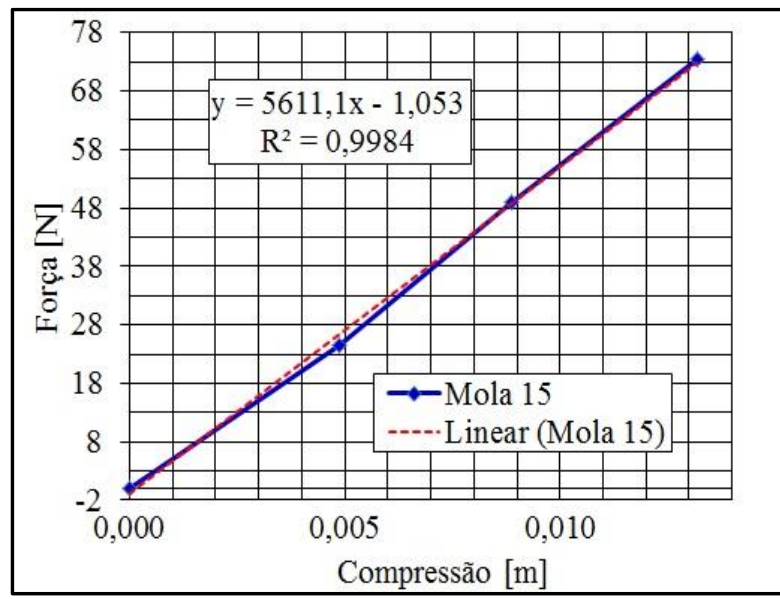

Figura 5.55 - Rigidez experimental mola 15

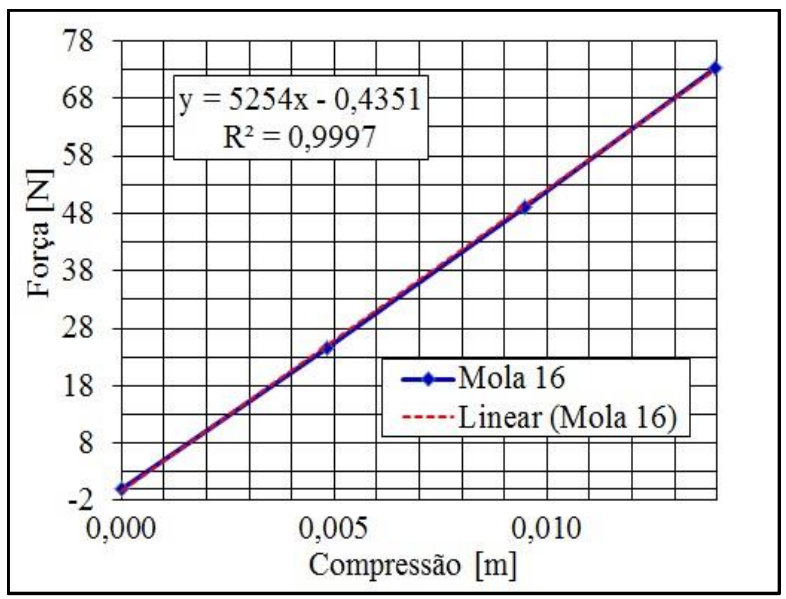

Figura 5.56 - Rigidez experimental mola 16

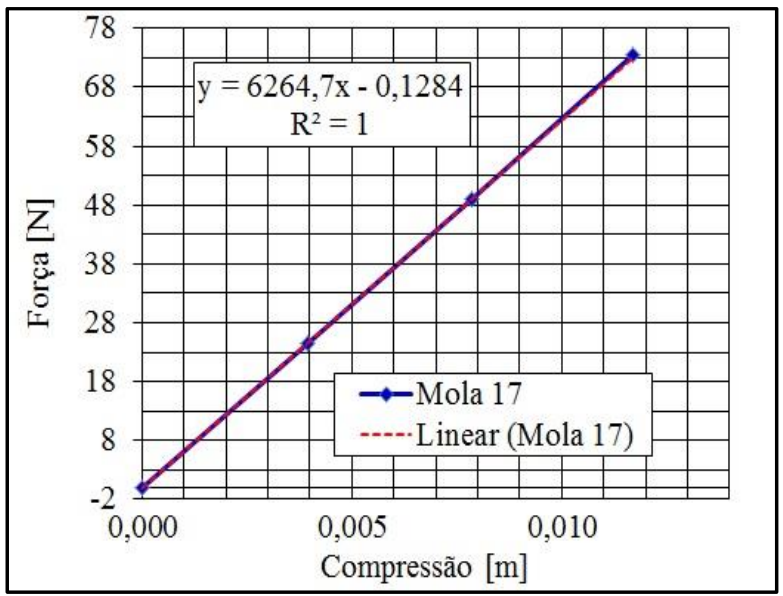

Figura 5.57 - Rigidez experimental mola 17

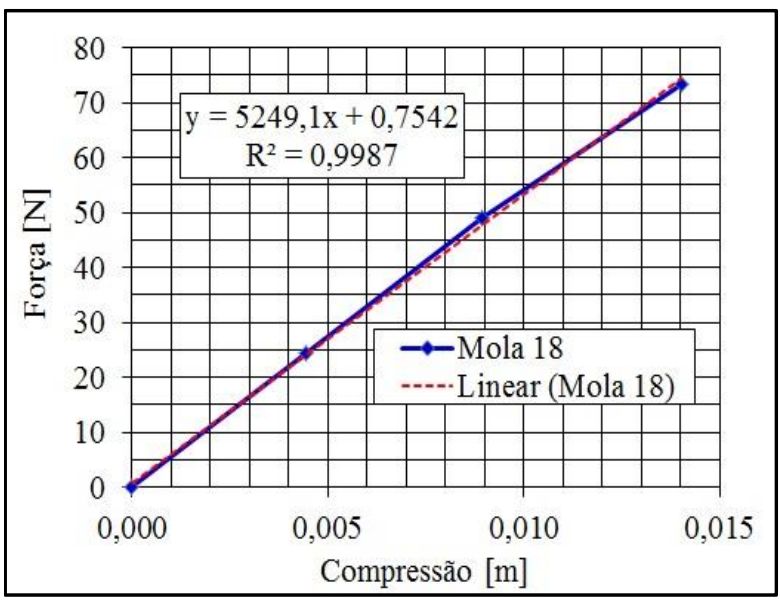

Figura 5.58 - Rigidez experimental mola 18 


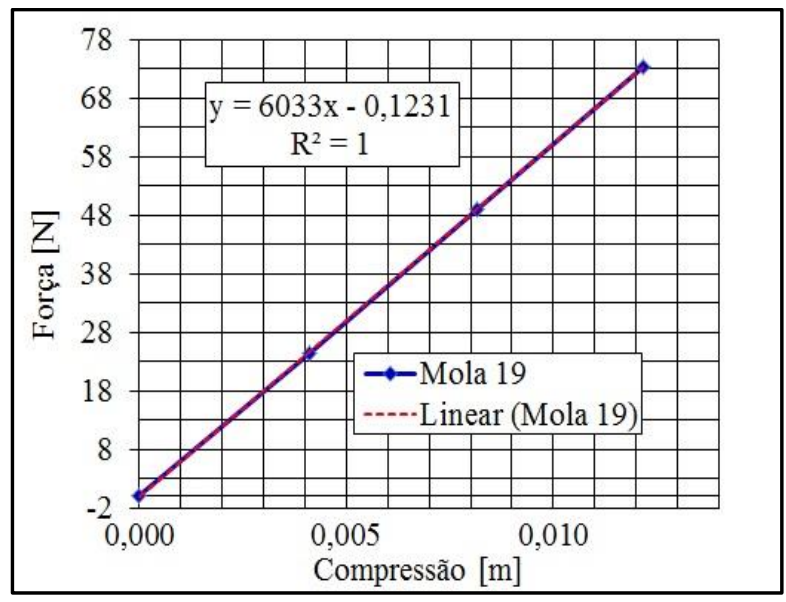

Figura 5.59 - Rigidez experimental mola 19

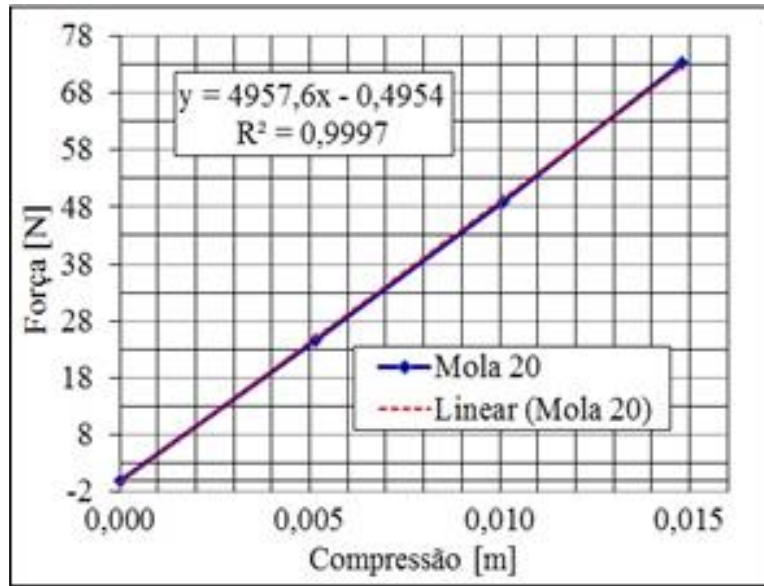

Figura 5.60 - Rigidez experimental mola 20

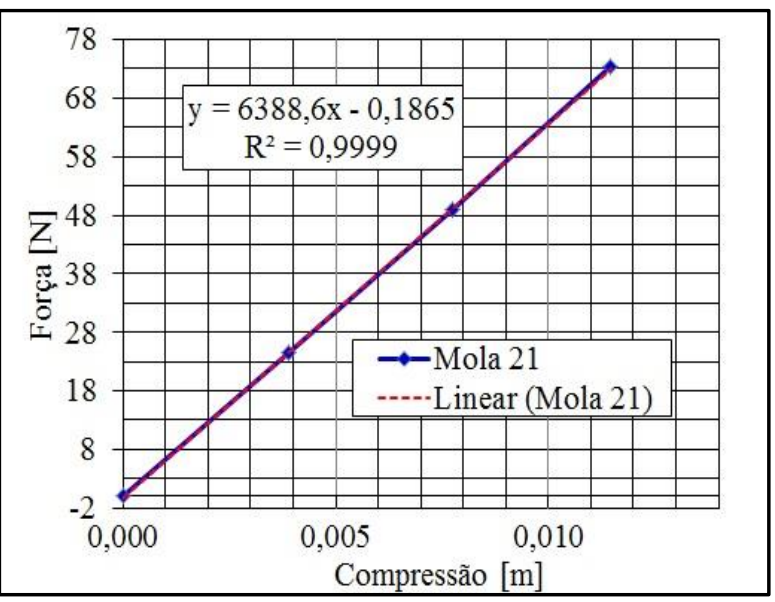

Figura 5.61 - Rigidez experimental mola 21

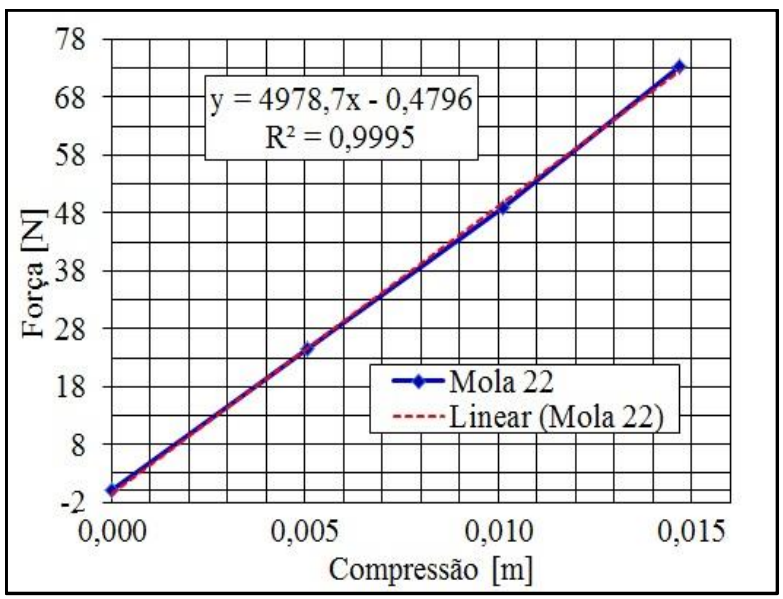

Figura 5.62 - Rigidez experimental mola 22

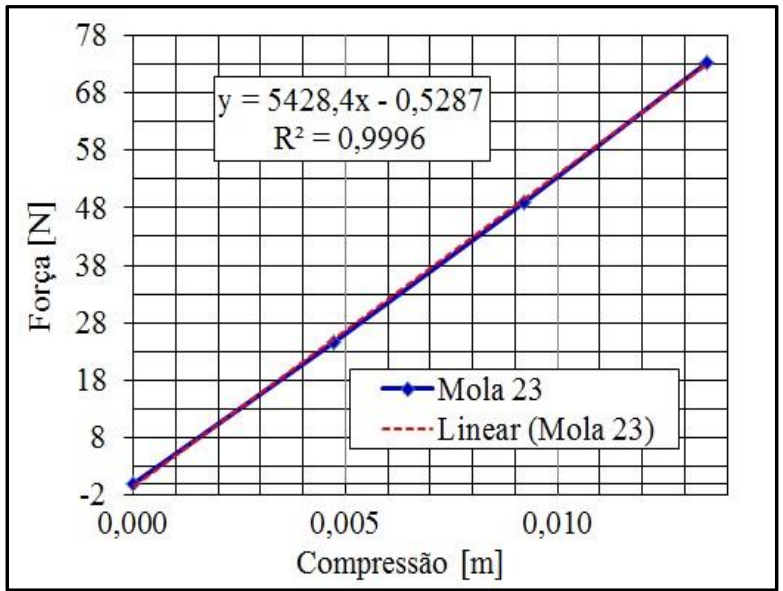

Figura 5.63 - Rigidez experimental mola 23

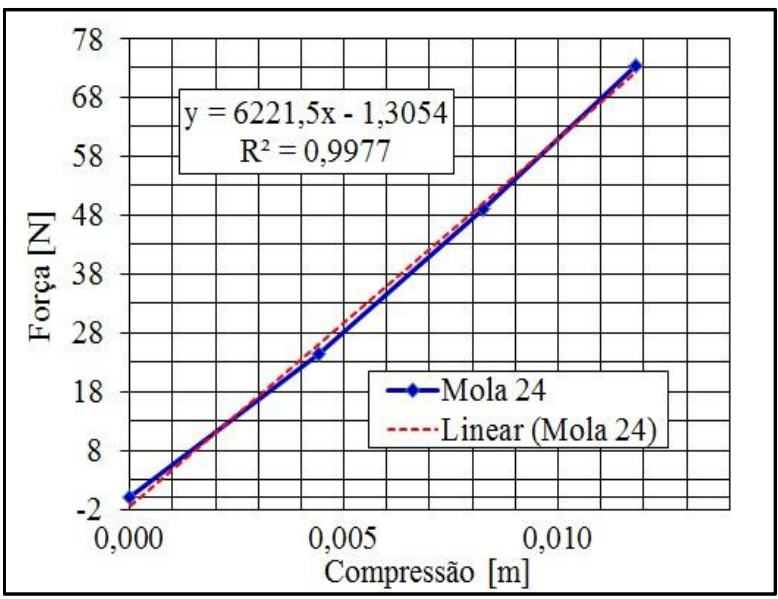

Figura 5.64 - Rigidez experimental mola 24 
As equações apresentadas nos gráficos das figuras anteriores foram obtidas ajustando a equação da linha reta pelo método dos mínimos quadrados, com as seguintes equações:

$$
\begin{aligned}
& a_{1}=\frac{n \sum x_{i} y_{i}-\sum x_{i} \sum y_{i}}{n \sum x_{i}^{2}-\left(\sum x_{i}\right)^{2}} \\
& a_{0}=\bar{y}-a_{1} \bar{x}
\end{aligned}
$$

Onde:

$\bar{y}$ e $\bar{x}$ são as medias de $y$ (peso) e $x$ (deformação), respectivamente.

O valor de $\mathrm{r}^{2}$ é a qualidade do ajuste. Quanto mais próximo estiver $\mathrm{r}^{2}$ da unidade melhor é o ajuste. Este coeficiente de determinação é uma medida da proporção da variação total dos dados em torno da média.

$$
r=\frac{n \sum x_{i} y_{i}-\left(\sum x_{i}\right)\left(\Sigma y_{i}\right)}{\sqrt{n \Sigma x_{i}^{2}-\left(\Sigma x_{i}\right)^{2}} \sqrt{n \Sigma y_{i}^{2}-\left(\Sigma y_{i}\right)^{2}}}
$$

Os cálculos dos valores de $a_{1}, a_{0}$ e $r^{2}$ se encontram nas tabelas do Anexo IV

$\mathrm{Na}$ Tabela 5.14 apresentam-se as molas que foram escolhidas para somar a rigidez total em paralelo dos dois módulos que são fabricados. As molas somam uma rigidez de 52511,3 N/m que é uma rigidez aproximada ao valor numérico do projeto de $51000 \mathrm{~N} / \mathrm{m}$, resultado que representa uma variação aproximada de 2,96\%. A rigidez das molas escolhidas para o projeto, testadas experimentalmente, apresentam valores um pouco diferentes dos valores de rigidez analítica encontrados na Tabela 5.12.

Tabela 5.14 - Molas instaladas colocadas no AMS.

\begin{tabular}{|c|c|c|c|c|c|}
\hline \multicolumn{3}{|c|}{ Módulo 1 } & \multicolumn{3}{c|}{ Módulo 2 } \\
\hline Mola N $^{\circ}$ & Altura [mm] & Rigidez [N/m] & Mola N & Altura [mm] & Rigidez [N/m] \\
\hline 3 & 67,0 & 5550,4 & 10 & 67,1 & 5351,5 \\
\hline 11 & 67,0 & 5130,2 & 13 & 67,4 & 5296,6 \\
\hline 16 & 67,0 & 5254,0 & 14 & 66,4 & 5314,9 \\
\hline 20 & 66,4 & 4957,6 & 18 & 67,3 & 5249,1 \\
\hline 22 & 66,4 & 4978,7 & 23 & 66,7 & 5428,4 \\
\hline \multicolumn{7}{|c|}{5} & 25870,8 & \multicolumn{3}{|c|}{$\Sigma$} & 26640,5 \\
\hline
\end{tabular}


As peças individuais necessárias para a construção do AMS são mostradas na Figura 5.65, e a numeração corresponde a:

1. Peça inferior que suporta as molas.

2. Peça base superior que suporta o peso do AMS.

3. Peça que junta as duas massas vibrantes.

4. Peça com a qual se obtêm a dissipação de energia juntamente com o eixo guia.

5. Porca guia dos parafusos verticais que sustentam o AMS.

6. Molas.

7. Eixo guia que permite a dissipação de energia por atrito em seco.

8. Eixo que suporta o AMS.

9. Chumbadores que juntam o AMS com laje.

10. Parafuso que junta as peças da massa vibrante do AMS.

11. Peça que conforma a peso da massa vibrante do AMS.

12. Parafuso para obter atrito.

13. Anéis que confinam as molas.

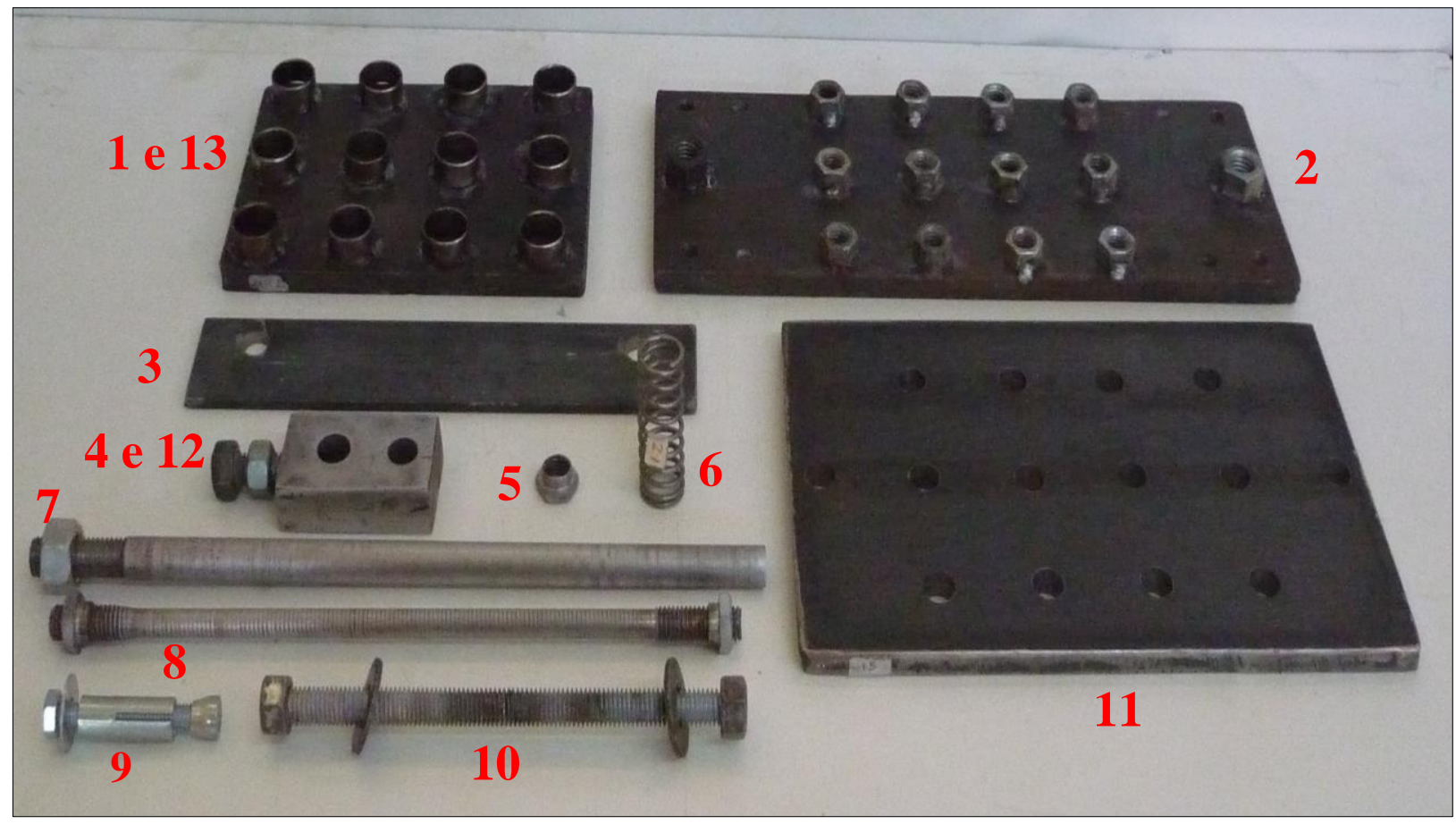

Figura 5.65 - Peças individuais que compõem o AMS. 
Fotografias do amortecedor construído na sua forma final são mostradas na Figura 5.66 e Figura 5.67. Após a construção finalizada do amortecedor, este foi pendurado embaixo da base da laje da plataforma de ensaios dinâmicos, e como já mencionado a localização do mesmo deve ser onde se apresenta o maior deslocamento da primeira forma modal, que é o ponto central da plataforma.

Uma tabela comparativa dos dados encontrados numérica e experimentalmente da massa e da rigidez do AMS são mostrados na Tabela 5.15.

Tabela 5.15 - Tabela comparativa de dados numéricos e experimentais da massa e rigidez.

\begin{tabular}{|c|c|c|c|}
\cline { 2 - 4 } \multicolumn{1}{c|}{} & Numérico & Experimental & Erro \\
\hline Massa $[\mathrm{M}]$ & $120 \mathrm{~kg}$ & $120,109 \mathrm{~kg}$ & $0,090 \%$ \\
\hline Rigidez $[\mathrm{k}]$ & $51000 \mathrm{~N} / \mathrm{m}$ & $52511,300 \mathrm{~N} / \mathrm{m}$ & $2,963 \%$ \\
\hline
\end{tabular}

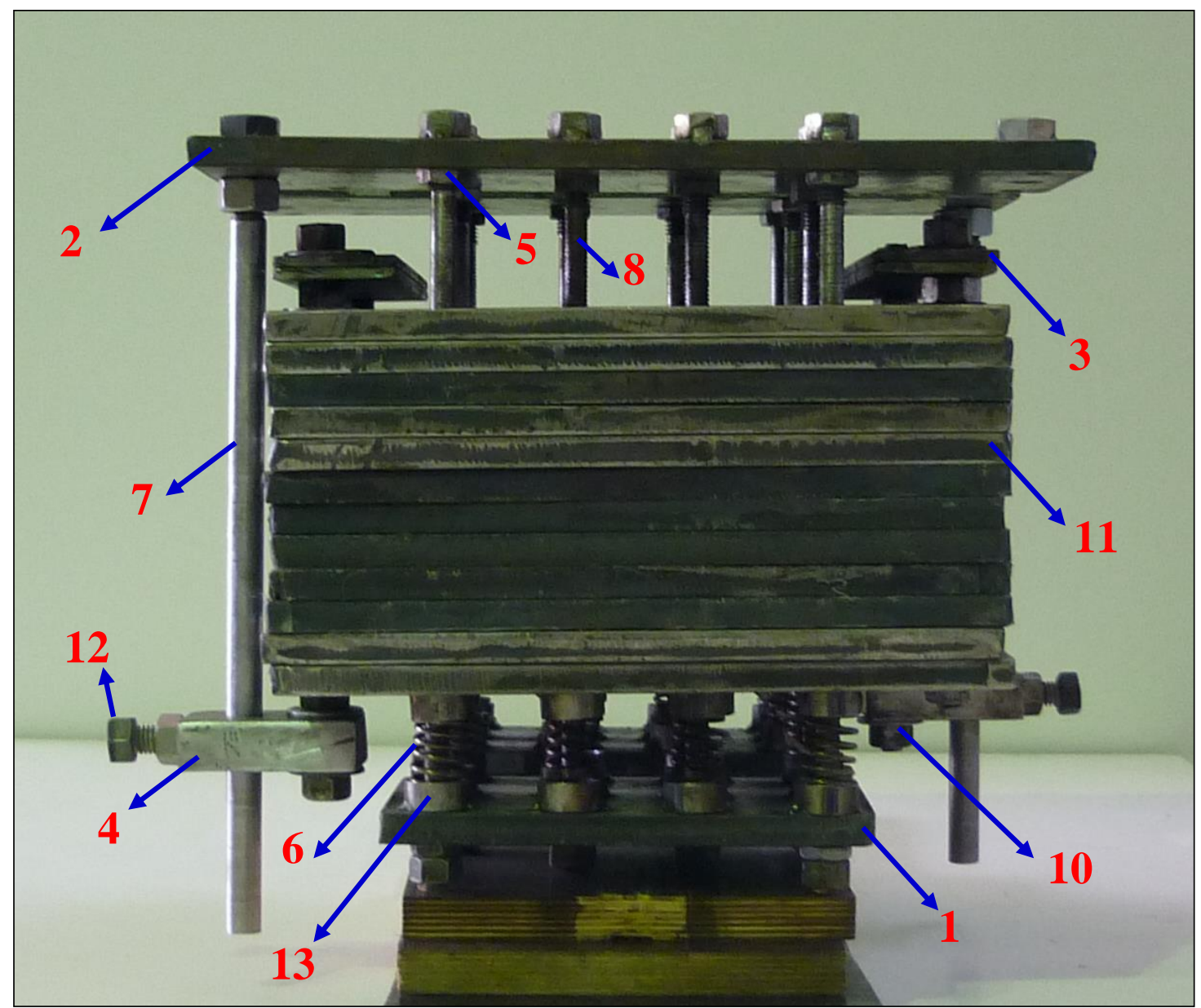

Figura 5.66 - Vista frontal AMS em sua forma final. 


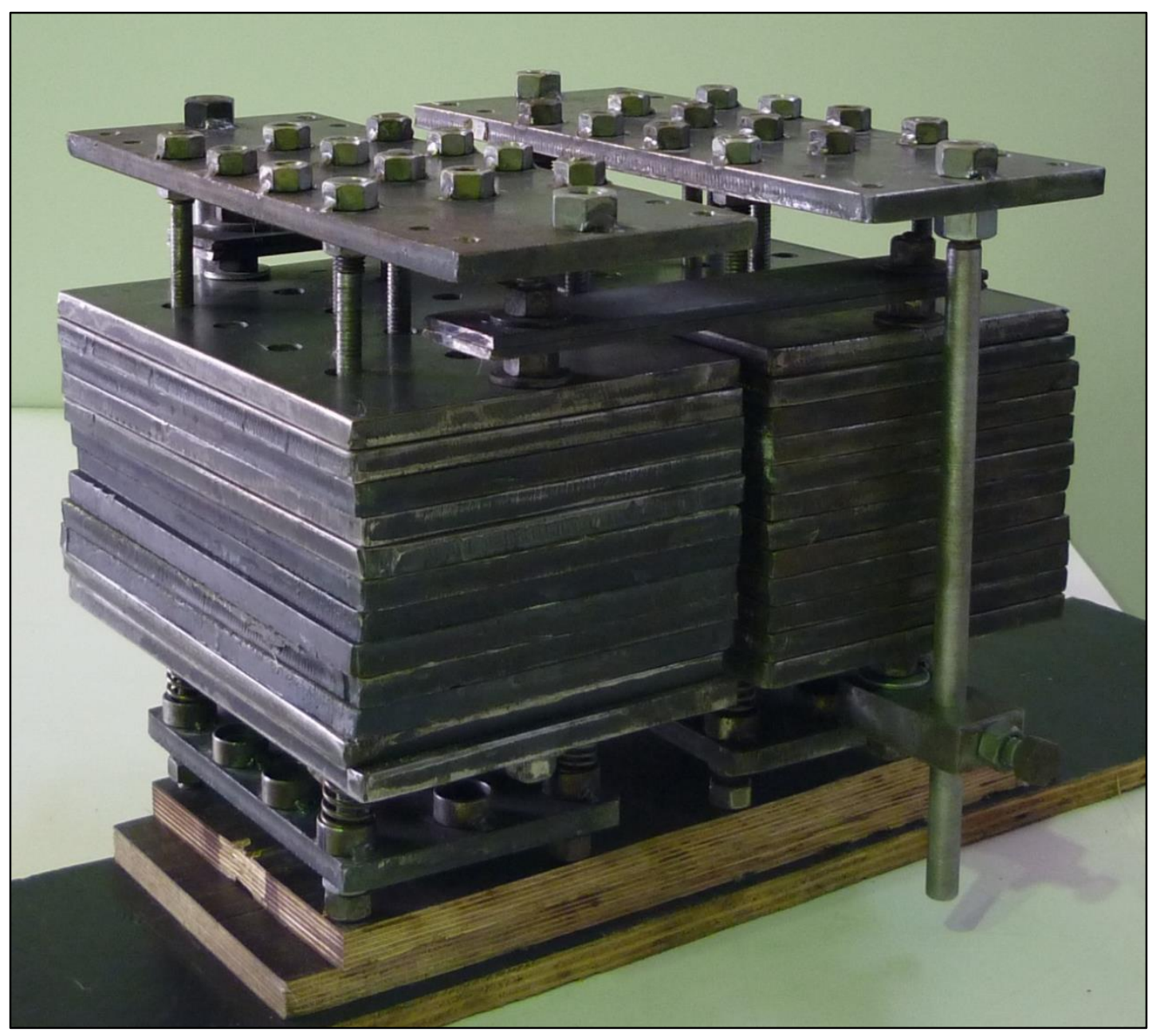

Figura 5.67 - AMS construído em sua forma final.

Na Figura 5.68 apresenta-se para maior clareza um desenho técnico do AMS com todas as peças do amortecedor na posição certa onde eventualmente podem ser feitas alterações na quantidade de parafusos, molas, chapas de aço.

O AMS foi concebido a partir de uma metodologia que permita alterações da massa, rigidez e amortecimento de modo a poder sintonizá-lo com facilidade em outras frequências. 


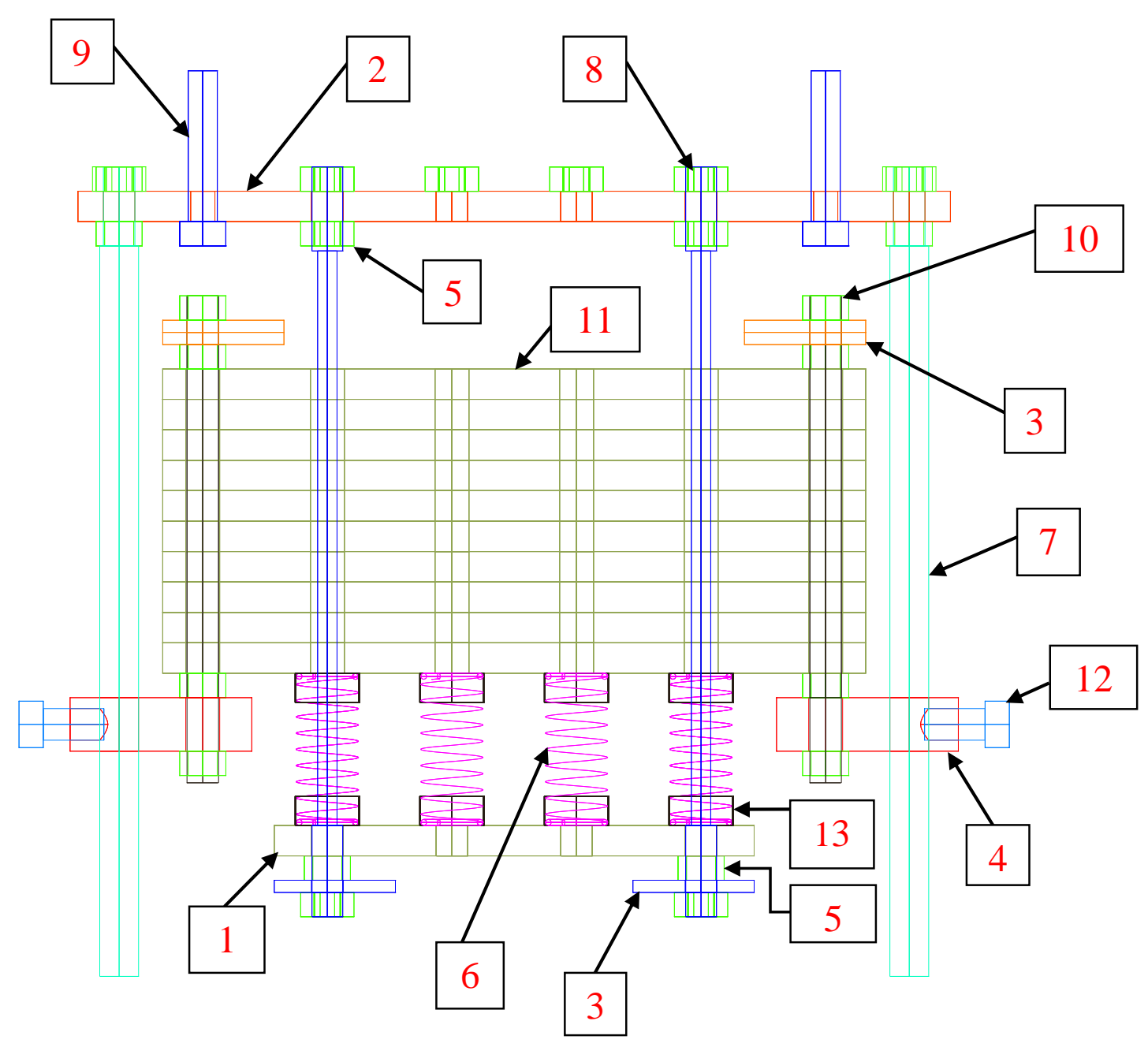

Figura 5.68 - Desenho técnico do amortecedor com todas suas partes.

\subsection{MONTAGEM DO AMS NA PLATAFORMA DE ENSAIOS DINAMICOS}

Concluída a construção e montagem do AMS com todas as suas peças, foi confeccionada uma chapa gabarito em madeira para facilitar a realização dos furos na plataforma onde foi pendurado o AMS.

Com esta placa gabarito almeja-se melhorar a precisão dos furos feitos na laje de concreto da plataforma, além de facilitar a instalação devido ao peso elevado do amortecedor, mais de 120 $\mathrm{kg}$, e o espaço reduzido sob a plataforma. 
O centro desta chapa gabarito em madeira está projetado para que coincida com centro de gravidade do AMS nos eixos X e Y. O furo central da chapa gabarito posteriormente coincidirá com o centro da laje em concreto, como consequência de um prévio estudo numérico no qual a massa, o amortecimento e rigidez do AMS foram concentrados no nó central da plataforma.

Para garantir uma correta posição dos furos na chapa gabarito de madeira, esta foi amarrada às chapas suporte do AMS com ajuda de dois sargentos, os quais fixavam a chapa de madeira. Foram feitos os furos após a correta localização com auxílio de uma furadeira.

Na Figura 5.69 apresenta-se a chapa gabarito em madeira com seus respectivos furos que coincidem com os furos das chapas suportes do AMS.

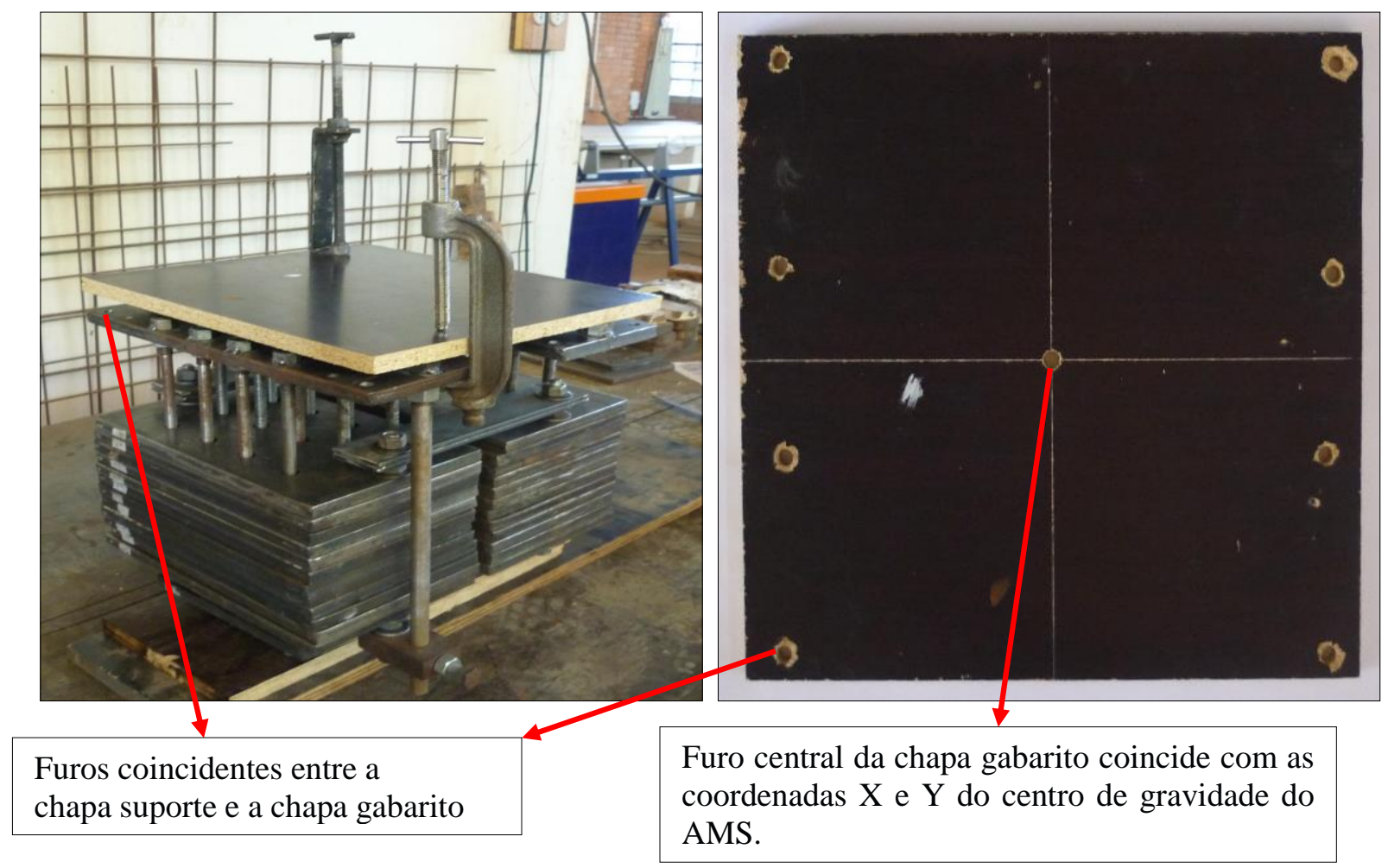

Figura 5.69 - Chapa gabarito de madeira utilizada na montagem do AMS.

Com a chapa gabarito pronta, o passo seguinte foi localizar o centro da plataforma com auxílio de uma trena. $\mathrm{O}$ centro da laje de concreto encontra-se localizado nas coordenadas $\mathrm{X}=3,05 \mathrm{~m}$ e $\mathrm{Y}=2,45 \mathrm{~m}$. Foi demarcado o centro da laje com giz com finalidade de fazer coincidir o centro da laje com o furo central da chapa gabarito. 
Utilizou-se um "Macaco hidráulico" para juntar temporalmente a chapa gabarito com a laje de concreto garantindo que a distância entre os furos fosse à correta.

A demarcação do centro da laje e a fixação da chapa de madeira com a laje de concreto se apresenta na Figura 5.70.
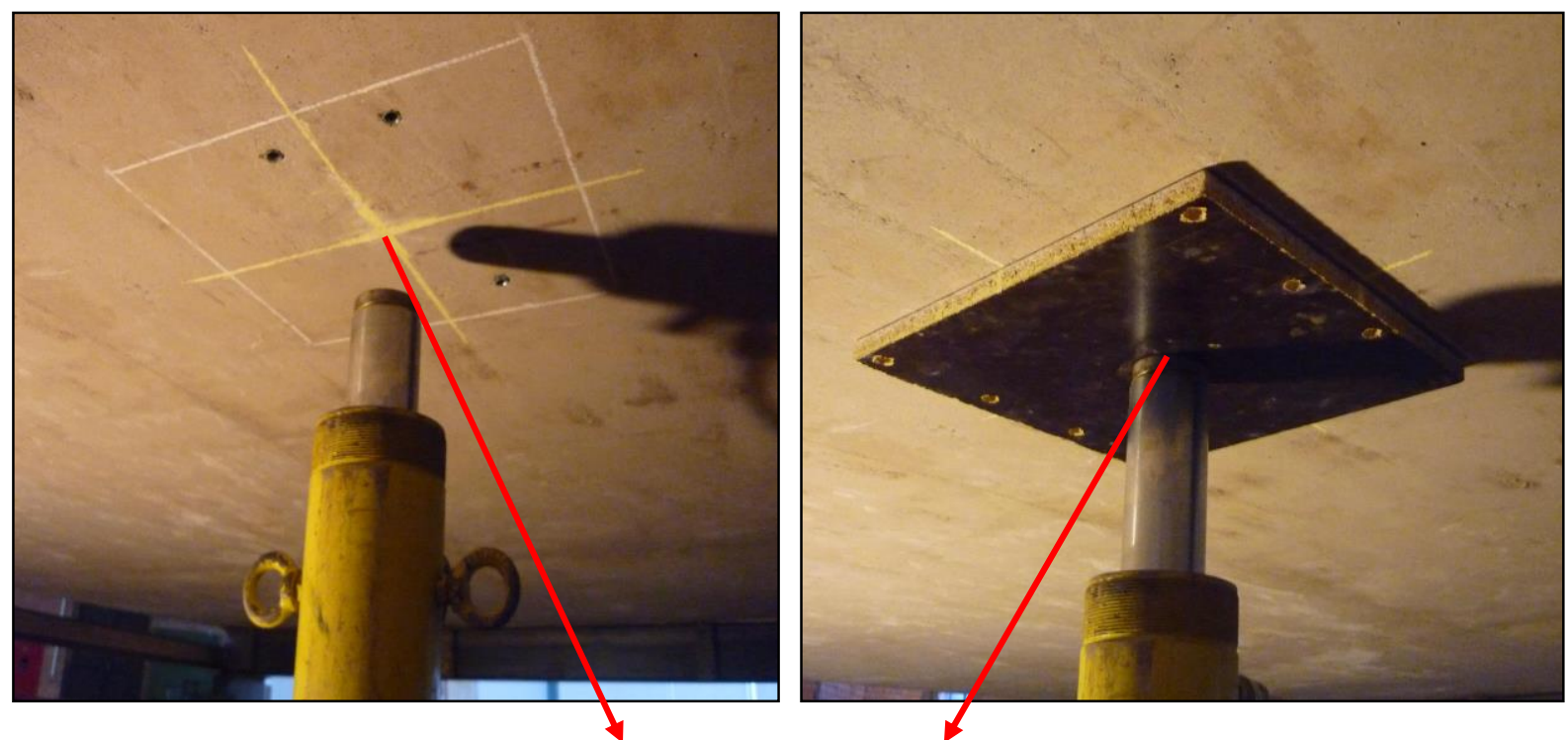

Centro da laje, furo central da chapa de madeira e coordenadas em x e y do centro de gravidade do AMS coincidem.

Figura 5.70 - Localização da chapa gabarito de madeira no centro da laje.

Após a colocação da chapa gabarito no centro da laje de concreto continuou-se fazendo os furos na laje através de uma furadeira. Estes furos têm como finalidade a posterior colocação dos chumbadores de aço os quais fixam todo o conjunto do AMS com a plataforma de ensaios dinâmicos. Na Figura 5.71 apresenta-se o processo de furação na laje de concreto para colocação dos oito chumbadores posicionados de forma que coincidam com 8 furos das chapas suporte do AMS. 

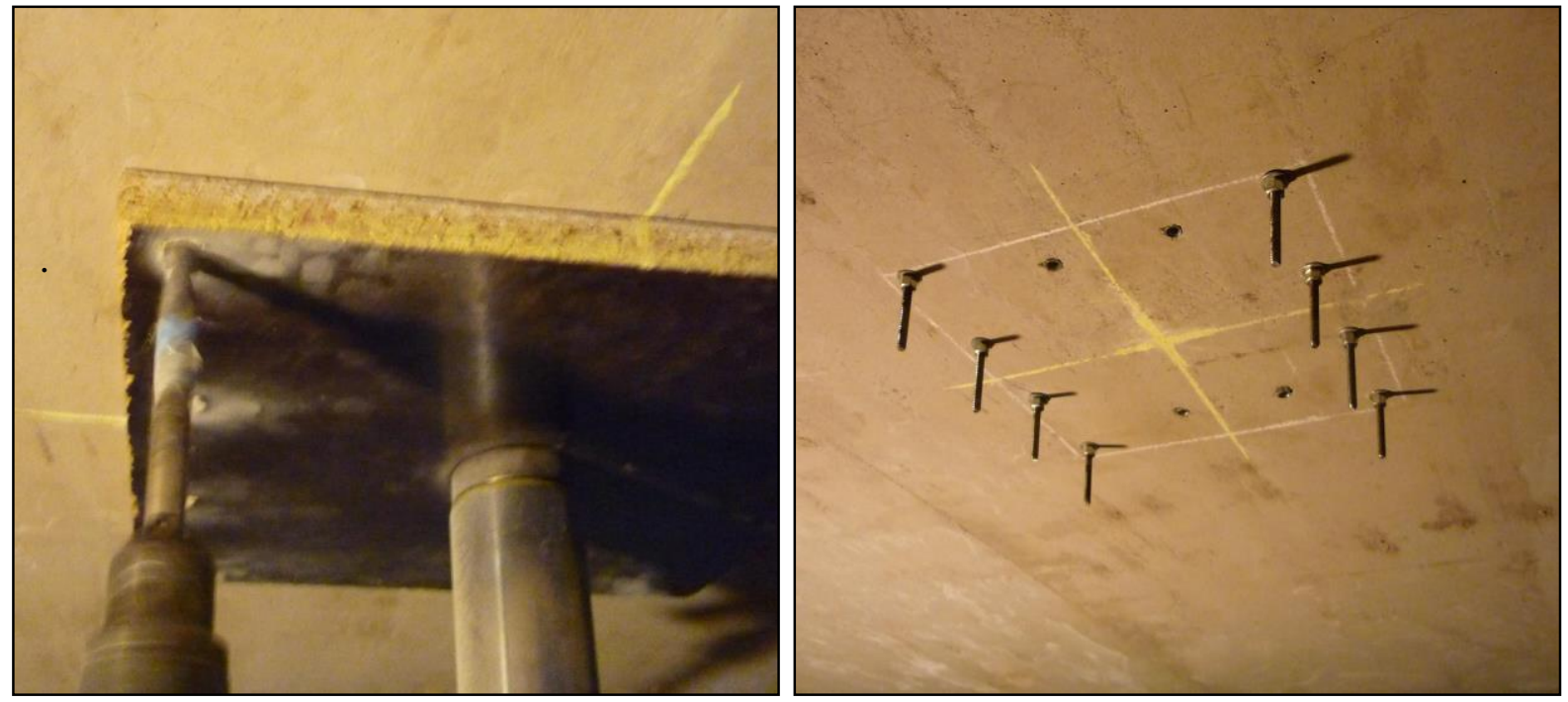

Figura 5.71 - Chumbadores de aço ancorados na laje de concreto.

Para o processo da montagem foi construído um suporte especial em madeira dotado de rodas. Este dispositivo foi construído com objetivo de facilitar o processo de montagem do AMS na plataforma de ensaios dinâmicos, já que os dois módulos dos amortecedores acoplados e demais peças chegam a pesar em torno de $140 \mathrm{~kg}$. Esta estrutura em madeira foi projeta para se acoplar a um cilindro hidráulico o qual se utiliza para levantar a estrutura de madeira junto com os dois módulos do AMS. Na Figura 5.72 apresenta-se o processo da montagem do AMS com ajuda da estrutura em madeira e o cilindro hidráulico.
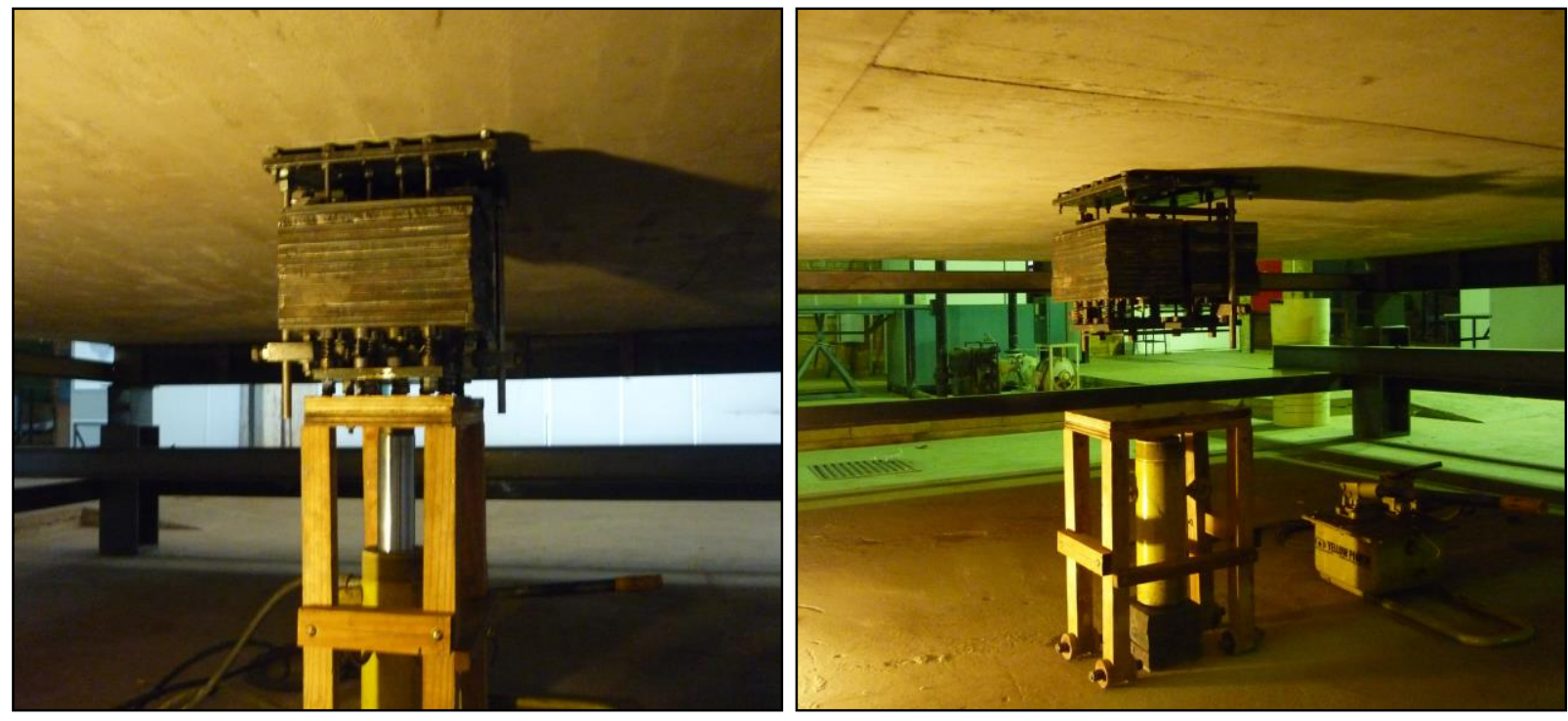

Figura 5.72 - Processo da montagem do AMS na base da laje da plataforma de ensaios dinâmicos. 
Conforme o dito anteriormente a colocação do amortecedor foi realizada no centro da plataforma, onde o centro de gravidade do AMS coincide com o centro geométrico da laje de concreto. A Figura 5.73 mostra a localização do AMS na laje de concreto.

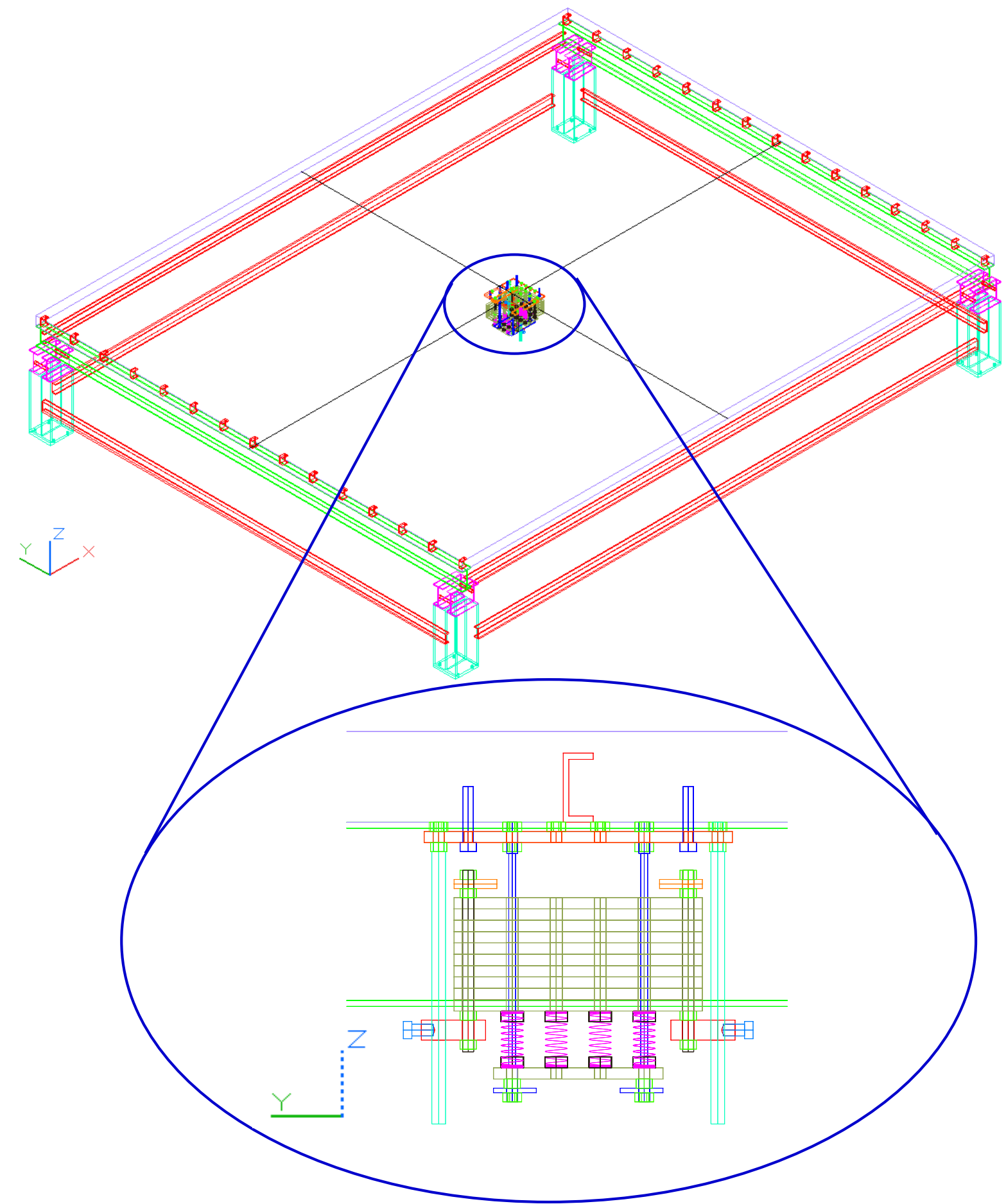

Figura 5.73 - Localização do AMS na laje de concreto da plataforma de ensaios dinâmicos. 
Dos estudos numéricos realizados da plataforma com um sistema de controle acoplado, foi projetado e construído um amortecedor de massa sintonizado para redução de vibrações verticais em pisos de concreto.

O AMS construído apresenta-se como um sistema de controle com características vantajosas como é sua forma fácil de construção e baixo custo de fabricação. 


\section{ANÁLISE EXPERIMENTAL}

Foram realizados ensaios de vibração livre e forçada na plataforma sem e com o AMS instalado. Nos primeiros ensaios basicamente determinaram-se as frequências naturais da estrutura além das formas modais associadas às primeiras frequências. Posteriormente, foram realizados testes em vibração forçada tinham como objetivo verificar o desempenho do AMS na redução de vibrações excessivas da plataforma. A programação e quantidade de ensaios experimentais são apresentados no Anexo V.

\subsection{ESTUDOS EXPERIMENTAIS EM VIBRAÇÃO FORÇADA}

\subsubsection{Ensaios experimentais de atividades ritmadas}

Com o AMS sintonizado próximo à frequência de ressonância $(\alpha)$ e acoplado na estrutura principal levaram-se a cabo testes com atividades ritmadas para observar o desempenho do amortecedor. Os ensaios se realizaram com uma pessoa caminhando e com grupos de 2, 3, 4 e 5 pessoas caminhando aleatoriamente durante 20 segundos. Foram realizados também ensaios com uma pessoa pulando continuamente no centro da laje durante 10 segundos e com grupos de pessoas de 3 e 5 indivíduos, distribuídos em toda a superfície da laje. Ensaios sincronizados com uma pessoa com os joelhos semidobrados tentando simular uma força harmônica também foram feitos. Foi simulada ainda uma força de impacto mediante uma pessoa pulando de uma carteira escolar sobre a laje e deixando-a vibrar posteriormente. Vale ressaltar que todos os ensaios foram realizados da mesma maneira, buscando boa repetitividade nos testes com e sem AMS. Desta maneira foram comparados os registros das acelerações dos diferentes ensaios para verificar o desempenho do AMS.

\subsubsection{Simulando força harmônica com os joelhos semidobrados na borda da laje}

Foram realizados ensaios de vibração forçada com e sem AMS, simulando uma força harmônica na borda livre da laje. Os ensaios consistiram em excitar a laje mediante o movimento de uma pessoa em pé com os joelhos semidobrados, balançando-se verticalmente segundo o ritmo das vibrações da laje durante aproximadamente 10 segundos, terminado este tempo se retirava a força excitadora e se deixava vibrar a laje durante 10 segundos mais. Um esboço dos ensaios em vibração forçada se apresenta na Figura 6.1. 
Na Figura 6.2 apresenta-se um histórico das acelerações quando a laje é excitada por meio de uma pessoa realizando uma força harmônica com os joelhos semidobrados na borda da laje durante 10 segundos, considerando a laje sem amortecedor (linha vermelha) e com amortecedor (linha azul). Na Figura 6.3 apresenta-se a resposta no domínio da frequência em vibração forçada durante os 10 primeiros segundos que atua a forca externa, já na Figura 6.4se apresenta a resposta no domínio da frequência em vibração livre que corresponde ao intervalo do tempo entre 10 e 20 segundos.

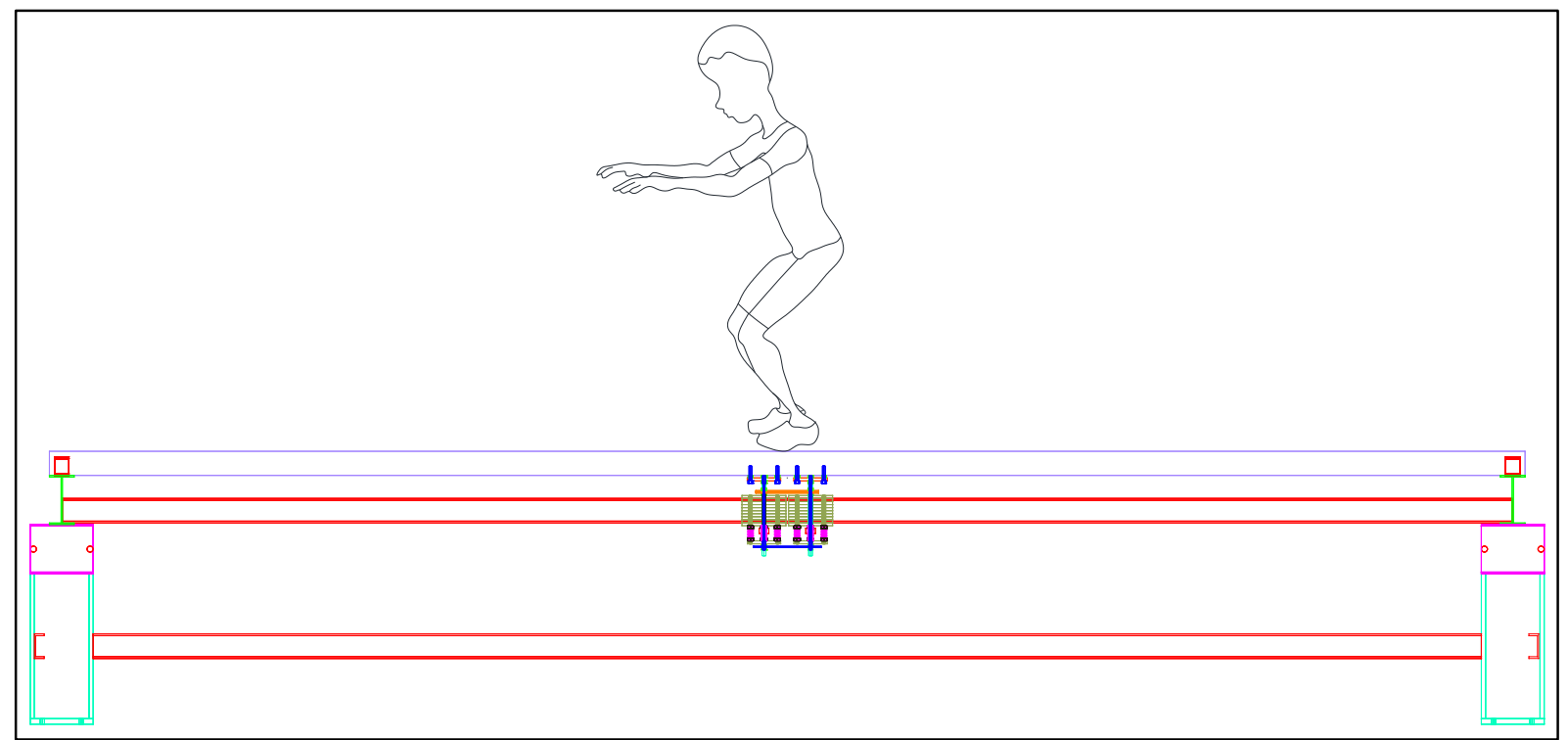

Figura 6.1 - Esboço dos ensaios em vibração forçada simulando força harmônica. 


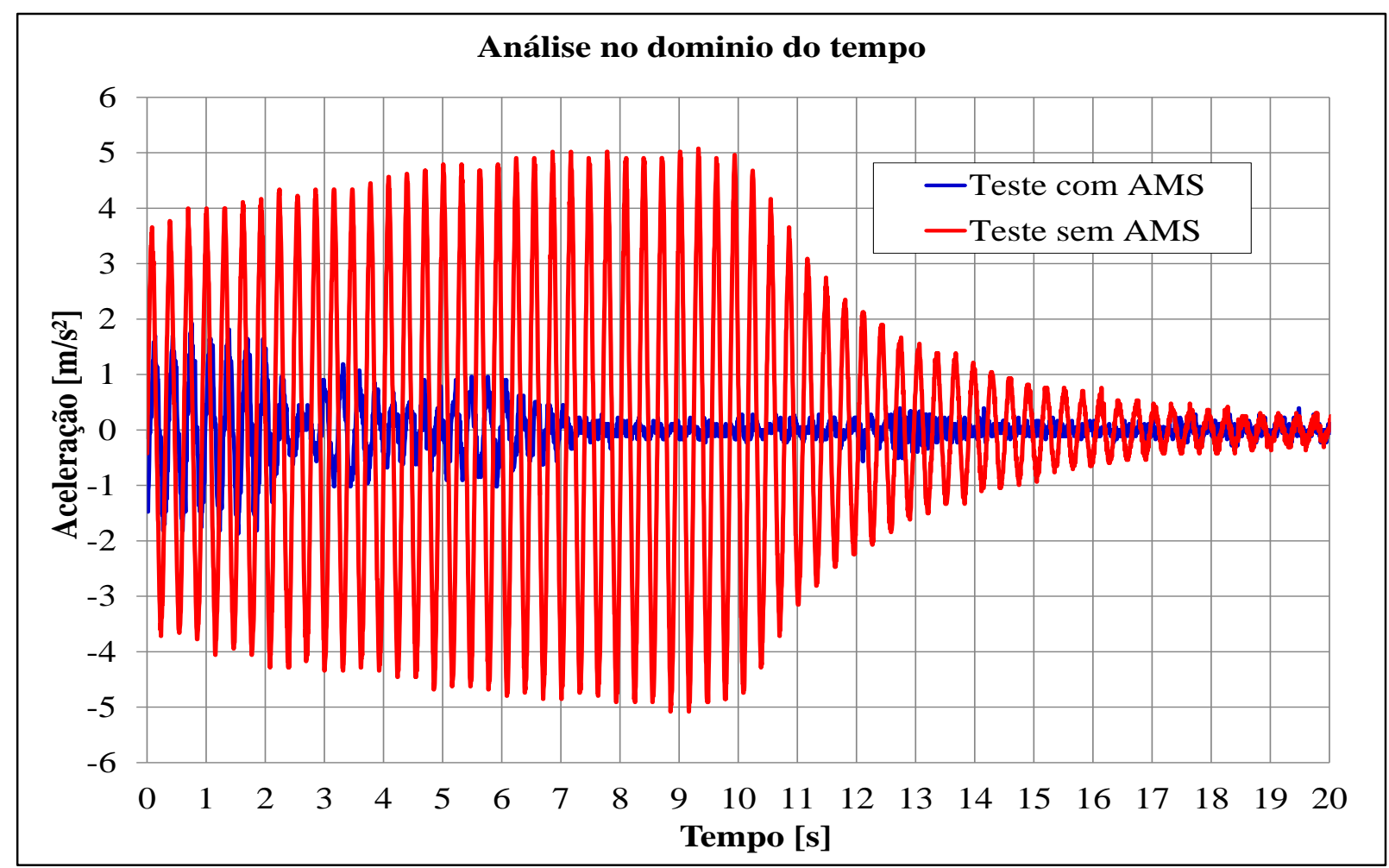

Figura 6.2 - Análise no domínio do tempo com e sem AMS. Teste de joelho semidobrados, simulando força harmônica.

Na Figura 6.2, como foi explicado, a força excitadora tem uma duração aproximada de 10 segundos. Na curva que corresponde ao ensaio sem AMS; se observam registros de até $5 \mathrm{~m} / \mathrm{s}^{2}$, que diminuem ao se retirar a força excitadora. A laje demora mais de 10 segundos para voltar à posição de equilíbrio, em repouso. Os registros dos ensaios com a instalação do AMS indicam, que as amplitudes das acelerações registradas são reduzidas em torno de $80 \%$.

Pode se dizer que para este tipo de excitação o AMS controla muito bem as vibrações na estrutura. A forma da resposta controlada (linha azul) é similar àquela obtida numericamente vide Figura 5.2. Nas duas figuras observa-se que quando o AMS começa a agir, percebe-se uma redução das amplitudes das acelerações até o ponto delas praticamente se anularem, logo depois ocorre uma amplificação na amplitude da resposta por um pequeno intervalo de tempo, passados uns poucos segundos inicia-se novamente a redução nas amplitudes das acelerações. Também pode-se observar que depois de cessar a força excitadora o AMS reduz a magnitude das acelerações a aproximadamente zero em menos de dois segundos. Isto mostra a boa performance 
do AMS, visto que a estrutura sem controle leva bem mais tempo para estabilizar-se, por volta de 10 segundos.

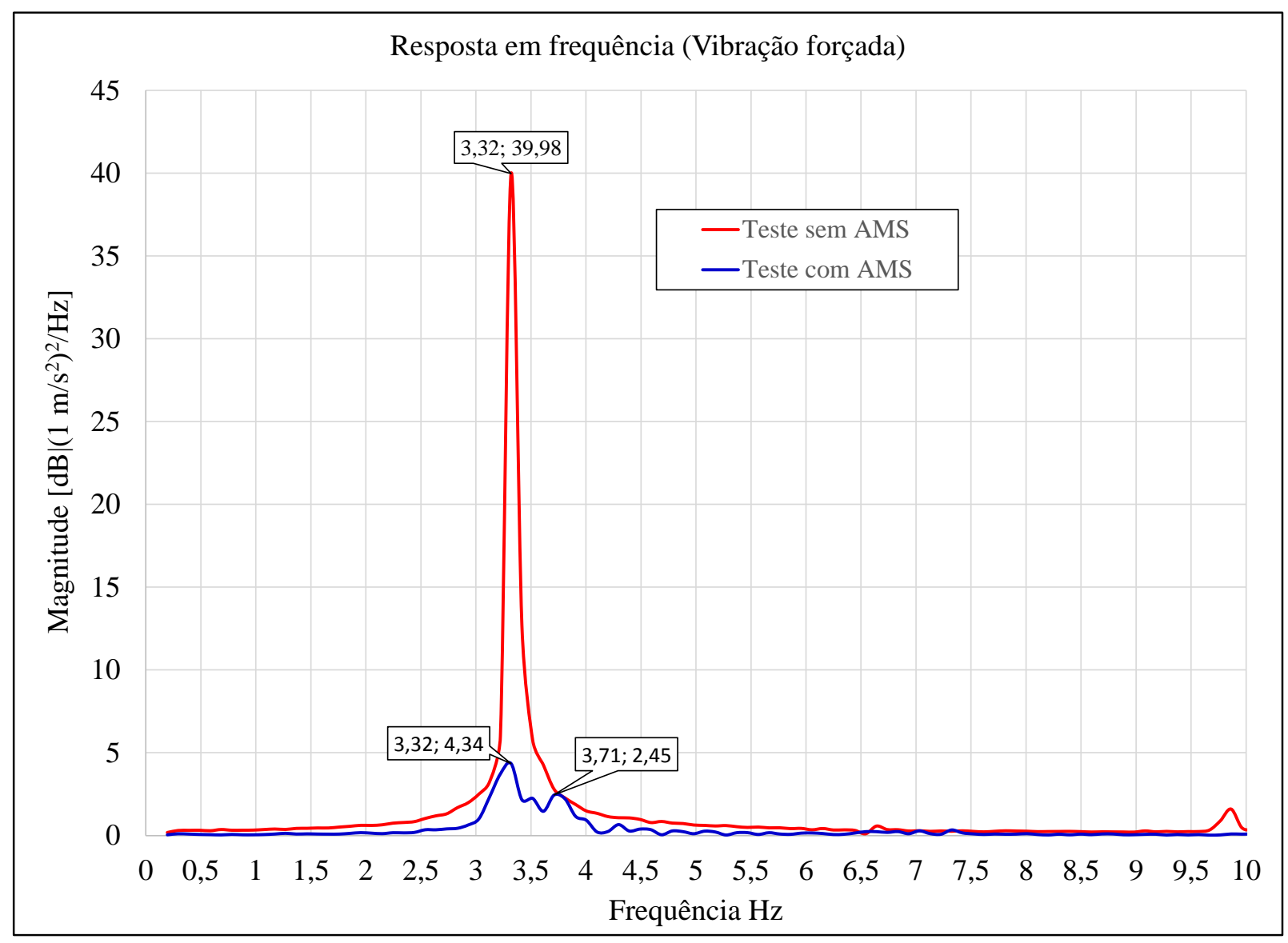

Figura 6.3 - Análise no domínio da frequência com e sem AMS. Teste de joelho semidobrado, simulando força harmônica. Vibração forçada 0-10 segundos.

Da Figura 6.3 pode-se dizer que tanto a linha em vermelho (sem AMS) como a linha em azul (com AMS) apresentam formatos semelhantes às curvas encontradas numericamente vide Figura 5.2. Com o sistema de controle a curva apresenta dois novos picos, modificando as frequências naturais da estrutura. Observa-se ainda que nos ensaios experimentais o AMS teve desempenho bastante satisfatório com uma forte redução nas magnitudes dos picos (em torno de $89 \%$ ) que passam de magnitude de resposta de 39,98 dB sem AMS para 4,34 dB com AMS. Esta redução de picos mostra a eficiência do AMS. 


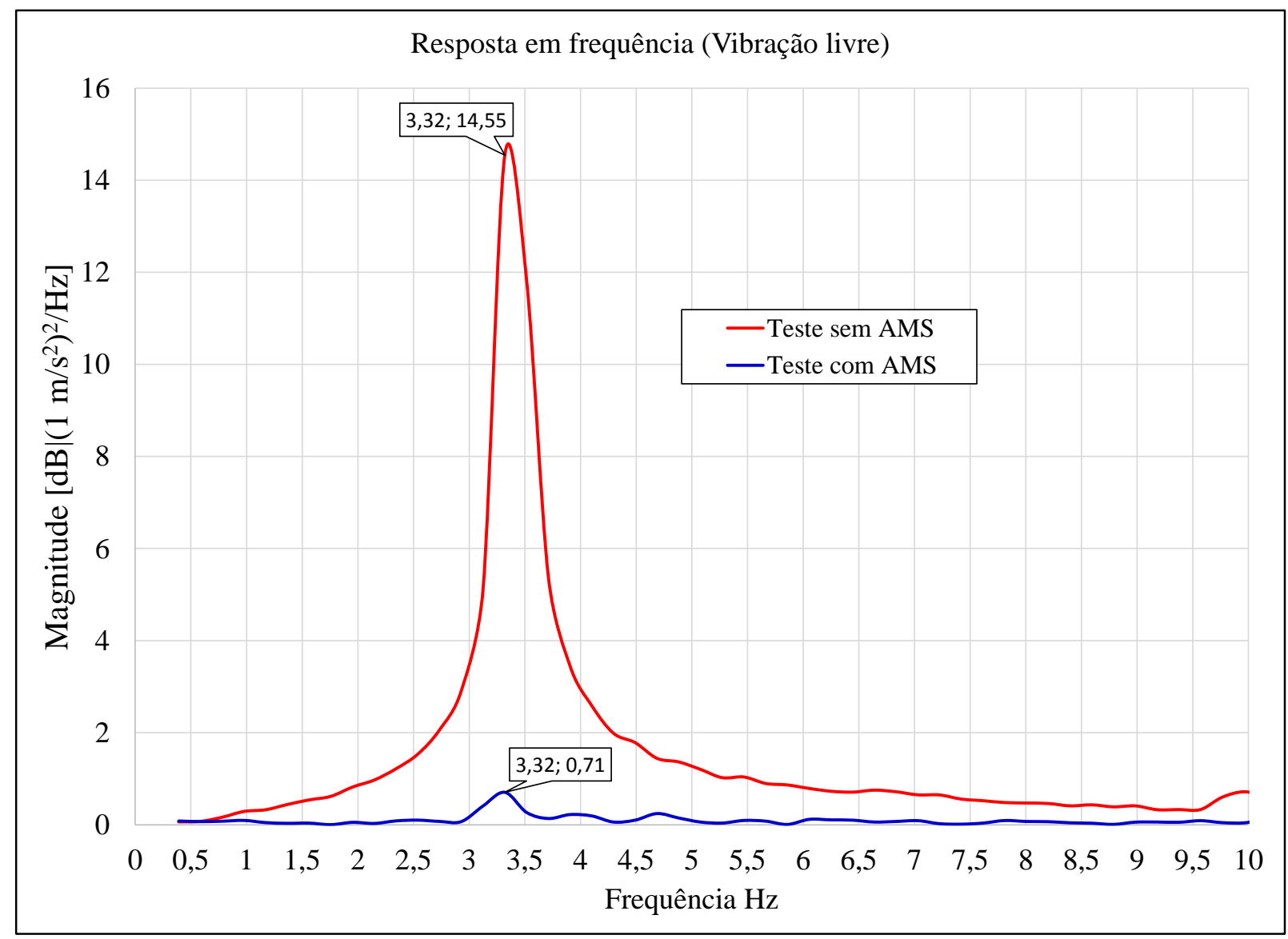

Figura 6.4 - Análise no domínio da frequência com e sem AMS. Teste de joelho semidobrado, simulando força harmônica. Vibração livre 10-20 segundos.

Na Figura 6.4 também se observa uma forte redução dos picos para o primeiro harmônico. A redução é de aproximadamente 95\%, o que significa uma boa calibração dos parâmetros do amortecedor.

No Anexo VII apresentam-se as outras figuras correspondentes aos demais ensaios em vibração forçada simulando força harmônica.

\subsubsection{Pulo continuo de uma pessoa no centro da laje e pulo de vários indivíduos espalhados em toda a superfície da laje}

Para a bateria de ensaios seguintes a laje é excitada da seguinte forma: inicialmente uma pessoa se mantém pulando de forma continua no centro da laje durante 10 segundos. Foi escolhida essa região para excitar a laje já que nesse ponto ocorrem os maiores deslocamentos associados ao primeiro modo, e assim desta maneira visa-se obter o melhor desempenho do AMS. 
Na Figura 6.5 apresenta-se a evolução no tempo da aceleração correspondente ao ensaio de pulo continuo de uma pessoa, verifica-se que as acelerações no caso com AMS em linha azul são mais uniformes devido à atuação do AMS. Comparando a Figura 6.2 com a Figura 6.5 pode dizer que o AMS tem melhor desempenho para carregamentos mais próximos de uma excitação harmônica que para excitações de força não uniformes repetitivas como são os impactos de pulos contínuos, ainda assim no ensaio em questão obtiveram-se reduções da resposta dinâmica consideráveis.

Tanto para o caso anterior (Figura 6.2), como para este caso (Figura 6.5) pode-se observar que após a retirada a força de excitação o AMS reduz completamente as acelerações em um intervalo de 2 segundos. No caso da estrutura sem amortecedor leva-se até um pouco mais de 9 segundos para a estrutura principal deixar de vibrar que é um tempo mais longo comparado com o tempo que demora o AMS em reduzir consideravelmente as amplitudes.

No estudo da análise no domínio do tempo podem ser verificadas reduções das acelerações na ordem de $70 \%$ perdendo um pouco de eficiência com relação ao caso anterior, mas ainda assim apresentando excelente desempenho.

A resposta no domínio da frequência considerando-se os 10 primeiros segundos sem controle e com AMS são mostradas na Figura 6.6, pode-se observar uma queda na amplitude de vibração do pico mais representativo de até 3,03 vezes o qual representa uma redução de 67,6\%. O primeiro pico em $1,86 \mathrm{~Hz}$ apresenta-se pela força induzida da pessoa que realiza o ensaio de vibração forçada.

Já na Figura 6.7 apresenta-se a resposta no domínio da frequência para a resposta em vibração livre (10-20 segundos), após cessar a força de excitação. Nesta figura observa-se uma redução na amplitude de vibração de aproximadamente de $94,4 \%$, maior do que para vibração forçada. Como conclusão pode dizer que o sistema de controle reduz muito bem as vibrações, neste caso de carregamento. 


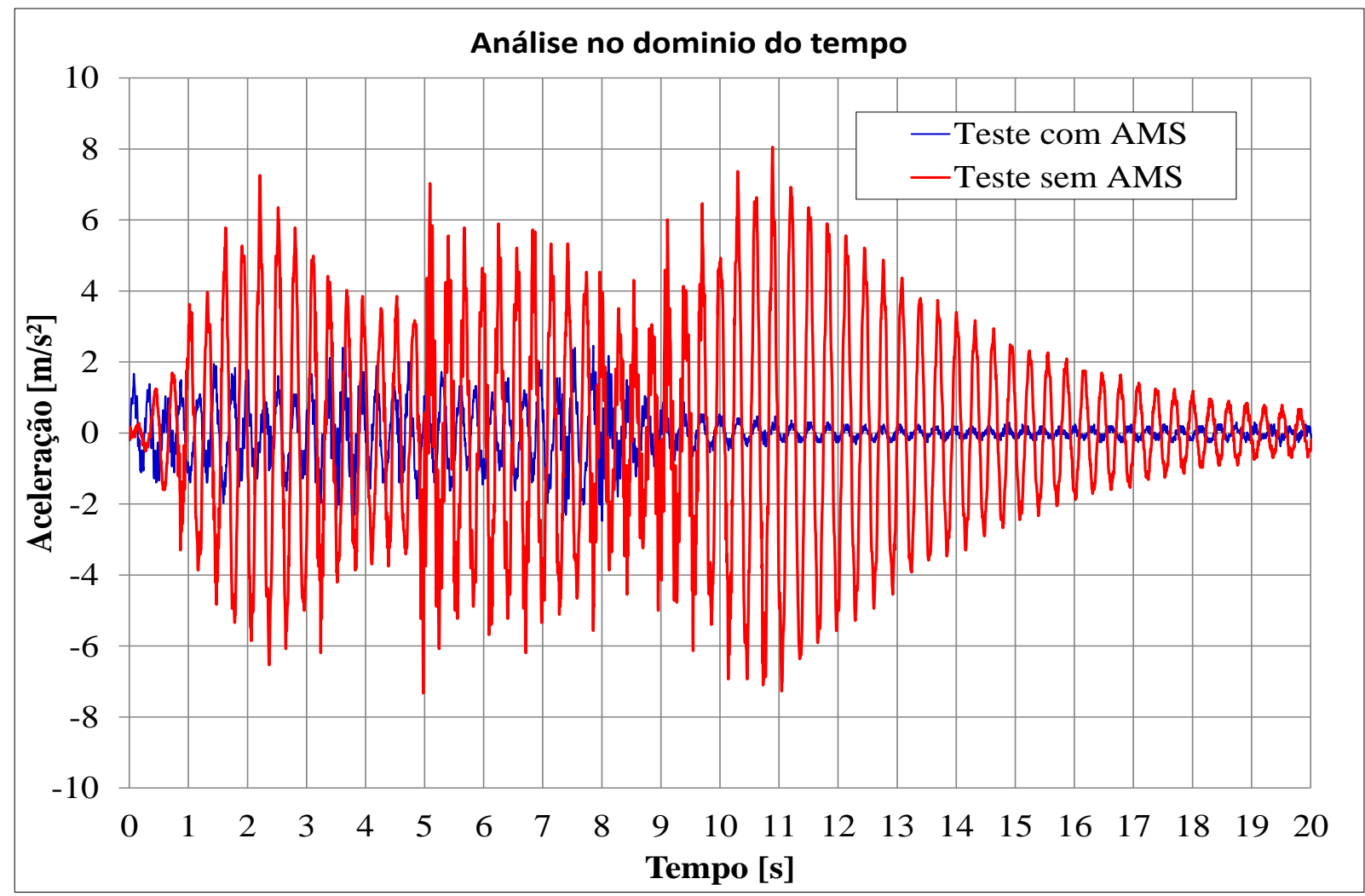

Figura 6.5 - Análise no domínio do tempo com e sem AMS. Ensaio com uma pessoa, pulo continuo durante 10 segundos.

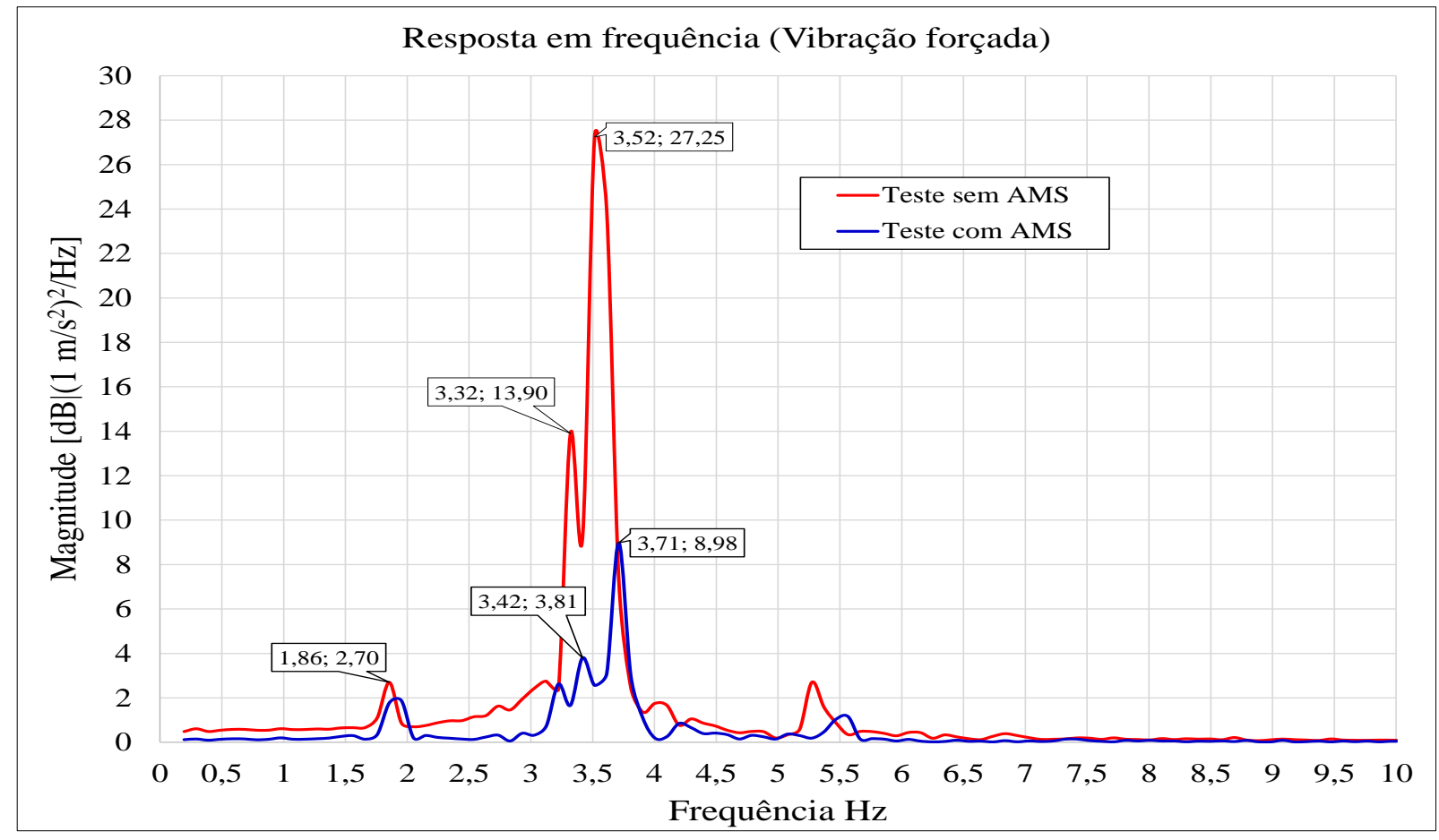

Figura 6.6 - Análise no domínio da frequência com e sem AMS. Ensaio com uma pessoa, pulo continuo. Vibração forçada 0-10 segundos. 


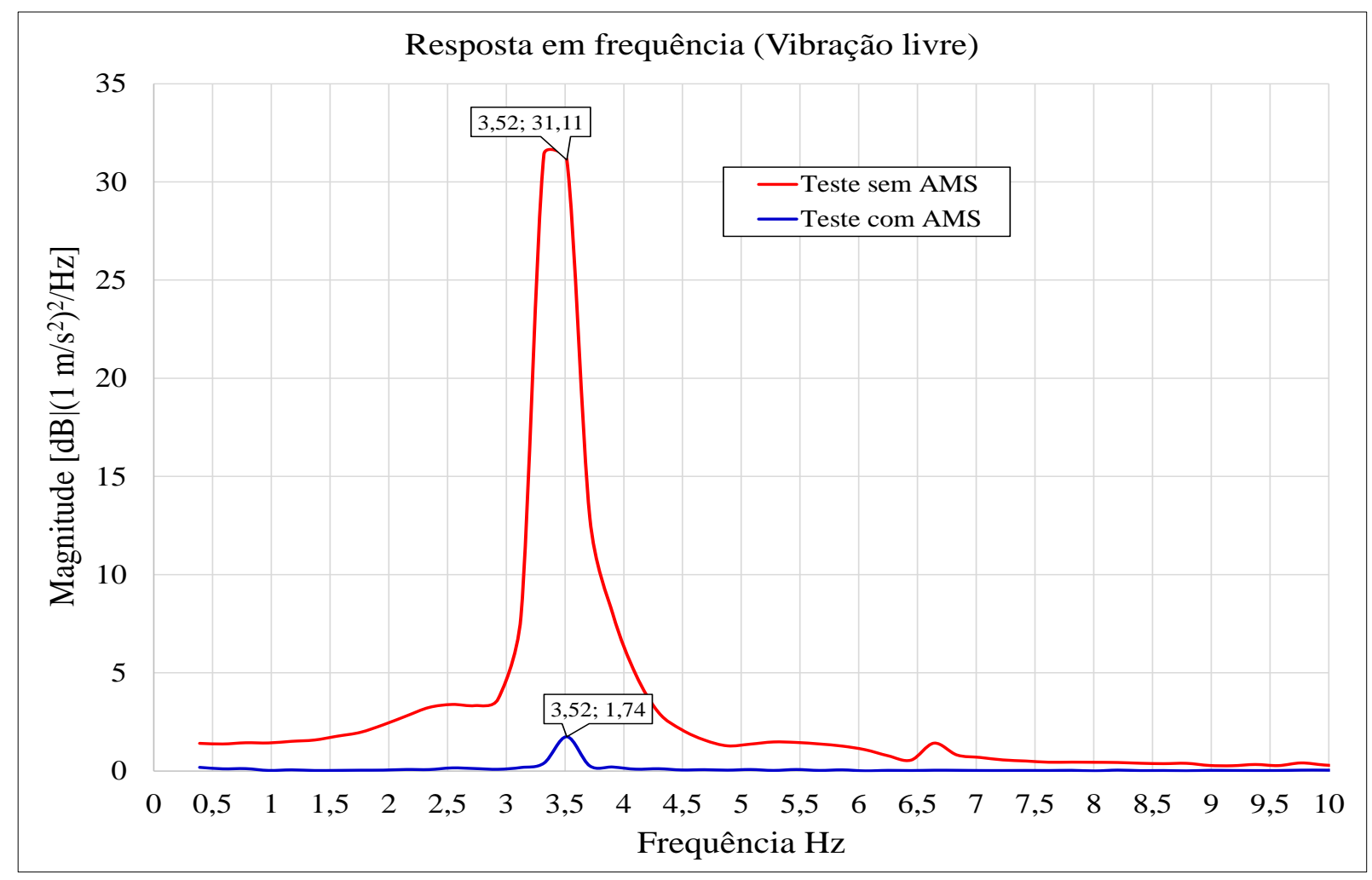

Figura 6.7 - Análise no domínio da frequência com e sem AMS. Ensaio com uma pessoa, pulo continuo. Vibração livre 10-20 segundos.

Outros ensaios com pulos contínuos acima da plataforma de ensaios dinâmicos considerando grupos de três e cinco pessoas foram realizados conforme mostra na Figura 6.8.

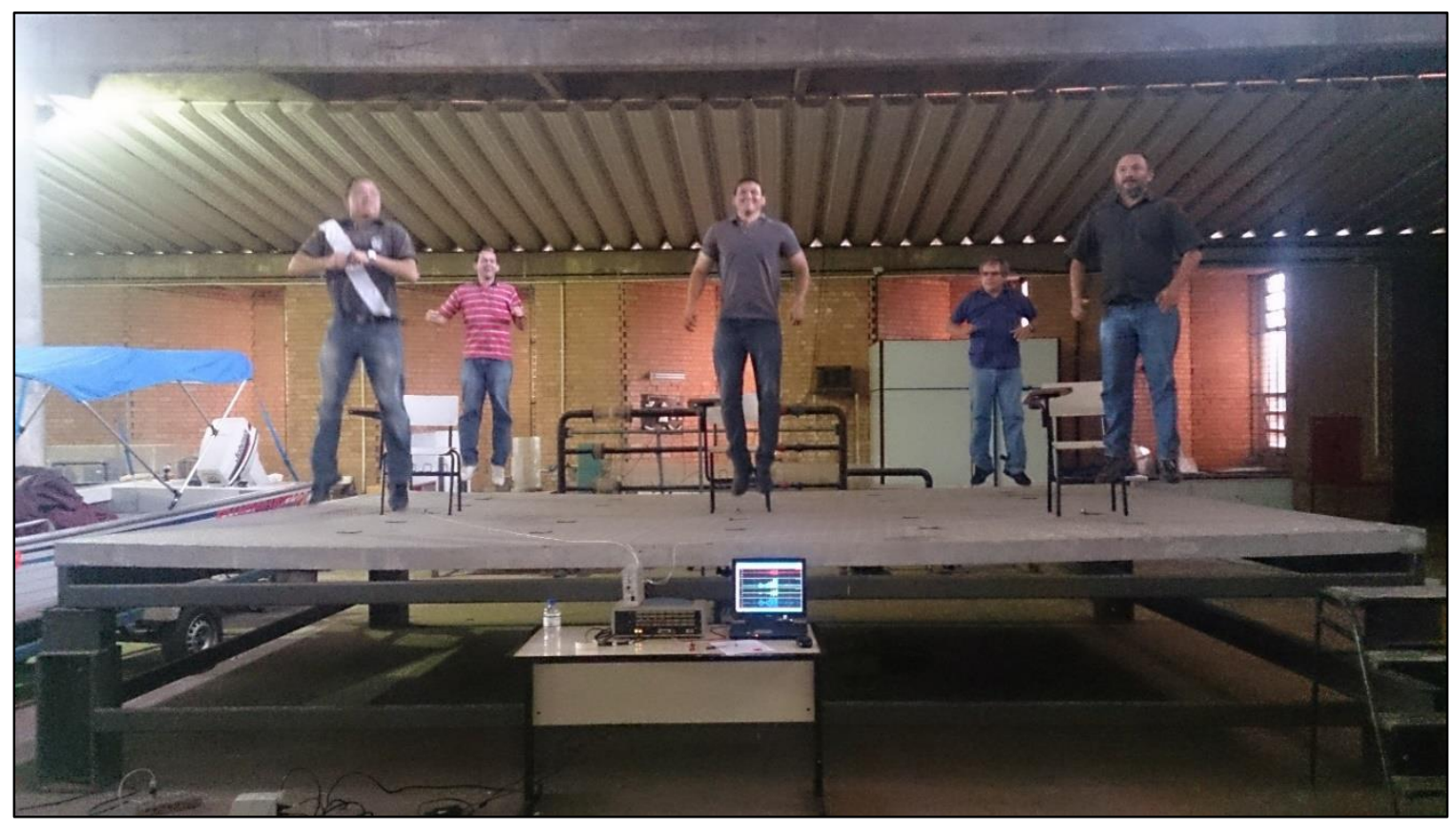

Figura 6.8 - Ensaios de vibração forçada. Pulos contínuos em grupo de 5 pessoas. 
Na Figura 6.9 , Figura 6.10 e Figura 6.11 se apresentam os resultados dos ensaios de um grupo de 3 pessoas pulando continuamente durante 10 segundos aproximadamente. A Figura 6.9 se refere a uma análise no domínio do tempo e a Figura 6.10 e Figura 6.11 a análises no domínio da frequência.

Observa-se que para este tipo de ensaio o AMS consegue também controlar as acelerações na laje de concreto. Tomando as máximas acelerações da Figura 6.9 para os ensaios com e sem AMS, pode-se chegar à conclusão que o amortecedor reduz em $31,1 \%$ a amplitude das acelerações.

$\mathrm{Na}$ análise no domínio da frequência do ensaio de vibração forçada de várias pessoas pulando acima da laje de 0 até 10 segundos (Figura 6.10) pode-se observar que a primeira frequência natural da estrutura é modificada de $3,52 \mathrm{~Hz}$ para $3,22 \mathrm{~Hz}$ com a introdução do amortecedor. A frequência que aparece aos $1,86 \mathrm{~Hz}$ deve-se a frequência induzida pelas três pessoas que realizam o ensaio de pulo continuo. Para este tipo de ensaio de vibração forçada o amortecedor tem um bom desempenho reduzindo a resposta em aproximadamente $39 \%$.

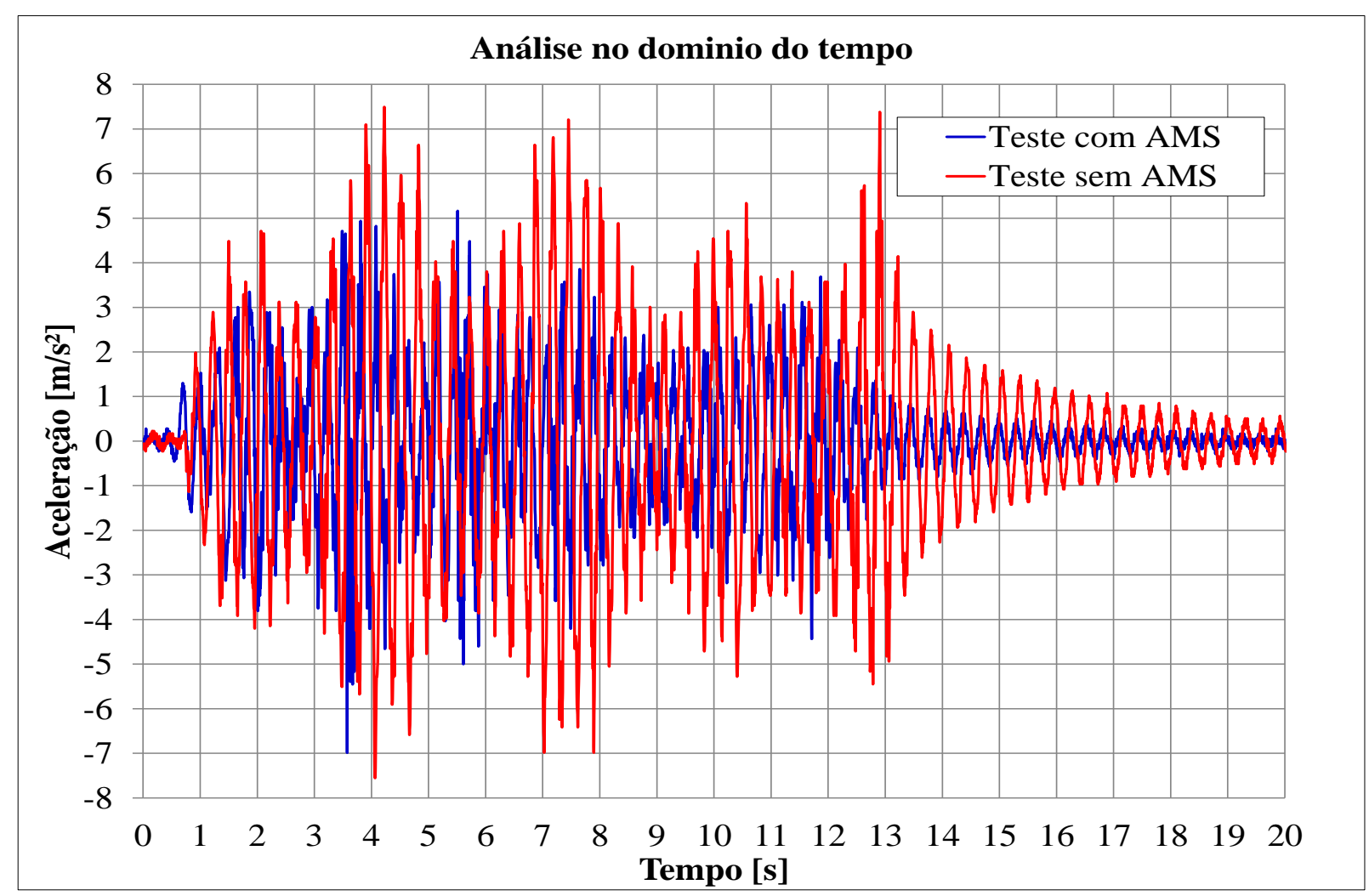

Figura 6.9 - Análise no domínio do tempo com e sem AMS. Grupo de 3 pessoas, pulo continuo de 10 segundos. 


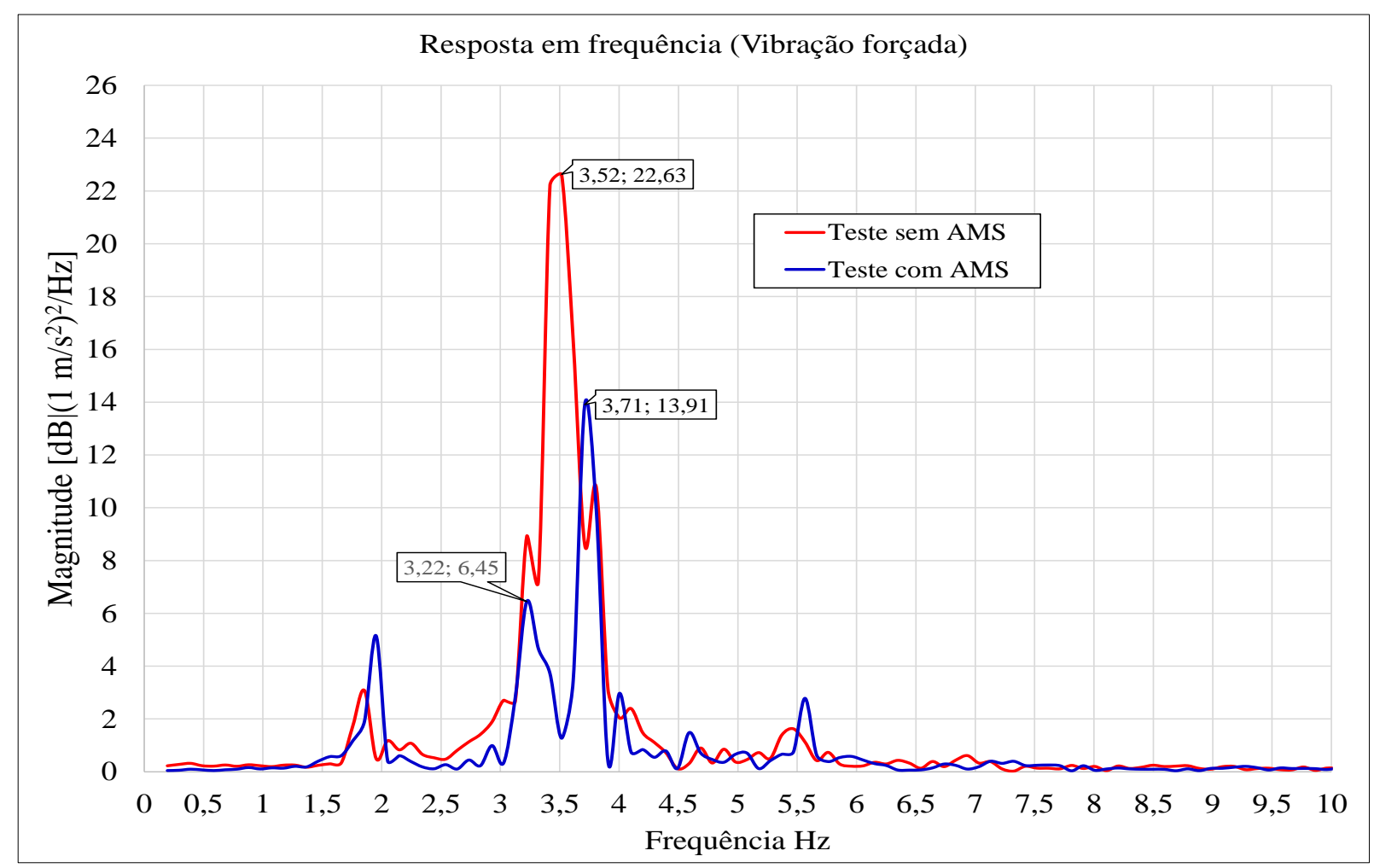

Figura 6.10 - Análise no domínio da frequência com e sem AMS. Grupo de 3 pessoas, pulo continuo. Vibração forçada 0-10 segundos.

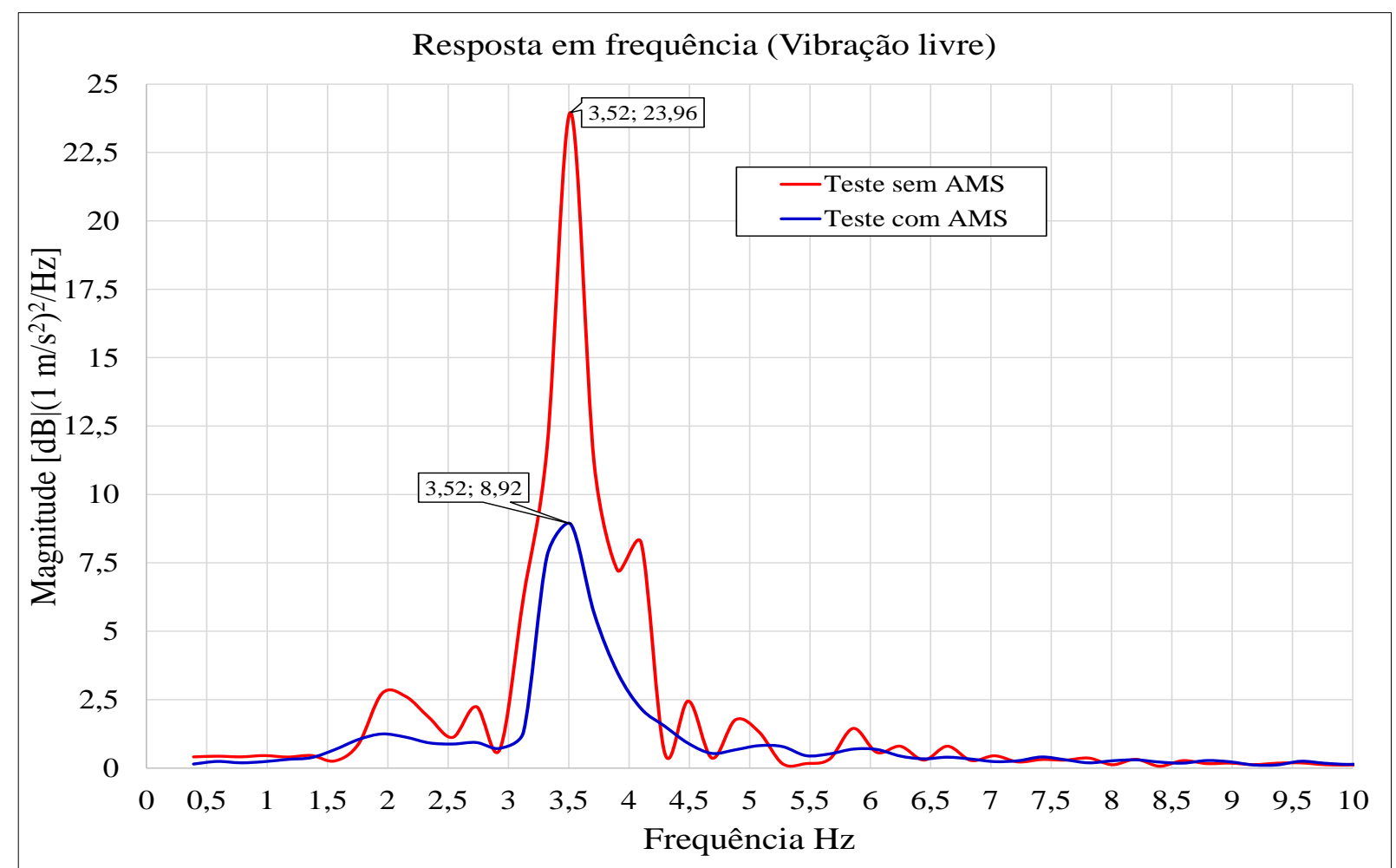

Figura 6.11 - Análise no domínio da frequência com e sem AMS. Grupo de 3 pessoas, pulo continuo. Vibração livre 10-20 segundos. 
$\mathrm{Na}$ resposta em frequência de vibração livre da figura Figura 6.11 pode-se observar que o amortecedor tem um bom desempenho com aproximadamente $63 \%$ de redução da amplitude de vibração.

Outras figuras apresentando resultados dos ensaios de pulo continuo se encontram no Anexo VIII.

\subsubsection{Pessoas caminhando na superfície da laje}

Em seguida for realizada uma serie de ensaios com grupos de 2,3,4, e 5 pessoas caminhando em toda a superfície da laje aleatoriamente durante um tempo de 20 segundos, conforme mostra a Figura 6.12

Nas Figura 6.13 e Figura 6.14 , apresentam-se, respectivamente, as respostas no domínio do tempo e no domínio da frequência para um grupo de 4 pessoas caminhando aleatoriamente.
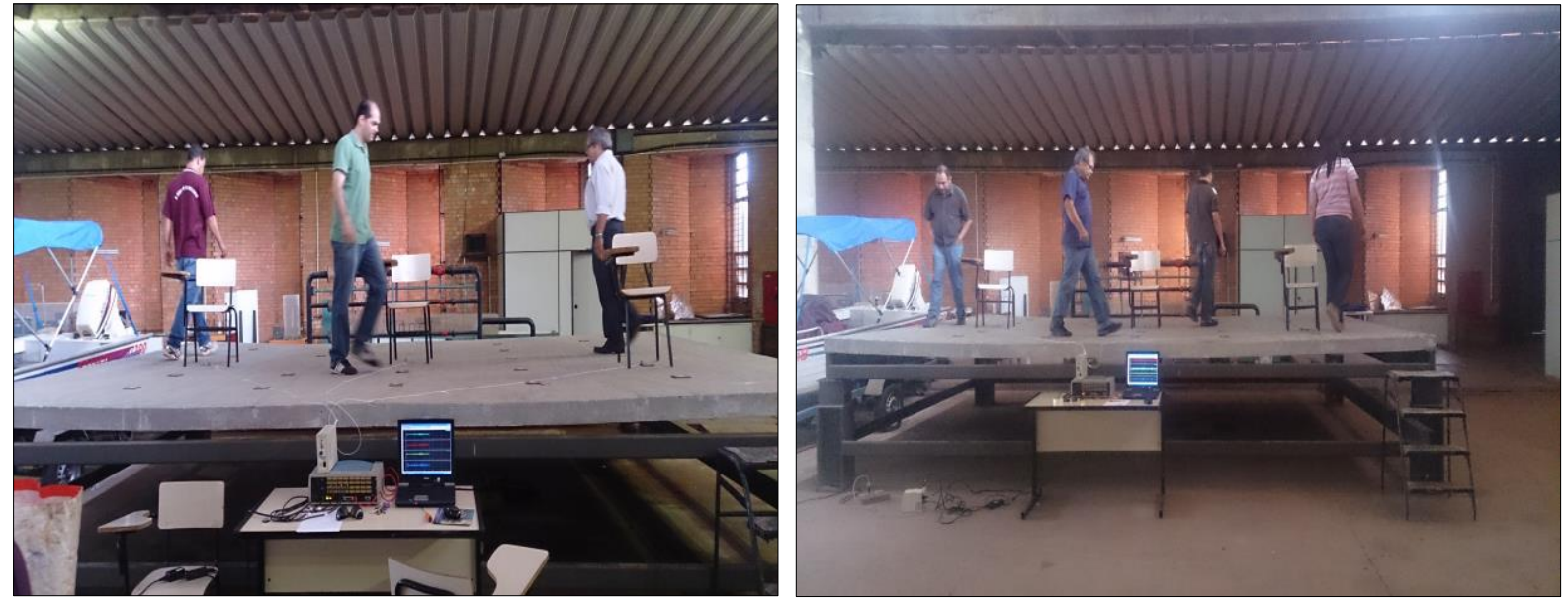

Figura 6.12 - Ensaios de vibração forçada. Pessoas caminhando aleatoriamente na superfície da laje em grupos de 3 e 4 pessoas. 


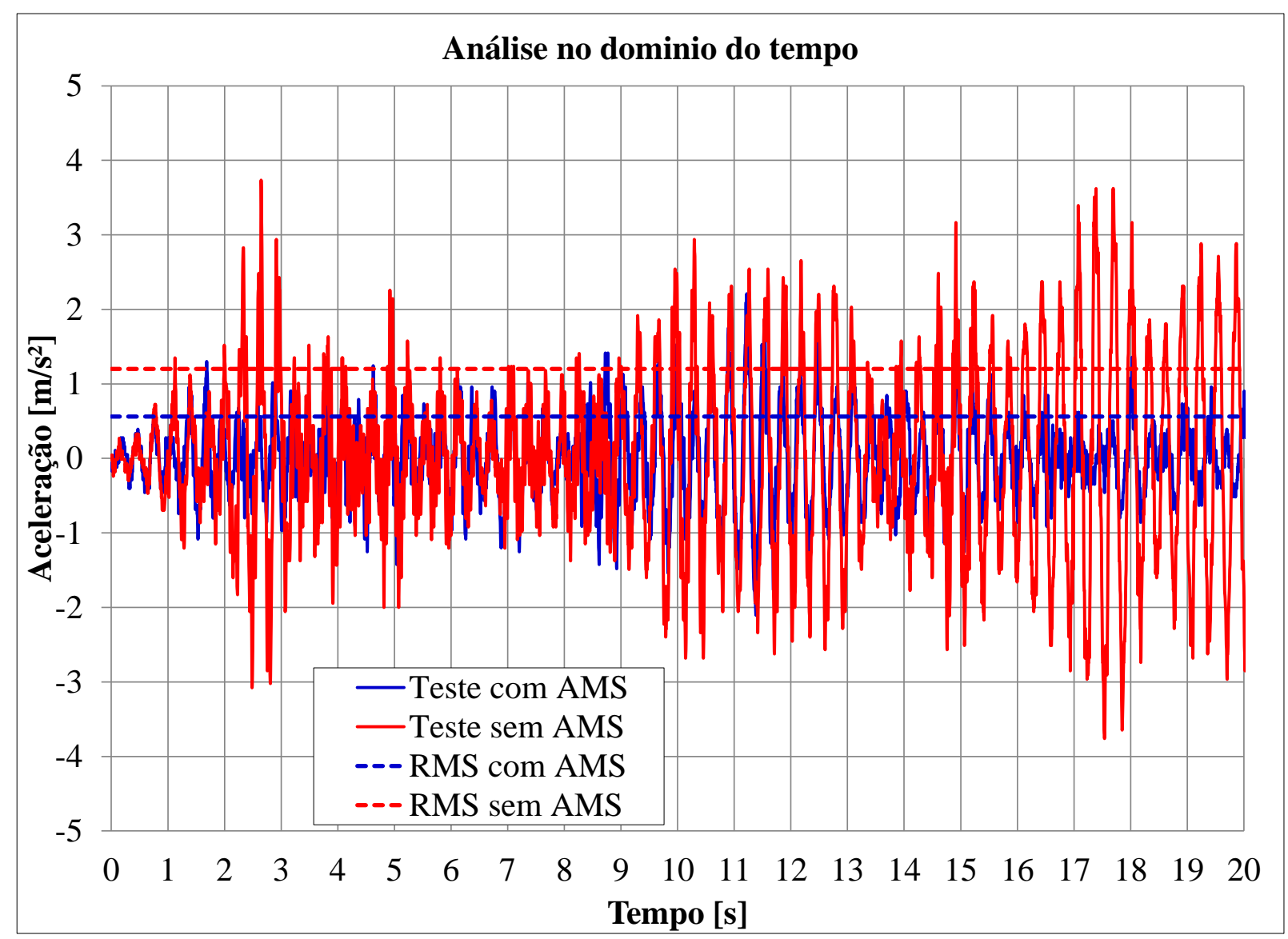

Figura 6.13 - Registro da aceleração no tempo com e sem AMS. Grupo de quatro pessoas, caminhando continua e aleatoriamente durante 20 segundos.

Da Figura 6.13 observa-se que o valor quadrático médio (rms) das acelerações é de 1,2 (linha horizontal vermelha no desenho) quando a estrutura não conta com o amortecedor e de 0,561 para o caso da laje com AMS (linha horizontal azul), o que significa uma redução de aproximadamente $53 \%$ na resposta.

A estrutura sem amortecedor apresenta acelerações máximas na faixa de 3,5 m/s e acoplando o AMS se registram acelerações máximas na faixa de $2 \mathrm{~m} / \mathrm{s}^{2}$.

Como foi mencionado anteriormente o AMS tem melhor desempenho quando é excitado por uma força harmônica constante produzindo altas amplitudes de aceleração (da ordem de $10 \mathrm{~m} / \mathrm{s}^{2}$ ) durante vários segundos. Movimentos não sincronizados de várias pessoas simultaneamente atuando de forma aleatória podem ainda em determinadas situações contribuir no amortecimento estrutural pela superposição de movimentos que se cruzam entre a laje o calçado 
das pessoas. Neste último caso observa-se que o amortecedor trabalha de forma satisfatória, porem com uma performance inferior em comparação aos casos anteriormente estudados.

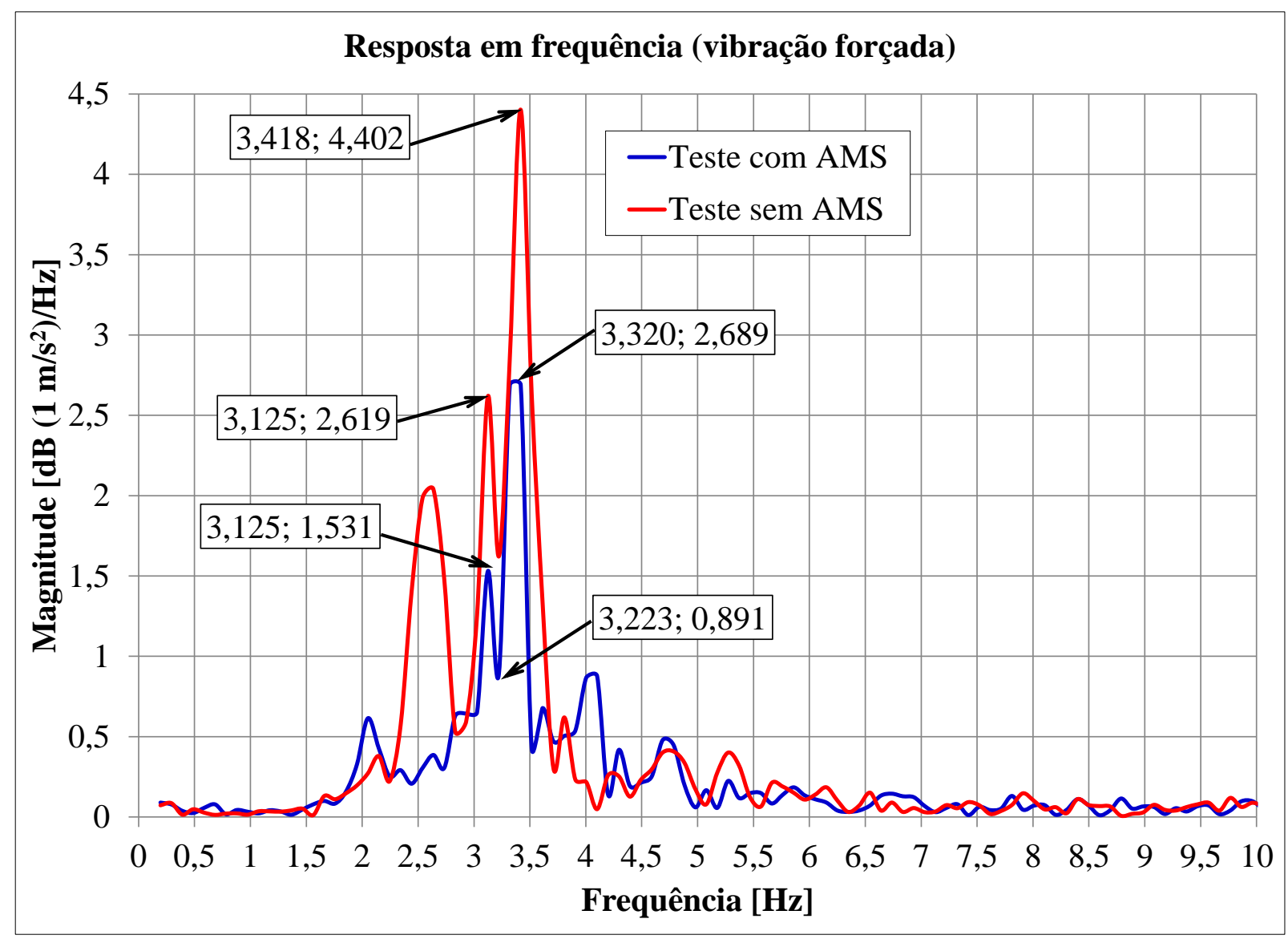

Figura 6.14 - Registro de aceleração no domínio da frequência com e sem AMS. Grupo pessoas caminhando 20 segundos.

Da resposta em frequência apresentada na Figura 6.14 pode-se observar que a diferença entre as amplitudes de pico da primeira frequência para a estrutura com e sem AMS não é tão significativa em relação aos ensaios anteriores com carregamentos de força harmônica e pulo continuo. Obtém-se para este caso uma relação entre picos aproximada de 1,64 comparada com a relação de picos de 11,04 da Figura 6.3 que tem um carregamento tipo harmônico, porém pode-se considerar ainda significativa a redução na amplitude das vibrações.

Os resultados obtidos com este tipo de ensaio variam muito uma vez que são, a rigor, difíceis de reproduzir da mesma forma, visto que as pessoas caminham aleatoriamente. Os demais resultados correspondentes aos ensaios de vibração forçada realizando atividade ritmada de caminhar acima da laje se encontram no Anexo IX. 


\subsubsection{Ensaio de vibração forçada mediante a ação que produz uma pessoa pulando desde uma carteira escolar}

Este ensaio consistiu em uma pessoa pulando do alto de uma carteira escolar no centro da plataforma e em seguida registrando-se as acelerações durante 20 segundos. Todos os pulos foram feitos no centro da laje, realizados pela mesma pessoa com peso de $75 \mathrm{~kg}$-f a qual pulava de uma carteira escolar com uma altura de $0,43 \mathrm{~m}$. A intenção ao fazer este tipo de ensaio foi saber qual seria o desempenho do AMS para forças de impacto sem repetição. A forma como foi executado o ensaio apresenta-se na Figura 6.15.

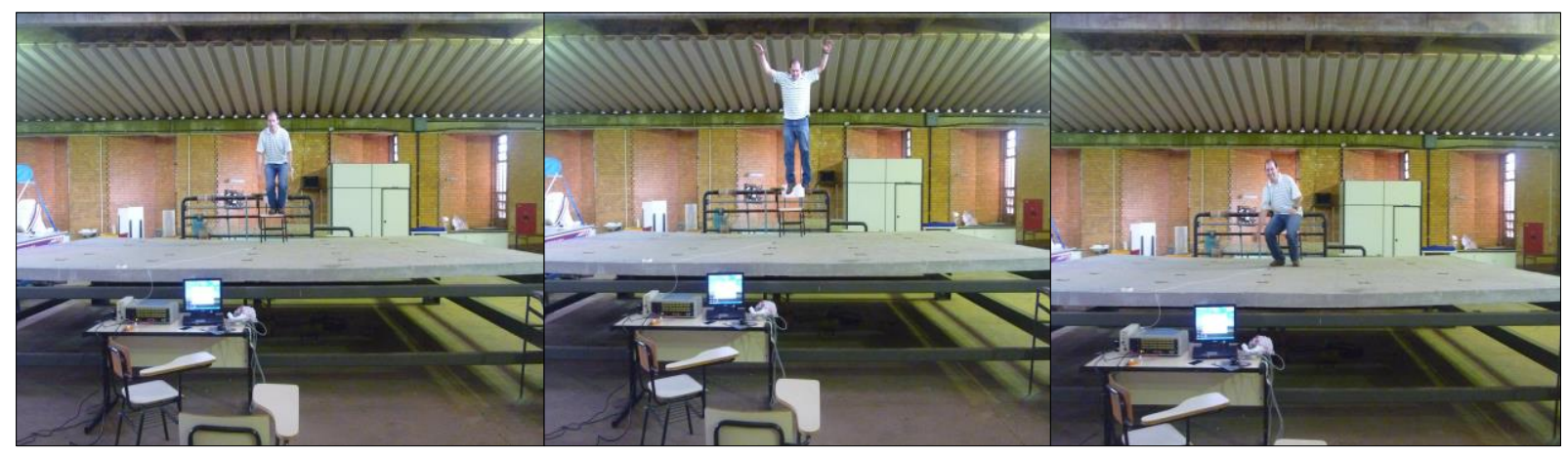

Figura 6.15 - Ensaio de uma pessoa pulando desde uma carteira escolar no centro da laje.

Na Figura 6.16 e na Figura 6.17 apresenta-se as respostas no domínio do tempo e no domínio da frequência, respectivamente, para este caso de carregamento. 


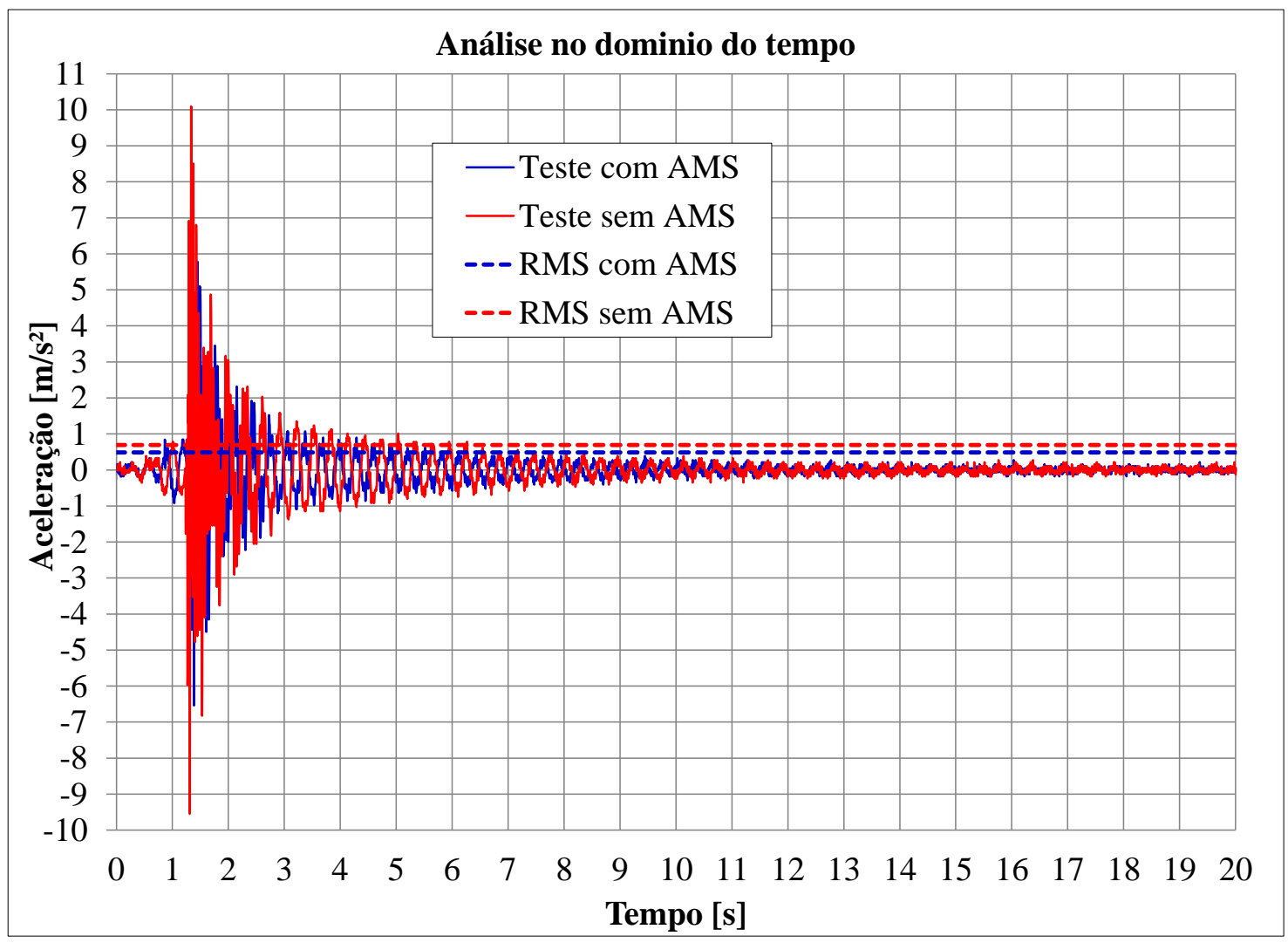

Figura 6.16 - Análise no domínio do tempo com e sem AMS. Impacto produzido por uma pessoa pulando desde uma carteira escolar.

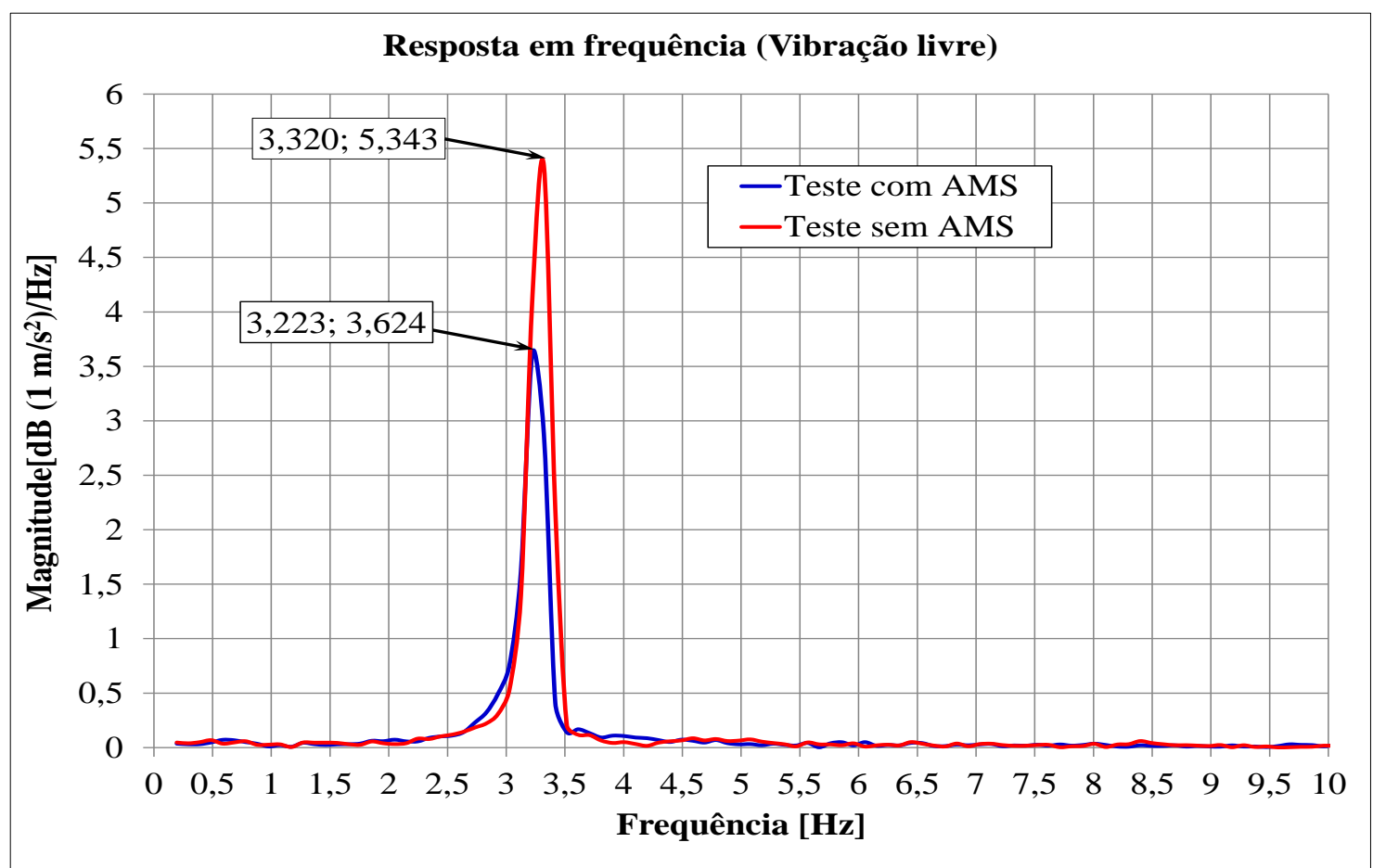

Figura 6.17 - Análise no domínio da frequência com e sem AMS. Impacto produzido por uma pessoa pulando desde uma carteira escolar. 
Na Figura 6.16 que corresponde aos registros das acelerações verticais da laje se observa que o AMS consegue reduzir levemente as acelerações no momento de impacto da força. Após 1 segundo de aplicada a força, tanto a estrutura sem controle como com AMS registram as mesmas acelerações até passados os 20 segundos de análise. Comparando os valores médios quadráticos das acelerações (RMS) da linha azul tracejada (com AMS) e da linha vermelha (sem AMS) não se observa muita diferença entre os resultados o que significa que o AMS não tem seu melhor desempenho na redução das acelerações para este classe de excitação.

A explicação para o desempenho pouco significativo do AMS neste caso é que o tempo da atuação da força externa é muito curto, o AMS precisa de um tempo maior para iniciar o seu movimento e assim transferir a energia, prejudicando o desempenho do amortecedor.

Para este tipo de ensaio também observa-se que na resposta em frequência, apresentada na Figura 6.17 não existe muita diferença entre o os dois picos principais das curvas com e sem controle. Confirmando a pouca eficiência já verificada na resposta no domínio do tempo.

Os demais resultados correspondentes a este tipo de ensaio são apresentados no Anexo X. 


\section{ANÁLISE ESTATÍSTICA DOS RESULTADOS DOS ENSAIOS EM VIBRAÇÃO FORÇADA}

O objetivo com este tratamento foi condensar uma quantidade numerosa de acelerações de todos os ensaios repetitivos em uma tabela, de modo que um valor aproximado de 16 mil registros foram condensados em umas poucas linhas, dispostas em classes ou categorias juntamente com suas frequências. Desta maneira saber o desempenho do amortecedor na redução das acelerações para os diferentes ensaios realizados.

\subsection{INTRODUÇÃO E DEFINIÇÕES}

Os resultados dos ensaios experimentais foram, analisados e interpretados por meio de tabelas e de um histograma de distribuição de frequências (Histograma).

Para cada tipo de ensaio foram reunidos dados (acelerações) repetitivos de no mínimo 4 ensaios iguais realizados em tempos diferentes e tratados estatisticamente. De cada conjunto de dados foram obtidos os valores extremos, máximo $\left(Z_{\max }\right)$ e mínimo $\left(Z_{\min }\right)$ da variável analisada, no caso as acelerações, a amplitude do conjunto de dados (L) definida como a diferença entre o valor máximo, o número de classes (k) que são os intervalos de variação da variável, e por último a amplitude da classe (h).

Segundo DeCoursey(2003), para determinar a quantidade de classes $(k)$, podem ser aplicadas a regra de Sturges ou regra do logaritmo, a regra da potência de 2, a regra da raiz quadrada e ainda o bom senso. Para calcular os parâmetros anteriores podem-se utilizar as seguintes equações:

$$
\begin{aligned}
& L=Z_{\text {max }}-Z_{\text {min }} \\
& k=1+3,3 \log (n) \\
& h=L / k
\end{aligned}
$$

Onde:

$n$ : Número total de dados de todos os ensaios.

Da regra de Sturges na equação (7.2) e (7.3) k e h devem ser arredondados convenientemente.

Para calcular os limites das classes se procede da seguinte forma: 
$1^{\text {a classe: }} Z_{\min }$ até $Z_{\min }+\mathrm{h}$

$2^{\mathrm{a}}$ classe: $Z_{\min }+\mathrm{h}$ até $Z_{\min }+2 * h$

$\mathrm{k}^{\mathrm{a}}$ classe: $\mathrm{Z}_{\min }+(\mathrm{k}-1) * \mathrm{~h}$ até $\mathrm{Z}_{\min }+\mathrm{k}^{*} \mathrm{~h}$

Para todos os cálculos das tabelas dos diferentes ensaios é utilizada a regra de Sturges.

\subsection{TRATAMENTO ESTATÍSTICO PARA OS ENSAIOS COM ESTIMULOS DE FORÇA QUE SIMULAM UMA AÇÃO HARMONICA NA BORDA DA LAJE}

\subsubsection{Excitação simulando força harmônica na plataforma sem AMS}

Como foi explicado anteriormente no item 6.1.1.1 do capitulo 6, foram realizados ensaios experimentais na plataforma simulando uma força harmônica na borda livre da laje.

Os registros de acelerações provenientes do acelerômetro 2 para este tipo de ensaio sem AMS que estão no Anexo VII foram condensados na Tabela 7.1

Tabela 7.1 - Amplitude e número de classes dos registros de acelerações dos ensaios simulando força harmônica na plataforma sem AMS.

\begin{tabular}{|l|c|}
\hline Número total de dados $[\mathrm{n}]$ & 16028 \\
\hline Valor mínimo dos ensaios $\left[\mathrm{Z}_{\min }\right]$ & $-10,397 \mathrm{~m} / \mathrm{s}^{2}$ \\
\hline Valor máximo dos ensaios $\left[\mathrm{Z}_{\max }\right]$ & $11,121 \mathrm{~m} / \mathrm{s}^{2}$ \\
\hline Amplitude conjunto de dados $[\mathrm{L}]$ & $21,518 \mathrm{~m} / \mathrm{s}^{2}$ \\
\hline $\mathrm{N}^{\circ}$ de classes $[\mathrm{k}]$ & 15 \\
\hline Amplitude da classe $[\mathrm{h}]$ & $1,435 \mathrm{~m} / \mathrm{s}^{2}$ \\
\hline
\end{tabular}

Com base na Tabela 7.1, foi calculada a Tabela 7.2 de distribuição de frequências por intervalos das acelerações registradas pelo acelerômetro 2. Nos diferentes ensaios a estrutura principal foi excitada simulando uma força harmônica na borda da laje. É de ressaltar que nestes testes a plataforma de ensaios dinâmicos não tinha acoplado nenhum tipo de sistema de controle.

Para todas as tabelas de distribuição de frequências por intervalos, do presente capitulo foi obtida uma média entre o valor do limite superior e o valor do limite inferior das acelerações $\left[\mathrm{m} / \mathrm{s}^{2}\right]$ para cada classe (Mi). Seguidamente, foram contados os registros de acelerações entre o 
limite inferior e o superior de cada classe que corresponde ao valor da frequência (ni) e com este valor de (ni) e a quantidade total de acelerações registradas em todas as classes, foram calculadas as porcentagens de frequências relativas (fi) como se apresenta na Tabela 7.2. Com os dados de (Mi) e (fi) foi construído o histograma de frequências de acelerações por intervalos que se apresenta na Figura 7.1.

Tabela 7.2 - Distribuição de frequências por intervalos de todos os registros das acelerações do acelerômetro 2, simulando força harmônica na plataforma sem AMS.

\begin{tabular}{|c|c|c|c|c|c|c|c|}
\hline \multicolumn{7}{|c|}{ Acelerômetro 2, teste 29,30,31,32 sem AMS } \\
\hline Classe & $\begin{array}{c}\text { Limite inferior } \\
\text { da classe }\end{array}$ & $\begin{array}{c}\text { Limite superior } \\
\text { da classe }\end{array}$ & $\begin{array}{c}\text { Média da classe } \\
\mathrm{Mi}\end{array}$ & $\begin{array}{c}\text { Frequência } \\
\text { ni }\end{array}$ & $\begin{array}{c}\text { Frequência } \\
\text { absoluta acumulada } \\
\mathrm{Ni}\end{array}$ & $\begin{array}{c}\text { Frequência } \\
\text { relativa } \\
\mathrm{fi}\end{array}$ & $\begin{array}{c}\text { Frequência } \\
\text { relativa acumulada } \\
\text { Fi }\end{array}$ \\
\hline 1 & $-10,397$ & $-8,963$ & $-9,680$ & 216 & 216 & 0,013 & 0,013 \\
\hline 2 & $-8,963$ & $-7,528$ & $-8,245$ & 855 & 1071 & 0,053 & 0,067 \\
\hline 3 & $-7,528$ & $-6,094$ & $-6,811$ & 802 & 1873 & 0,050 & 0,117 \\
\hline 4 & $-6,094$ & $-4,659$ & $-5,376$ & 812 & 2685 & 0,051 & 0,168 \\
\hline 5 & $-4,659$ & $-3,225$ & $-3,942$ & 831 & 3516 & 0,052 & 0,219 \\
\hline 6 & $-3,225$ & $-1,790$ & $-2,507$ & 1031 & 4547 & 0,064 & 0,284 \\
\hline 7 & $-1,790$ & $-0,356$ & $-1,073$ & 2157 & 6704 & 0,135 & 0,418 \\
\hline 8 & $-0,356$ & 1,079 & 0,362 & 4186 & 10890 & 0,261 & 0,679 \\
\hline 9 & 1,079 & 2,514 & 1,796 & 1276 & 12166 & 0,080 & 0,759 \\
\hline 10 & 2,514 & 3,948 & 3,231 & 839 & 13005 & 0,052 & 0,811 \\
\hline 11 & 3,948 & 5,383 & 4,665 & 752 & 13757 & 0,047 & 0,858 \\
\hline 12 & 5,383 & 6,817 & 6,100 & 700 & 14457 & 0,044 & 0,902 \\
\hline 13 & 6,817 & 8,252 & 7,534 & 746 & 15203 & 0,047 & 0,949 \\
\hline 14 & 8,252 & 9,686 & 8,969 & 696 & 15899 & 0,043 & 0,992 \\
\hline 15 & 9,686 & 11,121 & 10,403 & 129 & 16028 & 0,008 & 1,000 \\
\hline
\end{tabular}




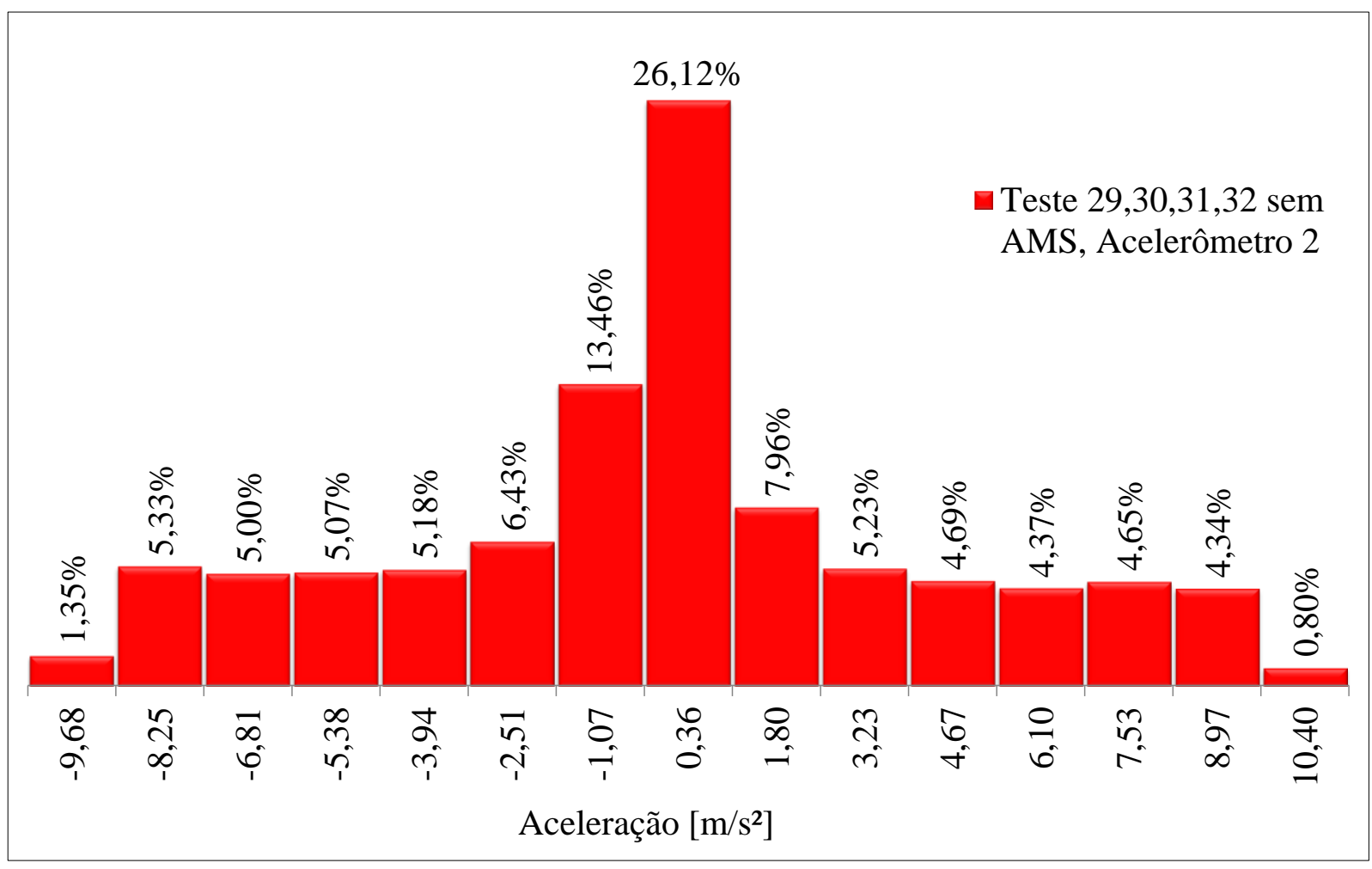

Figura 7.1 - Histograma de frequências de todas as acelerações registradas pelo acelerômetro 2 simulando força harmônica nos ensaios na plataforma sem AMS.

Do histograma de frequências por intervalos, da Figura 7.1, pode-se dizer que acelerações negativas (sentido vertical $\uparrow$ ) entre uma média de $-8,25 \mathrm{~m} / \mathrm{s}^{2}$ e $-3,94 \mathrm{~m} / \mathrm{s}^{2}$ se apresentam com porcentagens parecidos em torno do 5\%. Da mesma maneira acontece para acelerações positivas (sentido vertical $\downarrow$ ) que vão da média de $3,23 \mathrm{~m} / \mathrm{s}^{2}$ até $8,97 \mathrm{~m} / \mathrm{s}^{2}$ as quais se apresentam em porcentagens da mesma ordem em torno de 4,6\%. O anterior demostra que a plataforma sem sistema de controle oscila uniformemente. $\mathrm{O}$ ideal seria que a maior porcentagem de registros de médias das acelerações estivesse concentrada no centro do histograma sem ter barras de classes em seus lados, ou seja, que a maioria dos registros fossem acelerações mínimas concentradas em uma barra de classe. Neste tipo de ensaio não acontece isso, como se observa no histograma da Figura 7.1, uma vez que a estrutura analisada é muito flexível e o amortecimento estrutural é baixo como foi discutido em capítulos anteriores.

Para o caso estudado, observa-se que em torno de $74 \%$ dos registros tem uma média de aceleração superior a $0,36 \mathrm{~m} / \mathrm{s}^{2}$. 
Este tipo de análise estatístico confirma as elevadas acelerações que se apresentam em todos os ensaios apresentados no Anexo VII e que foram registradas pelo acelerômetro 2 localizado no centro da laje. Todos os demais resultados de tratamentos estatísticos de acelerações registrados pelos acelerômetros 1 e 3 são mostrados no Anexo XI.

\subsubsection{Excitação simulando força harmônica na plataforma com AMS}

Também se realizou a análise estatística dos ensaios de vibração forçada considerando uma força harmônica com atuação do sistema de controle (AMS). Os registros do acelerômetro 2 se apresentam na Tabela 7.3 e Tabela 7.4 e são recopilados na Figura 7.2

Tabela 7.3 - Amplitude e número de classes dos registros de acelerações dos ensaios simulando força harmônica na plataforma com AMS.

\begin{tabular}{|l|c|}
\hline Número total de dados $[\mathrm{n}]$ & 16028 \\
\hline Valor mínimo dos ensaios $\left[\mathrm{Z}_{\mathrm{min}}\right]$ & $-9,940 \mathrm{~m} / \mathrm{s}^{2}$ \\
\hline Valor máximo dos ensaios $\left[\mathrm{Z}_{\mathrm{max}}\right]$ & $12,486 \mathrm{~m} / \mathrm{s}^{2}$ \\
\hline Amplitude conjunto de dados $[\mathrm{L}]$ & $22,426 \mathrm{~m} / \mathrm{s}^{2}$ \\
\hline $\mathrm{N}^{\circ}$ de classes $[\mathrm{K}]$ & 15 \\
\hline Amplitude da classe $[\mathrm{h}]$ & $1,495 \mathrm{~m} / \mathrm{s}^{2}$ \\
\hline
\end{tabular}

Tabela 7.4 - Distribuição de frequências por intervalos de todos os registros das acelerações do acelerômetro 2, simulando força harmônica na plataforma com AMS.

\begin{tabular}{|c|c|c|c|c|c|c|c|}
\hline \multicolumn{7}{|c|}{ Acelerômetro 2, teste 30,31,32,33 com AMS } \\
\hline Classe & $\begin{array}{c}\text { Limite inferior } \\
\text { da classe }\end{array}$ & $\begin{array}{c}\text { Limite superior } \\
\text { da classe }\end{array}$ & $\begin{array}{c}\text { Média da classe } \\
\text { Mi }\end{array}$ & $\begin{array}{c}\text { Frequência } \\
\mathrm{ni}\end{array}$ & $\begin{array}{c}\text { Frequência } \\
\text { absoluta acumulada } \\
\mathrm{Ni}\end{array}$ & $\begin{array}{c}\text { Frequência } \\
\text { relativa } \\
\mathrm{fi}\end{array}$ & $\begin{array}{c}\text { Frequência } \\
\text { relativa acumulada } \\
\mathrm{Fi}\end{array}$ \\
\hline 1 & $-9,940$ & $-8,445$ & $-9,192$ & 19 & 19 & 0,001 & 0,001 \\
\hline 2 & $-8,445$ & $-6,949$ & $-7,697$ & 31 & 50 & 0,002 & 0,003 \\
\hline 3 & $-6,949$ & $-5,454$ & $-6,202$ & 41 & 91 & 0,003 & 0,006 \\
\hline 4 & $-5,454$ & $-3,959$ & $-4,707$ & 91 & 182 & 0,006 & 0,011 \\
\hline 5 & $-3,959$ & $-2,464$ & $-3,212$ & 392 & 574 & 0,024 & 0,036 \\
\hline 6 & $-2,464$ & $-0,969$ & $-1,717$ & 1124 & 1698 & 0,070 & 0,106 \\
\hline 7 & $-0,969$ & 0,526 & $-0,222$ & 12031 & 13729 & 0,751 & 0,857 \\
\hline 8 & 0,526 & 2,021 & 1,273 & 1521 & 15250 & 0,095 & 0,951 \\
\hline 9 & 2,021 & 3,516 & 2,768 & 550 & 15800 & 0,034 & 0,986 \\
\hline 10 & 3,516 & 5,011 & 4,263 & 103 & 15903 & 0,006 & 0,992 \\
\hline 11 & 5,011 & 6,506 & 5,759 & 60 & 15963 & 0,004 & 0,996 \\
\hline 12 & 6,506 & 8,001 & 7,254 & 43 & 16006 & 0,003 & 0,999 \\
\hline 13 & 8,001 & 9,496 & 8,749 & 10 & 16016 & 0,001 & 0,999 \\
\hline 14 & 9,496 & 10,991 & 10,244 & 6 & 16022 & 0,000 & 1,000 \\
\hline 15 & 10,991 & 12,486 & 11,739 & 5 & 16027 & 0,000 & 1,000 \\
\hline
\end{tabular}




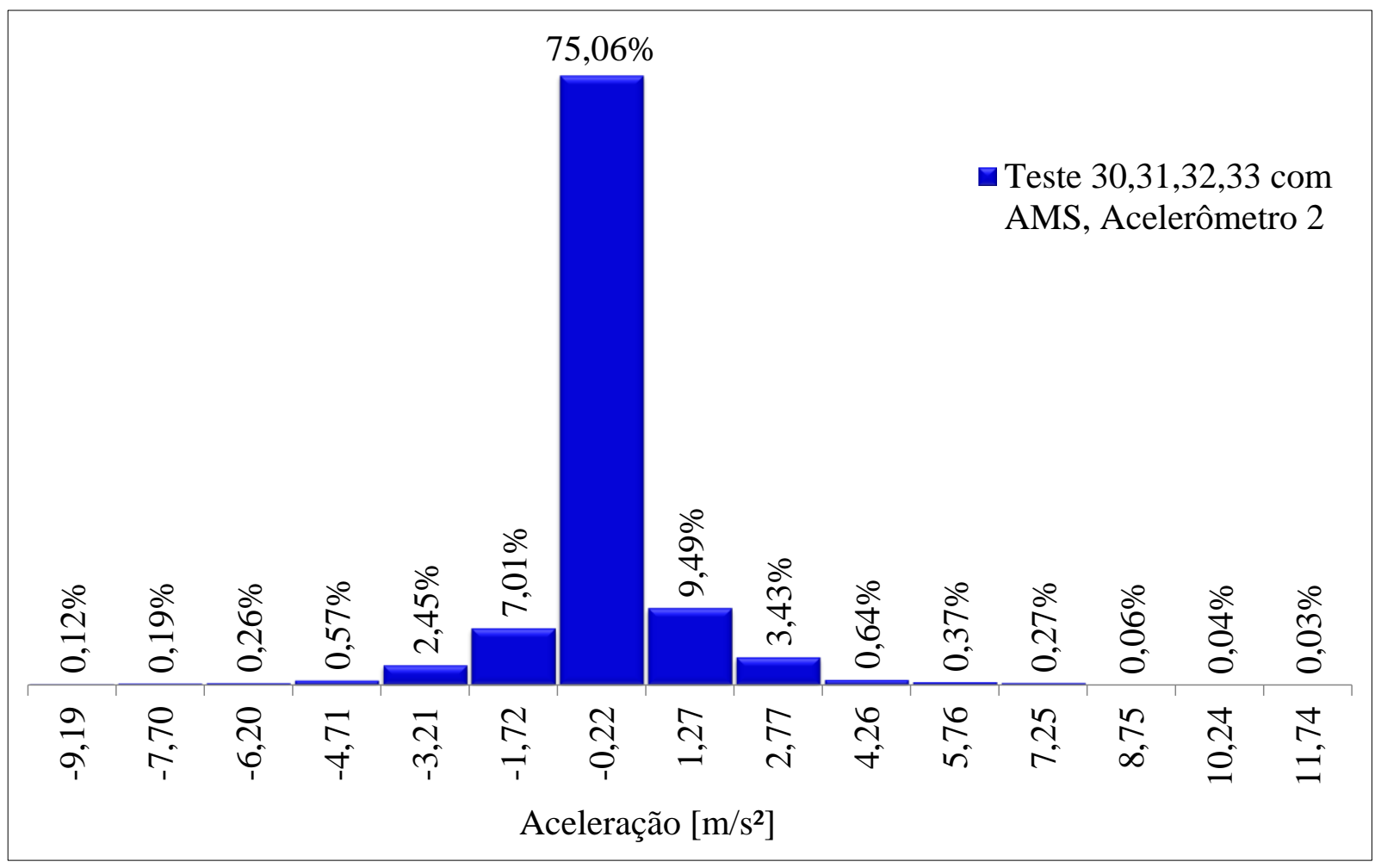

Figura 7.2 - Histograma de frequências de todas as acelerações registradas pelo acelerômetro 2 simulando força harmônica nos ensaios na plataforma com AMS.

Da Figura 7.2 se observa que o histograma de frequências para os ensaios simulando uma força harmônica na plataforma com atuação do AMS tem um 75\% dos registros das acelerações em torno de uma média de $-0,22 \mathrm{~m} / \mathrm{s}^{2}$ e as acelerações mais altas se encontram em porcentagens muito baixos, da ordem de menos de $1 \%$.

Nos 4 ensaios feitos com atuação do AMS se registraram algumas acelerações um pouco maiores que as acelerações que foram registradas sem sistema de controle. Estas maiores magnitudes de acelerações são devidas a que a força de excitação externa foi maior para os ensaios com o sistema de controle acoplado na plataforma. O máximo valor positivo registrado de acelerações com sistema de controle foi de $11,74 \mathrm{~m} / \mathrm{s}^{2}$ e o máximo valor registrado sem sistema de controle foi de $10,40 \mathrm{~m} / \mathrm{s}^{2}$. Mesmo assim com maiores acelerações registradas nos ensaios com sistema de controle, o AMS teve um bom desempenho reduzindo o registro de acelerações em geral.

Os demais registros captados pelos acelerômetros 1 e 3, também apresentam o mesmo comportamento no qual a maior porcentagem de registros de acelerações se concentra para 
acelerações de magnitudes baixas. Os registros dos acelerômetros 1, 2 e 3 dos demais ensaios realizados podem ser verificados no Anexo XI.

O histograma de frequências por intervalos da Figura 7.2 tem tendência de comportamento ideal que se espera de um sistema de controle bem sintonizado, onde a maior frequência de registros de acelerações corresponda a magnitudes da ordem de zero $\mathrm{m} / \mathrm{s}^{2}$.

\subsection{TRATAMENTO ESTATÍSTICO PARA OS ENSAIOS COM FORÇA DE EXCITAÇÃo Gerada Pelo PUlo CONTINUO de UMA PESSOA No CENTRO DA LAJE}

\subsubsection{Excitação com pulo continuo no centro da laje sem AMS}

Como já foi explicado no capítulo anterior foram feitos ensaios de pulos contínuos gerados por uma pessoa ou em grupos de várias pessoas. Na Tabela 7.5 e Tabela 7.6 se apresentam os resultados estatísticos dos resultados.

Tabela 7.5 - Amplitude e número de classes dos registros de acelerações dos ensaios simulando pulo continuo na plataforma sem AMS.

\begin{tabular}{|l|c|}
\hline Número total de dados $[\mathrm{n}]$ & 16028 \\
\hline Valor mínimo dos ensaios $\left[\mathrm{Z}_{\mathrm{min}}\right]$ & $-11,014 \mathrm{~m} / \mathrm{s}^{2}$ \\
\hline Valor máximo dos ensaios $\left[\mathrm{Z}_{\max }\right]$ & $12,717 \mathrm{~m} / \mathrm{s}^{2}$ \\
\hline Amplitude conjunto de dados $[\mathrm{L}]$ & $23,732 \mathrm{~m} / \mathrm{s}^{2}$ \\
\hline $\mathrm{N}^{\circ}$ de classes $[\mathrm{K}]$ & 15 \\
\hline Amplitude da classe $[\mathrm{h}]$ & $1,582 \mathrm{~m} / \mathrm{s}^{2}$ \\
\hline
\end{tabular}


Tabela 7.6 - Distribuição de frequências por intervalos de todos os registros das acelerações do acelerômetro 2, pulo continuo na plataforma sem AMS.

\begin{tabular}{|c|c|c|c|c|c|c|c|}
\hline \multicolumn{7}{|c|}{ Acelerômetro 2, teste 25,26,27,28 sem AMS } \\
\hline Classe & $\begin{array}{c}\text { Limite inferior } \\
\text { da classe }\end{array}$ & $\begin{array}{c}\text { Limite superior } \\
\text { da classe }\end{array}$ & $\begin{array}{c}\text { Média da classe } \\
\text { Mi }\end{array}$ & $\begin{array}{c}\text { Frequência } \\
\text { ni }\end{array}$ & $\begin{array}{c}\text { Frequência } \\
\text { asoluta acumulada } \\
\text { Ni }\end{array}$ & $\begin{array}{c}\text { Frequência } \\
\text { relativa } \\
\text { fi }\end{array}$ & $\begin{array}{c}\text { Frequência } \\
\text { relativa acumulada } \\
\text { Fi }\end{array}$ \\
\hline 1 & $-11,014$ & $-9,432$ & $-10,223$ & 36 & 36 & 0,002 & 0,002 \\
\hline 2 & $-9,432$ & $-7,850$ & $-8,641$ & 82 & 118 & 0,005 & 0,007 \\
\hline 3 & $-7,850$ & $-6,268$ & $-7,059$ & 229 & 347 & 0,014 & 0,022 \\
\hline 4 & $-6,268$ & $-4,686$ & $-5,477$ & 787 & 1134 & 0,049 & 0,071 \\
\hline 5 & $-4,686$ & $-3,104$ & $-3,895$ & 1258 & 2392 & 0,078 & 0,149 \\
\hline 6 & $-3,104$ & $-1,522$ & $-2,313$ & 1604 & 3996 & 0,100 & 0,249 \\
\hline 7 & $-1,522$ & 0,060 & $-0,731$ & 4659 & 8655 & 0,291 & 0,540 \\
\hline 8 & 0,060 & 1,643 & 0,851 & 3580 & 12235 & 0,223 & 0,763 \\
\hline 9 & 1,643 & 3,225 & 2,434 & 1560 & 13795 & 0,097 & 0,861 \\
\hline 10 & 3,225 & 4,807 & 4,016 & 1163 & 14958 & 0,073 & 0,933 \\
\hline 11 & 4,807 & 6,389 & 5,598 & 722 & 15680 & 0,045 & 0,978 \\
\hline 12 & 6,389 & 7,971 & 7,180 & 219 & 15899 & 0,014 & 0,992 \\
\hline 13 & 7,971 & 9,553 & 8,762 & 87 & 15986 & 0,005 & 0,997 \\
\hline 14 & 9,553 & 11,135 & 10,344 & 38 & 16024 & 0,002 & 1,000 \\
\hline 15 & 11,135 & 12,717 & 11,926 & 4 & 16028 & 0,000 & 1,000 \\
\hline
\end{tabular}

Da Tabela 7.6 se obtém a Figura 7.3 na qual são representadas a média da classe e a frequência relativa de ocorrência do registro das acelerações. Pode-se observar que acelerações altas, da ordem entre 7 e $2 \mathrm{~m} / \mathrm{s}^{2}$, ainda são representativas, em várias classes à direita e a esquerda da classe que apresenta menor média de aceleração que é $-0,73 \mathrm{~m} / \mathrm{s}^{2}$.

Esta distribuição de classes apresenta-se pela alta flexibilidade da laje e pelo baixo amortecimento dela em torno de $1,8 \%$, como foi discutido anteriormente. 


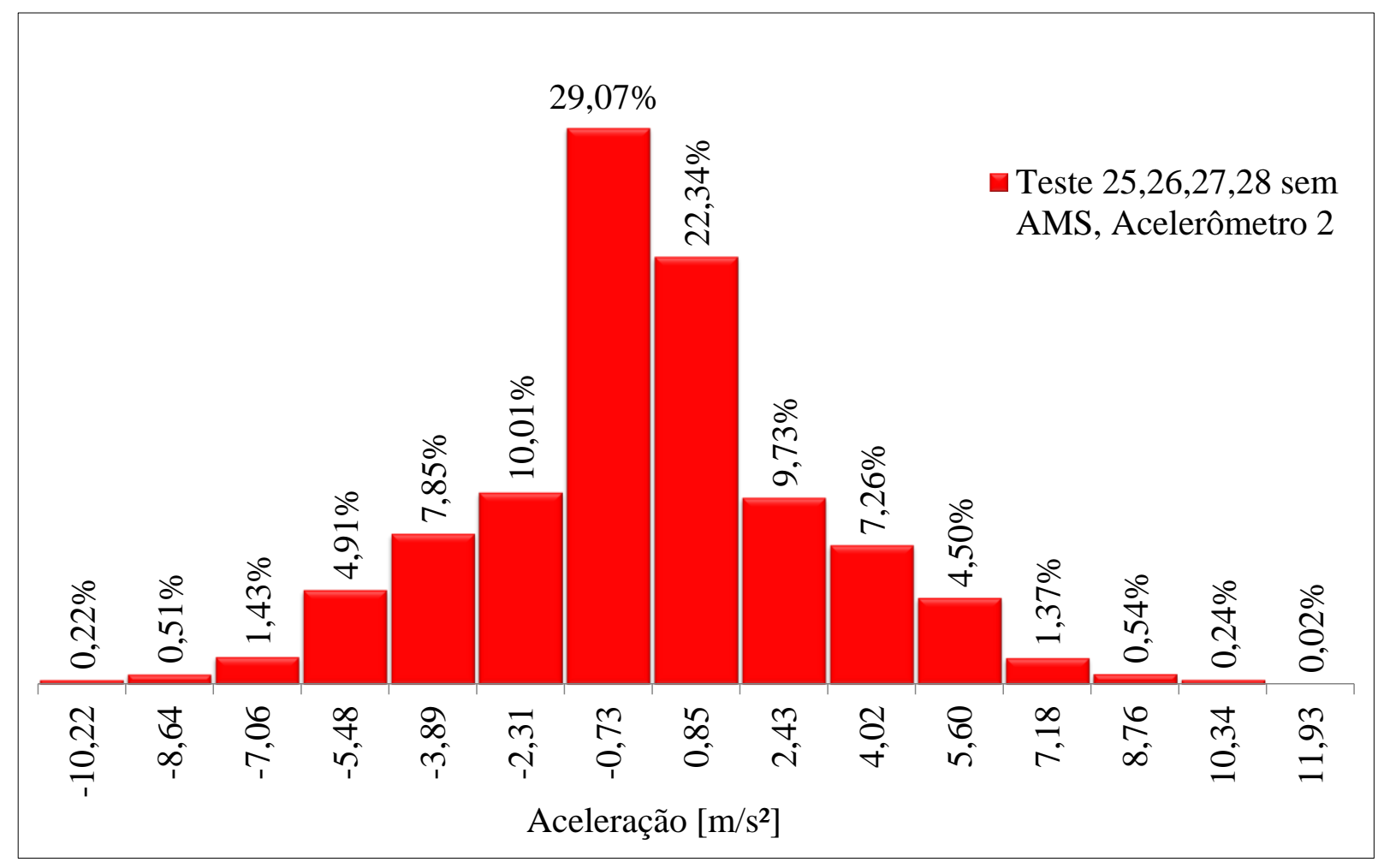

Figura 7.3 - Histograma de frequências de todas as acelerações registradas pelo acelerômetro 2 com pulo continuo nos ensaios na plataforma sem AMS.

\subsubsection{Excitação com pulo continuo no centro da laje com AMS}

Apresentam-se agora os resultados dos ensaios realizados com excitação de pulo continuo considerando a plataforma com AMS. Os ensaios foram feitos da mesma maneira com e sem AMS e sempre com a mesma pessoa para evitar variações dos resultados. Na Tabela 7.7 e Tabela 7.8 se apresenta uma síntese dos resultados dos quatro ensaios.

Tabela 7.7 - Amplitude e número de classes dos registros de acelerações dos ensaios simulando pulo continuo na plataforma com AMS.

\begin{tabular}{|l|c|}
\hline Número total de dados $[\mathrm{n}]$ & 16028 \\
\hline Valor mínimo dos ensaios $\left[\mathrm{Z}_{\mathrm{min}}\right]$ & $-2,943 \mathrm{~m} / \mathrm{s}^{2}$ \\
\hline Valor máximo dos ensaios $\left[\mathrm{Z}_{\mathrm{max}}\right]$ & $3,075 \mathrm{~m} / \mathrm{s}^{2}$ \\
\hline Amplitude conjunto de dados $[\mathrm{L}]$ & $6,018 \mathrm{~m} / \mathrm{s}^{2}$ \\
\hline $\mathrm{N}^{\circ}$ de classes $[\mathrm{K}]$ & 15 \\
\hline Amplitude da classe $[\mathrm{h}]$ & $0,401 \mathrm{~m} / \mathrm{s}^{2}$ \\
\hline
\end{tabular}


Tabela 7.8 - Distribuição de frequências por intervalos de todos os registros das acelerações do acelerômetro 2, com pulo continuo na plataforma com AMS.

\begin{tabular}{|c|c|c|c|c|c|c|c|}
\hline \multicolumn{7}{|c|}{ Acelerômetro 2, teste 9,10,11,12 com AMS } \\
\hline Classe & $\begin{array}{c}\text { Limite inferior } \\
\text { da classe }\end{array}$ & $\begin{array}{c}\text { Limite superior } \\
\text { da classe }\end{array}$ & $\begin{array}{c}\text { Média da classe } \\
\mathrm{Mi}\end{array}$ & $\begin{array}{c}\text { Frequência } \\
\mathrm{ni}\end{array}$ & $\begin{array}{c}\text { Frequência } \\
\text { asoluta acumulada } \\
\mathrm{Ni}\end{array}$ & $\begin{array}{c}\text { Frequência } \\
\text { relativa } \\
\mathrm{fi}\end{array}$ & $\begin{array}{c}\text { Frequência } \\
\text { relativa acumulada } \\
\mathrm{Fi}\end{array}$ \\
\hline 1 & $-2,943$ & $-2,542$ & $-2,742$ & 9 & 9 & 0,001 & 0,001 \\
\hline 2 & $-2,542$ & $-2,140$ & $-2,341$ & 17 & 26 & 0,001 & 0,002 \\
\hline 3 & $-2,140$ & $-1,739$ & $-1,940$ & 91 & 117 & 0,006 & 0,007 \\
\hline 4 & $-1,739$ & $-1,338$ & $-1,538$ & 322 & 439 & 0,020 & 0,027 \\
\hline 5 & $-1,338$ & $-0,937$ & $-1,137$ & 888 & 1327 & 0,055 & 0,083 \\
\hline 6 & $-0,937$ & $-0,535$ & $-0,736$ & 1190 & 2517 & 0,074 & 0,157 \\
\hline 7 & $-0,535$ & $-0,134$ & $-0,335$ & 2669 & 5186 & 0,167 & 0,324 \\
\hline 8 & $-0,134$ & 0,267 & 0,066 & 6974 & 12160 & 0,435 & 0,759 \\
\hline 9 & 0,267 & 0,668 & 0,468 & 1769 & 13929 & 0,110 & 0,869 \\
\hline 10 & 0,668 & 1,069 & 0,869 & 1188 & 15117 & 0,074 & 0,943 \\
\hline 11 & 1,069 & 1,471 & 1,270 & 676 & 15793 & 0,042 & 0,985 \\
\hline 12 & 1,471 & 1,872 & 1,671 & 185 & 15978 & 0,012 & 0,997 \\
\hline 13 & 1,872 & 2,273 & 2,072 & 36 & 16014 & 0,002 & 0,999 \\
\hline 14 & 2,273 & 2,674 & 2,474 & 12 & 16026 & 0,001 & 0,9999 \\
\hline 15 & 2,674 & 3,075 & 2,875 & 2 & 16028 & 0,0001 & 1,000 \\
\hline
\end{tabular}

Da tabela anterior é feita a Figura 7.4 correspondente ao histograma de frequências.

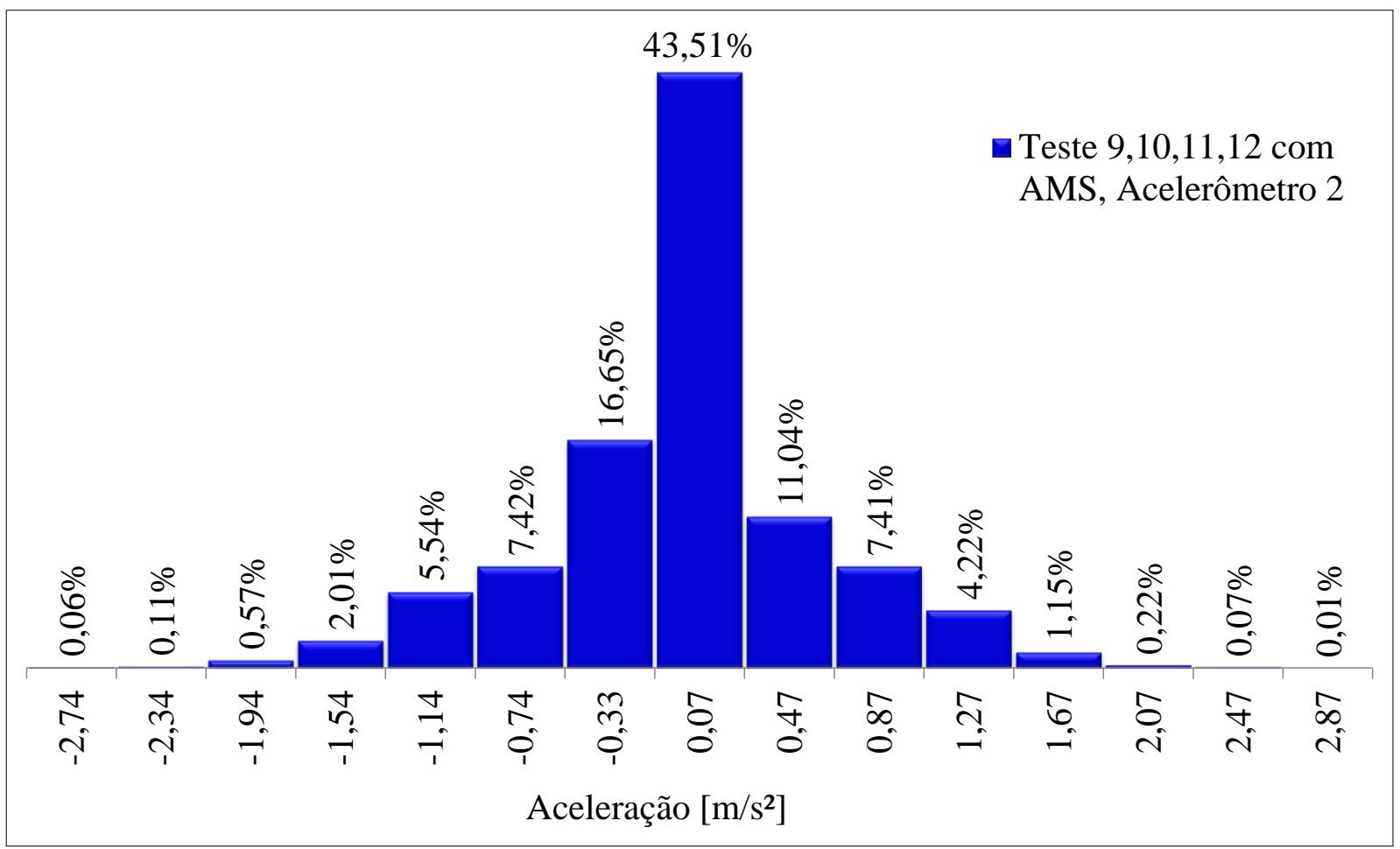

Figura 7.4 - Histograma de frequências de todas as acelerações registradas pelo acelerômetro 2 com pulo continuo nos ensaios na plataforma com AMS. 
Comparando os resultados da Figura 7.3 e da Figura 7.4 observasse que a incorporação do sistema de controle à estrutura implica em uma queda da média da aceleração máxima negativa de $-10,22 \mathrm{~m} / \mathrm{s}^{2}$ para uma aceleração de $-2,74 \mathrm{~m} / \mathrm{s}^{2}$ e também de uma média de aceleração máxima positiva de $11,93 \mathrm{~m} / \mathrm{s}^{2}$ para uma aceleração de $2,87 \mathrm{~m} / \mathrm{s}^{2}$.

Pode se afirmar que o AMS controla muito bem as acelerações nos 4 ensaios considerando a força gerada pelo pulo continuo de uma pessoa no centro da laje, já que um 43,51\% dos registros das acelerações médias tem valor mínimo muito pequeno, de $0,07 \mathrm{~m} / \mathrm{s}^{2}$. Por essa razão se considera que o AMS teve um desempenho ótimo na redução de acelerações.

Em testes individuas para este tipo de ensaio o sistema de controle obteve um desempenho de $70 \%$ na redução das acelerações como foi explicado na Figura 6.6. No Anexo XI se encontram os demais resultados dos histogramas e tabelas para este tipo de ensaio.

\subsection{TRATAMENTO ESTATÍSTICO PARA OS ENSAIOS COM FORÇA DE EXCITAÇÃO GERADA POR PESSOAS CAMINHANDO NA SUPERFICIE DA} LAJE

\subsubsection{Excitação gerada por pessoas caminhando na superfície da laje sem AMS}

Neste tipo de ensaios um grupo de pessoas excitava a plataforma mediante atividade ritmada de caminhar aleatoriamente durante 20 segundos. Os registros captados pelo acelerômetro 2 nos ensaios considerando um grupo de três pessoas foram processados estatisticamente e os resultados se condensam na Tabela 7.9, Tabela 7.10 e na Figura 7.5.

Tabela 7.9 - Amplitude e número de classes dos registros de acelerações dos ensaios de um grupo de três pessoas caminhando na plataforma sem AMS.

\begin{tabular}{|l|c|}
\hline Número total de dados $[\mathrm{n}]$ & 16028 \\
\hline Valor mínimo dos ensaios $\left[\mathrm{Z}_{\mathrm{min}}\right]$ & $-3,750 \mathrm{~m} / \mathrm{s}^{2}$ \\
\hline Valor máximo dos ensaios $\left[\mathrm{Z}_{\max }\right]$ & $3,744 \mathrm{~m} / \mathrm{s}^{2}$ \\
\hline Amplitude conjunto de dados $[\mathrm{L}]$ & $7,494 \mathrm{~m} / \mathrm{s}^{2}$ \\
\hline $\mathrm{N}^{\circ}$ de classes $[\mathrm{K}]$ & 15 \\
\hline Amplitude da classe $[\mathrm{h}]$ & $0,500 \mathrm{~m} / \mathrm{s}^{2}$ \\
\hline
\end{tabular}


Tabela 7.10 - Distribuição de frequências por intervalos de todos os registros das acelerações do acelerômetro 2, força de excitação grupo de 3 pessoas caminhando na plataforma sem AMS.

\begin{tabular}{|c|c|c|c|c|c|c|c|}
\hline \multicolumn{7}{|c|}{ Acelerômetro 2, teste 17,18,19,20 sem AMS } \\
\hline Classe & $\begin{array}{c}\text { Limite inferior } \\
\text { da classe }\end{array}$ & $\begin{array}{c}\text { Limite superior } \\
\text { da classe }\end{array}$ & $\begin{array}{c}\text { Média da classe } \\
\mathrm{Mi}\end{array}$ & $\begin{array}{c}\text { Frequência } \\
\mathrm{ni}\end{array}$ & $\begin{array}{c}\text { Frequência } \\
\text { absoluta acumulada } \\
\mathrm{Ni}\end{array}$ & $\begin{array}{c}\text { Frequência } \\
\text { relativa } \\
\mathrm{fi}\end{array}$ & $\begin{array}{c}\text { Frequência } \\
\text { relativa acumulada } \\
\mathrm{Fi}\end{array}$ \\
\hline 1 & $-3,750$ & $-3,250$ & $-3,500$ & 8 & 8 & 0,0005 & 0,0005 \\
\hline 2 & $-3,250$ & $-2,751$ & $-3,000$ & 29 & 37 & 0,0018 & 0,0023 \\
\hline 3 & $-2,751$ & $-2,251$ & $-2,501$ & 152 & 189 & 0,0095 & 0,012 \\
\hline 4 & $-2,251$ & $-1,751$ & $-2,001$ & 337 & 526 & 0,021 & 0,033 \\
\hline 5 & $-1,751$ & $-1,252$ & $-1,502$ & 785 & 1311 & 0,049 & 0,082 \\
\hline 6 & $-1,252$ & $-0,752$ & $-1,002$ & 1359 & 2670 & 0,085 & 0,167 \\
\hline 7 & $-0,752$ & $-0,253$ & $-0,502$ & 3018 & 5688 & 0,188 & 0,355 \\
\hline 8 & $-0,253$ & 0,247 & $-0,003$ & 4534 & 10222 & 0,283 & 0,638 \\
\hline 9 & 0,247 & 0,747 & 0,497 & 3076 & 13298 & 0,192 & 0,830 \\
\hline 10 & 0,747 & 1,246 & 0,997 & 1539 & 14837 & 0,096 & 0,926 \\
\hline 11 & 1,246 & 1,746 & 1,496 & 637 & 15474 & 0,040 & 0,965 \\
\hline 12 & 1,746 & 2,246 & 1,996 & 358 & 15832 & 0,022 & 0,988 \\
\hline 13 & 2,246 & 2,745 & 2,495 & 143 & 15975 & 0,009 & 0,997 \\
\hline 14 & 2,745 & 3,245 & 2,995 & 41 & 16016 & 0,003 & 0,999 \\
\hline 15 & 3,245 & 3,744 & 3,495 & 11 & 16027 & 0,001 & 1,000 \\
\hline
\end{tabular}

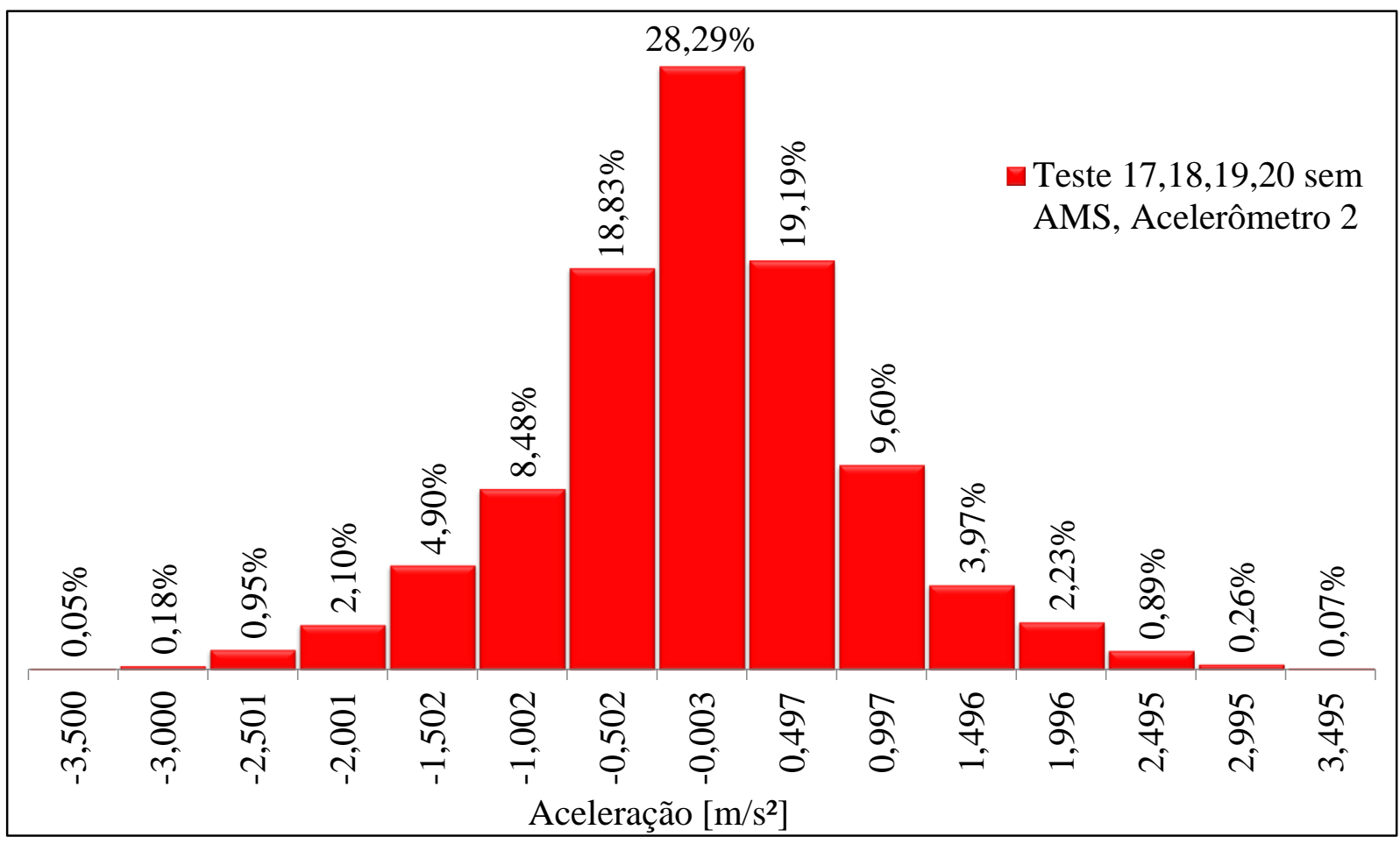

Figura 7.5 - Histograma de frequências de todas as acelerações registradas pelo acelerômetro 2 nos ensaios de três pessoas caminhado na plataforma sem AMS. 
Da Figura 7.5 se pode notar que as médias das acelerações nos extremos do histograma são menores comparadas com os ensaios anteriores (força harmônica e pulo continuo no centro da laje), uma vez que a força de excitação induzida pelo caminhar de três pessoas é menor que a forca gerada pelo pulo continuo de uma pessoa. Dessa forma, as acelerações resultam menores que nos casos estudados anteriormente.

À mesma constatação se chega quando se analisa a parte central do histograma com $84,39 \%$ dos registros das medidas das acelerações inferiores em valor absoluto a $1 \mathrm{~m} / \mathrm{s}^{2}$.

\subsubsection{Excitação gerada por pessoas caminhando na superfície da laje com AMS}

Também foram feitos ensaios com um grupo de três pessoas caminhando na superfície da laje, com atuação do AMS. O processamento dos resultados do acelerômetro 2 se apresenta nas Tabela 7.11 e Tabela 7.12 e na Figura 7.6.

Tabela 7.11 - Amplitude e número de classes dos registros de acelerações dos ensaios de um grupo de três pessoas caminhando na plataforma com AMS.

\begin{tabular}{|l|c|}
\hline Número total de dados $[\mathrm{n}]$ & 16028 \\
\hline Valor mínimo dos ensaios $\left[\mathrm{Z}_{\mathrm{min}}\right]$ & $-2,457 \mathrm{~m} / \mathrm{s}^{2}$ \\
\hline Valor máximo dos ensaios $\left[\mathrm{Z}_{\mathrm{max}}\right]$ & $2,540 \mathrm{~m} / \mathrm{s}^{2}$ \\
\hline Amplitude conjunto de dados $[\mathrm{L}]$ & $4,996 \mathrm{~m} / \mathrm{s}^{2}$ \\
\hline $\mathrm{N}^{\circ}$ de classes $[\mathrm{K}]$ & 15 \\
\hline Amplitude da classe $[\mathrm{h}]$ & $0,333 \mathrm{~m} / \mathrm{s}^{2}$ \\
\hline
\end{tabular}


Tabela 7.12 - Distribuição de frequências por intervalos de todos os registros das acelerações do acelerômetro 2, com força de excitação de grupo de 3 pessoas caminhando na plataforma com AMS.

\begin{tabular}{|c|c|c|c|c|c|c|c|}
\hline \multicolumn{7}{|c|}{ Acelerômetro 2, teste 5,6,7,8 com AMS } \\
\hline Classe & $\begin{array}{c}\text { Limite inferior } \\
\text { da classe }\end{array}$ & $\begin{array}{c}\text { Limite superior } \\
\text { da classe }\end{array}$ & $\begin{array}{c}\text { Média da classe } \\
\text { Mi }\end{array}$ & $\begin{array}{c}\text { Frequência } \\
\text { ni }\end{array}$ & $\begin{array}{c}\text { Frequência } \\
\text { absoluta acumulada } \\
\text { Ni }\end{array}$ & $\begin{array}{c}\text { Frequência } \\
\text { relativa } \\
\text { fi }\end{array}$ & $\begin{array}{c}\text { Frequência } \\
\text { relativa acumulada } \\
\text { Fi }\end{array}$ \\
\hline 1 & $-2,457$ & $-2,124$ & $-2,290$ & 13 & 13 & 0,001 & 0,001 \\
\hline 2 & $-2,124$ & $-1,790$ & $-1,957$ & 46 & 59 & 0,003 & 0,004 \\
\hline 3 & $-1,790$ & $-1,457$ & $-1,624$ & 137 & 196 & 0,009 & 0,012 \\
\hline 4 & $-1,457$ & $-1,124$ & $-1,291$ & 343 & 539 & 0,021 & 0,034 \\
\hline 5 & $-1,124$ & $-0,791$ & $-0,958$ & 1085 & 1624 & 0,068 & 0,101 \\
\hline 6 & $-0,791$ & $-0,458$ & $-0,625$ & 1903 & 3527 & 0,119 & 0,220 \\
\hline 7 & $-0,458$ & $-0,125$ & $-0,292$ & 3273 & 6800 & 0,204 & 0,424 \\
\hline 8 & $-0,125$ & 0,208 & 0,041 & 3398 & 10198 & 0,212 & 0,636 \\
\hline 9 & 0,208 & 0,541 & 0,375 & 3005 & 13203 & 0,187 & 0,824 \\
\hline 10 & 0,541 & 0,874 & 0,708 & 1576 & 14779 & 0,098 & 0,922 \\
\hline 11 & 0,874 & 1,207 & 1,041 & 775 & 15554 & 0,048 & 0,970 \\
\hline 12 & 1,207 & 1,540 & 1,374 & 301 & 15855 & 0,019 & 0,989 \\
\hline 13 & 1,540 & 1,873 & 1,707 & 123 & 15978 & 0,008 & 0,997 \\
\hline 14 & 1,873 & 2,206 & 2,040 & 39 & 16017 & 0,002 & 0,999 \\
\hline 15 & 2,206 & 2,540 & 2,373 & 11 & 16028 & 0,001 & 1,000 \\
\hline
\end{tabular}

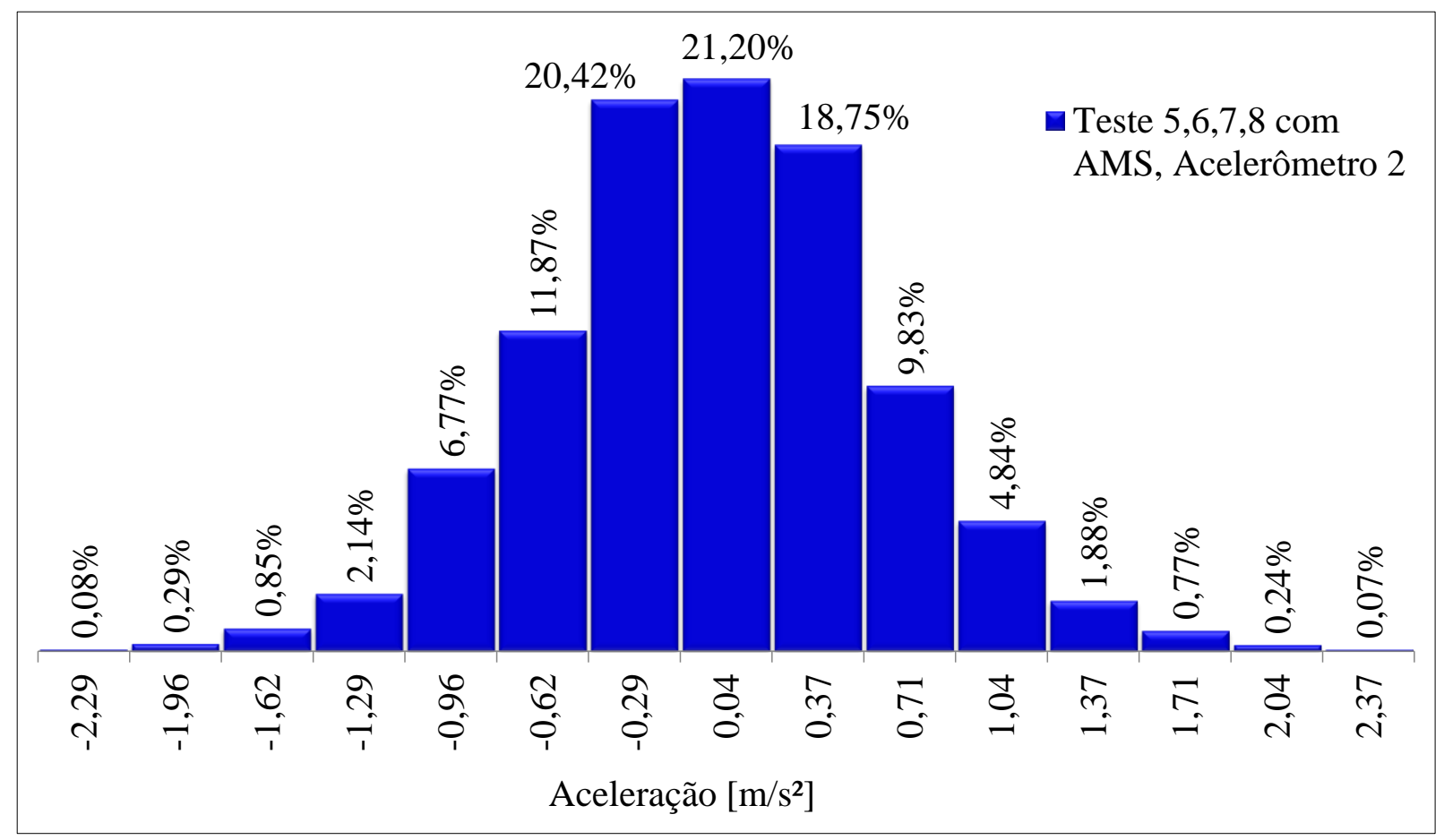

Figura 7.6 - Histograma de frequências de todas as acelerações registradas pelo acelerômetro 2 de três pessoas caminhado nos ensaios na plataforma com AMS. 
Comparando a Figura 7.6 com a Figura 7.5 observa-se que a incorporação do AMS reduz as acelerações, porém, como já observado, a sua atuação é mais significativa quando a excitação é mais intensa e a laje apresenta maiores amplitudes de vibração.

Revisando a Figura 7.6 se observa uma maior densidade de acelerações médias no centro do histograma intervalo de $[-1,1] \mathrm{m} / \mathrm{s}^{2}$, em torno de $93 \%$ delas são de menor magnitude, devido à pouca força de excitação dos pedestres ao caminhar. Neste caso, se considera que o AMS, embora provoque uma redução de aproximadamente $9 \%$ nas acelerações inferiores a $1 \mathrm{~m} / \mathrm{s}^{2} \mathrm{em}$ valor absoluto, não atua de forma tão significativamente com em outros casos.

Também pode se observar uma queda nas máximas acelerações médias dos extremos do histograma por exemplo nas acelerações negativas passa de $-3,50 \mathrm{~m} / \mathrm{s}^{2} \mathrm{sem}$ controle para -2,29 $\mathrm{m} / \mathrm{s}^{2}$ com controle e para acelerações positivas passa de $3,495 \mathrm{~m} / \mathrm{s}^{2}$ para $2,37 \mathrm{~m} / \mathrm{s}^{2}$ com o AMS.

\subsection{TRATAMENTO ESTATÍSTICO PARA OS ENSAIOS DE FORÇA DE EXCITAÇÃO QUE PRODUZ O IMPACTO DE UMA PESSOA PULANDO DESDE UMA CARTEIRA ESCOLAR}

\subsubsection{Excitação gerada pulando desde uma carteira escolar na superfície da laje sem AMS}

Por último foram analisados os resultados obtidos em ensaios considerando com excitação uma pessoa pulando desde uma carteira. Os ensaios foram realizados inicialmente na laje sem o amortecedor.

A força de impacto em todos os ensaios foi produzida por uma pessoa de $75 \mathrm{~kg}$-f que pulava desde uma carteira escolar de altura aproximada de $43 \mathrm{~cm}$ e ganhando mais $20 \mathrm{~cm}$ de altura após o pulo como foi apresentado na Figura 6.15.

Os resultados desta análise considerando os registros do acelerômetro 2 se resumem na Tabela 7.13, na Tabela 7.14 e na Figura 7.7. 
Tabela 7.13 - Amplitude e número de classes dos registros de acelerações dos ensaios que produz uma força de impacto na plataforma sem AMS.

\begin{tabular}{|l|c|}
\hline Número total de dados $[\mathrm{n}]$ & 16028 \\
\hline Valor mínimo dos ensaios $\left[\mathrm{Z}_{\min }\right]$ & $-14,142 \mathrm{~m} / \mathrm{s}^{2}$ \\
\hline Valor máximo dos ensaios $\left[\mathrm{Z}_{\max }\right]$ & $17,709 \mathrm{~m} / \mathrm{s}^{2}$ \\
\hline Amplitude conjunto de dados $[\mathrm{L}]$ & $31,851 \mathrm{~m} / \mathrm{s}^{2}$ \\
\hline $\mathrm{N}^{\circ}$ de classes $[\mathrm{K}]$ & 15 \\
\hline Amplitude da classe $[\mathrm{h}]$ & $2,123 \mathrm{~m} / \mathrm{s}^{2}$ \\
\hline
\end{tabular}

Tabela 7.14 - Distribuição de frequências por intervalos de todos os registros das acelerações do acelerômetro 2, força de excitação pulando desde carteira escolar na plataforma sem AMS.

\begin{tabular}{|c|c|c|c|c|c|c|c|}
\hline \multicolumn{7}{|c|}{ Acelerômetro 2, teste 21,22,23,24 sem AMS } \\
\hline Classe & $\begin{array}{c}\text { Limite inferior } \\
\text { da classe }\end{array}$ & $\begin{array}{c}\text { Limite superior } \\
\text { da classe }\end{array}$ & $\begin{array}{c}\text { Média da classe } \\
\mathrm{Mi}\end{array}$ & $\begin{array}{c}\text { Frequência } \\
\mathrm{ni}\end{array}$ & $\begin{array}{c}\text { Frequência } \\
\text { absoluta acumulada } \\
\mathrm{Ni}\end{array}$ & $\begin{array}{c}\text { Frequência } \\
\text { relativa } \\
\mathrm{fi}\end{array}$ & $\begin{array}{c}\text { Frequência } \\
\text { relativa acumulada } \\
\mathrm{Fi}\end{array}$ \\
\hline 1 & $-14,142$ & $-12,018$ & $-13,080$ & 1 & 1 & 0,00006 & 0,0001 \\
\hline 2 & $-12,018$ & $-9,895$ & $-10,957$ & 1 & 2 & 0,00006 & 0,00012 \\
\hline 3 & $-9,895$ & $-7,772$ & $-8,833$ & 3 & 5 & 0,0002 & 0,000 \\
\hline 4 & $-7,772$ & $-5,648$ & $-6,710$ & 10 & 15 & 0,001 & 0,001 \\
\hline 5 & $-5,648$ & $-3,525$ & $-4,587$ & 45 & 60 & 0,003 & 0,004 \\
\hline 6 & $-3,525$ & $-1,402$ & $-2,463$ & 192 & 252 & 0,012 & 0,016 \\
\hline 7 & $-1,402$ & 0,722 & $-0,340$ & 15124 & 15376 & 0,944 & 0,959 \\
\hline 8 & 0,722 & 2,845 & 1,783 & 563 & 15939 & 0,035 & 0,994 \\
\hline 9 & 2,845 & 4,969 & 3,907 & 57 & 15996 & 0,004 & 0,998 \\
\hline 10 & 4,969 & 7,092 & 6,030 & 20 & 16016 & 0,001 & 0,999 \\
\hline 11 & 7,092 & 9,215 & 8,154 & 4 & 16020 & 0,0002 & 0,9995 \\
\hline 12 & 9,215 & 11,339 & 10,277 & 3 & 16023 & 0,0002 & 0,9997 \\
\hline 13 & 11,339 & 13,462 & 12,400 & 2 & 16025 & 0,0001 & 0,9998 \\
\hline 14 & 13,462 & 15,585 & 14,524 & 2 & 16027 & 0,0001 & 0,9999 \\
\hline 15 & 15,585 & 17,709 & 16,647 & 1 & 16028 & 0,0001 & 1,0000 \\
\hline
\end{tabular}

Neste tipo de ensaio foram registrados os maiores picos de todas as acelerações negativas alcançando valores de $-14,142 \mathrm{~m} / \mathrm{s}^{2}$ e de acelerações positivas como for $17,709 \mathrm{~m} / \mathrm{s}^{2}$, devido ao forte impacto da força de excitação. 


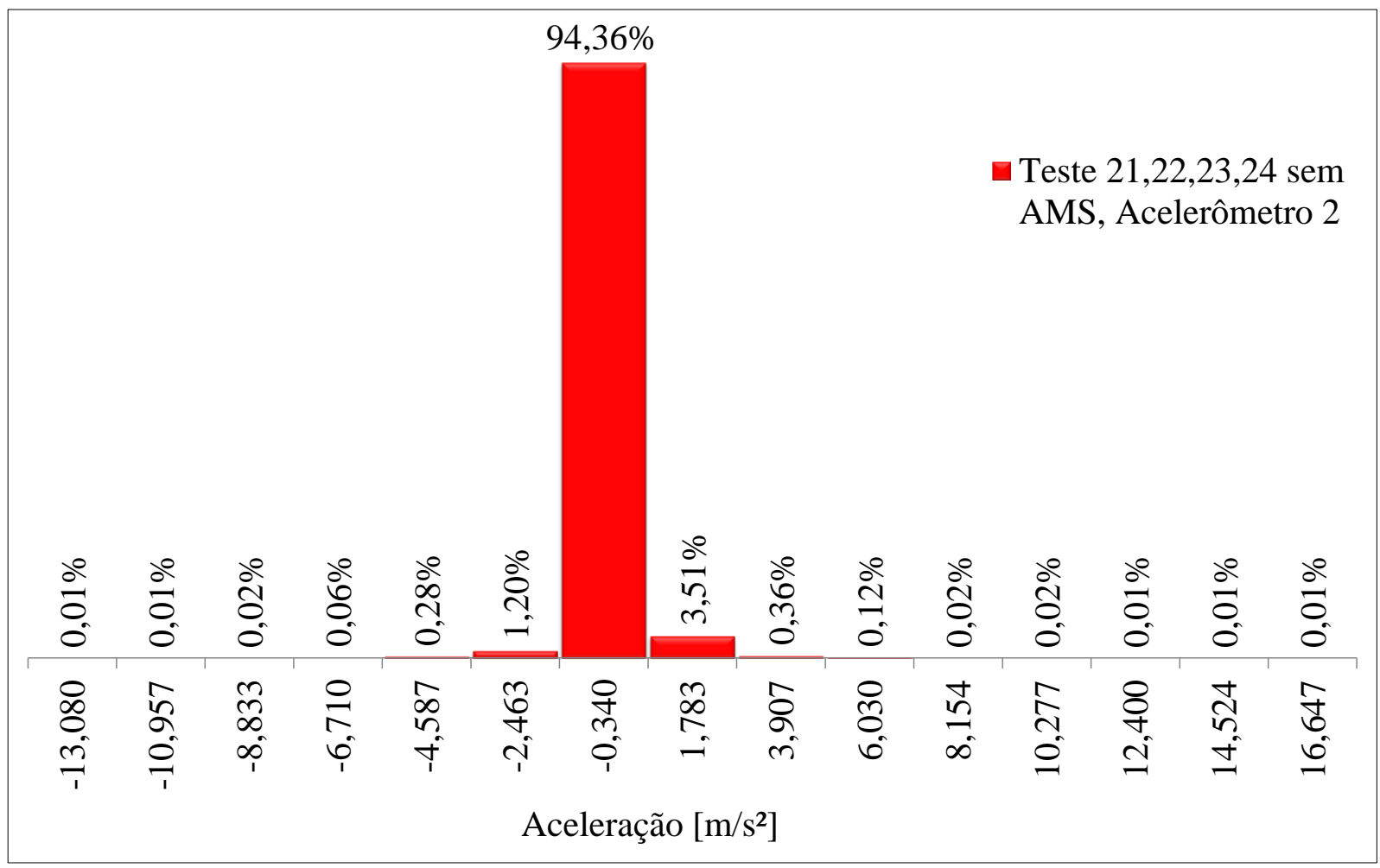

Figura 7.7 - Histograma de frequências de todas as acelerações registradas pelo acelerômetro 2 nos ensaios de pulo desde carteira escolar na plataforma sem AMS.

Na Figura 7.7 se observa que as maiores médias dos registros das acelerações se apresentam em porcentagens muito baixas devido a que a força de excitação atua por muito pouquíssimo tempo.

\subsubsection{Excitação gerada pulando desde uma carteira escolar na superfície da laje com AMS}

Os resultados dos ensaios realizados na laje com o amortecedor se resumem na Tabela 7.15, na Tabela 7.16 e na Figura 7.8.

Tabela 7.15 - Amplitude e número de classes dos registros de acelerações dos ensaios que produz uma força de impacto na plataforma com AMS.

\begin{tabular}{|l|c|}
\hline Número total de dados $[\mathrm{n}]$ & 16028 \\
\hline Valor mínimo dos ensaios $\left[\mathrm{Z}_{\mathrm{min}}\right]$ & $-7,967 \mathrm{~m} / \mathrm{s}^{2}$ \\
\hline Valor máximo dos ensaios $\left[\mathrm{Z}_{\mathrm{max}}\right]$ & $7,305 \mathrm{~m} / \mathrm{s}^{2}$ \\
\hline Amplitude conjunto de dados $[\mathrm{L}]$ & $15,272 \mathrm{~m} / \mathrm{s}^{2}$ \\
\hline $\mathrm{N}^{\circ}$ de classes $[\mathrm{K}]$ & 15 \\
\hline Amplitude da classe $[\mathrm{h}]$ & $1,018 \mathrm{~m} / \mathrm{s}^{2}$ \\
\hline
\end{tabular}


Tabela 7.16 - Distribuição de frequências por intervalos de todos os registros das acelerações do acelerômetro 2, com força de excitação pulando desde carteira escolar na plataforma com AMS.

\begin{tabular}{|c|c|c|c|c|c|c|c|}
\hline \multicolumn{7}{|c|}{ Acelerômetro 2, teste 09,10,11,12 com AMS } \\
\hline Classe & $\begin{array}{c}\text { Limite inferior } \\
\text { da classe }\end{array}$ & $\begin{array}{c}\text { Limite superior } \\
\text { da classe }\end{array}$ & $\begin{array}{c}\text { Média da classe } \\
\mathrm{Mi}\end{array}$ & $\begin{array}{c}\text { Frequência } \\
\mathrm{ni}\end{array}$ & $\begin{array}{c}\text { Frequência } \\
\text { absoluta acumulada } \\
\mathrm{Ni}\end{array}$ & $\begin{array}{c}\text { Frequência } \\
\text { relativa } \\
\mathrm{fi}\end{array}$ & $\begin{array}{c}\text { Frequência } \\
\text { relativa acumulada } \\
\mathrm{Fi}\end{array}$ \\
\hline 1 & $-7,967$ & $-6,949$ & $-7,458$ & 3 & 3 & 0,0002 & 0,0002 \\
\hline 2 & $-6,949$ & $-5,931$ & $-6,440$ & 1 & 4 & 0,0001 & 0,0002 \\
\hline 3 & $-5,931$ & $-4,912$ & $-5,422$ & 5 & 9 & 0,0003 & 0,0006 \\
\hline 4 & $-4,912$ & $-3,894$ & $-4,403$ & 9 & 18 & 0,0006 & 0,0011 \\
\hline 5 & $-3,894$ & $-2,876$ & $-3,385$ & 28 & 46 & 0,0017 & 0,0029 \\
\hline 6 & $-2,876$ & $-1,858$ & $-2,367$ & 70 & 116 & 0,004 & 0,007 \\
\hline 7 & $-1,858$ & $-0,840$ & $-1,349$ & 281 & 397 & 0,018 & 0,025 \\
\hline 8 & $-0,840$ & 0,178 & $-0,331$ & 13218 & 13615 & 0,825 & 0,849 \\
\hline 9 & 0,178 & 1,196 & 0,687 & 2179 & 15794 & 0,136 & 0,985 \\
\hline 10 & 1,196 & 2,215 & 1,706 & 151 & 15945 & 0,009 & 0,995 \\
\hline 11 & 2,215 & 3,233 & 2,724 & 37 & 15982 & 0,002 & 0,997 \\
\hline 12 & 3,233 & 4,251 & 3,742 & 18 & 16000 & 0,001 & 0,998 \\
\hline 13 & 4,251 & 5,269 & 4,760 & 18 & 16018 & 0,001 & 0,999 \\
\hline 14 & 5,269 & 6,287 & 5,778 & 4 & 16022 & 0,0002 & 0,9996 \\
\hline 15 & 6,287 & 7,305 & 6,796 & 5 & 16027 & 0,0003 & 1,000 \\
\hline
\end{tabular}

Comparando a Tabela 7.16 com a Tabela 7.14 se observa uma queda das acelerações máximas negativas de $-14,142 \mathrm{~m} / \mathrm{s}^{2}$ para $-7,967$ e uma queda das acelerações máximas positivas de 15,585 $\mathrm{m} / \mathrm{s}^{2}$ para $6,287 \mathrm{~m} / \mathrm{s}^{2}$ quando os ensaios se realizam na plataforma com sistema de controle.

Neste caso pode-se dizer que o AMS responde bem na redução das acelerações a pesar do pouco tempo de atuação da força excitadora. Nos demais registros de acelerações também se observou em geral queda das acelerações. 


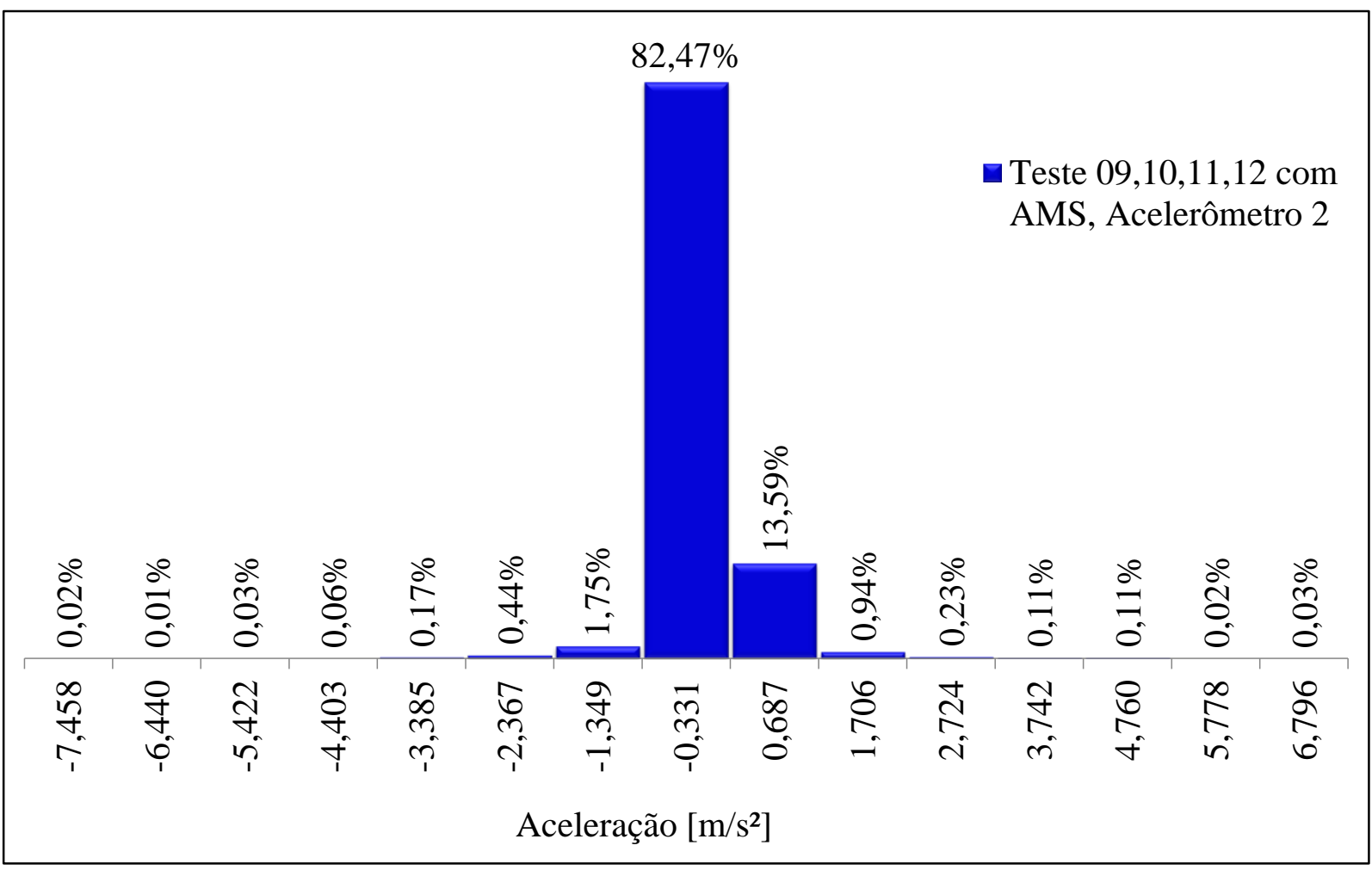

Figura 7.8 - Histograma de frequências de todas as acelerações registradas pelo acelerômetro 2 de pulo desde uma carteira escolar nos ensaios na plataforma com AMS.

Comparando o intervalo de $[-1,1] \mathrm{m} / \mathrm{s}^{2}$ na Figura 7.8 e Figura 7.7 pode observar-se que as porcentagens nas barras do histograma com ajuda do AMS tem um valor de 96,06\% que comparados com os valores de 94,36\% sem AMS daí como resultado uma eficiência do amortecedor de $1,7 \%$ na redução das acelerações médias.

O anterior desempenho do AMS e baixo porque o tempo de atuação da força de excitação externa é muito pequeno que pode estar na ordem de 125 até 500 milissegundos. 


\section{CONCLUSÕES E SUGESTÕES}

\subsection{CONCLUSÕES GERAIS}

Com o objetivo de propor uma metodologia de projeto para um sistema de controle de vibrações para pisos de edifícios, no presente trabalho foram realizados o projeto e a construção de um amortecedor de massa sintonizado (AMS). Este atua como um sistema de controle passivo para reduzir as significativas vibrações verticais que apresenta a plataforma de ensaios dinâmicos localizada no Laboratório de Estruturas da Universidade de Brasília.

A seguir apresentam-se os passos da metodologia adotada em conjunto com as principais conclusões obtidas a partir dos resultados:

Inicialmente uma análise paramétrica foi efetuada para o AMS.

Dois casos de controle estrutural utilizando AMS foram estudados numericamente, o primeiro variando-se os parâmetros para um único amortecedor, e o segundo para um sistema com vários amortecedores atuando simultaneamente. Os estudos numéricos foram realizados utilizando a linguagem de modelagem paramétrica APDL (ANSYS Parametric Design Language), ver Anexo XII.

Apresentaram-se 22 modelos numéricos diferentes, os 7 primeiros modelos correspondem ao primeiro caso de estudo que considera apenas um AMS no centro da laje e os 15 restantes são uma combinação vários AMS em quantidade e posição de atuação.

Para o primeiro caso estudado, o modelo sete apresentou melhor performance nas reduções das amplitudes de vibração na laje de concreto, devido a uma boa calibração do AMS.

O modelo 7 foi sintonizado na frequência de ressonância de $3,3 \mathrm{~Hz}$ e numericamente se conseguiu uma redução nas amplitudes da resposta em aproximadamente 82,96\%.

Através dos resultados da análise transiente do modelo 7 foi calculado aproximadamente o amortecimento estrutural. O sistema sem controle apresenta um amortecimento aproximado de $\xi=1,86 \%$ (Figura 5.4 linha em vermelho) e o sistema com controle apresentou $\xi=4,0 \%$ (Figura 5.4 linha em azul). Ocorreu uma acréscimo de 2,14\% no amortecimento da estrutura. 
No segundo estudo, como foi mencionado verificou-se a influência do número e da posição dos AMS. Foi analisada a utilização de 2 e 3 AMS. Neste caso, apresentou melhor desempenho uma configuração de 3 AMS dispostos em linha reta ao longo do eixo $Y$ (modelo 20), ver Figura 5.7.

Comparando os resultados numéricos da resposta do modelo 7 e do modelo 20 vide Figura 5.8, estes apresentam muito similares. No entanto, para a construção do AMS optou-se por trabalhar com o modelo 7 porque torna-se mais simples a construção e colocação de um único AMS ao invés de 3 AMS.

Dos resultados mencionados anteriormente pode-se chegar à seguinte conclusão:

O melhor sistema de controle passivo do amortecedor massa sintonizado AMS para reduzir as vibrações verticais produzidas pelos carregamentos oriundos de atividades humanas na plataforma de ensaios dinâmicos foi um único amortecedor de massa sintonizado com os seguintes parâmetros:

Massa M=120 Kg, Amortecimento C=360 Ns/m e Rigidez K=51000 N/m.

Os parâmetros encontrados numericamente serviram de base para o projeto apresentado na Figura 5.23 e Figura 5.24 e posterior construção do AMS, ver Figura 5.66.

O AMS construído tem a possibilidade de modificar os parâmetros de massa, de rigidez e também do valor de amortecimento equivalente dependendo das características do sistema principal a ser controlado. Em outras palavras é possível modificar a sintonização do mesmo e sua parcela de amortecimento. A variação dos parâmetros consiste em aumentar ou diminuir dependendo do caso as molas, as chapas de aço e o torque requerido no parafuso para obter o amortecimento por atrito em seco.

Lembrando que o AMS é do tipo passivo e que foi sintonizado para a primeira frequência natural experimental da plataforma que foi de $3,36 \mathrm{~Hz}$ ver Tabela $4.1 \mathrm{Com}$ as frequências naturais experimentais da estrutura e do AMS que foi aproximadamente de $3,516 \mathrm{~Hz}$ foi calculada a relação das frequências $\beta=1,05$. A relação de massas foi calculada com a massa real do amortecedor e com o valor teórico da massa da laje da plataforma: $\mu=1,67 \%$. 
O estudo numérico também serviu como base para através das formas modais da estrutura estudada, escolher a melhor posição do amortecedor para melhor performance na redução das vibrações. Verificou-se que a melhor posição para colocação do AMS seria o centro geométrico da plataforma.

Para a primeira forma modal as maiores amplitudes são na região central da laje ao longo do eixo $Y$ vide (Figura 4.15). Da análise numérica Tabela 5.3 demostrou-se que os melhores resultados foram obtidos quando os amortecedores eram localizados alongo do eixo $Y$, ver Figura 5.5.

A partir dos ensaios de vibração livre foram extraídas as formas modais experimentais através do software ARTeMIS.

As formas modais numéricas e experimentais foram comparadas mediante o estudo Modal Assurance Criterion MAC. Os resultados mostraram boa correspondência entre os dados numéricos e experimentais para as três primeiras formas modais, cujo valor do escalar foi maior ou igual a 0,9 em todos os casos, evidenciando resultados satisfatórios principalmente para o primeiro modo.

A correlação dos ensaios numéricos e experimentais para vibração livre foi satisfatório, pois a partir de um calculo aproximado pelo método do decremento logarítmico da Figura 5.4 obtevese um amortecimento de $\xi=1,86 \%$, e a partir dos ensaios experimentais, apresentados na Figura 4.15 obteve-se um amortecimento de $\xi=1,83 \%$.

Foram feitos ensaios experimentais de vibração forçada com atividades ritmadas na plataforma de ensaios dinâmicos, com finalidade de avaliar o desempenho do AMS experimentalmente e validar os resultados obtidos numericamente no início.

Todos os ensaios foram feitos com e sem o sistema de controle AMS, tentando reproduzir os ensaios várias vezes da mesma maneira para obter boa repetitividade. A finalidade de fazer os ensaios desta forma foi comparar as respostas da estrutura e observar o desempenho do AMS para cada tipo de ensaio, além de conseguir reunir dados com os quais fosse possível realizar análises estatísticas dos dados. 
Nos ensaios de vibração forçada simulando uma força harmônica todos os ensaios com atuação do sistema de controle mostraram um nível de desempenho excelente. As amplitudes de aceleração foram reduzidas em até $80 \%$. Uma vez retirada a força excitadora em vibração livre o amortecedor teve uma performance de $95 \%$, na redução da amplitudes de vibração.

Para a análise de todos os ensaios de vibração forçada simulando força harmônica sem ajuda do sistema de controle observou-se uma distribuição de porcentagens considerável em todas as classes do histograma da Figura 7.1, caso contrário do histograma da Figura 7.2 onde com ajuda do sistema de controle as maiores porcentagens de acelerações se concentraram em valores de magnitude baixa.

Da análise anterior, chegam-se na conclusão geral que o sistema de controle se comporta muito bem na redução das acelerações devida as forças de excitação harmônicas.

Nos testes em vibração forçada de pulos contínuos durante 10 segundos no centro da laje com auxílio do sistema de controle em ensaios individuais foram alcançadas reduções nas acelerações da ordem de $68 \%$. Após retirada a forca excitadora o AMS tem um desempenho de 94,4\% na redução das amplitudes de vibração.

No estudo estatístico de todos os ensaios de pulo continuo verificou-se que com a instalação do AMS foram reduzidas as medias das acelerações de magnitude $0,07 \mathrm{~m} / \mathrm{s}^{2} \mathrm{em}$ até $43,51 \%$ como poder se visto na Figura 7.4.

Para este tipo de ensaio também pode-se dizer que as máximas acelerações sem AMS que estiveram na ordem de $12 \mathrm{~m} / \mathrm{s}^{2}$ tiveram uma queda com atuação do AMS em valores máximos alcançados de $2,9 \mathrm{~m} / \mathrm{s}^{2}$.

Pode-se concluir portanto que o sistema de controle também tem bom desempenho para redução de acelerações com o tipo de excitação de pulo continuo.

Foram realizados também ensaios de vibração com forças de excitação que não tenham sequencias de estimulo regular como era o caso do caminhar em grupos com trajetórias aleatórias. 
Percebeu-se que em este tipo de ensaio o valor quadrático médio das acelerações tem uma redução de aproximadamente 53\% devido ao desempenho do AMS, ver Figura 6.13.

Na estatística de todos os ensaios feitos com pessoas caminhando os níveis máximos alcançados de eficiência do AMS na redução das acelerações no intervalo $[-1,1] \mathrm{m} / \mathrm{s}^{2}$ foi de $9,29 \%$. Valor mais baixo do que o alcançado nos ensaios anteriores, devido ao fato do grupo de pessoas não excitar suficientemente a estrutura.

Também se observou quedas máximas de acelerações sem sistema de controle de -3,750 e 3,744 $\mathrm{m} / \mathrm{s}^{2}$ para $-2,457$ e $2,540 \mathrm{~m} / \mathrm{s}^{2}$ com sistema de controle, vide Tabela 7.10 e Tabela 7.12 alcançando reduções da ordem de $34,5 \%$.

Dos ensaios de pessoas caminhando durante 20 segundos, pode-se entender que o AMS terá um bom desempenho desde que a duração da aplicação da força de excitação ocorra durante tempo suficiente e, além disso, que a força perturbadora seja representativa para estimular o desempenho ótimo do amortecedor.

Ensaios de vibração forçada com ação de excitação sem repetição da força de excitação e curta duração foram feitos como é o caso dos ensaios de pulo a partir de uma carteira escolar.

Observando os valores médios quadráticos das acelerações da Figura 6.16, para os ensaios pulando a partir de uma carteira escolar foi encontrada uma queda de $0,690 \mathrm{~m} / \mathrm{s}^{2} \mathrm{sem}$ AMS para $0,489 \mathrm{~m} / \mathrm{s}^{2}$ com AMS. Esta diferença de $0,201 \mathrm{~m} / \mathrm{s}^{2}$ é bem menor comparada com os demais ensaios mostrados anteriormente.

No estudo estatístico de todos os ensaios feitos pulando desde uma carteira escolar o sistema de controle apresentou um desempenho na redução das acelerações no trecho de maior densidade de $1,7 \%$, lembrando que o trecho com a maioria dos registros das acelerações foi de $[-1,1] \mathrm{m} / \mathrm{s}^{2}$ ver Figura 7.7 e Figura 7.8.

Conclui-se que o sistema de controle AMS não exibiu seu melhor desempenho para forças de excitação sem repetição e de curta duração, como foi o caso estudado em ensaios de forças de impacto, por exemplo, pulando desde uma carteira escolar. Apesar do AMS não ter seu melhor desempenho, comparado a outros casos de excitação, este provoca alguma redução na resposta dinâmica da estrutura. 
De conclusão geral pode dizer que o sistema de controle AMS tem desempenhos satisfatórios na redução de vibrações em estruturas de lajes de concreto quando as forças de excitação são repetitivas, com tempos de atuação maiores do que 3 segundos e com magnitudes de forças consideráveis que consigam fazer com que o AMS inicie seu funcionamento. Este sistema de controle se monstra como um sistema alternativo para evitar enrijecer as estruturas que tenham vibrações verticais excessivas causadas pelas pessoas.

Como foi observado nos ensaios experimentais, o sistema de controle AMS construído no laboratório de estruturas da UNB consegue reduzir bem as vibrações verticais geradas de atividades rítmicas como caminhar e pular.

O AMS também é eficiente na redução das vibrações devidas a forças de excitação de impacto com repetição e tempo de atuação considerável. Este sistema de controle especifico é um sistema inovador no que diz respeito ao seu baixo custo de fabricação, facilidade de construção e manutenção. Na sua concepção este AMS apresenta facilidade para alteração de massa, rigidez e amortecimento este último mediante o mecanismo de geração de atrito. Também é um sistema que pode ser utilizados em espaços reduzidos como, por exemplo, em forros de teto falso. Sua funcionalidade pode ser aproveitada em prédios como academias, escolas, passarelas, estádios e demais estruturas em concreto que tenham vibrações excessivas e nas quais se queira evitar enrijecer a estrutura com objetivo de reduzir custos e obter resultados quase equivalentes em termos de conforto.

Observando o bom desempenho do amortecedor na redução das amplitudes de vibração, conclui-se com uma sequência metodológica para projeto de um sistema de controle em pisos de concreto.

Inicialmente deve-se modelar numericamente a estrutura a qual tem problemas de vibração excessiva. Uma vez pronta a modelagem identificar as diferentes formas modais, e nos pontos de maior amplitude de vibração, colocar no modelo numérico o amortecedor a projetar. Os parâmetros ótimos iniciais de partida do amortecedor podem ser obtidos a traves da teoria de Den Hartog de um grau de liberdade. Em seguida procede-se um estudo paramétrico do amortecedor: massa, amortecimento, rigidez, posição e quantidade de amortecedores são variados. O processo anterior deve ser realizado para obter os melhores parâmetros do AMS no 
qual se consiga reduzir ao máximo as amplitudes de vibração da estrutura analisada. Com os parâmetros adequados de massa, amortecimento, rigidez, posição e quantidade de AMS, o próximo passo é a construção do sistema de controle de acordo com o apresentado no captitulo 5.

Com o AMS construído deve-se testar na estrutura física mediante ensaios de atividades ritmadas para observar o desempenho do sistema de controle na redução das vibrações verticais, as quais são produzidas por pedestres em sistemas de pisos de concreto.

\subsection{SUGESTÕES PARA TRABALHOS FUTUROS}

Pode-se continuar com esta pesquisa de forma aperfeiçoar o dispositivo que foi apresentado, procurando armazenar parte da energia que o sistema de controle dissipa, com por exemplo instalando um gerador elétrico no AMS, isto poderia ser feito colocando uma bobina elétrica na peça 4 da Figura 5.66 e fazendo com que a peça 7 da mesma figura seja um ímã.

Um amortecedor de massa sintonizada que alternativamente possa controlar ao mesmo tempo vibrações verticais e horizontais, causadas por pedestres.

Em relação ao atrito em seco dos AMS, é interessante pesquisar diferentes materiais de contato entre o parafuso e o eixo guia como se observa na Figura 5.23 e Figura 5.66 com finalidade de projetar o amortecimento por forças de Coulomb com materiais que apresentem menos desgaste e sejam mais eficientes na hora de dissipar a energia proveniente dos pisos com problemas. Possíveis materiais seriam: nylon, bronze, cobre e aço doce.

Continuar a pesquisa numérica e experimental em busca de outros sistemas de controle que tenham outra condição de amortecimento como seria o caso de um amortecedor visco-elástico no qual também tenha influência do amortecimento por forças de Coulomb.

Comparar estes dois dispositivos de controle em função do desempenho, custo, facilidade de construção e manutenção, disponibilidade de adaptação em espaços reduzidos como tetos falsos de residências, prédios de escolas, academias etc. 


\section{REFERÊNCIAS BIBLIOGRAFICAS}

Abrams, D. M., Two Coupled Oscillator Models: The Millennium Bridge and the Chimera State. PhD Dissertation, Faculty of the Graduate School of Cornell University. 2006.

Al-Hulwah. K., Kashani. R., Zoghi. M. Tuned Damping of Floor Vibration. Proceedings of IMECE2005, ASME International Mechanical Engineering Congress and Exposition, 2005, pp. $1-5$.

Allen, D.E., Pernica G. A simple Absorber For Walking Vibrations. Candian Journal of Civil Engineering. 1984, pp. 112-117.

Allen, D.E., Building Vibrations from Human Activities, Concrete International: Design and Construction, American Concrete Institute, Vol 12, No 6, 1990, pp. 66-73

ANSYS, Swanson Analysis Systems, Version 14.5, 2012

ARTeMIS, Modal 4.0

AutoCAD, 2013 Autodesk,Inc.

Bachmann, H. Case Studies of Structures With Man-Induced Vibrations. Journal of Structural Engineering, Vol 118, 1992, pp. 631-647.

Bachmann, H., Ammann, W. J., Deischl, F., Eisenmann, J., Floegl, I., Hirsch, G. H., Klein, G. K., Lande, G J., Mahrenholtz, O., Natke, H. G., Nussbaumer, H., Pretlove, A. J., Rainer, J. H., Saemann, E. U., Steinbeisseer, L. Vibration problems in structures: Practical Guidelines. Leight Korrigierter Nachdruck, 1997.

Barret, A.R., Dynamic Testing of In-Situ Composite Floors and Evaluation of Vibration Serviceability Using the Finite Element Method. PhD Dissertation, Virginia Polytechnic Institute and State University, Blacksburg, Virginia. 2006.

Battista, R. C., Redução e Controle de Vibrações em Estruturas, Notas de Aula, COPPE/UFRJ, Rio de Janeiro, 1993. 
Bell, D. H. A Tuned Mass Damper to Control Occupant Induced Floor Vibration. Proceedings of the Eighteenth Annual Meeting of the Vibration Institute, 1994, pp. 184-185.

Bigdeli, Y., Kim. D., Damping Effects of the Passive Control Devices on Structural Vibration Control: TMD, TLC and TLCD for Varying Total Masses. KSCE Journal of Civil Engineering. DOI 10.1007/s12205-015-0365-5. Springer. 2015

Blevins, R. D., Formulas for Natural Frequency and Mode Shape. Published by Van Nostrand Reinhold Company, 1979.

Borges, R. de C. E., Estudo preliminar com vistas à construção de uma plataforma para ensaios dinâmicos, Monografia de projeto final 2, Universidade de Brasília, Faculdade de Tecnologia Departamento de Engenharia Civil e Ambiental, UnB, Brasília DF, 2011.

Braun, S., Ewins, D., Rao, S. S., Encyclopedia of Vibration. Academic Press.2002, pp 267.

Brincker, R., Ventura, C. Introduction to Operational Modal Analysis. Jhon Wiley \& Sons, Ltd.2015, pp 266.

Campuzano, J. E., Plataforma de ensaios dinâmicos: Estudos Preliminares, Projeto e Construção. Dissertação de Mestrado. Universidade de Brasília. 2011.

Campuzano, J. E., De Castro. R., Ávila. S., Doz. G., Platform for dynamic tests: preliminary studies, design and construction. Ibracon Structures and Materials Journal, Vol 6, number 1, February 2013, pp. 55-74.

Canadian Standards Association. CAN3-S16.1-M84 : Steel Structures for Buildings - Limits States Design, Appendix G: Guide on Floor Vibrations, Canada, 1984.

CEB. Vibration problems in structures. Practical Guigelines. Bulletin D’Information No 209. Commité European du Béton, Zurich, August 1991.

Clough, R. W., Penzien. J. Dynamics of Structures. Computers \& Structures, Inc. 2003.

Dallard, P., Fitzpatrick, A. I., Flint, S., Le Bourva, A., Low, R., Smith and M.R. Willford, The London Millennium Footbridge. The Structural Engineer. Vol. 79, No 22, 2001, pp 17-33. 
De Castro, A. V., Comparação entre modelos numéricos e experimentais em análise dinâmica de placas. Dissertação de Mestrado. Universidade do Porto. 1996.

DeCoursey, W.J., Statistics and Probability for Engineering Applications, With Microsoft Excel. Newnes, Elsevier Science (USA), 2003.

De Silva, C. W., Vibration and Shock Handbook. Taylor \& Francis Group, LLC. 2005, Cap 32.8 .2

De Silva, C. W., Vibration Damping, Control, and Design. CRC Press. Taylor \& Francis Group. 2007, pp 1-15.

Den Hartog, J.P., Mechanical Vibrations. Dover Publications, Inc. New York, 1985.

DEUTSCHES INSTITUT FÛR NORMUNG, DIN 4150/2: Erschütterungen im Bauwesen; Einwirkungen auf Menschen in Gebäuden ("Vibrations in Building; Influence on Persons in Buildings”), Beuth Verlag GmBh, Berlin, 1975 bzw., 1990.

Ewins, D. J., Modal Testing: theory, practice, and application. Second Edition. Research Studies Press LTD, 2000.

Feng, M., Mita, A. Vibration Control of Tall Buildings Using Mega Sub Configuration. Journal of Engineering Mechanics. Vol. 10, 1995, pp.1082-1088.

Fiebig, W. Reduction of Vibrations of Pedestrian Bridges Using Tuned Mass Dampers (TMD). Wroclaw University of Technology, Institute of Machine Design. 2010. pp 165-174.

Fujino, Y., Abe, M. Design Formulas for Tuned Mass Dampers Based on a Perturbation Technique. Earthquake Engineering and Structural Dynamics, Vol 22, 1993, pp. 833-854.

García Reyes, L.E. Dinámica Estructural Aplicada al Diseño Sísmico. Universidad de los Andes, Facultad de Ingeniería, Departamento de Ingeniería Civil, Bogotá, Colombia. 1998

Gerb, Vibration Control Systems, Tuned Mass Dampers, Speactor Stands - Morumbi Soccer Stadium, São Paulo/Brazil, 1998. 
Gerb, Schwingungsisolierungen GmbH \& Co. KG. Vibration Protection for Structures, Buildings, Machinery and other Equipment with Tuned Mass Dampers, 2001.

Graham Kelly, S. Mechanical Vibrations Theory and Applications. Cengage Learning, 2012.

Gutierrez, M. Investigation of Passive Control of Irregular Building Structures Using Bidirectional Tuned Mass Damper. Ms Dissertation. The Ohio State University, 2012.

Hanagan, L. M., Murray, T. M., Premaratne, K. Controlling Floor Vibration with Active and Passive Devices. The Shock and Vibration Digest. Vol. 35, No 5, September 2003, pp. 347-365.

Harris, Cyril M. Shock and Vibration Handbook, Third edition, McGraw-Hill Book Company, 1988.

Hoang, N., Fujino,Y., Warnitchai, P. Optimal Tuned Mass Damper for Seismic Applications and Practical Formulas. Engineering Structures, Vol. 30, 2008, pp.707-715.

ISO 2631-2, International Organization for Standardization. Evaluation of Human Exposure to Whole-Body Vibration - Part 2: Human Exposure to Continuous and Shock-Induced Vibrations in Building (1 to $80 \mathrm{~Hz}$ ), Switzerland, 1989.

Juvinall, R. C., Marshek, K. M. Fundamentals of Machine Component Design. Fifth Edition. John Wiley \& Sons, INC. 2012.

Krenk, S. Hogsberg, J. Tuned Mass Absorbers on Damped Structures Under Random Load. Probabilistic Engineering Mechanics, Vol. 23, 2008, pp.408-415.

Koo, J. H., Using Magneto-Rheological Dampers in Semiactive Tuned Vibration Absorbers to Control Structural Vibrations. PhD Dissertation, Faculty of the Virginia Polytechnic Institute and State University, 2003.

Lamb, J. L., Using a Simple Cantilever Tuned-Mass Damper to Control Vibration in a Preexisting Composite Floor System. Structural Engenuity, Inc. March 2011, pp.1-9. 
Lima, D. V. F., Controle de Vibrações Induzidas em uma Laje de Academia de Ginástica com a Utilização de Amortecedores de Massa Sintonizados. Dissertação de mestrado, Universidade de Brasília, 2007.

Lindenberg, R.E., Fraczek. J., From Old to New: Vibration Issues with Old Buildings and Their New Office Spaces. Structures Congress, ASCE 2013, pp. 1747-1758.

Louroza, M. A., Utilização de Sistema de Absorção Passivo com Amortecimento de Coulomb para Redução de Vibrações Estruturais. Dissertação de Mestrado. COPPE/UFRJ, Universidade Federal do Rio de Janeiro. 1997.

MATLAB, The Language of Technical Computing, Version 7.8.0.347 (R2009a), February, 2009.

Maurer Söhne, Tuned Mass and Viscous Dampers. Technical Information and Products, 2011. pp 13.

Meirovitch, L. Analytical Methods in Vibrations, Macmillan, 1967.

Murray, T.M. Design to Prevent Floor Vibrations. Engineering Journal, AISC, Vol 12, No 3, 1975, pp. 82-87.

Murray, T.M., Allen, D.E., Ungar, E.E., Floor Vibration due to Human Activity, American Institute of Steel Construction (AISC-CISC), 2003.

Picauly, F., Priyosulistyo Hrc., Suhendro B., Triwiyono A. Tuned Mass Damper On Reinforced Concrete Slab With Additional "X-Shaped Metal" Absorver. 2nd International Conference on Sustainable Civil Engineering Structures and Construction Materials 2014 (SCESCM 2014), pp 204-212.

Rao, S. S. Mechanicals Vibrations. Fifth Edition. Prentice Hall PEARSON.2010, pp 842.

Reed, F. E. Dynamic Vibration Absorbers and Auxiliary Systems. Shock and Vibration Handbook, C. Harris, $3^{\text {rd }}$ Ed, Mc-Graw Hill, New York. 
Ritchey, J. K., Application of Magneto-Rheological Dampers in Tuned Mass Dampers for Floor Vibration Control. Ms Dissertation, Faculty of the Virginia Polytechnic Institute and State University. 2003

Roberts, T. M., Lateral Pedestrian Excitation of Footbridges, Journal of Bridge Engineering, Vol 10, No 1, January 1, 2005.

Rottmann, C. E., Murray, T. M. Use of Tuned Mass Dampers to Control Annoying Floor Vibrations. Research Report CE/VPI-ST-96/10, Virginia Polytechnic Institute and State University, Blacksburg, VA. 1996.

Rudinger, F. Optimal Absorber with Nonlinear Viscous Power Law Damping and White Noise Excitation. Journal of Engineering Mechanics, ASCE, Vol. 132, No 1, 2006. pp. 46-53.

Sadek, F., Mohraz, B., Taylor, A. W., Chung, R. M. A Method of Estimating the Parameters of Tuned Mass Dampers for Seismic Application. Earthquake Engineering and Structural Dynamics. Vol 26, 1997, pp. 617-635.

Saidi, Ibrahim. Development of a Viscoelastic Tuned Mass Damper to Reduce Walking Induced Vibrations in Building Floors. PhD Dissertation, Faculty of Engineering and Industrial Sciences Swinburne University of Technology. 2012.

Salamanca, H. E., Vibraciones Mecánicas. ME4701, Facultad de ciencias físicas y matemáticas Universidad de Chile, Capitulo 1, 2010.

Santos, M. D., Lima, D.V.F., Campuzano, J. E., Avila, S. M., Doz, G. N. Vibration Control of a Gym Floor Using Tuned Mass Dampers: A Numerical Analysis. Journal Modern Mechanical Engineering, Vol 3, 2013, pp. 9-16.

Serway, R.A., Jewett, J. W. Principles of Physics, a Calculus-Based Text. Fifth Edition. CENGAGE Learning. 2013.

Setareh, M., Hanson, R. D. Tuned Mass Dampers for Balcony Vibration Control. Journal of Structure Engineering, ASCE, Vol 18, No 3,1992, pp.723-740. 
Setareh, M., Ritchey, J. K., Baxter, A. J., Murray, T. M. Pendulum Tuned Mass Dampers for Floor Vibration Control. Journal of Performance of Constructed Facilities, ASCE, Vol 20, No 1, 2006, pp. 64-73.

Setareh, M., Ritchey, J. K., Murray, T. M., Koo, J. H., Ahmadian, M. Semiactive Tuned Mass Dampers for Floor Vibration Control. Journal of Structural Engineering, ASCE, Vol 133, 2007, pp. 242-250.

Shope, R., and Murray, T. M., Using Tuned Mass Dampers to Eliminate Annoying Floor Vibrations. Proceedings of Structures Congress XIII, ASCE, Boston, 2-5, Vol 1, 1995, pp. 339348.

Sika Brasil, Ficha de produto Sikadur 42 Cl. Edição Maio de 2007.

Thomsom. W. T. Teoria da Vibração com aplicações. Rio de Janeiro, 1978.

Thornton, C. H., Cuoco, D.A., Velivasakis E.E. Taming Structural Vibrations. Civil Engineering, 1990, pp. 57-59.

Varela, W. D. Modelo Teórico Experimental para Análise de Vibrações Induzidas por Pessoas Caminhando Sobre Lajes de Edifícios. Tese Doutorado, COPPE/UFRJ, Rio de Janeiro, 2004.

Varela, W.D., Battista, R. C. Control of Vibration Induced by People Walking on Large Span Composite Floor Decks. Engineering Structures. Vol. 33, No 9, 2011, pp. 2485-2494.

Villaverde, R. Reduction in Seismic Response with heavily-damped Vibration Absorbers. Earthquake Engineering and Structural Dynamics, Vol 13, 1985, pp. 33-42.

Warburton, G. Optimum Absorber Parameters for Various Combinations of Response and Excitation Parameters. Earthquake Engineering and Structural, Vol 10, 1982, pp. 381-440.

Webster, A. C., Vaicaitis, R. Applications Tuned Mass Dampers to Control Vibrations of Composite Floor Systems, Engineering Journal/ American Institute of Steel Construction, 1992, pp. 116-124. 


\section{Anexo I}

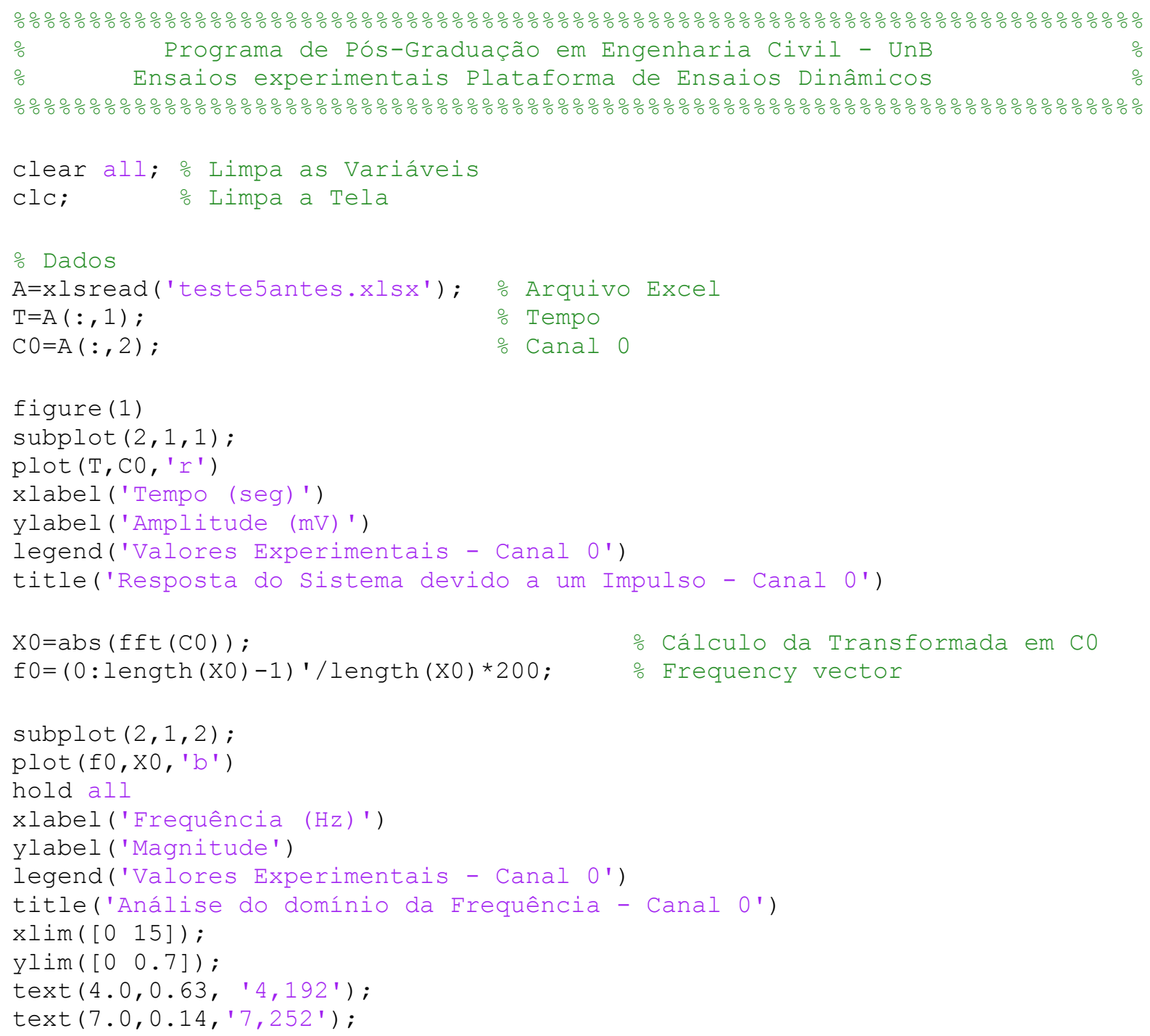




\section{Anexo II}

\section{CALCULOS DA RECUPERAÇAO DA PLATAFORMA DE ENSAIOS DINÂMICOS}

Carga por metro quadrado, peso do concreto armado.

$2500 \frac{\mathrm{kg}}{\mathrm{m}^{3}} * 0,1 \mathrm{~m}=250 \frac{\mathrm{kg}}{\mathrm{m}^{2}}$

\section{Carga acidental}

$150 \frac{\mathrm{kg}}{\mathrm{m}^{2}}$

\section{Total carga}

$250 \frac{\mathrm{kg}}{\mathrm{m}^{2}}+150 \frac{\mathrm{kg}}{\mathrm{m}^{2}}=400 \frac{\mathrm{kg}}{\mathrm{m}^{2}}$

\section{Áreas de carregamento}

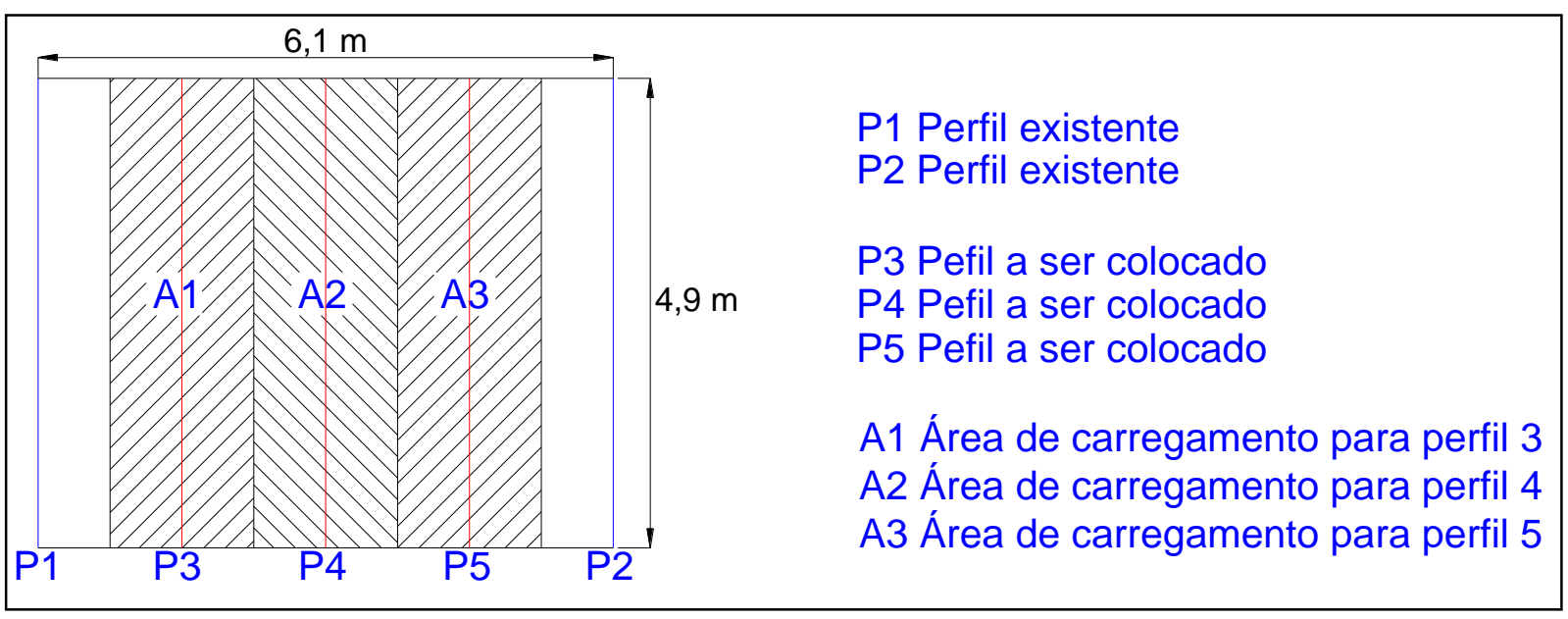

Figura Anexo II.1- Áreas de carregamento na laje da plataforma

Carregamento uniforme para os perfis 3, 4, 5

$150 m * 4,9 m * 400 \frac{\mathrm{kg}}{\mathrm{m}^{2}}=2940 \mathrm{~kg}$ 
$\frac{2940 \mathrm{~kg}}{4,9 \mathrm{~m}}=600 \frac{\mathrm{kg}}{\mathrm{m}}=6 \frac{\mathrm{kN}}{\mathrm{m}}$

\section{Posições e reações exercidas pelos macacos hidráulicos}

Foram utilizados nove macacos hidráulicos para o levantamento da laje, como se pode observar na gráfica.

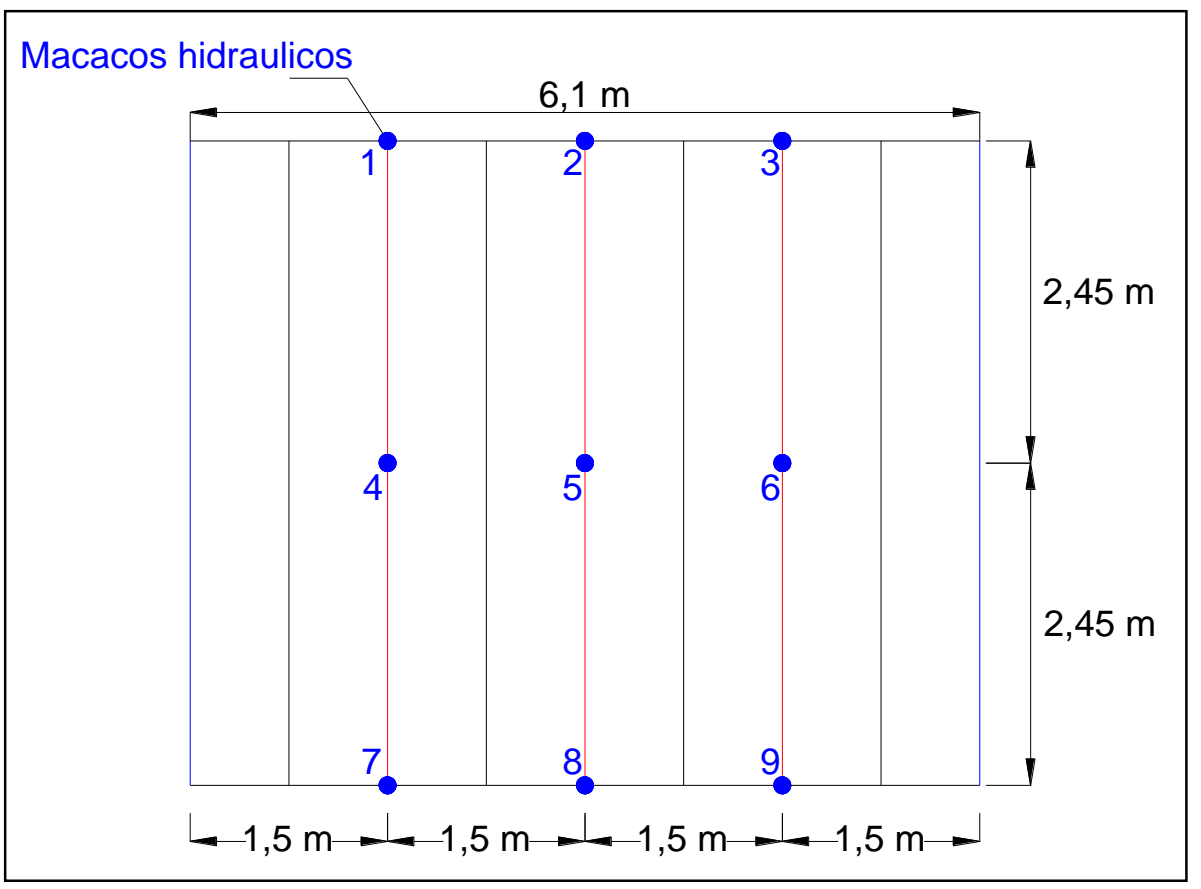

Figura Anexo II.2 - Colocação dos nove macacos hidráulicos.

Digrama de esforço cortante e momento fletor dos perfis de aço $3,4,5$

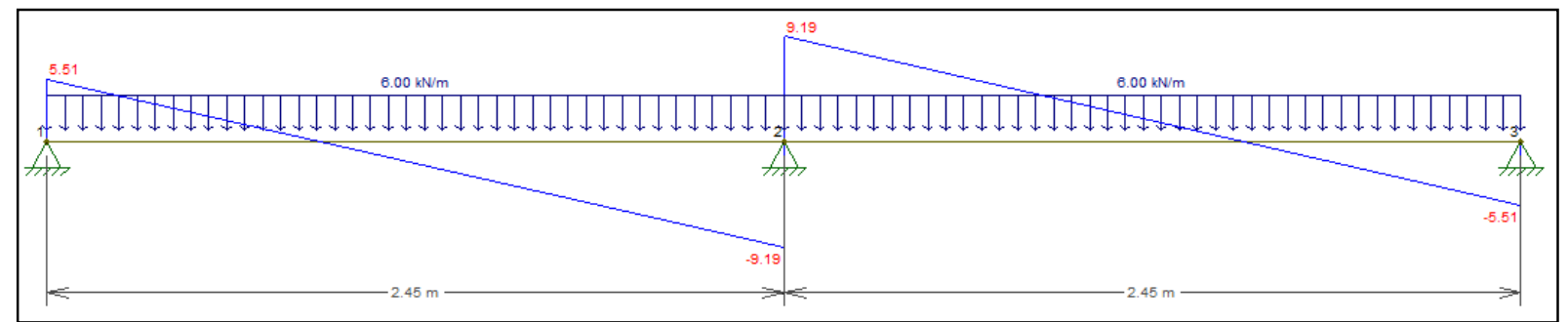

Figura Anexo II.3 - Diagrama de força cortante no perfil do aço.

Unidades da cortante em $\mathrm{kN}$ 


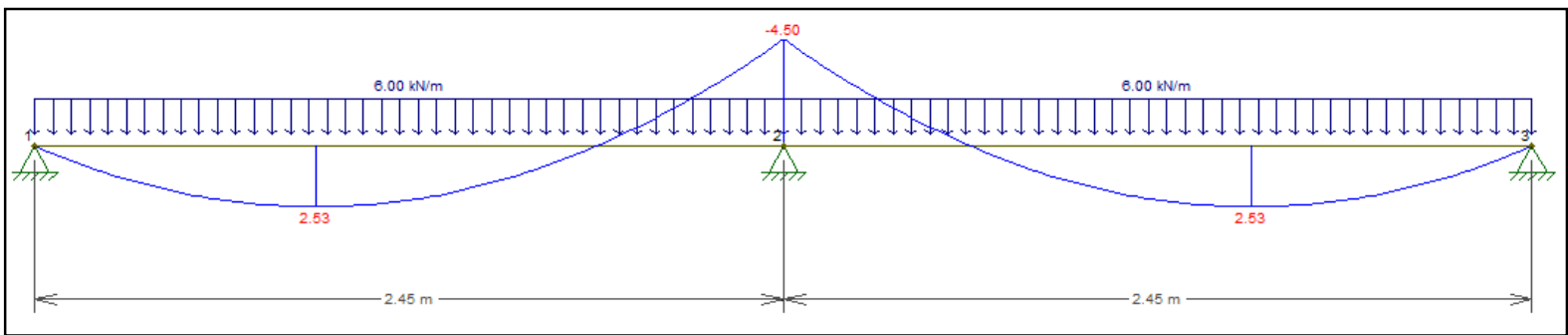

Figura Anexo II.4 - Diagrama de momento fletor no perfil do aço.

Unidades do momento fletor em $\mathrm{kNm}$

As reações exercidas pelos macacos hidráulicos serão nos apoios extremos de aproximadamente de $551 \mathrm{~kg}$ e no apoio interior de $1837 \mathrm{~kg}$.

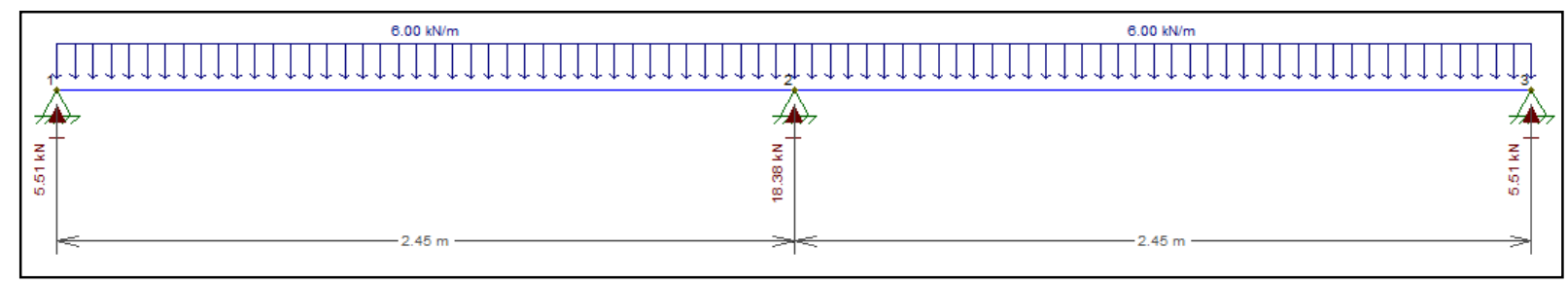

Figura Anexo II.5 - Reações exercida pelos macacos hidráulicos.

Com base nos cálculos anteriores foram colocados nove macacos com capacidade de levante cada um de 2 toneladas.

\section{Verificação dos perfis de aço}

\section{Perfis a ser comprados para levantar a laje}

Perfil $=\mathrm{W} 150 \times 18,0$

Dimensões do perfil.

$\mathrm{b}_{\mathrm{f}}=102 \mathrm{~mm}, \mathrm{t}_{\mathrm{f}}=7,1 \mathrm{~mm}, \mathrm{t}_{0}=5,8 \mathrm{~mm}, \mathrm{~h}=153 \mathrm{~mm}, \mathrm{~h}_{\mathrm{w}}=138,8 \mathrm{~mm}$

Comprimento entre os apoios $=245 \mathrm{~cm}$

Momento de projeto da viga $=4,5 \mathrm{kN} * \mathrm{~m}$

Flambagem local da mesa

$$
\lambda_{b}=\frac{b_{f}}{2 t_{f}}
$$


$\lambda_{b}=\frac{102}{14,2}=7,18301$

$\lambda_{p}=0,38 \sqrt{E / f_{y}}$

$\lambda_{p}=10,7$ para aço MR 250

$\lambda_{b} \leq \lambda_{p}$ Seção compacta

$7,18301 \leq 10,7 \rightarrow$ Perfil W 150 x 18,0 seção compacta.

Flambagem local da alma

$\lambda_{b}=\frac{h_{w}}{t_{0}}$

$\lambda_{b}=\frac{138,8}{5,8}=23,931$

$\lambda_{p}=106$ dupla simetria, para aço MR 250

$\lambda_{b} \leq \lambda_{p}$ Seção compacta

$23,931 \leq 106 \rightarrow$ Perfil W 150 x 18,0 seção compacta.

Momento nominal

$M_{n}=M_{p}=Z^{*} f_{y}$

$Z=b_{f} * t_{f}\left(h-t_{f}\right)+\frac{t_{0}}{4}\left(h-2 t_{f}\right)^{2}$

$Z=102 * 7,1 *(153-7,1)+\frac{5,8}{4}(153-2 * 7,1)^{2}=133595,668 \mathrm{~mm}^{3}$

$f_{y}=345 \mathrm{MPa}$ 
$M_{n}=46,0905 \mathrm{kN}^{*} \mathrm{~m}$

Momento resistente de projeto

$M_{d r e s t}=\frac{Z * f_{y}}{1,1}=41,90 k N * m$

$M_{\text {drest }} \leq M_{n}$

$41,90 \leq 46,09$ Ok perfil cumpre

Resistencia a flexão das vigas I com dois eixos de simetria, fletidos no plano da alma

Área do perfil $\mathrm{A}=2253,44 \mathrm{~mm}^{2}$

Momento de inercia $\mathrm{I}_{\mathrm{y}}=1255829,887 \mathrm{~mm}^{4}$

Raio de giração $i=\sqrt{\frac{I_{y}}{A}}=2,360708 \mathrm{~cm}$

Módulo de elasticidade do aço E = $200 \mathrm{GPa}$

Condições para se obter viga curta $l_{b} \leq l_{b p}=1,76 i \sqrt{\frac{E}{f_{y}}}$

$l_{b p}=1,76 * 2,360708 * \sqrt{\frac{200 * 10^{9}}{345 * 10^{6}}}=100,0369 \mathrm{~cm}$

$102 \geq 100,0369$ viga não é curta

$J=\frac{1}{3}\left(2 * b_{f} * t_{f}{ }^{3}+h * t_{0}{ }^{3}\right)$ momento de inércia à torção pura.

$J=33365,12987 \mathrm{~mm}^{4}$

$c_{w}=\frac{h^{2} I_{y}}{4}=\frac{(138,8+7,1)^{2} * 1255829,887}{4}$

$c_{w}=6683,1530 \mathrm{~cm}^{6}$ 
$\mathrm{W}_{\mathrm{x}}=129,9 \mathrm{~cm}^{3} \rightarrow$ Da tabela comercial

$\beta_{1}=\frac{\left(f_{y}-\sigma_{r}\right) w}{E J}$

or = tensão residual, $30 \%$ da tensão do escoamento do aço utilizado.

$l_{b r}=\frac{1,38 \sqrt{I_{y} J}}{J \beta_{1}} \sqrt{1+\sqrt{1+\frac{27 c_{w} \beta_{1}^{2}}{I_{y}}}}$

$l_{b r}=114,035 \mathrm{~cm}$

Condições para se obter viga longa $l_{b r}>l_{b}$

$114,0354 \mathrm{~cm}>102 \mathrm{~cm}$ viga é longa

$M_{a}, M_{b}$ e $M_{c}$, são os momentos fletores (em valor absoluto) no segmento de viga de comprimento $l_{b}$, respectivamente no pontos situados às distancias de $l_{b} / 4, l_{b} / 2$ e $3 l_{b} / 4$ de um dos dois pontos de contenção lateral.

$\mathrm{M}_{\mathrm{a}}=225,09375$

$\mathrm{M}_{\mathrm{b}}=225,09375$

$\mathrm{M}_{\mathrm{c}}=0$

$\mathrm{M}_{\max }=450,18$

$C_{b}=\frac{12,5 M_{\text {max }}}{2,5 M_{\text {max }}+3 M_{a}+4 M_{b}+3 M_{c}} \leq 3,0$

$\mathrm{Cb}=2,083313087$

$M_{n}=M_{c r}=C_{b} \frac{\pi^{2} E I_{y}}{l_{b}^{2}} \sqrt{\frac{c_{w}}{I_{y}}\left(1+0,039 \frac{J l_{b}^{2}}{C_{w}}\right)}$

$\mathrm{M}_{\mathrm{cr}}=92,4292335 \mathrm{kN} * \mathrm{~m}$

$\mathrm{M}_{\mathrm{dres}}=84,02657577 \mathrm{kN} * \mathrm{~m}<\mathrm{M}_{\mathrm{cr}}=92,4293335 \mathrm{kN} * \mathrm{~m}$ Ok perfil cumpre 
$\mathrm{G}=$ módulo de cisalhamento $=7700000 \mathrm{~N} / \mathrm{cm}^{2}$

Mcrf $=44,36911628 \mathrm{kN} * \mathrm{~m}$

Mdres $=40,33556026 \mathrm{kN} * \mathrm{~m}$

Mdres $=40,33556026 \mathrm{kN} * \mathrm{~m}<$ Mcrf $=44,36911628 \mathrm{kN} * \mathrm{~m}$ Ok perfil cumpre

Perfis de seção fechada

Propriedades da seção

$\mathrm{h}=100 \mathrm{~mm}$

$\mathrm{t}_{\mathrm{w}}=3,5 \mathrm{~mm}$

$\mathrm{b}=100 \mathrm{~mm}$

Momento projeto da viga $=4,5 \mathrm{kN} * \mathrm{~m}$

$\mathrm{E}=200 \mathrm{GPa}$

fy $=345 \mathrm{Mpa}$

Flambagem local da alma

$\lambda=28,57142857$ parâmetro de esbeltes

$\lambda_{\mathrm{p}}=58,2667529$ parâmetro de esbeltes correspondente à plastificação

$\lambda_{\mathrm{r}}=137,2398725$ parâmetro de esbeltes correspondente ao início de escoamento

como $\lambda<\lambda r$ Viga não esbelta

$\operatorname{Para} \lambda<\lambda_{\mathrm{p}}$

Para $M_{r d}=\frac{M_{p l}}{\gamma_{a 1}}, \operatorname{para} \lambda \leq \lambda_{p}$

Módulo plástico Z $=48910,75 \mathrm{~mm}^{3}$

$$
\begin{aligned}
& M_{p l}=Z * f_{y} \\
& M_{p l}=16,874209 \mathrm{kN} * m
\end{aligned}
$$




$$
M_{r d}=15,34019 k N * m
$$

Como $\mathrm{M}_{\mathrm{rd}}<\mathrm{M}_{\mathrm{pl}}$ Ok perfil cumpre

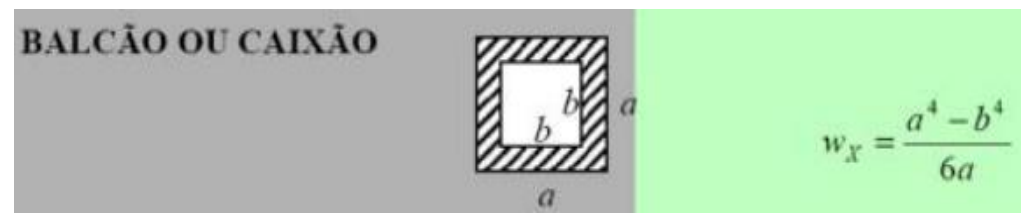

$$
\begin{aligned}
& w_{x}=\frac{a^{4}-b^{4}}{6 a} \\
& w_{x}=\frac{100^{4}-(100-2 * 3,5)^{4}}{6 * 100}
\end{aligned}
$$

$\mathrm{W}_{\mathrm{X}}=41991,3317 \mathrm{~mm}^{3}$

$$
\frac{Z}{w}=\frac{48910,75}{41991,3317}=1,164782
$$

$$
M_{r}=F_{y} * w
$$

$$
M_{r}=14,487009 k N * m
$$

Flambagem local da mesa

$\lambda=26,57142857$

$\lambda_{\mathrm{p}}=26,96643109$

$\lambda_{\mathrm{r}}=33,70803886$

Para $M_{r d}=\frac{M_{p l}}{\gamma_{a 1}}$, para $\lambda \leq \lambda_{p}$

$\mathrm{M}_{\mathrm{rd}}=15,34019 \mathrm{kN} * \mathrm{~m}$

$\mathrm{Mc}_{\mathrm{r}}=14,487009 \mathrm{kN} * \mathrm{~m}$ 
Flambagem local torção

$\mathrm{Mr}=10,140907 \mathrm{kN} * \mathrm{~m}$

$\mathrm{Cb}=2,083313087$

$\mathrm{J}=3,23251 * 10^{6} \mathrm{~m}^{4}$

Área $=\mathrm{A}=13,51 \mathrm{~cm}^{2}$

$\mathrm{l}_{\mathrm{b}}=250 \mathrm{~cm}$

$I_{y}=209,957 \mathrm{~cm}^{4}$

$\mathrm{r}_{\mathrm{y}}=3,942189572 \mathrm{~cm}$

$\lambda=63,41653424$

$\mathrm{M}_{\mathrm{cr}}=868,37966 \mathrm{kN} * \mathrm{~m}$

$\lambda_{\mathrm{p}}=101,8233881$

$\lambda_{\mathrm{r}}=2606,638597$

Calculo do esforço cortante e momentos fletor gerado na laje pela ação dos perfis $3,4,5$

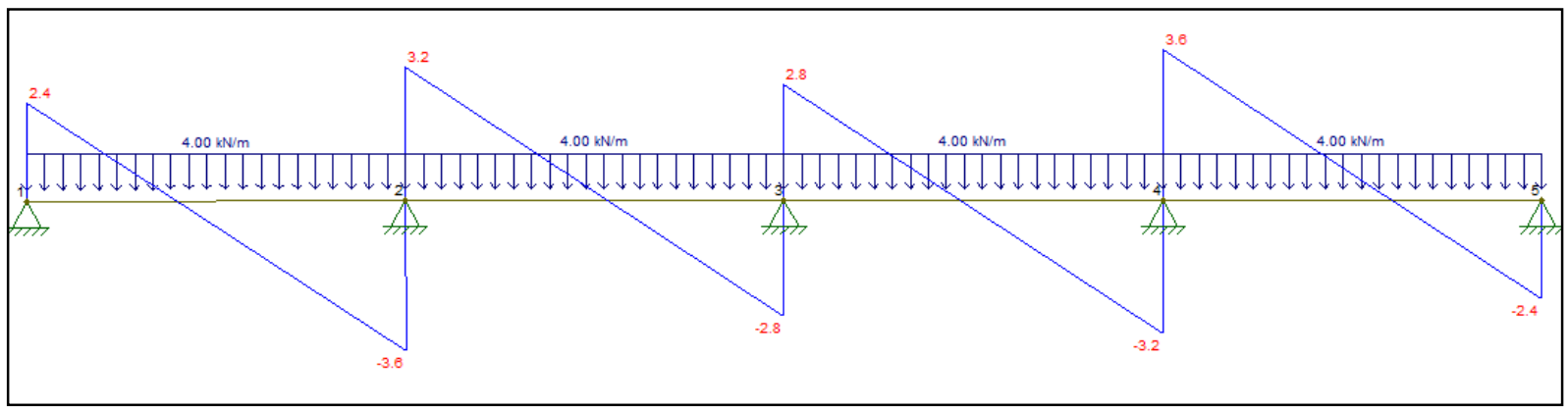

Figura Anexo II.6 - Diagrama de força cortante gerada na laje de concreto.

Unidades da cortante em $\mathrm{kN}$ 


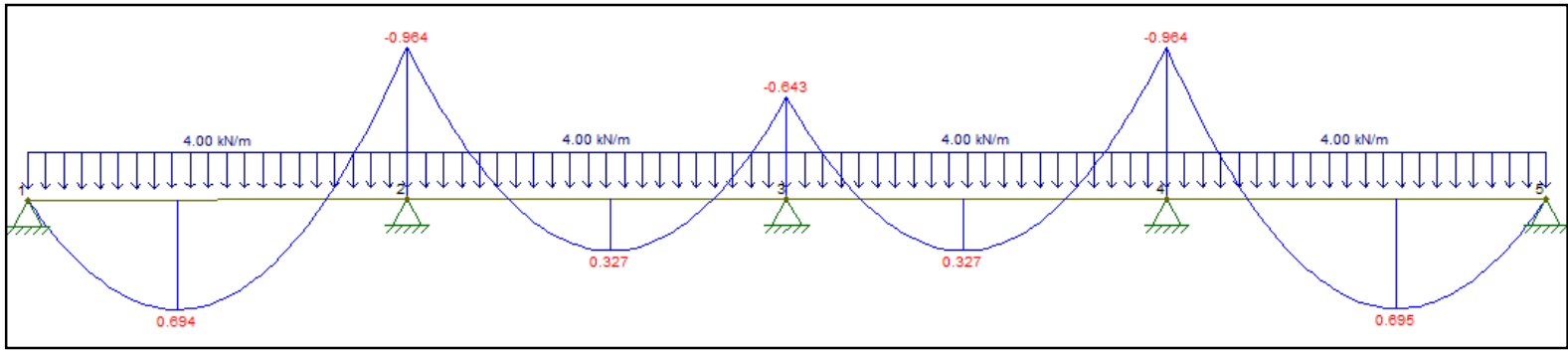

Figura Anexo II.7 - Diagrama de momento fletor gerado na laje de concreto.

Unidades do momento fletor em $\mathrm{kNm}$

\section{RECUPERAÇÃO DA PLATAFORMA}

Para tentar recuperar a flecha máxima de $70 \mathrm{~mm}$, levantou-se a laje mediante nove macacos hidráulicos e três perfis de aço distribuídos a distancias de $1,5 \mathrm{~m}$ ao longo do vão de $6,1 \mathrm{~m}$, criando-se desta forma apoios hiperestáticos. Foi utilizada esta quantidade de perfis e de macacos hidráulicos para obter valores mínimos de momentos negativos na laje, e assim gerar a menor ocorrência possível de trincas. A laje só tem armadura para momentos negativos nas duas bordas apoiadas. No vão central da laje, não foi colocada se colocou armadura para momentos negativos, devido a um estudo numérico realizado só ter apresentado valores de momentos positivos. (Borges, 2011)

Pelos momentos gerados nos apoios hiperestáticos (vide Figura Anexo II.7), criaram-se fissuras na laje de concreto. A laje foi suspensa com os nove macacos hidráulicos até alcançar uma contra flecha de $2 \mathrm{~cm}$. O processo de suspensão da laje e as fissuras são mostrados nas Figura Anexo II.8 a Figura Anexo II.10. 


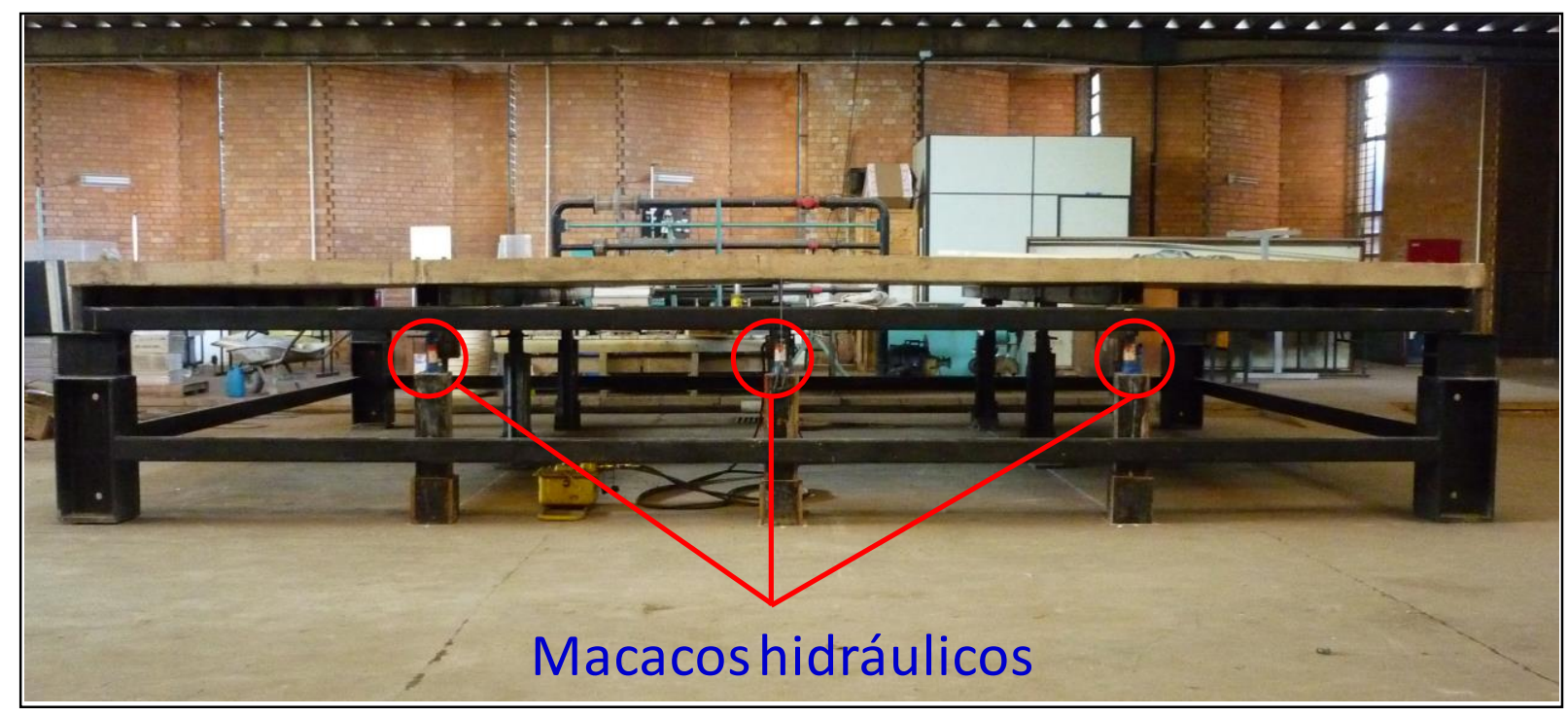

Figura Anexo II.8 - Levantamento da laje da plataforma com macacos hidráulicos.

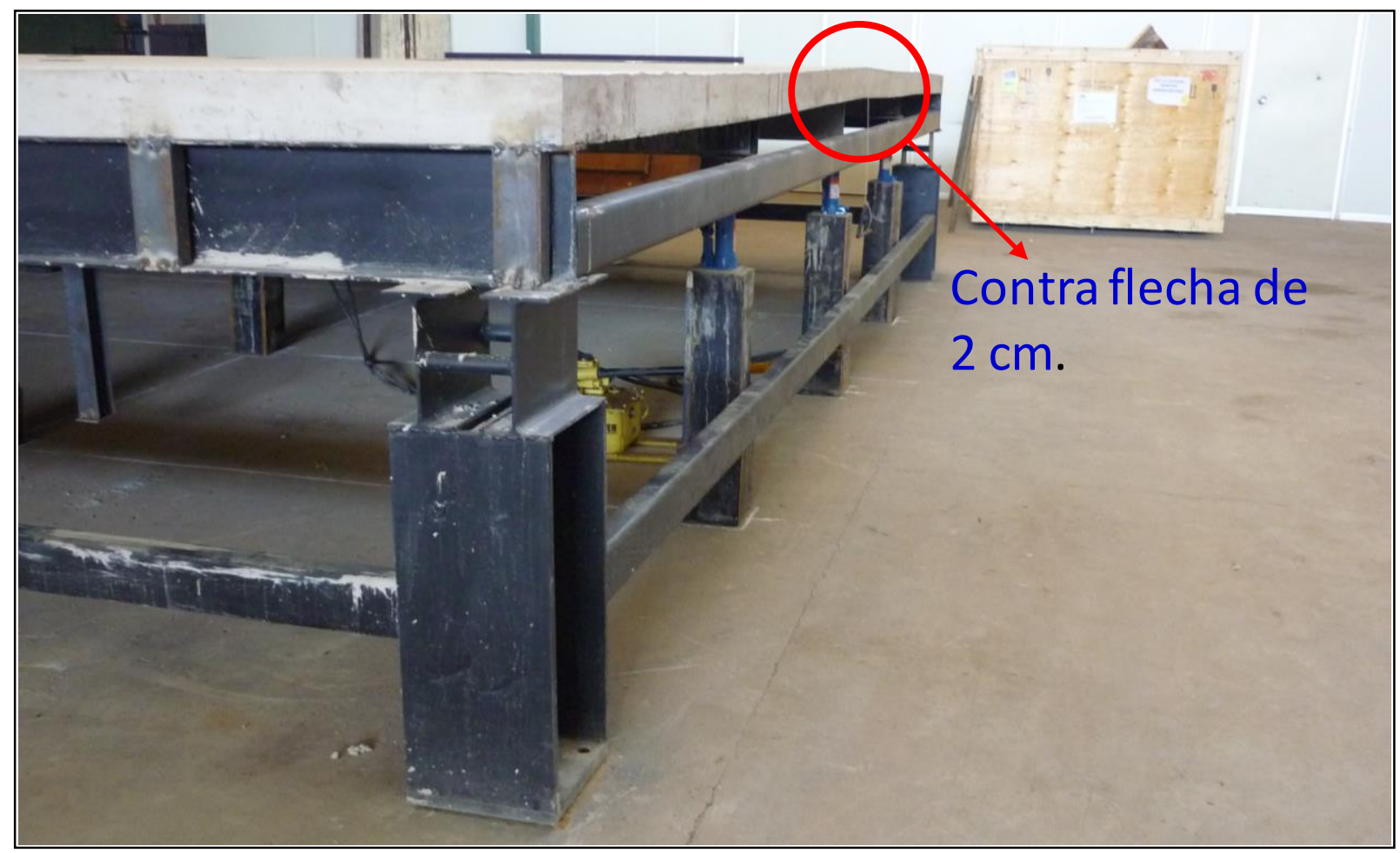

Figura Anexo II.9 - Contra flecha na laje de $2 \mathrm{~cm}$. 


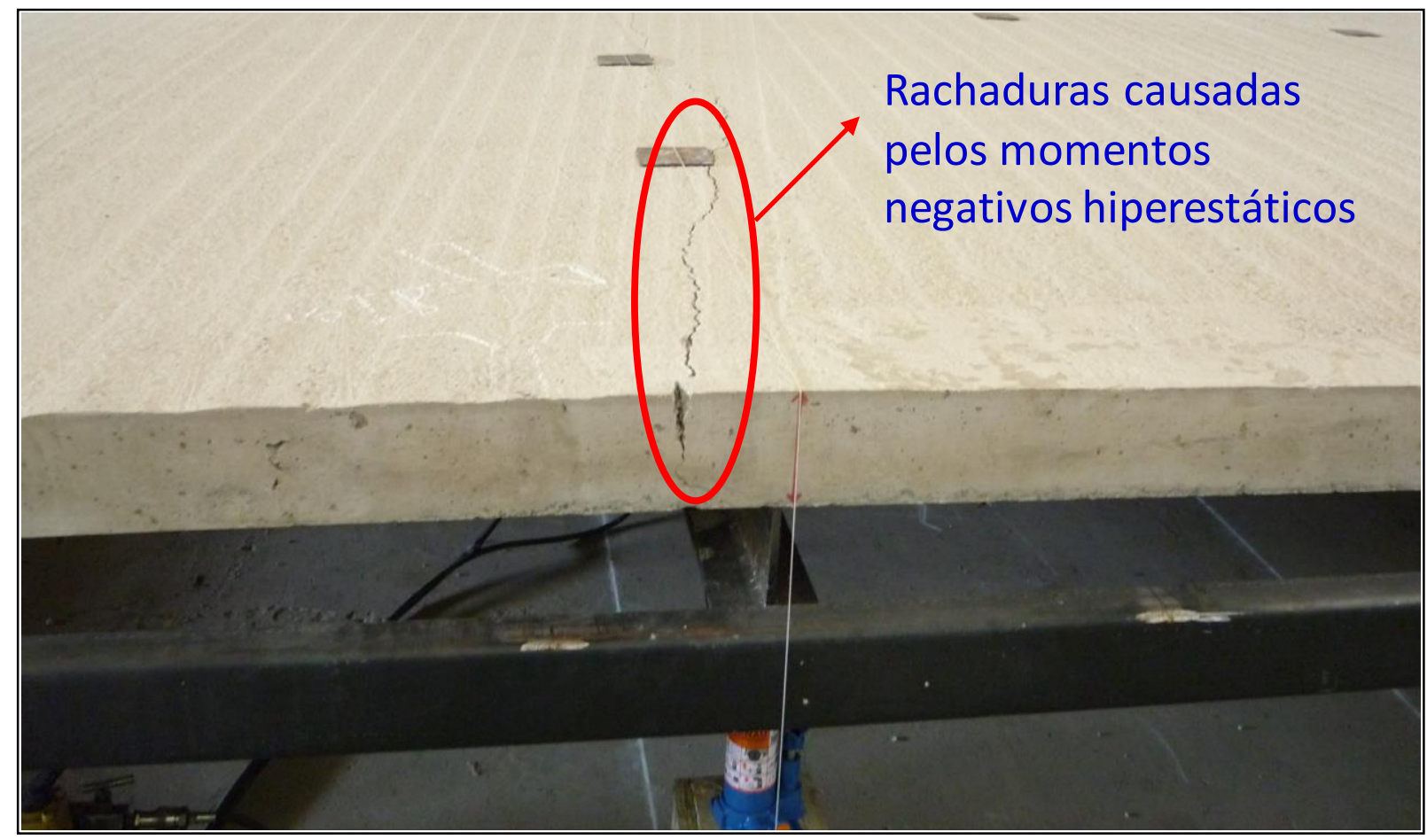

Figura Anexo II.10 - Fissuras apresentadas na laje pelos momentos negativos hiperestáticos.

Após o surgimento das fissuras no topo da laje pelos momentos negativos, as fissuras foram ampliadas com a finalidade de aplicar dentro das mesmas um produto especial para reforço da Sika.

O produto é um graute epóxi fluido de alta resistência mecânica e química. O produto utilizado foi Sikadur 42 CL, que é uma argamassa fluida à base de resinas epoxídicas modificadas de consistência fluida, $100 \%$ sólidos e fornecida em três componentes. (Sika, 2007).

Os dados técnicos do Sikadur 42 CL se apresentam na Tabela Anexo II.1. Para aplicar o produto foi necessário ampliar as rachaduras com ajuda de uma lixadora que tinha um disco especial para concreto armado. As larguras das rachaduras no topo foram de aproximadamente de 2,5 $\mathrm{cm}$, e de profundidade de 4,5 cm, como se pode observar na Figura Anexo II.11. Após de ampliar as rachaduras se precisou preparar a superfície antes de aplicar o produto. A preparação consistiu em deixar a superfície limpa, isenta de pó, partes soltas ou mal aderidas, sem impregnações de óleo, graxa, pintura etc. 
Tabela Anexo II.1 - Dados técnicos do produto Sikadur 42 CL. (Sika, 2007)

\begin{tabular}{|c|c|c|c|}
\hline Composição básica & \multicolumn{3}{|c|}{ Resina epóxi modificada, amina alifática e cargas minerais } \\
\hline Densidade $\left(25^{\circ} \mathrm{C}\right)$ & \multicolumn{3}{|c|}{$2,0 \mathrm{~kg} / \mathrm{l}$} \\
\hline \multirow{2}{*}{$\begin{array}{l}\text { Resistência à compressão } \\
\text { (ASTM C-349) }\end{array}$} & $24 \mathrm{~h}$ & 7 dias & 28 dias \\
\hline & Min $75 \mathrm{MPa}$ & Min $90 \mathrm{MPa}$ & Min $100 \mathrm{MPa}$ \\
\hline \multirow{2}{*}{$\begin{array}{l}\text { Resistência à flexão } \\
\text { (ASTM C-349) }\end{array}$} & $24 \mathrm{~h}$ & 7 dias & 28 dias \\
\hline & $24 \mathrm{MPa}$ & $27 \mathrm{MPa}$ & $29 \mathrm{MPa}$ \\
\hline Módulo de elasticidade & \multicolumn{3}{|c|}{$\sim 16 \mathrm{GPa}(\mathrm{ASTM} \mathrm{C}-580 / 98)$} \\
\hline Retração Linear & \multicolumn{3}{|c|}{$<0,02 \% \quad($ ASTM C-531) } \\
\hline $\begin{array}{l}\text { Coeficiente de expansão } \\
\text { térmica }\end{array}$ & \multicolumn{3}{|c|}{$26 \times 10^{-6} \mathrm{~mm} / \mathrm{mm} /{ }^{\circ} \mathrm{K}$ (ASTM C-531) } \\
\hline Espessura de aplicação & \multicolumn{3}{|c|}{ Mín 25 mm/ Máx 100 mm (por camada) } \\
\hline
\end{tabular}

Após ter a superfície preparada iniciou-se aplicação do produto preenchendo todas as rachaduras presentes na laje de concreto. Este processo consistiu em colocar manualmente o produto já preparado e depois compactando com uma pá de pedreiro, no interior das rachaduras num tempo máximo 50 minutos, para evitar o endurecimento do produto Sikadur 42 CL. Este procedimento de aplicação se pode observar na Figura Anexo II.12
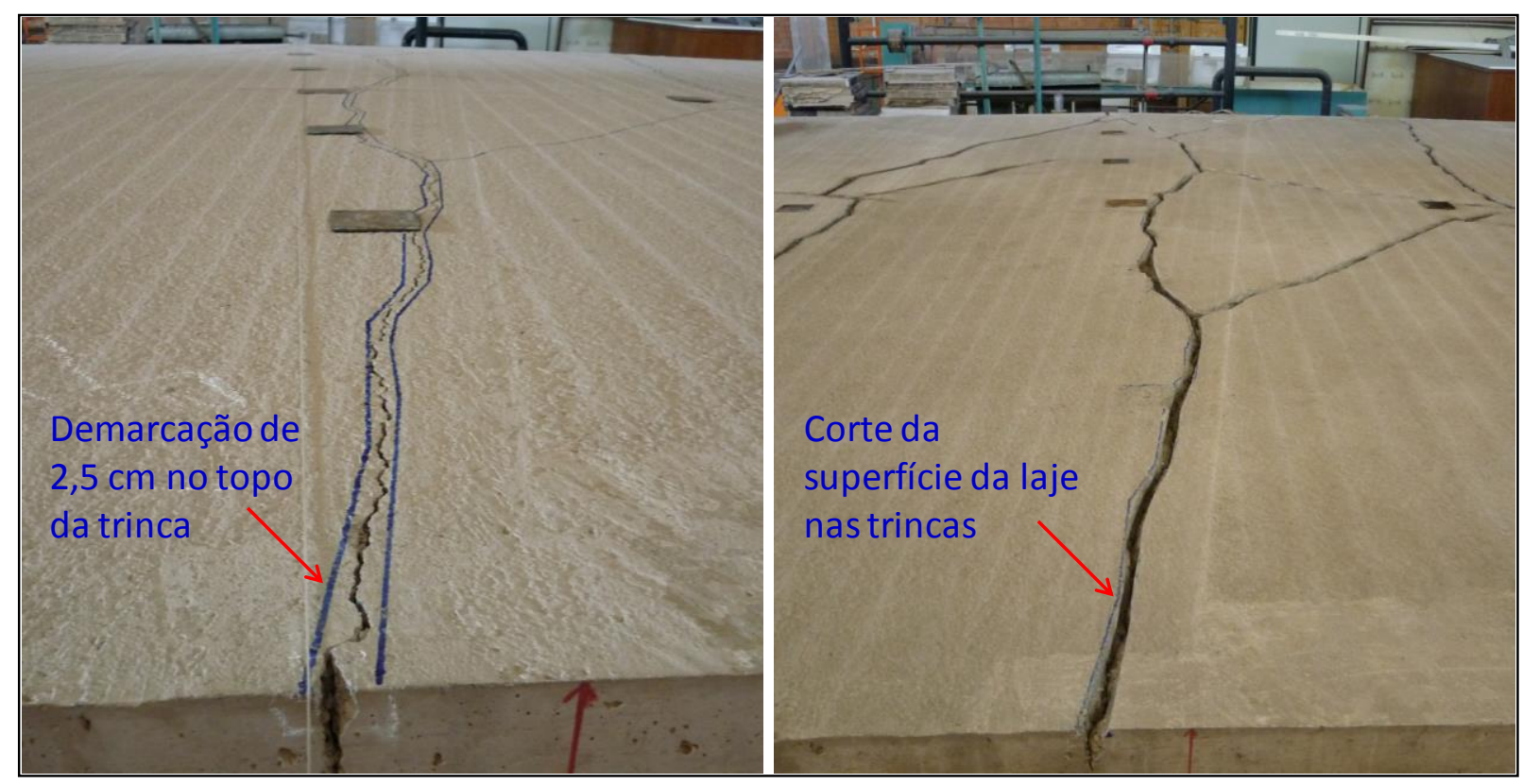

Figura Anexo II.11 - Demarcação e ampliação das trincas no topo da laje, gerada por momentos negativos hiperestáticos. 


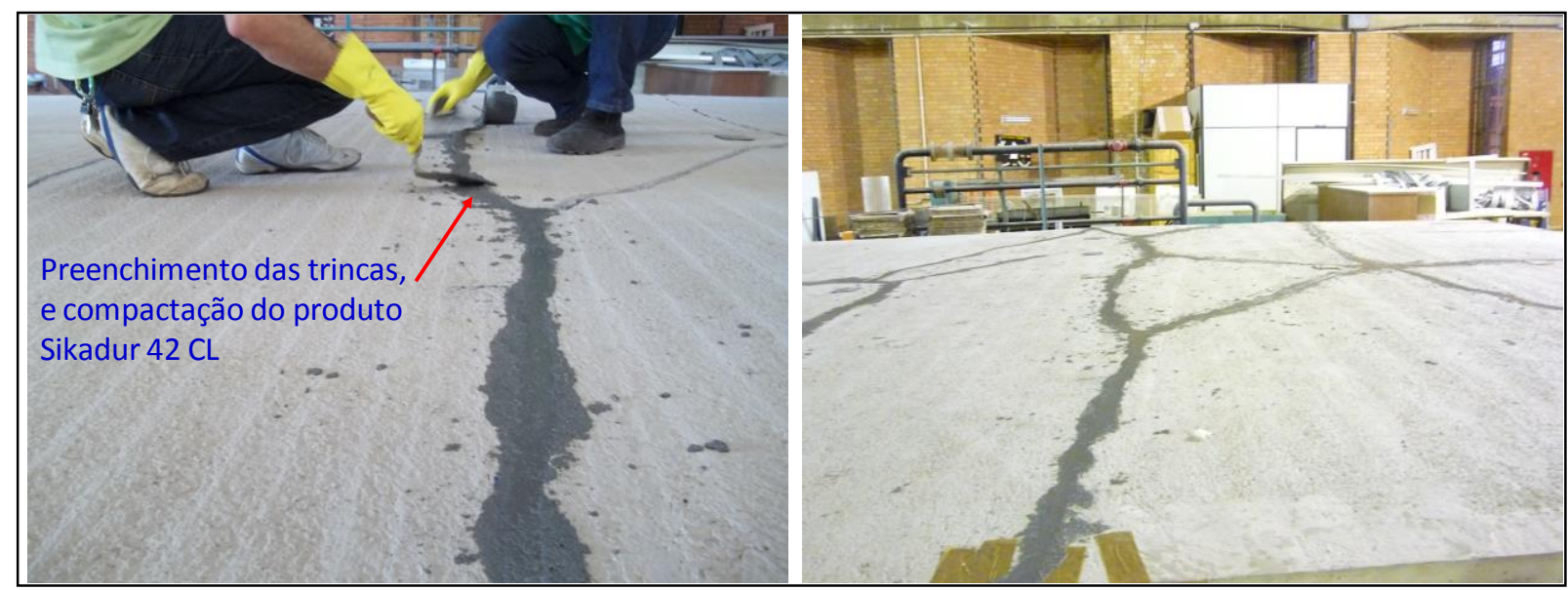

Figura Anexo II.12 - Preenchimento das trincas com produto Sikadur 42 CL

Após o preenchimento todas as rachaduras com o produto de Sikadur 42 CL e passados 28 dias para alcançar a máxima resistência a compressão de $100 \mathrm{MPa}$, se procedeu a retirar os nove macacos hidráulicos e os três perfis de aço que serviam como suporte temporário da laje para sua recuperação.

Uma vez retirados todos os suportes, verificou-se que a nova plataforma de ensaios dinâmicos apresentou uma flecha estática devida ao peso próprio de $23 \mathrm{~mm}$. Em resumo se passou de uma flecha estática inicial antes da recuperação de $70 \mathrm{~mm}$ para uma flecha estática após da recuperação de $23 \mathrm{~mm}$, o que implica uma redução da deflexão da laje em um 67\% aproximadamente. O resultado final da recuperação da laje é apresentado na Figura Anexo II.13.

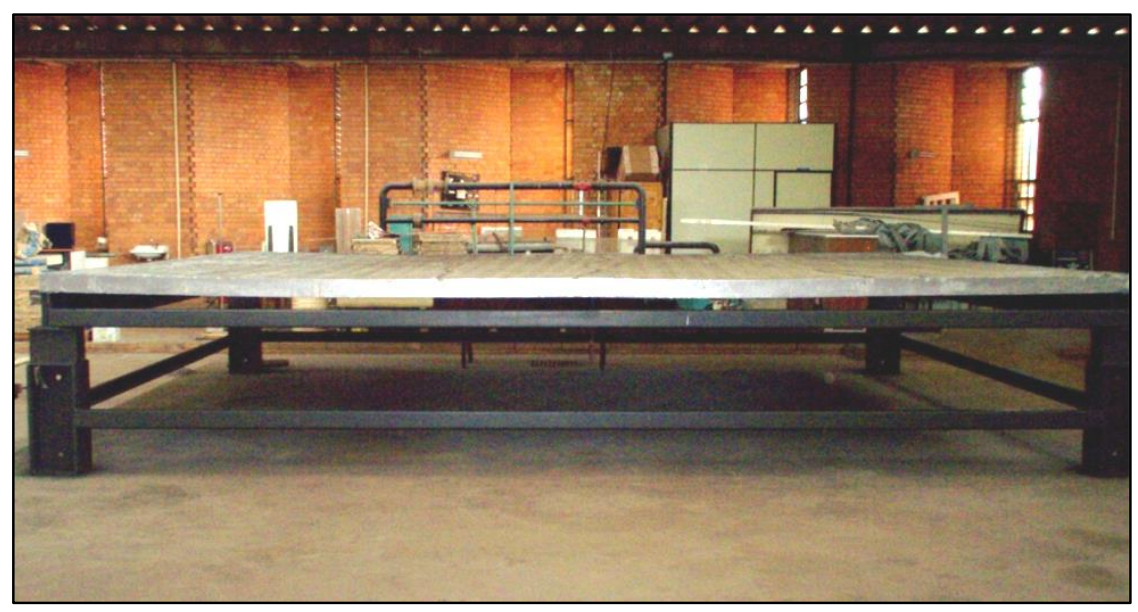

Figura Anexo II.13 - Panorâmica da plataforma de ensaios dinâmicos após da recuperação. 


\section{Anexo III}

ANÁLISE DOS DADOS NO DOMINIO DO TEMPO E NO DOMINIO DA FREQUENCIA, DOS ENSAIOS EXPERIMENTAIS EM VIBRAÇAO LIVRE, APÓS RECUPERAÇAO DA PLATAFORMA.

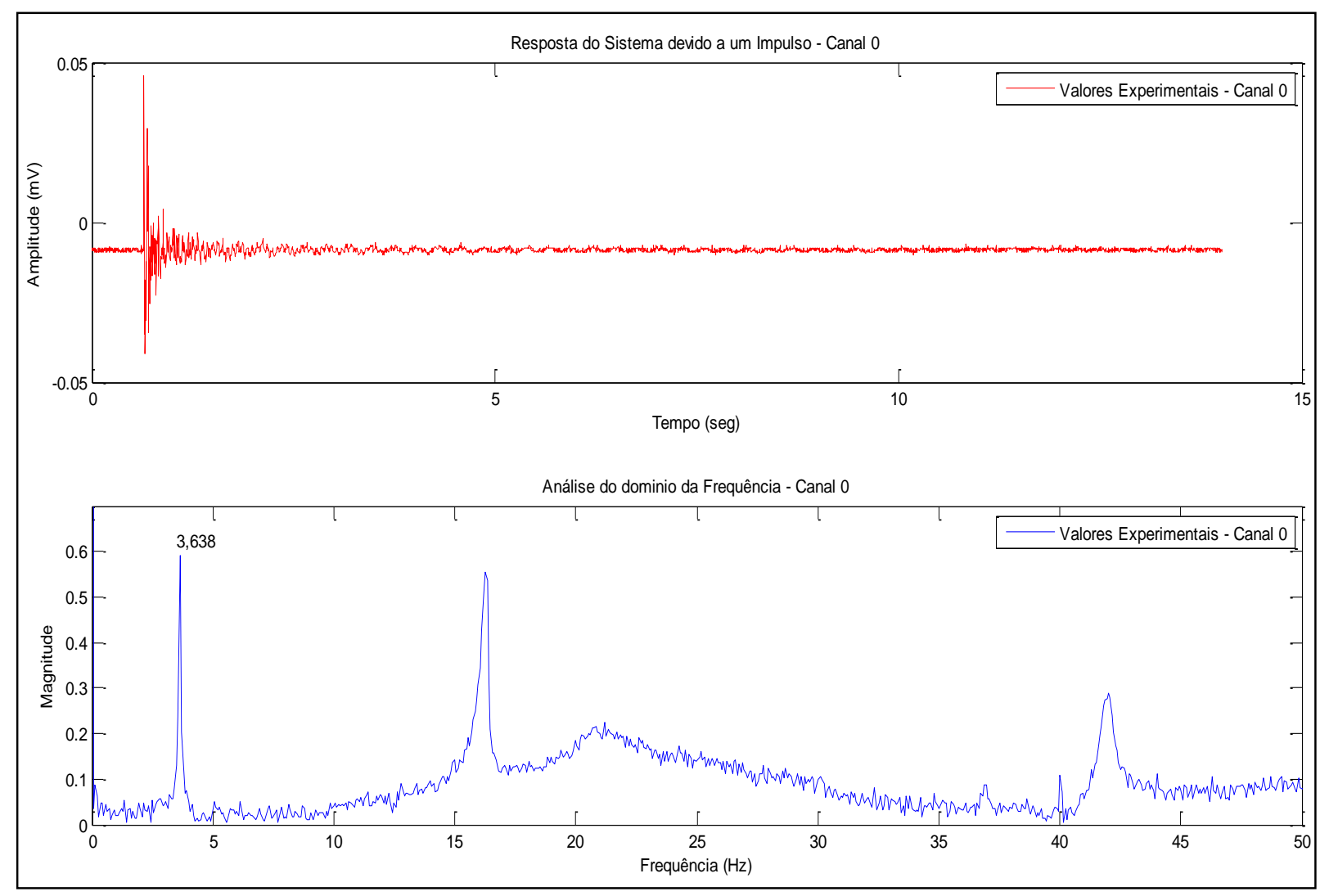

Figura Anexo III.1 - Resposta do sistema devido a um impulso com marreta (1). 


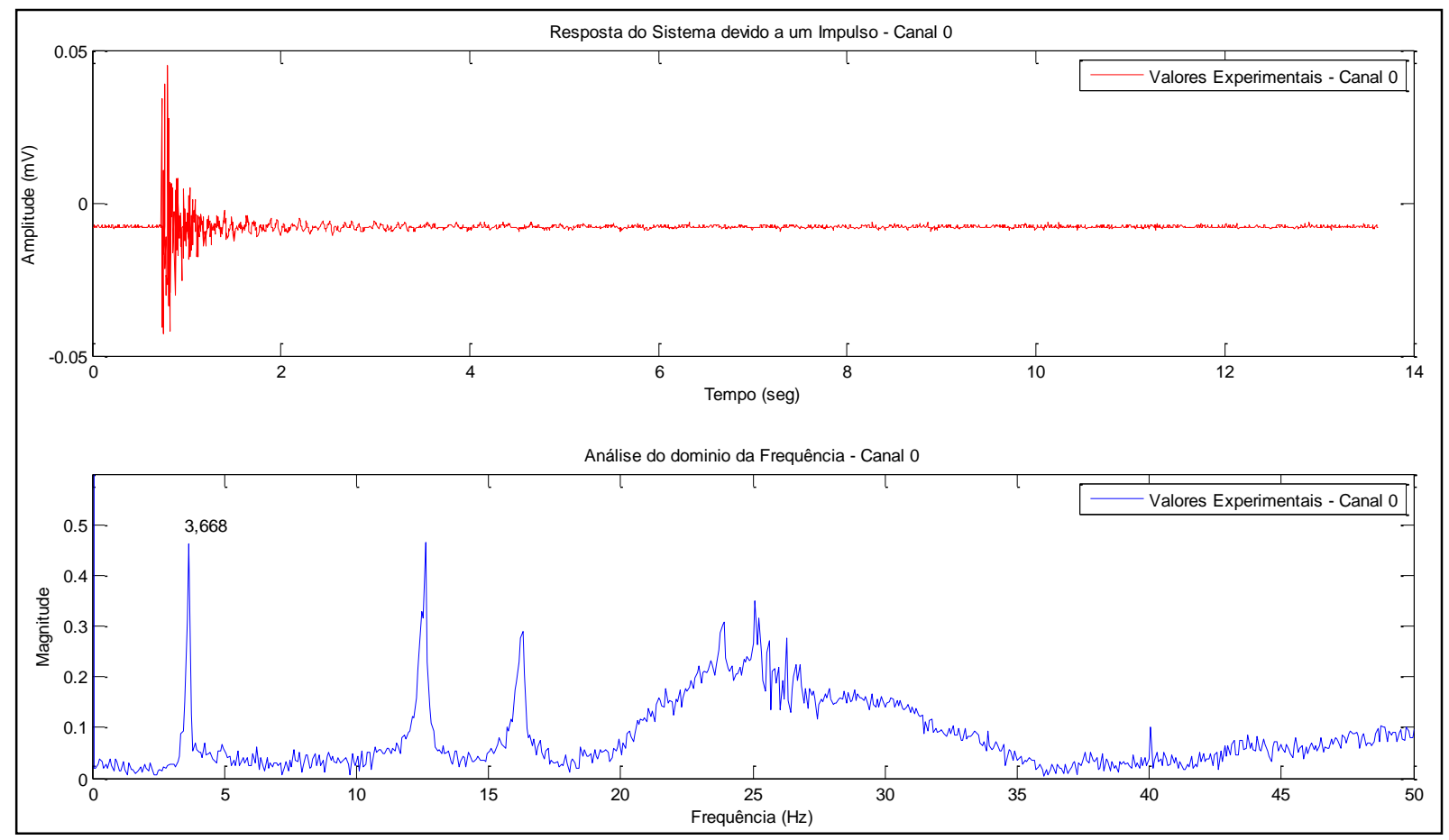

Figura Anexo III.2 - Resposta do sistema devido a um impulso com marreta (2).

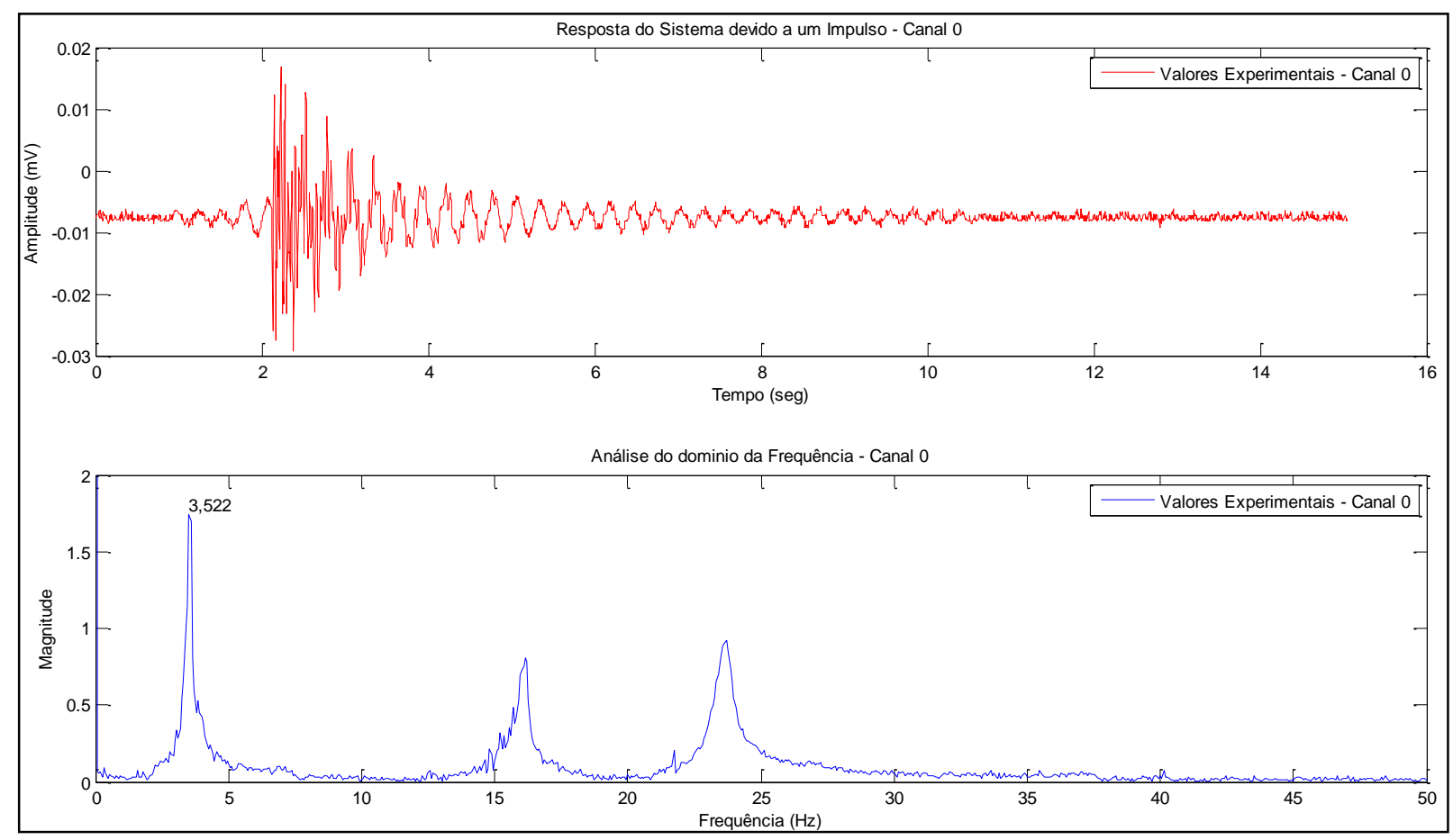

Figura Anexo III.3 - Resposta do sistema devido a um impulso com o calcanhar (1). 


\section{Anexo IV}

CALCULO EXPERIMENTAL DA RIGIDEZ DAS MOLAS UTILIZANO O METODO DOS MINIMOS QUADRADOS.

\begin{tabular}{|c|c|c|c|c|c|c|c|c|}
\hline \multicolumn{9}{|c|}{ Mola 1} \\
\hline $\mathrm{n}$ & $\mathrm{X}_{\mathrm{i}}$ & $\mathrm{y}_{\mathrm{i}}$ & $\mathrm{x}_{\mathrm{i}} \mathrm{y}_{\mathrm{i}}$ & $\mathrm{x}_{\mathrm{i}}^{2}$ & $\mathrm{yi}^{2}$ & $a_{1}$ & $a_{0}$ & $\mathrm{r}^{2}$ \\
\hline 1 & 0,00000 & 0,00000 & 0,00000 & 0,00000 & 0,00000 & \multirow{5}{*}{6355,5} & \multirow{5}{*}{$-1,2979$} & \multirow{5}{*}{0,9963} \\
\hline 2 & 0,00450 & 24,49900 & 0,11025 & 0,00002 & 600,20100 & & & \\
\hline 3 & 0,00772 & 49,02200 & 0,37845 & 0,00006 & 2403,15648 & & & \\
\hline 4 & 0,01171 & 73,37400 & 0,85921 & 0,00014 & 5383,74388 & & & \\
\hline$\Sigma$ & 0,02393 & 146,89500 & 1,34790 & 0,00022 & 8387,10136 & & & \\
\hline
\end{tabular}

\begin{tabular}{|c|c|c|c|c|c|c|c|c|}
\hline \multicolumn{9}{|c|}{ Mola 2} \\
\hline $\mathrm{n}$ & $\mathrm{x}_{\mathrm{i}}$ & $\mathrm{y}_{\mathrm{i}}$ & $\mathrm{x}_{\mathrm{i}} \mathrm{y}_{\mathrm{i}}$ & $x_{i}^{2}$ & $\mathrm{yi}^{2}$ & $\mathrm{a}_{1}$ & $\mathrm{a}_{0}$ & $r^{2}$ \\
\hline 1 & 0,000 & 0,00000 & 0,00000 & 0,00000 & 0,00000 & \multirow{5}{*}{6313,3} & \multirow{5}{*}{1,1169} & \multirow{5}{*}{0,9972} \\
\hline 2 & 0,00335 & 24,49900 & 0,08207 & 0,00001 & 600,20100 & & & \\
\hline 3 & 0,00782 & 49,02200 & 0,38335 & 0,00006 & 2403,15648 & & & \\
\hline 4 & 0,01139 & 73,37400 & 0,83573 & 0,00013 & 5383,74388 & & & \\
\hline$\Sigma$ & 0,02256 & 146,89500 & 1,30115 & 0,00020 & 8387,10136 & & & \\
\hline
\end{tabular}

\begin{tabular}{|c|c|c|c|c|c|c|c|c|}
\hline \multicolumn{9}{|c|}{ Mola 3} \\
\hline $\mathrm{n}$ & $\mathrm{x}_{\mathrm{i}}$ & $\mathrm{y}_{\mathrm{i}}$ & $\mathrm{x}_{\mathrm{i}} \mathrm{y}_{\mathrm{i}}$ & $x_{i}^{2}$ & $\mathrm{yi}^{2}$ & $\mathrm{a}_{1}$ & $\mathrm{a}_{0}$ & $r^{2}$ \\
\hline 1 & 0,00000 & 0,0000 & 0,00000 & 0,00000 & 0,00000 & \multirow{5}{*}{5550,4} & \multirow{5}{*}{$-0,1445$} & \multirow{5}{*}{0,9990} \\
\hline 2 & 0,00436 & 24,4990 & 0,10682 & 0,00002 & 600,20100 & & & \\
\hline 3 & 0,00912 & 49,0220 & 0,44708 & 0,00008 & 2403,15648 & & & \\
\hline 4 & 0,01309 & 73,3740 & 0,96047 & 0,00017 & 5383,74388 & & & \\
\hline$\Sigma$ & 0,02657 & 146,8950 & 1,51436 & 0,00027 & 8387,10136 & & & \\
\hline
\end{tabular}

\begin{tabular}{|c|c|c|c|c|c|c|c|c|}
\hline \multicolumn{9}{|c|}{ Mola 4} \\
\hline $\mathrm{n}$ & $\mathrm{x}_{\mathrm{i}}$ & $\mathrm{y}_{\mathrm{i}}$ & $\mathrm{x}_{\mathrm{i}} \mathrm{y}_{\mathrm{i}}$ & $x_{i}^{2}$ & $\mathrm{yi}^{2}$ & $\mathrm{a}_{1}$ & $\mathrm{a}_{0}$ & $r^{2}$ \\
\hline 1 & 0,00000 & 0,0000 & 0,00000 & 0,00000 & 0,00000 & \multirow{5}{*}{5834,5} & \multirow{5}{*}{0,1267} & \multirow{5}{*}{1,0000} \\
\hline 2 & 0,00415 & 24,4990 & 0,10167 & 0,00002 & 600,20100 & & & \\
\hline 3 & 0,00837 & 49,0220 & 0,41031 & 0,00007 & 2403,15648 & & & \\
\hline 4 & 0,01257 & 73,3740 & 0,92231 & 0,00016 & 5383,74388 & & & \\
\hline$\Sigma$ & 0,02509 & 146,8950 & 1,43430 & 0,00025 & 8387,10136 & & & \\
\hline
\end{tabular}




\begin{tabular}{|c|c|c|c|c|c|c|c|c|}
\hline \multicolumn{9}{|c|}{ Mola 5} \\
\hline $\mathrm{n}$ & $\mathrm{x}_{\mathrm{i}}$ & $\mathrm{y}_{\mathrm{i}}$ & $\mathrm{x}_{\mathrm{i}} \mathrm{y}_{\mathrm{i}}$ & $\mathrm{xi}^{2}$ & $\mathrm{yi}_{\mathrm{i}}^{2}$ & $\mathrm{a}_{1}$ & $\mathrm{a}_{0}$ & $r^{2}$ \\
\hline 1 & 0,00000 & 0,0000 & 0,00000 & 0,00000 & 0,00000 & \multirow{5}{*}{5840,7} & \multirow{5}{*}{0,1317} & \multirow{5}{*}{0,9998} \\
\hline 2 & 0,00419 & 24,4990 & 0,10265 & 0,00002 & 600,20100 & & & \\
\hline 3 & 0,00827 & 49,0220 & 0,40541 & 0,00007 & 2403,15648 & & & \\
\hline 4 & 0,01260 & 73,3740 & 0,92451 & 0,00016 & 5383,74388 & & & \\
\hline$\Sigma$ & 0,02506 & 146,8950 & 1,43258 & 0,00024 & 8387,10136 & & & \\
\hline
\end{tabular}

\begin{tabular}{|c|c|c|c|c|c|c|c|c|}
\hline \multicolumn{9}{|c|}{ Mola 6} \\
\hline $\mathrm{n}$ & $\mathrm{x}_{\mathrm{i}}$ & $\mathrm{y}_{\mathrm{i}}$ & $\mathrm{x}_{\mathrm{i}} \mathrm{y}_{\mathrm{i}}$ & $x_{i}^{2}$ & $\mathrm{y}_{\mathrm{i}}^{2}$ & $a_{1}$ & $\mathrm{a}_{0}$ & $r^{2}$ \\
\hline 1 & 0,00000 & 0,0000 & 0,00000 & 0,00000 & 0,00000 & \multirow{5}{*}{5900,0} & \multirow{5}{*}{$-0,2692$} & \multirow{5}{*}{0,9999} \\
\hline 2 & 0,00424 & 24,4990 & 0,10388 & 0,00002 & 600,20100 & & & \\
\hline 3 & 0,00841 & 49,0220 & 0,41228 & 0,00007 & 2403,15648 & & & \\
\hline 4 & 0,01243 & 73,3740 & 0,91204 & 0,00015 & 5383,74388 & & & \\
\hline$\Sigma$ & 0,02508 & 146,8950 & 1,42819 & 0,00024 & 8387,10136 & & & \\
\hline
\end{tabular}

\begin{tabular}{|c|c|c|c|c|c|c|c|c|}
\hline \multicolumn{9}{|c|}{ Mola 7} \\
\hline $\mathrm{n}$ & $\mathrm{x}_{\mathrm{i}}$ & $\mathrm{y}_{\mathrm{i}}$ & $\mathrm{x}_{\mathrm{i}} \mathrm{y}_{\mathrm{i}}$ & $x_{i}^{2}$ & $\mathrm{yi}^{2}$ & $\mathrm{a}_{1}$ & $\mathrm{a}_{0}$ & $r^{2}$ \\
\hline 1 & 0,0000 & 0,0000 & 0,00000 & 0,00000 & 0,00000 & \multirow{5}{*}{5912,1} & \multirow{5}{*}{0,0688} & \multirow{5}{*}{1,0000} \\
\hline 2 & 0,0041 & 24,4990 & 0,10118 & 0,00002 & 600,20100 & & & \\
\hline 3 & 0,0083 & 49,0220 & 0,40443 & 0,00007 & 2403,15648 & & & \\
\hline 4 & 0,0124 & 73,3740 & 0,91131 & 0,00015 & 5383,74388 & & & \\
\hline$\Sigma$ & 0,0248 & 146,8950 & 1,41692 & 0,00024 & 8387,10136 & & & \\
\hline
\end{tabular}

\begin{tabular}{|c|c|c|c|c|c|c|c|c|}
\hline \multicolumn{9}{|c|}{ Mola 8} \\
\hline $\mathrm{n}$ & $x_{i}$ & $\mathrm{y}_{\mathrm{i}}$ & $\mathrm{x}_{\mathrm{i}} \mathrm{y}_{\mathrm{i}}$ & $\mathrm{x}_{\mathrm{i}}{ }^{2}$ & $y_{i}^{2}$ & $a_{1}$ & $\mathrm{a}_{0}$ & $\mathrm{r}^{2}$ \\
\hline 1 & 0,0000 & 0,0000 & 0,00000 & 0,00000 & 0,00000 & \multirow{5}{*}{5628,1} & \multirow{5}{*}{$-0,5763$} & \multirow{5}{*}{0,9996} \\
\hline 2 & 0,0046 & 24,4990 & 0,11221 & 0,00002 & 600,20100 & & & \\
\hline 3 & 0,0089 & 49,0220 & 0,43532 & 0,00008 & 2403,15648 & & & \\
\hline 4 & 0,0131 & 73,3740 & 0,95753 & 0,00017 & 5383,74388 & & & \\
\hline$\Sigma$ & 0,0265 & 146,8950 & 1,50505 & 0,00027 & 8387,10136 & & & \\
\hline
\end{tabular}




\begin{tabular}{|c|c|c|c|c|c|c|c|c|}
\hline \multicolumn{9}{|c|}{ Mola 9} \\
\hline $\mathrm{n}$ & $\mathrm{x}_{\mathrm{i}}$ & $\mathrm{y}_{\mathrm{i}}$ & $\mathrm{x}_{\mathrm{i}} \mathrm{y}_{\mathrm{i}}$ & $\mathrm{xi}^{2}$ & $\mathrm{yi}_{\mathrm{i}}^{2}$ & $\mathrm{a}_{1}$ & $\mathrm{a}_{0}$ & $r^{2}$ \\
\hline 1 & 0,0000 & 0,0000 & 0,00000 & 0,00000 & 0,00000 & \multirow{5}{*}{6445,9} & \multirow{5}{*}{$-0,1628$} & \multirow{5}{*}{0,9999} \\
\hline 2 & 0,0039 & 24,4990 & 0,09530 & 0,00002 & 600,20100 & & & \\
\hline 3 & 0,0076 & 49,0220 & 0,37159 & 0,00006 & 2403,15648 & & & \\
\hline 4 & 0,0114 & 73,3740 & 0,83793 & 0,00013 & 5383,74388 & & & \\
\hline$\Sigma$ & 0,0229 & 146,8950 & 1,30482 & 0,00020 & 8387,10136 & & & \\
\hline
\end{tabular}

\begin{tabular}{|c|c|c|c|c|c|c|c|c|}
\hline \multicolumn{9}{|c|}{ Mola 10} \\
\hline$n$ & $\mathrm{x}_{\mathrm{i}}$ & $\mathrm{y}_{\mathrm{i}}$ & $\mathrm{x}_{\mathrm{i}} \mathrm{y}_{\mathrm{i}}$ & $x_{i}^{2}$ & $\mathrm{yi}^{2}$ & $\mathrm{a}_{1}$ & $\mathrm{a}_{0}$ & $r^{2}$ \\
\hline 1 & 0,00000 & 0,0000 & 0,00000 & 0,00000 & 0,00000 & \multirow{5}{*}{5351,5} & \multirow{5}{*}{$-0,7368$} & \multirow{5}{*}{0,9993} \\
\hline 2 & 0,00487 & 24,4990 & 0,11931 & 0,00002 & 600,20100 & & & \\
\hline 3 & 0,00942 & 49,0220 & 0,46179 & 0,00009 & 2403,15648 & & & \\
\hline 4 & 0,01371 & 73,3740 & 1,00596 & 0,00019 & 5383,74388 & & & \\
\hline$\Sigma$ & 0,02800 & 146,8950 & 1,58705 & 0,00030 & 8387,10136 & & & \\
\hline
\end{tabular}

\begin{tabular}{|c|c|c|c|c|c|c|c|c|}
\hline \multicolumn{9}{|c|}{ Mola 11} \\
\hline $\mathrm{n}$ & $\mathrm{x}_{\mathrm{i}}$ & $\mathrm{y}_{\mathrm{i}}$ & $\mathrm{x}_{\mathrm{i}} \mathrm{y}_{\mathrm{i}}$ & $x_{i}^{2}$ & $\mathrm{yi}^{2}$ & $\mathrm{a}_{1}$ & $\mathrm{a}_{0}$ & $r^{2}$ \\
\hline 1 & 0,00000 & 0,0000 & 0,00000 & 0,00000 & 0,00000 & \multirow{5}{*}{5130,2} & \multirow{5}{*}{$-0,8161$} & \multirow{5}{*}{0,9984} \\
\hline 2 & 0,00505 & 24,4990 & 0,12372 & 0,00003 & 600,20100 & & & \\
\hline 3 & 0,01000 & 49,0220 & 0,49022 & 0,00010 & 2403,15648 & & & \\
\hline 4 & 0,01422 & 73,3740 & 1,04338 & 0,00020 & 5383,74388 & & & \\
\hline$\Sigma$ & 0,02927 & 146,8950 & 1,65732 & 0,00033 & 8387,10136 & & & \\
\hline
\end{tabular}

\begin{tabular}{|c|c|c|c|c|c|c|c|c|}
\hline \multicolumn{9}{|c|}{ Mola 12} \\
\hline n & $\mathrm{x}_{\mathrm{i}}$ & $\mathrm{y}_{\mathrm{i}}$ & $\mathrm{x}_{\mathrm{i}} \mathrm{y}_{\mathrm{i}}$ & $\mathrm{x}_{\mathrm{i}}^{2}$ & $\mathrm{yi}^{2}$ & $a_{1}$ & $\mathrm{a}_{0}$ & $\mathrm{r}^{2}$ \\
\hline 1 & 0,00000 & 0,0000 & 0,00000 & 0,00000 & 0,00000 & \multirow{5}{*}{5788,1} & \multirow{5}{*}{0,2585} & \multirow{5}{*}{0,9998} \\
\hline 2 & 0,00417 & 24,4990 & 0,10216 & 0,00002 & 600,20100 & & & \\
\hline 3 & 0,00833 & 49,0220 & 0,40835 & 0,00007 & 2403,15648 & & & \\
\hline 4 & 0,01270 & 73,3740 & 0,93185 & 0,00016 & 5383,74388 & & & \\
\hline$\Sigma$ & 0,02520 & 146,8950 & 1,44236 & 0,00025 & 8387,10136 & & & \\
\hline
\end{tabular}




\begin{tabular}{|c|c|c|c|c|c|c|c|c|}
\hline \multicolumn{9}{|c|}{ Mola 13} \\
\hline $\mathrm{n}$ & $\mathrm{x}_{\mathrm{i}}$ & $\mathrm{y}_{\mathrm{i}}$ & $\mathrm{x}_{\mathrm{i}} \mathrm{y}_{\mathrm{i}}$ & $\mathrm{x}_{\mathrm{i}}^{2}$ & $\mathrm{yi}_{\mathrm{i}}^{2}$ & $\mathrm{a}_{1}$ & $\mathrm{a}_{0}$ & $r^{2}$ \\
\hline 1 & 0,00000 & 0,0000 & 0,00000 & 0,00000 & 0,00000 & \multirow{5}{*}{5296,6} & \multirow{5}{*}{0,0579} & \multirow{5}{*}{0,9992} \\
\hline 2 & 0,00449 & 24,4990 & 0,11000 & 0,00002 & 600,20100 & & & \\
\hline 3 & 0,00948 & 49,0220 & 0,46473 & 0,00009 & 2403,15648 & & & \\
\hline 4 & 0,01372 & 73,3740 & 1,00669 & 0,00019 & 5383,74388 & & & \\
\hline$\Sigma$ & 0,02769 & 146,8950 & 1,58142 & 0,00030 & 8387,10136 & & & \\
\hline
\end{tabular}

\begin{tabular}{|c|c|c|c|c|c|c|c|c|}
\hline \multicolumn{9}{|c|}{ Mola 14} \\
\hline$n$ & $\mathrm{x}_{\mathrm{i}}$ & $\mathrm{y}_{\mathrm{i}}$ & $\mathrm{x}_{\mathrm{i}} \mathrm{y}_{\mathrm{i}}$ & $x_{i}^{2}$ & $\mathrm{yi}^{2}$ & $\mathrm{a}_{1}$ & $\mathrm{a}_{0}$ & $r^{2}$ \\
\hline 1 & 0,00000 & 0,0000 & 0,00000 & 0,00000 & 0,00000 & \multirow{5}{*}{5314,9} & \multirow{5}{*}{0,0111} & \multirow{5}{*}{1,0000} \\
\hline 2 & 0,00460 & 24,4990 & 0,11270 & 0,00002 & 600,20100 & & & \\
\hline 3 & 0,00923 & 49,0220 & 0,45247 & 0,00009 & 2403,15648 & & & \\
\hline 4 & 0,01380 & 73,3740 & 1,01256 & 0,00019 & 5383,74388 & & & \\
\hline$\Sigma$ & 0,02763 & 146,8950 & 1,57773 & 0,00030 & 8387,10136 & & & \\
\hline
\end{tabular}

\begin{tabular}{|c|c|c|c|c|c|c|c|c|}
\hline \multicolumn{9}{|c|}{ Mola 15} \\
\hline $\mathrm{n}$ & $\mathrm{x}_{\mathrm{i}}$ & $\mathrm{y}_{\mathrm{i}}$ & $\mathrm{x}_{\mathrm{i}} \mathrm{y}_{\mathrm{i}}$ & $x_{i}^{2}$ & $\mathrm{yi}^{2}$ & $\mathrm{a}_{1}$ & $\mathrm{a}_{0}$ & $r^{2}$ \\
\hline 1 & 0,00000 & 0,00000 & 0,00000 & 0,00000 & 0,00000 & \multirow{5}{*}{5611,1} & \multirow{5}{*}{$-1,0530$} & \multirow{5}{*}{0,9984} \\
\hline 2 & 0,00488 & 24,49900 & 0,11956 & 0,00002 & 600,20100 & & & \\
\hline 3 & 0,00887 & 49,02200 & 0,43483 & 0,00008 & 2403,15648 & & & \\
\hline 4 & 0,01318 & 73,37400 & 0,96707 & 0,00017 & 5383,74388 & & & \\
\hline$\Sigma$ & 0,02693 & 146,8950 & 1,52145 & 0,00028 & 8387,10136 & & & \\
\hline
\end{tabular}

\begin{tabular}{|c|c|c|c|c|c|c|c|c|}
\hline \multicolumn{9}{|c|}{ Mola 16} \\
\hline $\mathrm{n}$ & $x_{i}$ & $\mathrm{yi}_{\mathrm{i}}$ & $\mathrm{x}_{\mathrm{i}} \mathrm{y}_{\mathrm{i}}$ & $\mathrm{xi}^{2}$ & $\mathrm{yi}^{2}$ & $\mathrm{a}_{1}$ & $\mathrm{a}_{0}$ & $\mathrm{r}^{2}$ \\
\hline 1 & 0,00000 & 0,0000 & 0,00000 & 0,00000 & 0,00000 & \multirow{5}{*}{5254,0} & \multirow{5}{*}{$-0,4351$} & \multirow{5}{*}{0,9997} \\
\hline 2 & 0,00483 & 24,4990 & 0,11833 & 0,00002 & 600,20100 & & & \\
\hline 3 & 0,00950 & 49,0220 & 0,46571 & 0,00009 & 2403,15648 & & & \\
\hline 4 & 0,01396 & 73,3740 & 1,02430 & 0,00019 & 5383,74388 & & & \\
\hline$\Sigma$ & 0,02829 & 146,8950 & 1,60834 & 0,00031 & 8387,10136 & & & \\
\hline
\end{tabular}




\begin{tabular}{|c|c|c|c|c|c|c|c|c|}
\hline \multicolumn{9}{|c|}{ Mola 17} \\
\hline $\mathrm{n}$ & $\mathrm{x}_{\mathrm{i}}$ & $\mathrm{y}_{\mathrm{i}}$ & $\mathrm{x}_{\mathrm{i}} \mathrm{y}_{\mathrm{i}}$ & $\mathrm{x}_{\mathrm{i}}^{2}$ & $\mathrm{yi}_{\mathrm{i}}^{2}$ & $\mathrm{a}_{1}$ & $\mathrm{a}_{0}$ & $r^{2}$ \\
\hline 1 & 0,00000 & 0,0000 & 0,00000 & 0,00000 & 0,00000 & \multirow{5}{*}{6264,7} & \multirow{5}{*}{$-0,1284$} & \multirow{5}{*}{1,0000} \\
\hline 2 & 0,00395 & 24,4990 & 0,09677 & 0,00002 & 600,20100 & & & \\
\hline 3 & 0,00787 & 49,0220 & 0,38580 & 0,00006 & 2403,15648 & & & \\
\hline 4 & 0,01171 & 73,3740 & 0,85921 & 0,00014 & 5383,74388 & & & \\
\hline$\Sigma$ & 0,02353 & 146,8950 & 1,34178 & 0,00021 & 8387,10136 & & & \\
\hline
\end{tabular}

\begin{tabular}{|c|c|c|c|c|c|c|c|c|}
\hline \multicolumn{9}{|c|}{ Mola 18} \\
\hline $\mathrm{n}$ & $\mathrm{x}_{\mathrm{i}}$ & $\mathrm{y}_{\mathrm{i}}$ & $\mathrm{x}_{\mathrm{i}} \mathrm{y}_{\mathrm{i}}$ & $\mathrm{x}_{\mathrm{i}}^{2}$ & $\mathrm{yi}^{2}$ & $\mathrm{a}_{1}$ & $\mathrm{a}_{0}$ & $r^{2}$ \\
\hline 1 & 0,00000 & 0,0000 & 0,00000 & 0,00000 & 0,00000 & \multirow{5}{*}{5249,1} & \multirow{5}{*}{0,7542} & \multirow{5}{*}{0,9987} \\
\hline 2 & 0,00446 & 24,4990 & 0,10927 & 0,00002 & 600,20100 & & & \\
\hline 3 & 0,00892 & 49,0220 & 0,43728 & 0,00008 & 2403,15648 & & & \\
\hline 4 & 0,01403 & 73,3740 & 1,02944 & 0,00020 & 5383,74388 & & & \\
\hline$\Sigma$ & 0,02741 & 146,8950 & 1,57598 & 0,00030 & 8387,10136 & & & \\
\hline
\end{tabular}

\begin{tabular}{|c|c|c|c|c|c|c|c|c|}
\hline \multicolumn{9}{|c|}{ Mola 19} \\
\hline $\mathrm{n}$ & $\mathrm{x}_{\mathrm{i}}$ & $\mathrm{y}_{\mathrm{i}}$ & $\mathrm{x}_{\mathrm{i}} \mathrm{y}_{\mathrm{i}}$ & $x_{i}^{2}$ & $\mathrm{yi}^{2}$ & $\mathrm{a}_{1}$ & $\mathrm{a}_{0}$ & $r^{2}$ \\
\hline 1 & 0,00000 & 0,0000 & 0,00000 & 0,00000 & 0,00000 & \multirow{5}{*}{6033,0} & \multirow{5}{*}{$-0,1231$} & \multirow{5}{*}{1,0000} \\
\hline 2 & 0,00411 & 24,4990 & 0,10069 & 0,00002 & 600,20100 & & & \\
\hline 3 & 0,00815 & 49,0220 & 0,39953 & 0,00007 & 2403,15648 & & & \\
\hline 4 & 0,01217 & 73,3740 & 0,89296 & 0,00015 & 5383,74388 & & & \\
\hline$\Sigma$ & 0,02443 & 146,8950 & 1,39318 & 0,00023 & 8387,10136 & & & \\
\hline
\end{tabular}

\begin{tabular}{|c|c|c|c|c|c|c|c|c|}
\hline \multicolumn{9}{|c|}{ Mola 20} \\
\hline $\mathrm{n}$ & $x_{i}$ & $\mathrm{y}_{\mathrm{i}}$ & $\mathrm{x}_{\mathrm{i}} \mathrm{y}_{\mathrm{i}}$ & $\mathrm{x}_{\mathrm{i}}^{2}$ & $y_{i}{ }^{2}$ & $a_{1}$ & $\mathrm{a}_{0}$ & $r^{2}$ \\
\hline 1 & 0,00000 & 0,0000 & 0,00000 & 0,00000 & 0,00000 & \multirow{5}{*}{4957,6} & \multirow{5}{*}{$-0,4954$} & \multirow{5}{*}{0,9997} \\
\hline 2 & 0,00515 & 24,4990 & 0,12617 & 0,00003 & 600,20100 & & & \\
\hline 3 & 0,01008 & 49,0220 & 0,49414 & 0,00010 & 2403,15648 & & & \\
\hline 4 & 0,01480 & 73,3740 & 1,08594 & 0,00022 & 5383,74388 & & & \\
\hline$\Sigma$ & 0,03003 & 146,8950 & 1,70625 & 0,00035 & 8387,10136 & & & \\
\hline
\end{tabular}




\begin{tabular}{|c|c|c|c|c|c|c|c|c|}
\hline \multicolumn{9}{|c|}{ Mola 21} \\
\hline $\mathrm{n}$ & $\mathrm{x}_{\mathrm{i}}$ & $\mathrm{y}_{\mathrm{i}}$ & $\mathrm{x}_{\mathrm{i}} \mathrm{y}_{\mathrm{i}}$ & $x_{i}^{2}$ & $\mathrm{yi}^{2}$ & $\mathrm{a}_{1}$ & $\mathrm{a}_{0}$ & $r^{2}$ \\
\hline 1 & 0,00000 & 0,0000 & 0,00000 & 0,00000 & 0,00000 & \multirow{5}{*}{6388,6} & \multirow{5}{*}{$-0,1865$} & \multirow{5}{*}{0,9999} \\
\hline 2 & 0,00388 & 24,4990 & 0,09506 & 0,00002 & 600,20100 & & & \\
\hline 3 & 0,00776 & 49,0220 & 0,38041 & 0,00006 & 2403,15648 & & & \\
\hline 4 & 0,01147 & 73,3740 & 0,84160 & 0,00013 & 5383,74388 & & & \\
\hline$\Sigma$ & 0,02311 & 146,8950 & 1,31707 & 0,00021 & 8387,10136 & & & \\
\hline
\end{tabular}

\begin{tabular}{|c|c|c|c|c|c|c|c|c|}
\hline \multicolumn{9}{|c|}{ Mola 22} \\
\hline $\mathrm{n}$ & $\mathrm{x}_{\mathrm{i}}$ & $\mathrm{y}_{\mathrm{i}}$ & $\mathrm{x}_{\mathrm{i}} \mathrm{y}_{\mathrm{i}}$ & $\mathrm{x}_{\mathrm{i}}^{2}$ & $\mathrm{yi}^{2}$ & $\mathrm{a}_{1}$ & $\mathrm{a}_{0}$ & $r^{2}$ \\
\hline 1 & 0,00000 & 0,0000 & 0,00000 & 0,00000 & 0,00000 & \multirow{5}{*}{4978,7} & \multirow{5}{*}{$-0,4796$} & \multirow{5}{*}{0,9995} \\
\hline 2 & 0,00508 & 24,4990 & 0,12445 & 0,00003 & 600,20100 & & & \\
\hline 3 & 0,01012 & 49,0220 & 0,49610 & 0,00010 & 2403,15648 & & & \\
\hline 4 & 0,01469 & 73,3740 & 1,07786 & 0,00022 & 5383,74388 & & & \\
\hline$\Sigma$ & 0,02989 & 146,8950 & 1,69842 & 0,00034 & 8387,10136 & & & \\
\hline
\end{tabular}

\begin{tabular}{|c|c|c|c|c|c|c|c|c|}
\hline \multicolumn{9}{|c|}{ Mola 23} \\
\hline $\mathrm{n}$ & $\mathrm{x}_{\mathrm{i}}$ & $\mathrm{y}_{\mathrm{i}}$ & $\mathrm{x}_{\mathrm{i}} \mathrm{y}_{\mathrm{i}}$ & $x_{i}^{2}$ & $\mathrm{y}_{\mathrm{i}}^{2}$ & $\mathrm{a}_{1}$ & $\mathrm{a}_{0}$ & $r^{2}$ \\
\hline 1 & 0,00000 & 0,0000 & 0,00000 & 0,00000 & 0,00000 & \multirow{5}{*}{5428,4} & \multirow{5}{*}{$-0,5287$} & \multirow{5}{*}{0,9996} \\
\hline 2 & 0,00472 & 24,4990 & 0,11564 & 0,00002 & 600,20100 & & & \\
\hline 3 & 0,00921 & 49,0220 & 0,45149 & 0,00008 & 2403,15648 & & & \\
\hline 4 & 0,01352 & 73,3740 & 0,99202 & 0,00018 & 5383,74388 & & & \\
\hline$\Sigma$ & 0,02745 & 146,8950 & 1,55914 & 0,00029 & 8387,10136 & & & \\
\hline
\end{tabular}

\begin{tabular}{|c|c|c|c|c|c|c|c|c|}
\hline \multicolumn{9}{|c|}{ Mola 24} \\
\hline $\mathrm{n}$ & $\mathrm{x}_{\mathrm{i}}$ & $\mathrm{y}_{\mathrm{i}}$ & $\mathrm{x}_{\mathrm{i}} \mathrm{y}_{\mathrm{i}}$ & $\mathrm{x}_{\mathrm{i}}{ }^{2}$ & $\mathrm{yi}_{\mathrm{i}}^{2}$ & $a_{1}$ & $\mathrm{a}_{0}$ & $\mathrm{r}^{2}$ \\
\hline 1 & 0,00000 & 0,0000 & 0,00000 & 0,00000 & 0,00000 & \multirow{5}{*}{6221,5} & \multirow{5}{*}{$-1,3054$} & \multirow{5}{*}{0,9977} \\
\hline 2 & 0,00441 & 24,4990 & 0,10804 & 0,00002 & 600,20100 & & & \\
\hline 3 & 0,00824 & 49,0220 & 0,40394 & 0,00007 & 2403,15648 & & & \\
\hline 4 & 0,01180 & 73,3740 & 0,86581 & 0,00014 & 5383,74388 & & & \\
\hline$\Sigma$ & 0,02445 & 146,8950 & 1,37780 & 0,00023 & 8387,10136 & & & \\
\hline
\end{tabular}




\section{Anexo V}

\section{Programação e quantidade de ensaios em vibração livre e forçada}

\begin{tabular}{|c|c|c|c|c|}
\hline Ensaio & Descrição & $\begin{array}{l}\text { Tempo de } \\
\text { ação }\end{array}$ & Tempo de Análise & $\mathrm{N}^{\circ}$ de acelerômetros \\
\hline Teste 1 & \multirow{7}{*}{$\begin{array}{c}\text { Impacto com o } \\
\text { calcanhar no centro } \\
\text { da laje. } \\
1 \text { Pessoa. }\end{array}$} & \multirow{7}{*}{1 segundo } & \multirow{11}{*}{20 segundos } & 1 acelerômetro na metade da laje \\
\hline Teste 2 & & & & \multirow{10}{*}{$\begin{array}{c}1 \text { acelerômetro na metade da laje, } \\
1 \text { acelerômetro no AMS. }\end{array}$} \\
\hline Teste 3 & & & & \\
\hline Teste 4 & & & & \\
\hline Teste 5 & & & & \\
\hline Teste 6 & & & & \\
\hline Teste 7 & & & & \\
\hline Teste 8 & \multirow{4}{*}{$\begin{array}{l}\text { Pulo continuo no } \\
\text { centro da laje. } \\
1 \text { Pessoa. Com } \\
\text { AMS. }\end{array}$} & \multirow{4}{*}{5 segundos } & & \\
\hline Teste 9 & & & & \\
\hline Teste 10 & & & & \\
\hline Teste 11 & & & & \\
\hline Teste 1 & \multirow{5}{*}{$\begin{array}{c}\text { Pulando desde uma } \\
\text { carteira escolar, no } \\
\text { centro da laje. } \\
1 \text { Pessoa. Com } \\
\text { AMS }\end{array}$} & \multirow{5}{*}{1 segundo } & \multirow{5}{*}{20 segundos } & \multirow{5}{*}{$\begin{array}{c}3 \text { acelerômetros espaçados na laje } \\
1 \text { acelerômetro no AMS. }\end{array}$} \\
\hline Teste 2 & & & & \\
\hline Teste 3 & & & & \\
\hline Teste 4 & & & & \\
\hline Teste 5 & & & & \\
\hline Teste 6 & \multirow{3}{*}{$\begin{array}{l}\text { Pulos contínuos no } \\
\text { centro da laje. } \\
1 \text { Pessoa. }\end{array}$} & \multirow{3}{*}{5 segundos } & \multirow{3}{*}{20 segundos } & \multirow{3}{*}{$\begin{array}{c}3 \text { acelerômetros espaçados na laje, } \\
1 \text { acelerômetro no AMS. }\end{array}$} \\
\hline Teste 7 & & & & \\
\hline Teste 8 & & & & \\
\hline Teste 9 & \multirow{4}{*}{$\begin{array}{l}\text { Caminhando em } \\
\text { toda área da laje. } \\
\text { 4 Pessoas. }\end{array}$} & \multirow{4}{*}{20 segundos } & \multirow{4}{*}{20 segundos } & \multirow{4}{*}{$\begin{array}{c}3 \text { acelerômetros espaçados na laje, } \\
1 \text { acelerômetro no AMS. }\end{array}$} \\
\hline Teste 10 & & & & \\
\hline Teste 11 & & & & \\
\hline Teste 12 & & & & \\
\hline Teste 13 & $\begin{array}{l}\text { Pulos contínuos em } \\
\text { toda área da laje. } \\
5 \text { Pessoas. }\end{array}$ & 20 segundos & 20 segundos & $\begin{array}{c}3 \text { acelerômetros espaçados na laje, } \\
1 \text { acelerômetro no AMS. }\end{array}$ \\
\hline Teste 14 & $\begin{array}{l}\text { Caminhando em } \\
\text { toda área da laje. } \\
5 \text { Pessoas. }\end{array}$ & 20 segundos & 20 segundos & $\begin{array}{c}3 \text { acelerômetros espaçados na laje, } \\
1 \text { acelerômetro no AMS. }\end{array}$ \\
\hline Teste 1 & \multirow{3}{*}{$\begin{array}{c}\text { Impacto com o } \\
\text { calcanhar no centro } \\
\text { da laje. } \\
\text { 1 Pessoa. }\end{array}$} & \multirow{3}{*}{1 segundo } & \multirow{3}{*}{20 segundos } & \multirow{3}{*}{1 acelerômetro no centro da laje. } \\
\hline Teste 2 & & & & \\
\hline Teste 3 & & & & \\
\hline Teste 4 & $\begin{array}{c}\text { Pulando desde uma } \\
\text { carteira escolar, no } \\
\text { centro da laje. } \\
1 \text { Pessoa. Sem } \\
\text { AMS. }\end{array}$ & 1 segundo & 20 segundos & 1 acelerômetro no centro da laje. \\
\hline
\end{tabular}




\begin{tabular}{|c|c|c|c|c|}
\hline Teste 5 & \multirow{3}{*}{$\begin{array}{c}\text { Pulando desde uma } \\
\text { carteira escolar, no } \\
\text { centro da laje. } \\
1 \text { Pessoa. Com } \\
\text { AMS }\end{array}$} & \multirow{3}{*}{1 segundo } & \multirow{3}{*}{20 segundos } & \multirow{3}{*}{$\begin{array}{l}1 \text { acelerômetro na metade da laje, } \\
1 \text { acelerômetro no AMS. }\end{array}$} \\
\hline Teste 6 & & & & \\
\hline Teste 7 & & & & \\
\hline Teste 8 & \multirow{4}{*}{$\begin{array}{l}\text { Pulo continuo no } \\
\text { centro da laje. } \\
1 \text { Pessoa. }\end{array}$} & \multirow{4}{*}{5 segundos } & \multirow{4}{*}{20 segundos } & \multirow{4}{*}{$\begin{array}{l}1 \text { acelerômetro na metade da laje, } \\
1 \text { acelerômetro no AMS. }\end{array}$} \\
\hline Teste 9 & & & & \\
\hline Teste 10 & & & & \\
\hline Teste 11 & & & & \\
\hline Teste 12 & $\begin{array}{c}\text { Caminhando em } \\
\text { toda área da laje. } \\
3 \text { Pessoas. }\end{array}$ & 20 segundos & 20 segundos & $\begin{array}{l}2 \text { acelerômetros na da laje, } \\
1 \text { acelerômetro no AMS. }\end{array}$ \\
\hline Teste 13 & \multirow{3}{*}{$\begin{array}{l}\text { Caminhando em } \\
\text { toda área da laje. } \\
4 \text { Pessoas. }\end{array}$} & \multirow{3}{*}{20 segundos } & \multirow{3}{*}{20 segundos } & \multirow{3}{*}{$\begin{array}{c}2 \text { acelerômetros espaçados na da } \\
\text { laje, } \\
1 \text { acelerômetro no AMS. }\end{array}$} \\
\hline Teste 14 & & & & \\
\hline Teste 15 & & & & \\
\hline Teste 1 & \multirow{3}{*}{$\begin{array}{l}\text { Movimento do } \\
\text { perfil frontal da } \\
\text { laje. }\end{array}$} & \multirow{3}{*}{20 segundos } & \multirow{3}{*}{20 segundos } & \multirow{3}{*}{$\begin{array}{c}3 \text { acelerômetros espaçados na laje, } \\
1 \text { acelerômetro no AMS. }\end{array}$} \\
\hline Teste 2 & & & & \\
\hline Teste 3 & & & & \\
\hline Teste 4 & \multirow{3}{*}{$\begin{array}{c}\text { Impacto com o } \\
\text { calcanhar no centro } \\
\text { da laje. } \\
\text { 1 Pessoa. }\end{array}$} & \multirow{3}{*}{1 segundo } & \multirow{3}{*}{20 segundos } & \multirow{3}{*}{$\begin{array}{c}3 \text { acelerômetros espaçados na laje, } \\
1 \text { acelerômetro no AMS. }\end{array}$} \\
\hline Teste 5 & & & & \\
\hline Teste 6 & & & & \\
\hline Teste 7 & \multirow{4}{*}{$\begin{array}{l}\text { Pulando desde uma } \\
\text { carteira escolar, no } \\
\text { centro da laje. } 1 \\
\text { Pessoa. }\end{array}$} & \multirow{4}{*}{1 segundo } & \multirow{4}{*}{20 segundos } & \multirow{4}{*}{$\begin{array}{c}3 \text { acelerômetros espaçados na laje, } 1 \\
\text { acelerômetro no AMS. }\end{array}$} \\
\hline Teste 8 & & & & \\
\hline Teste 9 & & & & \\
\hline Teste 10 & & & & \\
\hline Teste 11 & \multirow{5}{*}{$\begin{array}{l}\text { Pulo continuo no } \\
\text { centro da laje. } \\
1 \text { Pessoa. Com } \\
\text { AMS. }\end{array}$} & \multirow{5}{*}{5 segundos } & \multirow{5}{*}{20 segundos } & \\
\hline Teste 12 & & & & \\
\hline Teste 13 & & & & $\begin{array}{c}3 \text { acelerômetros espaçados na laje, } \\
1 \text { acelerômetro no AMS. }\end{array}$ \\
\hline Teste 14 & & & & \\
\hline Teste 15 & & & & \\
\hline Teste 1 & & & & \\
\hline Teste 2 & Pulo continuo no & 10 seoundos & 20 seoundos & 3 acelerômetros espaçados na laje, \\
\hline Teste 3 & 3 Pessoas. & 10 seguinuos & 20 seguntuos & 1 acelerômetro no AMS. \\
\hline Teste 4 & & & & \\
\hline Teste 5 & & & & \\
\hline Teste 6 & Caminhando em & 20 sooundos & 20 sooundos & 3 acelerômetros espaçados na laje, \\
\hline Teste 7 & 3 Pessoas. & 20 segunuos & 20 segunuos & 1 acelerômetro no AMS. \\
\hline Teste 8 & & & & \\
\hline Teste 9 & Pulo continuo no & & & \\
\hline Teste 10 & centro da laje. & 10 seoundos & 20 seoundos & 3 acelerômetros espaçados na laje, \\
\hline Teste 11 & 1 Pessoa. Com & 10 segunturs & 20 seguntuos & 1 acelerômetro no AMS. \\
\hline Teste 12 & & & & \\
\hline Teste 13 & & 10 segundos & 20 segundos & 3 acelerômetros espaçados na laje \\
\hline
\end{tabular}




\begin{tabular}{|c|c|c|c|c|}
\hline Teste 14 & \multirow{4}{*}{$\begin{array}{l}\text { Pulo continuo no } \\
\text { centro da laje. } \\
3 \text { Pessoas. Sem } \\
\text { AMS. }\end{array}$} & & & \\
\hline Teste 15 & & & & \\
\hline Teste 16 & & & & \\
\hline Teste 17 & & & & \\
\hline Teste 18 & \multirow{4}{*}{$\begin{array}{c}\text { Caminhando em } \\
\text { toda área da laje. } \\
3 \text { Pessoas. Sem } \\
\text { AMS. }\end{array}$} & \multirow{4}{*}{20 segundos } & \multirow{4}{*}{20 segundos } & \multirow{4}{*}{3 acelerômetros espaçados na laje } \\
\hline Teste 19 & & & & \\
\hline Teste 20 & & & & \\
\hline Teste 21 & & & & \\
\hline Teste 22 & \multirow{4}{*}{$\begin{array}{l}\text { Pulo continuo no } \\
\text { centro da laje. } \\
1 \text { Pessoa. Sem } \\
\text { AMS. }\end{array}$} & \multirow{4}{*}{10 segundos } & \multirow{4}{*}{20 segundos } & \multirow{4}{*}{3 acelerômetros espaçados na laje } \\
\hline Teste 23 & & & & \\
\hline Teste 24 & & & & \\
\hline Teste 25 & & & & \\
\hline Teste 26 & \multirow{4}{*}{$\begin{array}{c}\text { Movimento } \\
\text { sincronizado (com } \\
\text { os Joelhos semi- } \\
\text { dodrados). } \\
\text { Na borda da laje } \\
\text { Sem AMS. }\end{array}$} & \multirow{4}{*}{10 segundos } & \multirow{4}{*}{20 segundos } & \multirow{4}{*}{3 acelerômetros espaçados na laje } \\
\hline Teste 27 & & & & \\
\hline Teste 28 & & & & \\
\hline Teste 29 & & & & \\
\hline Teste 30 & \multirow{5}{*}{$\begin{array}{c}\text { Movimento } \\
\text { sincronizado (com } \\
\text { os Joelhos semi- } \\
\text { dodrados). } \\
\text { Na borda da laje } \\
\text { Com AMS. }\end{array}$} & \multirow{5}{*}{10 segundos } & \multirow{5}{*}{20 segundos } & \multirow{5}{*}{3 acelerômetros espaçados na laje } \\
\hline Teste 31 & & & & \\
\hline Teste 32 & & & & \\
\hline Teste 33 & & & & \\
\hline Teste 34 & & & & \\
\hline Teste 35 & \multirow{4}{*}{$\begin{array}{l}\text { Pulo continuo no } \\
\text { centro da laje. } \\
1 \text { Pessoa. Com } \\
\text { AMS. }\end{array}$} & \multirow{4}{*}{10 segundos } & \multirow{4}{*}{20 segundos } & \multirow{4}{*}{3 acelerômetros espaçados na laje } \\
\hline Teste 36 & & & & \\
\hline Teste 37 & & & & \\
\hline Teste 38 & & & & \\
\hline Teste 1 & \multirow{4}{*}{$\begin{array}{l}\text { Pulo continuo no } \\
\text { centro da laje. } \\
3 \text { Pessoas. Com } \\
\text { AMS }\end{array}$} & \multirow{4}{*}{10 segundos } & \multirow{4}{*}{20 segundos } & \multirow{4}{*}{$\begin{array}{c}3 \text { acelerômetros espaçados na laje, } \\
1 \text { acelerômetro no AMS. }\end{array}$} \\
\hline Teste 2 & & & & \\
\hline Teste 3 & & & & \\
\hline Teste 4 & & & & \\
\hline Teste 5 & Caminhando em & \multirow{4}{*}{20 segundos } & \multirow{4}{*}{20 segundos } & \\
\hline Teste 6 & toda área da laje. & & & 3 acelerômetros espaçados na laje, \\
\hline Teste 7 & 3 Pessoas. Com & & & 1 acelerômetro no AMS. \\
\hline Teste 8 & & & & \\
\hline Teste 9 & Pulando desde uma & & & \\
\hline Teste 10 & carteira escolar, no & 1 seoundo & 20 seoundos & 3 acelerômetros espaçados na laje, \\
\hline Teste 11 & 1 Pessoa. Com & 1 Segunar & 20 seguntuos & 1 acelerômetro no AMS. \\
\hline Teste 12 & AMS & & & \\
\hline Teste 13 & Pulo continuo no & & & \\
\hline Teste 14 & $\begin{array}{l}\text { centro da laje. } \\
3 \text { Pessoas. Sem }\end{array}$ & 10 segundos & 20 segundos & 3 acelerômetros espaçados na laje \\
\hline Teste 15 & AMS. & & & \\
\hline
\end{tabular}




\begin{tabular}{|c|c|c|c|c|}
\hline Teste 16 & & & & \\
\hline Teste 17 & \multirow{4}{*}{$\begin{array}{c}\text { Caminhando em } \\
\text { toda área da laje. } \\
3 \text { Pessoas. Sem } \\
\text { AMS. }\end{array}$} & \multirow{4}{*}{20 segundos } & \multirow{4}{*}{20 segundos } & \multirow{4}{*}{3 acelerômetros espaçados na laje } \\
\hline Teste 18 & & & & \\
\hline Teste 19 & & & & \\
\hline Teste 20 & & & & \\
\hline Teste 21 & \multirow{4}{*}{$\begin{array}{c}\text { Pulando desde uma } \\
\text { carteira escolar, no } \\
\text { centro da laje. } \\
\text { 1 Pessoa. Sem } \\
\text { AMS. }\end{array}$} & \multirow{4}{*}{1 segundo } & \multirow{4}{*}{20 segundos } & \multirow{4}{*}{3 acelerômetros espaçados na laje } \\
\hline Teste 22 & & & & \\
\hline Teste 23 & & & & \\
\hline Teste 24 & & & & \\
\hline Teste 25 & \multirow{4}{*}{$\begin{array}{c}\text { Pulo continuo no } \\
\text { centro da laje. } \\
1 \text { Pessoa. Sem } \\
\text { AMS. }\end{array}$} & \multirow{4}{*}{10 segundos } & \multirow{4}{*}{20 segundos } & \multirow{4}{*}{3 acelerômetros espaçados na laje } \\
\hline Teste 26 & & & & \\
\hline Teste 27 & & & & \\
\hline Teste 28 & & & & \\
\hline Teste 29 & \multirow{4}{*}{$\begin{array}{c}\text { Movimento } \\
\text { sincronizado (com } \\
\text { os Joelhos semi- } \\
\text { dodrados). } \\
\text { Na borda da laje } \\
\text { Sem AMS. }\end{array}$} & \multirow{4}{*}{10 segundos } & \multirow{4}{*}{20 segundos } & \multirow{4}{*}{3 acelerômetros espaçados na laje } \\
\hline Teste 30 & & & & \\
\hline Teste 31 & & & & \\
\hline Teste 32 & & & & \\
\hline
\end{tabular}




\section{Anexo VI}

Deslocamentos experimentais Teste 1.

\begin{tabular}{|c|c|c|c|c|c|c|c|}
\hline \multicolumn{8}{|c|}{ DESLOCAMENTOS EXPERIMENTAIS FEVEREIRO 14-2015 } \\
\hline \multirow{2}{*}{$\begin{array}{c}\text { Nó } \\
\text { experimental }\end{array}$} & \multicolumn{2}{|c|}{$\begin{array}{l}\text { Coordenadas } \\
\text { experimentais }\end{array}$} & \multirow{2}{*}{$\begin{array}{c}\text { UZ } 1 \text { modo Experimental } \\
\text { Fev 14-2015 } \\
\text { ( Acel canto laje) }\end{array}$} & \multirow{2}{*}{$\begin{array}{c}\text { UZ } 2 \text { modo Experimental } \\
\text { Fev 14-2015 } \\
\text { ( Acel canto laje) }\end{array}$} & \multirow{2}{*}{$\begin{array}{c}\text { UZ } 3 \text { modo Experimental } \\
\text { Fev 14-2015 } \\
\text { ( Acel canto laje) }\end{array}$} & \multirow{2}{*}{$\begin{array}{c}\text { UZ } 4 \text { modo Experimental } \\
\text { Fev 14-2015 } \\
\text { ( Acel canto laje) }\end{array}$} & \multirow{2}{*}{$\begin{array}{c}\text { UZ } 5 \text { modo Experimenta } \\
\text { Fev 14-2015 } \\
\text { ( Acel canto laje) }\end{array}$} \\
\hline & $\mathrm{X}$ & $\mathrm{Y}$ & & & & & \\
\hline 1 & 0,61 & 4,41 & 0,040687539 & $-0,009159777$ & $-0,102414602$ & $-0,022380583$ & $-0,096291786$ \\
\hline 2 & 1,22 & 4,41 & 0,083274393 & $-0,043706594$ & $-0,071056923$ & 0,368137991 & 0,077869371 \\
\hline 3 & 1,83 & 4,41 & 0,121926606 & $-0,110582629$ & $-0,064323152$ & $-0,112166072$ & 0,016313063 \\
\hline 4 & 2,44 & 4,41 & 0,137977929 & $-0,136389719$ & $-0,022944616$ & 0,066508168 & $-0,026479915$ \\
\hline 5 & 3,05 & 4,41 & 0,151978902 & $-0,195738313$ & $-0,014499571$ & 0,124314344 & 0,070815717 \\
\hline 6 & 3,66 & 4,41 & 0,148259593 & $-0,183839466$ & $-0,066214143$ & 0,095740426 & $-0,083746912$ \\
\hline 7 & 4,27 & 4,41 & 0,118476736 & $-0,14370888$ & $-0,129780522$ & 0,132906236 & $-0,026663912$ \\
\hline 8 & 4,88 & 4,41 & 0,085195227 & $-0,087097038$ & $-0,116664014$ & $-0,111130695$ & 0,006272809 \\
\hline 9 & 5,49 & 4,41 & 0,045257946 & $-0,007574136$ & $-0,064916357$ & $-0,013435269$ & 0,146006652 \\
\hline 10 & 0,61 & 3,92 & 0,047636644 & 0,057760029 & $-0,131211915$ & $-0,153544371$ & $-0,087583675$ \\
\hline 11 & 1,22 & 3,92 & 0,0842841 & 0,01269476 & $-0,120757646$ & 0,057802399 & $-0,008155817$ \\
\hline 12 & 1,83 & 3,92 & 0,120735551 & $-0,014743829$ & $-0,00621661$ & 0,024912829 & 0,035953072 \\
\hline 13 & 2,44 & 3,92 & 0,146949655 & $-0,073430764$ & 0,036563969 & $-0,015535446$ & 0,053447516 \\
\hline 14 & 3,05 & 3,92 & 0,147730426 & $-0,081373482$ & 0,063837718 & 0,01396429 & 0,048802941 \\
\hline 15 & 3,66 & 3,92 & 0,143902593 & $-0,072493862$ & 0,028112215 & 0,007615199 & $-0,117105269$ \\
\hline 16 & 4,27 & 3,92 & 0,125054238 & $-0,047263732$ & $-0,053447713$ & $-0,017968879$ & $-0,024858641$ \\
\hline 17 & 4,88 & 3,92 & 0,086352131 & 0,004554483 & $-0,091929894$ & 0,029792834 & $-0,049348776$ \\
\hline 18 & 5,49 & 3,92 & 0,045358616 & 0,06241419 & $-0,135298456$ & $-0,056208349$ & 0,13021462 \\
\hline 19 & 0,61 & 3,43 & 0,045228798 & 0,120527627 & $-0,157693807$ & $-0,005369212$ & 0,013007945 \\
\hline 20 & 1,22 & 3,43 & 0,085701428 & 0,096372054 & $-0,084442958$ & 0,025428446 & 0,0527555557 \\
\hline 21 & 1,83 & 3,43 & 0,123519302 & 0,061830874 & $-0,007271641$ & $-0,189162601$ & 0,010074274 \\
\hline 22 & 2,44 & 3,43 & 0,139625464 & 0,040979377 & 0,11365241 & $-0,095560383$ & 0,071056577 \\
\hline 23 & 3,05 & 3,43 & 0,15140423 & 0,029092084 & 0,096781474 & $-0,026623832$ & $-0,018845453$ \\
\hline 24 & 3,66 & 3,43 & 0,14813488 & 0,011458618 & 0,079250715 & $-0,186705084$ & 0,038612246 \\
\hline 25 & 4,27 & 3,43 & 0,119987153 & 0,049300723 & 0,020588088 & 0,019593595 & $-0,0107696$ \\
\hline 26 & 4,88 & 3,43 & 0,09099127 & 0,069707367 & $-0,099842432$ & $-0,035581387$ & 0,314795 \\
\hline 27 & 5,49 & 3,43 & 0,051171829 & 0,116056542 & $-0,159517566$ & $-0,077395192$ & 0,399731938 \\
\hline 28 & 0,61 & 2,94 & 0,049799559 & 0,170770054 & $-0,152000415$ & $-0,01312404$ & $-0,005705104$ \\
\hline 29 & 1,22 & 2,94 & 0,094422002 & 0,138800412 & $-0,061762085$ & $-0,025238354$ & $-0,046344733$ \\
\hline 30 & 1,83 & 2,94 & 0,120876588 & 0,118755866 & 0,029591238 & $-0,032091538$ & $-0,05491967$ \\
\hline 31 & 2,44 & 2,94 & 0,144240651 & 0,119958742 & 0,177032283 & 0,024542555 & $-0,03551224$ \\
\hline 32 & 3,05 & 2,94 & 0,156297214 & 0,082922228 & 0,262487914 & 0,021660719 & $-0,010778969$ \\
\hline 33 & 3,66 & 2,94 & 0,140744561 & 0,098342943 & 0,185760636 & 0,007759264 & 0,01441575 \\
\hline 34 & 4,27 & \begin{tabular}{|l|}
2,94 \\
\end{tabular} & 0,125196016 & 0,113581376 & 0,073208935 & $-0,020440665$ & $-0,060907961$ \\
\hline 35 & 4,88 & 2,94 & 0,093096815 & 0,122063318 & $-0,056280349$ & $-0,020126915$ & 0,148228783 \\
\hline 36 & 5,49 & 2,94 & 0,049425839 & 0,129816057 & $-0,110486162$ & $-0,060519313$ & 0,156418648 \\
\hline 37 & 0,61 & 2,45 & 0,049044861 & 0,184016033 & $-0,178704912$ & $-0,028752481$ & 0,035252898 \\
\hline 38 & 1,22 & 2,45 & 0,09279765 & 0,179593212 & $-0,088734222$ & $-0,026414787$ & $-0,097605678$ \\
\hline 39 & 1,83 & 2,45 & 0,117156249 & 0,16289975 & 0,050046663 & 0,004670286 & $-0,142059075$ \\
\hline 40 & 2,44 & 2,45 & 0,14214017 & 0,157155546 & 0,182511317 & 0,024534559 & 0,009396507 \\
\hline 41 & 3,05 & 2,45 & 0,154996495 & 0,162934814 & 0,257775931 & $-0,004151263$ & $-0,019434964$ \\
\hline
\end{tabular}


Deslocamentos experimentais Teste 1.

\begin{tabular}{|c|c|c|c|c|c|c|c|}
\hline \multicolumn{8}{|c|}{ DESLOCAMENTOS EXPERIMENTAIS FEVEREIRO 14-2015 } \\
\hline \multirow{2}{*}{$\begin{array}{c}\text { Nó } \\
\text { experimental }\end{array}$} & \multicolumn{2}{|c|}{$\begin{array}{l}\text { Coordenadas } \\
\text { experimentais }\end{array}$} & \multirow{2}{*}{$\begin{array}{c}\text { UZ } 1 \text { modo Experimental } \\
\text { Fev 14-2015 } \\
\text { (Acel canto laje) }\end{array}$} & \multirow{2}{*}{$\begin{array}{c}\text { UZ } 2 \text { modo Experimental } \\
\text { Fev 14-2015 } \\
\text { (Acel canto laje) }\end{array}$} & \multirow{2}{*}{$\begin{array}{c}\text { UZ } 3 \text { modo Experimental } \\
\text { Fev 14-2015 } \\
\text { ( Acel canto laje) }\end{array}$} & \multirow{2}{*}{$\begin{array}{c}\text { UZ } 4 \text { modo Experimental } \\
\text { Fev 14-2015 } \\
\text { ( Acel canto laje) }\end{array}$} & \multirow{2}{*}{$\begin{array}{c}\text { UZ } 5 \text { modo Experimental } \\
\text { Fev 14-2015 } \\
\text { ( Acel canto laje) }\end{array}$} \\
\hline & $\mathrm{X}$ & $\mathrm{Y}$ & & & & & \\
\hline 42 & 3,66 & 2,45 & 0,13978004 & 0,146133253 & 0,216504065 & 0,015235526 & 0,020884312 \\
\hline 43 & 4,27 & 2,45 & 0,124296748 & 0,177535934 & 0,093059372 & 0,012098411 & $-0,015337115$ \\
\hline 44 & 4,88 & 2,45 & 0,095779996 & 0,202343864 & $-0,034618308$ & $-0,145485933$ & 0,040600755 \\
\hline 45 & 5,49 & 2,45 & 0,050374473 & 0,181828828 & $-0,130134379$ & 0,064088927 & 0,030823002 \\
\hline 46 & 0,61 & 1,96 & 0,045559942 & 0,148319394 & $-0,157776167$ & $-0,082282348$ & 0,02089159 \\
\hline 47 & 1,22 & 1,96 & 0,085938031 & 0,112771717 & $-0,070807542$ & 0,29625035 & $-0,039073035$ \\
\hline 48 & 1,83 & 1,96 & 0,112710468 & 0,094415581 & 0,036918143 & $-0,252658567$ & 0,033971306 \\
\hline 49 & 2,44 & 1,96 & 0,140976846 & 0,074087291 & 0,143265096 & 0,019843944 & $-0,064210799$ \\
\hline 50 & 3,05 & 1,96 & 0,151713455 & 0,085698893 & 0,21564924 & 0,0205449 & $-0,024832274$ \\
\hline 51 & 3,66 & 1,96 & 0,138525414 & 0,099870917 & 0,158528266 & 0,023497921 & $-0,046276993$ \\
\hline 52 & 4,27 & 1,96 & 0,121379579 & 0,132996486 & 0,070815895 & 0,022520069 & $-0,031890505$ \\
\hline 53 & 4,88 & 1,96 & 0,091036641 & 0,168019412 & $-0,051400882$ & 0,048312455 & $-0,063723398$ \\
\hline 54 & 5,49 & 1,96 & 0,049536166 & 0,184077721 & $-0,153027419$ & $-0,089988315$ & $-0,00977631$ \\
\hline 55 & 0,61 & 1,47 & 0,046332181 & 0,12420499 & $-0,134734184$ & $-0,012838695$ & $-0,093759494$ \\
\hline 56 & 1,22 & 1,47 & 0,08726632 & 0,09050617 & $-0,084109786$ & $-0,178803114$ & 0,03292241 \\
\hline 57 & 1,83 & 1,47 & 0,114590837 & 0,052511835 & 0,00657088 & $-0,076211183$ & $-0,025029396$ \\
\hline 58 & 2,44 & 1,47 & 0,138508507 & 0,023146853 & 0,115881425 & $-0,041575618$ & 0,001999224 \\
\hline 59 & 3,05 & 1,47 & 0,149701744 & 0,013563042 & 0,14051149 & $-0,034301869$ & $-0,030644242$ \\
\hline 60 & 3,66 & 1,47 & 0,136489021 & 0,029617012 & 0,110428239 & $-0,039530808$ & $-0,011219699$ \\
\hline 61 & 4,27 & 1,47 & 0,122616519 & 0,072697267 & 0,02350486 & 0,014323308 & 0,087269095 \\
\hline 62 & 4,88 & 1,47 & 0,092148832 & 0,108875455 & $-0,074215606$ & $-0,082481654$ & 0,157871422 \\
\hline 63 & 5,49 & 1,47 & 0,047999466 & 0,125718825 & $-0,115760928$ & $-0,072137513$ & 0,005554459 \\
\hline 64 & 0,61 & 0,98 & 0,044772229 & 0,038188441 & $-0,109400394$ & $-0,01324394$ & $-0,056593602$ \\
\hline 65 & 1,22 & 0,98 & 0,084317629 & 0,003107201 & $-0,097460183$ & $-0,05724242$ & $-0,030580201$ \\
\hline 66 & 1,83 & 0,98 & 0,112087172 & $-0,046025004$ & $-0,038968932$ & 0,159117634 & 0,074043526 \\
\hline 67 & 2,44 & 0,98 & 0,137944988 & $-0,065827219$ & 0,057181755 & 0,03396456 & $-0,069888312$ \\
\hline 68 & 3,05 & 0,98 & 0,148678676 & $-0,090861033$ & 0,057651607 & $-0,054483306$ & 0,075824542 \\
\hline 69 & 3,66 & 0,98 & 0,13555935 & $-0,064497002$ & 0,029315555 & $-0,096248916$ & $-0,070776176$ \\
\hline 70 & 4,27 & 0,98 & 0,120895128 & $-0,032938603$ & $-0,036731095$ & 0,098679538 & 0,031996103 \\
\hline 71 & 4,88 & 0,98 & 0,089245747 & 0,02273944 & $-0,109215001$ & $-0,02850357$ & 0,046466662 \\
\hline 72 & 5,49 & 0,98 & 0,045942226 & 0,067096481 & $-0,109103114$ & $-0,030453273$ & 0,012258509 \\
\hline 73 & 0,61 & 0,49 & 0,040832083 & $-0,01717708$ & $-0,077937925$ & 0,104163097 & 0,12505344 \\
\hline 74 & 1,22 & 0,49 & 0,081875318 & $-0,067600659$ & $-0,0757106$ & 0,034055319 & $-0,008864112$ \\
\hline 75 & 1,83 & 0,49 & 0,111323423 & $-0,125848329$ & $-0,062056161$ & 0,000887327 & $-0,017718381$ \\
\hline 76 & 2,44 & 0,49 & 0,135867218 & $-0,175660296$ & $-0,028632982$ & 0,002968786 & $-0,05377501$ \\
\hline 77 & 3,05 & 0,49 & 0,147721648 & $-0,181278977$ & $-0,022794194$ & $-0,05273208$ & $-0,030887246$ \\
\hline 78 & 3,66 & 0,49 & 0,133645506 & $-0,164608712$ & $-0,047107536$ & $-0,021957553$ & 0,03731577 \\
\hline 79 & 4,27 & 0,49 & 0,121628764 & $-0,131083123$ & $-0,09924788$ & $-0,052534133$ & $-0,003897079$ \\
\hline 80 & 4,88 & 0,49 & 0,087723431 & $-0,072617793$ & $-0,136218401$ & 0,053070896 & $-0,037597397$ \\
\hline 81 & 5,49 & 0,49 & 0,043076982 & $-0,006992906$ & $-0,108060722$ & $-0,045572439$ & 0,056930086 \\
\hline
\end{tabular}


Deslocamentos numéricos Teste 1.

\begin{tabular}{|c|c|c|c|c|c|c|c|c|}
\hline \multicolumn{9}{|c|}{ DESLOCAMENTOS NUMÉRICOS FEVEREIRO 14-2015 } \\
\hline \multirow{2}{*}{$\begin{array}{c}\text { Nó } \\
\text { experimental }\end{array}$} & \multirow{2}{*}{$\begin{array}{c}\text { Nó } \\
\text { númerico }\end{array}$} & \multicolumn{2}{|c|}{ Coordenadas numericas } & \multirow{2}{*}{\begin{tabular}{|c|}
$\begin{array}{c}\text { Desloc 1ro modo, } \\
\text { Númerico }\end{array}$ \\
$\mathbf{U Z ~} \mathbf{f}=\mathbf{3 , 3 6 2 9 9} \mathbf{~ H z}$ \\
\end{tabular}} & \multirow{2}{*}{$\begin{array}{c}\begin{array}{c}\text { Desloc } 21 \text { modo, } \\
\text { Númerico }\end{array} \\
\text { UZ } \mathbf{f}=\mathbf{1 5 , 6 7 1 8 ~ H z} \\
\end{array}$} & \multirow{2}{*}{\begin{tabular}{|c|}
$\begin{array}{c}\text { Desloc } 27 \text { modo, } \\
\text { Númerico }\end{array}$ \\
$\mathbf{U Z ~} \mathbf{f}=\mathbf{2 3 , 6 3 6 5} \mathbf{~ H z}$ \\
\end{tabular}} & \multirow{2}{*}{\begin{tabular}{|c|}
$\begin{array}{c}\text { Desloc } 41 \text { modo, } \\
\text { Númerico }\end{array}$ \\
$\mathbf{U Z} \mathbf{f}=\mathbf{3 4 , 9 5 9} \mathbf{~ H z}$ \\
\end{tabular}} & \multirow{2}{*}{\begin{tabular}{|c|}
$\begin{array}{c}\text { Desloc } 51 \text { modo, } \\
\text { Númerico }\end{array}$ \\
$\mathbf{U Z ~} \mathbf{f = 5 1 , 5 9 1 ~} \mathbf{~ H z}$ \\
\end{tabular}} \\
\hline & & $\mathrm{X}$ númerico & Y númerico & & & & & \\
\hline 1 & 6056 & 0,60961 & 4,41803 & 0,004512400 & 0,000901950 & 0,004625100 & $-0,012060000$ & $-0,002523500$ \\
\hline 2 & 12131 & 1,21392 & 4,41803 & 0,008769700 & 0,006542400 & 0,001397300 & $-0,012472000$ & 0,004918800 \\
\hline 3 & 18206 & 1,81822 & 4,41803 & 0,012354000 & 0,011918000 & $-0,001799000$ & $-0,003923600$ & 0,011467000 \\
\hline 4 & 24524 & 2,44670 & 4,41803 & 0,015076000 & 0,016238000 & $-0,002344200$ & 0,008342100 & 0,010243000 \\
\hline 5 & 30599 & 3,05100 & 4,41803 & 0,016506000 & 0,018274000 & 0,001491600 & 0,015217000 & 0,000638830 \\
\hline 6 & 36674 & 3,65530 & 4,41803 & 0,015901000 & 0,016729000 & 0,010258000 & 0,008798900 & $-0,009811400$ \\
\hline 7 & 42749 & 4,25961 & 4,41803 & 0,013464000 & 0,012424000 & 0,019426000 & $-0,005246100$ & $-0,012361000$ \\
\hline 8 & 49067 & 4,88808 & 4,41803 & 0,009552800 & 0,006649100 & 0,021304000 & $-0,014133000$ & $-0,006214600$ \\
\hline 9 & 55142 & 5,49239 & 4,41803 & 0,004911000 & 0,000837110 & 0,014336000 & $-0,012112000$ & 0,001905600 \\
\hline 10 & 6031 & 0,60961 & 3,91598 & 0,004790800 & $-0,006278200$ & 0,009974300 & $-0,013520000$ & $-0,015238000$ \\
\hline 11 & 12106 & 1,21392 & 3,91598 & 0,008927500 & $-0,002037900$ & 0,003526600 & $-0,012648000$ & $-0,011552000$ \\
\hline 12 & 18181 & 1,81822 & 3,91598 & 0,012425000 & 0,002230900 & $-0,003260100$ & $-0,004719800$ & $-0,004644900$ \\
\hline 13 & 24499 & 2,44670 & 3,91598 & 0,015093000 & 0,005775100 & $-0,007565100$ & 0,005981300 & $-0,000171180$ \\
\hline 14 & 30574 & 3,05100 & 3,91598 & 0,016473000 & 0,007379000 & $-0,006708600$ & 0,011781000 & $-0,000204290$ \\
\hline 15 & 36649 & 3,65530 & 3,91598 & 0,016035000 & 0,006210900 & 0,000097225 & 0,007370600 & $-0,000136870$ \\
\hline 16 & 42724 & 4,25961 & 3,91598 & 0,013588000 & 0,002475300 & 0,009986600 & $-0,004881100$ & 0,003978000 \\
\hline 17 & 49042 & 4,88808 & 3,91598 & 0,009720800 & $-0,002169600$ & 0,014305000 & $-0,012440000$ & 0,011154000 \\
\hline 18 & 55117 & 5,49239 & 3,91598 & 0,005212700 & $-0,006586900$ & 0,011694000 & $-0,011693000$ & 0,015468000 \\
\hline 19 & 6007 & 0,60961 & 3,43402 & 0,005036500 & $-0,012188000$ & 0,014755000 & $-0,012910000$ & $-0,019592000$ \\
\hline 20 & 12082 & 1,21392 & 3,43402 & 0,009091800 & $-0,009142200$ & 0,005599900 & $-0,010989000$ & $-0,018715000$ \\
\hline 21 & 18157 & 1,81822 & 3,43402 & 0,012532000 & $-0,005770500$ & $-0,004408000$ & $-0,004232200$ & $-0,012699000$ \\
\hline 22 & 24475 & 2,44670 & 3,43402 & 0,015172000 & $-0,002842500$ & $-0,012233000$ & 0,004142000 & $-0,005758900$ \\
\hline 23 & 30550 & 3,05100 & 3,43402 & 0,016515000 & $-0,001533800$ & $-0,014096000$ & 0,008547000 & $-0,000543270$ \\
\hline 24 & 36625 & 3,65530 & 3,43402 & 0,016147000 & $-0,002562900$ & $-0,008838500$ & 0,005672900 & 0,005143400 \\
\hline 25 & 42700 & 4,25961 & 3,43402 & 0,013758000 & $-0,005830600$ & 0,001404300 & $-0,003726100$ & 0,012551000 \\
\hline 26 & 49018 & 4,88808 & 3,43402 & 0,009914500 & $-0,009532700$ & 0,008038600 & $-0,009561100$ & 0,019005000 \\
\hline 27 & 55093 & 5,49239 & 3,43402 & 0,005494200 & $-0,012762000$ & 0,009245700 & $-0,009821100$ & 0,020457000 \\
\hline 28 & 5982 & 0,60961 & 2,93197 & 0,005226000 & $-0,016550000$ & 0,018678000 & $-0,009546200$ & $-0,013627000$ \\
\hline 29 & 12057 & 1,21392 & 2,93197 & 0,009240200 & $-0,014446000$ & 0,007660300 & $-0,006857000$ & $-0,014102000$ \\
\hline 30 & 18132 & 1,81822 & 2,93197 & 0,012647000 & $-0,011623000$ & $-0,004891000$ & $-0,002116900$ & $-0,010383000$ \\
\hline 31 & 24450 & 2,44670 & 2,93197 & 0,015258000 & $-0,008977200$ & $-0,015568000$ & 0,002637500 & $-0,004987400$ \\
\hline 32 & 30525 & 3,05100 & 2,93197 & 0,016592000 & $-0,007861500$ & $-0,019856000$ & 0,004819800 & $-0,000304500$ \\
\hline 33 & 36600 & 3,65530 & 2,93197 & 0,016150000 & $-0,009022700$ & $-0,015512000$ & 0,003393800 & 0,004589300 \\
\hline 34 & 42675 & 4,25961 & 2,93197 & 0,013911000 & $-0,011996000$ & $-0,005729400$ & $-0,001548500$ & 0,010449000 \\
\hline 35 & 48993 & 4,88808 & 2,93197 & 0,010130000 & $-0,015213000$ & 0,002723200 & $-0,005104500$ & 0,014797000 \\
\hline 36 & 55068 & 5,49239 & 2,93197 & 0,005743200 & $-0,017485000$ & 0,006897300 & $-0,006037300$ & 0,014874000 \\
\hline 37 & 5958 & 0,60961 & 2,45000 & 0,005291600 & $-0,017913000$ & 0,020663000 & $-0,003855200$ & $-0,000160670$ \\
\hline 38 & 12033 & 1,21392 & 2,45000 & 0,009288700 & $-0,015908000$ & 0,009228800 & $-0,000572200$ & $-0,000032881$ \\
\hline 39 & 18108 & 1,81822 & 2,45000 & 0,012693000 & $-0,013330000$ & $-0,004241100$ & 0,001308000 & 0,000251330 \\
\hline 40 & 24426 & 2,44670 & 2,45000 & 0,015302000 & $-0,010943000$ & $-0,016344000$ & 0,001340300 & 0,000331100 \\
\hline 41 & 30501 & 3,05100 & 2,45000 & 0,016721000 & $-0,009945000$ & $-0,022605000$ & 0,000549240 & 0,000107410 \\
\hline 42 & 36576 & 3,65530 & 2,45000 & 0,016116000 & $-0,011239000$ & $-0,018099000$ & 0,000749520 & $-0,000188870$ \\
\hline
\end{tabular}


Deslocamentos numéricos Teste 1.

\begin{tabular}{|c|c|c|c|c|c|c|c|c|}
\hline \multicolumn{9}{|c|}{ DESLOCAMENTOS NUMÉRICOS FEVEREIRO 14-2015 } \\
\hline \multirow{2}{*}{$\begin{array}{c}\text { Nó } \\
\text { experimental }\end{array}$} & \multirow{2}{*}{$\begin{array}{c}\text { Nó } \\
\text { númerico }\end{array}$} & \multicolumn{2}{|c|}{ Coordenadas numericas } & \multirow{2}{*}{\begin{tabular}{|c|}
$\begin{array}{c}\text { Desloc 1ro modo, } \\
\text { Númerico }\end{array}$ \\
$\mathbf{U Z ~} \mathbf{f}=\mathbf{3 , 3 6 2 9 9} \mathbf{~ H z}$ \\
\end{tabular}} & \multirow{2}{*}{$\begin{array}{c}\begin{array}{c}\text { Desloc } 21 \text { modo, } \\
\text { Númerico }\end{array} \\
\mathbf{U Z ~} \mathbf{f}=\mathbf{1 5 , 6 7 1 8 ~ H z} \\
\end{array}$} & \multirow{2}{*}{\begin{tabular}{|c|}
$\begin{array}{c}\text { Desloc } 27 \text { modo, } \\
\text { Númerico }\end{array}$ \\
$\mathbf{U Z ~} \mathbf{f = 2 3 , 6 3 6 5} \mathbf{~ H z}$ \\
\end{tabular}} & \multirow{2}{*}{\begin{tabular}{|c|}
$\begin{array}{c}\text { Des loc } 41 \text { modo, } \\
\text { Númerico }\end{array}$ \\
$\mathbf{U Z ~} \mathbf{f}=\mathbf{3 4 , 9 5 9} \mathbf{~ H z}$ \\
\end{tabular}} & \multirow{2}{*}{\begin{tabular}{|c|}
$\begin{array}{c}\text { Desloc } 51 \text { modo, } \\
\text { Númerico }\end{array}$ \\
$\mathbf{U Z ~} \mathbf{f}=\mathbf{5 1 , 5 9 1} \mathbf{H z}$ \\
\end{tabular}} \\
\hline & & $\mathrm{X}$ númerico & Y númerico & & & & & \\
\hline 42 & 36576 & 3,65530 & 2,45000 & 0,016116000 & $-0,011239000$ & $-0,018099000$ & 0,000749520 & $-0,000188870$ \\
\hline 43 & 42651 & 4,25961 & 2,45000 & 0,014019000 & $-0,014122000$ & $-0,008961700$ & 0,001010000 & 0,000039810 \\
\hline 44 & 48969 & 4,88808 & 2,45000 & 0,010305000 & $-0,016998000$ & 0,000270190 & 0,000403980 & 0,000656690 \\
\hline 45 & 55044 & 5,49239 & 2,45000 & 0,005878100 & $-0,018819000$ & 0,005679900 & $-0,000986910$ & 0,000866840 \\
\hline 46 & 5934 & 0,60961 & 1,96803 & 0,005229100 & $-0,016229000$ & 0,020509000 & 0,003009400 & 0,013634000 \\
\hline 47 & 12009 & 1,21392 & 1,96803 & 0,009255700 & $-0,013978000$ & 0,010283000 & 0,006550400 & 0,014025000 \\
\hline 48 & 18084 & 1,81822 & 1,96803 & 0,012685000 & $-0,011268000$ & $-0,002503300$ & 0,005029300 & 0,010825000 \\
\hline 49 & 24402 & 2,44670 & 1,96803 & 0,015316000 & $-0,008844700$ & $-0,014574000$ & $-0,000244920$ & 0,005678600 \\
\hline 50 & 30477 & 3,05100 & 1,96803 & 0,016794000 & $-0,007791400$ & $-0,021501000$ & $-0,004719100$ & 0,000401210 \\
\hline 51 & 36552 & 3,65530 & 1,96803 & 0,016108000 & $-0,009045200$ & $-0,016682000$ & $-0,002326200$ & $-0,005280900$ \\
\hline 52 & 42627 & 4,25961 & 1,96803 & 0,014096000 & $-0,011587000$ & $-0,007526500$ & 0,003229800 & $-0,011057000$ \\
\hline 53 & 48945 & 4,88808 & 1,96803 & 0,010439000 & $-0,014482000$ & 0,001227400 & 0,006146100 & $-0,014570000$ \\
\hline 54 & 55020 & & 1,96803 & 0,005904000 & $-0,016840000$ & 0,005797100 & 0,004329200 & $-0,013995000$ \\
\hline 55 & 5909 & 0,60961 & 1,46598 & 0,005070000 & $-0,012096000$ & 0,018493000 & 0,009467000 & 0,019770000 \\
\hline 56 & 11984 & 1,21392 & 1,46598 & 0,009164800 & $-0,009054600$ & 0,010849000 & 0,013260000 & 0,018964000 \\
\hline 57 & 18059 & 1,81822 & 1,46598 & 0,012646000 & $-0,005736400$ & 0,000177210 & 0,008142300 & 0,013370000 \\
\hline 58 & 24377 & & 1,46598 & 0,015315000 & $-0,002872800$ & $-0,010445000$ & $-0,002779400$ & 0,006395900 \\
\hline 59 & 30452 & 3,05100 & 1,46598 & 0,016734000 & $-0,001604000$ & $-0,016181000$ & $-0,010874000$ & 0,000403960 \\
\hline 60 & 36527 & 3,65530 & 1,46598 & 0,016103000 & $-0,002849900$ & $-0,011507000$ & $-0,006399100$ & $-0,005961900$ \\
\hline 61 & 42602 & 4,25961 & 1,46598 & 0,014211000 & $-0,005598200$ & $-0,002644000$ & 0,004426900 & $-0,013622000$ \\
\hline 62 & 48920 & 4,88808 & 1,46598 & 0,010629000 & $-0,009120500$ & 0,004766000 & 0,011503000 & $-0,020327000$ \\
\hline 63 & 54995 & 5,49239 & 1,46598 & 0,005842500 & $-0,012389000$ & 0,006780400 & 0,008767400 & $-0,021082000$ \\
\hline 64 & 5885 & 0,60961 & 0,98402 & 0,004847500 & $-0,006345100$ & 0,015028000 & 0,014028000 & 0,014857000 \\
\hline 65 & 11960 & 1,21392 & 0,98402 & 0,009045900 & $-0,002205600$ & 0,010861000 & 0,018176000 & 0,011115000 \\
\hline 66 & 18035 & 1,81822 & 0,98402 & 0,012604000 & 0,001998400 & 0,003174100 & 0,009908000 & 0,004854700 \\
\hline 67 & 24353 & 2,44670 & 0,98402 & 0,015322000 & 0,005524300 & $-0,005104300$ & $-0,006087900$ & 0,000793090 \\
\hline 68 & 30428 & 3,05100 & 0,98402 & 0,016760000 & 0,007198400 & $-0,009353600$ & $-0,017842000$ & 0,000190100 \\
\hline 69 & 36503 & 3,65530 & 0,98402 & 0,016132000 & 0,005717300 & $-0,004341100$ & $-0,011278000$ & $-0,000346580$ \\
\hline 70 & 42578 & 4,25961 & 0,98402 & 0,014380000 & 0,002544100 & 0,004237600 & 0,004337400 & $-0,004747900$ \\
\hline 71 & 48896 & 4,88808 & 0,98402 & 0,010840000 & $-0,001870600$ & 0,009962500 & 0,015449000 & $-0,012604000$ \\
\hline 72 & 54971 & 5,49239 & 0,98402 & 0,005699000 & $-0,006361800$ & 0,008197600 & 0,011236000 & $-0,016662000$ \\
\hline 73 & 5860 & 0,60961 & 0,48197 & 0,004590500 & 0,000696420 & 0,010655000 & 0,017066000 & 0,001183200 \\
\hline 74 & 11935 & 1,21392 & 0,48197 & 0,008929800 & 0,006154400 & 0,010511000 & 0,021748000 & $-0,006560300$ \\
\hline 75 & 18010 & 1,81822 & 0,48197 & 0,012593000 & 0,011437000 & 0,006279100 & 0,010670000 & $-0,012119000$ \\
\hline 76 & 24328 & 2,44670 & 0,48197 & 0,015390000 & 0,015781000 & 0,000758940 & $-0,010043000$ & $-0,009660600$ \\
\hline 77 & 30403 & 3,05100 & 0,48197 & 0,016866000 & 0,017895000 & $-0,001670200$ & $-0,025129000$ & $-0,000016825$ \\
\hline 78 & 36478 & 3,65530 & 0,48197 & 0,016224000 & 0,016104000 & 0,003970100 & $-0,016831000$ & 0,010142000 \\
\hline 79 & 42553 & 4,25961 & 0,48197 & 0,014590000 & 0,012396000 & 0,012293000 & 0,002942700 & 0,012725000 \\
\hline 80 & 48871 & 4,88808 & 0,48197 & 0,011007000 & 0,006871900 & 0,015905000 & 0,017602000 & 0,005758000 \\
\hline 81 & 54946 & 5,49239 & 0,48197 & 0,005506500 & 0,000917330 & 0,009923100 & 0,012118000 & $-0,003104300$ \\
\hline
\end{tabular}


Deslocamentos experimentais Teste 2.

\begin{tabular}{|c|c|c|c|c|c|}
\hline \multicolumn{6}{|c|}{ DESLOCAMENTOS EXPERIMENTAIS FEVEREIRO 15-2015 } \\
\hline \multirow{2}{*}{$\begin{array}{c}\text { Nó } \\
\text { experimental }\end{array}$} & \multicolumn{2}{|c|}{$\begin{array}{l}\text { Coordenadas } \\
\text { experimentais }\end{array}$} & \multirow{2}{*}{$\begin{array}{c}\text { UZ } 1 \text { modo Experimental } \\
\text { Fev 15-2015 } \\
\text { ( Acel canto laje) }\end{array}$} & \multirow{2}{*}{$\begin{array}{c}\text { UZ } 2 \text { modo Experimental } \\
\text { Fev 15-2015 } \\
\text { ( Acel canto laje) }\end{array}$} & \multirow{2}{*}{$\begin{array}{c}\text { UZ } 3 \text { modo Experimenta } \\
\text { Fev 15-2015 } \\
\text { (Acel canto laje) } \\
\end{array}$} \\
\hline & $\mathrm{X}$ & $\mathrm{Y}$ & & & \\
\hline 1 & 0,61 & 4,41 & 0,041322093 & 0,013291417 & $-0,031437205$ \\
\hline 2 & 1,22 & 4,41 & 0,084804477 & 0,089196241 & $-0,096004849$ \\
\hline 3 & 1,83 & 4,41 & 0,118602853 & 0,160773856 & $-0,049131053$ \\
\hline 4 & 2,44 & 4,41 & 0,137204775 & 0,229349707 & 0,00817949 \\
\hline 5 & 3,05 & 4,41 & 0,148626194 & 0,224999209 & $-0,008098732$ \\
\hline 6 & 3,66 & 4,41 & 0,144417245 & 0,223795724 & $-0,010006955$ \\
\hline 7 & 4,27 & 4,41 & 0,114874235 & 0,161153654 & 0,004789692 \\
\hline 8 & 4,88 & 4,41 & 0,08614865 & 0,065266243 & $-0,053638713$ \\
\hline 9 & 5,49 & 4,41 & 0,043348078 & 0,01665173 & 0,005451109 \\
\hline 10 & 0,61 & 3,92 & 0,043374203 & $-0,063008005$ & 0,016808711 \\
\hline 11 & 1,22 & 3,92 & 0,08003683 & $-0,004787154$ & 0,003647806 \\
\hline 12 & 1,83 & 3,92 & 0,118622467 & 0,036902261 & $-0,031657223$ \\
\hline 13 & 2,44 & 3,92 & 0,143573181 & 0,035700863 & 0,023338439 \\
\hline 14 & 3,05 & 3,92 & 0,144654882 & 0,102807306 & $-0,002503279$ \\
\hline 15 & 3,66 & 3,92 & 0,142109084 & 0,066459433 & $-0,01975577$ \\
\hline 16 & 4,27 & 3,92 & 0,122578757 & 0,029930617 & 0,007117138 \\
\hline 17 & 4,88 & 3,92 & 0,084380363 & $-0,00722018$ & 0,018941742 \\
\hline 18 & 5,49 & 3,92 & 0,045082296 & $-0,028546171$ & 0,005334897 \\
\hline 19 & 0,61 & 3,43 & 0,049282114 & $-0,124233276$ & 0,001510859 \\
\hline 20 & 1,22 & 3,43 & 0,085972516 & $-0,089539654$ & 0,048256337 \\
\hline 21 & 1,83 & 3,43 & 0,122549221 & $-0,073137795$ & 0,014970612 \\
\hline 22 & 2,44 & 3,43 & 0,139634603 & $-0,02295724$ & $-0,019712964$ \\
\hline 23 & 3,05 & 3,43 & 0,149901259 & $-0,020106963$ & $-0,047632277$ \\
\hline 24 & 3,66 & 3,43 & 0,145721065 & $-0,032313532$ & $-0,022731968$ \\
\hline 25 & 4,27 & 3,43 & 0,119142621 & $-0,037854617$ & $-0,007793654$ \\
\hline 26 & 4,88 & 3,43 & 0,090632507 & $-0,056185647$ & $-0,011386142$ \\
\hline 27 & 5,49 & 3,43 & 0,049110987 & $-0,085579423$ & 0,005625563 \\
\hline 28 & 0,61 & 2,94 & 0,051032193 & $-0,138176127$ & 0,050238452 \\
\hline 29 & 1,22 & 2,94 & 0,09188998 & $-0,15682179$ & $-0,053752988$ \\
\hline 30 & 1,83 & 2,94 & 0,119098769 & $-0,12411685$ & $-0,046297185$ \\
\hline 31 & 2,44 & 2,94 & 0,146218726 & $-0,110265701$ & 0,0068185 \\
\hline 32 & 3,05 & 2,94 & 0,156933387 & $-0,058034291$ & $-0,017608726$ \\
\hline 33 & 3,66 & 2,94 & 0,14320886 & $-0,07381748$ & 0,000362343 \\
\hline 34 & 4,27 & 2,94 & 0,125087216 & $-0,121805093$ & $-0,019919082$ \\
\hline 35 & 4,88 & 2,94 & 0,094641066 & $-0,193597896$ & $-0,008555867$ \\
\hline 36 & 5,49 & 2,94 & 0,049772813 & $-0,190608256$ & 0,016375959 \\
\hline 37 & 0,61 & 2,45 & 0,05128808 & $-0,14702032$ & 0,021216848 \\
\hline 38 & 1,22 & 2,45 & 0,090117554 & $-0,145871949$ & 0,01008143 \\
\hline 39 & 1,83 & 2,45 & 0,116701563 & $-0,117641917$ & $-0,000966122$ \\
\hline 40 & 2,44 & 2,45 & 0,144189951 & $-0,121004904$ & $-0,024862479$ \\
\hline 41 & 3,05 & 2,45 & 0,155332374 & $-0,109639475$ & 0,04653221 \\
\hline
\end{tabular}


Deslocamentos experimentais Teste 2.

\begin{tabular}{|c|c|c|c|c|c|}
\hline \multicolumn{6}{|c|}{ DESLOCAMENTOS EXPERIMENTAIS FEVEREIRO 15-2015 } \\
\hline \multirow{2}{*}{$\begin{array}{c}\text { Nó } \\
\text { experimental }\end{array}$} & \multicolumn{2}{|c|}{$\begin{array}{l}\text { Coordenadas } \\
\text { experimentais }\end{array}$} & \multirow{2}{*}{$\begin{array}{c}\text { UZ } 1 \text { modo Experimental } \\
\text { Fev 15-2015 } \\
\text { ( Acel canto laje) }\end{array}$} & \multirow{2}{*}{$\begin{array}{c}\text { UZ } 2 \text { modo Experimental } \\
\text { Fev 15-2015 } \\
\text { ( Acel canto laje) }\end{array}$} & \multirow{2}{*}{$\begin{array}{c}\text { UZ } 3 \text { modo Experimental } \\
\text { Fev 15-2015 } \\
\text { ( Acel canto laje) }\end{array}$} \\
\hline & $\mathrm{X}$ & $\mathrm{Y}$ & & & \\
\hline 42 & 3,66 & 2,45 & 0,141524119 & $-0,095432935$ & 0,808449022 \\
\hline 43 & 4,27 & 2,45 & 0,124177283 & $-0,156240637$ & $-0,003706258$ \\
\hline 44 & 4,88 & 2,45 & 0,09358259 & $-0,164664029$ & $-0,051281493$ \\
\hline 45 & 5,49 & 2,45 & 0,049330847 & $-0,182320396$ & 0,021081471 \\
\hline 46 & 0,61 & 1,96 & 0,049955735 & $-0,122008137$ & 0,017532904 \\
\hline 47 & 1,22 & 1,96 & 0,090122095 & $-0,126753048$ & $-0,013887007$ \\
\hline 48 & 1,83 & 1,96 & 0,117234349 & $-0,038011548$ & $-0,011951873$ \\
\hline 49 & 2,44 & 1,96 & 0,143003466 & $-0,099885478$ & $-0,029138317$ \\
\hline 50 & 3,05 & 1,96 & 0,15341023 & $-0,08237961$ & $-0,003727801$ \\
\hline 51 & 3,66 & 1,96 & 0,139944808 & $-0,10963664$ & 0,000998521 \\
\hline 52 & 4,27 & 1,96 & 0,124057881 & $-0,134914123$ & $-0,019467699$ \\
\hline 53 & 4,88 & 1,96 & 0,092293815 & $-0,18126373$ & $-0,003592368$ \\
\hline 54 & 5,49 & 1,96 & 0,048517909 & $-0,186108901$ & 0,014305249 \\
\hline 55 & 0,61 & 1,47 & 0,047411517 & $-0,131037558$ & $-0,002804033$ \\
\hline 56 & 1,22 & 1,47 & 0,087813133 & $-0,082398451$ & $-0,016838337$ \\
\hline 57 & 1,83 & 1,47 & 0,116411621 & $-0,026584517$ & 0,00981029 \\
\hline 58 & 2,44 & 1,47 & 0,141294315 & $-0,010477894$ & 0,040333209 \\
\hline 59 & 3,05 & 1,47 & 0,152334302 & $-0,015185624$ & 0,085329515 \\
\hline 60 & 3,66 & 1,47 & 0,139697402 & $-0,045008611$ & 0,038988495 \\
\hline 61 & 4,27 & 1,47 & 0,121063488 & $-0,061346966$ & 0,028959127 \\
\hline 62 & 4,88 & 1,47 & 0,091307884 & $-0,099135863$ & 0,137030382 \\
\hline 63 & 5,49 & 1,47 & 0,046848794 & $-0,110824517$ & 0,052149181 \\
\hline 64 & 0,61 & 0,98 & 0,044014907 & $-0,045796787$ & 0,042419455 \\
\hline 65 & 1,22 & 0,98 & 0,085514775 & 0,00892398 & $-0,014886026$ \\
\hline 66 & 1,83 & 0,98 & 0,114355579 & 0,043306848 & $-0,009567841$ \\
\hline 67 & 2,44 & 0,98 & 0,138389663 & 0,074255581 & $-0,041232885$ \\
\hline 68 & 3,05 & 0,98 & 0,149374193 & 0,072916385 & 0,00492772 \\
\hline 69 & 3,66 & 0,98 & 0,136311154 & 0,058411718 & $-0,007003956$ \\
\hline 70 & 4,27 & 0,98 & 0,121773023 & 0,013351111 & 0,025141227 \\
\hline 71 & 4,88 & 0,98 & 0,090483137 & $-0,031217276$ & 0,02457903 \\
\hline 72 & 5,49 & 0,98 & 0,046001104 & $-0,059123498$ & $-0,0131735$ \\
\hline 73 & 0,61 & 0,49 & 0,042302453 & 0,025818413 & $-0,017205237$ \\
\hline 74 & 1,22 & 0,49 & 0,082610516 & 0,075103412 & $-0,037040564$ \\
\hline 75 & 1,83 & 0,49 & 0,110975467 & 0,130873144 & 0,020394782 \\
\hline 76 & 2,44 & 0,49 & 0,136945304 & 0,155089117 & 0,00810477 \\
\hline 77 & 3,05 & 0,49 & 0,148687677 & 0,171168756 & $-0,055948853$ \\
\hline 78 & 3,66 & 0,49 & 0,135408456 & 0,139041059 & 0,012294483 \\
\hline 79 & 4,27 & 0,49 & 0,119694399 & 0,133354556 & $-0,038796628$ \\
\hline 80 & 4,88 & 0,49 & 0,086311222 & 0,050338927 & 0,007060469 \\
\hline 81 & 5,49 & 0,49 & 0,041725714 & 0,019660537 & $-0,008320098$ \\
\hline
\end{tabular}


Deslocamentos numéricos Teste 2.

\begin{tabular}{|c|c|c|c|c|c|c|}
\hline \multicolumn{7}{|c|}{ DESLOCAMENTOS NUMÉRICOS FEVEREIRO 15-2015 } \\
\hline \multirow{2}{*}{$\begin{array}{c}\text { Nó } \\
\text { experimental }\end{array}$} & \multirow{2}{*}{$\begin{array}{c}\text { Nó } \\
\text { númerico }\end{array}$} & \multicolumn{2}{|c|}{$\begin{array}{c}\text { Coordenadas } \\
\text { numericas }\end{array}$} & \multirow{2}{*}{$\begin{array}{c}\text { Desloc 1ro modo, } \\
\text { Númerico } \\
\mathbf{U Z} \mathbf{f}=\mathbf{3 , 3 6 2 9 9} \mathbf{H z}\end{array}$} & \multirow{2}{*}{$\begin{array}{c}\begin{array}{c}\text { Desloc } 21 \text { modo, } \\
\text { Númerico }\end{array} \\
\mathbf{U Z ~} \mathbf{f}=\mathbf{1 5 , 6 7 1 8 ~ H z}\end{array}$} & \multirow{2}{*}{ 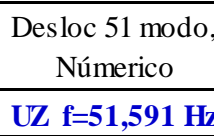 } \\
\hline & & $\mathrm{X}$ númerico & Ynúmerico & & & \\
\hline 1 & 6056 & 0,60961 & 4,41803 & 0,004512400 & 0,000901950 & $-0,002523500$ \\
\hline 2 & 12131 & 1,21392 & 4,41803 & 0,008769700 & 0,006542400 & 0,004918800 \\
\hline 3 & 18206 & 1,81822 & 4,41803 & 0,012354000 & 0,011918000 & 0,011467000 \\
\hline 4 & 24524 & 2,44670 & 4,41803 & 0,015076000 & 0,016238000 & 0,010243000 \\
\hline 5 & 30599 & 3,05100 & 4,41803 & 0,016506000 & 0,018274000 & 0,000638830 \\
\hline 6 & 36674 & 3,65530 & 4,41803 & 0,015901000 & 0,016729000 & $-0,009811400$ \\
\hline 7 & 42749 & 4,25961 & 4,41803 & 0,013464000 & 0,012424000 & $-0,012361000$ \\
\hline 8 & 49067 & 4,88808 & 4,41803 & 0,009552800 & 0,006649100 & $-0,006214600$ \\
\hline 9 & 55142 & 5,49239 & 4,41803 & 0,004911000 & 0,000837110 & 0,001905600 \\
\hline 10 & 6031 & 0,60961 & 3,91598 & 0,004790800 & $-0,006278200$ & $-0,015238000$ \\
\hline 11 & 12106 & 1,21392 & 3,91598 & 0,008927500 & $-0,002037900$ & $-0,011552000$ \\
\hline 12 & 18181 & 1,81822 & 3,91598 & 0,012425000 & 0,002230900 & $-0,004644900$ \\
\hline 13 & 24499 & 2,44670 & 3,91598 & 0,015093000 & 0,005775100 & $-0,000171180$ \\
\hline 14 & 30574 & 3,05100 & 3,91598 & 0,016473000 & 0,007379000 & $-0,000204290$ \\
\hline 15 & 36649 & 3,65530 & 3,91598 & 0,016035000 & 0,006210900 & $-0,000136870$ \\
\hline 16 & 42724 & 4,25961 & 3,91598 & 0,013588000 & 0,002475300 & 0,003978000 \\
\hline 17 & 49042 & 4,88808 & 3,91598 & 0,009720800 & $-0,002169600$ & 0,011154000 \\
\hline 18 & 55117 & 5,49239 & 3,91598 & 0,005212700 & $-0,006586900$ & 0,015468000 \\
\hline 19 & 6007 & 0,60961 & 3,43402 & 0,005036500 & $-0,012188000$ & $-0,019592000$ \\
\hline 20 & 12082 & 1,21392 & 3,43402 & 0,009091800 & $-0,009142200$ & $-0,018715000$ \\
\hline 21 & 18157 & 1,81822 & 3,43402 & 0,012532000 & $-0,005770500$ & $-0,012699000$ \\
\hline 22 & 24475 & 2,44670 & 3,43402 & 0,015172000 & $-0,002842500$ & $-0,005758900$ \\
\hline 23 & 30550 & 3,05100 & 3,43402 & 0,016515000 & $-0,001533800$ & $-0,000543270$ \\
\hline 24 & 36625 & 3,65530 & 3,43402 & 0,016147000 & $-0,002562900$ & 0,005143400 \\
\hline 25 & 42700 & 4,25961 & 3,43402 & 0,013758000 & $-0,005830600$ & 0,012551000 \\
\hline 26 & 49018 & 4,88808 & 3,43402 & 0,009914500 & $-0,009532700$ & 0,019005000 \\
\hline 27 & 55093 & 5,49239 & 3,43402 & 0,005494200 & $-0,012762000$ & 0,020457000 \\
\hline 28 & 5982 & 0,60961 & 2,93197 & 0,005226000 & $-0,016550000$ & $-0,013627000$ \\
\hline 29 & 12057 & 1,21392 & 2,93197 & 0,009240200 & $-0,014446000$ & $-0,014102000$ \\
\hline 30 & 18132 & 1,81822 & 2,93197 & 0,012647000 & $-0,011623000$ & $-0,010383000$ \\
\hline 31 & 24450 & 2,44670 & 2,93197 & 0,015258000 & $-0,008977200$ & $-0,004987400$ \\
\hline 32 & 30525 & 3,05100 & 2,93197 & 0,016592000 & $-0,007861500$ & $-0,000304500$ \\
\hline 33 & 36600 & 3,65530 & 2,93197 & 0,016150000 & $-0,009022700$ & 0,004589300 \\
\hline 34 & 42675 & 4,25961 & 2,93197 & 0,013911000 & $-0,011996000$ & 0,010449000 \\
\hline 35 & 48993 & 4,88808 & 2,93197 & 0,010130000 & $-0,015213000$ & 0,014797000 \\
\hline 36 & 55068 & 5,49239 & 2,93197 & 0,005743200 & $-0,017485000$ & 0,014874000 \\
\hline 37 & 5958 & 0,60961 & 2,45000 & 0,005291600 & $-0,017913000$ & $-0,000160670$ \\
\hline 38 & 12033 & 1,21392 & 2,45000 & 0,009288700 & $-0,015908000$ & $-0,000032881$ \\
\hline 39 & 18108 & 1,81822 & 2,45000 & 0,012693000 & $-0,013330000$ & 0,000251330 \\
\hline 40 & 24426 & 2,44670 & 2,45000 & 0,015302000 & $-0,010943000$ & 0,000331100 \\
\hline 41 & 30501 & 3,05100 & 2,45000 & 0,016721000 & $-0,009945000$ & 0,000107410 \\
\hline
\end{tabular}


Deslocamentos numéricos Teste 2.

\begin{tabular}{|c|c|c|c|c|c|c|}
\hline \multicolumn{7}{|c|}{ DESLOCAMENTOS NUMÉRICOS FEVEREIRO 15-2015 } \\
\hline \multirow{2}{*}{$\begin{array}{c}\text { Nó } \\
\text { experimental }\end{array}$} & \multirow{2}{*}{$\begin{array}{c}\text { Nó } \\
\text { númerico }\end{array}$} & \multicolumn{2}{|c|}{$\begin{array}{c}\text { Coordenadas } \\
\text { numericas }\end{array}$} & \multirow{2}{*}{$\begin{array}{c}\text { Desloc 1ro modo, } \\
\text { Númerico } \\
\mathbf{U Z ~} \mathbf{f}=\mathbf{3 , 3 6 2 9 9} \mathbf{~ H z}\end{array}$} & \multirow{2}{*}{$\begin{array}{c}\text { Desloc } 21 \text { modo, } \\
\text { Númerico }\end{array}$} & \multirow{2}{*}{$\begin{array}{c}\begin{array}{c}\text { Desloc } 51 \text { modo, } \\
\text { Númerico }\end{array} \\
\mathbf{U Z ~} \mathbf{f}=\mathbf{5 1 , 5 9 1} \mathbf{H z} \\
\end{array}$} \\
\hline & & $\mathrm{X}$ númerico & Ynúmerico & & & \\
\hline 42 & 36576 & 3,65530 & 2,45000 & 0,016116000 & $-0,011239000$ & $-0,000188870$ \\
\hline 43 & 42651 & 4,25961 & 2,45000 & 0,014019000 & $-0,014122000$ & 0,000039810 \\
\hline 44 & 48969 & 4,88808 & 2,45000 & 0,010305000 & $-0,016998000$ & 0,000656690 \\
\hline 45 & 55044 & 5,49239 & 2,45000 & 0,005878100 & $-0,018819000$ & 0,000866840 \\
\hline 46 & 5934 & 0,60961 & 1,96803 & 0,005229100 & $-0,016229000$ & 0,013634000 \\
\hline 47 & 12009 & 1,21392 & 1,96803 & 0,009255700 & $-0,013978000$ & 0,014025000 \\
\hline 48 & 18084 & 1,81822 & 1,96803 & 0,012685000 & $-0,011268000$ & 0,010825000 \\
\hline 49 & 24402 & 2,44670 & 1,96803 & 0,015316000 & $-0,008844700$ & 0,005678600 \\
\hline 50 & 30477 & 3,05100 & 1,96803 & 0,016794000 & $-0,007791400$ & 0,000401210 \\
\hline 51 & 36552 & 3,65530 & 1,96803 & 0,016108000 & $-0,009045200$ & $-0,005280900$ \\
\hline 52 & 42627 & 4,25961 & 1,96803 & 0,014096000 & $-0,011587000$ & $-0,011057000$ \\
\hline 53 & 48945 & 4,88808 & 1,96803 & 0,010439000 & $-0,014482000$ & $-0,014570000$ \\
\hline 54 & 55020 & 5,49239 & 1,96803 & 0,005904000 & $-0,016840000$ & $-0,013995000$ \\
\hline 55 & 5909 & 0,60961 & 1,46598 & 0,005070000 & $-0,012096000$ & 0,019770000 \\
\hline 56 & 11984 & 1,21392 & 1,46598 & 0,009164800 & $-0,009054600$ & 0,018964000 \\
\hline 57 & 18059 & 1,81822 & 1,46598 & 0,012646000 & $-0,005736400$ & 0,013370000 \\
\hline 58 & 24377 & 2,44670 & 1,46598 & 0,015315000 & $-0,002872800$ & 0,006395900 \\
\hline 59 & 30452 & 3,05100 & 1,46598 & 0,016734000 & $-0,001604000$ & 0,000403960 \\
\hline 60 & 36527 & 3,65530 & 1,46598 & 0,016103000 & $-0,002849900$ & $-0,005961900$ \\
\hline 61 & 42602 & 4,25961 & 1,46598 & 0,014211000 & $-0,005598200$ & $-0,013622000$ \\
\hline 62 & 48920 & 4,88808 & 1,46598 & 0,010629000 & $-0,009120500$ & $-0,020327000$ \\
\hline 63 & 54995 & 5,49239 & 1,46598 & 0,005842500 & $-0,012389000$ & $-0,021082000$ \\
\hline 64 & 5885 & 0,60961 & 0,98402 & 0,004847500 & $-0,006345100$ & 0,014857000 \\
\hline 65 & 11960 & 1,21392 & 0,98402 & 0,009045900 & $-0,002205600$ & 0,011115000 \\
\hline 66 & 18035 & 1,81822 & 0,98402 & 0,012604000 & 0,001998400 & 0,004854700 \\
\hline 67 & 24353 & 2,44670 & 0,98402 & 0,015322000 & 0,005524300 & 0,000793090 \\
\hline 68 & 30428 & 3,05100 & 0,98402 & 0,016760000 & 0,007198400 & 0,000190100 \\
\hline 69 & 36503 & 3,65530 & 0,98402 & 0,016132000 & 0,005717300 & $-0,000346580$ \\
\hline 70 & 42578 & 4,25961 & 0,98402 & 0,014380000 & 0,002544100 & $-0,004747900$ \\
\hline 71 & 48896 & 4,88808 & 0,98402 & 0,010840000 & $-0,001870600$ & $-0,012604000$ \\
\hline 72 & 54971 & 5,49239 & 0,98402 & 0,005699000 & $-0,006361800$ & $-0,016662000$ \\
\hline 73 & 5860 & 0,60961 & 0,48197 & 0,004590500 & 0,000696420 & 0,001183200 \\
\hline 74 & 11935 & 1,21392 & 0,48197 & 0,008929800 & 0,006154400 & $-0,006560300$ \\
\hline 75 & 18010 & 1,81822 & 0,48197 & 0,012593000 & 0,011437000 & $-0,012119000$ \\
\hline 76 & 24328 & 2,44670 & 0,48197 & 0,015390000 & 0,015781000 & $-0,009660600$ \\
\hline 77 & 30403 & 3,05100 & 0,48197 & 0,016866000 & 0,017895000 & $-0,000016825$ \\
\hline 78 & 36478 & 3,65530 & 0,48197 & 0,016224000 & 0,016104000 & 0,010142000 \\
\hline 79 & 42553 & 4,25961 & 0,48197 & 0,014590000 & 0,012396000 & 0,012725000 \\
\hline 80 & 48871 & 4,88808 & 0,48197 & 0,011007000 & 0,006871900 & 0,005758000 \\
\hline 81 & 54946 & 5,49239 & 0,48197 & 0,005506500 & 0,000917330 & $-0,003104300$ \\
\hline
\end{tabular}




\section{Deslocamentos experimentais Teste 3 .}

\begin{tabular}{|c|c|c|c|c|c|c|}
\hline \multicolumn{7}{|c|}{ DESLOCAMENTOS EXPERIMENTAIS FEVEREIRO 16-2015 } \\
\hline \multirow{2}{*}{$\begin{array}{c}\text { Nó } \\
\text { experimental }\end{array}$} & \multicolumn{2}{|c|}{$\begin{array}{l}\text { Coordenadas } \\
\text { experimentais }\end{array}$} & \multirow{2}{*}{$\begin{array}{c}\text { UZ } 1 \text { modo Experimental } \\
\text { Fev 16-2015 ( Acel centro laje) }\end{array}$} & \multirow{2}{*}{$\begin{array}{c}\text { UZ } 2 \text { modo Experimental } \\
\text { Fev 16-2015 ( Acel centro laje) }\end{array}$} & \multirow{2}{*}{$\begin{array}{c}\text { UZ } 3 \text { modo Experimental } \\
\text { Fev 16-2015 ( Acel centro laje) }\end{array}$} & \multirow{2}{*}{$\begin{array}{c}\text { UZ } 4 \text { modo Experimental } \\
\text { Fev 16-2015 ( Acel centro laje) }\end{array}$} \\
\hline & $\mathrm{X}$ & $\mathrm{Y}$ & & & & \\
\hline 1 & 0,61 & 4,41 & 0,040658323 & $-0,00229506$ & $-0,083839715$ & $-0,025895695$ \\
\hline 2 & 1,22 & 4,41 & 0,081393608 & 0,065642342 & $-0,11708773$ & $-0,005825294$ \\
\hline 3 & 1,83 & 4,41 & 0,114794309 & 0,122211191 & $-0,091570759$ & 0,02366878 \\
\hline 4 & 2,44 & 4,41 & 0,136431926 & 0,172611247 & $-0,061187176$ & $-0,018460591$ \\
\hline 5 & 3,05 & 4,41 & 0,148863174 & 0,194576613 & $-0,015255442$ & 0,029011352 \\
\hline 6 & 3,66 & 4,41 & 0,140145304 & 0,174395465 & $-0,047412139$ & $-0,026941338$ \\
\hline 7 & 4,27 & 4,41 & 0,119620759 & 0,136523093 & $-0,121999117$ & $-0,024358834$ \\
\hline 8 & 4,88 & 4,41 & 0,084421428 & 0,081617213 & $-0,122904887$ & $-0,021543315$ \\
\hline 9 & 5,49 & 4,41 & 0,044219204 & 0,00711738 & $-0,120613789$ & $-0,053064814$ \\
\hline 10 & 0,61 & 3,92 & 0,046420291 & $-0,062887794$ & $-0,110217594$ & 0,031261984 \\
\hline 11 & 1,22 & 3,92 & 0,083329563 & $-0,02629224$ & $-0,109772707$ & $-0,04520464$ \\
\hline 12 & 1,83 & 3,92 & 0,115789974 & 0,021829766 & $-0,031178201$ & 0,04111398 \\
\hline 13 & 2,44 & 3,92 & 0,142075246 & 0,056485124 & 0,049811076 & $-0,057060795$ \\
\hline 14 & 3,05 & 3,92 & 0,15064851 & 0,072228108 & 0,077736116 & 0,012838715 \\
\hline 15 & 3,66 & 3,92 & 0,141895453 & 0,075678785 & 0,027613052 & $-0,067297118$ \\
\hline 16 & 4,27 & 3,92 & 0,119740761 & 0,046929722 & $-0,022472333$ & $-0,018440668$ \\
\hline 17 & 4,88 & 3,92 & 0,08623026 & $-0,009515511$ & $-0,100015844$ & 0,068220262 \\
\hline 18 & 5,49 & 3,92 & 0,045273564 & $-0,056519476$ & $-0,128485401$ & 0,092983881 \\
\hline 19 & 0,61 & 3,43 & 0,047056338 & $-0,121661093$ & $-0,138039815$ & $-0,001133688$ \\
\hline 20 & 1,22 & 3,43 & 0,087045188 & $-0,106802179$ & $-0,078988108$ & $-0,052428239$ \\
\hline 21 & 1,83 & 3,43 & 0,120892677 & $-0,05698484$ & $-0,012037615$ & $-0,046503846$ \\
\hline 22 & 2,44 & 3,43 & 0,143013739 & $-0,040115605$ & 0,1191051 & $-0,062214861$ \\
\hline 23 & 3,05 & 3,43 & 0,151030755 & $-0,015608445$ & 0,169981263 & 0,02513408 \\
\hline 24 & 3,66 & 3,43 & 0,143861825 & $-0,02044455$ & 0,099143415 & $-0,074485431$ \\
\hline 25 & 4,27 & 3,43 & 0,123009496 & $-0,048210129$ & 0,013744054 & 0,011948544 \\
\hline 26 & 4,88 & 3,43 & 0,089199916 & $-0,079548115$ & $-0,061690051$ & 0,013097386 \\
\hline 27 & 5,49 & 3,43 & 0,047739961 & $-0,115576486$ & $-0,133297895$ & $-0,109245097$ \\
\hline 28 & 0,61 & 2,94 & 0,049000694 & $-0,17400781$ & $-0,154090678$ & $-0,026715423$ \\
\hline 29 & 1,22 & 2,94 & 0,087606772 & $-0,173468498$ & $-0,058042405$ & 0,013930213 \\
\hline 30 & 1,83 & 2,94 & 0,123856162 & $-0,144396561$ & 0,054350118 & 0,078897233 \\
\hline 31 & 2,44 & 2,94 & 0,144404776 & $-0,106565622$ & 0,160511004 & 0,027608046 \\
\hline 32 & 3,05 & 2,94 & 0,149377601 & $-0,10308372$ & 0,207659182 & 0,040590617 \\
\hline 33 & 3,66 & 2,94 & 0,14268 & $-0,093722613$ & 0,187457889 & 0,050478858 \\
\hline 34 & 4,27 & 2,94 & 0,120725395 & $-0,09978918$ & 0,069583187 & $-0,008732051$ \\
\hline 35 & 4,88 & 2,94 & 0,089365728 & $-0,138515313$ & $-0,046035271$ & 0,002716995 \\
\hline 36 & 5,49 & 2,94 & 0,050485834 & $-0,154770696$ & $-0,141317058$ & $-0,024371151$ \\
\hline 37 & 0,61 & 2,45 & 0,049026683 & $-0,191730592$ & $-0,159052356$ & $-0,035834353$ \\
\hline 38 & 1,22 & 2,45 & 0,086430497 & $-0,173515016$ & $-0,075145348$ & 0,022905874 \\
\hline 39 & 1,83 & 2,45 & 0,120353687 & $-0,158569652$ & 0,064204297 & $-0,051866949$ \\
\hline 40 & 2,44 & 2,45 & 0,142855061 & $-0,137684135$ & 0,167059016 & 0,043876961 \\
\hline 41 & 3,05 & 2,45 & 0,160516017 & $-0,127463136$ & 0,254168951 & $-0,00720072$ \\
\hline
\end{tabular}




\section{Deslocamentos experimentais Teste 3.}

\begin{tabular}{|c|c|c|c|c|c|c|}
\hline \multicolumn{7}{|c|}{ DESLOCAMENTOS EXPERIMENTAIS FEVEREIRO 16-2015 } \\
\hline \multirow{2}{*}{$\begin{array}{c}\text { Nó } \\
\text { experimental }\end{array}$} & \multicolumn{2}{|c|}{$\begin{array}{l}\text { Coordenadas } \\
\text { experimentais }\end{array}$} & \multirow{2}{*}{$\begin{array}{c}\text { UZ } 1 \text { modo Experimental } \\
\text { Fev 16-2015 ( Acel centro laje) }\end{array}$} & \multirow{2}{*}{$\begin{array}{c}\text { UZ } 2 \text { modo Experimental } \\
\text { Fev 16-2015 ( Acel centro laje) }\end{array}$} & \multirow{2}{*}{$\begin{array}{c}\text { UZ } 3 \text { modo Experimental } \\
\text { Fev 16-2015 ( Acel centro laje) }\end{array}$} & \multirow{2}{*}{$\begin{array}{c}\text { UZ } 4 \text { modo Experimental } \\
\text { Fev 16-2015 ( Acel centro laje) }\end{array}$} \\
\hline & $\mathrm{X}$ & $\mathrm{Y}$ & & & & \\
\hline 42 & 3,66 & 2,45 & 0,142781562 & $-0,13902556$ & 0,216706531 & 0,137476275 \\
\hline 43 & 4,27 & 2,45 & 0,122850059 & $-0,14832311$ & 0,102053322 & 0,047230614 \\
\hline 44 & 4,88 & 2,45 & 0,091524652 & $-0,165348382$ & $-0,031596108$ & 0,041009524 \\
\hline 45 & 5,49 & 2,45 & 0,049571957 & $-0,174714106$ & $-0,140151999$ & 0,057602309 \\
\hline 46 & 0,61 & 1,96 & 0,048978223 & $-0,186231558$ & $-0,159236089$ & 0,016416472 \\
\hline 47 & 1,22 & 1,96 & 0,086805694 & $-0,151467474$ & $-0,066965282$ & $-0,073344799$ \\
\hline 48 & 1,83 & 1,96 & 0,120246104 & $-0,112959104$ & 0,038788223 & 0,03625717 \\
\hline 49 & 2,44 & 1,96 & 0,139758215 & $-0,09413439$ & 0,148527136 & 0,007921164 \\
\hline 50 & 3,05 & 1,96 & 0,147343903 & $-0,085714209$ & 0,207129741 & $-0,020532216$ \\
\hline 51 & 3,66 & 1,96 & 0,142337098 & $-0,099073398$ & 0,172150809 & 0,07711593 \\
\hline 52 & 4,27 & 1,96 & 0,123718077 & $-0,115879073$ & 0,075467462 & 0,112926157 \\
\hline 53 & 4,88 & 1,96 & 0,092055702 & $-0,155407176$ & $-0,053110944$ & 0,065546421 \\
\hline 54 & 5,49 & 1,96 & 0,051375701 & $-0,18613691$ & $-0,139369044$ & 0,048325824 \\
\hline 55 & 0,61 & 1,47 & 0,047889336 & $-0,121449806$ & $-0,143704304$ & $-0,047769948$ \\
\hline 56 & 1,22 & 1,47 & 0,085710693 & $-0,100540967$ & $-0,089205567$ & 0,031718913 \\
\hline 57 & 1,83 & 1,47 & 0,139432615 & $-0,022792343$ & 0,097381659 & $-0,014671079$ \\
\hline 58 & 2,44 & 1,47 & 0,139432615 & $-0,022792343$ & 0,097381659 & $-0,014671079$ \\
\hline 59 & 3,05 & 1,47 & 0,148976863 & $-0,017355748$ & 0,142957409 & 0,017816519 \\
\hline 60 & 3,66 & 1,47 & 0,141885987 & $-0,041710069$ & 0,09375128 & 0,023394014 \\
\hline 61 & 4,27 & 1,47 & 0,121290766 & $-0,060665094$ & 0,035679718 & $-0,020778828$ \\
\hline 62 & 4,88 & 1,47 & 0,090707174 & $-0,096346943$ & $-0,057657015$ & 0,015231123 \\
\hline 63 & 5,49 & 1,47 & 0,048826086 & $-0,111321807$ & $-0,124699889$ & 0,074229277 \\
\hline 64 & 0,61 & 0,98 & 0,043600735 & $-0,053821945$ & $-0,108508817$ & $-0,089965028$ \\
\hline 65 & 1,22 & 0,98 & 0,081680235 & $-0,01733069$ & $-0,081811479$ & 0,049657214 \\
\hline 66 & 1,83 & 0,98 & 0,117937756 & 0,039301455 & $-0,045336488$ & $-0,10515019$ \\
\hline 67 & 2,44 & 0,98 & 0,138462461 & 0,065748511 & 0,024726349 & 0,020319151 \\
\hline 68 & 3,05 & 0,98 & 0,145021752 & 0,085712041 & 0,074606846 & 0,01494108 \\
\hline 69 & 3,66 & 0,98 & 0,141189249 & 0,075223434 & 0,044789114 & 0,047277257 \\
\hline 70 & 4,27 & 0,98 & 0,120497702 & 0,043594946 & $-0,033327321$ & $-0,026682603$ \\
\hline 71 & 4,88 & 0,98 & 0,089737701 & $-0,012126252$ & $-0,119169544$ & $-0,009987074$ \\
\hline 72 & 5,49 & 0,98 & 0,046845791 & $-0,061695173$ & $-0,126142079$ & $-0,017033191$ \\
\hline 73 & 0,61 & 0,49 & 0,040915539 & 0,016877387 & $-0,117162333$ & $-0,116979978$ \\
\hline 74 & 1,22 & 0,49 & 0,080033916 & 0,055776883 & $-0,11284879$ & 0,091476398 \\
\hline 75 & 1,83 & 0,49 & 0,114242081 & 0,128736451 & $-0,077791344$ & 0,003641088 \\
\hline 76 & 2,44 & 0,49 & 0,137624848 & 0,157867018 & $-0,040935126$ & 0,792042115 \\
\hline 77 & 3,05 & 0,49 & 0,14561576 & 0,181612021 & $-0,020600958$ & 0,016189931 \\
\hline 78 & 3,66 & 0,49 & 0,141748721 & 0,17332647 & $-0,051591039$ & $-0,10595814$ \\
\hline 79 & 4,27 & 0,49 & 0,119123062 & 0,135576485 & $-0,12532362$ & 0,02026023 \\
\hline 80 & 4,88 & 0,49 & 0,085675157 & 0,063483147 & $-0,082682502$ & 0,041273456 \\
\hline 81 & 5,49 & 0,49 & 0,043594699 & 0,009885133 & $-0,116536004$ & 0,009321678 \\
\hline
\end{tabular}


Deslocamentos numéricos Teste 3.

\begin{tabular}{|c|c|c|c|c|c|c|c|}
\hline \multicolumn{8}{|c|}{ DESLOCAMENTOS NUMÉRICOS FEVEREIRO 16-2015 } \\
\hline \multirow{2}{*}{$\begin{array}{c}\text { Nó } \\
\text { experimental }\end{array}$} & \multirow{2}{*}{$\begin{array}{c}\text { Nó } \\
\text { númerico }\end{array}$} & \multicolumn{2}{|c|}{ Coordenadas numericas } & \multirow{2}{*}{$\begin{array}{c}\text { Desloc 1ro modo, } \\
\text { Númerico } \\
\mathbf{U Z ~ f = 3 , 3 6 2 9 9 ~} \mathbf{H z}\end{array}$} & \multirow{2}{*}{ 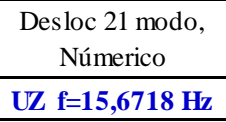 } & \multirow{2}{*}{$\begin{array}{c}\begin{array}{c}\text { Desloc } 27 \text { modo, } \\
\text { Númerico }\end{array} \\
\mathbf{U Z ~ f = 2 3 , 6 3 6 5 ~} \mathbf{~ H z} \\
\end{array}$} & \multirow{2}{*}{$\begin{array}{c}\begin{array}{c}\text { Desloc } 84 \text { modo, } \\
\text { Númerico }\end{array} \\
\mathbf{U Z} \mathbf{f}=\mathbf{8 4 , 8 7 9 1} \mathbf{~ H z} \\
\end{array}$} \\
\hline & & $\mathrm{X}$ númerico & Ynúmerico & & & & \\
\hline 1 & 6056 & 0,60961 & 4,41803 & 0,004512400 & 0,000901950 & 0,004625100 & 0,008199800 \\
\hline 2 & 12131 & 1,21392 & 4,41803 & 0,008769700 & 0,006542400 & 0,001397300 & 0,000705310 \\
\hline 3 & 18206 & 1,81822 & 4,41803 & 0,012354000 & 0,011918000 & $-0,001799000$ & $-0,003864200$ \\
\hline 4 & 24524 & 2,44670 & 4,41803 & 0,015076000 & 0,016238000 & $-0,002344200$ & $-0,002442200$ \\
\hline 5 & 30599 & 3,05100 & 4,41803 & 0,016506000 & 0,018274000 & 0,001491600 & $-0,000175840$ \\
\hline 6 & 36674 & 3,65530 & 4,41803 & 0,015901000 & 0,016729000 & 0,010258000 & 0,002460800 \\
\hline 7 & 42749 & 4,25961 & 4,41803 & 0,013464000 & 0,012424000 & 0,019426000 & 0,004841700 \\
\hline 8 & 49067 & 4,88808 & 4,41803 & 0,009552800 & 0,006649100 & 0,021304000 & 0,000357110 \\
\hline 9 & 55142 & 5,49239 & 4,41803 & 0,004911000 & 0,000837110 & 0,014336000 & $-0,007126400$ \\
\hline 10 & 6031 & 0,60961 & 3,91598 & 0,004790800 & $-0,006278200$ & 0,009974300 & 0,015837000 \\
\hline 11 & 12106 & 1,21392 & 3,91598 & 0,008927500 & $-0,002037900$ & 0,003526600 & 0,012454000 \\
\hline 12 & 18181 & 1,81822 & 3,91598 & 0,012425000 & 0,002230900 & $-0,003260100$ & 0,014319000 \\
\hline 13 & 24499 & 2,44670 & 3,91598 & 0,015093000 & 0,005775100 & $-0,007565100$ & 0,014730000 \\
\hline 14 & 30574 & 3,05100 & 3,91598 & 0,016473000 & 0,007379000 & $-0,006708600$ & 0,003351600 \\
\hline 15 & 36649 & 3,65530 & 3,91598 & 0,016035000 & 0,006210900 & 0,000097225 & $-0,010207000$ \\
\hline 16 & 42724 & 4,25961 & 3,91598 & 0,013588000 & 0,002475300 & 0,009986600 & $-0,012509000$ \\
\hline 17 & 49042 & 4,88808 & 3,91598 & 0,009720800 & $-0,002169600$ & 0,014305000 & $-0,012659000$ \\
\hline 18 & 55117 & 5,49239 & 3,91598 & 0,005212700 & $-0,006586900$ & 0,011694000 & $-0,015780000$ \\
\hline 19 & 6007 & 0,60961 & 3,43402 & 0,005036500 & $-0,012188000$ & 0,014755000 & 0,005905800 \\
\hline 20 & 12082 & 1,21392 & 3,43402 & 0,009091800 & $-0,009142200$ & 0,005599900 & 0,002221900 \\
\hline 21 & 18157 & 1,81822 & 3,43402 & 0,012532000 & $-0,005770500$ & $-0,004408000$ & 0,011832000 \\
\hline 22 & 24475 & 2,44670 & 3,43402 & 0,015172000 & $-0,002842500$ & $-0,012233000$ & 0,018016000 \\
\hline 23 & 30550 & 3,05100 & 3,43402 & 0,016515000 & $-0,001533800$ & $-0,014096000$ & 0,003469700 \\
\hline 24 & 36625 & 3,65530 & 3,43402 & 0,016147000 & $-0,002562900$ & $-0,008838500$ & $-0,013987000$ \\
\hline 25 & 42700 & 4,25961 & 3,43402 & 0,013758000 & $-0,005830600$ & 0,001404300 & $-0,012905000$ \\
\hline 26 & 49018 & 4,88808 & 3,43402 & 0,009914500 & $-0,009532700$ & 0,008038600 & $-0,004932000$ \\
\hline 27 & 55093 & 5,49239 & 3,43402 & 0,005494200 & $-0,012762000$ & 0,009245700 & $-0,007086500$ \\
\hline 28 & 5982 & 0,60961 & 2,93197 & 0,005226000 & $-0,016550000$ & 0,018678000 & $-0,014255000$ \\
\hline 29 & 12057 & 1,21392 & 2,93197 & 0,009240200 & $-0,014446000$ & 0,007660300 & $-0,021680000$ \\
\hline 30 & 18132 & 1,81822 & 2,93197 & 0,012647000 & $-0,011623000$ & $-0,004891000$ & $-0,004904200$ \\
\hline 31 & 24450 & 2,44670 & 2,93197 & 0,015258000 & $-0,008977200$ & $-0,015568000$ & 0,009926700 \\
\hline 32 & 30525 & 3,05100 & 2,93197 & 0,016592000 & $-0,007861500$ & $-0,019856000$ & 0,000818700 \\
\hline 33 & 36600 & 3,65530 & 2,93197 & 0,016150000 & $-0,009022700$ & $-0,015512000$ & $-0,009641900$ \\
\hline 34 & 42675 & 4,25961 & 2,93197 & 0,013911000 & $-0,011996000$ & $-0,005729400$ & 0,000441690 \\
\hline 35 & 48993 & 4,88808 & 2,93197 & 0,010130000 & $-0,015213000$ & 0,002723200 & 0,017718000 \\
\hline 36 & 55068 & 5,49239 & 2,93197 & 0,005743200 & $-0,017485000$ & 0,006897300 & 0,013262000 \\
\hline 37 & 5958 & 0,60961 & 2,45000 & 0,005291600 & $-0,017913000$ & 0,020663000 & $-0,022393000$ \\
\hline 38 & 12033 & 1,21392 & 2,45000 & 0,009288700 & $-0,015908000$ & 0,009228800 & $-0,030435000$ \\
\hline 39 & 18108 & 1,81822 & 2,45000 & 0,012693000 & $-0,013330000$ & $-0,004241100$ & $-0,012362000$ \\
\hline 40 & 24426 & 2,44670 & 2,45000 & 0,015302000 & $-0,010943000$ & $-0,016344000$ & 0,004363600 \\
\hline 41 & 30501 & 3,05100 & 2,45000 & 0,016721000 & $-0,009945000$ & $-0,022605000$ & $-0,001190400$ \\
\hline
\end{tabular}


Deslocamentos numéricos Teste 3.

\begin{tabular}{|c|c|c|c|c|c|c|c|}
\hline \multicolumn{8}{|c|}{ DESLOCAMENTOS NUMÉRICOS FEVEREIRO 16-2015 } \\
\hline \multirow{2}{*}{$\begin{array}{c}\text { Nó } \\
\text { experimental }\end{array}$} & \multirow{2}{*}{$\begin{array}{c}\text { Nó } \\
\text { númerico }\end{array}$} & \multicolumn{2}{|c|}{ Coordenadas numericas } & \multirow{2}{*}{$\begin{array}{c}\text { Desloc 1ro modo, } \\
\text { Númerico } \\
\mathbf{U Z ~} \mathbf{f}=\mathbf{3 , 3 6 2 9 9} \mathbf{~ H z}\end{array}$} & \multirow{2}{*}{$\begin{array}{c}\begin{array}{c}\text { Desloc } 21 \text { modo, } \\
\text { Númerico }\end{array} \\
\mathbf{U Z ~ f = 1 5 , 6 7 1 8 ~} \mathbf{~ H z} \\
\end{array}$} & \multirow{2}{*}{$\begin{array}{c}\begin{array}{c}\text { Desloc } 27 \text { modo, } \\
\text { Númerico }\end{array} \\
\mathbf{U Z ~} \mathbf{f}=\mathbf{2 3 , 6 3 6 5} \mathbf{~ H z} \\
\end{array}$} & \multirow{2}{*}{$\begin{array}{c}\begin{array}{c}\text { Desloc } 84 \text { modo, } \\
\text { Númerico }\end{array} \\
\mathbf{U Z} \mathbf{f}=\mathbf{8 4 , 8 7 9 1} \mathbf{~ H z} \\
\end{array}$} \\
\hline & & $\mathrm{X}$ númerico & Ynúmerico & & & & \\
\hline 42 & 36576 & 3,65530 & 2,45000 & 0,016116000 & $-0,011239000$ & $-0,018099000$ & $-0,006869300$ \\
\hline 43 & 42651 & 4,25961 & 2,45000 & 0,014019000 & $-0,014122000$ & $-0,008961700$ & 0,008259300 \\
\hline 44 & 48969 & 4,88808 & 2,45000 & 0,010305000 & $-0,016998000$ & 0,000270190 & 0,028495000 \\
\hline 45 & 55044 & 5,49239 & 2,45000 & 0,005878100 & $-0,018819000$ & 0,005679900 & 0,021672000 \\
\hline 46 & 5934 & 0,60961 & 1,96803 & 0,005229100 & $-0,016229000$ & 0,020509000 & $-0,011139000$ \\
\hline 47 & 12009 & 1,21392 & 1,96803 & 0,009255700 & $-0,013978000$ & 0,010283000 & $-0,017511000$ \\
\hline 48 & 18084 & 1,81822 & 1,96803 & 0,012685000 & $-0,011268000$ & $-0,002503300$ & $-0,003234000$ \\
\hline 49 & 24402 & 2,44670 & 1,96803 & 0,015316000 & $-0,008844700$ & $-0,014574000$ & 0,007756900 \\
\hline 50 & 30477 & 3,05100 & 1,96803 & 0,016794000 & $-0,007791400$ & $-0,021501000$ & $-0,001054200$ \\
\hline 51 & 36552 & 3,65530 & 1,96803 & 0,016108000 & $-0,009045200$ & $-0,016682000$ & $-0,009836800$ \\
\hline 52 & 42627 & 4,25961 & 1,96803 & 0,014096000 & $-0,011587000$ & $-0,007526500$ & 0,000226670 \\
\hline 53 & 48945 & 4,88808 & 1,96803 & 0,010439000 & $-0,014482000$ & 0,001227400 & 0,015611000 \\
\hline 54 & 55020 & 5,49239 & 1,96803 & 0,005904000 & $-0,016840000$ & 0,005797100 & 0,011097000 \\
\hline 55 & 5909 & 0,60961 & 1,46598 & 0,005070000 & $-0,012096000$ & 0,018493000 & 0,006835000 \\
\hline 56 & 11984 & 1,21392 & 1,46598 & 0,009164800 & $-0,009054600$ & 0,010849000 & 0,003980800 \\
\hline 57 & 18059 & 1,81822 & 1,46598 & 0,012646000 & $-0,005736400$ & 0,000177210 & 0,012206000 \\
\hline 58 & 24377 & 2,44670 & 1,46598 & 0,015315000 & $-0,002872800$ & $-0,010445000$ & 0,014422000 \\
\hline 59 & 30452 & 3,05100 & 1,46598 & 0,016734000 & $-0,001604000$ & $-0,016181000$ & 0,000294080 \\
\hline 60 & 36527 & 3,65530 & 1,46598 & 0,016103000 & $-0,002849900$ & $-0,011507000$ & $-0,013045000$ \\
\hline 61 & 42602 & 4,25961 & 1,46598 & 0,014211000 & $-0,005598200$ & $-0,002644000$ & $-0,010813000$ \\
\hline 62 & 48920 & 4,88808 & 1,46598 & 0,010629000 & $-0,009120500$ & 0,004766000 & $-0,003084800$ \\
\hline 63 & 54995 & 5,49239 & 1,46598 & 0,005842500 & $-0,012389000$ & 0,006780400 & $-0,006033400$ \\
\hline 64 & 5885 & 0,60961 & 0,98402 & 0,004847500 & $-0,006345100$ & 0,015028000 & 0,013947000 \\
\hline 65 & 11960 & 1,21392 & 0,98402 & 0,009045900 & $-0,002205600$ & 0,010861000 & 0,011921000 \\
\hline 66 & 18035 & 1,81822 & 0,98402 & 0,012604000 & 0,001998400 & 0,003174100 & 0,014947000 \\
\hline 67 & 24353 & 2,44670 & 0,98402 & 0,015322000 & 0,005524300 & $-0,005104300$ & 0,013173000 \\
\hline 68 & 30428 & 3,05100 & 0,98402 & 0,016760000 & 0,007198400 & $-0,009353600$ & 0,000641130 \\
\hline 69 & 36503 & 3,65530 & 0,98402 & 0,016132000 & 0,005717300 & $-0,004341100$ & $-0,010058000$ \\
\hline 70 & 42578 & 4,25961 & 0,98402 & 0,014380000 & 0,002544100 & 0,004237600 & $-0,010799000$ \\
\hline 71 & 48896 & 4,88808 & 0,98402 & 0,010840000 & $-0,001870600$ & 0,009962500 & $-0,009941700$ \\
\hline 72 & 54971 & 5,49239 & 0,98402 & 0,005699000 & $-0,006361800$ & 0,008197600 & $-0,014082000$ \\
\hline 73 & 5860 & 0,60961 & 0,48197 & 0,004590500 & 0,000696420 & 0,010655000 & 0,003825700 \\
\hline 74 & 11935 & 1,21392 & 0,48197 & 0,008929800 & 0,006154400 & 0,010511000 & $-0,001289100$ \\
\hline 75 & 18010 & 1,81822 & 0,48197 & 0,012593000 & 0,011437000 & 0,006279100 & $-0,001217300$ \\
\hline 76 & 24328 & 2,44670 & 0,48197 & 0,015390000 & 0,015781000 & 0,000758940 & 0,000357830 \\
\hline 77 & 30403 & 3,05100 & 0,48197 & 0,016866000 & 0,017895000 & $-0,001670200$ & $-0,000944580$ \\
\hline 78 & 36478 & 3,65530 & 0,48197 & 0,016224000 & 0,016104000 & 0,003970100 & 0,000320030 \\
\hline 79 & 42553 & 4,25961 & 0,48197 & 0,014590000 & 0,012396000 & 0,012293000 & 0,003920600 \\
\hline 80 & 48871 & 4,88808 & 0,48197 & 0,011007000 & 0,006871900 & 0,015905000 & 0,000850850 \\
\hline 81 & 54946 & 5,49239 & 0,48197 & 0,005506500 & 0,000917330 & 0,009923100 & $-0,007545900$ \\
\hline
\end{tabular}




\section{Deslocamentos experimentais Teste 4.}

\begin{tabular}{|c|c|c|c|c|c|c|}
\hline \multicolumn{7}{|c|}{ DESLOCAMENTOS EXPERIMENTAIS FEVEREIRO 17-2015 } \\
\hline \multirow{2}{*}{$\begin{array}{c}\text { Nó } \\
\text { experimental }\end{array}$} & \multicolumn{2}{|c|}{$\begin{array}{l}\text { Coordenadas } \\
\text { experimentais }\end{array}$} & \multirow{2}{*}{$\begin{array}{c}\text { UZ } 1 \text { modo Experimental } \\
\text { Fev 17-2015 } \\
\text { ( Acel centro laje) }\end{array}$} & \multirow{2}{*}{$\begin{array}{c}\text { UZ } 2 \text { modo Experimental } \\
\text { Fev 17-2015 } \\
\text { ( Acel centro laje) }\end{array}$} & \multirow{2}{*}{$\begin{array}{c}\text { UZ } 3 \text { modo Experimental } \\
\text { Fev 17-2015 } \\
\text { ( Acel centro laje) }\end{array}$} & \multirow{2}{*}{$\begin{array}{c}\text { UZ } 4 \text { modo Experimenta } \\
\text { Fev 17-2015 } \\
\text { ( Acel centro laje) }\end{array}$} \\
\hline & $\mathrm{X}$ & Y & & & & \\
\hline 1 & 0,61 & 4,41 & 0,041517755 & 0,007389933 & $-0,120477184$ & 0,049686763 \\
\hline 2 & 1,22 & 4,41 & 0,085132763 & 0,057252295 & $-0,110876456$ & 0,042223292 \\
\hline 3 & 1,83 & 4,41 & 0,119730725 & 0,127297619 & $-0,085298014$ & $-0,039424761$ \\
\hline 4 & 2,44 & 4,41 & 0,13725013 & 0,166622773 & $-0,020153159$ & 0,021658335 \\
\hline 5 & 3,05 & 4,41 & 0,150660761 & 0,191074801 & $-0,025062313$ & 0,049330633 \\
\hline 6 & 3,66 & 4,41 & 0,146151143 & 0,18727402 & $-0,064563026$ & $-0,046879101$ \\
\hline 7 & 4,27 & 4,41 & 0,116187127 & 0,127930378 & $-0,104605562$ & 0,007838289 \\
\hline 8 & 4,88 & 4,41 & 0,086347428 & 0,078144122 & $-0,138707617$ & $-0,003567612$ \\
\hline 9 & 5,49 & 4,41 & 0,043579301 & 0,015411469 & $-0,106941762$ & 0,033208671 \\
\hline 10 & 0,61 & 3,92 & 0,044554046 & $-0,070101061$ & $-0,130437196$ & $-0,04307496$ \\
\hline 11 & 1,22 & 3,92 & 0,081368734 & $-0,042993758$ & $-0,094924972$ & 0,025148105 \\
\hline 12 & 1,83 & 3,92 & 0,1201228 & 0,017495957 & $-0,030220336$ & 0,056363201 \\
\hline 13 & 2,44 & 3,92 & 0,145721764 & 0,058073895 & 0,040497009 & $-0,055844713$ \\
\hline 14 & 3,05 & 3,92 & 0,145674212 & 0,071371163 & 0,072078019 & 0,042688904 \\
\hline 15 & 3,66 & 3,92 & 0,143650959 & 0,078142652 & 0,033230227 & 0,054691663 \\
\hline 16 & 4,27 & 3,92 & 0,123863301 & 0,043076614 & $-0,041563212$ & $-0,036833635$ \\
\hline 17 & 4,88 & 3,92 & 0,084819443 & $-0,012644381$ & $-0,09846166$ & 0,021432021 \\
\hline 18 & 5,49 & 3,92 & 0,044271752 & $-0,050763489$ & $-0,125438525$ & 0,072940431 \\
\hline 19 & 0,61 & 3,43 & 0,049310154 & $-0,137894346$ & $-0,135467907$ & $-0,026112033$ \\
\hline 20 & 1,22 & 3,43 & 0,089395296 & $-0,092773698$ & $-0,091811607$ & 0,211200204 \\
\hline 21 & 1,83 & 3,43 & 0,123468452 & $-0,060564098$ & 0,016296141 & $-0,108998554$ \\
\hline 22 & 2,44 & 3,43 & 0,138614083 & $-0,03321407$ & 0,108507645 & 0,029741763 \\
\hline 23 & 3,05 & 3,43 & 0,150869893 & $-0,024263249$ & 0,101095125 & $-0,052191867$ \\
\hline 24 & 3,66 & 3,43 & 0,147628879 & $-0,024913082$ & 0,163070207 & 0,714502776 \\
\hline 25 & 4,27 & 3,43 & 0,119353184 & $-0,051654338$ & $-0,003080696$ & $-0,113443236$ \\
\hline 26 & 4,88 & 3,43 & 0,091808545 & $-0,096941829$ & $-0,07473193$ & 0,037728821 \\
\hline 27 & 5,49 & 3,43 & 0,049468356 & $-0,109486242$ & $-0,124668772$ & $-0,159630459$ \\
\hline 28 & 0,61 & 2,94 & 0,049612589 & $-0,193221305$ & $-0,17568043$ & $-0,006997284$ \\
\hline 29 & 1,22 & 2,94 & 0,085980406 & $-0,176416297$ & $-0,071681399$ & 0,000175246 \\
\hline 30 & 1,83 & 2,94 & 0,12283549 & $-0,126839042$ & 0,05082944 & $-0,046666944$ \\
\hline 31 & 2,44 & 2,94 & 0,146485478 & $-0,102755098$ & 0,183825598 & $-0,018390157$ \\
\hline 32 & 3,05 & 2,94 & 0,146791503 & $-0,095094449$ & 0,236071391 & 0,00213243 \\
\hline 33 & 3,66 & 2,94 & 0,145724598 & $-0,082263347$ & 0,17377069 & $-0,02592105$ \\
\hline 34 & 4,27 & 2,94 & 0,125408784 & $-0,107294116$ & 0,073062098 & $-0,007708195$ \\
\hline 35 & 4,88 & 2,94 & 0,088633891 & $-0,144609295$ & $-0,041386674$ & 0,032904902 \\
\hline 36 & 5,49 & 2,94 & 0,048751331 & $-0,134678809$ & $-0,111642012$ & $-0,055274844$ \\
\hline 37 & 0,61 & 2,45 & 0,049085234 & $-0,162078663$ & $-0,173937474$ & $-0,033074131$ \\
\hline 38 & 1,22 & 2,45 & 0,08992153 & $-0,160054041$ & $-0,074710743$ & $-0,031575789$ \\
\hline 39 & 1,83 & 2,45 & 0,118020306 & $-0,12331895$ & 0,048794235 & 0,002134138 \\
\hline 40 & 2,44 & 2,45 & 0,14389216 & $-0,127970626$ & 0,187676945 & 0,06028831 \\
\hline 41 & 3,05 & 2,45 & 0,146299511 & $-0,11381401$ & 0,230338093 & $-0,04562078$ \\
\hline
\end{tabular}




\section{Deslocamentos experimentais Teste 4.}

\begin{tabular}{|c|c|c|c|c|c|c|}
\hline \multicolumn{7}{|c|}{ DESLOCAMENTOS EXPERIMENTAIS FEVEREIRO 17-2015 } \\
\hline \multirow{2}{*}{$\begin{array}{c}\text { Nó } \\
\text { experimental }\end{array}$} & \multicolumn{2}{|c|}{$\begin{array}{l}\text { Coordenadas } \\
\text { experimentais }\end{array}$} & \multirow{2}{*}{$\begin{array}{c}\text { UZ } 1 \text { modo Experimental } \\
\text { Fev 17-2015 } \\
\text { ( Acel centro laje) }\end{array}$} & \multirow{2}{*}{$\begin{array}{c}\text { UZ } 2 \text { modo Experimental } \\
\text { Fev 17-2015 } \\
\text { (Acel centro laje) }\end{array}$} & \multirow{2}{*}{$\begin{array}{c}\text { UZ } 3 \text { modo Experimental } \\
\text { Fev 17-2015 } \\
\text { ( Acel centro laje) }\end{array}$} & \multirow{2}{*}{$\begin{array}{c}\text { UZ } 4 \text { modo Experimenta } \\
\text { Fev 17-2015 } \\
\text { ( Acel centro laje) }\end{array}$} \\
\hline & $\mathrm{X}$ & Y & & & & \\
\hline 42 & 3,66 & 2,45 & 0,147547507 & $-0,142992929$ & 0,22006222 & $-0,235649045$ \\
\hline 43 & 4,27 & 2,45 & 0,120356474 & $-0,158262697$ & 0,071732914 & $-0,074592208$ \\
\hline 44 & 4,88 & 2,45 & 0,092870296 & $-0,181457788$ & $-0,033259296$ & $-0,007039178$ \\
\hline 45 & 5,49 & 2,45 & 0,052479731 & $-0,187016439$ & $-0,116328423$ & 0,036190083 \\
\hline 46 & 0,61 & 1,96 & 0,048576775 & $-0,153834454$ & $-0,150027729$ & 0,021193394 \\
\hline 47 & 1,22 & 1,96 & 0,089104156 & $-0,138826816$ & $-0,08573219$ & $-0,011041683$ \\
\hline 48 & 1,83 & 1,96 & 0,117246017 & $-0,109031683$ & 0,054012498 & $-0,007762241$ \\
\hline 49 & 2,44 & 1,96 & 0,142171588 & $-0,091511652$ & 0,161965353 & 0,069991317 \\
\hline 50 & 3,05 & 1,96 & 0,15204603 & $-0,08475454$ & 0,201847097 & 0,036904787 \\
\hline 51 & 3,66 & 1,96 & 0,139419901 & $-0,095498335$ & 0,156549391 & 0,058664567 \\
\hline 52 & 4,27 & 1,96 & 0,124734687 & $-0,138859979$ & 0,080687813 & 0,052498417 \\
\hline 53 & 4,88 & 1,96 & 0,093926045 & $-0,154578682$ & $-0,035505121$ & 0,020709842 \\
\hline 54 & 5,49 & 1,96 & 0,049842599 & $-0,144637047$ & $-0,137205266$ & $-0,031794325$ \\
\hline 55 & 0,61 & 1,47 & 0,046572944 & $-0,104845847$ & $-0,129047245$ & $-0,085758175$ \\
\hline 56 & 1,22 & 1,47 & 0,087294822 & $-0,064587615$ & $-0,082404011$ & 0,058225134 \\
\hline 57 & 1,83 & 1,47 & 0,115393535 & $-0,061028247$ & $-0,006315908$ & $-0,067861846$ \\
\hline 58 & 2,44 & 1,47 & 0,140915874 & $-0,018252168$ & 0,116297378 & $-0,056737968$ \\
\hline 59 & 3,05 & 1,47 & 0,152634671 & $-0,011611529$ & 0,166539088 & 0,054096526 \\
\hline 60 & 3,66 & 1,47 & 0,139015045 & $-0,038665185$ & 0,108504116 & 0,041363863 \\
\hline 61 & 4,27 & 1,47 & 0,12242586 & $-0,061223283$ & 0,030649468 & $-3,22972 \mathrm{E}-05$ \\
\hline 62 & 4,88 & 1,47 & 0,093264374 & $-0,096919731$ & $-0,053584375$ & $-0,003888574$ \\
\hline 63 & 5,49 & 1,47 & 0,047429534 & $-0,11236087$ & $-0,119435847$ & $-0,043084797$ \\
\hline 64 & 0,61 & 0,98 & 0,04391934 & $-0,052854804$ & $-0,132650426$ & 0,02667473 \\
\hline 65 & 1,22 & 0,98 & 0,08510672 & $-0,004767861$ & $-0,097993311$ & 0,019467563 \\
\hline 66 & 1,83 & 0,98 & 0,113422922 & 0,047551133 & $-0,038683371$ & 0,031489015 \\
\hline 67 & 2,44 & 0,98 & 0,139332464 & 0,087951841 & 0,036185007 & 0,00621685 \\
\hline 68 & 3,05 & 0,98 & 0,150540667 & 0,097466591 & 0,051710282 & 0,090173514 \\
\hline 69 & 3,66 & 0,98 & 0,137029019 & 0,073643998 & 0,025217674 & $-0,074895338$ \\
\hline 70 & 4,27 & 0,98 & 0,121569024 & 0,034904607 & $-0,038449861$ & 0,070101978 \\
\hline 71 & 4,88 & 0,98 & 0,089692228 & $-0,026238673$ & $-0,10475711$ & $-0,024855733$ \\
\hline 72 & 5,49 & 0,98 & 0,045437094 & $-0,046127412$ & $-0,122788777$ & $-0,137376482$ \\
\hline 73 & 0,61 & 0,49 & 0,041895181 & 0,005734614 & $-0,082624653$ & 0,016824287 \\
\hline 74 & 1,22 & 0,49 & 0,080773483 & 0,07366849 & $-0,100348922$ & $-0,025126815$ \\
\hline 75 & 1,83 & 0,49 & 0,111326397 & 0,129783297 & $-0,05265049$ & $-0,018144922$ \\
\hline 76 & 2,44 & 0,49 & 0,137618415 & 0,209028673 & $-0,045873953$ & $-0,008665101$ \\
\hline 77 & 3,05 & 0,49 & 0,147303654 & 0,217910817 & $-0,026247876$ & 0,007870829 \\
\hline 78 & 3,66 & 0,49 & 0,135642783 & 0,193734656 & $-0,043497544$ & $-0,042696684$ \\
\hline 79 & 4,27 & 0,49 & 0,119532113 & 0,13163941 & $-0,114663632$ & 0,007686141 \\
\hline 80 & 4,88 & 0,49 & 0,087302419 & 0,05261644 & $-0,142663379$ & 0,028698005 \\
\hline 81 & 5,49 & 0,49 & 0,041096374 & $-0,001797609$ & $-0,127495219$ & 0,015199055 \\
\hline
\end{tabular}


Deslocamentos numéricos Teste 4.

\begin{tabular}{|c|c|c|c|c|c|c|c|}
\hline \multicolumn{8}{|c|}{ DESLOCAMENTOS NUMÉRICOS FEVEREIRO 17-2015 } \\
\hline \multirow{2}{*}{$\begin{array}{c}\text { Nó } \\
\text { experimental }\end{array}$} & \multirow{2}{*}{$\begin{array}{c}\text { Nó } \\
\text { númerico }\end{array}$} & \multicolumn{2}{|c|}{$\begin{array}{c}\text { Coordenadas } \\
\text { numericas }\end{array}$} & \multirow{2}{*}{$\begin{array}{c}\begin{array}{c}\text { Desloc 1ro modo, } \\
\text { Númerico }\end{array} \\
\mathbf{U Z ~} \mathbf{f = 3 , 3 6 2 9 9} \mathbf{~ H z} \\
\end{array}$} & \multirow{2}{*}{ 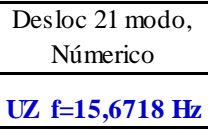 } & \multirow{2}{*}{\begin{tabular}{|c|}
$\begin{array}{c}\text { Des loc } 27 \text { modo, } \\
\text { Númerico }\end{array}$ \\
$\mathbf{U Z ~} \mathbf{f}=\mathbf{2 3 , 6 3 6 5} \mathbf{~ H z}$ \\
\end{tabular}} & \multirow{2}{*}{$\begin{array}{c}\begin{array}{c}\text { Desloc } 84 \text { modo, } \\
\text { Númerico }\end{array} \\
\mathbf{U Z ~} \mathbf{f = 9 0 , 4 5 8 9 ~ \mathbf { ~ H z }} \\
\end{array}$} \\
\hline & & $\mathrm{X}$ númerico & Y númerico & & & & \\
\hline 1 & 6056 & 0,60961 & 4,41803 & 0,004512400 & 0,000901950 & 0,004625100 & 0,003885900 \\
\hline 2 & 12131 & 1,21392 & 4,41803 & 0,008769700 & 0,006542400 & 0,001397300 & 0,009723300 \\
\hline 3 & 18206 & 1,81822 & 4,41803 & 0,012354000 & 0,011918000 & $-0,001799000$ & $-0,005855100$ \\
\hline 4 & 24524 & 2,44670 & 4,41803 & 0,015076000 & 0,016238000 & $-0,002344200$ & $-0,016250000$ \\
\hline 5 & 30599 & 3,05100 & 4,41803 & 0,016506000 & 0,018274000 & 0,001491600 & 0,000048560 \\
\hline 6 & 36674 & 3,65530 & 4,41803 & 0,015901000 & 0,016729000 & 0,010258000 & 0,016806000 \\
\hline 7 & 42749 & 4,25961 & 4,41803 & 0,013464000 & 0,012424000 & 0,019426000 & 0,005898900 \\
\hline 8 & 49067 & 4,88808 & 4,41803 & 0,009552800 & 0,006649100 & 0,021304000 & $-0,008746500$ \\
\hline 9 & 55142 & 5,49239 & 4,41803 & 0,004911000 & 0,000837110 & 0,014336000 & $-0,003805000$ \\
\hline 10 & 6031 & 0,60961 & 3,91598 & 0,004790800 & $-0,006278200$ & 0,009974300 & $-0,007567100$ \\
\hline 11 & 12106 & 1,21392 & 3,91598 & 0,008927500 & $-0,002037900$ & 0,003526600 & 0,011304000 \\
\hline 12 & 18181 & 1,81822 & 3,91598 & 0,012425000 & 0,002230900 & $-0,003260100$ & 0,008578600 \\
\hline 13 & 24499 & 2,44670 & 3,91598 & 0,015093000 & 0,005775100 & $-0,007565100$ & $-0,002051100$ \\
\hline 14 & 30574 & 3,05100 & 3,91598 & 0,016473000 & 0,007379000 & $-0,006708600$ & 0,000045910 \\
\hline 15 & 36649 & 3,65530 & 3,91598 & 0,016035000 & 0,006210900 & 0,000097225 & 0,001806300 \\
\hline 16 & 42724 & 4,25961 & 3,91598 & 0,013588000 & 0,002475300 & 0,009986600 & $-0,009668700$ \\
\hline 17 & 49042 & 4,88808 & 3,91598 & 0,009720800 & $-0,002169600$ & 0,014305000 & $-0,010695000$ \\
\hline 18 & 55117 & 5,49239 & 3,91598 & 0,005212700 & $-0,006586900$ & 0,011694000 & 0,005688900 \\
\hline 19 & 6007 & 0,60961 & 3,43402 & 0,005036500 & $-0,012188000$ & 0,014755000 & $-0,012957000$ \\
\hline 20 & 12082 & 1,21392 & 3,43402 & 0,009091800 & $-0,009142200$ & 0,005599900 & 0,010829000 \\
\hline 21 & 18157 & 1,81822 & 3,43402 & 0,012532000 & $-0,005770500$ & $-0,004408000$ & 0,014222000 \\
\hline 22 & 24475 & 2,44670 & 3,43402 & 0,015172000 & $-0,002842500$ & $-0,012233000$ & 0,004034400 \\
\hline 23 & 30550 & 3,05100 & 3,43402 & 0,016515000 & $-0,001533800$ & $-0,014096000$ & $-0,000467160$ \\
\hline 24 & 36625 & 3,65530 & 3,43402 & 0,016147000 & $-0,002562900$ & $-0,008838500$ & $-0,004937700$ \\
\hline 25 & 42700 & 4,25961 & 3,43402 & 0,013758000 & $-0,005830600$ & 0,001404300 & $-0,014664000$ \\
\hline 26 & 49018 & 4,88808 & 3,43402 & 0,009914500 & $-0,009532700$ & 0,008038600 & $-0,008422100$ \\
\hline 27 & 55093 & 5,49239 & 3,43402 & 0,005494200 & $-0,012762000$ & 0,009245700 & 0,011588000 \\
\hline 28 & 5982 & 0,60961 & 2,93197 & 0,005226000 & $-0,016550000$ & 0,018678000 & $-0,009576300$ \\
\hline 29 & 12057 & 1,21392 & 2,93197 & 0,009240200 & $-0,014446000$ & 0,007660300 & 0,008062200 \\
\hline 30 & 18132 & 1,81822 & 2,93197 & 0,012647000 & $-0,011623000$ & $-0,004891000$ & 0,008087400 \\
\hline 31 & 24450 & 2,44670 & 2,93197 & 0,015258000 & $-0,008977200$ & $-0,015568000$ & $-0,000569110$ \\
\hline 32 & 30525 & 3,05100 & 2,93197 & 0,016592000 & $-0,007861500$ & $-0,019856000$ & $-0,001190300$ \\
\hline 33 & 36600 & 3,65530 & 2,93197 & 0,016150000 & $-0,009022700$ & $-0,015512000$ & $-0,000834900$ \\
\hline 34 & 42675 & 4,25961 & 2,93197 & 0,013911000 & $-0,011996000$ & $-0,005729400$ & $-0,006055700$ \\
\hline 35 & 48993 & 4,88808 & 2,93197 & 0,010130000 & $-0,015213000$ & 0,002723200 & $-0,002980600$ \\
\hline 36 & 55068 & 5,49239 & 2,93197 & 0,005743200 & $-0,017485000$ & 0,006897300 & 0,010588000 \\
\hline 37 & 5958 & 0,60961 & 2,45000 & 0,005291600 & $-0,017913000$ & 0,020663000 & 0,001004200 \\
\hline 38 & 12033 & 1,21392 & 2,45000 & 0,009288700 & $-0,015908000$ & 0,009228800 & 0,004829700 \\
\hline 39 & 18108 & 1,81822 & 2,45000 & 0,012693000 & $-0,013330000$ & $-0,004241100$ & $-0,004397300$ \\
\hline 40 & 24426 & 2,44670 & 2,45000 & 0,015302000 & $-0,010943000$ & $-0,016344000$ & $-0,010094000$ \\
\hline 41 & 30501 & 3,05100 & 2,45000 & 0,016721000 & $-0,009945000$ & $-0,022605000$ & $-0,001068100$ \\
\hline
\end{tabular}


Deslocamentos numéricos Teste 4.

\begin{tabular}{|c|c|c|c|c|c|c|c|}
\hline \multicolumn{8}{|c|}{ DESLOCAMENTOS NUMÉRICOS FEVEREIRO 17-2015 } \\
\hline \multirow{2}{*}{$\begin{array}{c}\text { Nó } \\
\text { experimental }\end{array}$} & \multirow{2}{*}{$\begin{array}{c}\text { Nó } \\
\text { númerico }\end{array}$} & \multicolumn{2}{|c|}{$\begin{array}{c}\text { Coordenadas } \\
\text { numericas }\end{array}$} & \multirow{2}{*}{$\begin{array}{c}\begin{array}{c}\text { Desloc 1ro modo, } \\
\text { Númerico }\end{array} \\
\mathbf{U Z ~} \mathbf{f}=\mathbf{3 , 3 6 2 9 9} \mathbf{H z}\end{array}$} & \multirow{2}{*}{\begin{tabular}{|c|}
$\begin{array}{c}\text { Desloc } 21 \text { modo, } \\
\text { Númerico }\end{array}$ \\
$\mathbf{U Z ~} \mathbf{f}=\mathbf{1 5 , 6 7 1 8 ~} \mathbf{H z}$
\end{tabular}} & \multirow{2}{*}{\begin{tabular}{|c|}
$\begin{array}{c}\text { Desloc } 27 \text { modo, } \\
\text { Númerico }\end{array}$ \\
$\mathbf{U Z} \mathbf{f}=\mathbf{2 3 , 6 3 6 5} \mathbf{~ H z}$ \\
\end{tabular}} & \multirow{2}{*}{\begin{tabular}{|c|}
$\begin{array}{c}\text { Desloc } 84 \text { modo, } \\
\text { Númerico }\end{array}$ \\
$\mathbf{U Z ~ f} \mathbf{f}=\mathbf{9 0 , 4 5 8 9} \mathbf{H}$ \\
\end{tabular}} \\
\hline & & $\mathrm{X}$ númerico & Y númerico & & & & \\
\hline 42 & 36576 & 3,65530 & 2,45000 & 0,016116000 & $-0,011239000$ & $-0,018099000$ & 0,008650400 \\
\hline 43 & 42651 & 4,25961 & 2,45000 & 0,014019000 & $-0,014122000$ & $-0,008961700$ & 0,006413200 \\
\hline 44 & 48969 & 4,88808 & 2,45000 & 0,010305000 & $-0,016998000$ & 0,000270190 & $-0,000397280$ \\
\hline 45 & 55044 & 5,49239 & 2,45000 & 0,005878100 & $-0,018819000$ & 0,005679900 & 0,000668940 \\
\hline 46 & 5934 & 0,60961 & 1,96803 & 0,005229100 & $-0,016229000$ & 0,020509000 & 0,012939000 \\
\hline 47 & 12009 & 1,21392 & 1,96803 & 0,009255700 & $-0,013978000$ & 0,010283000 & 0,003333200 \\
\hline 48 & 18084 & 1,81822 & 1,96803 & 0,012685000 & $-0,011268000$ & $-0,002503300$ & $-0,013413000$ \\
\hline 49 & 24402 & 2,44670 & 1,96803 & 0,015316000 & $-0,008844700$ & $-0,014574000$ & $-0,015834000$ \\
\hline 50 & 30477 & 3,05100 & 1,96803 & 0,016794000 & $-0,007791400$ & $-0,021501000$ & 0,000529470 \\
\hline 51 & 36552 & 3,65530 & 1,96803 & 0,016108000 & $-0,009045200$ & $-0,016682000$ & 0,014800000 \\
\hline 52 & 42627 & 4,25961 & 1,96803 & 0,014096000 & $-0,011587000$ & $-0,007526500$ & 0,012196000 \\
\hline 53 & 48945 & 4,88808 & 1,96803 & 0,010439000 & $-0,014482000$ & 0,001227400 & $-0,002691200$ \\
\hline 54 & 55020 & 5,49239 & 1,96803 & 0,005904000 & $-0,016840000$ & 0,005797100 & $-0,011999000$ \\
\hline 55 & 5909 & 0,60961 & 1,46598 & 0,005070000 & $-0,012096000$ & 0,018493000 & 0,018171000 \\
\hline 56 & 11984 & 1,21392 & 1,46598 & 0,009164800 & $-0,009054600$ & 0,010849000 & 0,002286100 \\
\hline 57 & 18059 & 1,81822 & 1,46598 & 0,012646000 & $-0,005736400$ & 0,000177210 & $-0,013228000$ \\
\hline 58 & 24377 & 2,44670 & 1,46598 & 0,015315000 & $-0,002872800$ & $-0,010445000$ & $-0,011513000$ \\
\hline 59 & 30452 & 3,05100 & 1,46598 & 0,016734000 & $-0,001604000$ & $-0,016181000$ & 0,003145500 \\
\hline 60 & 36527 & 3,65530 & 1,46598 & 0,016103000 & $-0,002849900$ & $-0,011507000$ & 0,011285000 \\
\hline 61 & 42602 & 4,25961 & 1,46598 & 0,014211000 & $-0,005598200$ & $-0,002644000$ & 0,008445400 \\
\hline 62 & 48920 & 4,88808 & 1,46598 & 0,010629000 & $-0,009120500$ & 0,004766000 & $-0,004219700$ \\
\hline 63 & 54995 & 5,49239 & 1,46598 & 0,005842500 & $-0,012389000$ & 0,006780400 & $-0,016863000$ \\
\hline 64 & 5885 & 0,60961 & 0,98402 & 0,004847500 & $-0,006345100$ & 0,015028000 & 0,011551000 \\
\hline 65 & 11960 & 1,21392 & 0,98402 & 0,009045900 & $-0,002205600$ & 0,010861000 & $-0,001506500$ \\
\hline 66 & 18035 & 1,81822 & 0,98402 & 0,012604000 & 0,001998400 & 0,003174100 & $-0,005725600$ \\
\hline 67 & 24353 & 2,44670 & 0,98402 & 0,015322000 & 0,005524300 & $-0,005104300$ & 0,001080000 \\
\hline 68 & 30428 & 3,05100 & 0,98402 & 0,016760000 & 0,007198400 & $-0,009353600$ & 0,005795100 \\
\hline 69 & 36503 & 3,65530 & 0,98402 & 0,016132000 & 0,005717300 & $-0,004341100$ & $-0,000628680$ \\
\hline 70 & 42578 & 4,25961 & 0,98402 & 0,014380000 & 0,002544100 & 0,004237600 & $-0,001589600$ \\
\hline 71 & 48896 & 4,88808 & 0,98402 & 0,010840000 & $-0,001870600$ & 0,009962500 & 0,000130040 \\
\hline 72 & 54971 & 5,49239 & 0,98402 & 0,005699000 & $-0,006361800$ & 0,008197600 & $-0,007735500$ \\
\hline 73 & 5860 & 0,60961 & 0,48197 & 0,004590500 & 0,000696420 & 0,010655000 & $-0,004943200$ \\
\hline 74 & 11935 & 1,21392 & 0,48197 & 0,008929800 & 0,006154400 & 0,010511000 & $-0,009484400$ \\
\hline 75 & 18010 & 1,81822 & 0,48197 & 0,012593000 & 0,011437000 & 0,006279100 & 0,003478300 \\
\hline 76 & 24328 & 2,44670 & 0,48197 & 0,015390000 & 0,015781000 & 0,000758940 & 0,016311000 \\
\hline 77 & 30403 & 3,05100 & 0,48197 & 0,016866000 & 0,017895000 & $-0,001670200$ & 0,007098900 \\
\hline 78 & 36478 & 3,65530 & 0,48197 & 0,016224000 & 0,016104000 & 0,003970100 & $-0,016840000$ \\
\hline 79 & 42553 & 4,25961 & 0,48197 & 0,014590000 & 0,012396000 & 0,012293000 & $-0,013664000$ \\
\hline 80 & 48871 & 4,88808 & 0,48197 & 0,011007000 & 0,006871900 & 0,015905000 & 0,012089000 \\
\hline 81 & 54946 & 5,49239 & 0,48197 & 0,005506500 & 0,000917330 & 0,009923100 & 0,013403000 \\
\hline
\end{tabular}


Anexo VII

Análise no domínio do tempo (simulando força harmônica)
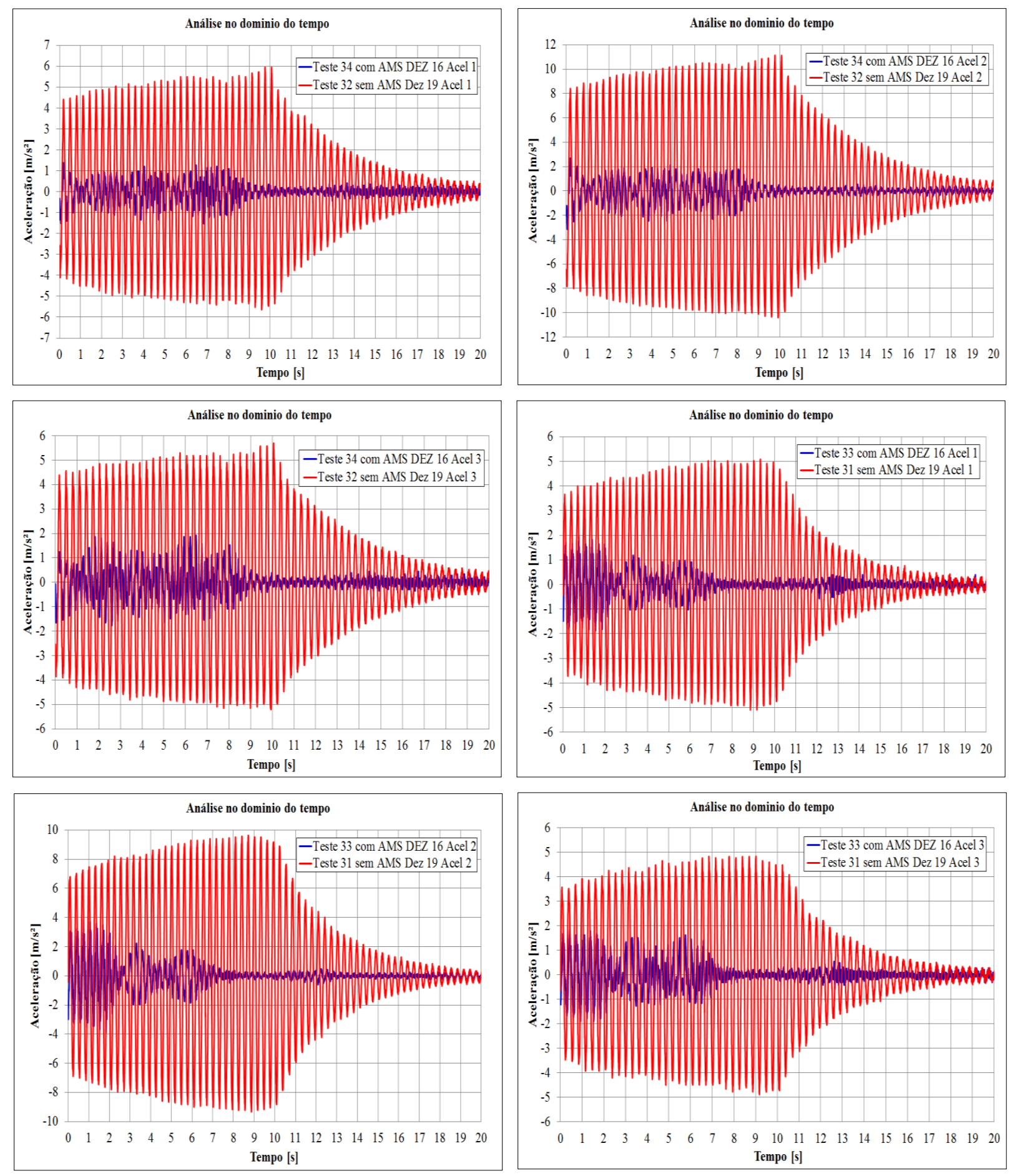

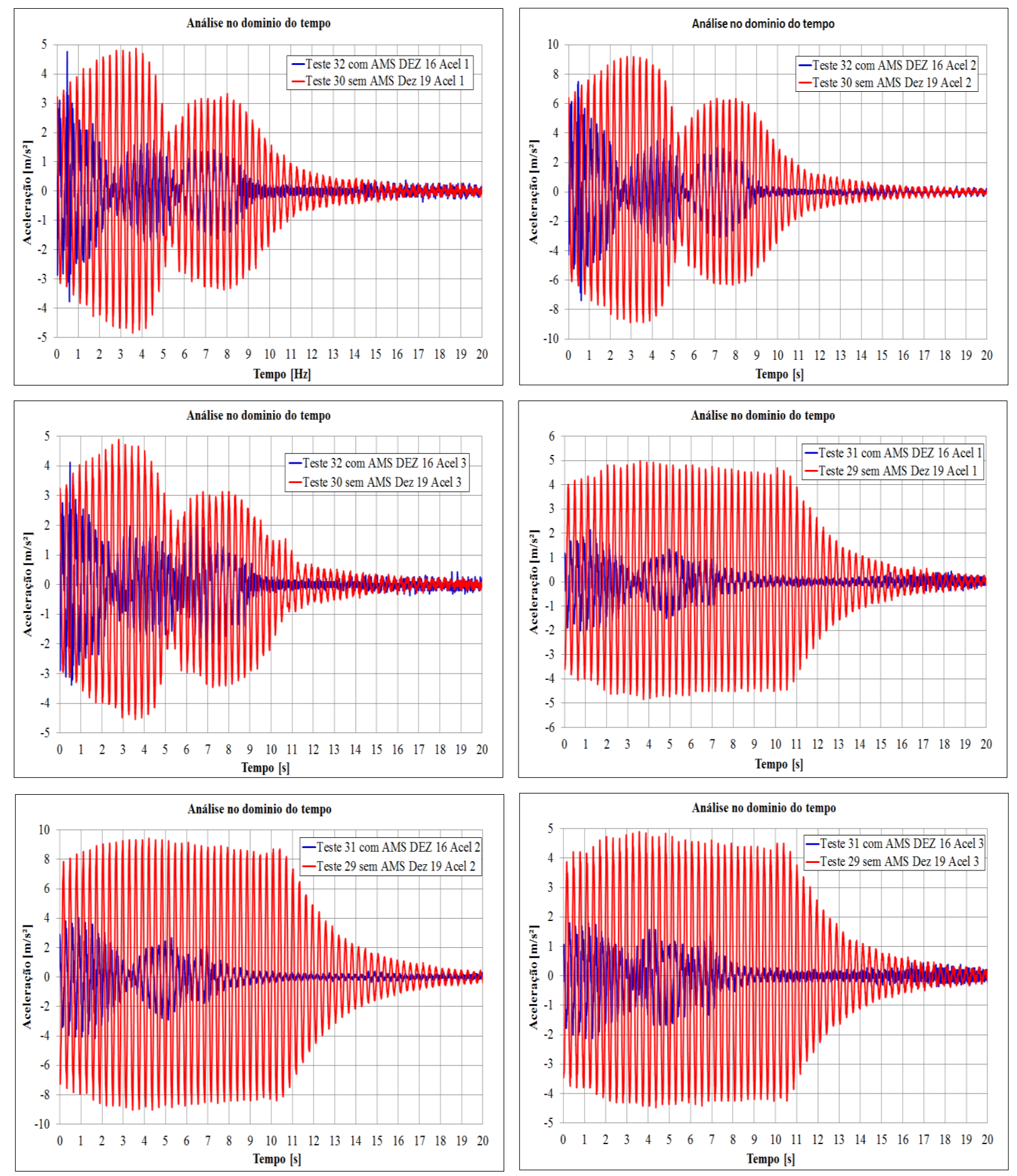


\section{Análise no domínio da frequência (simulando força harmônica)}
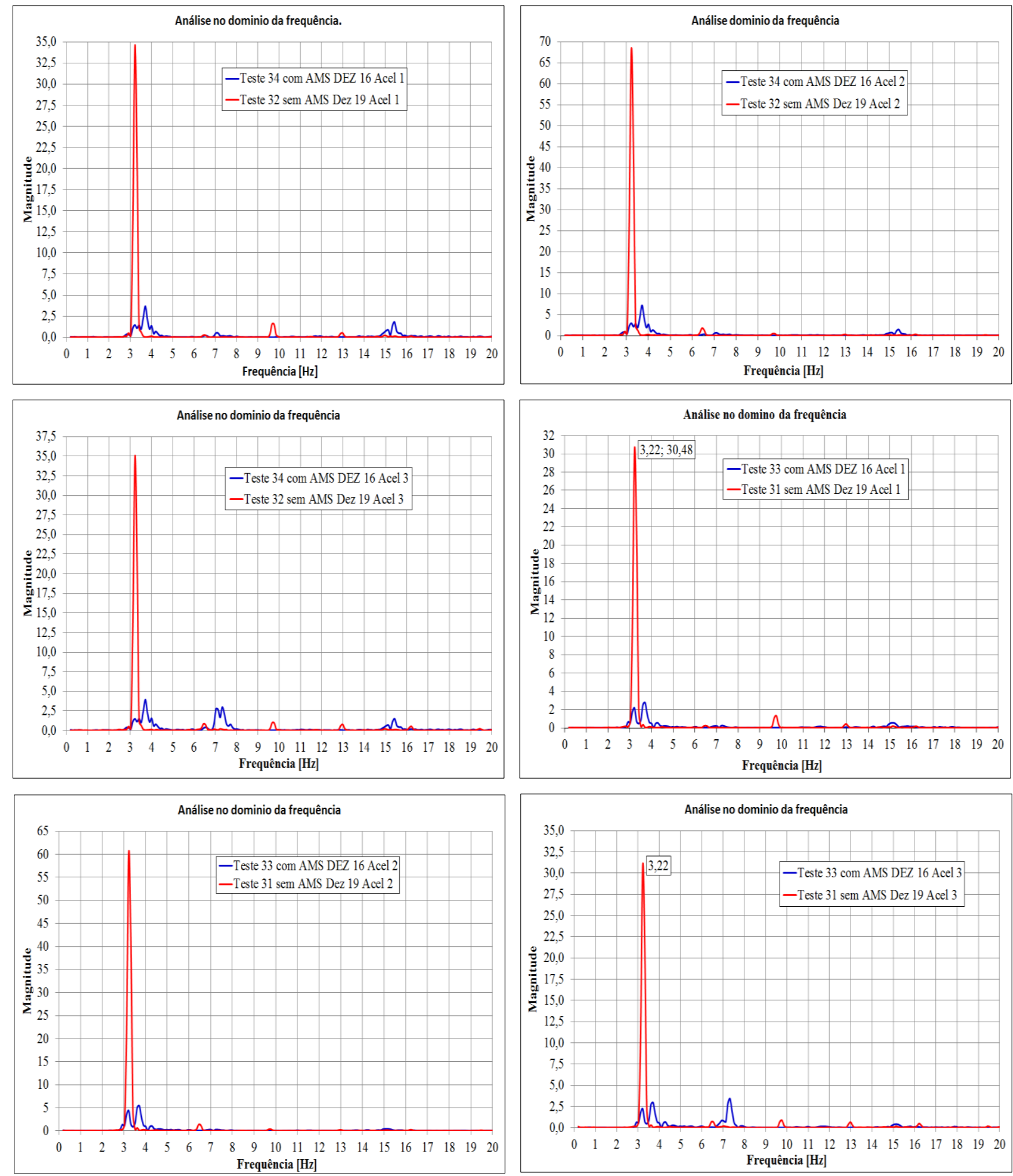

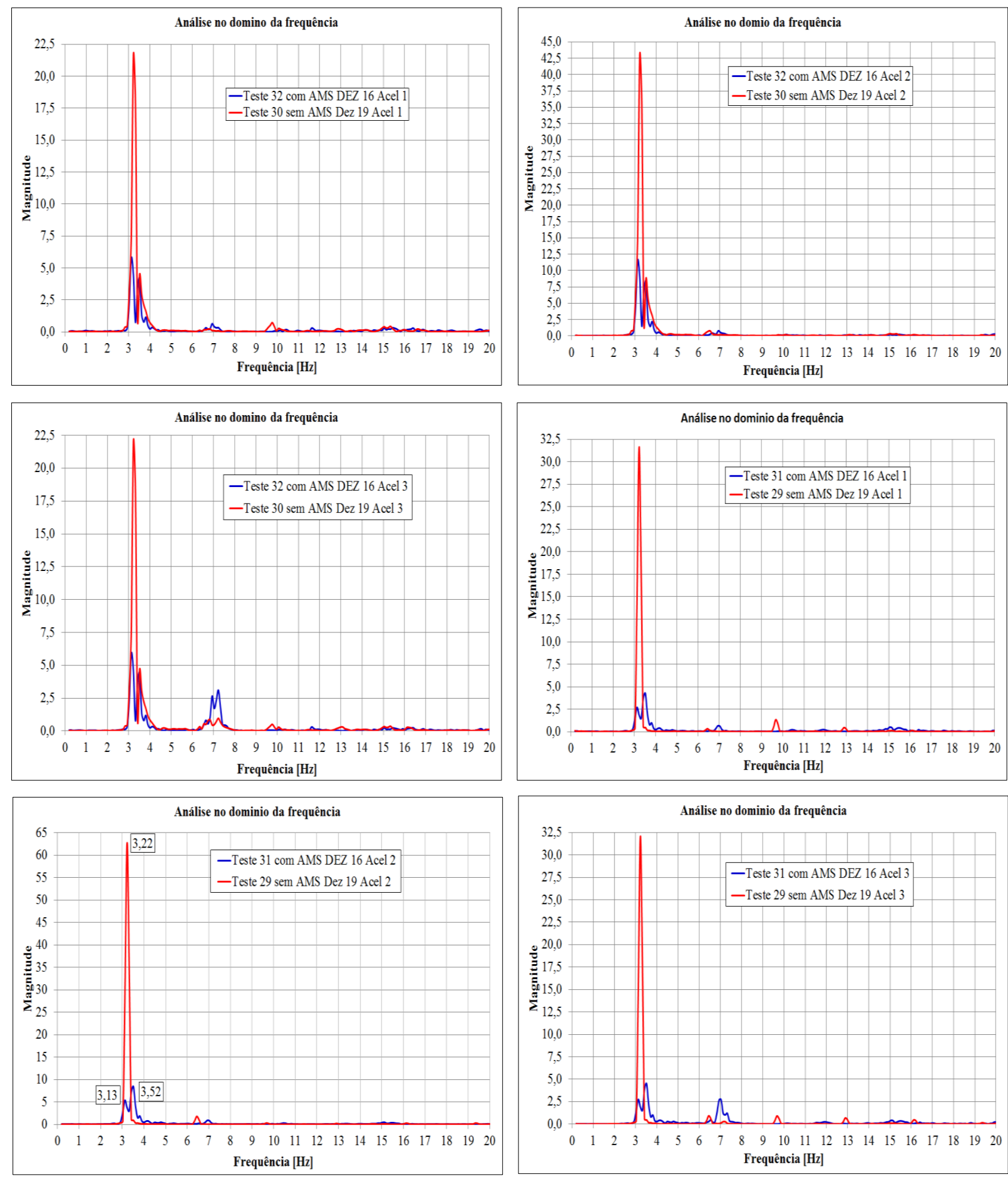


\section{Anexo VIII}

\section{Análise no domínio do tempo ( Uma pessoa pulando continuamente 10 Segundos)}
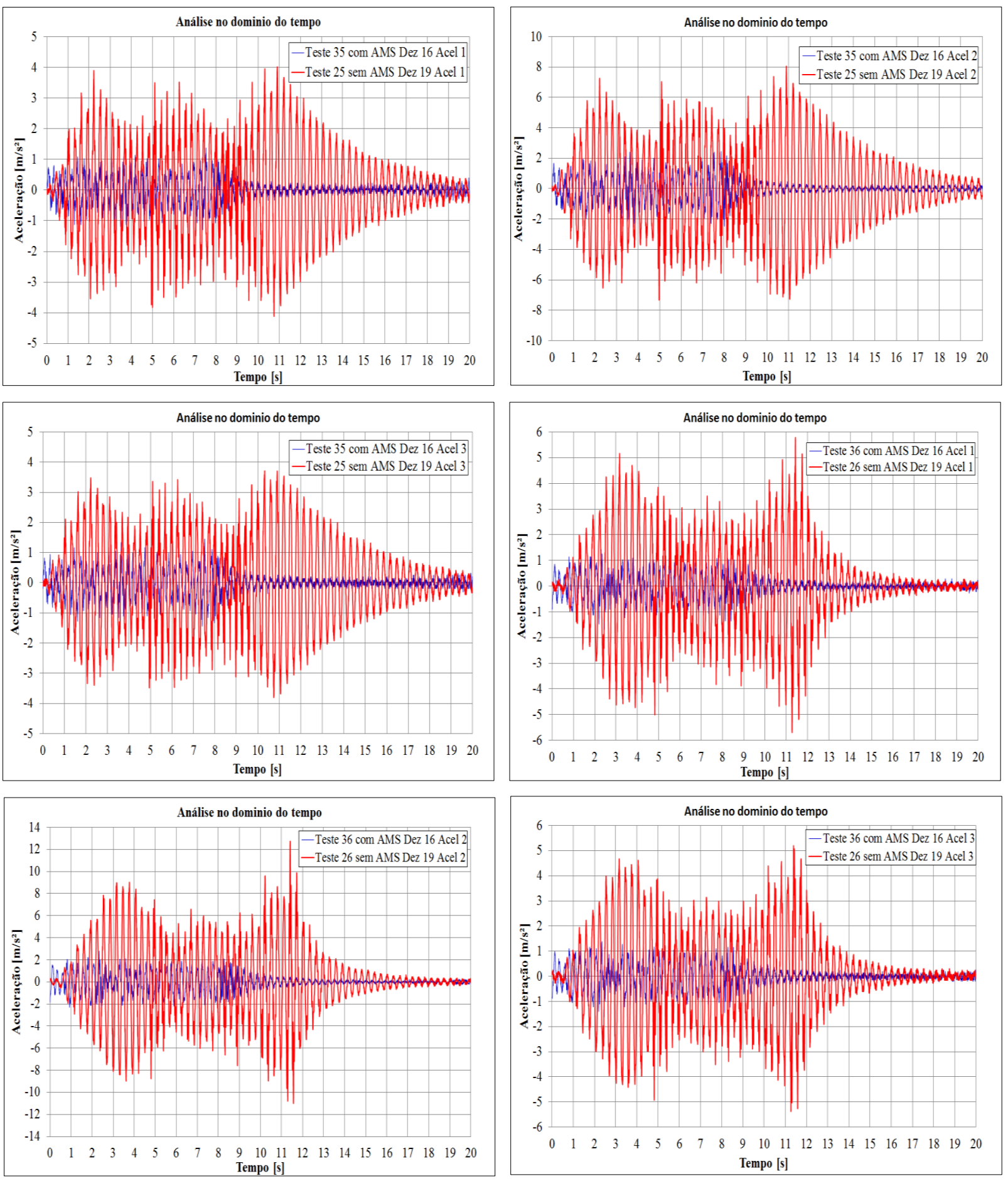

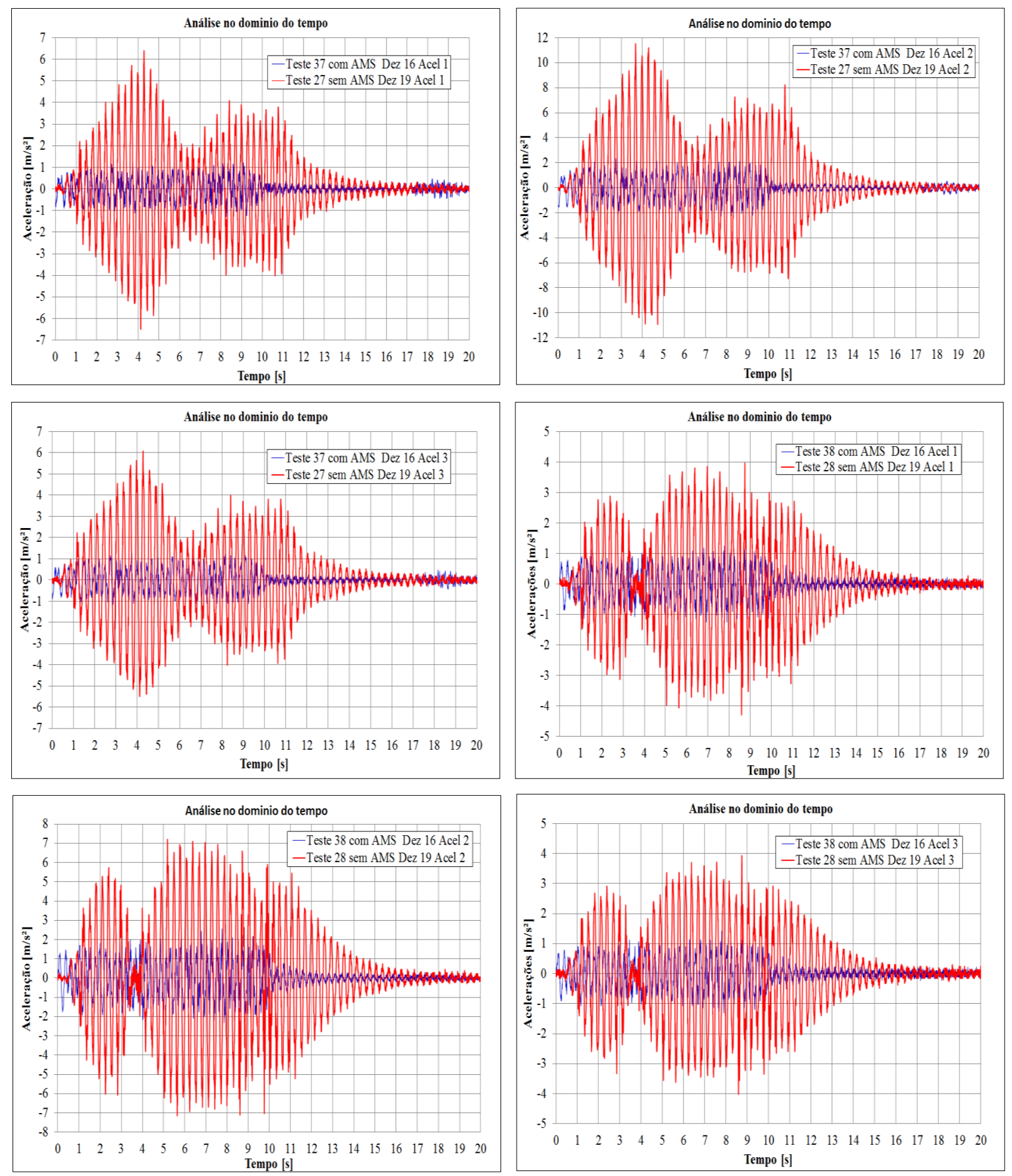


\section{Análise no domínio da frequência (Uma pessoa pulando continuamente 10 Segundos)}
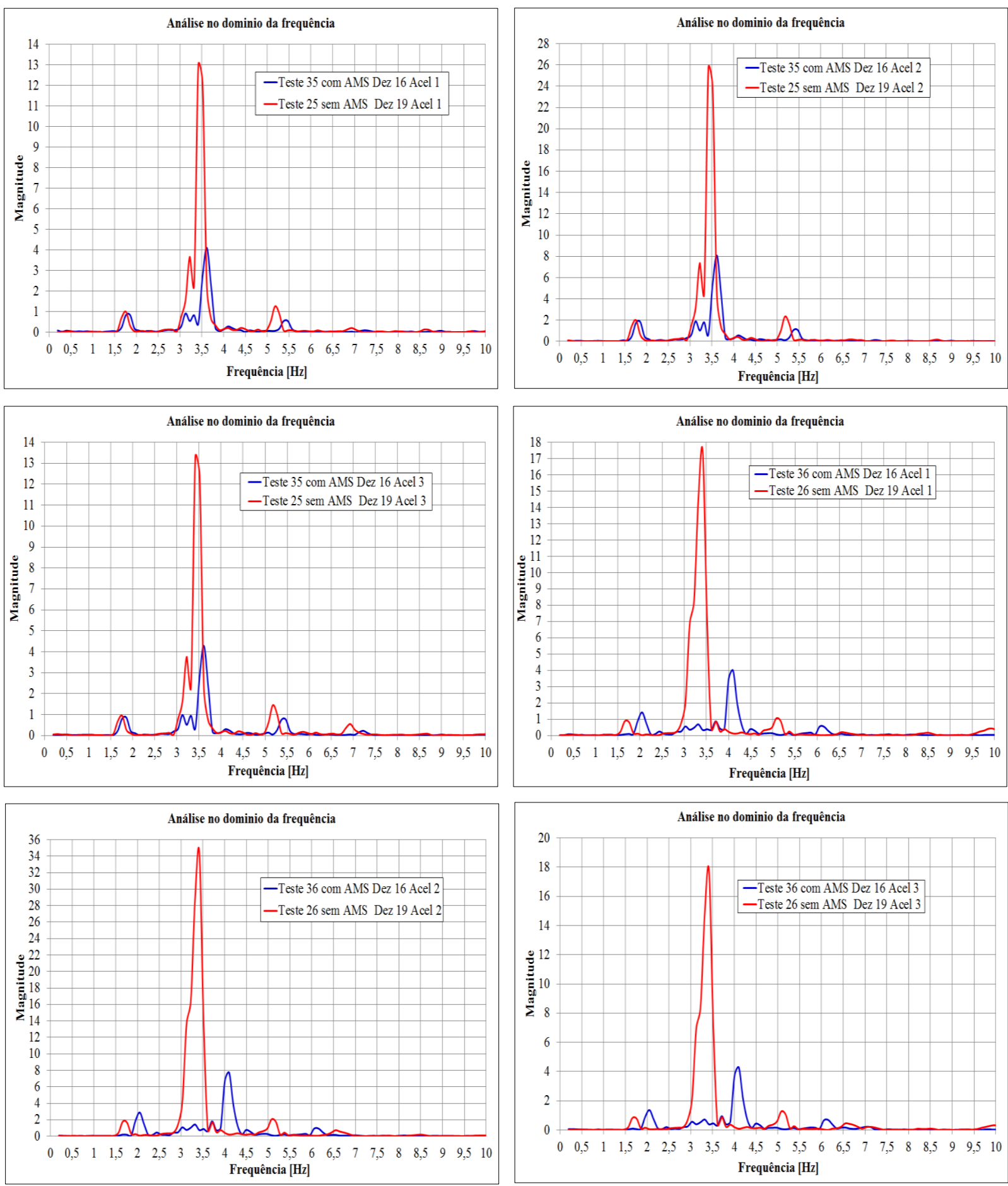

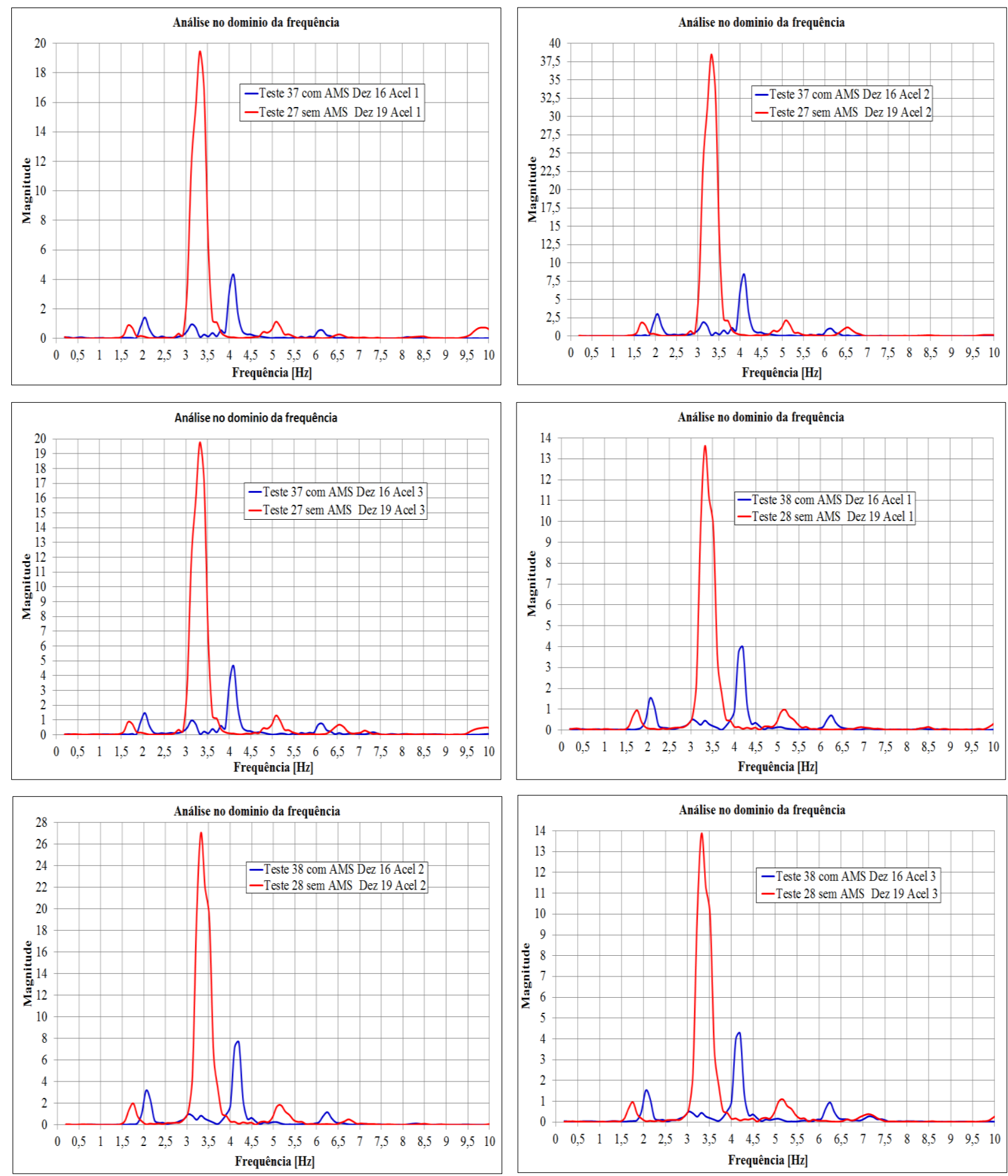


\section{Análise no domínio do tempo (Três pessoas pulando continuamente 10 Segundos)}
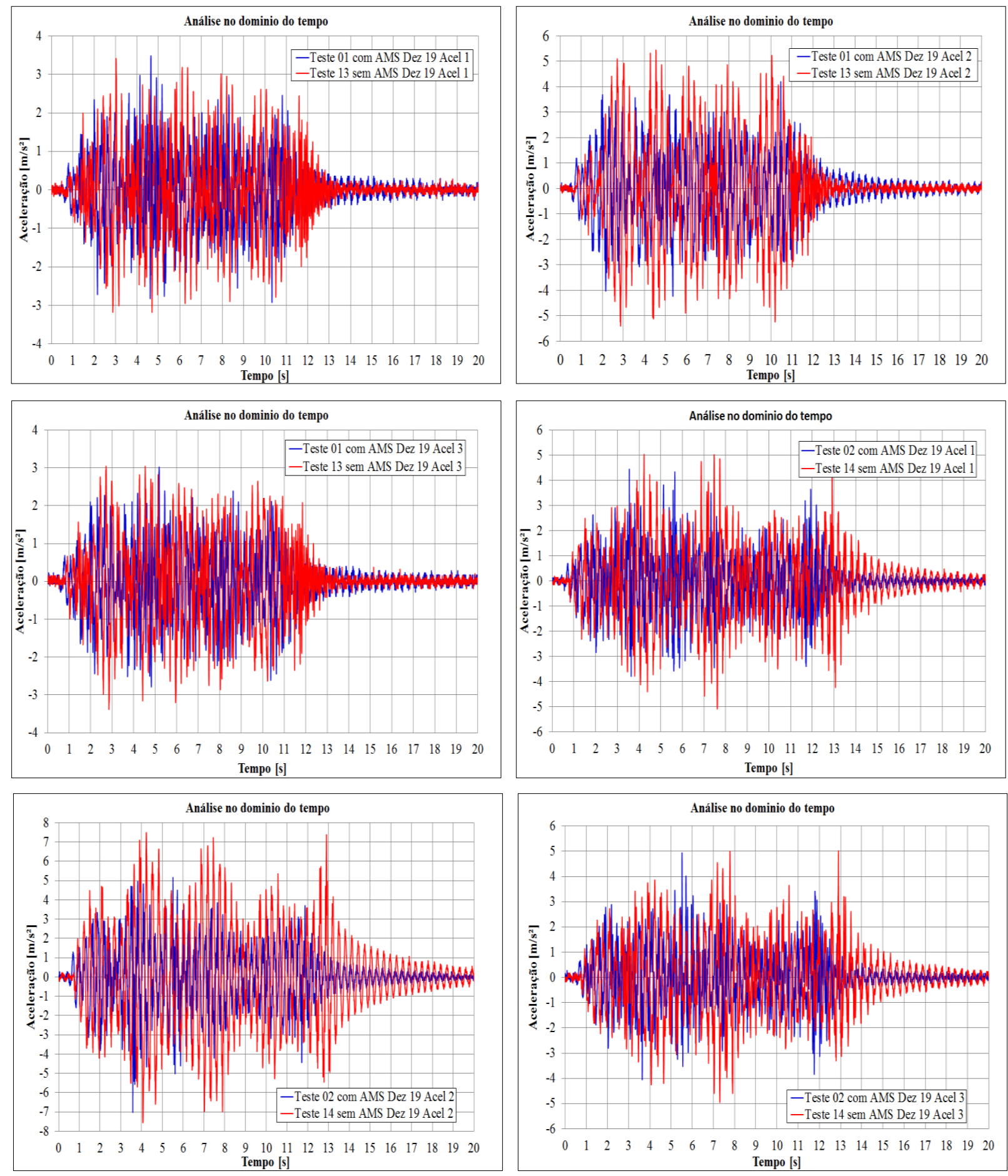

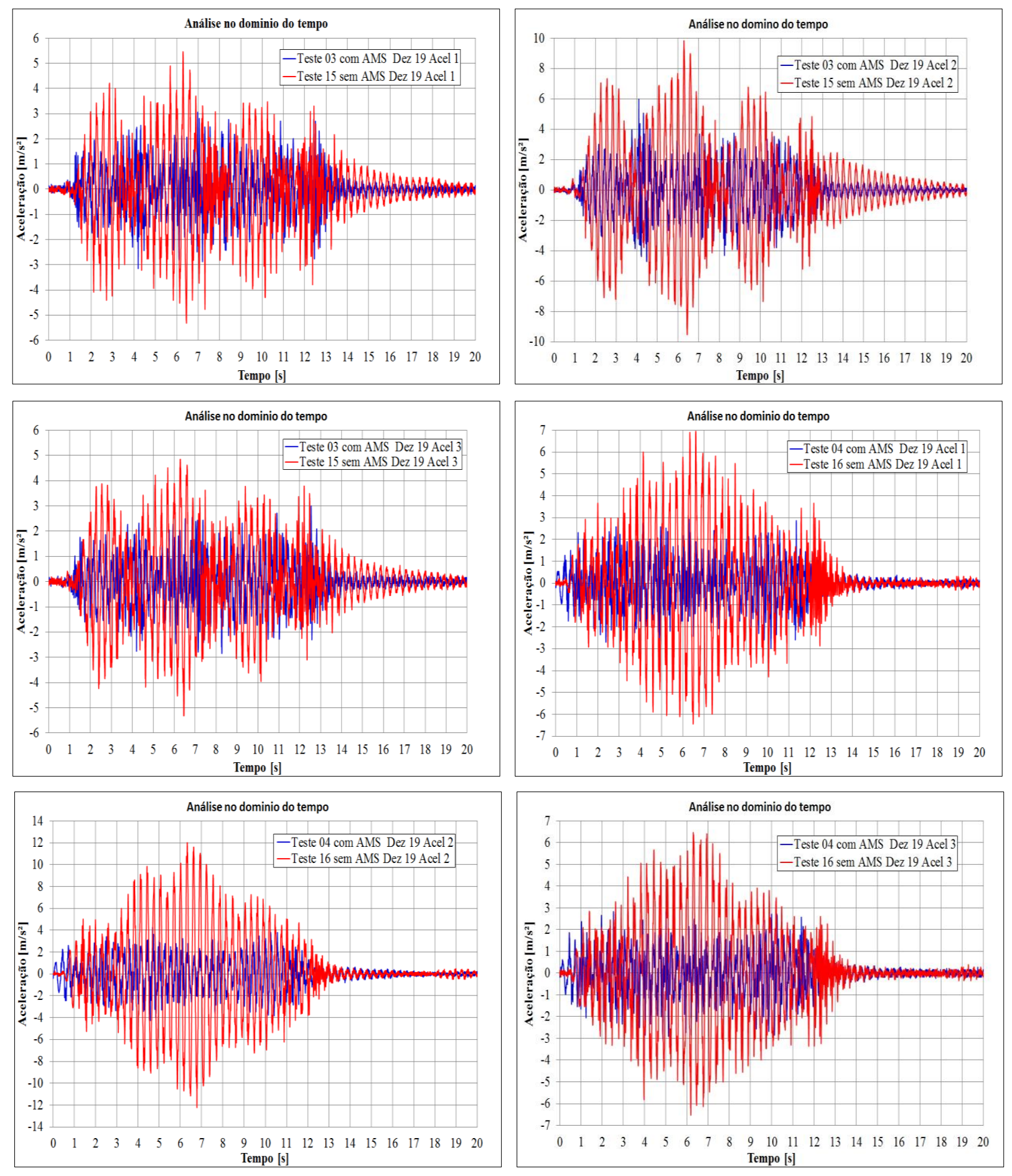


\section{Análise no domínio da frequência (Três pessoas pulando continuamente 10 Segundos)}
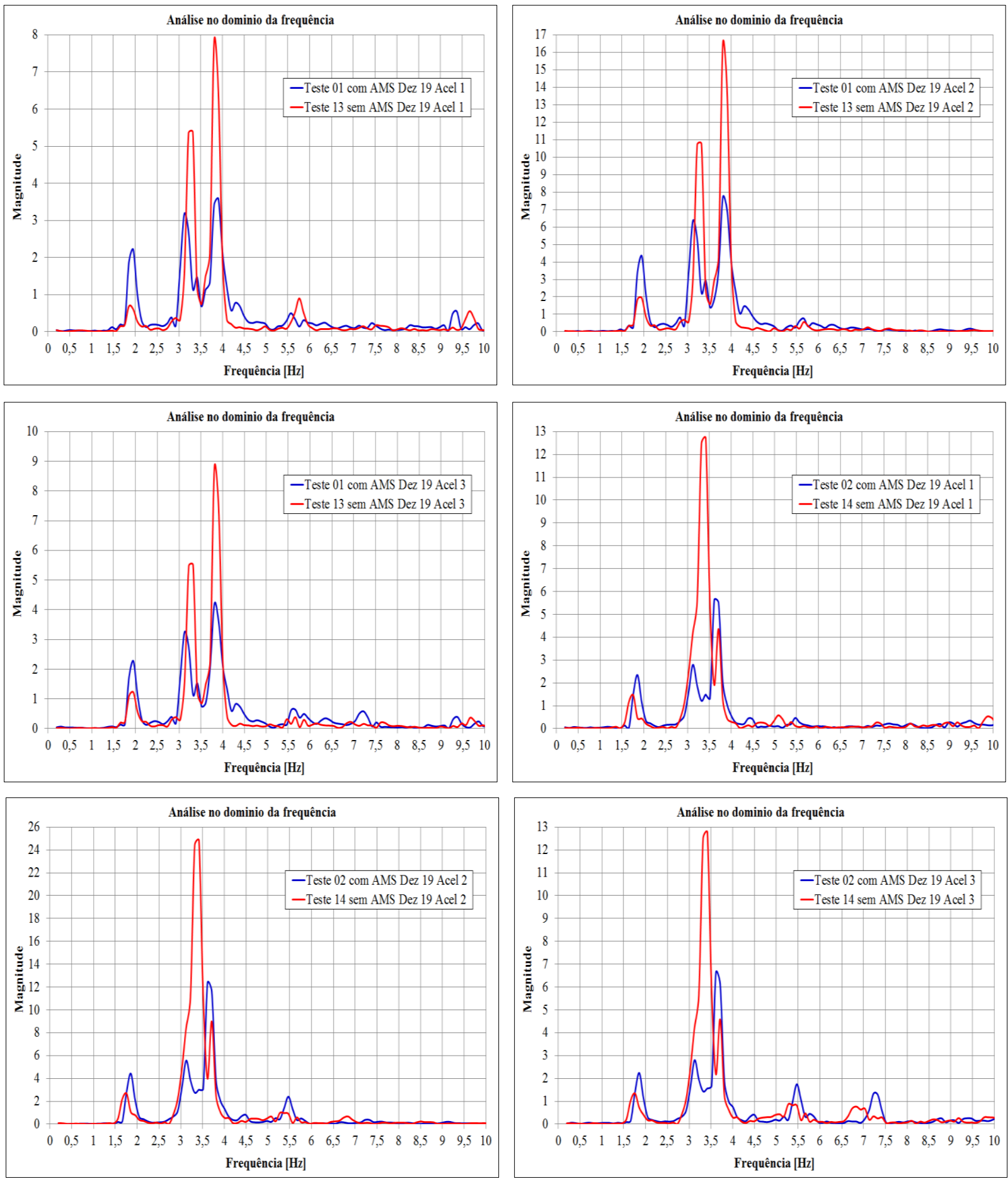

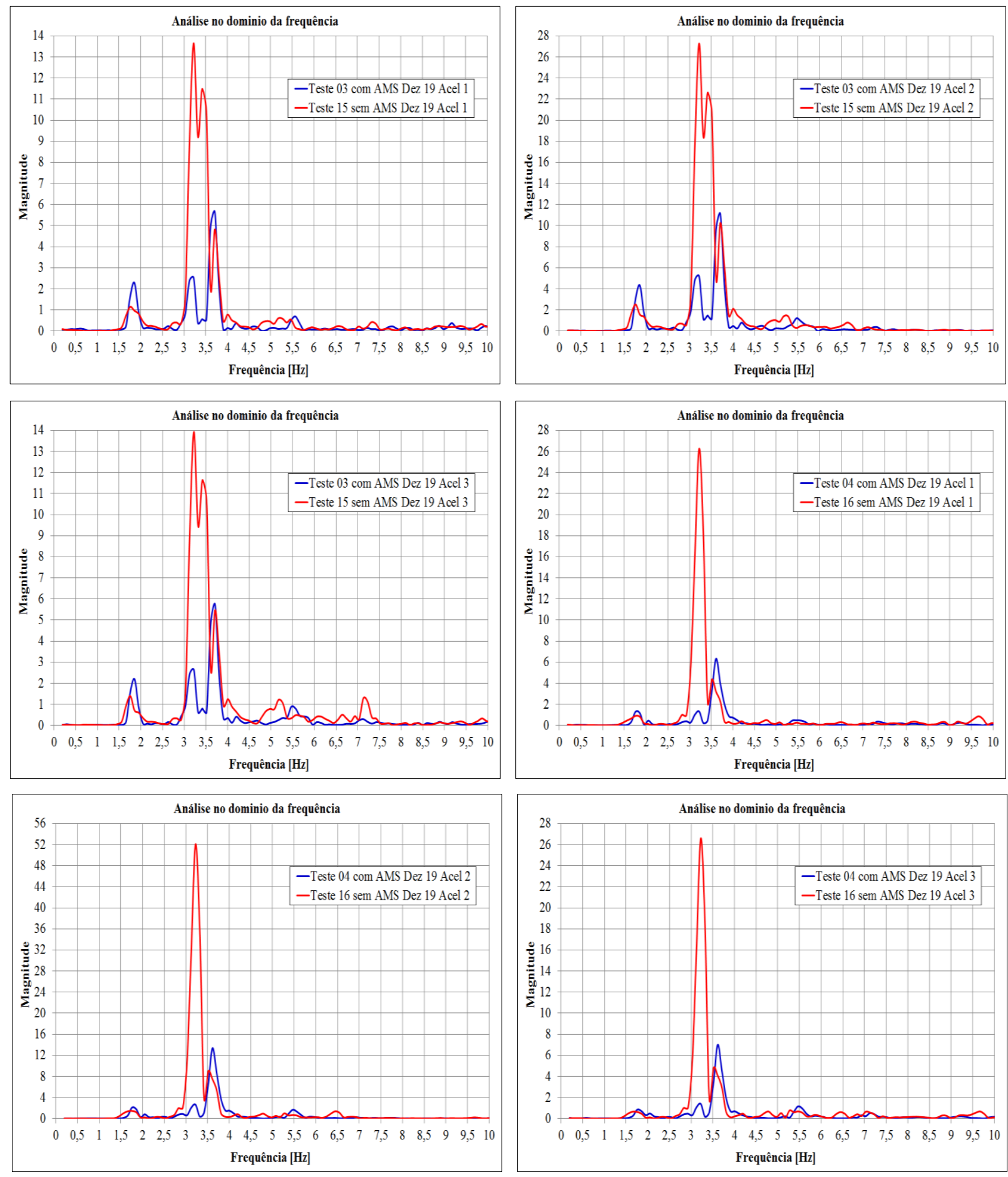


\section{Anexo IX}

\section{Análise no domínio do tempo (Grupo de pessoas caminhando 20 Segundos)}
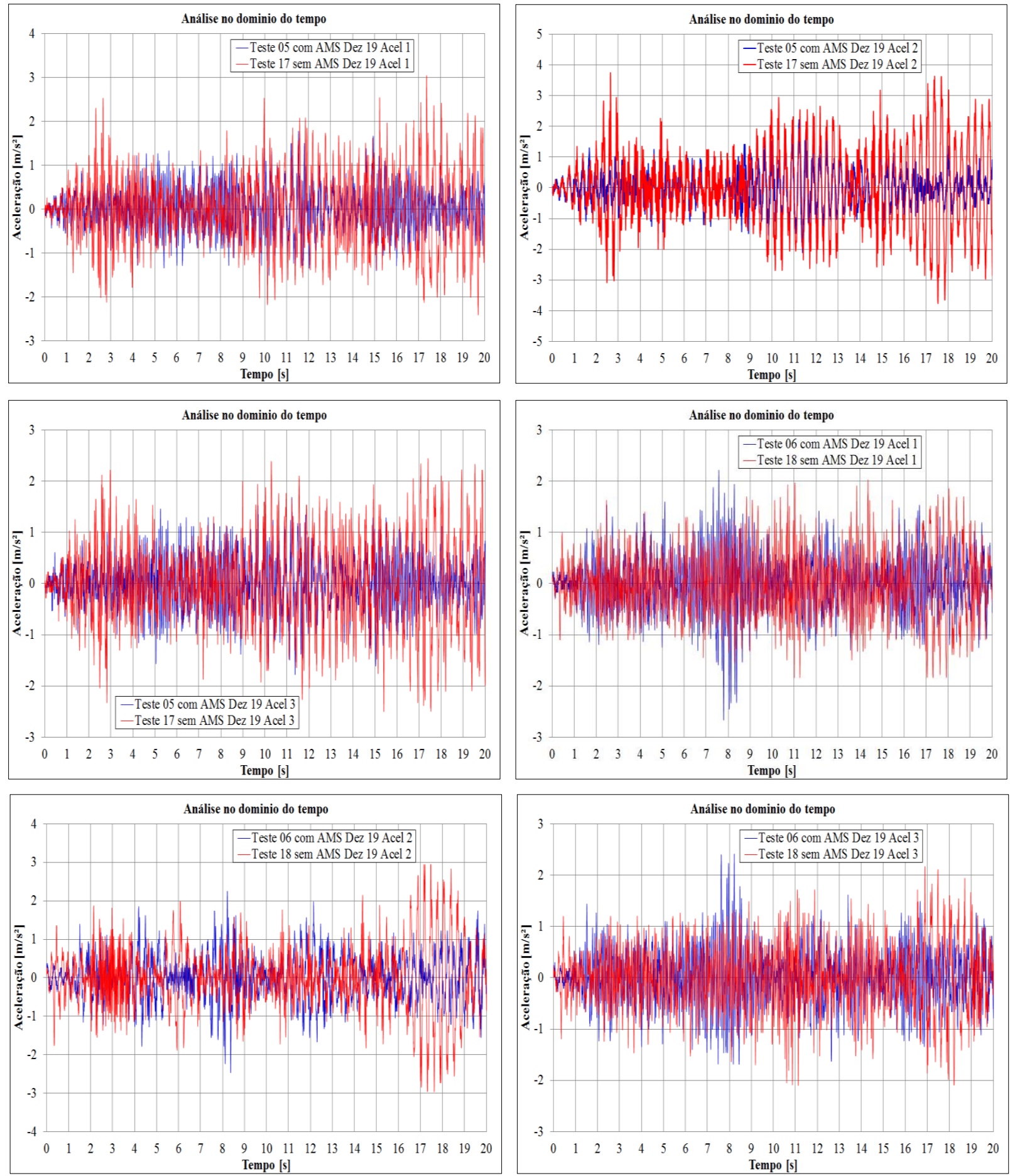

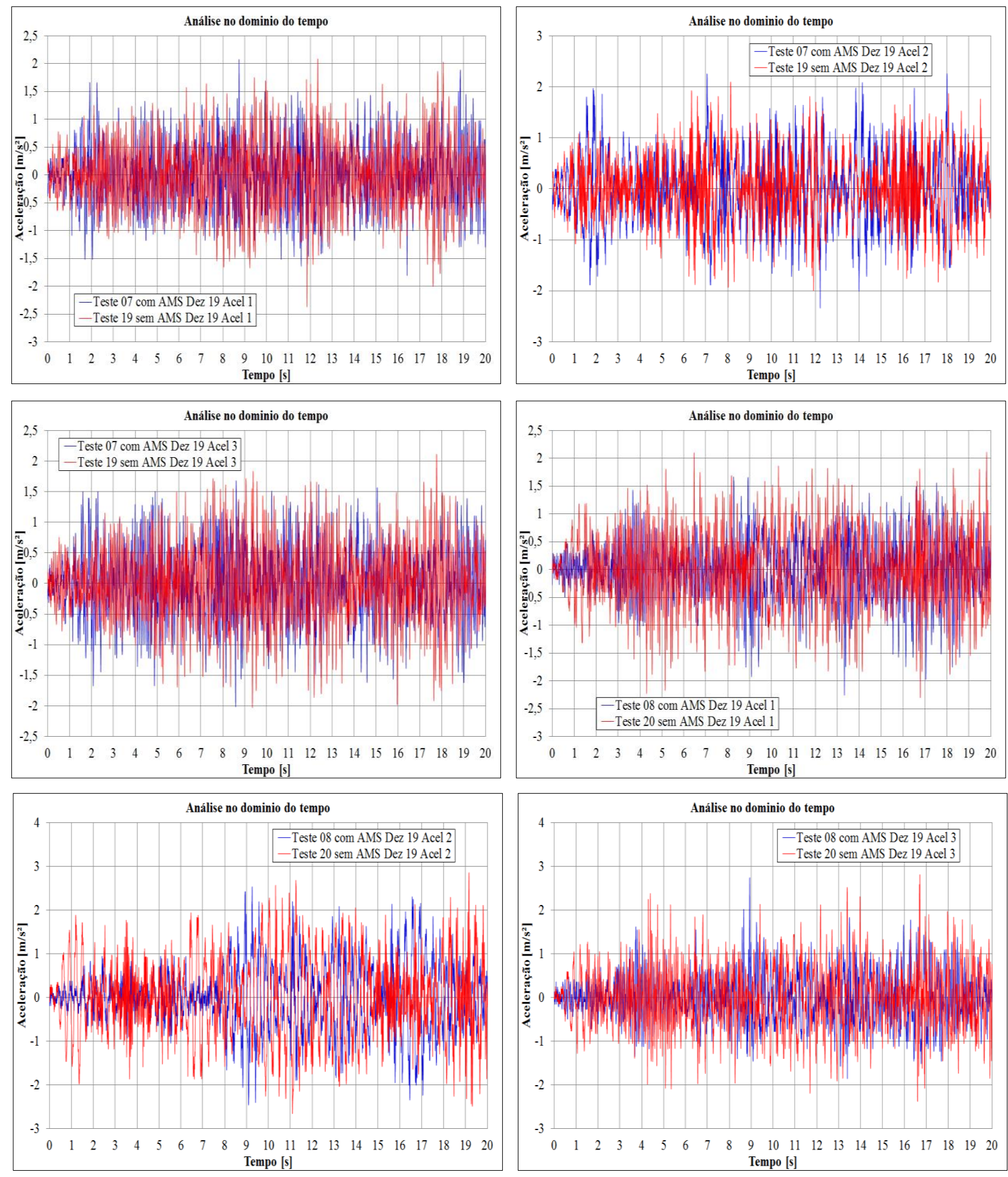


\section{Análise no domínio da frequência (Grupo de pessoas caminhando 20 Segundos)}
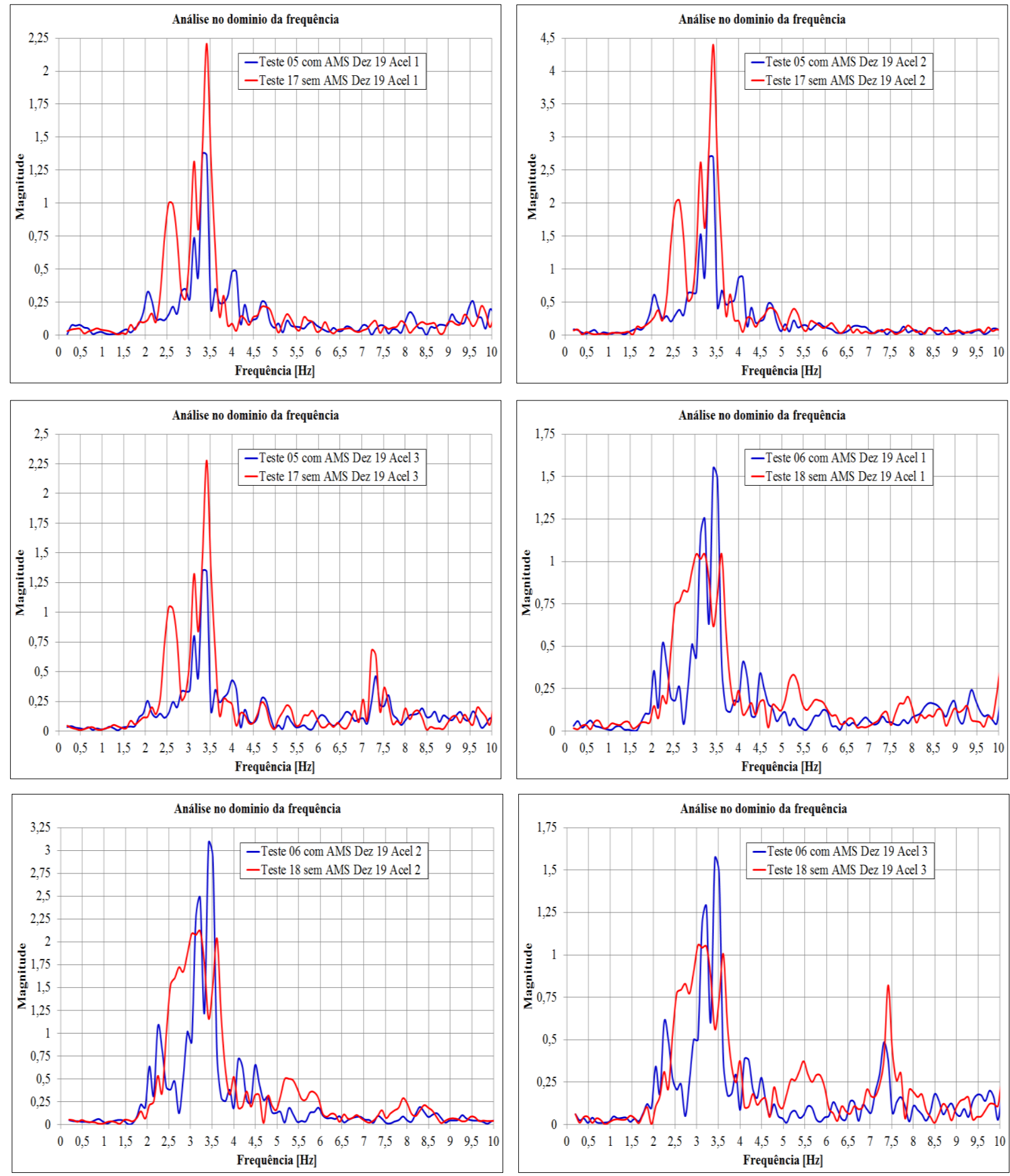

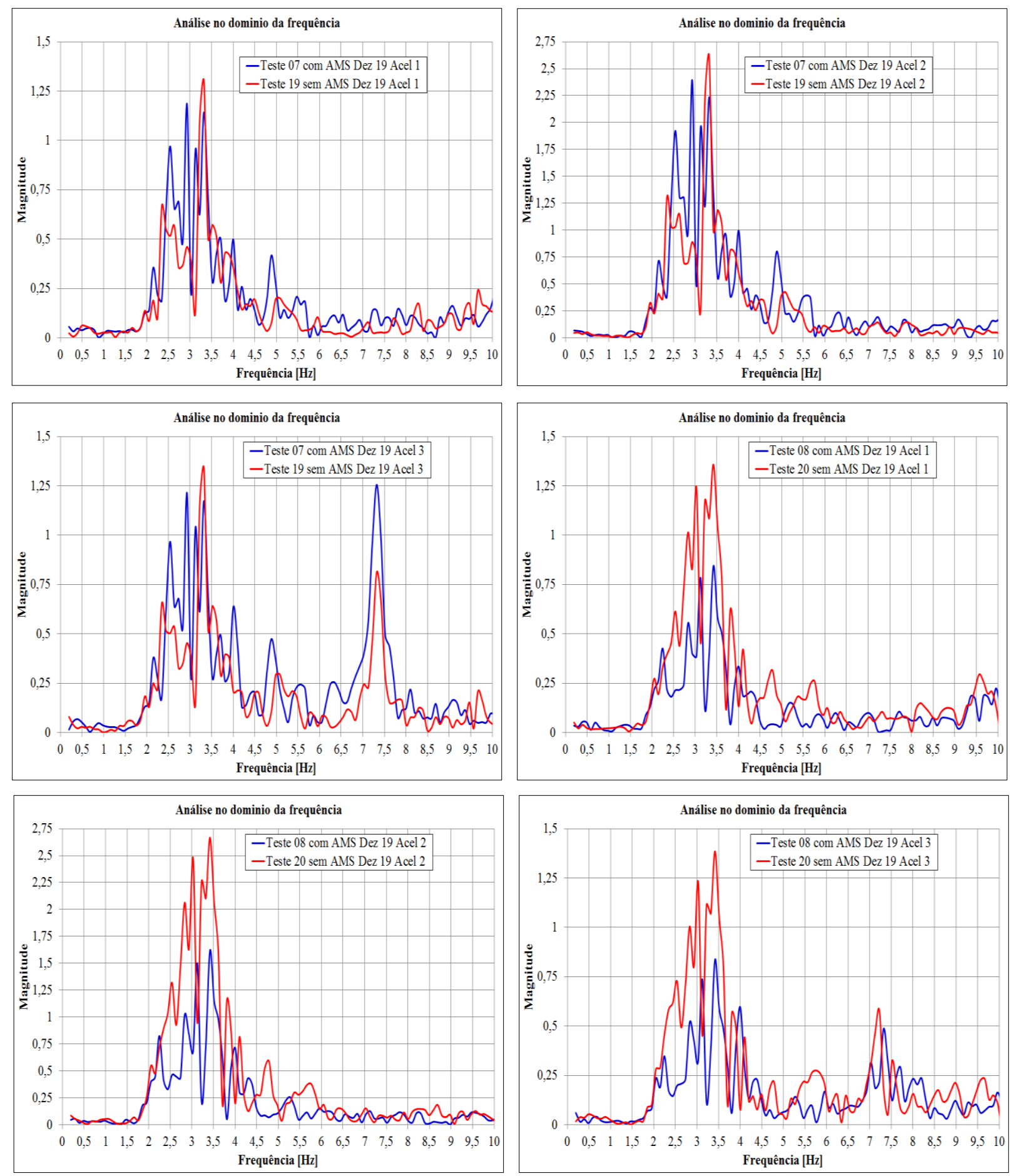


\section{Anexo X}

\section{Análise no domínio do tempo (Uma pessoa pulando desde uma carteira escolar)}
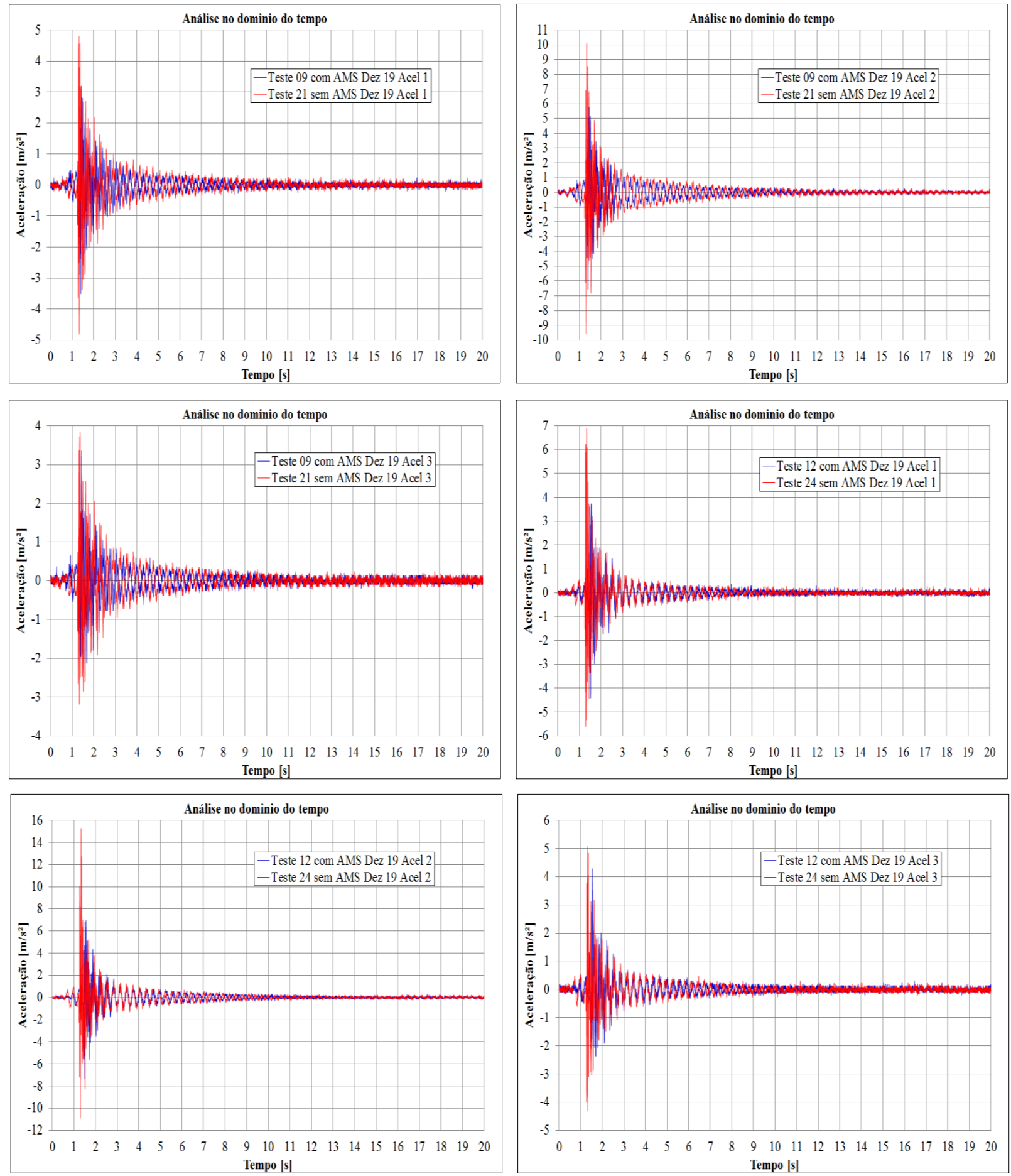


\section{Análise no domínio da frequência (Uma pessoa pulando desde uma carteira escolar)}
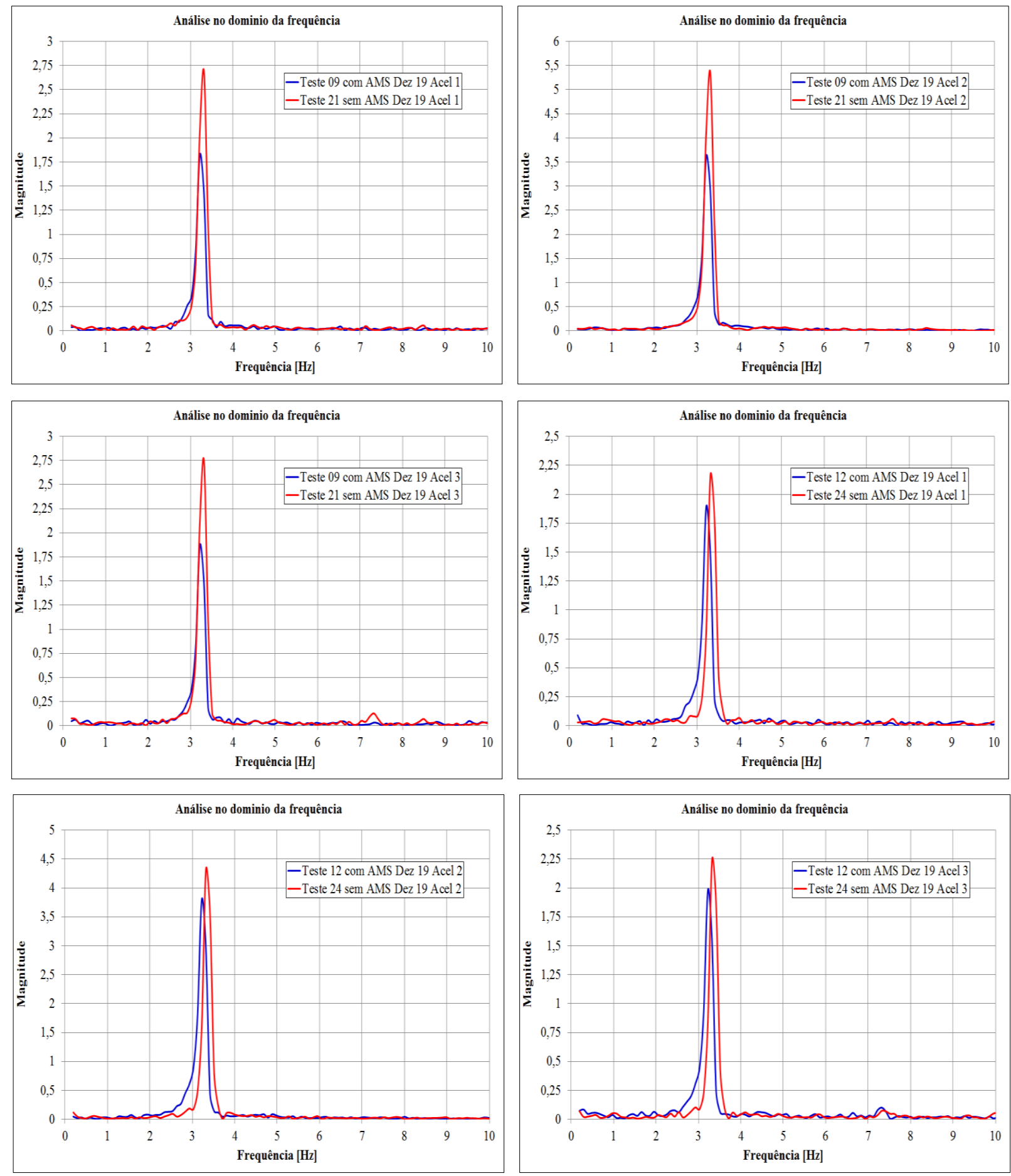


\section{Anexo XI}

Análise estatística sem e com controle para ensaios simulando força harmônica.
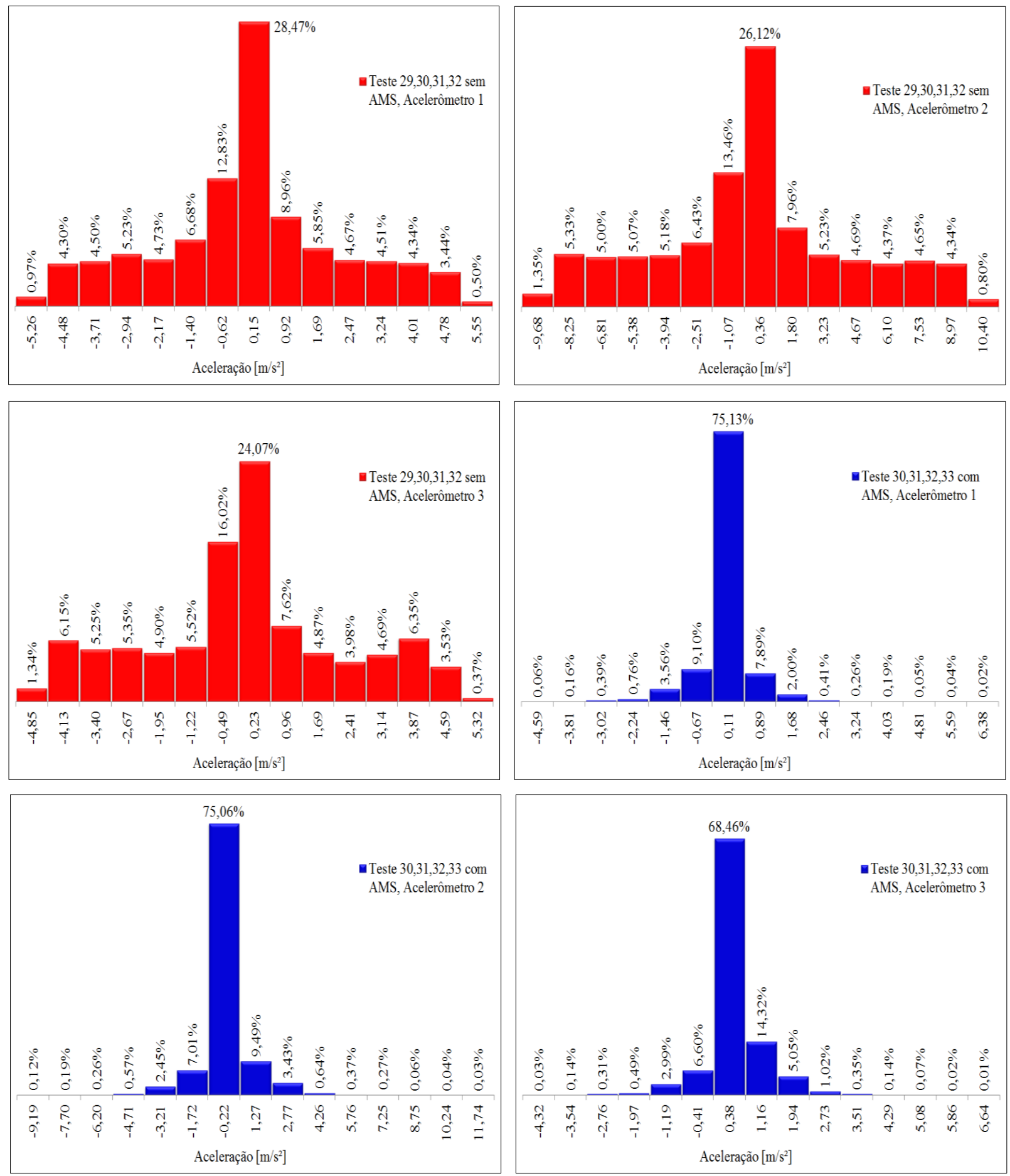


\section{Análise estatística sem e com controle para ensaios simulando força harmônica.}

\begin{tabular}{|c|c|c|c|c|c|c|c|}
\hline \multicolumn{7}{|c|}{ Acelerômetro 1, teste 29,30,31,32 sem AMS } \\
\hline Classe & $\begin{array}{c}\text { Limite inferior } \\
\text { da classe }\end{array}$ & $\begin{array}{c}\text { Limite superior } \\
\text { da classe }\end{array}$ & $\begin{array}{c}\text { Média da classe } \\
\mathrm{Mi}\end{array}$ & $\begin{array}{c}\text { Frequência } \\
\text { ni }\end{array}$ & $\begin{array}{c}\text { Frequência } \\
\text { absoluta acumulada } \\
\mathrm{Ni}\end{array}$ & $\begin{array}{c}\text { Frequência } \\
\text { relativa } \\
\mathrm{fi}\end{array}$ & $\begin{array}{c}\text { Frequência } \\
\text { relativa acumulada } \\
\mathrm{Fi}\end{array}$ \\
\hline 1 & $-5,642$ & $-4,870$ & $-5,256$ & 155 & 155 & 0,010 & 0,010 \\
\hline 2 & $-4,870$ & $-4,097$ & $-4,484$ & 690 & 845 & 0,043 & 0,053 \\
\hline 3 & $-4,097$ & $-3,325$ & $-3,711$ & 722 & 1567 & 0,045 & 0,098 \\
\hline 4 & $-3,325$ & $-2,553$ & $-2,939$ & 838 & 2405 & 0,052 & 0,150 \\
\hline 5 & $-2,553$ & $-1,781$ & $-2,167$ & 758 & 3163 & 0,047 & 0,197 \\
\hline 6 & $-1,781$ & $-1,009$ & $-1,395$ & 1071 & 4234 & 0,067 & 0,264 \\
\hline 7 & $-1,009$ & $-0,237$ & $-0,623$ & 2057 & 6291 & 0,128 & 0,393 \\
\hline 8 & $-0,237$ & 0,535 & 0,149 & 4563 & 10854 & 0,285 & 0,677 \\
\hline 9 & 0,535 & 1,307 & 0,921 & 1436 & 12290 & 0,090 & 0,767 \\
\hline 10 & 1,307 & 2,080 & 1,694 & 938 & 13228 & 0,059 & 0,825 \\
\hline 11 & 2,080 & 2,852 & 2,466 & 748 & 13976 & 0,047 & 0,872 \\
\hline 12 & 2,852 & 3,624 & 3,238 & 723 & 14699 & 0,045 & 0,917 \\
\hline 13 & 3,624 & 4,396 & 4,010 & 696 & 15395 & 0,043 & 0,961 \\
\hline 14 & 4,396 & 5,168 & 4,782 & 551 & 15946 & 0,034 & 0,995 \\
\hline 15 & 5,168 & 5,940 & 5,554 & 80 & 16026 & 0,005 & 1,000 \\
\hline
\end{tabular}

\begin{tabular}{|c|c|c|c|c|c|c|c|}
\hline \multicolumn{7}{|c|}{ Acelerômetro 2, teste 29,30,31,32 sem AMS } \\
\hline Classe & $\begin{array}{c}\text { Limite inferior } \\
\text { da classe }\end{array}$ & $\begin{array}{c}\text { Limite superior } \\
\text { da classe }\end{array}$ & $\begin{array}{c}\text { Média da classe } \\
\mathrm{Mi}\end{array}$ & $\begin{array}{c}\text { Frequência } \\
\mathrm{ni}\end{array}$ & $\begin{array}{c}\text { Frequência } \\
\text { absoluta acumulada } \\
\mathrm{Ni}\end{array}$ & $\begin{array}{c}\text { Frequência } \\
\text { relativa } \\
\mathrm{fi}\end{array}$ & $\begin{array}{c}\text { Frequência } \\
\text { relativa acumulada } \\
\text { Fi }\end{array}$ \\
\hline 1 & $-10,397$ & $-8,963$ & $-9,680$ & 216 & 216 & 0,013 & 0,013 \\
\hline 2 & $-8,963$ & $-7,528$ & $-8,245$ & 855 & 1071 & 0,053 & 0,067 \\
\hline 3 & $-7,528$ & $-6,094$ & $-6,811$ & 802 & 1873 & 0,050 & 0,117 \\
\hline 4 & $-6,094$ & $-4,659$ & $-5,376$ & 812 & 2685 & 0,051 & 0,168 \\
\hline 5 & $-4,659$ & $-3,225$ & $-3,942$ & 831 & 3516 & 0,052 & 0,219 \\
\hline 6 & $-3,225$ & $-1,790$ & $-2,507$ & 1031 & 4547 & 0,064 & 0,284 \\
\hline 7 & $-1,790$ & $-0,356$ & $-1,073$ & 2157 & 6704 & 0,135 & 0,418 \\
\hline 8 & $-0,356$ & 1,079 & 0,362 & 4186 & 10890 & 0,261 & 0,679 \\
\hline 9 & 1,079 & 2,514 & 1,796 & 1276 & 12166 & 0,080 & 0,759 \\
\hline 10 & 2,514 & 3,948 & 3,231 & 839 & 13005 & 0,052 & 0,811 \\
\hline 11 & 3,948 & 5,383 & 4,665 & 752 & 13757 & 0,047 & 0,858 \\
\hline 12 & 5,383 & 6,817 & 6,100 & 700 & 14457 & 0,044 & 0,902 \\
\hline 13 & 6,817 & 8,252 & 7,534 & 746 & 15203 & 0,047 & 0,949 \\
\hline 14 & 8,252 & 9,686 & 8,969 & 696 & 15899 & 0,043 & 0,992 \\
\hline 15 & 9,686 & 11,121 & 10,403 & 129 & 16028 & 0,008 & 1,000 \\
\hline
\end{tabular}

\begin{tabular}{|c|c|c|c|c|c|c|c|}
\hline \multicolumn{7}{|c|}{ Acelerômetro 3, teste 29,30,31,32 sem AMS } \\
\hline Classe & $\begin{array}{c}\text { Limite inferior } \\
\text { da classe }\end{array}$ & $\begin{array}{c}\text { Limite superior } \\
\text { da classe }\end{array}$ & $\begin{array}{c}\text { Média da classe } \\
\mathrm{Mi}\end{array}$ & $\begin{array}{c}\text { Frequência } \\
\text { ni }\end{array}$ & $\begin{array}{c}\text { Frequência } \\
\text { absoluta acumulada } \\
\mathrm{Ni}\end{array}$ & $\begin{array}{c}\text { Frequência } \\
\text { relativa } \\
\mathrm{fi}\end{array}$ & $\begin{array}{c}\text { Frequência } \\
\text { relativa acumulada } \\
\text { Fi }\end{array}$ \\
\hline 1 & $-5,216$ & $-4,489$ & $-4,853$ & 214 & 214 & 0,013 & 0,013 \\
\hline 2 & $-4,489$ & $-3,763$ & $-4,126$ & 986 & 1200 & 0,062 & 0,075 \\
\hline 3 & $-3,763$ & $-3,036$ & $-3,399$ & 842 & 2042 & 0,053 & 0,127 \\
\hline 4 & $-3,036$ & $-2,309$ & $-2,672$ & 857 & 2899 & 0,053 & 0,181 \\
\hline 5 & $-2,309$ & $-1,582$ & $-1,946$ & 785 & 3684 & 0,049 & 0,230 \\
\hline 6 & $-1,582$ & $-0,856$ & $-1,219$ & 884 & 4568 & 0,055 & 0,285 \\
\hline 7 & $-0,856$ & $-0,129$ & $-0,492$ & 2568 & 7136 & 0,160 & 0,445 \\
\hline 8 & $-0,129$ & 0,598 & 0,234 & 3858 & 10994 & 0,241 & 0,686 \\
\hline 9 & 0,598 & 1,324 & 0,961 & 1221 & 12215 & 0,076 & 0,762 \\
\hline 10 & 1,324 & 2,051 & 1,688 & 780 & 12995 & 0,049 & 0,811 \\
\hline 11 & 2,051 & 2,778 & 2,415 & 638 & 13633 & 0,040 & 0,851 \\
\hline 12 & 2,778 & 3,505 & 3,141 & 751 & 14384 & 0,047 & 0,897 \\
\hline 13 & 3,505 & 4,231 & 3,868 & 1017 & 15401 & 0,063 & 0,961 \\
\hline 14 & 4,231 & 4,958 & 4,595 & 566 & 15967 & 0,035 & 0,996 \\
\hline 15 & 4,958 & 5,685 & 5,321 & 60 & 16027 & 0,004 & 1,000 \\
\hline
\end{tabular}

\begin{tabular}{|c|c|c|c|c|c|c|c|}
\hline \multicolumn{7}{|c|}{ Acelerômetro 1, teste 30,31,32,33 com AMS } \\
\hline Classe & $\begin{array}{c}\text { Limite inferior } \\
\text { da classe }\end{array}$ & $\begin{array}{c}\text { Limite superior } \\
\text { da classe }\end{array}$ & $\begin{array}{c}\text { Média da classe } \\
\mathrm{Mi}\end{array}$ & $\begin{array}{c}\text { Frequência } \\
\text { ni }\end{array}$ & $\begin{array}{c}\text { Frequência } \\
\text { absoluta acumulada } \\
\mathrm{Ni}\end{array}$ & $\begin{array}{c}\text { Frequência } \\
\text { relativa } \\
\mathrm{fi}\end{array}$ & $\begin{array}{c}\text { Frequência } \\
\text { relativa acumulada } \\
\mathrm{Fi}\end{array}$ \\
\hline 1 & $-4,983$ & $-4,200$ & $-4,591$ & 9 & 9 & 0,001 & 0,001 \\
\hline 2 & $-4,200$ & $-3,416$ & $-3,808$ & 25 & 34 & 0,002 & 0,002 \\
\hline 3 & $-3,416$ & $-2,633$ & $-3,024$ & 62 & 96 & 0,004 & 0,006 \\
\hline 4 & $-2,633$ & $-1,849$ & $-2,241$ & 122 & 218 & 0,008 & 0,014 \\
\hline 5 & $-1,849$ & $-1,066$ & $-1,457$ & 570 & 788 & 0,036 & 0,049 \\
\hline 6 & $-1,066$ & $-0,282$ & $-0,674$ & 1458 & 2246 & 0,091 & 0,140 \\
\hline 7 & $-0,282$ & 0,501 & 0,110 & 12042 & 14288 & 0,751 & 0,891 \\
\hline 8 & 0,501 & 1,285 & 0,893 & 1264 & 15552 & 0,079 & 0,970 \\
\hline 9 & 1,285 & 2,068 & 1,677 & 321 & 15873 & 0,020 & 0,990 \\
\hline 10 & 2,068 & 2,852 & 2,460 & 65 & 15938 & 0,004 & 0,994 \\
\hline 11 & 2,852 & 3,635 & 3,244 & 42 & 15980 & 0,003 & 0,997 \\
\hline 12 & 3,635 & 4,419 & 4,027 & 31 & 16011 & 0,002 & 0,999 \\
\hline 13 & 4,419 & 5,202 & 4,811 & 8 & 16019 & 0,000 & 0,999 \\
\hline 14 & 5,202 & 5,986 & 5,594 & 6 & 16025 & 0,000 & 1,000 \\
\hline 15 & 5,986 & 6,769 & 6,378 & 3 & 16028 & 0,000 & 1,000 \\
\hline
\end{tabular}

\begin{tabular}{|c|c|c|c|c|c|c|c|}
\hline \multicolumn{7}{|c|}{ Acelerômetro 2, teste 30,31,32,33 com AMS } \\
\hline Classe & $\begin{array}{c}\text { Limite inferior } \\
\text { da classe }\end{array}$ & $\begin{array}{c}\text { Limite superior } \\
\text { da classe }\end{array}$ & $\begin{array}{c}\text { Média da classe } \\
\mathrm{Mi}\end{array}$ & $\begin{array}{c}\text { Frequência } \\
\mathrm{ni}\end{array}$ & $\begin{array}{c}\text { Frequência } \\
\text { absoluta acumulada } \\
\mathrm{Ni}\end{array}$ & $\begin{array}{c}\text { Frequência } \\
\text { relativa } \\
\mathrm{fi}\end{array}$ & $\begin{array}{c}\text { Frequência } \\
\text { relativa acumulada } \\
\text { Fi }\end{array}$ \\
\hline 1 & $-9,940$ & $-8,445$ & $-9,192$ & 19 & 19 & 0,001 & 0,001 \\
\hline 2 & $-8,445$ & $-6,949$ & $-7,697$ & 31 & 50 & 0,002 & 0,003 \\
\hline 3 & $-6,949$ & $-5,454$ & $-6,202$ & 41 & 91 & 0,003 & 0,006 \\
\hline 4 & $-5,454$ & $-3,959$ & $-4,707$ & 91 & 182 & 0,006 & 0,011 \\
\hline 5 & $-3,959$ & $-2,464$ & $-3,212$ & 392 & 574 & 0,024 & 0,036 \\
\hline 6 & $-2,464$ & $-0,969$ & $-1,717$ & 1124 & 1698 & 0,070 & 0,106 \\
\hline 7 & $-0,969$ & 0,526 & $-0,222$ & 12031 & 13729 & 0,751 & 0,857 \\
\hline 8 & 0,526 & 2,021 & 1,273 & 1521 & 15250 & 0,095 & 0,951 \\
\hline 9 & 2,021 & 3,516 & 2,768 & 550 & 15800 & 0,034 & 0,986 \\
\hline 10 & 3,516 & 5,011 & 4,263 & 103 & 15903 & 0,006 & 0,992 \\
\hline 11 & 5,011 & 6,506 & 5,759 & 60 & 15963 & 0,004 & 0,996 \\
\hline 12 & 6,506 & 8,001 & 7,254 & 43 & 16006 & 0,003 & 0,999 \\
\hline 13 & 8,001 & 9,496 & 8,749 & 10 & 16016 & 0,001 & 0,999 \\
\hline 14 & 9,496 & 10,991 & 10,244 & 6 & 16022 & 0,000 & 1,000 \\
\hline 15 & 10,991 & 12,486 & 11,739 & 5 & 16027 & 0,000 & 1,000 \\
\hline
\end{tabular}

\begin{tabular}{|c|c|c|c|c|c|c|c|}
\hline \multicolumn{7}{|c|}{ Acelerômetro 3, teste 30,31,32,33 com AMS } \\
\hline Classe & $\begin{array}{c}\text { Limite inferior } \\
\text { da classe }\end{array}$ & $\begin{array}{c}\text { Limite superior } \\
\text { da classe }\end{array}$ & $\begin{array}{c}\text { Média da classe } \\
\mathrm{Mi}\end{array}$ & $\begin{array}{c}\text { Frequência } \\
\text { ni }\end{array}$ & $\begin{array}{c}\text { Frequência } \\
\text { absoluta acumulada } \\
\mathrm{Ni}\end{array}$ & $\begin{array}{c}\text { Frequência } \\
\text { relativa } \\
\mathrm{fi}\end{array}$ & $\begin{array}{c}\text { Frequência } \\
\text { relativa acumulada } \\
\text { Fi }\end{array}$ \\
\hline 1 & $-4,716$ & $-3,933$ & $-4,325$ & 5 & 5 & 0,000 & 0,000 \\
\hline 2 & $-3,933$ & $-3,149$ & $-3,541$ & 22 & 27 & 0,001 & 0,002 \\
\hline 3 & $-3,149$ & $-2,366$ & $-2,758$ & 49 & 76 & 0,003 & 0,005 \\
\hline 4 & $-2,366$ & $-1,582$ & $-1,974$ & 79 & 155 & 0,005 & 0,010 \\
\hline 5 & $-1,582$ & $-0,799$ & $-1,191$ & 479 & 634 & 0,030 & 0,040 \\
\hline 6 & $-0,799$ & $-0,015$ & $-0,407$ & 1058 & 1692 & 0,066 & 0,106 \\
\hline 7 & $-0,015$ & 0,768 & 0,376 & 10973 & 12665 & 0,685 & 0,790 \\
\hline 8 & 0,768 & 1,552 & 1,160 & 2295 & 14960 & 0,143 & 0,933 \\
\hline 9 & 1,552 & 2,335 & 1,943 & 810 & 15770 & 0,051 & 0,984 \\
\hline 10 & 2,335 & 3,119 & 2,727 & 163 & 15933 & 0,010 & 0,994 \\
\hline 11 & 3,119 & 3,902 & 3,510 & 56 & 15989 & 0,003 & 0,998 \\
\hline 12 & 3,902 & 4,686 & 4,294 & 22 & 16011 & 0,001 & 0,999 \\
\hline 13 & 4,686 & 5,469 & 5,077 & 12 & 16023 & 0,001 & 1,000 \\
\hline 14 & 5,469 & 6,252 & 5,861 & 3 & 16026 & 0,000 & 1,000 \\
\hline 15 & 6,252 & 7,036 & 6,644 & 1 & 16027 & 0,000 & 1,000 \\
\hline
\end{tabular}


Análise estatística sem e com controle para ensaios de pulo continuo centro da laje.
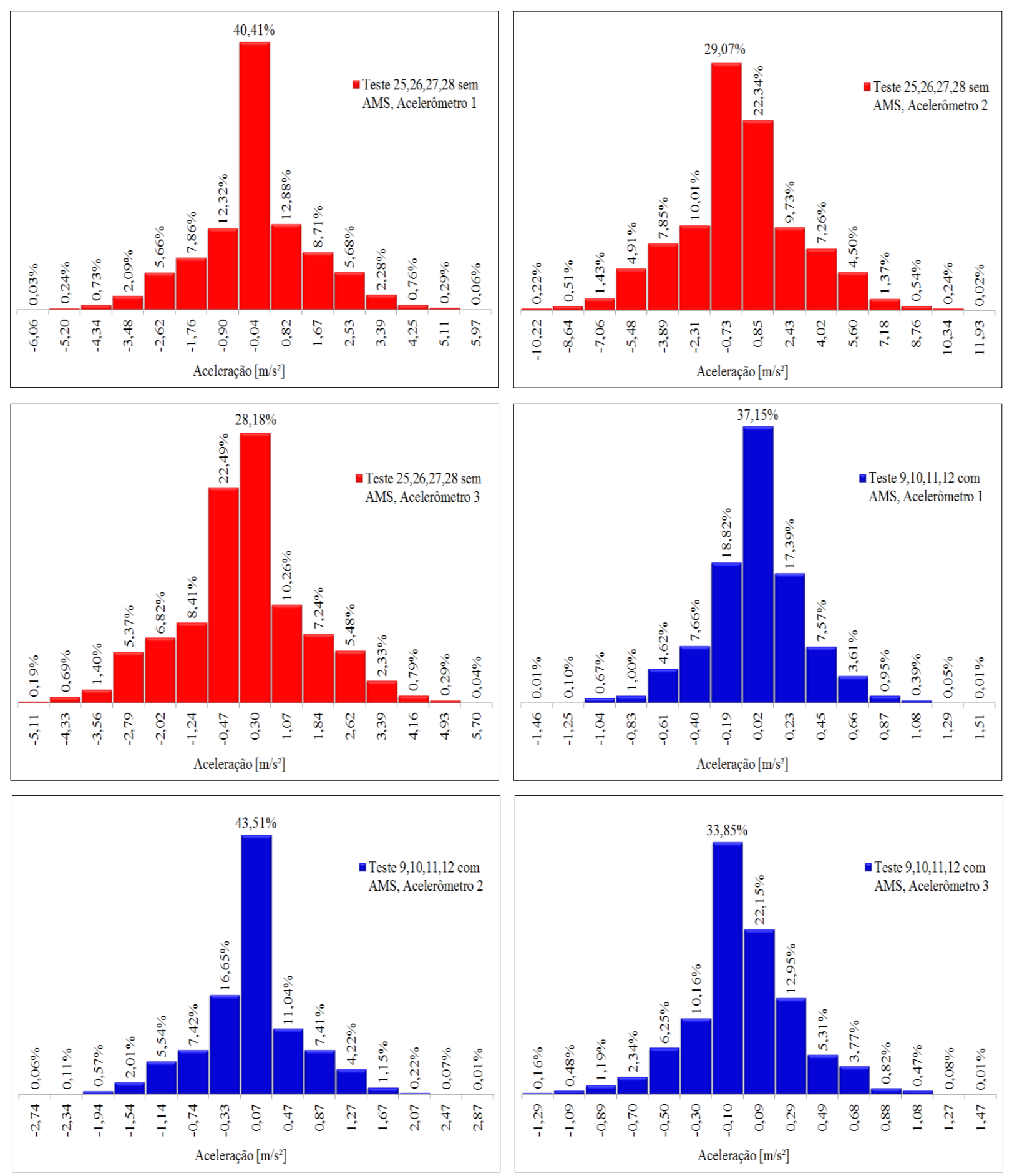


\section{Análise estatística sem e com controle para ensaios de pulo continuo centro da laje.}

\begin{tabular}{|c|c|c|c|c|c|c|c|}
\hline \multicolumn{7}{|c|}{ Acelerômetro 1, teste 25,26,27,28 sem AMS } \\
\hline Classe & $\begin{array}{c}\text { Limite inferior } \\
\text { da classe }\end{array}$ & $\begin{array}{c}\text { Limite superior } \\
\text { da classe }\end{array}$ & $\begin{array}{c}\text { Média da classe } \\
\mathrm{Mi}\end{array}$ & $\begin{array}{c}\text { Frequência } \\
\text { ni }\end{array}$ & $\begin{array}{c}\text { Frequência } \\
\text { absoluta acumulada } \\
\mathrm{Ni}\end{array}$ & $\begin{array}{c}\text { Frequência } \\
\text { relativa } \\
\mathrm{fi}\end{array}$ & $\begin{array}{c}\text { Frequência } \\
\text { relativa acumulada } \\
\mathrm{Fi}\end{array}$ \\
\hline 1 & $-6,488$ & $-5,629$ & $-6,058$ & 5 & 5 & 0,0003 & 0,0003 \\
\hline 2 & $-5,629$ & $-4,769$ & $-5,199$ & 39 & 44 & 0,002 & 0,003 \\
\hline 3 & $-4,769$ & $-3,910$ & $-4,340$ & 117 & 161 & 0,007 & 0,010 \\
\hline 4 & $-3,910$ & $-3,051$ & $-3,481$ & 335 & 496 & 0,021 & 0,031 \\
\hline 5 & $-3,051$ & $-2,192$ & $-2,621$ & 907 & 1403 & 0,057 & 0,088 \\
\hline 6 & $-2,192$ & $-1,333$ & $-1,762$ & 1260 & 2663 & 0,079 & 0,166 \\
\hline 7 & $-1,333$ & $-0,473$ & $-0,903$ & 1975 & 4638 & 0,123 & 0,289 \\
\hline 8 & $-0,473$ & 0,386 & $-0,044$ & 6477 & 11115 & 0,404 & 0,693 \\
\hline 9 & 0,386 & 1,245 & 0,815 & 2064 & 13179 & 0,129 & 0,822 \\
\hline 10 & 1,245 & 2,104 & 1,675 & 1396 & 14575 & 0,087 & 0,909 \\
\hline 11 & 2,104 & 2,963 & 2,534 & 910 & 15485 & 0,057 & 0,966 \\
\hline 12 & 2,963 & 3,823 & 3,393 & 366 & 15851 & 0,023 & 0,989 \\
\hline 13 & 3,823 & 4,682 & 4,252 & 122 & 15973 & 0,008 & 0,997 \\
\hline 14 & 4,682 & 5,541 & 5,111 & 46 & 16019 & 0,003 & 0,999 \\
\hline 15 & 5,541 & 6,400 & 5,971 & 9 & 16028 & 0,001 & 1,000 \\
\hline
\end{tabular}

\begin{tabular}{|c|c|c|c|c|c|c|c|}
\hline \multicolumn{7}{|c|}{ Acelerômetro 2, teste $25,26,27,28$ sem AMS } \\
\hline \begin{tabular}{c|c|c|c|c|c|c|c|} 
Limite inferior \\
da classe
\end{tabular} & $\begin{array}{c}\text { Limite superior } \\
\text { da classe }\end{array}$ & $\begin{array}{c}\text { Média da classe } \\
\mathrm{Mi}\end{array}$ & $\begin{array}{c}\text { Frequência } \\
\mathrm{ni}\end{array}$ & $\begin{array}{c}\text { Frequência } \\
\text { absoluta acumulada } \\
\mathrm{Ni}\end{array}$ & $\begin{array}{c}\text { Frequência } \\
\text { relativa } \\
\mathrm{fi}\end{array}$ & $\begin{array}{c}\text { Frequência } \\
\text { relativa acumulada } \\
\mathrm{Fi}\end{array}$ \\
\hline 1 & $-11,014$ & $-9,432$ & $-10,223$ & 36 & 36 & 0,002 & 0,002 \\
\hline 2 & $-9,432$ & $-7,850$ & $-8,641$ & 82 & 118 & 0,005 & 0,007 \\
\hline 3 & $-7,850$ & $-6,268$ & $-7,059$ & 229 & 347 & 0,014 & 0,022 \\
\hline 4 & $-6,268$ & $-4,686$ & $-5,477$ & 787 & 1134 & 0,049 & 0,071 \\
\hline 5 & $-4,686$ & $-3,104$ & $-3,895$ & 1258 & 2392 & 0,078 & 0,149 \\
\hline 6 & $-3,104$ & $-1,522$ & $-2,313$ & 1604 & 3996 & 0,100 & 0,249 \\
\hline 7 & $-1,522$ & 0,060 & $-0,731$ & 4659 & 8655 & 0,291 & 0,540 \\
\hline 8 & 0,060 & 1,643 & 0,851 & 3580 & 12235 & 0,223 & 0,763 \\
\hline 9 & 1,643 & 3,225 & 2,434 & 1560 & 13795 & 0,097 & 0,861 \\
\hline 10 & 3,225 & 4,807 & 4,016 & 1163 & 14958 & 0,073 & 0,933 \\
\hline 11 & 4,807 & 6,389 & 5,598 & 722 & 15680 & 0,045 & 0,978 \\
\hline 12 & 6,389 & 7,971 & 7,180 & 219 & 15899 & 0,014 & 0,992 \\
\hline 13 & 7,971 & 9,553 & 8,762 & 87 & 15986 & 0,005 & 0,997 \\
\hline 14 & 9,553 & 11,135 & 10,344 & 38 & 16024 & 0,002 & 1,000 \\
\hline 15 & 11,135 & 12,717 & 11,926 & 4 & 16028 & 0,000 & 1,000 \\
\hline
\end{tabular}

\begin{tabular}{|c|c|c|c|c|c|c|c|}
\hline \multicolumn{7}{|c|}{ Acelerômetro 3, teste 25,26,27,28 sem AMS } \\
\hline Classe & $\begin{array}{c}\text { imite inferior } \\
\text { da classe }\end{array}$ & $\begin{array}{c}\text { Limite superior } \\
\text { da classe }\end{array}$ & $\begin{array}{c}\text { Média da classe } \\
\mathrm{Mi}\end{array}$ & $\begin{array}{c}\text { Frequência } \\
\text { ni }\end{array}$ & $\begin{array}{c}\text { Frequência } \\
\text { absoluta acumulada } \\
\mathrm{Ni}\end{array}$ & $\begin{array}{c}\text { Frequência } \\
\text { relativa } \\
\mathrm{fi}\end{array}$ & $\begin{array}{c}\text { Frequência } \\
\text { relativa acumulada } \\
\mathrm{Fi}\end{array}$ \\
\hline 1 & $-5,492$ & $-4,720$ & $-5,106$ & 30 & 30 & 0,002 & 0,002 \\
\hline 2 & $-4,720$ & $-3,947$ & $-4,333$ & 111 & 141 & 0,007 & 0,009 \\
\hline 3 & $-3,947$ & $-3,175$ & $-3,561$ & 225 & 366 & 0,014 & 0,023 \\
\hline 4 & $-3,175$ & $-2,403$ & $-2,789$ & 861 & 1227 & 0,054 & 0,077 \\
\hline 5 & $-2,403$ & $-1,631$ & $-2,017$ & 1093 & 2320 & 0,068 & 0,145 \\
\hline 6 & $-1,631$ & $-0,859$ & $-1,245$ & 1348 & 3668 & 0,084 & 0,229 \\
\hline 7 & $-0,859$ & $-0,087$ & $-0,473$ & 3605 & 7273 & 0,225 & 0,454 \\
\hline 8 & $-0,087$ & 0,685 & 0,299 & 4517 & 11790 & 0,282 & 0,736 \\
\hline 9 & 0,685 & 1,458 & 1,071 & 1645 & 13435 & 0,103 & 0,838 \\
\hline 10 & 1,458 & 2,230 & 1,844 & 1161 & 14596 & 0,072 & 0,911 \\
\hline 11 & 2,230 & 3,002 & 2,616 & 878 & 15474 & 0,055 & 0,965 \\
\hline 12 & 3,002 & 3,774 & 3,388 & 373 & 15847 & 0,023 & 0,989 \\
\hline 13 & 3,774 & 4,546 & 4,160 & 127 & 15974 & 0,008 & 0,997 \\
\hline 14 & 4,546 & 5,318 & 4,932 & 47 & 16021 & 0,003 & 1,000 \\
\hline 15 & 5,318 & 6,090 & 5,704 & 6 & 16027 & 0,000 & 1,000 \\
\hline
\end{tabular}

\begin{tabular}{|c|c|c|c|c|c|c|c|}
\hline \multicolumn{7}{|c|}{ Acelerômetro 1, teste 9,10,11,12 com AMS } \\
\hline Classe & $\begin{array}{c}\text { Limite inferior } \\
\text { da classe }\end{array}$ & $\begin{array}{c}\text { Limite superior } \\
\text { da classe }\end{array}$ & $\begin{array}{c}\text { Média da classe } \\
\mathrm{Mi}\end{array}$ & $\begin{array}{c}\text { Frequência } \\
\text { ni }\end{array}$ & $\begin{array}{c}\text { Frequência } \\
\text { absoluta acumulada } \\
\mathrm{Ni}\end{array}$ & $\begin{array}{c}\text { Frequência } \\
\text { relativa } \\
\mathrm{fi}\end{array}$ & $\begin{array}{c}\text { Frequência } \\
\text { relativa acumulada } \\
\text { Fi }\end{array}$ \\
\hline 1 & $-1,568$ & $-1,356$ & $-1,462$ & 2 & 2 & 0,0001 & 0,0001 \\
\hline 2 & $-1,356$ & $-1,144$ & $-1,250$ & 16 & 18 & 0,001 & 0,001 \\
\hline 3 & $-1,144$ & $-0,932$ & $-1,038$ & 108 & 126 & 0,007 & 0,008 \\
\hline 4 & $-0,932$ & $-0,721$ & $-0,827$ & 161 & 287 & 0,010 & 0,018 \\
\hline 5 & $-0,721$ & $-0,509$ & $-0,615$ & 740 & 1027 & 0,046 & 0,064 \\
\hline 6 & $-0,509$ & $-0,297$ & $-0,403$ & 1228 & 2255 & 0,077 & 0,141 \\
\hline 7 & $-0,297$ & $-0,085$ & $-0,191$ & 3016 & 5271 & 0,188 & 0,329 \\
\hline 8 & $-0,085$ & 0,127 & 0,021 & 5954 & 11225 & 0,371 & 0,700 \\
\hline 9 & 0,127 & 0,339 & 0,233 & 2787 & 14012 & 0,174 & 0,874 \\
\hline 10 & 0,339 & 0,551 & 0,445 & 1214 & 15226 & 0,076 & 0,950 \\
\hline 11 & 0,551 & 0,763 & 0,657 & 578 & 15804 & 0,036 & 0,986 \\
\hline 12 & 0,763 & 0,975 & 0,869 & 153 & 15957 & 0,010 & 0,996 \\
\hline 13 & 0,975 & 1,187 & 1,081 & 62 & 16019 & 0,004 & 0,999 \\
\hline 14 & 1,187 & 1,399 & 1,293 & 8 & 16027 & 0,000 & 1,000 \\
\hline 15 & 1,399 & 1,611 & 1,505 & 1 & 16028 & 0,000 & 1,000 \\
\hline
\end{tabular}

\begin{tabular}{|c|c|c|c|c|c|c|c|}
\hline \multicolumn{7}{|c|}{ Acelerômetro 2, teste 9,10,11,12 com AMS } \\
\hline Classe & $\begin{array}{c}\text { Limite inferior } \\
\text { da classe }\end{array}$ & $\begin{array}{c}\text { Limite superior } \\
\text { da classe }\end{array}$ & $\begin{array}{c}\text { Média da classe } \\
\mathrm{Mi}\end{array}$ & $\begin{array}{c}\text { Frequência } \\
\mathrm{ni}\end{array}$ & $\begin{array}{c}\text { Frequência } \\
\text { absoluta acumulada } \\
\mathrm{Ni}\end{array}$ & $\begin{array}{c}\text { Frequência } \\
\text { relativa } \\
\mathrm{fi}\end{array}$ & $\begin{array}{c}\text { Frequência } \\
\text { relativa acumulada } \\
\mathrm{Fi}\end{array}$ \\
\hline 1 & $-2,943$ & $-2,542$ & $-2,742$ & 9 & 9 & 0,001 & 0,001 \\
\hline 2 & $-2,542$ & $-2,140$ & $-2,341$ & 17 & 26 & 0,001 & 0,002 \\
\hline 3 & $-2,140$ & $-1,739$ & $-1,940$ & 91 & 117 & 0,006 & 0,007 \\
\hline 4 & $-1,739$ & $-1,338$ & $-1,538$ & 322 & 439 & 0,020 & 0,027 \\
\hline 5 & $-1,338$ & $-0,937$ & $-1,137$ & 888 & 1327 & 0,055 & 0,083 \\
\hline 6 & $-0,937$ & $-0,535$ & $-0,736$ & 1190 & 2517 & 0,074 & 0,157 \\
\hline 7 & $-0,535$ & $-0,134$ & $-0,335$ & 2669 & 5186 & 0,167 & 0,324 \\
\hline 8 & $-0,134$ & 0,267 & 0,066 & 6974 & 12160 & 0,435 & 0,759 \\
\hline 9 & 0,267 & 0,668 & 0,468 & 1769 & 13929 & 0,110 & 0,869 \\
\hline 10 & 0,668 & 1,069 & 0,869 & 1188 & 15117 & 0,074 & 0,943 \\
\hline 11 & 1,069 & 1,471 & 1,270 & 676 & 15793 & 0,042 & 0,985 \\
\hline 12 & 1,471 & 1,872 & 1,671 & 185 & 15978 & 0,012 & 0,997 \\
\hline 13 & 1,872 & 2,273 & 2,072 & 36 & 16014 & 0,002 & 0,999 \\
\hline 14 & 2,273 & 2,674 & 2,474 & 12 & 16026 & 0,001 & 1,000 \\
\hline 15 & 2,674 & 3,075 & 2,875 & 2 & 16028 & 0,000 & 1,000 \\
\hline
\end{tabular}

\begin{tabular}{|c|c|c|c|c|c|c|c|}
\hline \multicolumn{7}{|c|}{ Acelerômetro 3 , teste 9,10,11,12 com AMS } \\
\hline Classe & $\begin{array}{c}\text { cimite inferior } \\
\text { da classe }\end{array}$ & $\begin{array}{c}\text { Limite superior } \\
\text { da classe }\end{array}$ & $\begin{array}{c}\text { Média da classe } \\
\mathrm{Mi}\end{array}$ & $\begin{array}{c}\text { Frequência } \\
\text { ni }\end{array}$ & $\begin{array}{c}\text { Frequência } \\
\text { absoluta acumulada } \\
\mathrm{Ni}\end{array}$ & $\begin{array}{c}\text { Frequência } \\
\text { relativa } \\
\mathrm{fi}\end{array}$ & $\begin{array}{c}\text { Frequência } \\
\text { relativa acumulada } \\
\text { Fi }\end{array}$ \\
\hline 1 & $-1,384$ & $-1,187$ & $-1,286$ & 25 & 25 & 0,002 & 0,002 \\
\hline 2 & $-1,187$ & $-0,990$ & $-1,089$ & 77 & 102 & 0,005 & 0,006 \\
\hline 3 & $-0,990$ & $-0,794$ & $-0,892$ & 191 & 293 & 0,012 & 0,018 \\
\hline 4 & $-0,794$ & $-0,597$ & $-0,695$ & 375 & 668 & 0,023 & 0,042 \\
\hline 5 & $-0,597$ & $-0,400$ & $-0,498$ & 1001 & 1669 & 0,062 & 0,104 \\
\hline 6 & $-0,400$ & $-0,203$ & $-0,302$ & 1629 & 3298 & 0,102 & 0,206 \\
\hline 7 & $-0,203$ & $-0,006$ & $-0,105$ & 5425 & 8723 & 0,338 & 0,544 \\
\hline 8 & $-0,006$ & 0,190 & 0,092 & 3551 & 12274 & 0,222 & 0,766 \\
\hline 9 & 0,190 & 0,387 & 0,289 & 2075 & 14349 & 0,129 & 0,895 \\
\hline 10 & 0,387 & 0,584 & 0,486 & 851 & 15200 & 0,053 & 0,948 \\
\hline 11 & 0,584 & 0,781 & 0,682 & 605 & 15805 & 0,038 & 0,986 \\
\hline 12 & 0,781 & 0,978 & 0,879 & 132 & 15937 & 0,008 & 0,994 \\
\hline 13 & 0,978 & 1,175 & 1,076 & 76 & 16013 & 0,005 & 0,999 \\
\hline 14 & 1,175 & 1,371 & 1,273 & 13 & 16026 & 0,001 & 1,000 \\
\hline 15 & 1,371 & 1,568 & 1,470 & 2 & 16028 & 0,000 & 1,000 \\
\hline
\end{tabular}




\section{Análise estatística sem e com controle para ensaios de pessoas caminhando na laje.}
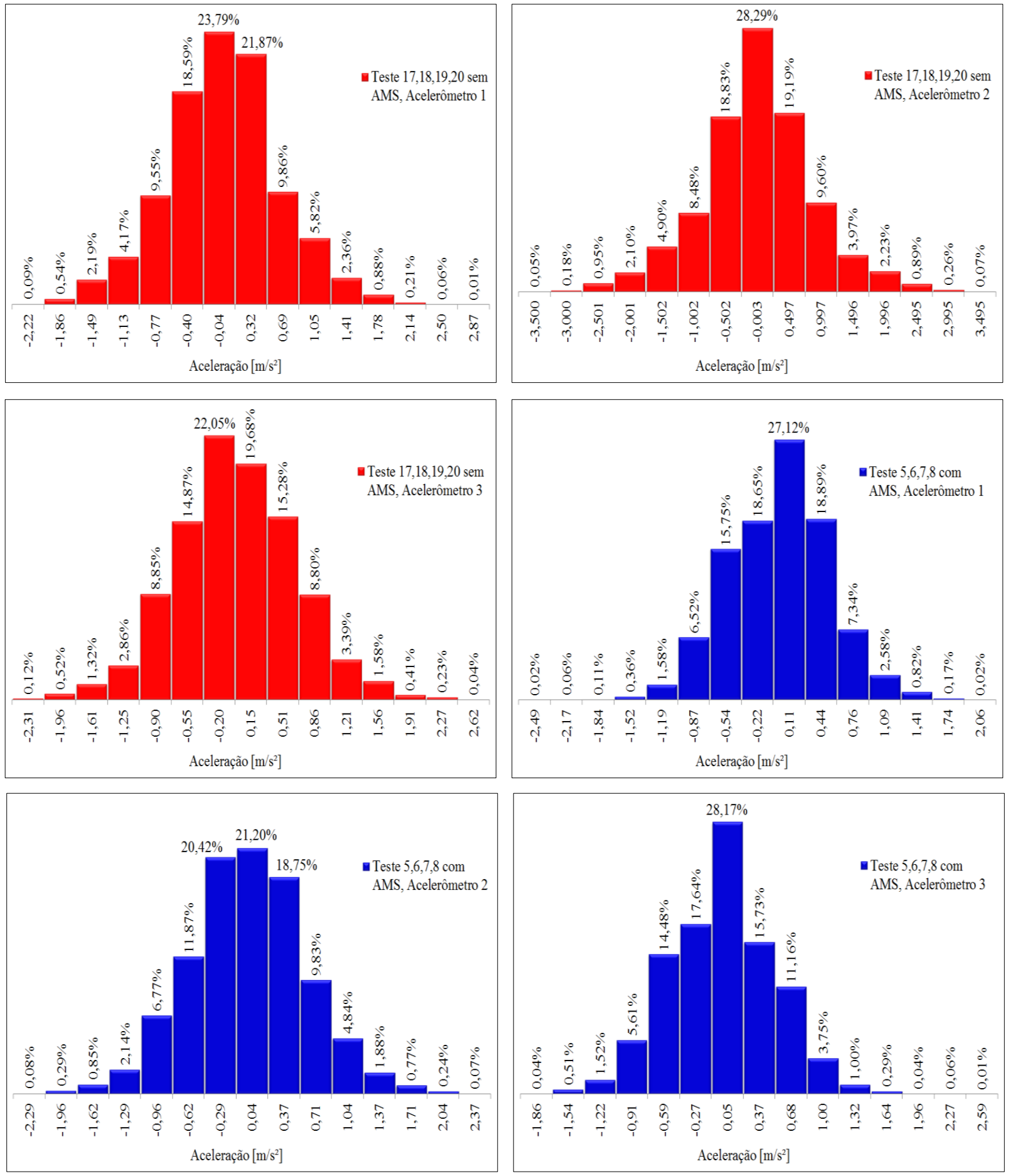


\section{Análise estatística sem e com controle para ensaios de pessoas caminhando na laje.}

\begin{tabular}{|c|c|c|c|c|c|c|c|}
\hline \multicolumn{7}{|c|}{ Acelerômetro 1, teste $17,18,19,20$ sem AMS } \\
\hline Classe & $\begin{array}{c}\text { cimite inferior } \\
\text { da classe }\end{array}$ & $\begin{array}{c}\text { Limite superior } \\
\text { da classe }\end{array}$ & $\begin{array}{c}\text { Média da classe } \\
\mathrm{Mi}\end{array}$ & $\begin{array}{c}\text { Frequência } \\
\text { ni }\end{array}$ & $\begin{array}{c}\text { Frequência } \\
\text { absoluta acumulada } \\
\mathrm{Ni}\end{array}$ & $\begin{array}{c}\text { Frequência } \\
\text { relativa } \\
\mathrm{fi}\end{array}$ & $\begin{array}{c}\text { Frequência } \\
\text { relativa acumulada } \\
\mathrm{Fi}\end{array}$ \\
\hline 1 & $-2,401$ & $-2,038$ & $-2,219$ & 15 & 15 & 0,001 & 0,001 \\
\hline 2 & $-2,038$ & $-1,674$ & $-1,856$ & 86 & 101 & 0,005 & 0,006 \\
\hline 3 & $-1,674$ & $-1,311$ & $-1,493$ & 351 & 452 & 0,022 & 0,028 \\
\hline 4 & $-1,311$ & $-0,948$ & $-1,129$ & 668 & 1120 & 0,042 & 0,070 \\
\hline 5 & $-0,948$ & $-0,584$ & $-0,766$ & 1531 & 2651 & 0,096 & 0,165 \\
\hline 6 & $-0,584$ & $-0,221$ & $-0,403$ & 2979 & 5630 & 0,186 & 0,351 \\
\hline 7 & $-0,221$ & 0,142 & $-0,039$ & 3813 & 9443 & 0,238 & 0,589 \\
\hline 8 & 0,142 & 0,506 & 0,324 & 3505 & 12948 & 0,219 & 0,808 \\
\hline 9 & 0,506 & 0,869 & 0,687 & 1581 & 14529 & 0,099 & 0,906 \\
\hline 10 & 0,869 & 1,232 & 1,051 & 933 & 15462 & 0,058 & 0,965 \\
\hline 11 & 1,232 & 1,596 & 1,414 & 379 & 15841 & 0,024 & 0,988 \\
\hline 12 & 1,596 & 1,959 & 1,777 & 141 & 15982 & 0,009 & 0,997 \\
\hline 13 & 1,959 & 2,322 & 2,141 & 34 & 16016 & 0,002 & 0,999 \\
\hline 14 & 2,322 & 2,686 & 2,504 & 10 & 16026 & 0,001 & 1,000 \\
\hline 15 & 2,686 & 3,049 & 2,868 & 1 & 16027 & 0,000 & 1,000 \\
\hline
\end{tabular}

\begin{tabular}{|c|c|c|c|c|c|c|c|}
\hline \multicolumn{7}{|c|}{ Acelerômetro 2, teste 17,18,19,20 sem AMS } \\
\hline Classe & $\begin{array}{c}\text { Limite inferior } \\
\text { da classe }\end{array}$ & $\begin{array}{c}\text { Limite superior } \\
\text { da classe }\end{array}$ & $\begin{array}{c}\text { Média da classe } \\
\mathrm{Mi}\end{array}$ & $\begin{array}{c}\text { Frequência } \\
\mathrm{ni}\end{array}$ & $\begin{array}{c}\text { Frequência } \\
\text { absoluta acumulada } \\
\mathrm{Ni}\end{array}$ & $\begin{array}{c}\text { Frequência } \\
\text { relativa } \\
\mathrm{fi}\end{array}$ & $\begin{array}{c}\text { Frequência } \\
\text { relativa acumulada } \\
\mathrm{Fi}\end{array}$ \\
\hline 1 & $-3,750$ & $-3,250$ & $-3,500$ & 8 & 8 & 0,000 & 0,000 \\
\hline 2 & $-3,250$ & $-2,751$ & $-3,000$ & 29 & 37 & 0,002 & 0,002 \\
\hline 3 & $-2,751$ & $-2,251$ & $-2,501$ & 152 & 189 & 0,009 & 0,012 \\
\hline 4 & $-2,251$ & $-1,751$ & $-2,001$ & 337 & 526 & 0,021 & 0,033 \\
\hline 5 & $-1,751$ & $-1,252$ & $-1,502$ & 785 & 1311 & 0,049 & 0,082 \\
\hline 6 & $-1,252$ & $-0,752$ & $-1,002$ & 1359 & 2670 & 0,085 & 0,167 \\
\hline 7 & $-0,752$ & $-0,253$ & $-0,502$ & 3018 & 5688 & 0,188 & 0,355 \\
\hline 8 & $-0,253$ & 0,247 & $-0,003$ & 4534 & 10222 & 0,283 & 0,638 \\
\hline 9 & 0,247 & 0,747 & 0,497 & 3076 & 13298 & 0,192 & 0,830 \\
\hline 10 & 0,747 & 1,246 & 0,997 & 1539 & 14837 & 0,096 & 0,926 \\
\hline 11 & 1,246 & 1,746 & 1,496 & 637 & 15474 & 0,040 & 0,965 \\
\hline 12 & 1,746 & 2,246 & 1,996 & 358 & 15832 & 0,022 & 0,988 \\
\hline 13 & 2,246 & 2,745 & 2,495 & 143 & 15975 & 0,009 & 0,997 \\
\hline 14 & 2,745 & 3,245 & 2,995 & 41 & 16016 & 0,003 & 0,999 \\
\hline 15 & 3,245 & 3,744 & 3,495 & 11 & 16027 & 0,001 & 1,000 \\
\hline
\end{tabular}

\begin{tabular}{|c|c|c|c|c|c|c|c|}
\hline \multicolumn{7}{|c|}{ Acelerômetro 3, teste $17,18,19,20$ sem AMS } \\
\hline Classe & $\begin{array}{c}\text { Limite inferior } \\
\text { da classe }\end{array}$ & $\begin{array}{c}\text { Limite superior } \\
\text { da classe }\end{array}$ & $\begin{array}{c}\text { Média da classe } \\
\mathrm{Mi}\end{array}$ & $\begin{array}{c}\text { Frequência } \\
\mathrm{ni}\end{array}$ & $\begin{array}{c}\text { Frequência } \\
\text { absoluta acumulada } \\
\mathrm{Ni}\end{array}$ & $\begin{array}{c}\text { Frequência } \\
\text { relativa } \\
\mathrm{fi}\end{array}$ & $\begin{array}{c}\text { Frequência } \\
\text { relativa acumulada } \\
\mathrm{Fi}\end{array}$ \\
\hline 1 & $-2,486$ & $-2,134$ & $-2,310$ & 19 & 19 & 0,001 & 0,001 \\
\hline 2 & $-2,134$ & $-1,782$ & $-1,958$ & 83 & 102 & 0,005 & 0,006 \\
\hline 3 & $-1,782$ & $-1,430$ & $-1,606$ & 212 & 314 & 0,013 & 0,020 \\
\hline 4 & $-1,430$ & $-1,078$ & $-1,254$ & 458 & 772 & 0,029 & 0,048 \\
\hline 5 & $-1,078$ & $-0,726$ & $-0,902$ & 1419 & 2191 & 0,089 & 0,137 \\
\hline 6 & $-0,726$ & $-0,374$ & $-0,550$ & 2384 & 4575 & 0,149 & 0,285 \\
\hline 7 & $-0,374$ & $-0,022$ & $-0,198$ & 3534 & 8109 & 0,220 & 0,506 \\
\hline 8 & $-0,022$ & 0,330 & 0,154 & 3155 & 11264 & 0,197 & 0,703 \\
\hline 9 & 0,330 & 0,682 & 0,506 & 2449 & 13713 & 0,153 & 0,856 \\
\hline 10 & 0,682 & 1,034 & 0,858 & 1410 & 15123 & 0,088 & 0,944 \\
\hline 11 & 1,034 & 1,386 & 1,210 & 543 & 15666 & 0,034 & 0,977 \\
\hline 12 & 1,386 & 1,738 & 1,562 & 254 & 15920 & 0,016 & 0,993 \\
\hline 13 & 1,738 & 2,090 & 1,914 & 65 & 15985 & 0,004 & 0,997 \\
\hline 14 & 2,090 & 2,442 & 2,266 & 37 & 16022 & 0,002 & 1,000 \\
\hline 15 & 2,442 & 2,794 & 2,618 & 6 & 16028 & 0,000 & 1,000 \\
\hline
\end{tabular}

\begin{tabular}{|c|c|c|c|c|c|c|c|}
\hline Classe & $\begin{array}{c}\text { Limite inferior } \\
\text { da classe }\end{array}$ & $\begin{array}{c}\text { Limite superior } \\
\text { da classe }\end{array}$ & $\begin{array}{c}\text { Média da classe } \\
\mathrm{Mi}\end{array}$ & $\begin{array}{c}\text { Frequência } \\
\mathrm{ni}\end{array}$ & $\begin{array}{c}\text { Frequência } \\
\text { absoluta acumulada } \\
\mathrm{Ni}\end{array}$ & $\begin{array}{c}\text { Frequência } \\
\text { relativa } \\
\mathrm{fi}\end{array}$ & $\begin{array}{c}\text { Frequência } \\
\text { relativa acumulada } \\
\mathrm{Fi}\end{array}$ \\
\hline 1 & $-2,656$ & $-2,331$ & $-2,494$ & 3 & 3 & 0,000 & 0,000 \\
\hline 2 & $-2,331$ & $-2,005$ & $-2,168$ & 10 & 13 & 0,001 & 0,001 \\
\hline 3 & $-2,005$ & $-1,680$ & $-1,843$ & 17 & 30 & 0,001 & 0,002 \\
\hline 4 & $-1,680$ & $-1,354$ & $-1,517$ & 58 & 88 & 0,004 & 0,005 \\
\hline 5 & $-1,354$ & $-1,029$ & $-1,192$ & 254 & 342 & 0,016 & 0,021 \\
\hline 6 & $-1,029$ & $-0,703$ & $-0,866$ & 1045 & 1387 & 0,065 & 0,087 \\
\hline 7 & $-0,703$ & $-0,378$ & $-0,541$ & 2524 & 3911 & 0,157 & 0,244 \\
\hline 8 & $-0,378$ & $-0,052$ & $-0,215$ & 2990 & 6901 & 0,187 & 0,431 \\
\hline 9 & $-0,052$ & 0,273 & 0,110 & 4347 & 11248 & 0,271 & 0,702 \\
\hline 10 & 0,273 & 0,599 & 0,436 & 3027 & 14275 & 0,189 & 0,891 \\
\hline 11 & 0,599 & 0,924 & 0,761 & 1176 & 15451 & 0,073 & 0,964 \\
\hline 12 & 0,924 & 1,250 & 1,087 & 414 & 15865 & 0,026 & 0,990 \\
\hline 13 & 1,250 & 1,575 & 1,413 & 132 & 15997 & 0,008 & 0,998 \\
\hline 14 & 1,575 & 1,901 & 1,738 & 27 & 16024 & 0,002 & 1,000 \\
\hline 15 & 1,901 & 2,226 & 2,064 & 3 & 16027 & 0,000 & 1,000 \\
\hline
\end{tabular}

\begin{tabular}{|c|c|c|c|c|c|c|c|}
\hline \multicolumn{7}{|c|}{ Acelerômetro 2, teste 5,6,7,8 com AMS } \\
\hline Classe & $\begin{array}{c}\text { Limite inferior } \\
\text { da classe }\end{array}$ & $\begin{array}{c}\text { Limite superior } \\
\text { da classe }\end{array}$ & $\begin{array}{c}\text { Média da classe } \\
\mathrm{Mi}\end{array}$ & $\begin{array}{c}\text { Frequência } \\
\text { ni }\end{array}$ & $\begin{array}{c}\text { Frequência } \\
\text { absoluta acumulada } \\
\mathrm{Ni}\end{array}$ & $\begin{array}{c}\text { Frequência } \\
\text { relativa } \\
\mathrm{fi}\end{array}$ & $\begin{array}{c}\text { Frequência } \\
\text { relativa acumulada } \\
\mathrm{Fi}\end{array}$ \\
\hline 1 & $-2,457$ & $-2,124$ & $-2,290$ & 13 & 13 & 0,001 & 0,001 \\
\hline 2 & $-2,124$ & $-1,790$ & $-1,957$ & 46 & 59 & 0,003 & 0,004 \\
\hline 3 & $-1,790$ & $-1,457$ & $-1,624$ & 137 & 196 & 0,009 & 0,012 \\
\hline 4 & $-1,457$ & $-1,124$ & $-1,291$ & 343 & 539 & 0,021 & 0,034 \\
\hline 5 & $-1,124$ & $-0,791$ & $-0,958$ & 1085 & 1624 & 0,068 & 0,101 \\
\hline 6 & $-0,791$ & $-0,458$ & $-0,625$ & 1903 & 3527 & 0,119 & 0,220 \\
\hline 7 & $-0,458$ & $-0,125$ & $-0,292$ & 3273 & 6800 & 0,204 & 0,424 \\
\hline 8 & $-0,125$ & 0,208 & 0,041 & 3398 & 10198 & 0,212 & 0,636 \\
\hline 9 & 0,208 & 0,541 & 0,375 & 3005 & 13203 & 0,187 & 0,824 \\
\hline 10 & 0,541 & 0,874 & 0,708 & 1576 & 14779 & 0,098 & 0,922 \\
\hline 11 & 0,874 & 1,207 & 1,041 & 775 & 15554 & 0,048 & 0,970 \\
\hline 12 & 1,207 & 1,540 & 1,374 & 301 & 15855 & 0,019 & 0,989 \\
\hline 13 & 1,540 & 1,873 & 1,707 & 123 & 15978 & 0,008 & 0,997 \\
\hline 14 & 1,873 & 2,206 & 2,040 & 39 & 16017 & 0,002 & 0,999 \\
\hline 15 & 2,206 & 2,540 & 2,373 & 11 & 16028 & 0,001 & 1,000 \\
\hline
\end{tabular}

\begin{tabular}{|c|c|c|c|c|c|c|c|}
\hline \multicolumn{7}{|c|}{ Acelerômetro 3, teste 5,6,7,8 com AMS } \\
\hline Classe & $\begin{array}{c}\text { cimite inferior } \\
\text { da classe }\end{array}$ & $\begin{array}{c}\text { Limite superior } \\
\text { da classe }\end{array}$ & $\begin{array}{c}\text { Média da classe } \\
\text { Mi }\end{array}$ & $\begin{array}{c}\text { Frequência } \\
\text { ni }\end{array}$ & $\begin{array}{c}\text { Frequência } \\
\text { absoluta acumulada } \\
\mathrm{Ni}\end{array}$ & $\begin{array}{c}\text { Frequência } \\
\text { relativa } \\
\mathrm{fi}\end{array}$ & $\begin{array}{c}\text { Frequência } \\
\text { relativa acumulada } \\
\text { Fi }\end{array}$ \\
\hline 1 & $-2,019$ & $-1,701$ & $-1,860$ & 6 & 6 & 0,000 & 0,000 \\
\hline 2 & $-1,701$ & $-1,383$ & $-1,542$ & 81 & 87 & 0,005 & 0,005 \\
\hline 3 & $-1,383$ & $-1,065$ & $-1,224$ & 244 & 331 & 0,015 & 0,021 \\
\hline 4 & $-1,065$ & $-0,747$ & $-0,906$ & 899 & 1230 & 0,056 & 0,077 \\
\hline 5 & $-0,747$ & $-0,429$ & $-0,588$ & 2321 & 3551 & 0,145 & 0,222 \\
\hline 6 & $-0,429$ & $-0,111$ & $-0,270$ & 2827 & 6378 & 0,176 & 0,398 \\
\hline 7 & $-0,111$ & 0,207 & 0,048 & 4515 & 10893 & 0,282 & 0,680 \\
\hline 8 & 0,207 & 0,525 & 0,366 & 2521 & 13414 & 0,157 & 0,837 \\
\hline 9 & 0,525 & 0,843 & 0,684 & 1789 & 15203 & 0,112 & 0,949 \\
\hline 10 & 0,843 & 1,161 & 1,002 & 601 & 15804 & 0,037 & 0,986 \\
\hline 11 & 1,161 & 1,479 & 1,320 & 160 & 15964 & 0,010 & 0,996 \\
\hline 12 & 1,479 & 1,797 & 1,638 & 46 & 16010 & 0,003 & 0,999 \\
\hline 13 & 1,797 & 2,115 & 1,956 & 7 & 16017 & 0,000 & 0,999 \\
\hline 14 & 2,115 & 2,433 & 2,274 & 10 & 16027 & 0,001 & 1,000 \\
\hline 15 & 2,433 & 2,750 & 2,591 & 1 & 16028 & 0,000 & 1,000 \\
\hline
\end{tabular}


Análise estatística sem e com controle para ensaios pulos desde carteira escolar.
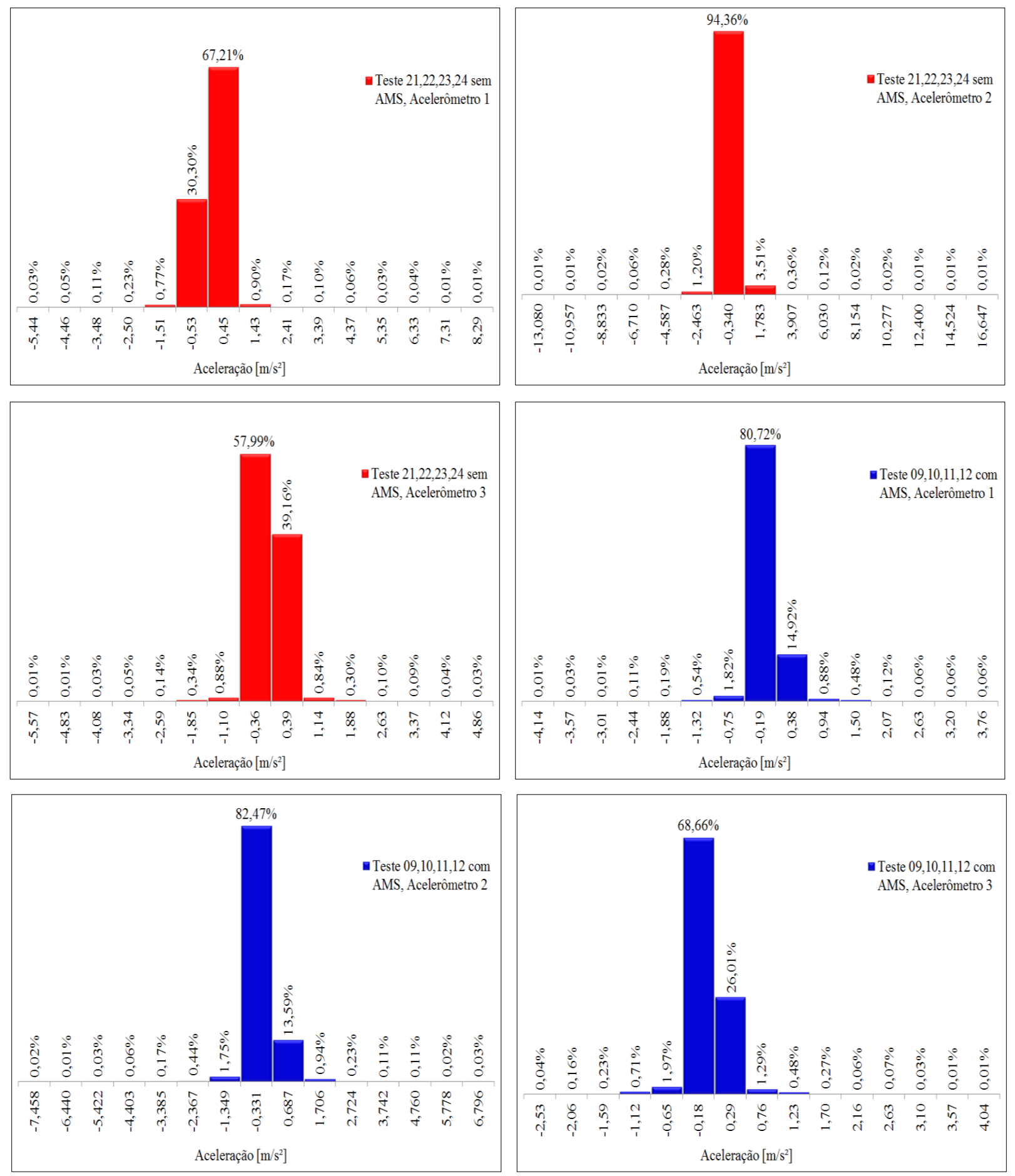


\section{Análise estatística sem e com controle para ensaios pulos desde carteira escolar.}

\begin{tabular}{|c|c|c|c|c|c|c|c|}
\hline \multicolumn{7}{|c|}{ Acelerômetro 1, teste 21,22,23,24 sem AMS } \\
\hline Classe & $\begin{array}{c}\text { Limite inferior } \\
\text { da classe }\end{array}$ & $\begin{array}{c}\text { Limite superior } \\
\text { da classe }\end{array}$ & $\begin{array}{c}\text { Média da classe } \\
\mathrm{Mi}\end{array}$ & $\begin{array}{c}\text { Frequência } \\
\mathrm{ni}\end{array}$ & $\begin{array}{c}\text { Frequência } \\
\text { absoluta acumulada } \\
\mathrm{Ni}\end{array}$ & $\begin{array}{c}\text { Frequência } \\
\text { relativa } \\
\mathrm{fi}\end{array}$ & $\begin{array}{c}\text { Frequência } \\
\text { relativa acumulada } \\
\mathrm{Fi}\end{array}$ \\
\hline 1 & $-5,926$ & $-4,946$ & $-5,436$ & 5 & 5 & 0,0003 & 0,0003 \\
\hline 2 & $-4,946$ & $-3,966$ & $-4,456$ & 8 & 13 & 0,0005 & 0,001 \\
\hline 3 & $-3,966$ & $-2,985$ & $-3,475$ & 17 & 30 & 0,001 & 0,002 \\
\hline 4 & $-2,985$ & $-2,005$ & $-2,495$ & 37 & 67 & 0,002 & 0,004 \\
\hline 5 & $-2,005$ & $-1,025$ & $-1,515$ & 123 & 190 & 0,008 & 0,012 \\
\hline 6 & $-1,025$ & $-0,044$ & $-0,535$ & 4856 & 5046 & 0,303 & 0,315 \\
\hline 7 & $-0,044$ & 0,936 & 0,446 & 10772 & 15818 & 0,672 & 0,987 \\
\hline 8 & 0,936 & 1,916 & 1,426 & 145 & 15963 & 0,009 & 0,996 \\
\hline 9 & 1,916 & 2,897 & 2,406 & 27 & 15990 & 0,002 & 0,998 \\
\hline 10 & 2,897 & 3,877 & 3,387 & 16 & 16006 & 0,001 & 0,999 \\
\hline 11 & 3,877 & 4,857 & 4,367 & 9 & 16015 & 0,001 & 0,999 \\
\hline 12 & 4,857 & 5,837 & 5,347 & 5 & 16020 & 0,0003 & 0,9995 \\
\hline 13 & 5,837 & 6,818 & 6,328 & 6 & 16026 & 0,0004 & 0,9999 \\
\hline 14 & 6,818 & 7,798 & 7,308 & 1 & 16027 & 0,0001 & 0,9999 \\
\hline 15 & 7,798 & 8,778 & 8,288 & 1 & 16028 & 0,0001 & 1,0000 \\
\hline
\end{tabular}

\begin{tabular}{|c|c|c|c|c|c|c|c|}
\hline \multicolumn{7}{|c|}{ Acelerômetro 2, teste 21,22,23,24 sem AMS } \\
\hline Classe & $\begin{array}{c}\text { Limite inferior } \\
\text { da classe }\end{array}$ & $\begin{array}{c}\text { Limite superior } \\
\text { da classe }\end{array}$ & $\begin{array}{c}\text { Média da classe } \\
\mathrm{Mi}\end{array}$ & $\begin{array}{c}\text { Frequência } \\
\mathrm{ni}\end{array}$ & $\begin{array}{c}\text { Frequência } \\
\text { absoluta acumulada } \\
\mathrm{Ni}\end{array}$ & $\begin{array}{c}\text { Frequência } \\
\text { relativa } \\
\mathrm{fi}\end{array}$ & $\begin{array}{c}\text { Frequência } \\
\text { relativa acumulada } \\
\mathrm{Fi}\end{array}$ \\
\hline 1 & $-14,142$ & $-12,018$ & $-13,080$ & 1 & 1 & 0,00006 & 0,0001 \\
\hline 2 & $-12,018$ & $-9,895$ & $-10,957$ & 1 & 2 & 0,00006 & 0,00012 \\
\hline 3 & $-9,895$ & $-7,772$ & $-8,833$ & 3 & 5 & 0,0002 & 0,000 \\
\hline 4 & $-7,772$ & $-5,648$ & $-6,710$ & 10 & 15 & 0,001 & 0,001 \\
\hline 5 & $-5,648$ & $-3,525$ & $-4,587$ & 45 & 60 & 0,003 & 0,004 \\
\hline 6 & $-3,525$ & $-1,402$ & $-2,463$ & 192 & 252 & 0,012 & 0,016 \\
\hline 7 & $-1,402$ & 0,722 & $-0,340$ & 15124 & 15376 & 0,944 & 0,959 \\
\hline 8 & 0,722 & 2,845 & 1,783 & 563 & 15939 & 0,035 & 0,994 \\
\hline 9 & 2,845 & 4,969 & 3,907 & 57 & 15996 & 0,004 & 0,998 \\
\hline 10 & 4,969 & 7,092 & 6,030 & 20 & 16016 & 0,001 & 0,999 \\
\hline 11 & 7,092 & 9,215 & 8,154 & 4 & 16020 & 0,0002 & 0,9995 \\
\hline 12 & 9,215 & 11,339 & 10,277 & 3 & 16023 & 0,0002 & 0,9997 \\
\hline 13 & 11,339 & 13,462 & 12,400 & 2 & 16025 & 0,0001 & 0,9998 \\
\hline 14 & 13,462 & 15,585 & 14,524 & 2 & 16027 & 0,0001 & 0,9999 \\
\hline 15 & 15,585 & 17,709 & 16,847 & 1 & 16028 & 0,0001 & 1,0000 \\
\hline
\end{tabular}

\begin{tabular}{|c|c|c|c|c|c|c|c|}
\hline \multicolumn{7}{|c|}{ Acelerômetro 3, teste 21,22,23,24 sem AMS } \\
\hline Classe & $\begin{array}{c}\text { Limite inferior } \\
\text { da classe }\end{array}$ & $\begin{array}{c}\text { Limite superior } \\
\text { da classe }\end{array}$ & $\begin{array}{c}\text { Média da classe } \\
\mathrm{Mi}\end{array}$ & $\begin{array}{c}\text { Frequência } \\
\text { ni }\end{array}$ & $\begin{array}{c}\text { Frequência } \\
\text { absoluta acumulada } \\
\mathrm{Ni}\end{array}$ & $\begin{array}{c}\text { Frequência } \\
\text { relativa } \\
\mathrm{fi}\end{array}$ & $\begin{array}{c}\text { Frequência } \\
\text { relativa acumulada } \\
\mathrm{Fi}\end{array}$ \\
\hline 1 & $-5,948$ & $-5,202$ & $-5,575$ & 1 & 1 & 0,00006 & 0,00006 \\
\hline 2 & $-5,202$ & $-4,457$ & $-4,829$ & 1 & 2 & 0,00006 & 0,00012 \\
\hline 3 & $-4,457$ & $-3,711$ & $-4,084$ & 5 & 7 & 0,0003 & 0,0004 \\
\hline 4 & $-3,711$ & $-2,965$ & $-3,338$ & 8 & 15 & 0,0005 & 0,001 \\
\hline 5 & $-2,965$ & $-2,220$ & $-2,592$ & 22 & 37 & 0,001 & 0,002 \\
\hline 6 & $-2,220$ & $-1,474$ & $-1,847$ & 54 & 91 & 0,003 & 0,006 \\
\hline 7 & $-1,474$ & $-0,728$ & $-1,101$ & 141 & 232 & 0,009 & 0,014 \\
\hline 8 & $-0,728$ & 0,017 & $-0,355$ & 9294 & 9526 & 0,580 & 0,594 \\
\hline 9 & 0,017 & 0,763 & 0,390 & 6277 & 15803 & 0,392 & 0,986 \\
\hline 10 & 0,763 & 1,509 & 1,136 & 135 & 15938 & 0,008 & 0,994 \\
\hline 11 & 1,509 & 2,254 & 1,881 & 48 & 15986 & 0,003 & 0,997 \\
\hline 12 & 2,254 & 3,000 & 2,627 & 16 & 16002 & 0,001 & 0,998 \\
\hline 13 & 3,000 & 3,746 & 3,373 & 14 & 16016 & 0,001 & 0,9993 \\
\hline 14 & 3,746 & 4,491 & 4,118 & 7 & 16023 & 0,0004 & 0,9997 \\
\hline 15 & 4,491 & 5,237 & 4,864 & 5 & 16028 & 0,0003 & 1,000 \\
\hline
\end{tabular}

\begin{tabular}{|c|c|c|c|c|c|c|c|}
\hline Classe & $\begin{array}{c}\text { Limite inferior } \\
\text { da classe }\end{array}$ & $\begin{array}{c}\text { Limite superior } \\
\text { da classe }\end{array}$ & $\begin{array}{c}\text { Média da classe } \\
\mathrm{Mi}\end{array}$ & $\begin{array}{c}\text { Frequência } \\
\mathrm{ni}\end{array}$ & $\begin{array}{c}\text { Frequência } \\
\text { absoluta acumulada } \\
\mathrm{Ni}\end{array}$ & $\begin{array}{c}\text { Frequência } \\
\text { relativa } \\
\mathrm{fi}\end{array}$ & $\begin{array}{c}\text { Frequência } \\
\text { relativa acumulada } \\
\mathrm{Fi}\end{array}$ \\
\hline 1 & $-4,418$ & $-3,854$ & $-4,136$ & 1 & 1 & 0,0001 & 0,0001 \\
\hline 2 & $-3,854$ & $-3,290$ & $-3,572$ & 5 & 6 & 0,0003 & 0,0004 \\
\hline 3 & $-3,290$ & $-2,726$ & $-3,008$ & 2 & 8 & 0,0001 & 0,0005 \\
\hline 4 & $-2,726$ & $-2,162$ & $-2,444$ & 17 & 25 & 0,001 & 0,002 \\
\hline 5 & $-2,162$ & $-1,598$ & $-1,880$ & 30 & 55 & 0,002 & 0,003 \\
\hline 6 & $-1,598$ & $-1,034$ & $-1,316$ & 86 & 141 & 0,005 & 0,009 \\
\hline 7 & $-1,034$ & $-0,470$ & $-0,752$ & 292 & 433 & 0,018 & 0,027 \\
\hline 8 & $-0,470$ & 0,094 & $-0,188$ & 12938 & 13371 & 0,807 & 0,834 \\
\hline 9 & 0,094 & 0,658 & 0,376 & 2392 & 15763 & 0,149 & 0,983 \\
\hline 10 & 0,658 & 1,222 & 0,940 & 141 & 15904 & 0,009 & 0,992 \\
\hline 11 & 1,222 & 1,786 & 1,504 & 77 & 15981 & 0,005 & 0,997 \\
\hline 12 & 1,786 & 2,350 & 2,068 & 19 & 16000 & 0,001 & 0,998 \\
\hline 13 & 2,350 & 2,914 & 2,632 & 10 & 16010 & 0,001 & 0,9989 \\
\hline 14 & 2,914 & 3,478 & 3,196 & 9 & 16019 & 0,001 & 0,9994 \\
\hline 15 & 3,478 & 4,042 & 3,760 & 9 & 16028 & 0,0006 & 1,000 \\
\hline
\end{tabular}

\begin{tabular}{|c|c|c|c|c|c|c|c|}
\hline \multicolumn{7}{|c|}{ Acelerômetro 2, teste $09,10,11,12$ com AMS } \\
\hline Classe & $\begin{array}{c}\text { Limite inferior } \\
\text { da classe }\end{array}$ & $\begin{array}{c}\text { Limite superior } \\
\text { da classe }\end{array}$ & $\begin{array}{c}\text { Média da classe } \\
\mathrm{Mi}\end{array}$ & $\begin{array}{c}\text { Frequência } \\
\text { ni }\end{array}$ & $\begin{array}{c}\text { Frequência } \\
\text { absoluta acumulada } \\
\mathrm{Ni}\end{array}$ & $\begin{array}{c}\text { Frequência } \\
\text { relativa } \\
\mathrm{fi}\end{array}$ & $\begin{array}{c}\text { Frequência } \\
\text { relativa acumulada } \\
\mathrm{Fi}\end{array}$ \\
\hline 1 & $-7,967$ & $-6,949$ & $-7,458$ & 3 & 3 & 0,0002 & 0,0002 \\
\hline 2 & $-6,949$ & $-5,931$ & $-6,440$ & 1 & 4 & 0,0001 & 0,0002 \\
\hline 3 & $-5,931$ & $-4,912$ & $-5,422$ & 5 & 9 & 0,0003 & 0,0006 \\
\hline 4 & $-4,912$ & $-3,894$ & $-4,403$ & 9 & 18 & 0,0006 & 0,0011 \\
\hline 5 & $-3,894$ & $-2,876$ & $-3,385$ & 28 & 46 & 0,0017 & 0,0029 \\
\hline 6 & $-2,876$ & $-1,858$ & $-2,367$ & 70 & 116 & 0,004 & 0,007 \\
\hline 7 & $-1,858$ & $-0,840$ & $-1,349$ & 281 & 397 & 0,018 & 0,025 \\
\hline 8 & $-0,840$ & 0,178 & $-0,331$ & 13218 & 13615 & 0,825 & 0,849 \\
\hline 9 & 0,178 & 1,196 & 0,687 & 2179 & 15794 & 0,136 & 0,985 \\
\hline 10 & 1,196 & 2,215 & 1,706 & 151 & 15945 & 0,009 & 0,995 \\
\hline 11 & 2,215 & 3,233 & 2,724 & 37 & 15982 & 0,002 & 0,997 \\
\hline 12 & 3,233 & 4,251 & 3,742 & 18 & 16000 & 0,001 & 0,998 \\
\hline 13 & 4,251 & 5,269 & 4,760 & 18 & 16018 & 0,001 & 0,999 \\
\hline 14 & 5,269 & 6,287 & 5,778 & 4 & 16022 & 0,0002 & 0,9996 \\
\hline 15 & 6,287 & 7,305 & 6,796 & 5 & 16027 & 0,0003 & 1,000 \\
\hline
\end{tabular}

\begin{tabular}{|c|c|c|c|c|c|c|c|}
\hline \multicolumn{7}{|c|}{ Acelerômetro 3, teste 09,10,11,12 com AMS } \\
\hline Classe & $\begin{array}{c}\text { Limite inferior } \\
\text { da classe }\end{array}$ & $\begin{array}{c}\text { Limite superior } \\
\text { da classe }\end{array}$ & $\begin{array}{c}\text { Média da classe } \\
\mathrm{Mi}\end{array}$ & $\begin{array}{c}\text { Frequência } \\
\text { ni }\end{array}$ & $\begin{array}{c}\text { Frequência } \\
\text { absoluta acumulada } \\
\mathrm{Ni}\end{array}$ & $\begin{array}{c}\text { Frequência } \\
\text { relativa } \\
\mathrm{fi}\end{array}$ & $\begin{array}{c}\text { Frequência } \\
\text { relativa acumulada } \\
\text { Fi }\end{array}$ \\
\hline 1 & $-2,764$ & $-2,294$ & $-2,529$ & 6 & 6 & 0,0004 & 0,0004 \\
\hline 2 & $-2,294$ & $-1,825$ & $-2,060$ & 25 & 31 & 0,0016 & 0,0019 \\
\hline 3 & $-1,825$ & $-1,356$ & $-1,590$ & 37 & 68 & 0,0023 & 0,0042 \\
\hline 4 & $-1,356$ & $-0,886$ & $-1,121$ & 113 & 181 & 0,007 & 0,011 \\
\hline 5 & $-0,886$ & $-0,417$ & $-0,652$ & 316 & 497 & 0,020 & 0,031 \\
\hline 6 & $-0,417$ & 0,052 & $-0,182$ & 11005 & 11502 & 0,687 & 0,718 \\
\hline 7 & 0,052 & 0,522 & 0,287 & 4169 & 15671 & 0,260 & 0,978 \\
\hline 8 & 0,522 & 0,991 & 0,756 & 207 & 15878 & 0,013 & 0,991 \\
\hline 9 & 0,991 & 1,460 & 1,226 & 77 & 15955 & 0,005 & 0,995 \\
\hline 10 & 1,460 & 1,930 & 1,695 & 44 & 15999 & 0,003 & 0,998 \\
\hline 11 & 1,930 & 2,399 & 2,164 & 9 & 16008 & 0,001 & 0,999 \\
\hline 12 & 2,399 & 2,868 & 2,634 & 12 & 16020 & 0,0007 & 0,9995 \\
\hline 13 & 2,868 & 3,338 & 3,103 & 5 & 16025 & 0,0003 & 0,9998 \\
\hline 14 & 3,338 & 3,807 & 3,572 & 2 & 16027 & 0,0001 & 0,9999 \\
\hline 15 & 3,807 & 4,276 & 4,042 & 1 & 16028 & 0,0001 & 1,0000 \\
\hline
\end{tabular}




\section{Anexo XII \\ APDL ANSYS, GERAÇÃO DO MODELO NUMERICO.}

FINISH

/CLEAR

/PREP7

/TITLE, Plataforma de ensaios dinâmicos, elementos SHELL63, BEAM4 e COMBIN40.

!************************

! Variável a ser mudadas !

!***********************!

esp $=0.1$

$\mathrm{Ec}=23800 \mathrm{e} 6$

! Espessura da laje

$\mathrm{Es}=200 \mathrm{E} 9$

! Módulo de elasticidade do concreto para um fck de $25 \mathrm{Mpa}(\mathrm{N} / \mathrm{m} 2)$

$\mathrm{vc}=0.2$

! Módulo elasticidade do aço (N/m2)

$\mathrm{vs}=0.3$

! Coeficiente de Poisson do concreto

$\mathrm{dc}=2500$

! Coeficiente de Poisson do aço

$\mathrm{ds}=7850$

! Densidade do concreto armado $(\mathrm{Kg} / \mathrm{m} 3)$

camada $=0.045$

! Densidade do aço $(\mathrm{Kg} / \mathrm{m} 3)$

ex $2=16 \mathrm{e} 9$

!Espessura da camada do sikadur $42 \mathrm{cl}$

cp $2=0.2$

!modulo de elasticidade do sikadur $42 \mathrm{cl}$

densidade $2=2000$

!coeficiente de poisson do sikadur $42 \mathrm{cl}$

!densidade do sikadur $42 \mathrm{cl}$

! Perfil de aço W200x19.3 tipo "I"

$\mathrm{A}=0.00251 \quad$ ! Área do perfil de aço tipo "I" (m2)

$\mathrm{I}=0.00001686 \quad$ ! Inércia do perfil de aço tipo "I" (m4)

$\mathrm{h}=0.203$

$\mathrm{bf}=0.102$

! Altura do perfil de aço tipo "I" (m)

$\mathrm{tf}=0.0065$

! Comprimento da mesa do perfil de aço tipo "I" (m)

$\mathrm{tw}=0.0058$

! Espessura da mesa do perfil de aço tipo "I" (m)

$\mathrm{Ms}=19.3$

! Espessura da alma do perfil de aço tipo "I" (m)

! Massa por unidade de comprimento do perfil do aço tipo "I" $(\mathrm{kg} / \mathrm{m})$

! Enrijecedores de aço de bitola de 1 polegada

$\mathrm{db}=0.0254 \quad$ ! Diâmetro da barra circular que serve de enrijecedor (m)

! Dimensões da laje

$1=4.9 \quad$ ! Comprimento da laje do concreto e do perfil de aço (m)

Dis $=6 \quad$ ! Distância entre eixos do perfil de aço (m)

! Pilar do aço tipo "H" (Cavalete)

$\mathrm{Apc}=0.011212 \quad$ ! Área do perfil de aço tipo "H" (m2)

$\mathrm{Ipc}=0.000137 \quad$ ! Inércia do perfil de aço tipo "H" (m4)

$\mathrm{hpc}=0.26$

$\mathrm{bfpc}=0.25$

! Altura do perfil de aço tipo "H" (m)

$\mathrm{tfpc}=0.017$

! Comprimento da mesa do perfil de aço tipo "H" (m)

$\mathrm{twpc}=0.012$

$\mathrm{Mspc}=88.0142$

$\mathrm{cpc}=0.6$

! Espessura da mesa do perfil de aço tipo "H" (m)

! Espessura da alma do perfil de aço tipo "H" (m)

! Massa por unidade de comprimento do perfil de aço tipo "H" $(\mathrm{kg} / \mathrm{m})$

! Comprimento do perfil de aço tipo "H" (m) 
! Bases de aço

Base $=0.0254 \quad$ ! Espessura da base dos pilares de aço tipo "H" (m)

! Perfil de Aço tipo "U"

$\begin{array}{ll}\text { hc }=0.1016 & \text { ! Altura do perfil de aço tipo "U" (m) } \\ \text { bfc }=0.04020 & \text { ! Comprimento da mesa do perfil de aço tipo "U" (m) } \\ \text { tfc }=0.00752 & \text { ! Espessura da mesa do perfil de aço tipo "U" (m) } \\ \text { twc }=0.00467 & \text { ! Espessura da alma do perfil de aço tipo "U" (m) } \\ \text { Msc }=8.04 & \text { ! Massa por unidade de comprimento do perfil de aço tipo "U" (kg/m) }\end{array}$

! Tamanho da malha dos elementos finitos

ndiv $=0.020081967213 \quad$ !Tamanho malha aço $(\mathrm{m})$

ndivc $=244 \quad$ ! Tamanho da malha concreto $(\mathrm{m})$

!************************!

! Definição da geometria !

!***********************!

! Definição dos keypoints do perfil de aço esquerdo tipo "I"

$\mathrm{K}, 1,0,0,0$

! Cria o keypoint número 1 com coordenadas $0,0,0$

$\mathrm{K}, 2, \mathrm{bf} / 2,0,0$

$\mathrm{K}, 3, \mathrm{bf}, 0,0$

$\mathrm{K}, 4, \mathrm{bf} / 2,0,-\mathrm{h}+\mathrm{hc}$

$\mathrm{K}, 5, \mathrm{bf} / 2, \mathrm{bfc},-\mathrm{h}+\mathrm{hc}$

$\mathrm{K}, 6, \mathrm{bf} / 2, \mathrm{bfc},-\mathrm{h}$

$\mathrm{K}, 7, \mathrm{bf} / 2,0,-\mathrm{h}$

$\mathrm{K}, 8,0,0,-\mathrm{h}$

$\mathrm{K}, 9, \mathrm{bf}, 0,-\mathrm{h}$

$\mathrm{K}, 10,0,1,0$

$\mathrm{K}, 11, \mathrm{bf} / 2,1,0$

$\mathrm{K}, 12, \mathrm{bf}, 1,0$

$\mathrm{K}, 13, \mathrm{bf} / 2,1,-\mathrm{h}+\mathrm{hc}$

$\mathrm{K}, 14, \mathrm{bf} / 2,1-\mathrm{bfc},-\mathrm{h}+\mathrm{hc}$

$\mathrm{K}, 15, \mathrm{bf} / 2,1-\mathrm{bfc},-\mathrm{h}$

$\mathrm{K}, 16, \mathrm{bf} / 2,1,-\mathrm{h}$

$\mathrm{K}, 17,0,1,-\mathrm{h}$

$\mathrm{K}, 18, \mathrm{bf}, 1,-\mathrm{h}$

! Definição das áreas do perfil de aço esquerdo tipo "I"

A, $1,2,11,10$

! Cria o área 1 mediante a união dos keypoints $1,2,11,10$

A, 2,3,12,11

! Área 2

A, 2,4,5,14,13,11

! Área 3

A,4,7,6,15,16,13,14,5 ! Área 4

A,8,7,6,15,16,17 ! Área 5

A, $7,9,18,16,15,6$ ! Área 6

AGLUE, 1,2,3,4 ! União entre as áreas 1,2,3,4

AGLUE,3,4,5,6 ! União entre as áreas 3,4,5,6

! Definição dos keypoints do perfil de aço direito tipo "I" 
K,19,Dis, 0,0

$\mathrm{K}, 20$,Dis+bf $/ 2,0,0$

$\mathrm{K}, 21$,Dis+bf, 0,0

$\mathrm{K}, 22, \mathrm{Dis}+\mathrm{bf} / 2,0,-\mathrm{h}+\mathrm{hc}$

$\mathrm{K}, 23$,Dis+bf/2,bfc,-h+hc

$\mathrm{K}, 24, \mathrm{Dis}+\mathrm{bf} / 2, \mathrm{bfc},-\mathrm{h}$

$\mathrm{K}, 25$,Dis+bf/2,0,-h

K,26,Dis, $0,-h$

$\mathrm{K}, 27$, Dis+bf, $0,-\mathrm{h}$

$\mathrm{K}, 28$, Dis, $, 1,0$

$\mathrm{K}, 29$, Dis $+\mathrm{bf} / 2,1,0$

$\mathrm{K}, 30$,Dis+bf, 1,0

$\mathrm{K}, 31, \mathrm{Dis}+\mathrm{bf} / 2,1,-\mathrm{h}+\mathrm{hc}$

K,32,Dis+bf/2,1-bfc,-h+hc

$\mathrm{K}, 33$, Dis $+\mathrm{bf} / 2, \mathrm{l}-\mathrm{bfc},-\mathrm{h}$

$\mathrm{K}, 34, \mathrm{Dis}+\mathrm{bf} / 2,1,-\mathrm{h}$

$\mathrm{K}, 35$,Dis,, ,-h

$\mathrm{K}, 36$,Dis+bf,l,-h

! Definição das áreas do perfil de aço direito tipo "I"
! Cria o keypoint número 19 com coordenadas Dis,0,0

A,19,20,29,28 ! Cria o área 7 mediante a união dos keypoints $19,20,29,28$

A, $20,21,30,29$

! Área 8

A, 20,22,23,32,31,29 ! Área 9

A,22,25,24,33,34,31,32,23 ! Área 10

A, 26,25,24,33,34,35 ! Área 11

A,25,27,36,34,33,24 ! Área 12

AGLUE, 7,8,9,10 ! União entre as áreas 7,8,9,10

AGLUE,9,10,11,12 ! União entre as áreas 9,10,11,12

! Criação das áreas dos perfis "U" para fechar quadro das laterais, com comprimento de $6 \mathrm{~m}$ (parte da frente)

A,5,4,22,23 ! Cria o área 13 mediante a união dos keypoints 5,4,22,23

$\mathrm{A}, 4,7,25,22 \quad$ ! Área 14

A, $6,7,25,24 \quad$ ! Área 15

AGLUE,13,14,15 ! União entre as áreas 13,14,15

! Criação das áreas dos perfis "U" para fechar quadro das laterais, com comprimento de $6 \mathrm{~m}$ (parte de trás)

A,14,13,31,32 ! Cria o área 16 mediante a união dos keypoints 14,13,31,32

A, $13,16,34,31 \quad$ ! Área 17

A, $15,16,34,33 \quad$ ! Área 18

AGLUE,16,17,18 ! União entre as áreas 16,17,18

! Definiç̧ão da área da laje

A,1,2,3,19,20,21,30,29,28,12,11,10 !Cria área 19 mediante a união dos keypoints $1,2,3,19,20,21,30, \ldots, 10$

! Criação do perfil esquerdo dianteiro de aço tipo "I" que são perpendiculares aos outros perfis de comprimento ! de $6 \mathrm{~m}$.

$\mathrm{K}, 37, \mathrm{bf} / 2-\mathrm{hpc} / 2,0,-\mathrm{h} \quad$ ! Cria o keypoint número 37 com coordenadas bf/2-hpc/2,0,-h

$\mathrm{K}, 38, \mathrm{bf} / 2+\mathrm{hpc} / 2,0,-\mathrm{h}$ 
K,39,bf/2+hpc/2,bf/2,-h

$\mathrm{K}, 40, \mathrm{bf} / 2+\mathrm{hpc} / 2, \mathrm{bf},-\mathrm{h}$

$\mathrm{K}, 41, \mathrm{bf} / 2-\mathrm{hpc} / 2, \mathrm{bf},-\mathrm{h}$

$\mathrm{K}, 42, \mathrm{bf} / 2-\mathrm{hpc} / 2, \mathrm{bf} / 2, \mathrm{-h}$

$\mathrm{K}, 43, \mathrm{bf} / 2-\mathrm{hpc} / 2, \mathrm{bf} / 2,-1.5^{*} \mathrm{~h}$

$\mathrm{K}, 44, \mathrm{bf} / 2+\mathrm{hpc} / 2, \mathrm{bf} / 2,-1.5 * \mathrm{~h}$

$\mathrm{K}, 45, \mathrm{bf} / 2-\mathrm{hpc} / 2,0,-2 * \mathrm{~h}$

$\mathrm{K}, 46, \mathrm{bf} / 2+\mathrm{hpc} / 2,0,-2 * \mathrm{~h}$

$\mathrm{K}, 47, \mathrm{bf} / 2+\mathrm{hpc} / 2, \mathrm{bf} / 2,-2 * \mathrm{~h}$

$\mathrm{K}, 48, \mathrm{bf} / 2+\mathrm{hpc} / 2, \mathrm{bf},-2 * \mathrm{~h}$

$\mathrm{K}, 49, \mathrm{bf} / 2-\mathrm{hpc} / 2, \mathrm{bf},-2 * \mathrm{~h}$

$\mathrm{K}, 50, \mathrm{bf} / 2-\mathrm{hpc} / 2, \mathrm{bf} / 2,-2 * \mathrm{~h}$

! Definição das áreas do perfil esquerdo dianteiro de aço tipo "I" que são perpendiculares aos outros perfis de ! comprimento de $6 \mathrm{~m}$.

$\begin{array}{ll}\text { A, 37,38,39,42 } & \text { ! Cria área } 20 \text { mediante a união } \\ \text { A,39,40,41,42 } & \text { ! Área } 21 \\ \text { A,42,43,50,47,44,39 } & \text { ! Área } 22 \\ \text { A,45,46,47,50 } & \text { ! Área } 23 \\ \text { A,47,48,49,50 } & \text { ! Área } 24 \\ & \\ \text { AGLUE,20,21,22 } & \text { ! União entre as áreas 20,21,22 } \\ \text { AGLUE,22,23,24 } & \text { ! União entre as áreas 22,23,24 }\end{array}$

! Criação do perfil esquerdo dianteiro de aço tipo "I" que são perpendiculares aos outros perfis de comprimento ! de $6 \mathrm{~m}$.

K,51,bf/2-hpc/2,bfpc-bf,-h ! Cria o keypoint número 51 com coordenadas bf/2 hpc/2,bfpc-bf,-h

$\mathrm{K}, 52, \mathrm{bf} / 2+\mathrm{hpc} / 2, \mathrm{bfpc}-\mathrm{bf},-\mathrm{h}$

$\mathrm{K}, 53, \mathrm{bf} / 2+\mathrm{hpc} / 2, \mathrm{bfpc}-\mathrm{bf}+\mathrm{bf} / 2,-\mathrm{h}$

$\mathrm{K}, 54, \mathrm{bf} / 2+\mathrm{hpc} / 2, \mathrm{bfpc}-\mathrm{bf}+\mathrm{bf},-\mathrm{h}$

$\mathrm{K}, 55, \mathrm{bf} / 2-\mathrm{hpc} / 2, \mathrm{bfpc}-\mathrm{bf}+\mathrm{bf},-\mathrm{h}$

$\mathrm{K}, 56, \mathrm{bf} / 2-\mathrm{hpc} / 2, \mathrm{bfpc}-\mathrm{bf}+\mathrm{bf} / 2,-\mathrm{h}$

$\mathrm{K}, 57, \mathrm{bf} / 2-\mathrm{hpc} / 2, \mathrm{bfpc}-\mathrm{bf}+\mathrm{bf} / 2,-1.5 * \mathrm{~h}$

$\mathrm{K}, 58, \mathrm{bf} / 2+\mathrm{hpc} / 2, \mathrm{bfpc}-\mathrm{bf}+\mathrm{bf} / 2,-1.5 * \mathrm{~h}$

$\mathrm{K}, 59, \mathrm{bf} / 2-\mathrm{hpc} / 2, \mathrm{bfpc}-\mathrm{bf},-2 * \mathrm{~h}$

$\mathrm{K}, 60, \mathrm{bf} / 2+\mathrm{hpc} / 2, \mathrm{bfpc}-\mathrm{bf},-2 * \mathrm{~h}$

$\mathrm{K}, 61, \mathrm{bf} / 2+\mathrm{hpc} / 2, \mathrm{bfpc}-\mathrm{bf}+\mathrm{bf} / 2,-2 * \mathrm{~h}$

$\mathrm{K}, 62, \mathrm{bf} / 2+\mathrm{hpc} / 2, \mathrm{bfpc}-\mathrm{bf}+\mathrm{bf},-2 * \mathrm{~h}$

$\mathrm{K}, 63, \mathrm{bf} / 2-\mathrm{hpc} / 2, \mathrm{bfpc}-\mathrm{bf}+\mathrm{bf},-2 * \mathrm{~h}$

$\mathrm{K}, 64, \mathrm{bf} / 2-\mathrm{hpc} / 2, \mathrm{bfpc}-\mathrm{bf}+\mathrm{bf} / 2,-2 * \mathrm{~h}$

! Definiç̧ão das áreas do perfil esquerdo dianteiro de aço tipo "I" que são perpendiculares aos outros perfis de ! comprimento de $6 \mathrm{~m}$.

A,51,52,53,56

A,53,54,55,56

A,56,57,64,61,58,53

A, 59,60,61,64

$\mathrm{A}, 61,62,63,64$

AGLUE, 25,26,27

AGLUE, 27,28,29

LSTR,43,57
! Cria área 25 mediante a união dos keypoints 51,52,53,56

! Área 26

! Área 27

! Área 28

! Área 29

! União entre as áreas $25,26,27$

! União entre as áreas 27,28,29

! Criação dos enrijecedores (linha) entre os keypoints 43,57 
! Criação do perfil direito dianteiro de aço tipo "I" que são perpendiculares aos outros perfis ! de comprimento de ! $6 \mathrm{~m}$.

$\mathrm{K}, 65, \mathrm{Dis}+\mathrm{bf} / 2-\mathrm{hpc} / 2,0,-\mathrm{h} \quad$ ! Cria o keypoint número 65 com coordenadas Dis+bf/2 hpc/2,0,-h

$\mathrm{K}, 66, \mathrm{Dis}+\mathrm{bf} / 2+\mathrm{hpc} / 2,0,-\mathrm{h}$

$\mathrm{K}, 67, \mathrm{Dis}+\mathrm{bf} / 2+\mathrm{hpc} / 2, \mathrm{bf} / 2,-\mathrm{h}$

$\mathrm{K}, 68, \mathrm{Dis}+\mathrm{bf} / 2+\mathrm{hpc} / 2, \mathrm{bf},-\mathrm{h}$

$\mathrm{K}, 69, \mathrm{Dis}+\mathrm{bf} / 2-\mathrm{hpc} / 2, \mathrm{bf},-\mathrm{h}$

$\mathrm{K}, 70$,Dis+bf/2-hpc/2,bf/2,-h

$\mathrm{K}, 71, \mathrm{Dis}+\mathrm{bf} / 2-\mathrm{hpc} / 2, \mathrm{bf} / 2,-1.5 * \mathrm{~h}$

$\mathrm{K}, 72, \mathrm{Dis}+\mathrm{bf} / 2+\mathrm{hpc} / 2, \mathrm{bf} / 2,-1.5 * \mathrm{~h}$

$\mathrm{K}, 73$,Dis+bf/2-hpc/2,0,-2*h

$\mathrm{K}, 74, \mathrm{Dis}+\mathrm{bf} / 2+\mathrm{hpc} / 2,0,-2 * \mathrm{~h}$

$\mathrm{K}, 75, \mathrm{Dis}+\mathrm{bf} / 2+\mathrm{hpc} / 2, \mathrm{bf} / 2,-2 * \mathrm{~h}$

K,76,Dis+bf/2+hpc/2,bf,-2*h

$\mathrm{K}, 77, \mathrm{Dis}+\mathrm{bf} / 2-\mathrm{hpc} / 2, \mathrm{bf},-2 * \mathrm{~h}$

$\mathrm{K}, 78, \mathrm{Dis}+\mathrm{bf} / 2-\mathrm{hpc} / 2, \mathrm{bf} / 2,-2 * \mathrm{~h}$

! Definição das áreas do perfil direito dianteiro de aço tipo "I" que são perpendiculares aos outros perfis de ! comprimento de $6 \mathrm{~m}$.

$\begin{array}{ll}\text { A,65,66,67,70 } & \text { ! Cria área 25 mediante a união dos keypoints 65,66,67,70 } \\ \text { A,67,68,69,70 } & \text { ! Área 31 } \\ \text { A,70,71,78,75,72,67 } & \text { ! Área 32 } \\ \text { A,73,74,75,78 } & \text { ! Área 33 } \\ \text { A,75,76,77,78 } & \text { ! Área 34 } \\ & \\ \text { AGLUE,30,31,32 } & \text { ! União entre as áreas 30,31,32 } \\ \text { AGLUE,32,33,34 } & \text { ! União entre as áreas 32,33,34 }\end{array}$

! Criação do perfil direito dianteiro de aço tipo "I" que são perpendiculares aos outros perfis ! de comprimento de ! $6 \mathrm{~m}$.

K,79,Dis+bf/2-hpc/2,bfpc-bf,-h ! Cria o keypoint número 79 com coordenadas Dis+bf/2-hpc/2,bfpc-bf,-h $\mathrm{K}, 80$,Dis+bf/2+hpc/2,bfpc-bf,-h

$\mathrm{K}, 81, \mathrm{Dis}+\mathrm{bf} / 2+\mathrm{hpc} / 2, \mathrm{bfpc}-\mathrm{bf}+\mathrm{bf} / 2,-\mathrm{h}$

$\mathrm{K}, 82$,Dis+bf/2+hpc/2,bfpc-bf+bf,-h

$\mathrm{K}, 83$,Dis+bf/2-hpc/2,bfpc-bf+bf,-h

$\mathrm{K}, 84, \mathrm{Dis}+\mathrm{bf} / 2-\mathrm{hpc} / 2, \mathrm{bfpc}-\mathrm{bf}+\mathrm{bf} / 2,-\mathrm{h}$

$\mathrm{K}, 85$,Dis+bf/2-hpc/2,bfpc-bf+bf/2,-1.5*h

$\mathrm{K}, 86, \mathrm{Dis}+\mathrm{bf} / 2+\mathrm{hpc} / 2, \mathrm{bfpc}-\mathrm{bf}+\mathrm{bf} / 2,-1.5 * \mathrm{~h}$

$\mathrm{K}, 87, \mathrm{Dis}+\mathrm{bf} / 2-\mathrm{hpc} / 2, \mathrm{bfpc}-\mathrm{bf},-2 * \mathrm{~h}$

$\mathrm{K}, 88$,Dis+bf/2+hpc/2,bfpc-bf,-2*h

$\mathrm{K}, 89, \mathrm{Dis}+\mathrm{bf} / 2+\mathrm{hpc} / 2, \mathrm{bfpc}-\mathrm{bf}+\mathrm{bf} / 2,-2 * \mathrm{~h}$

K,90,Dis+bf/2+hpc/2,bfpc-bf $+b f,-2 * h$

$\mathrm{K}, 91, \mathrm{Dis}+\mathrm{bf} / 2-\mathrm{hpc} / 2, \mathrm{bfpc}-\mathrm{bf}+\mathrm{bf},-2 * \mathrm{~h}$

K,92,Dis+bf/2-hpc/2,bfpc-bf+bf/2,-2*h

! Definição das áreas do perfil direito dianteiro de aço tipo "I" que são perpendiculares aos ! outros perfis de ! comprimento de $6 \mathrm{~m}$.

A,79,80,81,84 ! Cria área 35 mediante a união dos keypoints $79,80,81,84$

A,81,82,83,84 ! Área 36

$\mathrm{A}, 84,85,92,89,86,81 \quad$ ! Área 37 


$\begin{array}{ll}\text { A,87,88,89,92 } & \text { ! Área } 38 \\ \text { A,89,90,91,92 } & \text { ! Área } 39 \\ \text { AGLUE,35,36,37 } & \text { ! União entre as áreas 35,36,37 } \\ \text { AGLUE,37,38,39 } & \text { ! União entre as áreas 37,38,39 } \\ \text { LSTR,71,85 } & \text { ! Criação dos enrijecedores (linha) entre os keypoints 71,85 } \\ \text { LSTR,72,86 } & \text { ! Criação dos enrijecedores (linha) entre os keypoints 72,86 }\end{array}$

! Criação do perfil esquerdo detrás de aço tipo "I" que são perpendiculares aos outros perfis ! de comprimento de ! $6 \mathrm{~m}$.

K,93,bf/2-hpc/2,l-bfpc,-h ! Cria o keypoint número 93 com coordenadas bf/2-hpc/2,l-bfpc,-h

$\mathrm{K}, 94, \mathrm{bf} / 2+\mathrm{hpc} / 2,1-\mathrm{bfpc},-\mathrm{h}$

$\mathrm{K}, 95, \mathrm{bf} / 2+\mathrm{hpc} / 2, \mathrm{l}-\mathrm{bfpc}+\mathrm{bf} / 2,-\mathrm{h}$

K,96,bf/2+hpc/2,l-bfpc+bf,-h

$\mathrm{K}, 97, \mathrm{bf} / 2-\mathrm{hpc} / 2,1-\mathrm{bfpc}+\mathrm{bf},-\mathrm{h}$

$\mathrm{K}, 98, \mathrm{bf} / 2-\mathrm{hpc} / 2, \mathrm{l}-\mathrm{bfpc}+\mathrm{bf} / 2,-\mathrm{h}$

$\mathrm{K}, 99, \mathrm{bf} / 2-\mathrm{hpc} / 2, \mathrm{l}-\mathrm{bfpc}+\mathrm{bf} / 2,-1.5 * \mathrm{~h}$

$\mathrm{K}, 100, \mathrm{bf} / 2+\mathrm{hpc} / 2, \mathrm{l}-\mathrm{bfpc}+\mathrm{bf} / 2,-1.5 * \mathrm{~h}$

$\mathrm{K}, 101, \mathrm{bf} / 2-\mathrm{hpc} / 2,1-\mathrm{bfpc},-2 * \mathrm{~h}$

$\mathrm{K}, 102, \mathrm{bf} / 2+\mathrm{hpc} / 2,1-\mathrm{bfpc},-2 * \mathrm{~h}$

$\mathrm{K}, 103, \mathrm{bf} / 2+\mathrm{hpc} / 2, \mathrm{l}-\mathrm{bfpc}+\mathrm{bf} / 2,-2 * \mathrm{~h}$

$\mathrm{K}, 104, \mathrm{bf} / 2+\mathrm{hpc} / 2, \mathrm{l}-\mathrm{bfpc}+\mathrm{bf},-2 * \mathrm{~h}$

$\mathrm{K}, 105, \mathrm{bf} / 2-\mathrm{hpc} / 2, \mathrm{l}-\mathrm{bfpc}+\mathrm{bf},-2 * \mathrm{~h}$

$\mathrm{K}, 106, \mathrm{bf} / 2-\mathrm{hpc} / 2,1-\mathrm{bfpc}+\mathrm{bf} / 2,-2 * \mathrm{~h}$

! Definição das áreas do perfil esquerdo detrás de aço tipo "I" que são perpendiculares aos outros perfis de ! comprimento de $6 \mathrm{~m}$.
A, $93,94,95,98$
! Cria área 40 mediante a união dos keypoints 93,94,95,98
A, $95,96,97,98$
! Área 41
A,98,99,106,103,100,95
! Área42
A, 101,102,103,106
! Área 43
A, 103,104,105,106
! Área 44
AGLUE, 40,41,42
! União entre as áreas 40,41,42
AGLUE,42,43,44
! União entre as áreas 42,43,44
! Criação do perfil esquerdo detrás de aço tipo "I" que são perpendiculares aos outros perfis ! de comprimento de ! $6 \mathrm{~m}$.

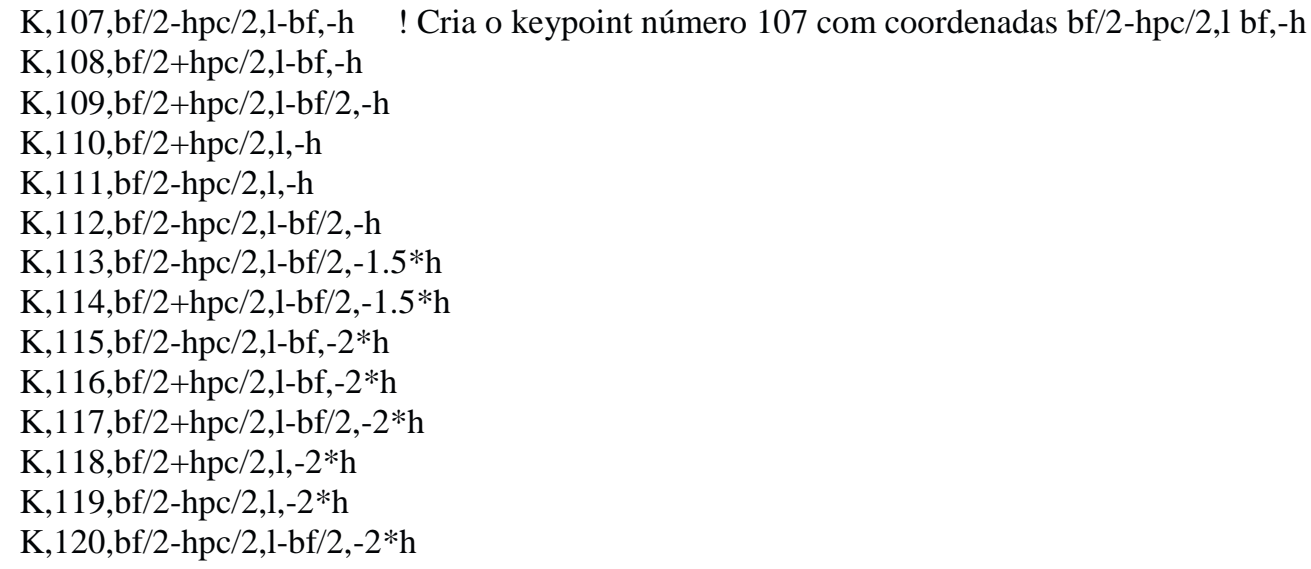


! Definição das áreas do perfil esquerdo detrás de aço tipo "I" que são perpendiculares aos outros perfis de

! comprimento de $6 \mathrm{~m}$.

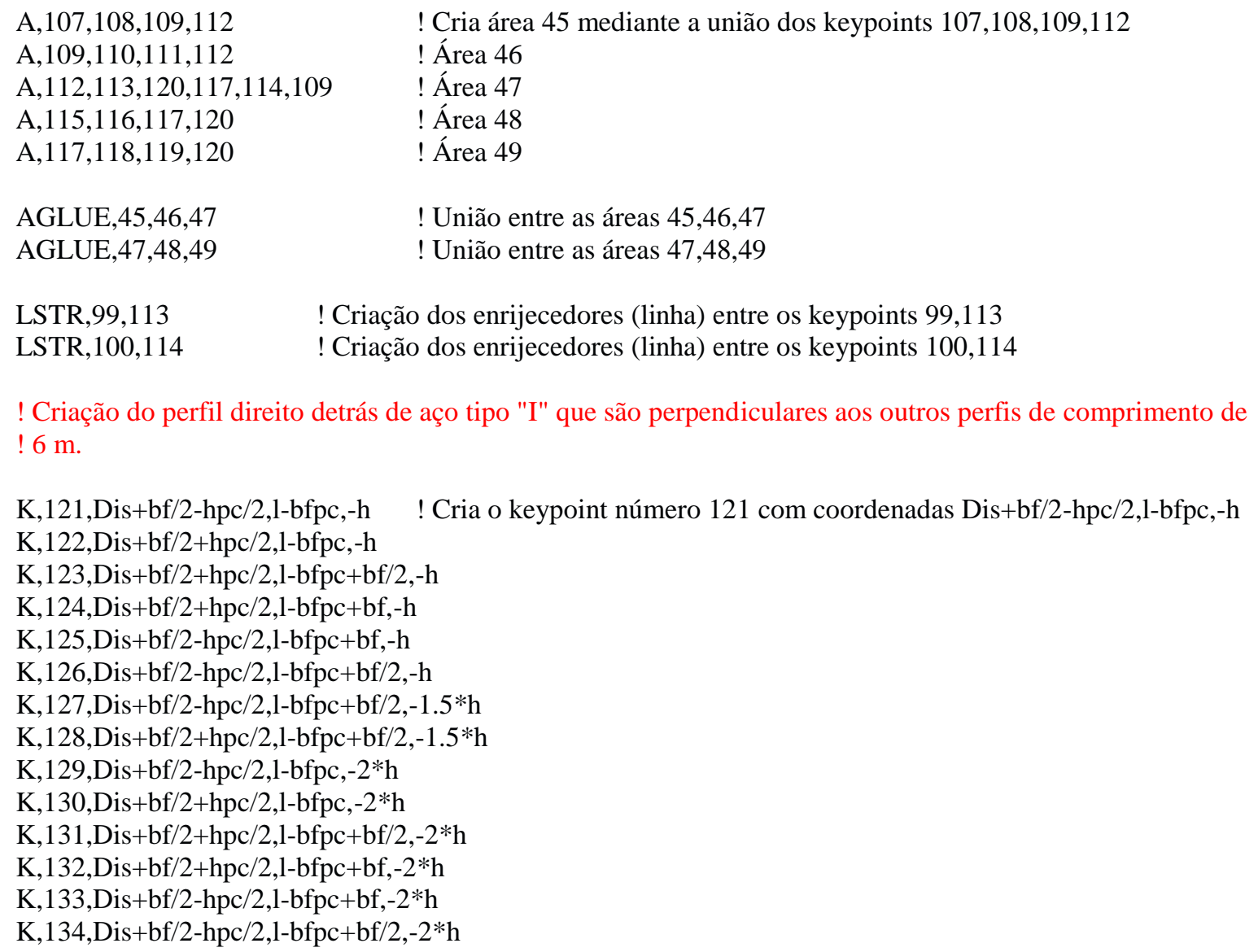

LSTR, 99,113

! Criação dos enrijecedores (linha) entre os keypoints 99,113

LSTR, 100,114

! Criação dos enrijecedores (linha) entre os keypoints 100,114

! Criação do perfil direito detrás de aço tipo "I" que são perpendiculares aos outros perfis de comprimento de ! $6 \mathrm{~m}$.

K,121,Dis+bf/2-hpc/2,l-bfpc,-h ～! Cria o keypoint número 121 com coordenadas Dis+bf/2-hpc/2,l-bfpc,-h $\mathrm{K}, 122, \mathrm{Dis}+\mathrm{bf} / 2+\mathrm{hpc} / 2, \mathrm{l}-\mathrm{bfpc},-\mathrm{h}$

$\mathrm{K}, 123, \mathrm{Dis}+\mathrm{bf} / 2+\mathrm{hpc} / 2, \mathrm{l}-\mathrm{bfpc}+\mathrm{bf} / 2,-\mathrm{h}$

$\mathrm{K}, 124, \mathrm{Dis}+\mathrm{bf} / 2+\mathrm{hpc} / 2,1-\mathrm{bfpc}+\mathrm{bf},-\mathrm{h}$

$\mathrm{K}, 125$,Dis+bf/2-hpc/2,l-bfpc+bf,-h

$\mathrm{K}, 126, \mathrm{Dis}+\mathrm{bf} / 2-\mathrm{hpc} / 2,1-\mathrm{bfpc}+\mathrm{bf} / 2,-\mathrm{h}$

K,127,Dis+bf/2-hpc/2,1-bfpc+bf/2,-1.5*h

$\mathrm{K}, 128$,Dis+bf/2+hpc/2,1-bfpc+bf/2,-1.5*h

K, 129,Dis+bf/2-hpc/2,1-bfpc,-2*h

$\mathrm{K}, 130, \mathrm{Dis}+\mathrm{bf} / 2+\mathrm{hpc} / 2,1-\mathrm{bfpc},-2 * \mathrm{~h}$

$\mathrm{K}, 131, \mathrm{Dis}+\mathrm{bf} / 2+\mathrm{hpc} / 2,1-\mathrm{bfpc}+\mathrm{bf} / 2,-2 * \mathrm{~h}$

$\mathrm{K}, 132$,Dis+bf/2+hpc/2,1-bfpc+bf,-2*h

$\mathrm{K}, 133, \mathrm{Dis}+\mathrm{bf} / 2-\mathrm{hpc} / 2,1-\mathrm{bfpc}+\mathrm{bf},-2 * \mathrm{~h}$

K, 134,Dis+bf/2-hpc/2,l-bfpc+bf/2,-2*h

! Definição das áreas do perfil direito detrás de aço tipo "I" que são perpendiculares aos outros perfis de ! comprimento de $6 \mathrm{~m}$.
A, $121,122,123,126$
A, $123,124,125,126$
A, 126,127,134,131,128,123
A, $129,130,131,134$
A, 131,132,133,134
! Cria área 50 mediante a união dos keypoints $121,122,123,126$
! Área 51
! Área 52
! Área 53
! Área 54
AGLUE,50,51,52
! União entre as áreas 50,51,52
AGLUE,52,53,54
! União entre as áreas 52,53,54
! Criação do perfil direito detrás de aço tipo "I" que são perpendiculares aos outros perfis de ! comprimento de ! $6 \mathrm{~m}$.

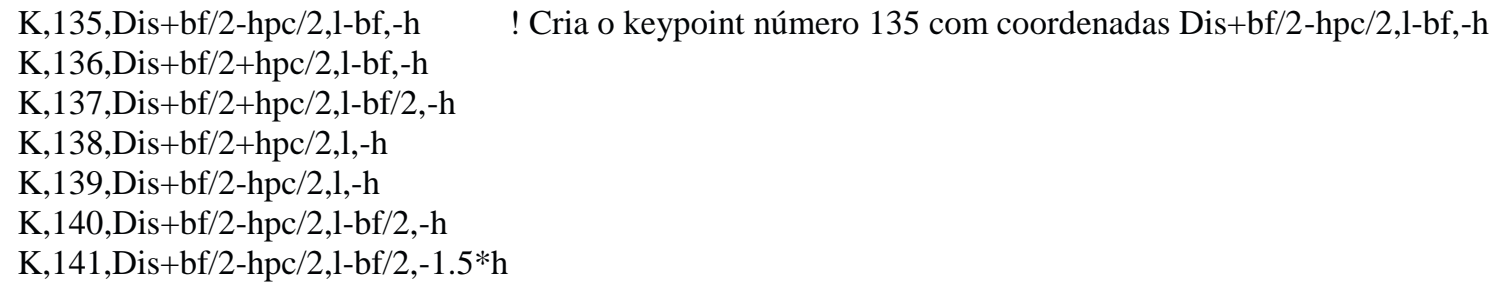


$\mathrm{K}, 142, \mathrm{Dis}+\mathrm{bf} / 2+\mathrm{hpc} / 2,1-\mathrm{bf} / 2,-1.5 * \mathrm{~h}$

K,143,Dis+bf/2-hpc/2,1-bf,-2*h

$\mathrm{K}, 144, \mathrm{Dis}+\mathrm{bf} / 2+\mathrm{hpc} / 2, \mathrm{l}-\mathrm{bf},-2 * \mathrm{~h}$

$\mathrm{K}, 145, \mathrm{Dis}+\mathrm{bf} / 2+\mathrm{hpc} / 2,1-\mathrm{bf} / 2,-2 * \mathrm{~h}$

$\mathrm{K}, 146$,Dis+bf/2+hpc/2,1,-2*h

$\mathrm{K}, 147$, Dis+bf/2-hpc/2,1,-2*h

$\mathrm{K}, 148$,Dis+bf/2-hpc/2,1-bf/2,-2*h

! Definição das áreas do perfil direito detrás de aço tipo "I" que são perpendiculares aos outros perfis de

! comprimento de $6 \mathrm{~m}$.

\begin{tabular}{|c|c|}
\hline & ! Cria área 55 mediante a união dos keypoints $135,136,137,140$ \\
\hline A, $137,138,139,140$ & ! Área 56 \\
\hline A, $140,141,148,145,142,137$ & ! Área 57 \\
\hline \multirow{2}{*}{$\mathrm{A}, 143,144,145,148$} & ! Área 58 \\
\hline & ! Área 59 \\
\hline \multirow{2}{*}{$\begin{array}{l}\text { AGLUE,55,56,57 } \\
\text { AGLUE,57,58,59 }\end{array}$} & ! União entre as áreas 55,56,57 \\
\hline & ! União entre as áreas 57,58,59 \\
\hline \multirow{2}{*}{$\begin{array}{l}\text { LSTR, } 127,141 \\
\text { LSTR, } 128,142\end{array}$} & Criação dos enrijecedores (linha) entre os keypoints 127,141 \\
\hline & Criação dos enrijecedores (linha) entre os keypoints 128,142 \\
\hline \multicolumn{2}{|c|}{ ! Criação do pilar de aço tipo "H" (Cavalete) } \\
\hline
\end{tabular}

$\mathrm{K}, 149, \mathrm{bf} / 2-\mathrm{hpc} / 2, \mathrm{bfpc} / 2,-2 * \mathrm{~h} \quad$ ! Cria o keypoint número $149 \mathrm{com}$ coordenadas bf/2 hpc/2,bfpc/2,-2*h

$\mathrm{K}, 150, \mathrm{bf} / 2+\mathrm{hpc} / 2, \mathrm{bfpc} / 2,-2 * \mathrm{~h}$

$\mathrm{K}, 151, \mathrm{bf} / 2+\mathrm{hpc} / 2,0,-2 * \mathrm{~h}-\mathrm{cpc} / 2+\mathrm{hc} / 2$

$\mathrm{K}, 152, \mathrm{bf} / 2+\mathrm{hpc} / 2, \mathrm{bfc},-2 * \mathrm{~h}-\mathrm{cpc} / 2+\mathrm{hc} / 2$

$\mathrm{K}, 153, \mathrm{bf} / 2+\mathrm{hpc} / 2, \mathrm{bfpc} / 2,-2 * \mathrm{~h}-\mathrm{cpc} / 2+\mathrm{hc} / 2$

$\mathrm{K}, 154, \mathrm{bf} / 2+\mathrm{hpc} / 2,0,-2 * \mathrm{~h}-\mathrm{cpc} / 2-\mathrm{hc} / 2$

$\mathrm{K}, 155, \mathrm{bf} / 2+\mathrm{hpc} / 2, \mathrm{bfc},-2 * \mathrm{~h}-\mathrm{cpc} / 2-\mathrm{hc} / 2$

$\mathrm{K}, 156, \mathrm{bf} / 2+\mathrm{hpc} / 2, \mathrm{bfpc} / 2,-2 * \mathrm{~h}-\mathrm{cpc} / 2-\mathrm{hc} / 2$

$\mathrm{K}, 157, \mathrm{bf} / 2-\mathrm{hpc} / 2, \mathrm{bfpc} / 2,-2 * \mathrm{~h}-\mathrm{cpc} / 2+\mathrm{hc} / 2$

$\mathrm{K}, 158, \mathrm{bf} / 2-\mathrm{hpc} / 2+\mathrm{bfc}, \mathrm{bfpc} / 2,-2 * \mathrm{~h}-\mathrm{cpc} / 2+\mathrm{hc} / 2$

$\mathrm{K}, 159, \mathrm{bf} / 2-\mathrm{hpc} / 2, \mathrm{bfpc} / 2,-2 * \mathrm{~h}-\mathrm{cpc} / 2-\mathrm{hc} / 2$

$\mathrm{K}, 160, \mathrm{bf} / 2-\mathrm{hpc} / 2+\mathrm{bfc}, \mathrm{bfpc} / 2,-2 * \mathrm{~h}-\mathrm{cpc} / 2-\mathrm{hc} / 2$

$\mathrm{K}, 161, \mathrm{bf} / 2+\mathrm{hpc} / 2,0,-2 * \mathrm{~h}-\mathrm{cpc}$

$\mathrm{K}, 162, \mathrm{bf} / 2+\mathrm{hpc} / 2, \mathrm{bfpc} / 2,-2 * \mathrm{~h}-\mathrm{cpc}$

$\mathrm{K}, 163, \mathrm{bf} / 2+\mathrm{hpc} / 2, \mathrm{bfpc}-\mathrm{bf}+\mathrm{bf},-2 * \mathrm{~h}-\mathrm{cpc}$

$\mathrm{K}, 164, \mathrm{bf} / 2-\mathrm{hpc} / 2,0,-2 * \mathrm{~h}-\mathrm{cpc}$

$\mathrm{K}, 165, \mathrm{bf} / 2-\mathrm{hpc} / 2, \mathrm{bfpc} / 2,-2 * \mathrm{~h}-\mathrm{cpc}$

$\mathrm{K}, 166, \mathrm{bf} / 2-\mathrm{hpc} / 2, \mathrm{bfpc},-2 * \mathrm{~h}-\mathrm{cpc}$

! Definição das áreas do pilar esquerdo dianteiro

$\begin{array}{ll}\text { A, } 46,47,48,150,153,152,151 & \text { ! Área } 60 \\ \text { A, } 151,152,153,156,155,154 & \text { ! Área61 } \\ \text { A, } 154,155,156,162,161 & \text { ! Área62 } \\ \text { A, } 156,153,150,60,61,62,163,162 & \text { ! Área } 63 \\ \text { A, } 45,50,49,149,157,159,165,164 & \text { ! Área } 64 \\ \text { A, } 149,59,64,63,166,165 & \text { ! Área65 } \\ \text { A, } 149,150,153,158,157 & \text { ! Área } 66 \\ \text { A, } 157,158,153,156,160,159 & \text { ! Área } 67\end{array}$



A, $159,160,156,162,165$
! Área 68
AGLUE,60,61,62,63,66,67,68
! União entre as áreas 60,61,62,63,66,67,68
AGLUE,64,65,66,67,68
! União entre as áreas 64,65,66,67,68

! Pilar direito dianteiro

$\mathrm{K}, 167, \mathrm{Dis}+\mathrm{bf} / 2-\mathrm{hpc} / 2, \mathrm{bfpc} / 2,-2 * \mathrm{~h}$ ! Cria o keypoint número $167 \mathrm{com}$ coordenadas Dis+bf/2-hpc/2,bfpc/2,-2*h

$\mathrm{K}, 168, \mathrm{Dis}+\mathrm{bf} / 2+\mathrm{hpc} / 2, \mathrm{bfpc} / 2,-2 * \mathrm{~h}$

$\mathrm{K}, 169$,Dis+bf/2-hpc/2,0,-2*h-cpc/2+hc/2

$\mathrm{K}, 170$,Dis+bf/2-hpc/2,bfc,-2*h-cpc/2+hc/2

$\mathrm{K}, 171$,Dis+bf/2-hpc/2,bfpc/2,-2*h-cpc/2+hc/2

$\mathrm{K}, 172$,Dis+bf/2-hpc/2,0,-2*h-cpc/2-hc/2

K, 173,Dis+bf/2-hpc/2,bfc,-2*h-cpc/2-hc/2

$\mathrm{K}, 174, \mathrm{Dis}+\mathrm{bf} / 2-\mathrm{hpc} / 2, \mathrm{bfpc} / 2,-2 * \mathrm{~h}-\mathrm{cpc} / 2-\mathrm{hc} / 2$

$\mathrm{K}, 175$,Dis+bf/2+hpc/2,bfpc/2,-2*h-cpc/2+hc/2

$\mathrm{K}, 176$,Dis+bf/2+hpc/2-bfc,bfpc/2,-2*h-cpc/2+hc/2

$\mathrm{K}, 177$,Dis+bf/2+hpc/2,bfpc/2,-2*h-cpc/2-hc/2

$\mathrm{K}, 178$,Dis+bf/2+hpc/2-bfc,bfpc/2,-2*h-cpc/2-hc/2

$\mathrm{K}, 179, \mathrm{Dis}+\mathrm{bf} / 2+\mathrm{hpc} / 2,0,-2 * \mathrm{~h}-\mathrm{cpc}$

$\mathrm{K}, 180, \mathrm{Dis}+\mathrm{bf} / 2+\mathrm{hpc} / 2, \mathrm{bfpc} / 2,-2 * \mathrm{~h}-\mathrm{cpc}$

$\mathrm{K}, 181$,Dis+bf/2+hpc/2,bfpc-bf+bf,-2*h-cpc

$\mathrm{K}, 182$,Dis+bf/2-hpc/2,0,-2*h-cpc

$\mathrm{K}, 183$,Dis+bf/2-hpc/2,bfpc/2,-2*h-cpc

$\mathrm{K}, 184$,Dis+bf/2-hpc/2,bfpc-bf+bf,-2*h-cpc

! Definição das áreas do pilar direito dianteiro

$\begin{array}{ll}\text { A }, 73,78,77,167,171,170,169 & \text { !Área } 69 \\ \text { A } 169,170,171,174,173,172 & \text { !Área } 70 \\ \text { A, } 172,173,174,183,182 & \text { !Área } 71 \\ \text { A, } 167,87,92,91,184,183 & \text { !Área } 72 \\ \text { A, } 74,75,76,168,175,177,180,179 & \text { !Área } 73 \\ \text { A, } 168,88,89,90,181,180,177,175 & \text { !Área } 74 \\ \text { A, } 167,168,175,176,171 & \text { !Área } 75 \\ \text { A, } 171,176,175,177,178,174 & \text { !Área } 76 \\ \text { A, } 174,178,177,180,183 & \text { !Área } 77\end{array}$

AGLUE,69,70,71,72,75,76,77 ! União entre as áreas 69,70,71,72,75,76,77

AGLUE,73,74,75,76,77 ! União entre as áreas 73,74,75,76,77

! Pilar esquerdo detrás

$\mathrm{K}, 185, \mathrm{bf} / 2-\mathrm{hpc} / 2,1-\mathrm{bfpc} / 2,-2 * \mathrm{~h} \quad$ ! Cria o keypoint número $185 \mathrm{com}$ coordenadas bf/2-hpc/2,1-bfpc/2,-2*h

$\mathrm{K}, 186, \mathrm{bf} / 2+\mathrm{hpc} / 2,1-\mathrm{bfpc} / 2,-2 * \mathrm{~h}$

$\mathrm{K}, 187, \mathrm{bf} / 2-\mathrm{hpc} / 2,1-\mathrm{bfpc} / 2,-2 * \mathrm{~h}-\mathrm{cpc} / 2+\mathrm{hc} / 2$

$\mathrm{K}, 188, \mathrm{bf} / 2-\mathrm{hpc} / 2+\mathrm{bfc}, 1-\mathrm{bfpc} / 2,-2 * \mathrm{~h}-\mathrm{cpc} / 2+\mathrm{hc} / 2$

$\mathrm{K}, 189, \mathrm{bf} / 2+\mathrm{hpc} / 2,1-\mathrm{bfpc} / 2,-2 * \mathrm{~h}-\mathrm{cpc} / 2+\mathrm{hc} / 2$

$\mathrm{K}, 190, \mathrm{bf} / 2-\mathrm{hpc} / 2,1-\mathrm{bfpc} / 2,-2 * \mathrm{~h}-\mathrm{cpc} / 2-\mathrm{hc} / 2$

$\mathrm{K}, 191, \mathrm{bf} / 2-\mathrm{hpc} / 2+\mathrm{bfc}, 1-\mathrm{bfpc} / 2,-2 * \mathrm{~h}-\mathrm{cpc} / 2-\mathrm{hc} / 2$

K,192,bf/2+hpc/2,1-bfpc/2,-2*h-cpc/2-hc/2

$\mathrm{K}, 193, \mathrm{bf} / 2+\mathrm{hpc} / 2,1,-2 * \mathrm{~h}-\mathrm{cpc} / 2+\mathrm{hc} / 2$

$\mathrm{K}, 194, \mathrm{bf} / 2+\mathrm{hpc} / 2,1-\mathrm{bfc},-2 * \mathrm{~h}-\mathrm{cpc} / 2+\mathrm{hc} / 2$

$\mathrm{K}, 195, \mathrm{bf} / 2+\mathrm{hpc} / 2,1,-2 * \mathrm{~h}-\mathrm{cpc} / 2-\mathrm{hc} / 2$

$\mathrm{K}, 196, \mathrm{bf} / 2+\mathrm{hpc} / 2,1-\mathrm{bfc},-2 * \mathrm{~h}-\mathrm{cpc} / 2-\mathrm{hc} / 2$

$\mathrm{K}, 197, \mathrm{bf} / 2+\mathrm{hpc} / 2,1-\mathrm{bfpc},-2 * \mathrm{~h}-\mathrm{cpc}$ 
K,198,bf/2+hpc/2,1-bfpc/2,-2*h-cpc

K,199,bf/2+hpc/2,1,-2*h-cpc

$\mathrm{K}, 200, \mathrm{bf} / 2-\mathrm{hpc} / 2,1-\mathrm{bfpc},-2 * \mathrm{~h}-\mathrm{cpc}$

$\mathrm{K}, 201, \mathrm{bf} / 2-\mathrm{hpc} / 2,1-\mathrm{bfpc} / 2,-2 * \mathrm{~h}-\mathrm{cpc}$

$\mathrm{K}, 202, \mathrm{bf} / 2-\mathrm{hpc} / 2,1,-2 * \mathrm{~h}-\mathrm{cpc}$

! Definição das áreas do pilar esquerdo detrás

A, $101,106,105,185,187,190,201,200$

A, $185,115,120,119,202,201,190,187$

A, 102,103,104,186,189,192,198,197

A, 186,116,117,118,193,194,189

A, 189,194,193,195,196,192

A, 192,196,195,199,198

A, $185,186,189,188,187$

A, $187,188,189,192,191,190$

A, 190,191,192,198,201

AGLUE,78,79,84,85,86

AGLUE, $80,81,82,83,84,85,86$
! Área 78

! Área 79

! Área 80

! Área 81

! Área 82

! Área 83

! Área 84

! Área 85

! Área 86

! União entre as áreas 78,79,84,85,86

! União entre as áreas $80,81,82,83,84,85,86$

! Pilar direito detrás

$\mathrm{K}, 203$,Dis+bf/2-hpc/2,1-bfpc/2,-2*h! Cria o keypoint número 203 com coordenadas Dis+bf/2-hpc/2,1-bfpc/2,-2*h

$\mathrm{K}, 204, \mathrm{Dis}+\mathrm{bf} / 2+\mathrm{hpc} / 2,1-\mathrm{bfpc} / 2,-2 * \mathrm{~h}$

$\mathrm{K}, 205, \mathrm{Dis}+\mathrm{bf} / 2+\mathrm{hpc} / 2, \mathrm{l}-\mathrm{bfpc} / 2,-2 * \mathrm{~h}-\mathrm{cpc} / 2+\mathrm{hc} / 2$

K,206,Dis+bf/2+hpc/2-bfc,1-bfpc/2,-2*h-cpc/2+hc/2

K,207,Dis+bf/2-hpc/2,l-bfpc/2,-2*h-cpc/2+hc/2

$\mathrm{K}, 208$,Dis+bf/2+hpc/2,1-bfpc/2,-2*h-cpc/2-hc/2

K,209,Dis+bf/2+hpc/2-bfc,1-bfpc/2,-2*h-cpc/2-hc/2

K,210,Dis+bf/2-hpc/2,1-bfpc/2,-2*h-cpc/2-hc/2

$\mathrm{K}, 211$,Dis+bf/2-hpc/2,1,-2*h-cpc/2+hc/2

K,212,Dis+bf/2-hpc/2,1-bfc,- $2 * \mathrm{~h}-\mathrm{cpc} / 2+\mathrm{hc} / 2$

K,213,Dis+bf/2-hpc/2,1,-2*h-cpc/2-hc/2

K,214,Dis+bf/2-hpc/2,1-bfc,-2*h-cpc/2-hc/2

$\mathrm{K}, 215$,Dis+bf/2+hpc/2,1-bfpc,-2*h-cpc

$\mathrm{K}, 216$,Dis+bf/2+hpc/2,1-bfpc/2,-2*h-cpc

$\mathrm{K}, 217, \mathrm{Dis}+\mathrm{bf} / 2+\mathrm{hpc} / 2,1,-2 * \mathrm{~h}-\mathrm{cpc}$

$\mathrm{K}, 218$,Dis+bf/2-hpc/2,1-bfpc,-2*h-cpc

K,219,Dis+bf/2-hpc/2,1-bfpc/2,-2*h-cpc

$\mathrm{K}, 220$,Dis+bf/2-hpc/2,1,-2*h-cpc

! Definição das áreas do pilar direito detrás

$\begin{array}{ll}\text { A, } 129,134,133,203,207,210,219,218 & \text { ! Área } 87 \\ \text { A,203,143,148,147,211,212,207 } & \text { ! Área } 88 \\ \text { A,207,212,211,213,214,210 } & \text { ! Área } 89 \\ \text { A,210,214,213,220,219 } & \text { ! Área } 90 \\ \text { A, } 130,131,132,204,205,208,216,215 & \text { ! Área } 91 \\ \text { A,204,144,145,146,217,216 } & \text { ! Área } 92 \\ \text { A,203,204,205,206,207 } & \text { ! Área 93 } \\ \text { A,207,206,205,208,209,210 } & \text { ! Área } 94 \\ \text { A,210,209,208,216,219 } & \text { ! Área 95 }\end{array}$

AGLUE, 87,88,89,90,93,94,95

! União entre as áreas 87,88,89,90,93,94,95

AGLUE,91,92,93,94,95

! União entre as áreas 91,92,93,94,95 
!Criação dos contraventamentos, perfil de aço tipo "U"

! Definição das áreas do contraventamento dianteiro
A, $152,151,169,170$
! Área 96
A, $151,154,172,169$
! Área 97
A, $155,154,172,173$
! Área 98

! Definição das áreas do contraventamento direito
A, $176,175,205,206$
! Área 99
A, $175,177,208,205$
! Área 100
A, 178,177,208,209
! Área 101

! Definição das áreas do contraventamento detrás
A,212,211,193,194
! Área 102
A, 211,213,195,193
! Área 103
A,214,213,195,196
! Área 104

! Definição das áreas do contraventamento esquerdo
A, $188,187,157,158$
! Área 105
A, $187,190,159,157$
! Área 106
A, 191,190,159,160
! Área 107

! Criação das bases dos pilares tipo "H"

! Base esquerda dianteira
A, 164,161,162,163,166,165
! Área 108 Base direita dianteira
A, $182,179,180,181,184,183$
! Área 109 Base esquerda detrás
A,200,197,198,199,202,201
! Área 110 Base direita detrás
A,218,215,216,217,220,219
! Área 111 Fusão das linhas y keypoints

! Fusão e compressão de todas as linhas

NUMCMP,LINE
NUMMRG,KP, , , ,LOW

AOVLAP,ALL

AGLUE,ALL
! Procedimento de fusão y compressão das linhas ! Fusão dos pontos de coincidência

! Transpassa todas as áreas

! União de todas as áreas

! Criação dos tipos de elementos

ET,1,SHELL63

KEYOPT $1,1,0$

KEYOPT, 1,2,0

KEYOPT, 1,3,0

KEYOPT, $1,5,2$

KEYOPT, $1,6,0$

KEYOPT, 1,7,0
! Criação do elemento tipo SHELL63

! Inclui as tensões nos nodos 
KEYOPT, 1,8,0

KEYOPT, 1,9,0

KEYOPT,1,11,0

\author{
ET,2,BEAM4 \\ KEYOPT,2,2,0 \\ KEYOPT, 2,6,1 \\ KEYOPT, 2,7,0 \\ KEYOPT, 2,9,0 \\ KEYOPT,2,10,0 \\ ! Criação do elementos tipo BEAM4 \\ ! Inclui resultados de força e momento \\ ! Criação das constantes reais
}

$\begin{array}{ll}\text { R,1,esp,0,0,0,0,0, } & \text { ! Constante real } 1 \text { do elemento SHELL63 (para a laje) } \\ \text { RMORE,0,0,0, } & \text { ! Adição das constantes reais } 1 \text { que faltam do elemento SHELL63 } \\ \text { R,10,camada,0,0,0,0,0, } & \text { ! Constante real } 10 \text { do elemento SHELL63 (para a laje-fissuras) } \\ \text { RMORE,0,0,0, } & \text { ! Adição das constantes reais } 10 \text { que faltam do elemento SHELL63 } \\ \text { R,2,tf,0,0,0,0,0, } & \text { ! Constante real } 2 \text { do elemento SHELL63 (espessura da mesa ! do perfil W200x19.3) } \\ \text { RMORE,0,0,0, } & \text { ! Adição das constantes reais } 2 \text { que faltam do elemento SHELL63 } \\ \text { R,3,tw,0,0,0,0,0, } & \text { ! Constante real } 3 \text { do elemento SHELL63 (espessura da alma do perfil W200x19.3) } \\ \text { RMORE,0,0,0, } & \text { ! Adição das Constantes reais } 3 \text { que faltam do elemento SHELL63 }\end{array}$

$\mathrm{R}, 4, \mathrm{db} * \mathrm{db} * 3.14159265 / 4,(\mathrm{db} * \mathrm{db} * \mathrm{db} * \mathrm{db}) * 3.14159265 / 64,(\mathrm{db} * \mathrm{db} * \mathrm{db} * \mathrm{db}) * 3.1415927 / 64,,, \quad$ !Constantes ! reais 4 de BEAM4 (Seção !dos enrijecedores)

RMORE, , , , , , ! Adição das Constantes reais 4 que faltam do elemento BEAM4

R,5,tfpc,0,0,0,0,0, ! Constante real 5 do elemento SHELL63 (espessura da mesa, para pilar tipo "H")

RMORE,0,0,0, ! Adição das Constantes reais 5 que faltam do elemento SHELL63

R,6,twpc,0,0,0,0,0, ! Constante real 6 do elemento SHELL63 (espessura da alma, para pilar tipo "H")

RMORE,0,0,0, ! Adição das Constantes reais 6 que faltam do elemento SHELL63

R,7,Base,0,0,0,0,0, ! Constante real 7 do elemento SHELL63 (Base para pilar tipo "H")

RMORE,0,0,0, ! Adição das Constantes reais 7 que faltam do elemento SHELL63

$\mathrm{R}, 8, \mathrm{tfc}, 0,0,0,0,0$, ! Constante real 8 do elemento SHELL63 (espessura da mesa , perfil tipo "U", fechar quadro )

RMORE,0,0,0, ! Adição das Constantes reais 8 que faltam do elemento SHELL63

R,9,twc,0,0,0,0,0,! Constante real 9 do elemento SHELL63 (espessura da alma , perfil tipo "U", fechar quadro )

RMORE,0,0,0, ! Adição das Constantes reais 9 que faltam do elemento SHELL63

! Propriedades do material de concreto

MP,EX,1,Ec ! Módulo de elasticidade do concreto material 1

MP,NUXY,1,vc ! Coeficiente de Poisson do concreto material 1

MP,dens, $1, \mathrm{dc}$ ! Densidade do concreto material 1

! Propriedades do material epoxi Sika $42 \mathrm{CL}$

MP,EX,2,ex2

MP,PRXY,2,cp2

MP,dens,2,densidade2

! Propriedades do aço

MP,EX,3,Es

MP,NUXY,3,vs

MP,dens,3,ds

! Módulo de elasticidade do aço material 2

! Coeficiente de Poisson do aço material 2

! Densidade do aço material 2

!*********************** !

! Discretização da estrutura!

! ***********************! 
TYPE, 1

MAT, 1

REAL, 1

ESYS, 0

SECNUM,

ESIZE,0,ndivc, AMESH, 112
! Define por atributos o tipo de material 1, para este caso SHELL63

! Define por atributos o material 1 para este caso concreto

! Define por atributos as constantes reais 1 do material 1 para este caso concreto

! Define por atributos o sistema de elementos coordenados

! Modelagem das fissuras

*ask,trincas,'Analise com trincas sim[1] nao[2]',1

*if,trincas, eq, 1 , then

TYPE, 1

MAT, 2

REAL,2

! Trinca A

*do,i,89,31565,244

EMODIF,i,MAT,2,

*enddo

! Trinca B

EMODIF,31808,MAT,2,

EMODIF,32051,MAT,2,

EMODIF,32294,MAT,2,

EMODIF,32537,MAT,2, EMODIF,32780,MAT,2,

! Trinca C

*do,i,33024,36684,244

EMODIF,i,MAT,2,

*enddo

! Trinca F

EMODIF,36929,MAT,2

EMODIF,37174,MAT,2

EMODIF,37419,MAT,2

EMODIF,37664,MAT,2

EMODIF,37909,MAT,2

EMODIF,38153,MAT,2

EMODIF,38397,MAT,2

EMODIF,38641,MAT,2

EMODIF,38886,MAT,2

EMODIF,39131,MAT,2

EMODIF,39376,MAT,2

EMODIF,39621,MAT,2

EMODIF,39866,MAT,2

EMODIF,40110,MAT,2

EMODIF,40354,MAT,2

EMODIF,40598,MAT,2

EMODIF,40843,MAT,2

EMODIF,41088,MAT,2

EMODIF,41333,MAT,2

! Define o número de divisões da malha dos elementos finitos

! Coloca a malha na área 112 do material concreto 
EMODIF,41578,MAT,2 EMODIF,41823,MAT,2 EMODIF,42067,MAT,2 EMODIF,42311,MAT,2 EMODIF,42555,MAT,2 EMODIF,42799,MAT,2 EMODIF,43044,MAT,2 EMODIF,43289,MAT,2 EMODIF,43534,MAT,2 EMODIF,43779,MAT,2 EMODIF,44023,MAT,2 EMODIF,44267,MAT,2 EMODIF,44511,MAT,2 EMODIF,44755,MAT,2 EMODIF,44999,MAT,2 EMODIF,45244,MAT,2 EMODIF,45489,MAT,2 EMODIF,45734,MAT, 2 EMODIF,45979,MAT,2 EMODIF,46224,MAT,2 EMODIF,46468,MAT,2 EMODIF,46712,MAT,2 EMODIF,46956,MAT,2 EMODIF,47200,MAT,2 EMODIF,47445,MAT,2 EMODIF,47690,MAT,2 EMODIF,47935,MAT,2 EMODIF,48180,MAT,2 EMODIF,48424,MAT,2 EMODIF,48668,MAT,2 EMODIF,48912,MAT,2 EMODIF,49156,MAT,2 EMODIF,49401,MAT,2 EMODIF,49646,MAT,2 EMODIF,49891,MAT,2 EMODIF,50135,MAT,2 EMODIF,50379,MAT,2 EMODIF,50623,MAT,2 EMODIF,50867,MAT,2 EMODIF,51112,MAT,2 EMODIF,51357,MAT,2 EMODIF,51602,MAT,2 EMODIF,51846,MAT,2 EMODIF,52090,MAT,2 EMODIF,52334,MAT,2 EMODIF,52579,MAT,2 EMODIF,52823,MAT,2 EMODIF,53068,MAT,2 EMODIF,53312,MAT,2 EMODIF,53556,MAT,2 EMODIF,53800,MAT,2 EMODIF,54045,MAT,2 EMODIF,54289,MAT,2 EMODIF,54534,MAT,2 EMODIF,54778,MAT,2 EMODIF,55022,MAT,2 
EMODIF,55266,MAT,2 EMODIF,55510,MAT,2 EMODIF,55755,MAT,2 EMODIF,55999,MAT,2 EMODIF,56243,MAT,2 EMODIF,56487,MAT,2 EMODIF,56731,MAT,2 EMODIF,56975,MAT,2 EMODIF,57219,MAT,2 EMODIF,57463,MAT,2 EMODIF,57707,MAT,2 EMODIF,57951,MAT,2 EMODIF,58195,MAT,2 EMODIF,58439,MAT,2 EMODIF,58684,MAT,2 EMODIF,58928,MAT,2 EMODIF,59173,MAT,2 EMODIF,59417,MAT,2

EMODIF,36929,REAL,2 EMODIF,37174,REAL, 2 EMODIF,37419,REAL,2 EMODIF,37664,REAL,2 EMODIF,37909,REAL,2 EMODIF,38153,REAL,2 EMODIF,38397,REAL,2 EMODIF,38641,REAL,2 EMODIF,38886,REAL,2 EMODIF,39131,REAL,2 EMODIF,39376,REAL,2 EMODIF,39621,REAL,2 EMODIF,39866,REAL,2 EMODIF,40110,REAL,2 EMODIF,40354,REAL,2 EMODIF,40598,REAL,2 EMODIF,40843,REAL,2 EMODIF,41088,REAL, 2 EMODIF,41333,REAL,2 EMODIF,41578,REAL,2 EMODIF,41823,REAL,2 EMODIF,42067,REAL,2 EMODIF,42311,REAL,2 EMODIF,42555,REAL,2 EMODIF,42799,REAL,2 EMODIF,43044,REAL,2 EMODIF,43289,REAL,2 EMODIF,43534,REAL,2 EMODIF,43779,REAL,2 EMODIF,44023,REAL,2 EMODIF,44267,REAL,2 EMODIF,44511,REAL,2 EMODIF,44755,REAL,2 EMODIF,44999,REAL,2 EMODIF,45244,REAL,2 EMODIF,45489,REAL,2 EMODIF,45734,REAL,2 
EMODIF,45979,REAL,2 EMODIF,46224,REAL,2 EMODIF,46468,REAL,2 EMODIF,46712,REAL,2 EMODIF,46956,REAL,2 EMODIF,47200,REAL,2 EMODIF,47445,REAL,2 EMODIF,47690,REAL,2 EMODIF,47935,REAL,2 EMODIF,48180,REAL,2 EMODIF,48424,REAL,2 EMODIF,48668,REAL,2 EMODIF,48912,REAL,2 EMODIF,49156,REAL,2 EMODIF,49401,REAL,2 EMODIF,49646,REAL,2 EMODIF,49891,REAL,2 EMODIF,50135,REAL,2 EMODIF,50379,REAL,2 EMODIF,50623,REAL,2 EMODIF,50867,REAL,2 EMODIF,51112,REAL,2 EMODIF,51357,REAL,2 EMODIF,51602,REAL,2 EMODIF,51846,REAL,2 EMODIF,52090,REAL,2 EMODIF,52334,REAL,2 EMODIF,52579,REAL,2 EMODIF,52823,REAL,2 EMODIF,53068,REAL,2 EMODIF,53312,REAL,2 EMODIF,53556,REAL,2 EMODIF,53800,REAL,2 EMODIF,54045,REAL,2 EMODIF,54289,REAL,2 EMODIF,54534,REAL,2 EMODIF,54778,REAL,2 EMODIF,55022,REAL,2 EMODIF,55266,REAL,2 EMODIF,55510,REAL,2 EMODIF,55755,REAL,2 EMODIF,55999,REAL,2 EMODIF,56243,REAL,2 EMODIF,56487,REAL,2 EMODIF,56731,REAL,2 EMODIF,56975,REAL,2 EMODIF,57219,REAL,2 EMODIF,57463,REAL,2 EMODIF,57707,REAL,2 EMODIF,57951,REAL,2 EMODIF,58195,REAL,2 EMODIF,58439,REAL,2 EMODIF,58684,REAL,2 EMODIF,58928,REAL,2 EMODIF,59173,REAL,2 EMODIF,59417,REAL,2 
! Trinca I

EMODIF,49182,MAT,2

EMODIF,49427,MAT,2

EMODIF,49671,MAT,2

EMODIF,49916,MAT,2

EMODIF,50160,MAT,2

EMODIF,50405,MAT,2

EMODIF,50649,MAT,2

EMODIF,50893,MAT,2

EMODIF,51138,MAT,2

EMODIF,51382,MAT,2

EMODIF,51626,MAT,2

EMODIF,51871,MAT,2

EMODIF,52115,MAT,2

EMODIF,52359,MAT,2

EMODIF,52603,MAT,2

EMODIF,52848,MAT,2

EMODIF,53092,MAT,2

EMODIF,53336,MAT,2

EMODIF,53581,MAT,2

EMODIF,53825,MAT,2

EMODIF,54069,MAT,2

EMODIF,54314,MAT,2

EMODIF,54558,MAT,2

EMODIF,54802,MAT,2

EMODIF,55047,MAT,2

EMODIF,55291,MAT,2

EMODIF,55535,MAT,2

EMODIF,55780,MAT,2

EMODIF,56024,MAT,2

EMODIF,56268,MAT,2

EMODIF,56513,MAT,2

EMODIF,56757,MAT,2

EMODIF,57002,MAT,2

EMODIF,57247,MAT,2

EMODIF,57492,MAT,2

EMODIF,57736,MAT,2

EMODIF,57981,MAT,2

EMODIF,58226,MAT,2

EMODIF,58471,MAT,2

EMODIF,58716,MAT,2

EMODIF,58961,MAT,2

EMODIF,59206,MAT,2

EMODIF,59451,MAT,2

EMODIF,49182,REAL,2 EMODIF,49427,REAL,2 EMODIF,49671,REAL,2 EMODIF,49916,REAL,2 EMODIF,50160,REAL,2 EMODIF,50405,REAL,2 EMODIF,50649,REAL,2 EMODIF,50893,REAL,2 EMODIF,51138,REAL,2 EMODIF,51382,REAL,2 
EMODIF,51626,REAL,2 EMODIF,51871,REAL,2 EMODIF,52115,REAL,2 EMODIF,52359,REAL,2 EMODIF,52603,REAL,2 EMODIF,52848,REAL,2 EMODIF,53092,REAL,2 EMODIF,53336,REAL,2 EMODIF,53581,REAL,2 EMODIF,53825,REAL,2 EMODIF,54069,REAL,2 EMODIF,54314,REAL,2 EMODIF,54558,REAL,2 EMODIF,54802,REAL,2 EMODIF,55047,REAL,2 EMODIF,55291,REAL,2 EMODIF,55535,REAL,2 EMODIF,55780,REAL,2 EMODIF,56024,REAL,2 EMODIF,56268,REAL,2 EMODIF,56513,REAL,2 EMODIF,56757,REAL,2 EMODIF,57002,REAL,2 EMODIF,57247,REAL, 2 EMODIF,57492,REAL,2 EMODIF,57736,REAL,2 EMODIF,57981,REAL,2 EMODIF,58226,REAL,2 EMODIF,58471,REAL,2 EMODIF,58716,REAL,2 EMODIF,58961,REAL,2 EMODIF,59206,REAL,2 EMODIF,59451,REAL,2

! Trinca $\mathrm{H}$

EMODIF,49181,MAT,2 EMODIF,49425,MAT,2 EMODIF,49669,MAT,2 EMODIF,49912,MAT,2 EMODIF,50155,MAT,2 EMODIF,50399,MAT,2 EMODIF,50643,MAT, 2 EMODIF,50887,MAT,2 EMODIF,51130,MAT, 2 EMODIF,51374,MAT,2 EMODIF,51618,MAT,2 EMODIF,51862,MAT,2 EMODIF,52105,MAT,2 EMODIF,52349,MAT, 2 EMODIF,52593,MAT, 2 EMODIF,52837,MAT, 2 EMODIF,53080,MAT,2 EMODIF,53324,MAT,2 EMODIF,53568,MAT, 2 EMODIF,53812,MAT, 2 EMODIF,54055,MAT,2 
EMODIF,54299,MAT,2 EMODIF,54543,MAT, 2 EMODIF,54787,MAT,2 EMODIF,55031,MAT,2 EMODIF,55275,MAT,2 EMODIF,55518,MAT,2 EMODIF,55762,MAT,2 EMODIF,56006,MAT,2 EMODIF,56250,MAT,2 EMODIF,56494,MAT,2 EMODIF,56737,MAT,2 EMODIF,56981,MAT,2 EMODIF,57225,MAT,2 EMODIF,57468,MAT,2 EMODIF,57712,MAT,2 EMODIF,57956,MAT,2 EMODIF,58200,MAT,2 EMODIF,58443,MAT,2 EMODIF,58687,MAT,2 EMODIF,58930,MAT,2

EMODIF,49181,REAL,2 EMODIF,49425,REAL,2 EMODIF,49669,REAL,2 EMODIF,49912,REAL,2 EMODIF,50155,REAL,2 EMODIF,50399,REAL,2 EMODIF,50643,REAL,2 EMODIF,50887,REAL,2 EMODIF,51130,REAL,2 EMODIF,51374,REAL,2 EMODIF,51618,REAL,2 EMODIF,51862,REAL,2 EMODIF,52105,REAL,2 EMODIF,52349,REAL,2 EMODIF,52593,REAL,2 EMODIF,52837,REAL, 2 EMODIF,53080,REAL,2 EMODIF,53324,REAL,2 EMODIF,53568,REAL,2 EMODIF,53812,REAL,2 EMODIF,54055,REAL,2 EMODIF,54299,REAL,2 EMODIF,54543,REAL,2 EMODIF,54787,REAL,2 EMODIF,55031,REAL,2 EMODIF,55275,REAL,2 EMODIF,55518,REAL,2 EMODIF,55762,REAL,2 EMODIF,56006,REAL,2 EMODIF,56250,REAL, 2 EMODIF,56494,REAL,2 EMODIF,56737,REAL,2 EMODIF,56981,REAL,2 EMODIF,57225,REAL,2 EMODIF,57468,REAL,2 
EMODIF,57712,REAL,2 EMODIF,57956,REAL,2 EMODIF,58200,REAL,2 EMODIF,58443,REAL,2 EMODIF,58687,REAL,2 EMODIF,58930,REAL,2

! Trinca G

EMODIF,31810,MAT,2 EMODIF,32054,MAT, 2 EMODIF,32299,MAT, 2 EMODIF,32543,MAT, 2 EMODIF,32788,MAT, 2 EMODIF,33032,MAT,2 EMODIF,33277,MAT, 2 EMODIF,33521,MAT, 2 EMODIF,33766,MAT, 2 EMODIF,34010,MAT, 2 EMODIF,34255,MAT,2 EMODIF,34499,MAT,2 EMODIF,34744,MAT,2 EMODIF,34988,MAT,2 EMODIF,35233,MAT,2 EMODIF,35478,MAT,2 EMODIF,35723,MAT, 2 EMODIF,35967,MAT,2 EMODIF,36212,MAT,2 EMODIF,36457,MAT,2 EMODIF,36701,MAT, 2 EMODIF,36946,MAT, 2 EMODIF,37191,MAT,2 EMODIF,37435,MAT, 2 EMODIF,37680,MAT,2 EMODIF,37925,MAT,2 EMODIF,38170,MAT,2 EMODIF,38415,MAT,2 EMODIF,38660,MAT, 2 EMODIF,38905,MAT, 2 EMODIF,39150,MAT,2 EMODIF,39395,MAT,2 EMODIF,39640,MAT,2 EMODIF,39885,MAT,2 EMODIF,40130,MAT,2 EMODIF,40375,MAT,2

EMODIF,31810,REAL,2 EMODIF,32054,REAL,2 EMODIF,32299,REAL,2 EMODIF,32543,REAL,2 EMODIF,32788,REAL,2 EMODIF,33032,REAL,2 EMODIF,33277,REAL,2 EMODIF,33521,REAL,2 EMODIF,33766,REAL,2 EMODIF,34010,REAL,2 EMODIF,34255,REAL,2 
EMODIF,34499,REAL,2 EMODIF,34744,REAL,2 EMODIF,34988,REAL,2 EMODIF,35233,REAL,2 EMODIF,35478,REAL,2 EMODIF,35723,REAL,2 EMODIF,35967,REAL,2 EMODIF,36212,REAL,2 EMODIF,36457,REAL,2 EMODIF,36701,REAL,2 EMODIF,36946,REAL,2 EMODIF,37191,REAL,2 EMODIF,37435,REAL,2 EMODIF,37680,REAL,2 EMODIF,37925,REAL,2 EMODIF,38170,REAL,2 EMODIF,38415,REAL,2 EMODIF,38660,REAL,2 EMODIF,38905,REAL,2 EMODIF,39150,REAL,2 EMODIF,39395,REAL,2 EMODIF,39640,REAL,2 EMODIF,39885,REAL,2 EMODIF,40130,REAL,2 EMODIF,40375,REAL,2

! Trinca J *do,i,36982,49182,244 EMODIF,i,MAT,2, *enddo

*do,i,36982,49182,244 EMODIF,i,REAL,2, *enddo

! Trinca V *do,i,188,13120,244 EMODIF,i,MAT,2, *enddo

*do,i,188,13120,244 EMODIF,i,REAL,2, *enddo

! Trinca U

EMODIF,197,MAT,2 EMODIF,441,MAT,2 EMODIF,685,MAT,2 EMODIF,929,MAT,2 EMODIF,1173,MAT,2 EMODIF,1417,MAT,2 EMODIF, 1660,MAT,2 EMODIF,1904,MAT,2 EMODIF,2148,MAT,2 EMODIF,2392,MAT,2 
EMODIF,2636,MAT,2 EMODIF,2880,MAT,2 EMODIF,3123,MAT,2 EMODIF,3367,MAT,2 EMODIF,3611,MAT,2 EMODIF,3855,MAT,2 EMODIF,4099,MAT,2 EMODIF,4343,MAT,2 EMODIF,4586,MAT,2 EMODIF,4830,MAT,2 EMODIF,5074,MAT,2 EMODIF,5318,MAT,2 EMODIF,5562,MAT,2 EMODIF,5806,MAT,2 EMODIF,6049,MAT,2 EMODIF,6293,MAT,2 EMODIF,6537,MAT,2 EMODIF,6781,MAT,2 EMODIF,7025,MAT,2 EMODIF,7269,MAT,2 EMODIF,7512,MAT,2 EMODIF,7756,MAT,2 EMODIF,8000,MAT,2 EMODIF,8244,MAT,2 EMODIF,8488,MAT,2 EMODIF,8732,MAT,2 EMODIF,8975,MAT,2 EMODIF,9219,MAT,2 EMODIF,9463,MAT,2 EMODIF,9707,MAT,2 EMODIF,9951,MAT,2 EMODIF,10195,MAT,2 EMODIF,10438,MAT,2 EMODIF,10682,MAT,2 EMODIF,10926,MAT,2 EMODIF,11170,MAT,2 EMODIF,11414,MAT,2 EMODIF,1 1658,MAT,2 EMODIF,11901,MAT,2 EMODIF,12145,MAT,2 EMODIF,12389,MAT,2 EMODIF,12633,MAT,2 EMODIF,12877,MAT,2 EMODIF,13121,MAT,2 EMODIF,13364,MAT,2 EMODIF,13608,MAT,2 EMODIF,13852,MAT,2 EMODIF,14096,MAT,2 EMODIF,14340,MAT,2 EMODIF,14584,MAT,2 EMODIF,14828,MAT,2

EMODIF,197,REAL,2 EMODIF,441,REAL,2 EMODIF,685,REAL,2 EMODIF,929,REAL,2 
EMODIF,1173,REAL,2 EMODIF,1417,REAL,2 EMODIF,1660,REAL,2 EMODIF,1904,REAL,2 EMODIF,2148,REAL,2 EMODIF,2392,REAL,2 EMODIF,2636,REAL, 2 EMODIF,2880,REAL,2 EMODIF,3123,REAL,2 EMODIF,3367,REAL,2 EMODIF,3611,REAL,2 EMODIF,3855,REAL,2 EMODIF,4099,REAL,2 EMODIF,4343,REAL,2 EMODIF,4586,REAL,2 EMODIF,4830,REAL,2 EMODIF,5074,REAL,2 EMODIF,5318,REAL,2 EMODIF,5562,REAL,2 EMODIF,5806,REAL,2 EMODIF,6049,REAL,2 EMODIF,6293,REAL,2 EMODIF,6537,REAL,2 EMODIF,6781,REAL,2 EMODIF,7025,REAL,2 EMODIF,7269,REAL,2 EMODIF,7512,REAL,2 EMODIF,7756,REAL,2 EMODIF,8000,REAL,2 EMODIF,8244,REAL,2 EMODIF,8488,REAL,2 EMODIF,8732,REAL,2 EMODIF,8975,REAL,2 EMODIF,9219,REAL,2 EMODIF,9463,REAL,2 EMODIF,9707,REAL,2 EMODIF,9951,REAL,2 EMODIF,10195,REAL,2 EMODIF,10438,REAL,2 EMODIF,10682,REAL,2 EMODIF,10926,REAL,2 EMODIF,11170,REAL,2 EMODIF,11414,REAL,2 EMODIF,11658,REAL,2 EMODIF,11901,REAL,2 EMODIF,12145,REAL,2 EMODIF,12389,REAL,2 EMODIF,12633,REAL,2 EMODIF,12877,REAL,2 EMODIF,13121,REAL,2 EMODIF,13364,REAL,2 EMODIF,13608,REAL,2 EMODIF,13852,REAL,2 EMODIF,14096,REAL,2 EMODIF,14340,REAL,2 EMODIF,14584,REAL,2 
EMODIF,14828,REAL,2

! Trinca N

EMODIF,119,MAT,2

EMODIF,363,MAT,2

EMODIF,607,MAT,2

EMODIF,851,MAT,2

EMODIF,1095,MAT,2

EMODIF,1339,MAT,2

EMODIF,1583,MAT,2

EMODIF,1827,MAT,2

EMODIF,2071,MAT,2

EMODIF,2316,MAT,2

EMODIF,2560,MAT,2

EMODIF,2804,MAT,2

EMODIF,3048,MAT,2

EMODIF,3292,MAT,2

EMODIF,3536,MAT,2

EMODIF,3780,MAT,2

EMODIF,4024,MAT,2

EMODIF,4268,MAT,2

EMODIF,4513,MAT,2

EMODIF,4757,MAT,2

EMODIF,5001,MAT,2

EMODIF,5245,MAT,2

EMODIF,5489,MAT,2

EMODIF,5733,MAT,2

EMODIF,5977,MAT,2

EMODIF,6221,MAT,2

EMODIF,6465,MAT,2

EMODIF,6710,MAT,2

EMODIF,6954,MAT,2

EMODIF,7198,MAT,2

EMODIF,7442,MAT,2

EMODIF,7686,MAT,2

EMODIF,7930,MAT,2

EMODIF,8174,MAT,2

EMODIF,8418,MAT,2

EMODIF,8662,MAT,2

EMODIF,8907,MAT,2

EMODIF,9151,MAT,2

EMODIF,9395,MAT,2

EMODIF,9639,MAT,2

EMODIF,9883,MAT,2

EMODIF,10127,MAT,2

EMODIF,10371,MAT,2

EMODIF,10615,MAT,2

EMODIF,10859,MAT,2

EMODIF,11104,MAT,2

EMODIF,11348,MAT,2

EMODIF,1 1592,MAT,2

EMODIF,11836,MAT,2

EMODIF,12080,MAT,2

EMODIF,12324,MAT,2

EMODIF,12568,MAT,2

EMODIF,12812,MAT,2 
EMODIF,13056,MAT,2 EMODIF,13301,MAT,2 EMODIF,13545,MAT,2 EMODIF,13789,MAT,2 EMODIF,14033,MAT,2 EMODIF,14277,MAT,2 EMODIF,14521,MAT,2 EMODIF,14765,MAT,2 EMODIF,15009,MAT,2 EMODIF,15253,MAT,2 EMODIF,15498,MAT,2

EMODIF,119,REAL,2 EMODIF,363,REAL,2 EMODIF,607,REAL,2 EMODIF,851,REAL,2 EMODIF,1095,REAL,2 EMODIF,1339,REAL,2 EMODIF,1583,REAL,2 EMODIF,1827,REAL,2 EMODIF,2071,REAL,2 EMODIF,2316,REAL, 2 EMODIF,2560,REAL,2 EMODIF, 2804,REAL,2 EMODIF,3048,REAL,2 EMODIF,3292,REAL,2 EMODIF,3536,REAL,2 EMODIF,3780,REAL,2 EMODIF,4024,REAL,2 EMODIF,4268,REAL,2 EMODIF,4513,REAL,2 EMODIF,4757,REAL,2 EMODIF,5001,REAL,2 EMODIF,5245,REAL,2 EMODIF,5489,REAL,2 EMODIF,5733,REAL,2 EMODIF,5977,REAL,2 EMODIF,6221,REAL,2 EMODIF,6465,REAL,2 EMODIF,6710,REAL,2 EMODIF,6954,REAL,2 EMODIF,7198,REAL,2 EMODIF,7442,REAL,2 EMODIF,7686,REAL,2 EMODIF,7930,REAL,2 EMODIF,8174,REAL,2 EMODIF,8418,REAL,2 EMODIF,8662,REAL,2 EMODIF,8907,REAL,2 EMODIF,9151,REAL,2 EMODIF,9395,REAL,2 EMODIF,9639,REAL,2 EMODIF,9883,REAL,2 EMODIF,10127,REAL,2 EMODIF,10371,REAL,2 EMODIF,10615,REAL,2 
EMODIF,10859,REAL,2 EMODIF,11104,REAL,2 EMODIF,11348,REAL,2 EMODIF,11592,REAL,2 EMODIF,11836,REAL,2 EMODIF,12080,REAL,2 EMODIF,12324,REAL,2 EMODIF,12568,REAL,2 EMODIF,12812,REAL,2 EMODIF,13056,REAL,2 EMODIF,13301,REAL,2 EMODIF,13545,REAL,2 EMODIF,13789,REAL,2 EMODIF,14033,REAL,2 EMODIF,14277,REAL,2 EMODIF,14521,REAL,2 EMODIF,14765,REAL,2 EMODIF,15009,REAL,2 EMODIF,15253,REAL,2 EMODIF,15498,REAL,2

! Trinca N

EMODIF,15743,MAT,2 EMODIF, 15987,MAT, 2 EMODIF, 16232,MAT,2 EMODIF, 16476,MAT,2 EMODIF,16721,MAT,2 EMODIF,16965,MAT,2 EMODIF,17210,MAT, 2 EMODIF, 17454,MAT, 2 EMODIF, 17699,MAT, 2 EMODIF,17943,MAT,2 EMODIF,18188,MAT,2 EMODIF,18432,MAT,2 EMODIF,18677,MAT,2 EMODIF,18921,MAT,2 EMODIF,19166,MAT,2 EMODIF,19410,MAT,2 EMODIF,19655,MAT,2 EMODIF,19899,MAT,2 EMODIF,20144,MAT,2 EMODIF,20388,MAT, 2 EMODIF,20633,MAT,2 EMODIF,20877,MAT,2 EMODIF,21122,MAT,2 EMODIF,21366,MAT,2 EMODIF,21611,MAT,2 EMODIF,21855,MAT,2 EMODIF,22100,MAT,2 EMODIF, 22344,MAT, 2 EMODIF,22589,MAT, 2 EMODIF,22833,MAT,2 EMODIF,23078,MAT,2 EMODIF,23322,MAT,2 EMODIF,23567,MAT, 2 EMODIF,23811,MAT,2 
EMODIF,24056,MAT,2 EMODIF,24300,MAT,2 EMODIF,24545,MAT,2 EMODIF,24789,MAT,2 EMODIF,25034,MAT,2 EMODIF,25278,MAT,2 EMODIF,25523,MAT,2 EMODIF,25767,MAT,2 EMODIF,26012,MAT,2 EMODIF,26256,MAT,2 EMODIF,26501,MAT,2 EMODIF,26745,MAT,2 EMODIF,26990,MAT,2 EMODIF,27234,MAT,2 EMODIF,27479,MAT,2 EMODIF,27723,MAT,2 EMODIF,27968,MAT,2 EMODIF,28212,MAT,2 EMODIF,28457,MAT,2 EMODIF,28701,MAT,2 EMODIF,28946,MAT,2 EMODIF,29190,MAT,2 EMODIF,29435,MAT,2 EMODIF,29680,MAT,2 EMODIF,29925,MAT,2 EMODIF,30170,MAT,2 EMODIF,30415,MAT,2 EMODIF,30660,MAT,2 EMODIF,30905,MAT,2 EMODIF,31150,MAT,2 EMODIF,31151,MAT,2 EMODIF,31152,MAT,2 EMODIF,31153,MAT,2 EMODIF,31154,MAT,2

EMODIF,15743,REAL,2 EMODIF,15987,REAL,2 EMODIF,16232,REAL,2 EMODIF,16476,REAL,2 EMODIF,16721,REAL,2 EMODIF,16965,REAL,2 EMODIF,17210,REAL,2 EMODIF,17454,REAL,2 EMODIF, 17699,REAL,2 EMODIF,17943,REAL,2 EMODIF,18188,REAL,2 EMODIF,18432,REAL,2 EMODIF,18677,REAL,2 EMODIF,18921,REAL,2 EMODIF,19166,REAL,2 EMODIF,19410,REAL,2 EMODIF,19655,REAL,2 EMODIF,19899,REAL,2 EMODIF,20144,REAL,2 EMODIF,20388,REAL,2 EMODIF,20633,REAL,2 
EMODIF,20877,REAL,2 EMODIF,21122,REAL,2 EMODIF,21366,REAL,2 EMODIF,21611,REAL,2 EMODIF,21855,REAL,2 EMODIF,22100,REAL,2 EMODIF,22344,REAL,2 EMODIF,22589,REAL,2 EMODIF,22833,REAL,2 EMODIF,23078,REAL,2 EMODIF,23322,REAL,2 EMODIF,23567,REAL,2 EMODIF,23811,REAL,2 EMODIF,24056,REAL,2 EMODIF,24300,REAL,2 EMODIF,24545,REAL,2 EMODIF,24789,REAL,2 EMODIF,25034,REAL,2 EMODIF,25278,REAL,2 EMODIF,25523,REAL,2 EMODIF,25767,REAL,2 EMODIF,26012,REAL,2 EMODIF,26256,REAL,2 EMODIF,26501,REAL,2 EMODIF,26745,REAL,2 EMODIF,26990,REAL,2 EMODIF,27234,REAL,2 EMODIF,27479,REAL,2 EMODIF,27723,REAL,2 EMODIF,27968,REAL,2 EMODIF,28212,REAL,2 EMODIF,28457,REAL,2 EMODIF,28701,REAL,2 EMODIF,28946,REAL,2 EMODIF,29190,REAL,2 EMODIF,29435,REAL,2 EMODIF,29680,REAL,2 EMODIF,29925,REAL,2 EMODIF,30170,REAL,2 EMODIF,30415,REAL,2 EMODIF,30660,REAL,2 EMODIF,30905,REAL,2 EMODIF,31150,REAL,2 EMODIF,31151,REAL,2 EMODIF,31152,REAL,2 EMODIF,31153,REAL,2 EMODIF,31154,REAL,2

! Trinca T

EMODIF,15072,MAT,2 EMODIF,15316,MAT,2 EMODIF,15560,MAT,2 EMODIF,15803,MAT,2 EMODIF,16047,MAT,2 EMODIF,16291,MAT,2 EMODIF,16534,MAT,2 
EMODIF,16778,MAT,2 EMODIF,17022,MAT,2 EMODIF,17265,MAT,2 EMODIF,17509,MAT,2 EMODIF,17753,MAT,2 EMODIF,17996,MAT,2 EMODIF,18240,MAT,2 EMODIF,18484,MAT,2 EMODIF,18727,MAT,2 EMODIF,18971,MAT,2 EMODIF,19215,MAT,2 EMODIF,19458,MAT,2 EMODIF,19702,MAT,2 EMODIF,19946,MAT,2 EMODIF,20189,MAT,2 EMODIF,20433,MAT,2 EMODIF,20677,MAT,2 EMODIF,20920,MAT,2 EMODIF,21164,MAT,2 EMODIF,21408,MAT,2 EMODIF,21651,MAT,2 EMODIF,21895,MAT,2 EMODIF,22139,MAT,2 EMODIF,22382,MAT,2 EMODIF,22626,MAT,2 EMODIF,22870,MAT,2 EMODIF,23113,MAT,2 EMODIF,23357,MAT,2 EMODIF,23601,MAT,2 EMODIF,23844,MAT,2 EMODIF,24088,MAT,2 EMODIF,24332,MAT,2 EMODIF,24575,MAT,2 EMODIF,24819,MAT,2 EMODIF,25063,MAT,2 EMODIF,25306,MAT,2 EMODIF,25550,MAT,2 EMODIF,25794,MAT,2 EMODIF,26037,MAT,2 EMODIF,26281,MAT,2 EMODIF,26525,MAT,2 EMODIF,26768,MAT,2 EMODIF,27012,MAT,2 EMODIF,27256,MAT,2 EMODIF,27499,MAT,2 EMODIF,27743,MAT,2 EMODIF,27987,MAT,2 EMODIF,28230,MAT,2 EMODIF,28474,MAT,2 EMODIF,28718,MAT,2 EMODIF,28961,MAT,2 EMODIF,29205,MAT,2 EMODIF,29449,MAT,2 EMODIF,29692,MAT,2 EMODIF,29936,MAT,2 EMODIF,30180,MAT,2 
EMODIF,30423,MAT,2 EMODIF,30667,MAT,2

EMODIF,30911,MAT,2

EMODIF,15072,REAL,2 EMODIF,15316,REAL,2 EMODIF,15560,REAL,2 EMODIF,15803,REAL,2 EMODIF,16047,REAL,2 EMODIF,16291,REAL,2 EMODIF,16534,REAL,2 EMODIF,16778,REAL,2 EMODIF, 17022,REAL,2 EMODIF, 17265,REAL,2 EMODIF, 17509,REAL,2 EMODIF,17753,REAL,2 EMODIF,17996,REAL,2 EMODIF,18240,REAL,2 EMODIF,18484,REAL,2 EMODIF,18727,REAL,2 EMODIF,18971,REAL,2 EMODIF,19215,REAL,2 EMODIF,19458,REAL,2 EMODIF,19702,REAL,2 EMODIF,19946,REAL,2 EMODIF,20189,REAL,2 EMODIF,20433,REAL,2 EMODIF,20677,REAL,2 EMODIF,20920,REAL,2 EMODIF,21164,REAL,2 EMODIF,21408,REAL,2 EMODIF,21651,REAL,2 EMODIF,21895,REAL,2 EMODIF,22139,REAL,2 EMODIF,22382,REAL,2 EMODIF,22626,REAL,2 EMODIF,22870,REAL,2 EMODIF,23113,REAL,2 EMODIF,23357,REAL,2 EMODIF,23601,REAL,2 EMODIF,23844,REAL,2 EMODIF,24088,REAL,2 EMODIF,24332,REAL,2 EMODIF,24575,REAL,2 EMODIF,24819,REAL,2 EMODIF,25063,REAL,2 EMODIF,25306,REAL,2 EMODIF,25550,REAL,2 EMODIF,25794,REAL,2 EMODIF,26037,REAL,2 EMODIF,26281,REAL,2 EMODIF,26525,REAL,2 EMODIF,26768,REAL,2 EMODIF,27012,REAL,2 EMODIF,27256,REAL,2 EMODIF,27499,REAL,2 
EMODIF,27743,REAL,2 EMODIF,27987,REAL,2 EMODIF,28230,REAL,2 EMODIF,28474,REAL,2 EMODIF,28718,REAL,2 EMODIF,28961,REAL,2 EMODIF,29205,REAL,2 EMODIF,29449,REAL,2 EMODIF,29692,REAL,2 EMODIF,29936,REAL,2 EMODIF,30180,REAL,2 EMODIF,30423,REAL,2 EMODIF,30667,REAL,2 EMODIF,30911,REAL,2

! Trinca O
EMODIF,31393,MAT,2
EMODIF,31636,MAT,2
EMODIF,31879,MAT,2
EMODIF,32122,MAT,2
EMODIF,32365,MAT,2
EMODIF,32608,MAT,2
EMODIF,32851,MAT,2
EMODIF,33094,MAT,2
EMODIF,33337,MAT,2
EMODIF,33580,MAT,2
EMODIF,33823,MAT,2
EMODIF,34066,MAT,2
EMODIF,34309,MAT,2
EMODIF,34552,MAT,2
EMODIF,34795,MAT,2
EMODIF,35038,MAT,2
EMODIF,35281,MAT,2
EMODIF,35524,MAT,2
EMODIF,35767,MAT,2
EMODIF,36010,MAT,2
EMODIF,36253,MAT,2
EMODIF,36496,MAT,2
EMODIF,36739,MAT,2

EMODIF,31393,REAL,2 EMODIF,31636,REAL,2 EMODIF,31879,REAL,2 EMODIF,32122,REAL,2 EMODIF,32365,REAL,2 EMODIF,32608,REAL,2 EMODIF,32851,REAL,2 EMODIF,33094,REAL,2 EMODIF,33337,REAL,2 EMODIF,33580,REAL,2 EMODIF,33823,REAL,2 EMODIF,34066,REAL,2 EMODIF,34309,REAL,2 EMODIF,34552,REAL,2 EMODIF,34795,REAL,2 
EMODIF,35038,REAL,2 EMODIF,35281,REAL,2 EMODIF,35524,REAL,2 EMODIF,35767,REAL,2 EMODIF,36010,REAL,2 EMODIF,36253,REAL,2 EMODIF,36496,REAL,2 EMODIF,36739,REAL,2

! Trinca Q

EMODIF,31155,MAT,2 EMODIF,31156,MAT,2 EMODIF,31157,MAT, 2 EMODIF,31158,MAT,2 EMODIF,31403,MAT,2 EMODIF,31404,MAT,2 EMODIF,31405,MAT, 2 EMODIF,31406,MAT,2 EMODIF,31651,MAT,2 EMODIF,31652,MAT,2 EMODIF,31653,MAT,2 EMODIF,31654,MAT,2 EMODIF,31899,MAT,2 EMODIF,31900,MAT,2 EMODIF,31901,MAT,2 EMODIF,31902,MAT,2 EMODIF,32147,MAT,2 EMODIF,32148,MAT,2 EMODIF,32149,MAT, 2 EMODIF,32150,MAT,2 EMODIF,32395,MAT,2 EMODIF,32396,MAT, 2 EMODIF,32397,MAT,2 EMODIF,32398,MAT,2

EMODIF,31155,REAL,2 EMODIF,31156,REAL,2 EMODIF,31157,REAL,2 EMODIF,31158,REAL,2 EMODIF,31403,REAL,2 EMODIF,31404,REAL,2 EMODIF,31405,REAL,2 EMODIF,31406,REAL,2 EMODIF,31651,REAL,2 EMODIF,31652,REAL,2 EMODIF,31653,REAL,2 EMODIF,31654,REAL,2 EMODIF,31899,REAL,2 EMODIF,31900,REAL,2 EMODIF,31901,REAL,2 EMODIF,31902,REAL,2 EMODIF,32147,REAL,2 EMODIF,32148,REAL,2 EMODIF,32149,REAL,2 EMODIF,32150,REAL,2 EMODIF,32395,REAL,2 
EMODIF,32396,REAL,2 EMODIF,32397,REAL,2

EMODIF,32398,REAL,2

! Trinca R

*do,i,32399,32419,1

EMODIF,i,MAT,2,

*enddo

*do,i,32399,32419,1

EMODIF,i,REAL,2,

*enddo

! Trinca $\mathrm{S}$

EMODIF,32664,MAT,2

EMODIF,32665,MAT,2

EMODIF,32666,MAT,2

EMODIF,32667,MAT,2

EMODIF,32668,MAT,2

EMODIF,32913,MAT,2

EMODIF,32914,MAT,2

EMODIF,32915,MAT,2

EMODIF,32916,MAT,2

EMODIF,32917,MAT,2

EMODIF,33162,MAT,2

EMODIF,33163,MAT,2

EMODIF,33164,MAT,2

EMODIF,33165,MAT,2

EMODIF,33166,MAT,2

EMODIF,33411,MAT,2

EMODIF,33412,MAT,2

EMODIF,33413,MAT,2

EMODIF,33414,MAT,2

EMODIF,33415,MAT,2

EMODIF,33660,MAT,2

EMODIF,33661,MAT,2

EMODIF,33662,MAT,2

EMODIF,33663,MAT,2

EMODIF,33664,MAT,2

EMODIF,33909,MAT,2

EMODIF,33910,MAT,2

EMODIF,33911,MAT,2

EMODIF,33912,MAT,2

EMODIF,33913,MAT,2

EMODIF,34158,MAT,2

EMODIF,34159,MAT,2

EMODIF,34160,MAT,2

EMODIF,32664,REAL,2 EMODIF,32665,REAL,2 EMODIF,32666,REAL,2 EMODIF,32667,REAL,2 EMODIF,32668,REAL,2 EMODIF,32913,REAL,2 EMODIF,32914,REAL,2 EMODIF,32915,REAL,2 
EMODIF,32916,REAL,2 EMODIF,32917,REAL,2 EMODIF,33162,REAL,2 EMODIF,33163,REAL,2 EMODIF,33164,REAL,2 EMODIF,33165,REAL,2 EMODIF,33166,REAL,2 EMODIF,33411,REAL,2 EMODIF,33412,REAL,2 EMODIF,33413,REAL,2 EMODIF,33414,REAL,2 EMODIF,33415,REAL,2 EMODIF,33660,REAL,2 EMODIF,33661,REAL,2 EMODIF,33662,REAL,2 EMODIF,33663,REAL,2 EMODIF,33664,REAL,2 EMODIF,33909,REAL,2 EMODIF,33910,REAL,2 EMODIF,33911,REAL,2 EMODIF,33912,REAL,2 EMODIF,33913,REAL,2 EMODIF,34158,REAL,2 EMODIF,34159,REAL,2 EMODIF,34160,REAL,2

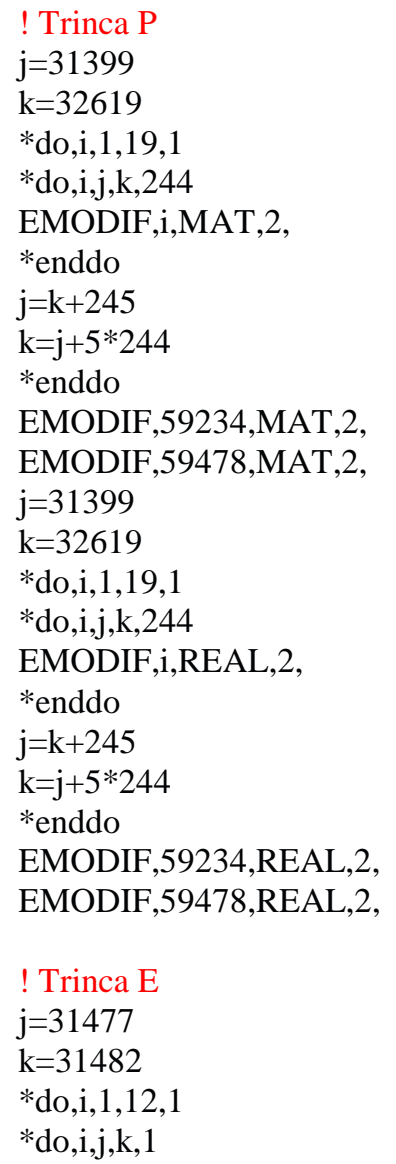


EMODIF,i,MAT,2,

*enddo

$\mathrm{j}=\mathrm{k}+245$

$\mathrm{k}=\mathrm{j}+4$

*enddo

$\mathrm{j}=31477$

$\mathrm{k}=31482$

*do,i, $1,12,1$

$*$ do, i, , , k, 1

EMODIF,i,REAL,2,

*enddo

$\mathrm{j}=\mathrm{k}+245$

$\mathrm{k}=\mathrm{j}+4$

*enddo

! Trinca D

$\mathrm{j}=34222$

$\mathrm{k}=34224$

*do, i, $1,7,1$

$*$ do,i,j,k,1

EMODIF,i,MAT,2,

*enddo

$\mathrm{j}=\mathrm{k}-243$

$\mathrm{k}=\mathrm{j}+2$

*enddo

EMODIF,32779,MAT,2,

$\mathrm{j}=34222$

$\mathrm{k}=34224$

*do,i, $1,7,1$

*do, $\mathrm{i}, \mathrm{j}, \mathrm{k}, 1$

EMODIF,i,REAL,2,

*enddo

$\mathrm{j}=\mathrm{k}-243$

$\mathrm{k}=\mathrm{j}+2$

*enddo

EMODIF,32779,REAL,2,

! Trinca K

$\mathrm{j}=31357$

$\mathrm{k}=31601$

*do,i, $1,12,1$

*do,i,j,k,244

EMODIF,i,MAT,2,

*enddo

$\mathrm{j}=\mathrm{k}+245$

$\mathrm{k}=\mathrm{j}+1 * 244$

*enddo

EMODIF,36981,MAT,2,

$\mathrm{j}=31357$

$\mathrm{k}=31601$

*do,i, $1,12,1$

*do,i,j,k,244

EMODIF,i,REAL,2,

*enddo

$\mathrm{j}=\mathrm{k}+245$

$\mathrm{k}=\mathrm{j}+1 * 244$ 
*enddo

EMODIF,36981,REAL,2,

! Trinca $\mathrm{M}$

$\mathrm{j}=15496$

$\mathrm{k}=15984$

*do, i, 1,4,1

*do,i,j,k,244

EMODIF,i,MAT,2,

*enddo

$\mathrm{j}=\mathrm{k}+243$

$\mathrm{k}=\mathrm{j}+2 * 244$

*enddo

$\mathrm{j}=15496$

$\mathrm{k}=15984$

*do, i, $1,4,1$

*do,i,j,k,244

EMODIF,i,REAL,2,

*enddo

$\mathrm{j}=\mathrm{k}+243$

$\mathrm{k}=\mathrm{j}+2 * 244$

*enddo

! Trinca L

$\mathrm{j}=18422$

$\mathrm{k}=21350$

*do,i, $1,4,1$

*do,i,j,k,244

EMODIF,i,MAT,2,

*enddo

$\mathrm{j}=\mathrm{k}+245$

$\mathrm{k}=\mathrm{j}+12 * 244$

*enddo

EMODIF,31113,MAT,2,

$\mathrm{j}=18422$

$\mathrm{k}=21350$

*do, i, $1,4,1$

*do,i,j,k,244

EMODIF,i,REAL,2,

*enddo

$\mathrm{j}=\mathrm{k}+245$

$\mathrm{k}=\mathrm{j}+12 * 244$

*enddo

EMODIF,31113,REAL,2,

/NUMBER, 1

/PNUM,MAT,1

/REPLOT

*endIf

TYPE,1 ! Define por atributos o tipo de material 1, para este caso SHELL63

MAT,3 ! Define por atributos o material 2, para este caso aço

REAL,2 ! Define por atributos as constantes reais do material 2, para este caso aço

ESYS,0 ! Define por atributos sistema de elementos coordenados. 
SECNUM,

ESIZE,ndiv,0, ! Define o número de divisões da malha

AMESH, 1 ! Coloca a malha na área 1 do material aço constante real 2 espessura da mesa Perfil esquerdo AMESH, 2

AMESH,23

AMESH,24

AMESH,28

AMESH,29

AMESH,43

AMESH,44

AMESH,48

AMESH,49

AMESH,113

AMESH,114

AMESH, 117

AMESH, 118

AMESH,119

AMESH,120

AMESH,121

AMESH,122

AMESH, 123

AMESH,131

AMESH,132

AMESH,133

AMESH,134

AMESH,135

AMESH,136

AMESH,137

AMESH,161

AMESH,162

AMESH,163

AMESH,164

AMESH,170

AMESH, 172

AMESH, 175

AMESH,176

AMESH,177

AMESH, 178

AMESH,179

AMESH, 180

AMESH,181

AMESH,182

AMESH,183

AMESH,184

AMESH,185

AMESH,186

AMESH, 187

AMESH, 188

AMESH,189

AMESH,190

AMESH,191

AMESH,192

AMESH,213

AMESH,214 
AMESH,7 AMESH,8

AMESH,33

AMESH,34

AMESH,38

AMESH,39

AMESH,53

AMESH,54

AMESH,58

AMESH,59

AMESH,115

AMESH,116

AMESH,124

AMESH,125

AMESH,126

AMESH, 127

AMESH,128

AMESH,129

AMESH,130

AMESH,138

AMESH,139

AMESH,140

AMESH, 141

AMESH, 142

AMESH, 143

AMESH,144

AMESH,165

AMESH,166

AMESH, 167

AMESH,168

AMESH,171

AMESH,174

AMESH,193

AMESH,194

AMESH,195

AMESH,196

AMESH,197

AMESH,198

AMESH,199

AMESH,200

AMESH,201

AMESH,202

AMESH,203

AMESH,204

AMESH,205

AMESH,206

AMESH,207

AMESH,208

AMESH,209

AMESH,210

AMESH,215

AMESH,216

TYPE, 1

MAT,3

REAL,3
! Coloca a malha na área 7 do material aço constante real 2 espessura da mesa perfil direito 
ESYS,0 ! Define por atributos sistema de elementos coordenados.

SECNUM,

ESIZE,ndiv,0, ! ! Define o número de divisões da malha Perfil esquerdo W200x19.3

AMESH,3

! Coloca a malha na área 3 do material aço constante real 3 da alma perfil esquerdo

AMESH,227

AMESH, 228

AMESH,231

AMESH,232

AMESH,235

! Malha Perfil direito W200x19.3

AMESH,9 ! Coloca a malha na área 3 do material aço constante real 3 da alma (Perfil direito W200x19.3)

AMESH,229

AMESH,230

AMESH,233

AMESH,234

AMESH,236

TYPE,2 ! Define por atributos o tipo de material 2, para este caso BEAM4

MAT,3 ! Define por atributos o material 2, para este caso aço

REAL,4 ! Define por atributos as constantes 4 reais do material 2 para este caso enrijecedor do perfil

ESYS,0 ! Define por atributos sistema de elementos coordenados

SECNUM,

! Malha dos enrijecedores do perfil W200x19.3

LESIZE,ndiv,0, ! ! Define o número de divisões da malha dos enrijecedores do perfil esquerdo.

LMESH,93

! Coloca a malha na linha 93 do material aço constante real 4

LMESH,94

LMESH, 169

LMESH,170

LESIZE,ndiv,0, ! ! Define o número de divisões da malha dos enrijecedores do perfil direito.

LMESH,131

LMESH,132

LMESH,207

LMESH,208

! Coloca a malha na linha 131 do material aço constante real 4

! Malha das mesas do pilar de aço tipo "H"

TYPE,1 ! Define por atributos o tipo de material 1, para este caso SHELL63

MAT,3 ! Define por atributos o material 2, para este caso aço

REAL,5 ! Define por atributos as constantes 5 reais do material 2 espessura das mesas pilar tipo !"H"

ESYS,0 ! Define por atributos sistema de elementos coordenados

SECNUM,

! Lado esquerdo

ESIZE,ndiv,0, ! Define o número de divisões da malha

AMESH,60 ! Coloca a malha na área 60 do material aço constante real 5 espessura da mesa pilar tipo "H"

AMESH,61

AMESH,62

AMESH,63 
AMESH,64

AMESH,79

AMESH, 80

AMESH, 81

AMESH,82

AMESH,83

AMESH,147

AMESH,148

AMESH, 153

AMESH, 154

AMESH,217

AMESH,219

! Lado direito

ESIZE,ndiv,0,

AMESH,70

AMESH,71

AMESH,73

AMESH,78

AMESH,87

AMESH, 88

AMESH,89

AMESH,90

AMESH,96

AMESH,151

AMESH,152

AMESH,159

AMESH,160

AMESH,218

AMESH,220

! Malha das almas do pilar de aço tipo "H"

TYPE,1 ! Define por atributos o tipo de material 1, para este caso SHELL63

MAT,3

REAL, 6

ESYS, 0

! Define por atributos o material 2, para este caso aço

! Define por atributos as constantes 6 reais do material 2 espessura da alma do pilar tipo "H"

SECNUM,

! Define por atributos sistema de elementos coordenados

! Lado esquerdo

ESIZE,ndiv,0, ! Define o número de divisões da malha

AMESH,66 ! Coloca a malha na área 66 do material aço constante real 6 espessura da alma pilar tipo "H"

AMESH,67

AMESH,68

AMESH, 84

AMESH, 85

AMESH,86

! Lado direito

ESIZE,ndiv,0, ! Define o número de divisões da malha

AMESH,75 ! Coloca a malha na área 75 do material aço constante real 6 espessura da alma pilar tipo "H" AMESH,76 
AMESH,77

AMESH,93

AMESH,94

AMESH,95

TYPE,1 ! Define por atributos o tipo de material 1, para este caso SHELL63

MAT,3 ! Define por atributos o material 2, para este caso aço

REAL,7 ! Define por atributos as constantes 7 reais do material 2 bases do aço do pilar tipo "H"

ESYS,0 ! Define por atributos sistema de elementos coordenados

SECNUM,

! Lado esquerdo

ESIZE,ndiv,0, ! Define o número de divisões da malha

AMESH,145 ! Coloca a malha na área 145 do material aço constante real 7 bases do pilar tipo "H"

AMESH, 146

AMESH, 155

AMESH,156

! Lado direito

ESIZE,ndiv,0,

AMESH, 149

AMESH, 150

AMESH, 157

AMESH,158

! Define o número de divisões da malha

! Coloca a malha na área 149 do material aço constante real 7 bases do pilar tipo "H"

TYPE,1 ! Define por atributos o tipo de material 1, para este caso SHELL63

MAT,3 ! Define por atributos o material 2, para este caso aço

REAL, 8

ESYS,0

! Define por atributos as constantes 8 reais do material 2 espessura da mesa perfil tipo "U"

SECNUM,

! Lado dianteiro

ESIZE,ndiv,0, ! Define o número de divisões da malha

AMESH,13 ! Coloca a malha na área 13 do material aço constante real 8 espessura mesa do perfil tipo "U"

AMESH,92

AMESH,98

AMESH,169

! Lado direito

ESIZE,ndiv,0, ! Define o número de divisões da malha

AMESH,223 ! Coloca a malha na área 223 do material aço constante real 8 espessura mesa do perfil tipo "U" AMESH,224

! Lado detrás

ESIZE,ndiv,0, ! Define o número de divisões da malha

AMESH,16 ! Coloca a malha na área 16 do material aço constante real 8 espessura mesa do perfil tipo "U"

AMESH,102

AMESH,104

AMESH, 173

! Lado esquerdo 
ESIZE,ndiv,0, ! Define o número de divisões da malha

AMESH,221 ! Coloca a malha na área 221 do material aço constante real 8 espessura mesa do perfil tipo "U"

AMESH,222

TYPE, 1 ! Define por atributos o tipo de material 1, para este caso SHELL63

MAT,3 ! Define por atributos o material 2, para este caso aço

REAL,9 ! Define por atributos as constantes 8 reais do material 2 espessura alma perfil tipo "U"

ESYS, 0 ! Define por atributos sistema de elementos coordenados

SECNUM,

! Lado dianteiro

ESIZE,ndiv,0, ! Define o número de divisões da malha

AMESH,97 ! Coloca a malha na área 97 do material aço constante real 9 espessura da alma perfil tipo "U"

AMESH,225

! Lado direito

ESIZE,ndiv,0, ! Define o número de divisões da malha

AMESH,211 ! Coloca a malha na área 211 do material aço constante real 9 espessura da alma perfil tipo "U"

! Lado detrás

ESIZE,ndiv,0, ! Define o número de divisões da malha

AMESH,226 ! Coloca a malha na área 226 do material aço constante real 9 espessura da alma perfil tipo "U"

AMESH,103

! Lado esquerdo

ESIZE,ndiv,0, ! Define o número de divisões da malha

AMESH,212 ! Coloca a malha na área 212 do material aço constante real 9 espessura da alma perfil tipo "U"

! Condições de contorno nas bases do pilar tipo "H"

DA,145,UX, ! Não permite movimento na área da base 145 na direção $X$

DA,145,UY, ! Não permite movimento na área da base 145 na direção $Y$

DA,145,UZ, ! Não permite movimento na área da base 145 na direção $Z$

DA, 146,UX,

DA, 146,UY,

DA, 146,UZ,

DA, 149,UX,

DA, 149,UY,

DA, 149,UZ,

DA, 150,UX,

DA, 150,UY,

DA, 150,UZ,

DA, 155,UX,

DA, 155,UY,

DA, 155,UZ,

DA, 156,UX, 
DA, 156,UY,

DA, 156,UZ,

DA, 157,UX,

DA, 157,UY,

DA, 157,UZ,

DA, 158,UX,

DA, 158,UY,

DA, 158,UZ,

!DL,6, ux,

!DL,6,uy,

!DL,6,,uz,

!DL, 27, ux,

!DL, 27, uy,

!DL,27,,uz,

ACEL, $0,0,9.81, \quad$ ! Coloca o valor da gravidade na direção Z AUTOTS, 1

! Amortecimento do sistema AMS

*ask,amortecido,'sistema amortecido? [sim=1] [nao=0]',1

*if,amortecido,eq, 1 ,then

*ask,k,'rigidez da mola [N/m]?',51000

*ask,c,'coeficiente de amortecimento [Ns/m]?',360

*ask,m,'Massa amortecedor [kg]?',120

*ask,dir,'direcao de amortecimento [x=1] [y=2] [z=3]',3

*if,dir,eq, 1 ,then

$\operatorname{dir}=1$

*endif

$*$ if,dir,eq, 2,then

$\operatorname{dir}=2$

*endif

*if,dir,eq,3,then

$\operatorname{dir}=3$

*endif

ET,3,combin40,,dir,,,2

$\mathrm{r}, 11, \mathrm{k}, \mathrm{c}, \mathrm{m},$,

TYPE, 3

MAT, 2

REAL, 11

*ask,Namortecedores,'Quantos amortecedores quer colocar?',1

*do,j,1,Namortecedores, 1

*ask,node,'no onde se quere colocar o amortecedor?',30501 !nó central 30501

$\mathrm{n}, 500000+\mathrm{j}, \mathrm{nx}($ node),ny(node)

e, node, $500000+j$

*enddo

*endif 
!*********!

! Solução !

!*********!

*ask, analise,'Que tipo de analise quere fazer [Modal=1] [Harmonico=2]',2

*if,analise,eq, 1 ,then

!ANALISE MODAL

*ask,Nfrequencias,'Quantas frequências quere obter',10

finish

/solu

antype, 2

modopt,lanb,Nfrequencias

eqslv,spar

mxpand, $0,, 0$

lumpm,0

pstres, 0

modopt,lanb,Nfrequencias, 0,0, ,off

/status,solu

solve

*endif

*if,analise,eq, 2 ,then

!ANALISE HARMONICO

finish

/solu

antype,harmonic

hropt,full

*ask,fi,'Começo da analise de frequência [Hz]?',0

*ask,ff,'Final da analise de frequência [Hz]?',10

*ask,passo,'Subpassos [-]?',100

*ask,dmprat,'Amortecimento estrutural [-]?',0.02

*ask,forza,'Intensidade da forca [N]?',-3000

*ask,Nodeatuaf,'No onde atua a forca?',30501

*ask,dir,'direcao em que atua a forca na laje $[\mathrm{x}=1][\mathrm{y}=2][\mathrm{z}=3]^{\prime}, 3$

*if,dir,eq, 1 ,then

$\operatorname{dir}=' f x^{\prime}$

*endif

*if,dir,eq, 2,then

dir='fy'

*endif

*if,dir,eq, 3,then

dir='fz'

*endif

f,Nodeatuaf,dir,forca

harfrq,fi,ff

nsubst,passo

solve

finish

/post26

numvar, 10,

nsol,2,30501,u,x,desl_em_X_no_30501 
nsol,3,30501,u,y,desl_em_Y_no_30501

nsol,4,30501,u,z,desl_em_Z_no_30501

plvar, $2,3,4$

finish

*endif

!! APÓS DE OBTER OS RESULTADOS DO CODIGO ANTEIROR, PODE-SE ENCONCTRAR !! DISSIPAÇÃO DE ENERGIA POR CICLO.

!dissipação de energia por ciclo

/post1

set, $1, \operatorname{nint}($ passo/2), 1,0

etable,Txy,smisc, 3

*get,REALUY,node,30501,u, ,

*get,REALFY,etab, 1 ,elem, 8774

set, 1,nint(passo/2),1,1

etable,Txy,smisc, 3

*get,IMAGUY,node,30501,u,z

*get,IMAGFY,etab, 1,elem, 8774

Deslocamento $=\operatorname{sqrt}($ REALUY $* * 2+\mathrm{IMAGUY} * * 2)$

MEMBFORC $=\operatorname{sqrt}($ REALFY $* * 2+$ IMAGFY $* * 2)$

LOSSMODM $=2 *$ dmprat

*afun,deg

*dim,mimatriz,table,360,2

*do,ICOUNT, 1,360

mimatriz $(\operatorname{ICOUNT}, 2)=\mathrm{MEMBFORC} * \cos (\mathrm{ICOUNT})$

mimatriz $($ ICOUNT, 1$)=-$ LOSSMODM $*$ MEMBFORC $* \sin ($ ICOUNT $)+$ MEMBFORC $* \cos ($ ICOUNT $)$

mimatriz $($ ICOUNT, 0$)=$ Deslocamento $* \cos ($ ICOUNT $)$

*enddo

/axlab,x,Deslocamento (Real)

/axlab,y,Forza (Real)

/gthk,curve,2

/gcol, $1, \mathrm{Fd}+\mathrm{Fk}$

/gcol,2,Fk

*vplot,mimatriz(1,0),mimatriz $(1,1), 2$ 